
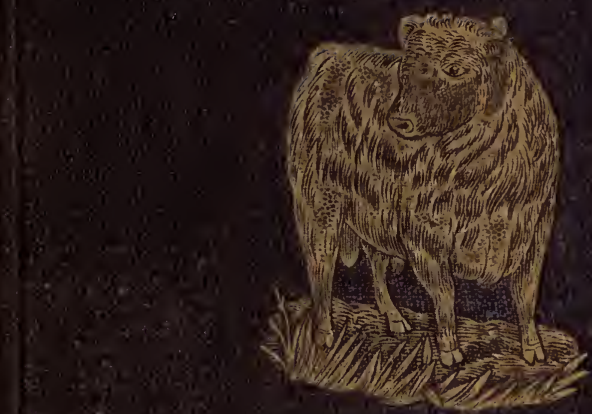

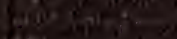

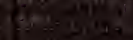

$60^{4}$

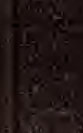

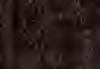




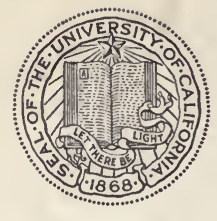

\section{LIBRARY}

\section{THE UNIVERSITY OF CALIFORNIA} SANTA BARBARA

PRESENTED BY

Mr. Robert E. Easton 





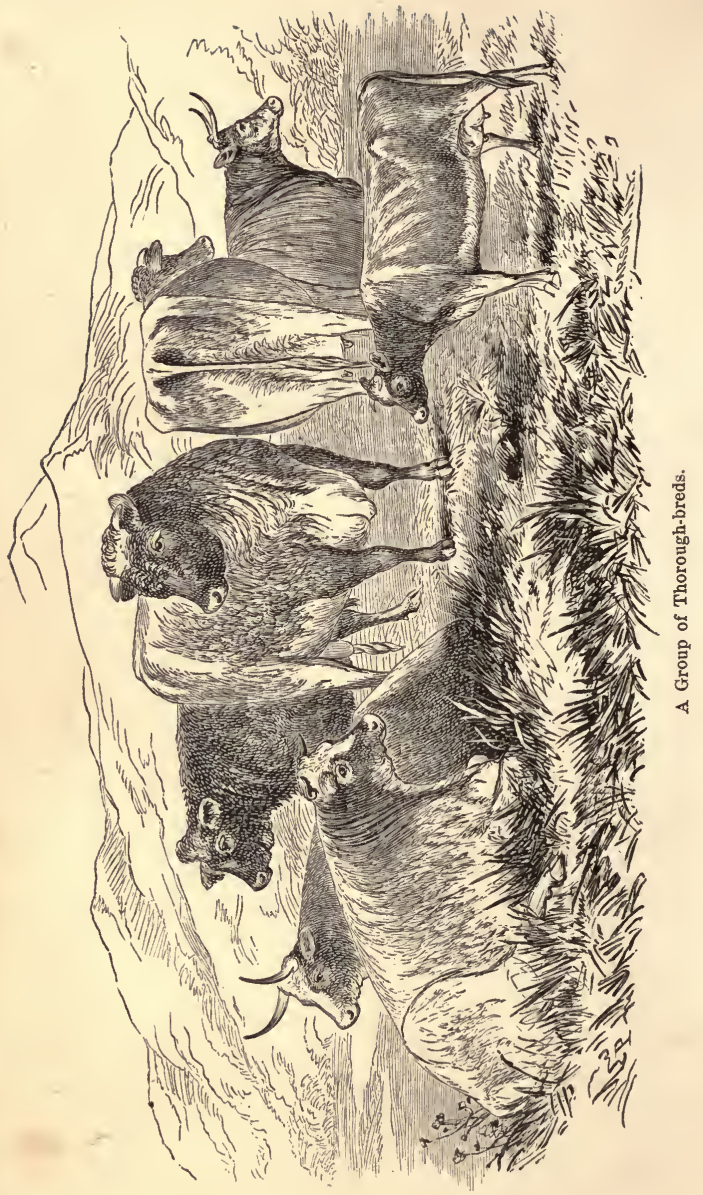


irsosurter

\title{
AMERICAN CATTLE:
}

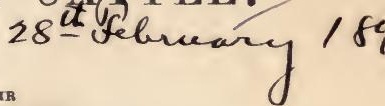

THEIR

HISTORY，BREEDING

$A N D$

MANAGEMENT.

BY LEWIS F. ALLEN,

LATE PRESIDENT NEW TORK STATE AGRICULTUKAL BOCIETY, EDITOR "AXERIOAN BHORT-HOKN HERD BOOK," AUTHOR "RURAL ARCHITECTURE," ETO., ETO.

\author{
NEW YOKK : \\ ORANGE JUDD AND COMPANY, \\ 245 BROADWAY.
}


Entered according to Act of Congress, in the year 1868 , BY LEWIS F. ALLEN,

In the Clerk's office of the District Court of the United States, for whe Northert District of New York.

WARREN, JOHNSON \& Co.

Stereotypers, Printers and Binders,

Buffalo, N. Y. 


\section{PREF A CE.}

THE object of this work is not only to give a historical account of the Bovine race, to suggest to our farmers, and cattle breeders, the best methods of their production and management, but to exalt and ennoble its pursuit to the dignity to which it is entitled, in the various departments of American agriculture.

I have contemplated a work of this kind for many years past. Indeed, its plan was partly shadowed out near twenty years ago; but on reflection, I made up my mind that more personal observation was required than $I$ then possessed, and also, that further experience in the use of the better, improved breeds of foreign cattle, among our farmers and cattle breeders, was desirable, to give that extended range of information which so important an interest demanded.

More than forty years ago, it was felt by those largely engaged in stock growing for beef purposes, that our "native" cattle were lamentably deficient in their most desirable, as well as profitable qualities, and instead of attempting to improve and raise our American native 
stock to the desired standard of excellence, the better way was to resort to such European breeds as, by a long course of intelligent culture; already possessed the properties required. It was so with our dairy, or milking stock. As a race, they were lamentably deficient in the uniformity of their milking qualities, and the yields they produced. We needed better ones, and to undertake to build them up from the miscellaneous herds, composed of all congregated mixtures, as they are, without any certain basis to commence upon, was a hazardous, and almost interminable labor, as well as uncertain mode of procedure. Hence, numerous importations of the choice breeds of foreign cattle have been made, involving an outlay of millions of dollars in the aggregate. The propagation of these cattle, the success that has attended them, and the popularity which they have achieved among our intelligent farmers, and breeders, has confirmed the wisdom of those enterprising men who embarked their capital and labor in their introduction.

Further knowledge in relation to these foreign breeds, of their breeding, and rearing, together with their beneficial uses in elevating the qualities of our old native stock, through their adaptability in crossing their blood upon them, has now, beyond a question, decided the necessity of a book on "American Cattle." Therefore, such as it is, this volume goes forth to the public. 
I believe it is the first work of the kind, so general in its scope of observation, which has been written, collated, or published in our country. We have been favored with sundry publications, relating to cattle in the way of Dairy Cows, and some of the departments connected with their use-able, useful, instructive publications, toobut not comprising so full and general a range of the subject as is here proposed. This work is not intended to interfere with them; each may be essential-necessary, indeed-to convey all the information which may be required on so extensive and ramified a subject.

A book which should embrace all that is here undertaken, together with the productive results appertaining to neat cattle, as the Dairy, and other economical industries, could not well be consolidated into a single, acceptable volume. It would involve a more intimate, and wider range of experience and observation, than can well be combined in one individual effort. So far as suggestion, or instruction, is concerned, I have chosen only to take the creature from its conception, and carry it through life to its proper and ultimate destination-the ox to the yoke, the bullock to the shambles, the cow to the pail, or the propagation of her young-and there leave them. The DAIRY, and its management, are referred to other, and more competent hands.

This Preface ought not to be concluded without saying that I have gleaned somewhat, much indeed, from the 
observations, writings, and publications of others, both abroad and at home, perhaps more experienced than myself. To such, I feel largely indebted, and give my acknowledgments. But those observations have been scattered in such fragmentary and miscellaneous ways, as to be beyond the reach of the inquirer, without more labor and expense to combine them into accessible form than can well be done by the mass, or even a few of those seeking them.

I trust that here may be found embodied all those various materiel which will prove acceptable to the wide spread community interested in the breeding and improvement of our herds, and that they may be benefited by my labors. With this trust, the following pages are submitted.

Buffalo, N. Y., 1868.

$$
\text { LEWIS F. ALLEN. }
$$




\section{CONTENTS.}

\section{INTRODUCTION.}

Number of Cattle in the United States and Territories-Value of the same-Value of Beef, Bntter, Cheese, and Labor of Oxen......................... 11

\section{CHAPTER I.}

The Climate and Solls of North America, as adapted to the production of Neat Cattle

\section{CHAPTER II.}

Neat Cattle-Their History-Misrepresentations by Artists-Spoken of in the BibleIn India-In Egypt-Among the Romans-In Europe.

\section{CIIAPTER III.}

Ifistory of American Cattle-Introduction by the Spanish into Mexico-By the Eng. lish into Virginia-By the Dutch into New York-By the English into other Coloules.

\section{CHAPTER IV.}

Quality, Condition and Appearance of our Native Cattle-Amalgamation of Different Breeds-Result of the different mixtures............................ \&4

\section{CHAPTER V.}

The Anatomical and Economical Points of Cattle-Illnstration of Points-Grod Points-Bad Points-Texan Cattle-Comparison of Good and Poor Cattle... 41

\section{CHAPTER VI.}

Improved Breeds of Cattle-What are they ?-Cattle of Great Britain-Their Progress there-Their Division into Breeds-Improvement in them-Youatt's His-

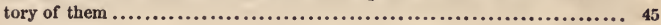

\section{CHAPTER VII.}

Middle-horned Cattle-The Devons-History-Description-Polnts-Bull-Cow, as a Milker-Ox, as a Worker-As a Beef Animal-Their Introduction to, and Progress in America............................................. 50 


\section{CHAPTER VIII.}

The Herefords-History-Description-Bull-Cow, as a Milker-Ox, as a WorkerAs a Beef Animal-Their Introduction to, and Progress in America........ 62

CHAPTER IX.

The Long-horns-History-Description-Bull-Cow, as a Milker-Ox, as a WorkerAs a Beef Animal-Their Introdnction into America-Their Extinction here.. 75

CHAPTER $\mathbf{X}$.

The Cattle of Scotland-The West Highiands-Their History, and Present Condltion-Value as Beef Animals-Little Value for the Dairy-Their Fitness for the Mountain Ranges and Western Plains of America..................... 85

\section{CHAPTER XI.}

The Galloways-Their Hlstory-Description-Manner of Breeding them-Introduction to America-Valne as Grazing, and Beef Animals................. 99

CHAPTER XII.

The Ayrshires-Their Origin and History-Description-Improvement in their Breeding, and Quality for the Dalry-Milk Production-In America-As a Beef Anlmal...................................................... 111

\section{CHAPTER XIII.}

The Alderney, Jersey, Guernsey, or Channel Island Cattle-Their Origin and History-Description-Introduction to America-Value as Milkers-As a Worker, and Beef Animal............................................ 128

\section{CHAPTER XIV.}

The Short-horns-Their Pretended History by Berry, in Youatt-Their True History-Charles and Robert Coling-Short-hurns in America-CharacteristicsDescription of them-As a Dairy Cow-As a Working Ox-As a Beef AnimalTheir Proper Homes-Their Predominance in the Herds of Britain........ 134

\section{CHAPTER XV.}

The Holstein, or Dutch Cattle-Their History-Description of them-Introduction to America-Mr. Chenery's Importations-Their nses-For the Dairy-As a Worker -As a Beef Animal. 166

\section{CHAPTER XVI.}

The Spanlsh, or Texan Cattle-Origin and History-Introduction into Mexico-Migration to Texas and Californla-Description-Beef Qualities-Diseases attending them . 174

\section{CHAPTER XVII.}

What is the Best Breed of Cattle?-What they are Wanted for-Fach may be the Best Breed for Certain Localities 


\section{CHAPTER XVIII.}

What Constitutes a Good Animal ?-Coarse Cattle-Fine Cattle-Beauty-Perfection 187

\section{CIIAPTER XIX.}

On Breeding-General Principles-Rules for Good Breeding-In-and-in BreedingExamples-Establishing the Variety as an Improved Breed-Contending Opinlons . . . 192

\section{CHAPTER XX.}

Treatment of Breeding Cows-Strange Influences-Mistaken Theories-Doctor Harvey's Essay-Occasional Barrenness-Professor Tanner'a Essay-Mr. E. W. Stewart's Remarks-Feeding in Advanced Stages of Pregnancy-Duration of Pregnancy..................................................... 219

\section{CHAPTER XXI.}

Breeding Grade Cattle for Grazing-Breeding Dairy Cow8-Do not Change the Breed-Age at which Heifers should be Bred-Rearing and Treatment of Bulls. 254

\section{CHAPTER XXI.}

Rearing Stock Calves-Their Treatment-Calves for Veal-Calves Running with the Cows-Handling Young Animals-Shelter-Rearing Thorough bred Heifers-Influencing the Sex of Culves.................................... 2tit

\section{CHAPTER XXII.}

Beef Cattle-Differences in Breed-Regularity of Condition-Proper Ages for Fattening-Modes of Feeding-Shape of Fat Cattle-Cattle in the London Markets, by Mr. A. B. Allen-Transportation of Stock to Market-Railway Cattle Yards ..................................................... 276

\section{CHAPTER XXIV.}

Working Oxen-Rearing, Matching, and Training-Devons and Herefords the Best Breeds for Labor............................................ 293

\section{CHAPTER XXV.}

Cattle Food-The Grasses-Full Feed and Water-Shade in Pastureg-Change of Pastures-Winter Forage, and Care of Neat Stock-What Winter Feeding and Care of Stock Should be-Barns and Sheds........................ 297

\section{CHAPTER XXVI.}

Summer Food for Dairy Cows-Pastures-Soiling-Proper Solling Crops-The Best Kind of Corn for Soiling-Mr. E. W. Stewart's Experiments-Condition of Animals Soiled-Effect of Soiling npon the Product of Milk-Saving in FencesSaving in Manure-Saving in Land-Method of Feeding-Arrangement of Anlmals-Another Experiment-Fall Feeding-Winter Feeding............. 309 


\section{CIIAPTER XXVII.}

Sale Milk Dairies-Value of Milk Sold in the City of New York-In the United States-Swill Milk-Good Miik-Cooking Food-Why Fodder Should be CntMixing Food-Straw Cntters-Vaines of Different Food-Steam Apparatus-Results of Cooking-Experiments, \&c

\section{CHAPTER XXVII.}

Milk Cows-Their Selection-Mr. Magne's Essay on their General Character-Marks -Shape-Appearance-Hygienic Conditions-Selections for Breeding-Mr. Haxton's Modes of Selection-Guenon's Theory, \&c...................... 365

\section{CHAPTER XXIX.}

The Common Mode of Obtaining Dairy Cows-Milking, \&c............... 402

\section{CHAPTER XXX.}

Value Invested in Cows-Low Average in Production-Dairy Soils-Dairy Factories -Dairy Women-Love of Fine Cattle........................ 408

\section{CHAPTER XXXI.}

Miscellaneous-Pregnancy, and What Foliows-As Maternity Approaches-Marks Indleating Ages of Cattio-Discases, Treatment, and Cures-Habits and Tricks of Cattle-Kicking Cows-Kicking Oxen-Breachy Animais-Cows Sucking Themselves-Hooking and Quarreling....................... 415

\section{CHAPTER XXXII.}

Diseases Proper-Water Treatment-Garget-Pnerperal, or Milk Fever-Wounds, Bruises, Sprains, \&c.-Lowson's Treatise on Diseases and Cures......... 433

\section{CHAPTER XXXIII}

Castration-Spaying Heifers and Cows-Free-Martins-Drinking Water-Bloody, and Curdly Miik-Handiing-Proof-Large or Overgrown Cattle......... 516 


\section{INTRODUCTION.}

That the value of American Neat Cattle, as a branch of our agricultural interests, may be fairly understood and appreciated, some statistical facts and estimates are submitted.

The census reports for the years 1850 and 1860 give the following returns for the United States and Territories:

1850.

1860.

$\begin{array}{lrrr}\text { Milk Cows, } & \text {. } & 6,385,094 & 8,728,862 \\ \text { Working Oxen, } & & 1,700,694 & 2,240,075 \\ \text { Other Cattle, . } & \text {. } & \text {. } 10,293,069 & 14,671,400\end{array}$

Thus showing an increase in ten years, of about one-third, or $33 \frac{1}{3}$ per cent. in numbers; and, although, during the past eight years, since the year 1859, in which the last census was taken, four of these years, 1861 to 1865 , have been, during the war in the Southern States, a period of extraordinary consumption, waste, and depreciation in the numbers of their cattle of all descriptions, still, the aggregate of the entire neat stock of the conntry must have considerably increased.

The number of cattle in thirteen of those States, more or less disturbed and overrun by the armies at various times-leaving out Maryland - in the census reports of 1860 , was as follows:

Milk Cows, .

Working Oxen,

Other Cattle,
$3,305,953$

$1,732,232$

- $7,782,635$ 
Showing that nearly 40 per cent. of the milk cows; nearly 80 per cent. of the working oxen, and upwards of 50 per cent. of "other cattle" were owned in the Southern States, including Missouri. Of "other cattle," however, 2,733,267, or nearly one-third, belonged to the single State of Texas, where enormous numbers of semi-wild animals rove over the wide plains and savannas of its extensive territory, but of far less value per head, (probably not exceeding one-half,) than those under the same denomination in the other Southern States. So, also, of their milk cows, which were 598,086 in number, or about eighteen per cent. of the whole; and as of these cows probably three-fourths of them are as untamed as their "other cattle," and devoted only to the production and rearing of young stock, they cannot be denominated as "milk cows" proper, as they are in most other of those States; and are, therefore, of about the same proportionate value as "other cattle," with which they range. The working oxen of Texas, (172,243 in number,) devoted to labor purposes, we let stand.

Excluding, therefore, the Texan herds-working oxen alsoas less valuable than those of the other States at large, we class them separately; and calling the aggregate stock of all the Southern States now what they were at the last census-the waste of the war taken from what would be the natural increase in times of uninterrupted agricultural advancement-we may now put the numbers of the whole South as they were in 1860 , deducting Texas, viz.:

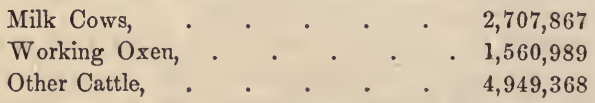

The natural increase of the cattle of the Northern States, including Maryland and Delaware, not much disturbed by the war, counting it as from the increase from the years 1850 and 
1860 , at about 33 per cent. every ten years, or 23 per cent. for seven years, would be thus:

Milk Cows, in 1860 , . . 5,422,909

Working Oxen, in 1860, . . . 507,843

Other Cattle, in 1860, . . . 6,888,765

To these, add, say twenty per cent. for the six to seven years' increase, and the numbers would now be, in the Northern States and Territories:

Milk Cows

Working Oxen, . . . . 609,411

Other Cattle, . . . . $8,266,518$

Thus, the present number of cattle in all the States and Territories, excluding Texas, stands, in 1867:

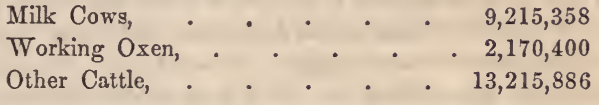

The value of these cattle may be safely put as follows:

Cows, at $\$ 40$ each, . . . $\$ 368,614,320$

Working Oxen, at $\$ 50$ each, . . 108,520,000

Other Cattle, at $\$ 30$ each, . . . $396,476,580$

$\$ 873,610,900$

Add the Texan cattle:

Milk Cows,

Working Oxen, . . . . 172,243

Other Cattle, . . . . . 2,773,267

The value of which may be:

Milk Cows, at $\$ 25$ each, . . $\$ 31,952,150$

Working Oxen, at $\$ 40$ each, . . 6,889,720

Other Cattle, at $\$ 15$ each, . . 41,599,005

$\$ 80,440,875$

Here we have an aggregate value of $\$ 954,051,775$-near a 
thousand millions of dollars-in $28,145,240$ head of neat cattle of all descriptions.

That the value of this stock is not over-estimated, we may state that the price of good dairy cows now ranges in the Northern States at $\$ 50$ to $\$ 100$ each, and working oxen at $\$ 150$ to $\$ 250$ a pair, according to age and quality. "Other cattle," which range from the last spring calves to heifers of three years, and steers of four years of age, the youngest of which are worth $\$ 5$, and the oldest $\$ 50$, in their pastures, are not over-valued. In our estimates of value; are not counted the thousands of "improved" blood cattle, of the different breeds, now becoming widely diffused over extensive portions of the country, and would, if properly accredited, add some millions to the aggregate value of our cattle herds. It may be said that our currency is inflated to thirty per cent. above gold prices, and a great depreciation will follow when we come to a specie basis. No matter. We take things as they are. We may safely estimate our working capital in neat stock, for the next five years, at a THOUSAND MILLION of dollars, and consider whether that amount invested by a nation containing near forty millions of people in the aggregate, is not worth improving and caring forso much so, at least, as to study, and find out ways for their improvement in breeding, rearing, and feeding-to raise them to the perfection of which they are capable, by more care than we have been accustomed to bestow upon them, without much increased cost in their food. This we believe to be both possible and practicable, and if these pages shall only in an imperfect degree, accomplish the object, our purposes will be answered.

Our Agriculture, in all its branches, is but in the gristle of improvement. The scarcity and high price of labor has compelled us to invent and use labor-saving implements and machinery in many departments. We drain, and ditch, and bring our waste lands under cultivation, and cultivate those we 
have long been accustomed to work, better than of old. We plow, and we sow, and we mow, and we reap, and harvest, and secure our crops somewhat better than our fathers did. We build better barns and shelters for our crops and farm stock than they could afford. We do many things better than they were accustomed to do, in the less enlightened days of their experi ence. We have numerous agricultural papers, edited by intelligent men and teachers. We interchange our ideas through them. We have our annual Agricultural Society meetings and exhibitions, in a majority of our States, and in multitudes of counties, and towns, and neighborhoods of the different States. Our stock, in the main, is better than the farm stock of fifty years ago; but it can be made better by thirty per cent. than it is, by a trifle more knowledge and experience than we now possess, and a better practice in taking care of them. We owe an immense debt of gratitude to those generous and enterprising men who, of late years, at so much cost and pains, have expended their time and money in introducing improved breeds from abroad, and urging attention to them upon those who, but for their efforts, would still be groping in the dullness of past times, and delving through all their abortive attempts to "get on," and strive, in their own darkness, at success.

It is to be regretted that there exists no accurate data on which to compute the annual slaughter and consumption of beef and veal in our country. No returns of this kind have been made in the census department of the government, and it is impossible to fairly conjecture its extent. New York City, and its immediate vicinity absorbs about 6,000 head of beeves weekly, making 312,000 per annum, besides multitudes of veal calves, and large numbers of milk cows, store cattle and working oxen, which are bought for use in the surrounding country, and of which we seldom hear anything again. The Philadelphia and Baltimore markets probably take as many more, and the New 
England cities along the sea-board, an equal number, making a round million in the aggregate; and the Southern sea board cities 200,000 more, including Washington, Mobile and New Orleans, making $1,200,000$. It is not too much to compute the consumption of the inland cities, towns and villages, altogether, at three times the number-3,600,000-swelling the aggregate to the sum of, say $5,000,000$ a year.* The value of these may safely be put at $\$ 60$ each, on the owner's farm, thus raising the entire sum to $\$ 300,000,000$, and perhaps higher, besides the heavy amounts which are slaughtered and packed in the interior for exportation abroad, amounting to some millions of dollars more. To these items, add the value of butter and cheese produced from cows, and the labor of working oxen, and the cattle interest of the country swells to an enormous aggregate.

The quantity of butter produced, in the census returns of the year 1860 , was $460,509,854$ pounds, being an increase of 46 per cent. over the returns of 1850 . The quantity of cheese, in

*To be more exact, so far as the consumption of New York Clty and lts immediate vicinity is concerned, we give below a condensed table taken from the New York Tribune Cattle Market reports for the year 1866, showing the annual receipts of all varietles of stock for the past thirteen years, and the prices at which beef has ruler for the year 1866.

"The welght, at whlch the eattle areraged, are only for the four quarters of the carcass, which includes, in value, the hide and tallow, as they are not paid for ontside of the meat.

RECEIPTS OF STOCK FOR A SERIES OF YEARS.

\begin{tabular}{|c|c|c|c|c|c|}
\hline $\begin{array}{l}\text { Beeves } \\
\ldots 169,864\end{array}$ & $\begin{array}{c}\text { Cows. } \\
13,131\end{array}$ & $\begin{array}{c}\text { Calves. } \\
68,534\end{array}$ & $\begin{array}{l}\text { Shcep. } \\
555,479\end{array}$ & $\begin{array}{l}\text { Swlne. } \\
252.386\end{array}$ & An. Totnl. \\
\hline $.155,564$ & 12,110 & 47,969 & 588,741 & 318,107 & $1,152,491$ \\
\hline $.187,057$ & 12.857 & 43,081 & 452,739 & $\mathbf{3 4 5 , 9 1 1}$ & $1,051,645$ \\
\hline 162,243 & 12,840 & 34,218 & 444,036 & 288,94 & 912,321 \\
\hline 191,874 & 10,128 & 37,675 & 447,445 & 551,479 & $1,238,601$ \\
\hline $.205,272$ & 9,492 & 43,769 & 404.894 & 399.685 & $1,068,092$ \\
\hline 226,9233 & 7,144 & 39,436 & 518,750 & 323,918 & $1,11^{\circ}, 181$ \\
\hline $.222,835$ & 5,749 & 32,368 & 512,336 & 559,421 & $1,333,229$ \\
\hline $1862 . . \ldots \ldots \ldots \ldots$ & 5,378 & 30,465 & 494,842 & $1,148,209$ & $1,907,880$ \\
\hline $363 \ldots \ldots \ldots \ldots \ldots \ldots 264,091$ & 6,470 & 35,709 & 519.316 & $1,101.617$ & $1,927,203$ \\
\hline $.267,609$ & $7_{4} 6035$ & 75,621 & 782,462 & 660,270 & $1,789,347$ \\
\hline ...........273,274 & 6,161 & 77,991 & 836,733 & 573,197 & $1,761,335$ \\
\hline 208,882 & 4,885 & 62,114 & $1,030,621$ & 666,392 & $2,062,891$ \\
\hline
\end{tabular}


the returns of 1860 , was $105,875,135$ pounds, being 340,000 pounds more than in 1850 . These are dairy farm products, to say nothing of the large amount of butter and cheese made for immediate consumption in private families, of which no accurate returns were made. Then, again, is the great consumption of milk in the cities, market towns, and villages of the United States, for which no returns can be found, and even an approximation in quantity cannot be accurately made.

The value of the butter and cheese, at present prices, may be estimated at something like this :

Butter, $460,500,000$ pounds, at 25 cents, home value, . . . . . $\$ 115,112,500$

Cheese, $105,875,000$ pounds, at 15 cents, home value, . $15,881,250$

$\$ 130,993,750$

Making, say, $\$ 131,000,000$ for these two articles. Of cheese, about $15,000,000$ pounds were then exported abroad, and the amount has since largely increased-all, chiefly the produce of the Northern States. The value of hides and tallow may be

MONTHLY RECEIPTS OF 1866.

Beeves. Cows. Calves, Sheep. Swine. All kinds.

\begin{tabular}{|c|c|c|c|c|c|}
\hline $.26,337$ & 505 & 2,259 & 88,819 & 72,417 & 190,337 \\
\hline February. & 306 & 1,411 & 66,249 & 36,893 & 124,063 \\
\hline March ... & 532 & 2,411 & 60,922 & 25,609 & 108,361 \\
\hline April ...... & 425 & 7,202 & 56,772 & 34,439 & 120.947 \\
\hline 28,289 & 471 & 9,281 & 73,085 & 62,126 & 173,252 \\
\hline $.23,572$ & 316 & 6,829 & 68,559 & 59,397 & 158,673 \\
\hline $.26,602$ & 5 & 7.510 & 83,693 & 48,443 & 166,774 \\
\hline .24 & & 4 & 92. & 42,489 & 164,937 \\
\hline mber. & & 5,385 & 94,536 & 48,564 & 175.718 \\
\hline ober... & & 7,762 & 135,301 & 91,865 & 268,346 \\
\hline 25 & & 4.405 & 108,744 & 72,003 & 211.2 \\
\hline ecember ............... & & 2006 & 101.279 & 72147 & \\
\hline
\end{tabular}

"If we value all the beeves at the estimated average price of $151 / \mathrm{c}$. per lb. for the net weight of meat, and rate them at only $7 / 4 \mathrm{cwt}$. each, it will make the enormous sum of thirty-three millions two hundred and twenty-three thousand seven hundred and twenty-three dollars and twelve cents $(\$ 33,223,723.12)$.

At the prices sbove stated, the beef animals would sverage $\$ 116.50$ each, from which the expenses of taking them from the farm to market must be deducted, averaging $\$ 15$ to $\$ 35$ each, according to the distance which they are transported. 
included in that of slaughtered cattle, as above stated. The prices of butter and cheese are placed low, as their wholesale home prices have ruled within the year 1866 at an average of full 30 cents for butter, and 17 cents for cheese.

Thus, the annual product of our neat stock may be estimated, within bounds, at:

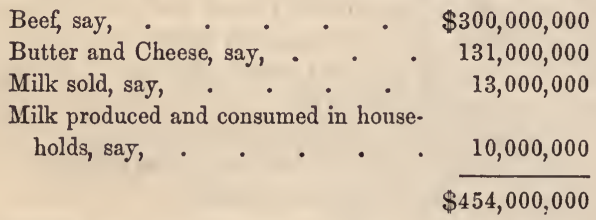

To this sum add the value of the labor of 2,240,000 working oxen at 25 cents each per day for 250 days in the year, besides the cost of keeping, making $\$ 140,000,000$, and we have a sum total of $\$ 594,000,000$ per annum; and adding the veals slaughtered in all parts of the country, we safely put down an aggregate of SIX HUNDRED MILLIONS OF DOLLARS a year produced from the neat cattle of the United States and their Territories.

An interest so enormous in its investment and production-a large per centage of which, we admit, is chargeable to the food it consumes and the labor expended upon it-merits the best consideration of every one concerned, and a close study of how much profit is to be derived from it. The amount of profit is comparative, depending on the quality of the animals, the care expended upon them, and their consumption of food. That this profit is far less than it should be in a country like this, is manifest in the wretched classes of cattle that are kept throughout a large portion of our territory, the lax manner in which they are cared, or rather uncared, for, and the stinted quantities of food they are allowed. Thus, there is evident 
necessity for increased attention to the selection of breeds, as well as to their breeding, rearing, feeding, and the general attention bestowed upon them, and which it will be the object of these pages to suggest and enforce.

The Americans, perhaps, of all people so intelligent and active in their agricultural pursuits, have been the least enterprising in improving their breeds of cattle, or in best cultivating those which they have. It may be owing somewhat to the wide resources in land which we possess, that such facts exist, but more to the want of study in the close economy which ought to dictate our policy. At all events, we are far behind what we should be, with the advantages at hand. The United States ought to possess, and cultivate extensively the best races of cattle known. Instead of that, we possess but a comparative few of the improved breeds, which are making their progress among our farmers either by the extension of their blood in its purity, or by infusion into our common stocks, with far less celerity than they ought. Yet, we are progressing.

Before closing this introduction, a word may be said of the material from which the text of our further pages is gathered. This work is not claimed as altogether original in its matter, although it is in language and manner. We have drawn what was necessary from European authorities of various kinds, both printed, and verbal. TVe have also made use of such domestic information of like character as we considered sound authority. Added to these, thirty odd years of personal experience, and close observation in the best breeds of European, as well as native American cattle, and of their breeding and previous treatment, has led us to discriminate between the erroneous and true, and as much as lies in our power, to exclude the one, and adopt the other. Could all the discussions, essays, histories, and accounts which have appeared in our published books and agricultural periodicals, be cullected and condensed into portable 
form, our own present labors would be unnecessary ; but lying, as these sources of information do, in fugitive volumes, or diversely scattered papers, they are both inaccessible and unavail. able to the mass of inquirers.

Although having preferences for some breeds of cattle for general use, over others, it is hoped that we can fully appreciate and do justice to them all, in their own proper merits, and for the particular localities to which they are best adapted, and give to the public a truthful exposition of the subjects of which we write, in all its bearings and economies. 


\section{AMERICAN CATTLE.}

\section{CHAPTER I.}

THE CLIMATES AND SOILS OF NORTH AMERICA, AS ADAPTED TO THE PRODUOTION OF NEAT CATTLE.

Is the diversities of climate, from the Gulf of St. Lawrence on the north, to the Gulf of Mexico on the south, and from the Atlantic Ocean on the east, to the Pacific on the west, with the various elevations and depressions of the surfaces of country between, we have a range of temperature, the most favorable to the production and sustenance of neat cattle in all their best known varieties, probably, on the globe. Eminently healthful to those foreign breeds inhabiting like climates at home, they have been as successfully bred here, where introduced, with less tendencies to those diseases which vex them there, while our soils produce herbage attractive to their appetites, and favorable to the best development of their natures.

From the Mediterranean on the south, to the Baltic on the north; from the mountains of the upper Rhine in Germany and Switzerland, to the western coasts of Ireland, Normandy and Spain, the cattle of Europe have crossed the ocean, to find their homes in the congenial climates and soils of America, with the cmigrating people, who reared them in their native lands. 
In their new homes they have bred and multiplied, with equal, if not better success than in the lands they left, although subjected to the vicissitudes of change of locality, less care, and in many instances, inadequate supplies of forage. The early cattle of America had to contend with hardships, like thcir owners; but surmounting them all, they multiplied and thrived apace, soon supplying all the wants of the increasing population, and yielding provisions for a growing export trade abroad. In the southern countries, they ranged on the fertile plains and sought their food throughout the year, ignorant of enclosure, and needless of shelter, while further north, as the climate became less favorable, and more care for their welfare was demanded, they found equally congenial homes amid the choicer grasses, and under the more comfortable shelter provided by their possessors.

The virgin soils of a new country are undoubtedly more free from diseasing influences, than regions tilled or pastured for many centuries. Yet, if annoyed by insects, or subjected to miasmatic influences prejudicial to their welfare, in the new settlements, these disappear with progressive cultivation, and in the two hundred and fifty years of their existence on American soil, taken altogether, our country has proved the healthiest cattle region in the world. Neither "cattle plagues" or other deadly infectious diseases have devastated our herds, unless in an occasional instance by importation from abroad; and although local disorders to some extent have sometimes appeared, a timely care and precaution have prevented their spread, and stopped their ravages.

The various soils and elevations of America, furnish in abundance their chnicest food, and the only discretion needed for their profitable culture is to select those varieties of cattle best applicable to the positions they are to occupy, and the uses demanded of them. Happily, these varieties are either already at hand, or within available reach, and it only needs examination to determine the kinds required, and sufficient means to avail ourselves of 
their possession. Wild natural grasses, of succulent growth and nutritious quality, abound in our prairies and open plains, while our wooded regions, reduced to cultivation, readily yield the domestic grasses in the richest abundance. In our cotton, rice, and sugar growing latitudes, where little attention has been given to the growth of cattle, or providing the grasses for them, they do not thrive so well, but in the hill and mountain districts of those States, with a proper regard to their provision, they flourish and prove a profitable branch of husbandry. As yet, so intent have been the people of the Southern States to seize upon the most available portions of the soil for quick returns for their capital and labor, that the more elevated regions within them have bcen neglected, until the idea has more or less prevailed, that even for neat cattle they were unprofitable. But that delusion is fast wearing away. Their climates are eminently healthful, their soils, though broken, are good, their valleys are rich, their springs and streams pure and abundant, and it only needs an increase of their population, and the application of vigorous and intelligent labor to convert those salubrious waste districts into the finest of pastures and meadows, and speckle them with herds. So, extending over all the ranges and spurs of the Alleganies, from the mild temperatures of Georgia and Alabama, through the Carolinas and Tennessee, the higher degrees of Kentucky, the two Virginias, and Pennsylvania, those mountain regions may become the great pastural country of the Atlantic States. So, also, with the slopes and valleys of the Rocky Mountains and Sierra Nevadas of the far West. As in the Highland districts of Scotland, and their contiguous islands, and the neighboring Continent, but on an immensely larger scale, among all these American mountains, and plains, the lighter and more active races of cattle may breed and range in multitudinous numbers, to be driven and fed for market on the lower plains and cultivated farms of the more populous grain growing States. 
As a country, we are in the merest infancy in cattle growing. We have no adequate infusion of the best breeds, in their variety, with which to populate these unreclaimed lands, if we had them reduced to a fitness for occupation. These varieties, or breeds, have existed for centuries in Europe, and are now bred to such perfection in their good qualities, as the cattle of no other portion of the world have attained.

The domestic animals of all countries, partake more or less of a character given to them as the result of the pursuits of the people who inhabit them; and let their original race or condition be what they may, they gradually assimulate to the treatment and uses to which they are subjected. The finest greyhound, pointer, or spaniel dog, in the hands of an uncivilized American Indian, in the course of generations will become the sneaking, savage cur that follows at the heels of his vagrant master, so that his once aristocratic lineage can hardly be detected. So, the neat cattle, of whatever original or cultivated race, no matter if the pure blood of centuries has coursed uncontaminated through their veins, may become altogether estranged in appearance, by abuse, or the hardships of long and neglected endurance. Being thus fortunate, in possessing a country, fitted in its various climates, soils, and altitudes for the best developement of which the several races of cattle are capable, we have only to direct our attention to that extent of cultivation which is necessary to attain the most profitable results.

To the fitness of the various known breeds, or races of cattle, to the different soils, climates, and localities of our wide country, we shall address our remarks as we proceed. 


\section{CHAPTER II.}

\section{NEAT CATTLE-THEIR HISTORY.}

THe genus Bos, as a domesticated animal, has been the useful and cherished companion of man from the earlicst date of history, either sacred or profane. That they were highly valued in days most ancient, we may know, from their being objects of labor, sacrifice, and worship, by different nations and people. They were esteemed articles of wealth, and sources of prosperity, and were probably cared for and cultivated with equal solicitude as any other domestic animal attached to husbandry, or of use as food. What was their normal condition as to race or breed, as we understand races and breeds, little or nothing is known, nor is it necessary that we do know. That they were then, in their chief essentials, as now, we have no reason to doubt; and that they may have been improved, or that they deteriorated in condition as civilization progressed, or waned, with the people who held then in subjection, we have little reason to question. The hieroglyphics of Egypt, most ancient in date, rude as were all their representations of man, things, and animals, give us no accurate likeness of what they might have been among that ingenious and wonderful people, and they were probably as highly cultivated among them as any where else in cotemporary timcs. The earliest representations or pictures we have, give them rugged forms, enormous length of upright, or spreading horns, and gaunt appearance. The clinates of the East permitted them to live throughout the year in the open air, and we may well suppose that nature supplied 
them with the rough, long hair necessary for their protection, so usually represented in their portraits by the artists of more civilized nations.

In the modern world, among the more highly cultivated classes of society, in polite literature it has been considered vulgar to talk of cattle, or to illustrate them other than as appendages to scenery, landscape, and rural representations among a rude and uncultivated people. So, too, with artists. The latter have composed cattle scenes, and introduced them as accessory to landscapes in their paintings, and so grossly have they misrepresented their forms for "artistic effect," as to caricature and give the ugliest appearances to them. Claude Lorraine, Salvator Rosa, Poussin, and others of the most celebrated schools of landscape painting of olden time, as well as Paul Potter, Van Ostade, and others of more modern date, made their cows, bulls, and oxell vulgar and uncouth in shape, and wretched in condition. Even landscape painters of the present day, with a silly affectation of "art," will put nothing resembling the noble contour of our improved cattle into a picture, but select some unhappy brute, depleted with poverty, and unkempt, as a wild buffalo in appearance, to give piquancy and effect to their drawings. For such slanderers of these noble animals, we have $n$ respect whatever, nor for the taste of artists in the way of cattle, while yielding an unqualified admiration to their fidelity and skill in other subjects.

Our modern animal painters have done better. Landseer, and Herring, among the English artists, have accorded somewhat of justice to their objects, while some of the Continental, and American artists in that line, have drawn our improved domestic animals - cattle as well as others-with admirable truth and fairness.

The ancients har a high respect and admiration for their cattle. Wc cannot admire the Egyptian worship of their ox, apis-a 
magnificent tomb of which has been recently exhumed-nor do we look with complacency on the present worship of the Brahma bull, which has been from time immemorial an object of Pagan idolatry in India; but it is evident that these subjects of adoration originated in a most devout appreciation of the admirable and useful qualities of the genus to which they belonged.

The author of the book of Job, which the eminent sacred chronologist, Doctor Hales, dates back to the year 2,337 before the Christian Era-whether that author was Job himself, or one of his cotemporaries-had a most poetic appreciation of the value of domestic animals. He makes Job in the days of his revived prosperity, the owwner of "one thousand yoke of oxen," in the enumeration of his great wealth of goods and chattels. Jeremiah-B. C. 628 years, in one of his Prophesies-speaks of "a fair heifer." Among the Pagan writers, Homer, eighteen hundred years before the Christian Era, celebrates the noble bullocks with "golden knobs," or balls, "on the tips of their horns," and describes the manner of the artisan in putting them on. Among the heathen deities, Juno is named as "ox eyed," in those clear and liquid features of her countenance. Virgil, who wrote his Georgiacs just before the birth of Christ, celebrates the beautiful cattle of the Roman Campagnas, and their value in the agriculture of the people.

Oxen were used for labor in husbandry, and more or less in commerce, in all countries where neat cattle were kept, and could endure the climate well, as being the most convenient beast of burden. It is probable that they were bred in their best estate by those who used them, and the cows were cultivated for dairy and household uses in the family. As they spread west and north into the higher latitudes and elevations of Europe, they somewhat changed their characters and became, as now known there, acclimated and fitted to their new conditions, and inured to the habits of the people who kept them. We may 
suppose, too, that in the severer climates they were afforded somewhat of shelter, and more pains-taking in food and treatment, than in the milder latitudes where they had long ranged, and with such increased care, improved in quality and appearance. They took, possibly, somewhat different shapes, and conformed, more or less, to the uses to which they were subjected. The Moors of Spain reared great herds of neat cattle, and from them descended the dominant races of Spanish herds. They were there the progenitors of the savage and headstrong bulls still sacrificed in the arena of bull-fights and picadores. The Gauls of France, bred the gentler and more economical forms of cattle adapted to a better husbandry.

By what gradual, peculiar, or natural progresses these Euro. pean cattle acquired their present distinctive characteristics, we have no definite information. History is either altogether silent or obscure on these subjects, and we have no better guide than conjecture to inform us. Throughout Western Europe numerous different breeds exist, of diverse qualities, all more or less useful for the purposes to which they are applied, and profitable to the people who breed and rear them. Italy, France, Spain, Germany, Switzerland, Holland, and other Northern countries, each have their peculiar national breeds, while England, Scotland and Ireland have many varieties widely divergent in character and appearance. Indeed, it is not necessary, unless for speculation or curiosity, that we know the particulars of their history or progress, inasmuch as we, in America, are already in possession of the best breeds of Western Europe, fully answering our own immediate purposes, and have successfully naturalized them on our soils. 


\section{CHAP'TER III.}

HISTORY OF AMERICAN CATTLE-INTRODUCED BY THE SPANIARDS INTO MEXICO-BX THE ENGLISH INTO VIRGINIA-BY THE DUTCH INTO NEW YORK-BY THE ENGLISH INTO OTHER COLONIES.

IT has been said, or conjectured, by some speculative antiqua. rians, that neat cattle were introduced to the Continent of America by the "Northmen," who are supposed to have made a descent on to the coast from North-western Europe some centuries before the discovery of the Continent by Columbus. This, however, is simply a conjecture, as no cattle were known before they were brought out by the Spanish and Portuguese emigrants, a few years after the voyages of Columbus. In the year 1519, the Spaniard, Cortez, discovered Mexico. He first made a landing at Vera Cruz, and not long afterwards penetrated to the City of Mexico, then ruled by Montezuma. The object of Cortez and his party was conquest. They were accompanied by a troop of horses, on which his cavalry were mounted for military purposes; but we have no account of any cattle in his expedition. Mexico soon became a colony of Spain, and was rapidly settled by emigrants from that country. Their first object was gold, and trade with the natives, and to their acquisitions followed agriculture, which brought in cattle from Spain.

We may suppose that cattle were introduced there as early as the year 1525, and in the nild climate and abundant pasturage which the country afforded, they rapidly increased. As Mexico became peopled and spread her population along the coast, and 
into the interior, in the course of time Texas was reached, and there were spread the foundations for the immense herds of Mexican, or, as we now call them, Texan cattle. California was afterwards settled by the Spanish Mexicans, who drove their cattle thither, and in time, scattered over it numerous herds. Of these we will speak hereafter.

In what are now the "United States," the first English colonial settlement was made in Virginia, on the James river, in the year 1607 , by a colony of a hundred men, which, by suffering, disease, and want of food, was reduced within a year, to thirty-eight. In 1609 , by new emigrations, the colony was increased to five hundred persons; but in a few months they were reduced by death to sixty. Many cows were carried from the West India Islands to Virginia in 1610 , and 1611 . In succeeding years more adventurers came out, but in 1622, three hundred and forty-seven men, women and children were massacred by Indians, and the colony, in effect, broken up. Whether their cattle were also destroyed, we have no account; but the settlement was soon after renewed under better auspices and protection, and neat cattle were further introduced and propagated.

New York was first settled in the year 1614, by the Dutch. That colony, after some vicissitudes, prospered. The first importation of neat cattle there, is said to have been in the year 1625 , from the mother country, Holland, and they rapidly increased in numbers, both in breeding and further importation.

In 1620, the English Plymouth colony landed in Massachusetts. In 1623, further English colonies came out and settled at Boston, and in New Hampshire. In 1624, the first arrival of cattle entered Massachusetts Bay. These were soon followed by other arrivals. New Jersey was settled by the Dutch in 1624 , and Delaware by the Swedes in 1627 , who brought cattle with them. The early records of New Hampshire state that in 
the years 1631, '32 and '33, Captain John Mason made several importations of cattle into that State from Denmark, to supply the Danish emigrants who had settled on the Piscalaqua river. These Danish cattle were coarse, large beasts, and yellowish in color. Settlements were made in Maryland in 1633; in North and South Carolina in 1660 and 1670; and in Pennsylvania in 1682 , all by the English, who either with the first settlers, or soon after, brought cattle over, chiefly from the counties nearest the ports from which they sailed. In all probability, numerous importations of cattle were annually made into the several col. onies, during successive years, as the emigrants came in rapidly, and the few early importations, with their increase, were insufficient to supply their wants. That cattle multiplied, both by natural increase and importation, is evident. We see it recorded, that in the year 1636, a party of emigrants went out to settle the town of Northboro, Massachusetts, thirty miles west of Boston, and in a company of one hundred men, women and children, they drove with them one hundred and sixty cattleand that was but twelve years after the first importation into the colony.

From these diverse and miscellaneous beginnings, our "native" cattle originated. Of what distinctive breeds they were selected, if selected with reference to breed at all, we have no information, nor, at this distance of time, can we be at all certain. Distinct breeds did then exist, well defined in their characteristics, both in England, and Scotland, and we are to presume, that needy and necessitous as the emigrants mostly were-going out for "conscience sake," as many of them did, and in a hope to better their fortunes with all-they paid litlle regard to breed or race in their cattle, so that they gave milk, performed labor, and propagated their kind.

As the colonists grew in numbers, and prospered in gear, their cattle, now become a leading branch of husbandry, aided 
much in their subsistence. Fanilies of considerable wealth from "home," began to add their numbers to the earlier emigrants, and brought with them domestic stock of various kind, provided them forage, and gave them shelter, and in some instances, probably, selected choice specimens from favorite breeds in the localities from whence they came, with which to improve those previously imported, or their descendants, the then native herds. But in a new country, harrassed by hostile savages, difficult of locomo. tion and intercourse with each other in distant settlements, their cattle were localized and confined to their own immediate neighborhoods, pushing out into new districts only with the adventurous parties forming settlements, where they could, of necessity, pay little attention to selection or "improvement" in their herds. They took such as they had, or such as they could get, at the least possible cost, as "browse" for the first few years was their principal forage in winter, "leeks" in spring, and coarse grass in summer and autumn for pasturage. The best they could do was to provide food for their families, and let their cattle shift for themselves. We presume however, that the earlier colonists, having become well settled and thrifty in circumstances, cared well for their herds and measurably improved their quality.

Thus, undoubtedly, stood the condition of the neat cattle of the colonies down into the years 1700 , and after. We have accounts that, as the merchants of the sea-coast towns grew rich, some enterprising ones made importations of choice breeds from England, which were driven into the country neighborhoods, and very considerably benefited their common stock.

In the year 1608, Quebec, in Lower Canada, was founded by the French, and soon afterwards, colonists came in considerable numbers from the western coast of France, and brought with them the little Normandy, or Brittany cattle, closely allied in blood, appearance, and quality, to the "Alderney" cows of the Channel Islands. They are now propagated in all Lower 
Canada, and throughout the many ancient French seignories in large numbers, forming their principal stock of neat cattle. They proved excellent milkers, hardy, easy of keep, and profitable for the dairy. They are also tolerable for the yoke, and for beef. In their remote distance, and limited intercourse with the people of the English colonies, it is not probable that their herds became intermixed. We have no accounts of the kind, and the peculiar characteristics of the cattle now there, after nearly two hundred years of acclimation and breeding, show no relations with the New England stock of our Northern States. 


\section{CHAPTER IV.}

QUALITY, CONDITION, AND APPEARANCE OF OUR NATIVE CATtLE

To arrive at a full understanding of the varied character which our American cattle present to a discriminating eye, we must know something of the prevailing breeds of the several European localities from which their progenitors were derived. For the present, we leave out the Spanish cattle of Mexico, as they are localized only in the far South-west, and do not comprise any considerable portion of our ordinary herds. They are now driven into the upper States, in few numbers, only for slaughter, and are not recognized as belonging to our "native" stock.

The Dutch settlers of New York brought their first cattle from Holland. Those cattle then, as now, were distinctive in their appearance, of fair size, roughly formed, black and white mostly, in color, with red occasionally intermixed; short, stubbed, and crumpled in the horn; good milkers, and generally useful animals. These cattle, for many years, followed the Dutch settlements along up the valley of the Hudson river and its tributaries, and became the chief stock of those localities.

We know little of the early cattle of Virginia, only that they came from the West Indies, and England; but as the eastern sections of the State were not a pastoral country, cattle were only a secondary interest in the agriculture of the people, and little attention was paid to their improvement. The Swedes brought some cattle with them into Delaware-of what character we are uninformed-but as they were soon superceded by the English, 
no doubt the herds of the latter became the leading stock. The early English settlers of the Carolinas brought cattle with them from their native land, and although numbers of the Huguenots from France followed them, and probably brought French cattle from Normandy, the English stock became the predominating race. North, and east of New York, the first settlements were mostly English, followed afterwards by a few Scotch, and occasionally by Protestants from the North of Ireland, and some Danes, into New Hampshire, and Maine. Thus the great preponderance of the early importations of cattle were from Britain, and as the Dutch colony of New York was subdued and occupied by the English in the year 1664, after which the New England people poured rapidly into the territory immediately adjoining their different settlements, we may suppose their neat stock followed and became the predominating cattle of their districts. Thus, the cattle of the colonies were mainly of British origin.

In a country of salubrious climate, a genial soil, in the hands of industrious and pains-taking people, with an eye to thrift, their neat cattle multiplied rapidly, and we may suppose, that after a fifty years' settlement, they required few further inportations. From what parts of England, or Scotland, and of what particular breeds these importations were derived, judging from their appearances at a later day, may become a question. We have noticed the characteristics of the early Dutch cattle, and even at the present day, strong resemblances to them are found in some of the localities where the descendants of the settlers from Holland still remain. Some inquirers have with great confidence asserted, judging from the cleaner limbs, the red color, and activity of the working oxen of New England, that the Devons were the original stock of its colonies, fortified by the fact that the first settlers were from Plymouth, a city of Devon. shire, on the western coast of England, the favored home of 
that breed. But, in answer to that conclusion, the first cattle were imported into Boston, four years later than the Plymouth colony, and Boston was called after a town in Lincolnshire, on the eastern ceast of England, though history is silent as to the particular localities from which these cattle were drawn. It is safe to conclude that the various importations were selected from the counties nearest the ports where the animals were shipped, and were of such character as the people selecting them had been accustomed, or were partial to, and that the herds thus brought out were an aggregation of several of the different breeds, which, once in the colonies, became intermixed in all possible degrees, without regard to their original stock, and taking such character as the fancy or taste of their different owners preferred. Hence, they became here a mixed race, partaking more or less in appearance of their original blood, some predominating over others.

The Devons, red in color, clean limbed, and sprightly in action, undoubtedly came over, and were many in number, as their descendants, more or less strong in the original blood, have shown. The Herefords, also, were here, with their larger bodies, white faces and throats. The coarser short-horns of Lincolnshire, from its own port of Boston, came too, with great carcasses, loosely put together, mixed colors, bountiful in milk, and strong for labor. The long-horns from Lancashire, shipped at its port of Liverpool, occasionally came out, as shown in many New England cattle late in the last century, and early in this. The polled, or hornless cows of Suffolk, and Norfolk, and possibly some Galloways from Scotland, came, as their descendants are still scen in the numerous polled cattle of Long Island, New Jersey, and a few other localities. With many people these polled cows, famous for milk, are decided favorites. It is probable, also, that an occasional shipment of Alderney, or the Channel - Island cattle, was made from the const of Hampshire, where 
they have long been kept, and now and then a Kyloe, from the South of Scotland. From all these sources, our native cattle originated, and so strongly have their different characteristics prevailed, that even now, in the localities where they have long been kept, an occasional one may be found in which a preponderance of the original blood "crops out," denoting its probable descent.

As emigration proceeded from the eastern coast to the interior, their neat cattle went with the people, intermixing still more in their new and scattered localities, until they became an indefinite compound of all their original breeds, and composing, as we now find them, a multitude of all possible sorts, colors, shapes and sizes. Thus our "native cattle," as we call them, have no distinctive character, or quality, although in some of the States, as a stock, they are better than in others. In the rough lands of New England where oxen were, and are still chiefly used for farm labor, and the dairy has long been an important branch of agricultural industry, their oxen are admirable for work, and their cows celebrated for their dairy qualities. They had also been bred with more care to selection than in almost any other section. The farmers preferred the red color, and high, spreading horns, leaning more towards the Devons, and Herefords. In fact, during the last century, and the earlier part of the present, the New England cattle were spoken of by many partial admirers as a "breed," so carefully had certain qualities been cultivated in them by their breeders. The "South Branch" of the Potomac, in Western Virginia, a broad, fertile, and fine pastoral region, has long been, down to a late day, celebrated for its fine cattle. From them sprung the well-known herds of the "Blue Grass" regions of Kentucky, and the Scioto valley, famous in the Philadelphia and Baltimore markets as beef cattle, before the short-horns of the "Patton stock," and the "importations of 1817 " were sent among them. 
The best cattle have not always followed the best lands. Those people who planted themselves in the finer grain growing regions of the interior, although using oxen for labor, more or less, until their farms were subdued and brought into easier cultivation, abandoned them for horses, as beasts of labor, and became indifferent to any selection of breeds; and as they did not become graziers, or dairymen, except for domestic use, and the supply of the local markets with beef and butter, they paid little attention to their cows, in comparison with those who made beef, and butter, and cheese their chief staples; thus their cattle stock was inferior. It was so with the planting interests of the South; cattle became a secondary object throughout the Middle and Southern States, and so remained until a comparatively recent time.

The result of all these indefinite and purposeless intermixtures of breed is now daily seen in herds which are brought into our eastern markets, from the principal stock growing States-a huge preponderance of inferior animals, both bullocks and cows. They are of all possible shapes, colors, and character, from the very worst to tolerably good, except in those districts where "improved" blood has been introduced, and better care in breeding and keeping has been practiced. There, really fine cattle are to be found. The chief defects of these common cattle are in their lack of early maturity, (requiring five to seven years to mature them, ) hard "handling," prominence of bone, a large pro. portion of offal to flesh, and an uncertainty both as to the quantity and quality of milk with the cows-all resulting from negligence, and want of care in breeding and using them. It would appear from the looks of these animals, that the best bull calves-if there were any best about them-were made into steers, and the meanest kept for propagating their race, and the best heifers, tending to early maturity, were turned into beef, while the worst were reserved for breeding, and the dairy. 
Such might be supposed the rule. That there have been, and still are, many exceptions to the above somewhat broad remark, is admitted, but these exceptions are of stock belonging to painstaking individuals and communities in the best cattle rearing districts, rather than among the farmers generally.

As to the profit of breeding, rearing, and fattening cattle of the lower qualities above noticed, perhaps the less said the better. That there was not, and is not any profit in them, compared with well selected, and well bred animals of the kind, is certain. They are great consumers of food in proportion to the flesh they carry, as a beef animal; and although numerous instances of wonderful feats at the pail have been recorded of the cows, yet the uncertainty of even these good cows pro. ducing an offspring equally meritorious, has been an utter bar to establishing a race, from among themselves, of superior, or even standard value for the dairy. It is a chance medley affair altogether-a mere ticket in a lottery, the chances of drawing a blank greater than that of a prize.

To the farmer, then, desirous of getting a foundation for a profitable stock, either for beef, working oxen, or the dairy, from such incongruous intermixtures, his chances are, at the best, precarious. He may make selections from them, perhaps, which will promise something, and by a long course of pains-taking he may improve them to some perceptible extent; but at the end of a lifetime he will find the same things on his hands at last. Thus, his efforts will prove, in the absence of really good breeds crossed upon them, a failure. That he may make selections of cows from such stock, on which, with the use of bulls of good established breeds, he can build up valuable herds for the shambles, the yoke, and the dairy, is certain. These native cows, from the necessities of the case, must be the foundation on which he must rely for that purpose, the manner of which we shall more thoroughly discuss hereafter. 
In summing up the foregoing remarks, the reader will conclude that the writer has little affection for our "native" cattle. In the mass, he has not. Yet there are wide and numerous exceptions, and among these exceptions we can name no definite class of the natives among which to particularize. Our choice would be of individual animals only, not of herds taken as they run. Even on those of our choice, we would not rely for improvement by breeding among themselves only, but by the introduction of pure bred bulls of some established breed, would we look for permanent progress in our herds. 


\section{CHAPTER V.}

THE ANATOMICAL AND ECONOMICAL POINTS OF CATTLE.

As a good deal will hereafter necessarily be said upon the various points of cattle, an illustration of them is given in the animal itself. It is the outline side view of a well bred shorthorn ox, but applicable to any other breed-or no breed-as well, and will show the various parts more or less valuable as a consumable article, or as delineating qualities, the prominence in which, in either sex, may render them desirable for the uses which are to be made of them.

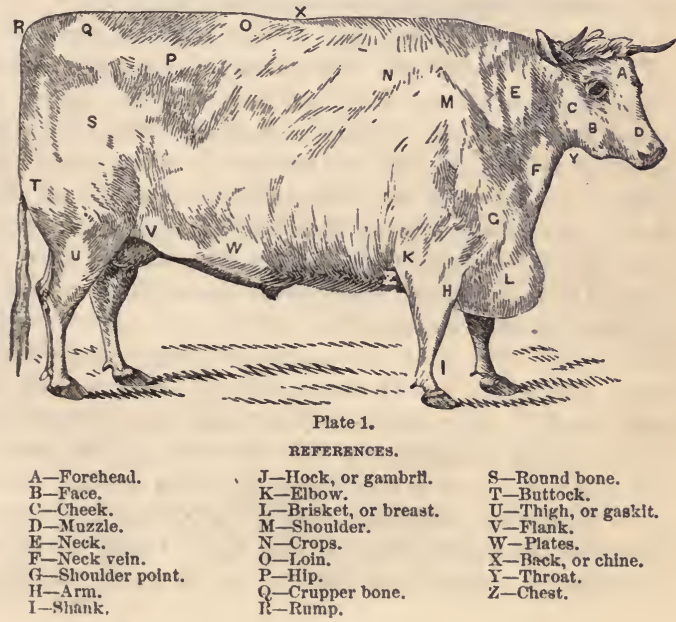


These points it is necessary that every cattle manager should understand, as they are the marks which, in their development, or absence, make up a great share of the value, or beauty, or ugliness of shape of the animal. The prominence of these points vary in the different breeds, or races. They also indicate, measurably, to what uses, and to what soils, the animals more strongly showing them, are best adapted, and a familiarity with the terms necessary to mark the criticisms which breeders or graziers may make on them.

A rear view of the animal, which is hardly necessary to give, would develop another point which is omitted in the diagram, viz.: The "twist," or junction of the thighs, the proper position of which, high or low, is quite important in adding to or subtracting from the value of the beast. The point is named here, as a reference may frequently be made to it hereafter.

The true value of an animal for beef purposes, depends on its lightness of "offal" when slaughtered, in comparison with its flesh; therefore the less bone, and poor flesh, the better. A coarse and open bone, by which is meant an undue growth and protuberance of that portion of the carcass, carries with it less valuable flesh than a fine, compact bone; therefore no more bone is necessary than, in its proper position and development, will give the substance and breadth necessary to carry the amount of flesh required. Some cartle are so loosely, or sleazily put together that the ligaments necessary to connect the different parts of their bodies are unnecessarily large, making tough meat, though ever so well fed; thus rough, coarse animals are unprofitable in every way, as they are large consumers of food, and weigh less at slaughtering than the more compact ones of less apparent size, while their flesh is of inferior quality. Coarse bone bears more offal (bone is offal,) in worthless flesh, in pro. portion to live weight, than fine bone does. Coarse bone gives more dewlap, and loose skin, than fine, and as the hide is usually 
of less value than flesh, an undue weight of hide is unprofitable. Coarse bone gives less tallow, too, a larger belly, more paunch, and less lungs, besides more "daylight" under the carcass-all bad points. In short, a coarse, rough boned beast is bad, all round, while a smooth, fine bone, properly placed, is a great. excellence, either in a bullock for slaughter, a working ox, or a milking cow; and this fineness should prevail thronghout, from the muzzle to the tail, and the hoofs. As a rule, strength, activity, and good constitution accompany fine boned animals, while comparative weakness, sluggishness, and tendency to disease accompany large boned ones. Horn is offal; therefore an undue development of it is worthless-not only worthless, but a damage, and like bone, an utter loss in the weight of carcass. Hide being of less value, no greater development of that material is needed than to answer its purpose of protection to the flesh and muscle beneath it; therefore a rough, thick, and heary hide is a bad point; yet whatever the hide may be, it should be sufficiently loose and flexible to the touch to indicate an elastic flesh within it. The head-usually all offal-is in most instances a fair indication of the character of a heast. A coarse, bony head almost always accompanies a coarse boned body, and a comely, handsome head a fine boned one. So with the tail, coarse or fine, as the creature itself may be.

Having given a diagram of a comely, well bred beast, we now refer to some decidedly bad ones. It might be considered hardly worth while to do so, when one can so readily find them out of doors, but for ready comparison we refer to the cut of Texan cattle in another place, and the analysis of points just given in the good beast, may be applied to them to mark the difference.

In the Texan cattle, their deficiencies throughout are seen in striking contrast to the firm, even fleshed carcass of the other. The flat rib, narrow chest, ragged dewlap, thin flank, long leg, 
and the looseness of the anatomy generally, contrasted with the round springing rib, wide chest, clean neck, deep flank, short leg, and compact carcass of the other, shows the superiority of the latter in every way, so that the merest neophyte cannot mistake the difference; yet the spectator in our cattle markets will see many more bad specimens than good ones, and many of the bad not much better than the Texans; or, if all their unnecessary offal, by extraordinary pains and feeding, be covered with a reasonable quantity of flesh, it is done at a great waste of good fodder.

Men inured by long habit to a partiality for the common cattle, always contending that "the breed is in the mouth," and blindly averse to all improvement, may insist on the equality of their rough beasts to the finer ones. But it is of no use. Measured by the scales, both animal and food, and the time it takes to bring the creature to the block-the only way to settle the matter-they must be unprofitable; and, compared with improved animals, the time, labor, and food bestowed on them by their owners, is measurably lost. Our beef eating population -and almost all are such-know the difference between the good and poor article. They will take the one at a good price, provided the article can be had at all, and reject the other at a lower one. Our agriculture is now sufficiently advanced to breed and rear good animals, while the poor should be discarded; and it is a waste of both time and money to adhere to the poor, so long as the valuable ones can be procured. Nothing but sheer ignorance, or obstinacy, can be an apology for adhering to a bad practice in anything; and when only a common diligence and foresight is necessary to acquire the good, he who doggedly persists in the bad, deserves little sympathy, either for his want of success, or absolute losses. 


\section{CHAPTER VI.}

\section{IMPROVED BREEDS OF CATTLE-WHAT ARE THEY?}

Having demonstrated-satisfactorily, we trust-the absence of a due utility in the common cattle of our country, and the need of something better, we arrive at the consideration of those distinct breeds, of fureign origin, which are to aid in exalting our herds to those points of excellence so eagerly desired by all who appreciate our singular advantages of soil and climate for the attainment of that object.

It is no new thing to say that Great Britain in its insular position, its redundant population, its energetic enterprise, and the absolute necessity which has compelled the development of every resource at command to improve the condition of its agriculture, stands in advance of all nations with which we are acquainted, in the excellence of its neat cattle. Its enlightened land holders and farmers have taken the different local breeds long familiar to their various districts, and by a wise selection, care in breeding, and the application of proper food and treatment, produced specimens of bovine excellence at once the admiration, and worthy the imitation of all who aspire to equally high attainments in their stock. We say this in no fulsome laudation, but with a settled conviction of the fact. We have tested in our own country, the results of their efforts in the improvement of their various breeds of cattle, and finding them to answer our purposes equally well, it is wise in us to follow their example as it was discreet in them, for their own benefit, to become our models. Satisfied, therefore, that we 
cannot resort to a better source for the purposes we seek, a description of several of their most approwed breeds is necessary, that their application to our uses may be understood, and on due consideration, adopted.

Great Britain is an old country. England-all, probably, of it that was worth the conquest-was invaded and possessed by the Romans before the Christian Era. It was held by them so long as they had the power, and until the unconquered spirit of the ancient Britons, after near four centuries of Roman rule, drove the more civilized invaders out and re-established their own authority. Barbarians, when the Romans invaded them, comparative barbarism still held sway over the people when the Romans went out. The adjoining and even less civilized people of Scotland, were hardly worth a conquest by the Romans, had they sought it. They held their own muuntain fastnesses and barren islands, and only suffered by the occasional inroads of the neighboring continental invaders, who long afterwards rav. aged England. With the conquering Saxons, in the fifth century, eame into England some beiter dawnings of civilization and progress in the arts of life; but with the invasion of the Normans in the eleventh century, under the first William, began the progress which has since advanced England, and afterward Scotland, to a higher civilization, and their agriculture to a more perfect condition than that of any other country in Europe.

Cattle, always numerous in England, furnished the people with food in their flesh, and partial clothing in their skins. They were exported to countries abroad, with various other articles of commerce, under the dominion of the Romans. While the Danes were ravaging England with varied success under the Saxon rule, cattle were brought in from the neighboring continent, and also exported from the island. They were kept in such numbers as to be a considerable portion of the wealth of the people, and oxen were mueh used for labor. With the 
dominion of the Normans, came the division of the land into the great estates given to the retainers of the Conqueror, and the gradual zubdivision and settlement of these estates into farms, the establishment of a tenantry, and after a long time, an improvement in their agriculture. There was little intercourse among the people belonging to different localities. Roads were few and bad; for some centuries, the tenants mostly paid their rent in kind. Of the cattle reared on the farms, the surplus were chiefly driven away by dealers who purchased them of the farmer at his own door, or at the neighboring cattle fair. The home herds were thus localized, and became indigenous to the soils on which they were reared. Hence breeds were gradually established in different districts, or localities, although their peculiarities may have followed them from remote periods, or been introduced from abroad. So they descended, and we hear little of them, or their improvement, until a late period in the history of British agriculture.

Early after the year 1700, when Great Britain had become one of the first commercial nations, her commerce whitening every sea, and her foreign conquests and colonial settlements reaching various quarters of the globe, her manufactures become a source of great national wealth, and the enclosure of her waste lands and the highest improvement of her acres had become indispensable to the welfare of the people, we begin to hear of the improvement of her breeds of cattle. Many papers and books have been written about these breeds by various authors, some in the last century, and more in the present. Among all the authors, Youatt, the most elaborate, and discriminating in races, and breeds, together with the compilations of their several histories-so far as he could find them-has been the chief. This author, a man of education and a Veterinary Surgeon, living in the vicinity of London, was employed by "The Society for the Diffusion of Uscful Knowledge" to com- 
pile a work on "British Cattle." The book is chiefly compiled from various contributions sent to him by men of knowledge and experience on the subject, with accounts obtained from other authors, and their publications, aided by personal observations of his own. It is an excellent book, on the whole, and contains, probably, a more correct body of information in that line than can be drawn from any other individual source, though not altogether free from error, or prejudice. We have drawn a share of our information from Youatt, some from other wellknown British writers of the last century, others in the present century, as well as some from American writers. We do not name all our authorities-very few, indeed-as many of them were authorities to Youatt, as well as to our own writers, and we find more or less of them quoted and repeated by all. It is sufficient to say, that we have examined and analyzed, with much care, these various authorities, preserving such as bore the semblance of truth and probability in their accounts, and rejecting those only, not necessary to our purpose.

British cattle, by general consent of these authors, appear to be subdivided into four distinct classes-the middle-liorned, longhorned, short-horned, and polled, or hornless. They all have, or until recently, had their own various localities and districts in the several parts of England and Scotland, where they have existed from a remote period. Each were favorites among the farmers and breeders of their homes, rarely taken out of their districts, except for market, and until after the middle of the last century, like the people who reared them, strangers to other parts of the kingdom, and migrating back and forth no farther than to the nearest market towns, or district fairs. Thus they became homogeneous, deeply interbred among their own tribes, and closely retaining their own distinctive qualities, uncontaminated by the blood of other breeds, and transmitting their qualities and characteristics with a pertinacity and truth, of which 
those giving the subject little study, can scarce realize. As such they have come to us, and only as such we know them.

We commence a description of the different breeds, which our volume is intended to enumerate, with the middle-horned breeds of England; and first of these, take that one apparently most ancient in lineage. 


\section{CHAPTER VII.}

\section{MIDDLE-HORNED CATTLE-THE DEVONS.}

THis beautiful race has been considered, by some authors, aboriginal, and are claimed to have been known in England at the time of its invasion by the Romans. It is certain that their fineness of limb, uniformity of color, delicacy of proportion, and depth of breeding, give them claims to a distinction which no other race of English cattle exhibit; and be the fact of their - remote origin as it may, there is no necessity of disputing it, or speculating on other probabilities. They are like no others, and by no intermixture of any other known breeds have they been, or can they be produced.

In what degrees of excellence the Devons existed during past centuries, we are unable to say; but that they possessed valuable qualities which endeared them strongly to the people who bred them is certain. Great attention has been paid to their improvement during a century past, and probably not neglected for centuries before. Not a single infusion of the blood of other known cattle can be detected in them, and for their improve. ment, as Devons, none other can be devised. In the good judgment, sagacity, skill, care, and pains-taking of their breeders alone, must be sought the means by which they stand in their present condition of excellence and beauty.

As no written description can convey to the unpracticed eye their exact appearance, we shall illustrate them by accurate portraits, taken from life, and as the portraits cannot show them in all their points, a more particular description is added. 
The head-lean in flesh, is rather short, the forehead broad, the face slightly dishing, and tapering gracefully to a fine, clean, yellow muzzle. The eye-bright, prominent, and surrounded by a ring of orange colored, or yellow skin. The horn-upright,

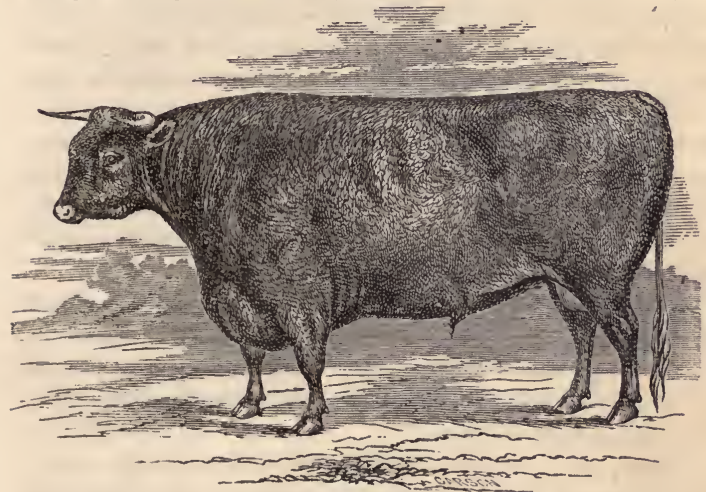

Plate 2. Devon Bull.

and curving outward, cream colored, black at the tips, graceful in its setting, and rather long, for the size of the animal. The ear-well set, and lively in action. The neck-on a level (in the bull slightly arching) with the head and shoulders; full at its junction with the breast, clean, and without dewlap. The shoulders-fine, open, (somewhat slanting, like those of the horse,) and on a level with the back. The neck-vein-full, and smooth. The arm-delicate, and the leg below the knee, small, terminating in a clean, dull brown, and somewhat striped hoof. The brisket-full, and projecting well forward. The cropswell filled, and even with the shoulders. The back-straight from the shoulders to the tail. The ribs-springing out roundly from the back, and running low down, to enclose a full chest, 
and setting well back towards the hips, giving a snug, neat belly. The flanks-full, and low. The hips-wide, and level with the back. The loin-full, and level. The thigh-well fleshed and full, the lower part somewhat thin, and gracefully tapering to the hock; the leg below, small, flat, and sinewy. The twist-(the space between the thighs) well let down, and open. The tail-taper, like a drum stick, and terminating with a brush of white hair. The color-invariably a cherry red, sometimes showing a lighter, or deeper shade, and the skin, under the hair, a rich cream color. The bull, of course, will show the stronger, and masculine character of his sex, while the ox will develop the finer points of his condition, and the cow, all the delicacy and refinement belonging to her race.

In the roundness, and fullness which accompany the proper development of the points named, the silky, wavy laying of the hair, and the elastio touch of the flesh as the finger is pressed upon it, every beholder will at once see, in appearance, a most bloodlike and graceful animal.

In size, the Devon is medium, compared with our native cattle. A well grown ox, in good working condition, will range from 1,400 to 1,600 pounds live weight. The bull from 1,000 to 1,200 , and the cow from 800 to 1,000 pounds. They sometimes exceed the heaviest of these weights, but such are the average. Fatted to a high degree, they will, of course, weigh heavier. In size, it is said, in England, that they are larger than they were a hundred years ago, before the attention of their breeders was thoroughly attracted to their improvement. From time immemorial they were chiefly bred in the northerly part of Devonshire, (and thus called North Devons,) one of the south. western counties, in a mild climate, abounding in good pasturage. They have since spread into the adjoining counties, and many years ago, (within the present century,) were taken into the higher county of Norfolk, on the Eastern Coast, by the late Earl 
of Leicester, (then the noted Mr. Coke, of Holkham, a distinguished farmer, and landed proprietor,) as he considered them eminently fitted for grazing on the light sandy soil of his estates. They are now bred in many other counties of England, and are decided favorites on hilly soils, where their lighter weights and activity in movement are better adapted to grazing and labor than the more sluggish cattle of the heavier breeds.

The most noted breeders of Devon cattle in England, for the past forty years, have been the Davy brothers, Messrs. Quartly, Merson, Childs, Turner, the Duke of Bedford, and some others in the west of England, the Earl of Leicester, and. Mr. Bloomfield, in Norfolk, and among the earliest of the improvers, the Lords Somerville, and Western. From the herds of all these breeders, noted prize animals have been drawn, and their fame has largely added to the popularity and dissemination of the breed. As an economical animal, the Devon may be classed under three distinct heads, viz.: for the dairy, the yoke and the shambles.

\section{AS A DAIRY COW,}

The Devon may be called medium, in the quantity of milk she yields, and in its quality, superior. The older, or unimproved race, were somewhat noted for the quantities of milk they produced, as well as its good quality. A gallon of Devon milk yielded more butter than that of almost any other breed, as it does now, except the Alderney. But their improvers, in the attainment of a finer form, and heavier substance in their animals, perhaps sacrificed somewhat of the quantity of milk, for the more liberal development of flesh, well knowing that both flesh and milk could not thrive equally together in the same animal; although, when the milk ceased, the flesh came on with due rapidity, under generous feed. Yet, with an eye to breeding her solely for milk, she is well fitted for a dairy cow. Docile in temper, easy of keep, placable in disposition, she is 
readily managed. Her udder is soft, tidy in shape, with thin, silky hair upon it, clean, taper teats, easily drawn, and every way satisfactory to her keeper.

We submit a portrait of a well bred cow, dry of her milk and fatted, in which will readily be seen the fully developed characteristics of her race.

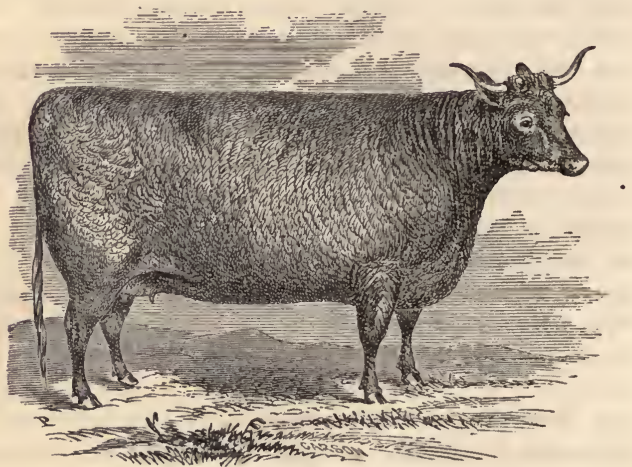

Plate 3. Devon Cow.

As an evidence of the milking qualities of the Devons, very considerable dairies of them have long been kept in England. In Youatt, is an account by Mr. Conyers, of Epping, who, in the year 1788, kept a dairy of them. "He preferred the Devons on account of their large produce, whether in milk, butter, or by suckling. He thought that they lield their milk longer than any other sort that he had tried; that they were liable to fewer disorders in their udders; and being of small size, they did not eat more than half what larger cows consumed. He thus sums up his account of them: 'Upon an average, ten cows gave me sixty pounds of butter per week, in summer, and twenty-four 
pounds in the winter. A good North Devon cow fats two calves a year.'" Other favorable accounts are given, yet some are different. They speak of a less quantity of milk given by Devons, but the quality as remarkably rich. Count de Gourcy, an intelligent French agriculturist, and traveler in England, remarked that Mr. Bloomfield's Devon cows, on the estate of Lord Leicester, in Norfolk, each averaged four pounds of butter per week, the year round.

It is to be regretted that English published accounts of the dairy production of the Devons are so meager. We have fuller and more favorable accounts of them in America. Mr. George Patterson, of Maryland, who, for many years has owned the largest herd of pure bred Devons in the United States-some seventy or eighty in number-remarked to the writer, when at his farm in the year 1842, that his cows were better milkers, and yielded more butter on an average than any other breed. His stock is descended from some of the best animals of $\mathrm{Mr}$. Bloomfield, the principal breeder of the superior herd of the Earl of Leicester, (both already noticed,) and since crossed by occasional imported bulls from the same herd. Mr. Patterson has always bred his cows with a special eye to their milking properties, and in them and their descendants, in different parts of the country, have been found many remarkable good milkers. Other accounts, entered in our memoranda at the time, were equally satisfactory. We have good authority of some of them yielding ten to twelve pounds of butter per week.

Other breeders who have kept choice herds of Devons for several years, have repeatedly assured us that they were superior milkers. They have given 18,20, and 22 quarts of milk per day, for months after calving, under steady milking.

Our own experience has been something in this line. We have kept thorough bred Devons thirty-four years-sometimes as high as twenty-five or thirty (not all milk cows) in number. 
Many of them have been excellent milkers, and some of them extraordinary, for their size. We once had two three year old heifers, with their first calves, which gave for some three months after calving, on pasture only, with steady milking, an average of eighteen quarts per day; and from cows which we have at different times sold to go to other States, the accounts of their milk have been equally good. It is but fair to say however, that after we commenced crossing our cows with bulls of later importations, some fifteen years after the commencement of the herd, the large milkers were not so numerous, although the cattle from these crosses were somewhat finer. The bulls we used were apparently bred from stocks highly improved, with an effort more to develop their feeding properties, than for the dairy. After all, our Devons yielded, on an average, quite as much as any common cows we ever kept, with much less consumption of forage.

With all her alleged deficiencies, the Devon possesses the inherent qualities of a good milker. Her dairy faculties may be bred out of her by neglect of that important item, and with a view to give her an earlier maturity, and more weight of flesh; but even under that system, she will occasionally persist, as we have known in various instances, in giving a large flow of milk, exceeding many common cows of equal size. On the whole, from the accumulated accounts we have received from time to time, coupled with our own experience, we pronounce the Devons, as a race, when bred with an eye to the development of the dairy quality, considering their size, and consumption of food, good dairy cows, both in the quantity of milk they give, and the butter it yields.

\section{AS A WORKING OX.}

In this valuable quality, no animal of the same size and weight equals the Devon-for the following reasons: They are, among cattle, what the "thorough bred" is among horses. According 
to their size, they combine more fineness of bone, more muscular power, more intelligence, activity, and "bottom," than any other breed. They have the slanting shoulder of the horse, better fitted to receive the yoke, and carry it easier to themselves than any others, except the Herefords.

With all workers of oxen, the nearer a beast approaches $m$ shape, appearance, and action to the Devon, the more valuable he is considered, according to weight. For ordinary farm labor, either at the plow, the wagon, or the cart, he is equal to all common duties, and on the road his speed and endurance is unrivalled. It is in these qualities that the New England oxen excel others of the country generally, and why the people of that section often call their red oxen "Devonshires," when they cannot, to a certainty, trace any, or but a small portion of that blood in them, only by a general appearance and somewhat like action.

For active, handy labor on the farm, or highway, under the careful hand of one who likes and properly tends him, the Devon is every thing that is required of an ox, in docility, intelligence, and readiness, for any reasonable task demanded of him. Their uniformity in style, shape, and color, render them easily matched, and their activity in movement. particularly on rough and hilly grounds, give them, for farm labor, almost equal value to the horse, with easier keep, cheaper food, and less care. The presence of a well conditioned yoke of Devon cattle in the market place at once attests their value, and twenty-five to fifty dollars, and even more price over others of the common stock are freely given by the purchaser.

The Devon, in his lack of great size, is not so strong a draught ox as some of the other breeds-the Herefords, for instance-or perhaps some of the larger of the common cattle; but, "for his inches," no horned beast can outwork him. On light soils, and on hilly roads, none other equals him, although we intend to give 
all their due share of merit. Our cut is that of a prize stall-fed steer, at four years old. It shows his flesh-taking qualities in high perfection.

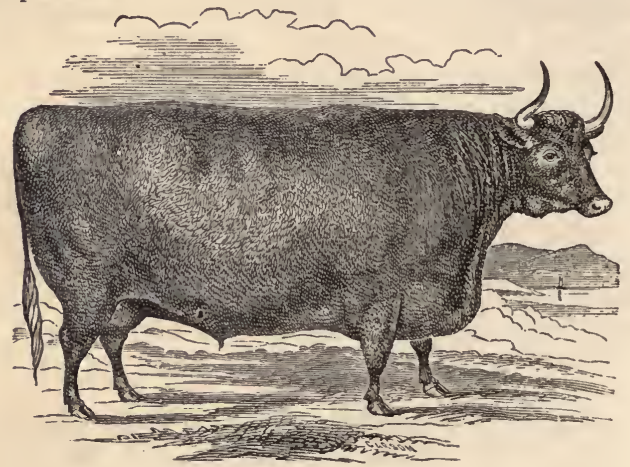

Plate 4. Devon Ox.

AS A BEEF ANIMAL,

We must place the Devon in the first class, for fineness of flesh and delicacy of flavor. Its compact bone gives it the one, and its rapid and thorough development under good feeding gives it the other. In growth and size it matures early, equal to the short-horn, and its meat is finer grained, juicy, and nicely marbled, (the lean and fat intermixed.) In the London markets, Devon beef bears the highest price of any, except the Highland Scot-usually a penny a pound over that of larger breeds, and our American butchers quickly pick the Devons from a drove, when they can find them, before most others. They feed well, take on flesh rapidly, and in the quality of their flesh, are all that can be desired.

The following weights of Devons from the London, Smithfield markets, are giren : 
One 5 years 11 months old, dead net weight, 1,593 lbs.; one 3 years 7 months old, dead net weight, (rough tallow $160 \mathrm{lbs}$.) 1,316 lbs.; one 3 years 10 months old, dead net weight, (rough tallow $128 \mathrm{lbs}$.) $904 \mathrm{lbs}$. The Earl of Leicester's steers, at four years old, on his Holkham estates, gave dead net weights of $1,000,1,200$, and even 1,400 lbs. Those of the Duke of Norfolk, near Bury, in Suffolk, made 900 to 1,000 pounds each. These were all highly fed, and possibly, some of them, prize beef.

A 3 years 10 months old steer, in Genesee County, N. Y., gave, dead net weight, 1,200 lbs._-hide and rough tallow included-the latter being over 100 lbs. The late Mr. Lemuel Hurlburt, of Winchester, Connecticut, fed a pair three-fourths Devon cattle, having worked them till six years old, and fed them 15 months afterwards. Their weights were as follows:

$$
\begin{aligned}
& \text { No. 1-Carcass, . . . 1,438 lbs. } \\
& \text { Hide, . . } 117 \text { lbs. } \\
& \text { Tallow, . . . } 175 \text { lbs. }-1,730 \text { lbs. } \\
& \text { No. 2-Carcass, . . . 1,528 lbs. } \\
& \text { Hide, . . } 115 \text { lbs. } \\
& \text { Tallow, . . } 213 \text { lbs.-1,856 lbs. }
\end{aligned}
$$

We have had slaughtered many of our own grass fed steers, three-fourths, to seven-eighths, and thorough bred Devon, at $31 / 2$ years, which made 700 to $850 \mathrm{lbs}$. net weight of beef, hide, and tallow, and never fed anything but grass and hay, from calves.

After all we have said of the Devon-and our praise is not too high-popular opinion in America has, to a considerable extent, classed him as too small in size for the most profitable uses-"They haven't growth enough." But for their apparent size, and actual measurement, no animal of his race, not even a short-horn, will weigh a heavier carcass of the best meat, laid on in the choicest parts. With some, his want of size is an available objection, with others not. In the Southern States the Devon is often preferred to any other breed. They gather 
their food with more ease, they bear the climate well, are more free from diseases than many others. On our high lands and mountain ranges, with short grasses, sometimes not easy of access to heavier cattle, they must prove profitable graziers, and as a beef producing animal will answer a valuable purpose where others would fail.

\section{DEVONS IN THE UNITED STATES.}

It is a subject of regret that our accounts of the earlier introduction of these cattle to this country are so meager. There is little doubt, from the appearance of many of the New England cattle in the last and present centuries, that some Devons, in their purity, were early brought into Massachusetts. Traditional tales of their neat limbed, sprightly, red, high-horned cattle, have existed, and that they sprung from a Devon cross is beyond a question. But we have no particular published records of these importations until the year 1817, when Messrs. Caton \& Patterson, merchants of Baltimore, Maryland, received several of them from "Mr. Coke, of Holkham."

-These, a few years afterwards, fell into the hands of Mr. Geo. Patterson, (already noticed,) son of one of the importing partners, who retains their descendants to the present time. This stock has been largely multiplied, and spread through various parts of the country.

A year later-1818-Rufus King, the distinguished statesman, of Jamaica, Long Island, N. Y., imported a few animals from Mr. Coke's herd.

Not long after the Caton \& Patterson stock came over, Mr. Henry Thompson made an importation of a few Devons into Baltimore. There may have been some few other importations into Boston, or other ports, about the same time, or a little later than these, but we have no particular accounts of them.

About the year 1835-6, an English farmer named Vernon, 
brought a bull and cow into Genesee County, N. Y., from the herd of Mr. Davy, in England.

In 184- the Massachusetts Agricultural Society made a considerable importation of Devons into that State, which were some time afterwards distributed in various parts of New England.

About the years 1852-3, Mr. L. G. Morris, of Westchester, N. Y., imported several Devons from the herds of Mr. Quartly, and others, in Devonshire.

About the same years, Mr. Ambrose Stevens, of Batavia, N. Y., brought out a number from the herds of Messrs. Davy, Merson, and others.

Concurrent with these two last, Mr. C. S. Wainright, of Rhinebeck, N. Y., made two or three different importations from the best and most popular breeds abroad.

A few years later, the late Mr. Edward G. Faile, of Westchester, N. Y., imported several superior Devons from the choice herds of Deronshire.

These comprise all that we now recollect, and were of the choicest selections-the cattle equal, probably, in style and quality, to any in England. All these herds have been carefully bred, and their produce widely disseminated. If preserved and bred as they should be, they will continue of great benefit in improving the lighter cattle stocks of our country.

It may be well to remark that the race of which we have written, are called, in England, "North" Devons, as distinguishing them from another called "South" Devons-a somewhat larger, coarser, and less esteemed variety, existing in South Devonshire, and the adjoining county of Sussex. 


\section{CHAPTER VIII.}

\section{THE HEREFORDS.}

AFTER giving so extended a chapter on the Devons-which we have partially done for convenient reference in remarking on some other breeds, to save frequent repetition-it will not be necessary to describe the Herefords so minutely. Although comparatively little known in this country, they are a valuable breed, and their origin dates far back in the history of English cattle. The principal counties in England in which they are kept, are Hereford, Shropshire, Gloucester, and Oxford, and some counties adjoining Hereford, in Wales. They are also found in other counties, but thóse named are their principal homes.

Ever since breeds of cattle have been discussed, in modern days, the Hereford has been named as of ancient descent. To what extent, concurrent with other breeds, they have been improved, it is not easy to say; but that they have received great attention within a century past, and no doubt been much improved, is certain, as we learn by English authorities. The Herefords of a hundred years ago, were deep red-almost brown -in color, with mottled faces; now, they are usually red, with shades sometimes running into light, or yellowish red, with white faces, throats, bellies, and sometimes backs, and occasionally a roan of red and white mixed, and more rarely, an almost clear white, with red ears, is found among them.

From a "lecture" delivered by Mr. T. Duckham, on Hereford cattle, in the Royal Agricultural College, at Cirencester, Eng., we extract the following: 
"Mr. Rowlandson, in his prize report on the 'Farming of Herefordshire,' published in the Journal of the Royal Agricultural Society of England, Vol. 32, says, 'the Herefords were originally brown, or reddish-brown.' He also relates the following story of the appearance of a white-faced bull in the herd of Mr. Tully, Huntington, near Hereford: 'About the middle of the last century, $(1750$,$) the cow-man came to the$ house, announcing as a remarkable fact, that the favorite cow had produced a white-faced bull calf. This had never been known to have occurred before, and as a curiosity, it was agreed that the animal should be kept and reared as a future sire;' and adds, 'that the progeny of this very bull became celebrated for white faces." "

"The same authority (Mr. Rowlandson) gives an interesting extract from history, showing that in the tenth century, (A. D. 900, ) a celebrated breed of white cattle, with red ears, prevailed in Wales, of which that part of the county of Hereford on the north side of the river Wye formed a portion. He tells us that a law of 'Howell the Good' fixed compensation to be paid for injuries done by one of the princes towards another, at one hundred white cows, with red ears, and a bull of the same color; and if the cattle were of a dark or black color, then one hundred and fifty in number instead of a hundred, and adds: 'Speed records, that Maude de Brehos, in order to appease King John, who was highly incensed against her husband, made a present to the Queen, of four hundred cows and one bull from Brecknockshire, (in Wales,) all white, with red ears.' These facts, he says, 'are suggestive of the mode in which the whitefaces have originated.' "

This last transaction must have taken place soon after the year A. D. 1200, for John held the throne only seventeen years, having taken it in 1199 , and dying in 1216-a long time for a white color in cattle to be held in abeyance, and then to crop out 
five hundred years afterwards! This may all be possible, and the Hereford breed of cattle, if original in Wales, may have existed time immemorial, for, as they say that certain Welsh families trace their pedigrees back anterior to Adam, we may give a pretty remote date to the origin of their cattle!

Mr. Duckham further remarks: "An old and much respected friend of mine, the late Mr. Welles, also entertained the idea that they were originally self-colored (red) like the Devons, and 'that the breed characterized as the mottle-faced, took its origin from a mixture of the old self-colored, with some accidentally possessing white marks.' As regards the white cows with red ears, I think the light grey, or white Hereford, may fairly be considered to be descended from them; and there are red-withwhite-face breeders, who advance that they can trace them as being the breed of their ancestors, for the past two hundred years."

Be all these facts, traditions, or surmises, as they may, these grey and white colors now appear in cattle bearing all other marks of true Herefords, and they must be admitted as indigeneous to the breed. Some of the very best specimens of the race liave been of those lighter and mixed colors.

In our researches among English authorities, we find less said of the Hereford, its history, and breeding, than almost any other well known breed. Youatt devotes but four pages to them, knowing little of them himself, and having not much information from others. What we have gleaned from English accounts, is chiefly in fugitive papers and magazines, by sundry writers and breeders; but more fortunately for the present purpose, we have had several years' close and almost daily observation, in a herd of imported Herefords and their descendants, which were kept near us, as well as of occasional observation of other importations, which have given us a more intimate knowledge of them than volumes of books, without such personal observation, could have done. 
Perhaps we cannot convey a better description of the Hereford, after giving accurate portraits of the sexes, than to say: give a Devon a quarter more size, somewhat more proportionate bone and horn, a trifle shorter leg, and longer body, a little coarser in every part, and you have a good Hereford, in all excepting color.

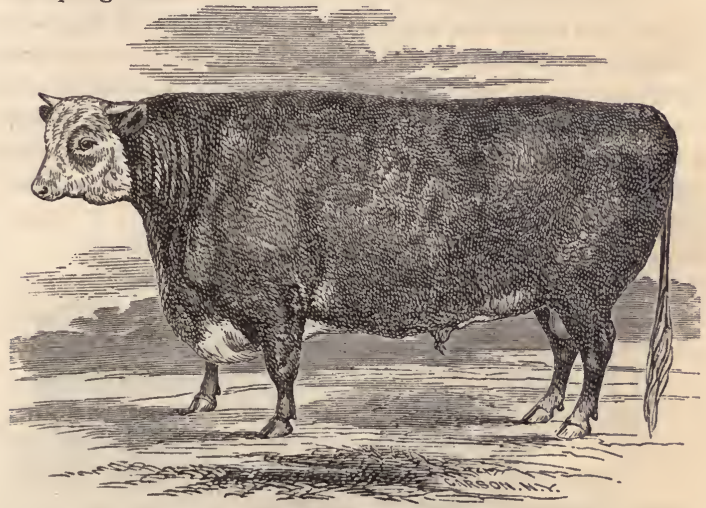

Plate 5. Hereford Bull.

Our plate is an accurate copy of one in the (English) Farmers' Magazine, true to life, and amply just to the original, both in color, and proportion. We have seen one that might have stood equally well for the portrait.

As useful cattle, the Herefords are a good breed. We are aware that their introduction into the United States has not been, in comparison with some other breeds, successful in popularity or extended distribution; but that fact decides nothing as to the positive merits of the stock itself. Partiality, prejudice on the part of our cattle breeders, or -pre-occupation of the ground by other breeds which meet the general approbation, 
may keep them for a time in the back-ground; but their actual merits once known, they may have a fair trial, and achieve a substantial success.

Like the Devon, we place the Hereford under three distinct heads; and first,

\section{AS A DAIRY COW.}

In this virtue she has little reputation, either in England or America. We have found no English authority, except a rare instance or two, which gives her much credit as a milker. Possibly this may have arisen from the fact that the Hereford districts are grazing, and not dairy. The milk is rich, but too little of it-not much more than to rear her calf in good condition. She dries early.

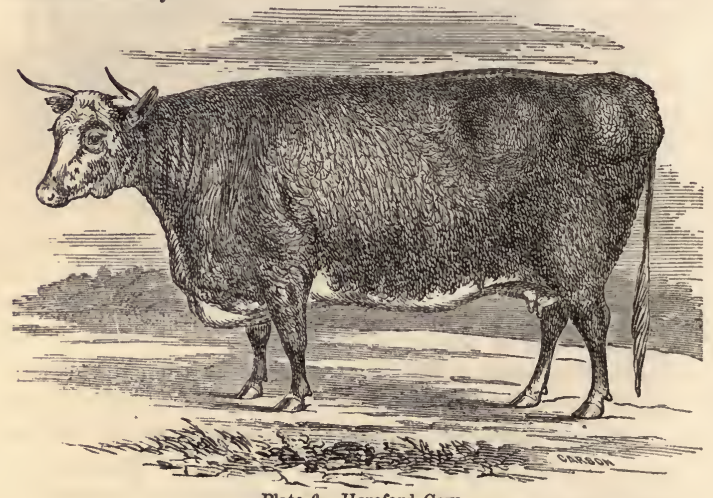

Plate 6. Hereford Cow.

If she ever was a milker before her modern improvement began, the milking faculty has been sacrificed for a ready tendency to flesh, which has been obtained in a high degree in her race. We have seen a dozen of them milked tlirough three or 
four successive seasons, and the yields were such as wonld be unsatisfactory to a modern dairyman. Now and then a fair milker turned up, but they were in a minority of numbers; taken together they were less than ordinary, for the season. We will not therefore discuss this question further, but pass to another quality as yielding greater pleasure in the relation.

\section{AS A WORKING Ox,}

The Hereford is the peer of any other, and superior to most. Large, strong, muscular, well developed in form, noble, and stately in carriage, he suggests all that need be found in an honest, true worker. At full maturity-say six years old-he girts 7 to $7 \frac{1}{2}$ feet behind the shoulders, in ordinary condition, to the Devon's 6 to $61 / 2$ feet, and is every way the more powerful, if not quite so quick, or active. A team of two, three, or four yokes of Herefords, under the control of a good driver, for "a long pull, a strong pull, and a pull altogether," is the perfection of bovine strength and majesty. The joints of the ox are well knit, his sinews strong, his shoulders slant well to the yoke, and he carries his load well, be it at the plow, the cart, or the wagon. He is kindly, intelligent, honest in his labor. We liave seen them from half, to three-quarters blood, crossed from the common cow, and up to thorough bred, all of great excellence as draught beasts, well matched, and admirable in all their points. The Hereford blood is strong in marking its descent. From the bulls which were kept in our neighborhood eighteen years ago, crossed upon cows which run on the adjacent commons, in their summer pasturage, we now, in their progeny, to later generations, frequently see cows and oxen but a quarter, an eighth, or sixteenth in blood-got by scrub bulls-that show strong Hereford marks in form and color.

We once reared an ox got by a Hereford bull, on a wretched little black cow, which proved to be a fine, stately ox, of a 
brindle (black and red mixed) color, and a better worker we never knew. At eight years old we fed him off on grass, and a little corn meal only, and he gave us 1,200 pounds of beef, hide and tallow. Where hay and pasturage are cheap, and the farmer has a taste for the business, it must be a profitable invest. ment to obtain a thorough bred Hereford bull, cross him on well selected native red cows, and rear and break steers for the markets where good working oxen are in demand. The strong blood of the bull will give uniformity in shape, and color, so that the steers may be easily matched, and if not wanted for the yoke, they are equally valuable, as other cattle, for feeding, and the shambles.

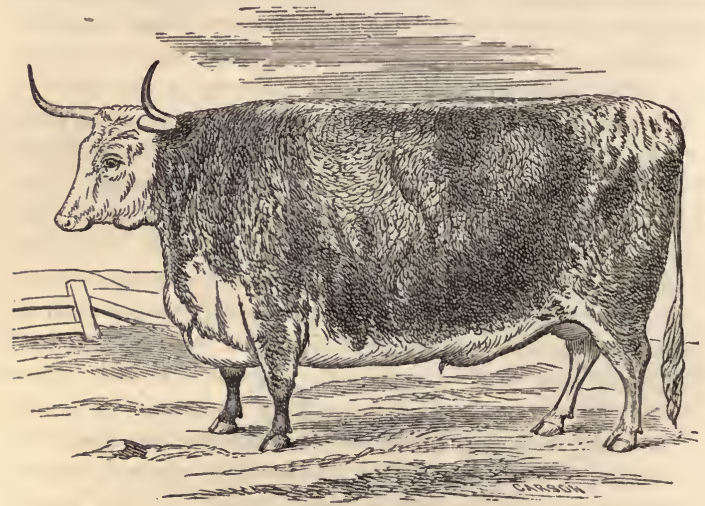

Plate 7. Hereford $\mathrm{Ox}$.

AS A BEEF ANIMAL,

The Hereford is superior. They feed kindly, are thrifty in growth, mature early-at three and four years old-and prove well on the butchers' block. We are aware that they have not now a general popularity in the great cattle breeding regions of 
our Western States. Few of them have been introduced there, and those, perhaps: not in the right hands to push them to the best advantage. We could wish for them a fairer trial; but the prejudice against the cows as milkers, and the lack in their taking appearance as a highly distinctive race, in comparison with the more popular short-horns, have kept them back in public demand. Their time has not yet come; and it may be, that in the right hands, and with a more critical observation among our cattle breeders and graziers, they may achieve a reputation as a grazing beast, equal to some now considered their superiors.

In their native counties in England, they still hold a high rank, and at the prize shows in the London markets compete successfully with other improved breeds. With all the deficiencies which the advocates of other breeds allege against them, the Herefords still retain their reputation among their English breeders, who hold on to them with a pertinacity which shows an unabated confidence in their merits and profit as a true grazier's beast. We might show recorded tables of their trials, in England, with short-horns, and the relative profits of their feeding for market, in which the Herefords gained an advantage on the score of economy; but as the trials were not from birth to slanghter, and the comparative early advantages of each breed were omitted in the account, a repetition of the tables here would not be conclusive.

There has been much controversy in England, and there might be some in America, were there Herefords enough here to raise the question, as to the manner in which they have been improved within the last eighty or ninety years. Their opponents allege that they have had a stealthy short-horn cross, and it is not certain that in these controversies the Hereford breeders have always denied it. All the accounts that we have seen, show that the old Herefords were dark red, almost brown in color, 
with mottled red and white faces, and little or no white on the throat, belly, or back. The improved Herefords are of lighter red, with white faces usually, (although we have seen some of the old style of color,) and occasionally one will "crop out" with a lively short-horn roan all over. We once saw a purely white one in color, with no red, except the ears, her parents, bull and cow, being red, with white faces; and another, an imported cow, with drooping, half-length horns. These are certainly out of line with the true Herefords, and the short-horn advocates charge that such offshoots betray short-horn blood. Be the facts of their breeding as they may, the differences in color and horn, are palpable. That these appearances have not injured the animals themselves, is evident, for they were admirable Herefords in all their valuable points, as any among their congeners of the true colors, and upright spread of horns. We, at least, shall not take sides in the controversy. It is sufficient to note the facts as we have seen them.

\section{THE HEREFORDS IN AMERICA.}

At what date they were first imported into this country, we have no accurate account; but that some Herefords came out among the early importations, is evident, from the occasional marks of the breed aniong our native cattle where late importatious have not been known. In the year 1816 or' 17 the great Kentucky statesman, Henry Clay, imported two pairs of them into his State, and put them on his farm at Ashland. They were bred for a time with each other, and the bulls were crossed with other cows; but it is certain that they left no permanent impress on the herds of that vicinity, as Mr. Clay himself became a breeder of short-horns soon afterwards, and eventually discarded the blood from his herds, if he had for any length of time retained it. No trace of them is now scen in Kentucky. A few years later, Admiral Sir Isaac Coffin, of the English 
Navy, a native of Massachusetts, sent out a Hereford bull, and possibly a cow or two, to some of his friends in that State. The bull was considerably used in crossing with the native cows, and thirty years ago or more, we saw several fine bullocks with strong marks of the breed, in the vicinity where he was kept. There may have been small importations made into other States during the next fifteen years, but of them we have no definite knowledge.

The largest known importation of Herefords into the United States, was made about the year 1840, upwards of twenty in number, by an Englishman, into the city of New York, and taken into Jefferson county, of that State. A year or two afterwards the bulk of the herd were removed to the farm of Mr. Erastus Corning, near Albany; N. Y., and some of them went into Vermont, where they were for some years bred, sold, and scattered. Of this herd, Mr. A. B. Allen, editor of the American Agriculturist in 1843, thus speaks: "We had seen some specimens when in England, in 1840, but lad no idea of the fine herd at Albany until we saw them last December. We were surprised at the superb show the Herefords made at the various Agricultural Șociety meetings we attended in England, and certainly one of the finest lots of cattle we ever saw, was a large herd of pure Hereford steers, grazing on the banks of the Thames, in the neighborhood of the grand old town of Oxford. As fat cattle, the Herefords have lately held a sharp rivalry with the short-horns, and their beef is in high favor in the London markets. They make no claim, as yet, to being milkers. * * * W We think the stock at Albany would compare favorably with the best we met of this breed in England. * * * * We found these cattle to excel particularly in the brisket, and loin, two very important points in all animals destined for the butcher, and especially necessary, if we make 
them into beef for the English market; and being of great constitution and hardy, they make most excellent grazing cattle."

While the stock were at his farm, Mr. Corning, with his accustomed liberality and enterprise, sent their importer out again to England to purchase more animals, which safely arrived, and were added to the herd. They were then successfully bred for several years, many sales made into different and distant parts of the United States, and they acquired considerable popularity. The herd was subsequently divided, Mr. Corning retaining his share, and his partner taking his, some twenty or more in number, on to a farm three or four miles from Buffalo, on the banks of the Niagara. Here they were bred, and several sales made, to go to different parts of the country, during the four or five years they remained; but the herd gradually waned, mainly from want of proper care and system in their keeping. With their owner they then migrated into the rich valley of the Genesee. near Geneseo. In that locality, if anywhere, they ought to have succeeded. But in two or three years further they went to Tioga county, near Owego, where they had another fitful stay of a year or two, and then removed elsewhere, since which we have no record of them whatever,- "run out," and sacrificed, in all probability, by mismanagement.

Mr. Corning retained his herd at his farm, where he has successfully bred, and made sales from them since, and in the hands of his son, Mr. E. Corning, Jr., who is more an amateur than a professed cattle breeder, added to by occasional importations from England, they remain fine specimens of their race.

Mr. George Clark, at Springfield, Otsego county, N. Y., obtained several Herefords from this herd, and, we believe, made an importation or two from England. He bred them successfully, distributed his bulls on to several of his farms, and bred, and still breeds many excellent grade Herefords from the com. 
mon cows. His bullocks have, in past years, been highly approved in the New York Cattle Markets.

About the year, 1852-3, Messrs. Thomas Aston, and John Humphries, two English farmers in Elyria, Ohio, near Lake Erie, imported several fine Herefords. They bred them well, and successfully, as seen in the specimens we have several times met, but with what success in their sales we have no intimate knowledge.

In the years 1860 and ' 61, Mr. Frederick Wm. Stone, of Guelph, Canada West, made two importations of superior Here- . fords from the herds of Lord Bateman, in Herefordshire, and the late Lord Berwick, in the adjoining county of Shropshire, Eng. land, numbering, together, two bulls, and eleven cows and heifors. These were remarkable for their high breeding, and generally, good points. From them, down to January, 1867, there were bred about sixty, and about half the number have been sold at satisfactory prices, and distributed, mostly into the United States. Some of the cows have proved excellent milkers, and all, together with the crosses of the bulls on common cows, have proved profitable grazing animals. But as they have had to encounter a sharp competition in Canada, where the short-horns have for some years, previous to the introduction of the Herefords, held dominion, as improved stock, and Mr. Stone himself a prominent short-horn breeder, the qualities of the Herefords have won their success, against such odds, solely by their own merits. Such a fact is no small testimonial to their excellencc.

There have, we believe, been some few other small importations of Herefords made within the past twenty years, but we have no particular account of them, or at what ports they were landed.

Qn the whole, the Herefords have not had a fair trial in the United States, in the hands of veteran cattle brceders, who had the means and opportunity to properly test them by a thorough 
and persistent course of breeding. Had the fine herd which was for several years on Mr. Corning's farm, been taken to good grazing lands in New York, or some of the Western States, and properly cared for, their history, we fancy, would have been far different from that which is here recorded.

We trust that the herd of Mr. Stone, in its various distributions, may have a fair and thorough trial, satisfied as we are that the Herefords, as a breed, have positive, and well established merits, in their great thrift, and good flesh producing qualities. 


\section{CHAPTER IX.}

THE LONG-HORNS.

Ir is still a disputed question in England, whether this somewhat remarkable race of cattle originated in the north-western English counties of Lancashire, Westmoreland, and the adjoining part of the West Riding of Yorkshire, or in Ireland, as from time immemorial they appear to have been natives of both countries, and probably were intermixed, more or less, by importations from one to the other. The characteristics of the cattle of each country are so identical, that they are acknowledged to be of the same primitive race, although it is contended by English authorities that the Irish long-horns were coarser and less cultivated in their breeding than the English.

Youatt says: "In the district of Craven, a fertile corner of the West Riding of Yorkshire, bordering on Lancashire, and separated from Westmoreland chiefly by the western moorlands, there has been, from the earliest records of British Agriculture, a peculiar breed of cattle. They were distinguished from the home-breds of other counties by a disproportionate and frequently uubecoming length of horn. In the old breed this horn frequently projected nearly horizontal on either side, but as the cattle were improved, the horn assumed other directions; it hung down so that the animal could scarcely graze, or it curved so as to threaten to meet before the muzzle, and so also to prevent the beast from grazing; or immediately under the jaw, and so to lock the lower jaw; or the points presented themselves against the bones of the nose and face, threatening to perforate them. We have given a similar description of the Irish breed. In proportion as the breed became improved, the horns lengthened, and they are 
characteristically ' distinguished by the name of 'The LongHorns.' Cattle of a similar description were found in the districts of Lancashire, bordering on Craven, and also in the South. eastern parts of Westmoreland; but tradition, in both of these districts, pointed to Craven as the original habitation of the long-horn breed. If there gradually arose any difference between them, it was that the Craven beasts were the broadest in the chine, the shortest, the handsomest, and the quickest feeders; the Lancashire ones were larger, longer in the quarters, but with a fall behind the shoulders, and not so level on the chine. Whence these cattle were derived, is still a disputed point."

The breed gradually spread into the adjoining more midland counties, and as the cows were good milkers, they became permanently established in the dairies, where they have long been kept, and are to a considerable extent retained to the present day; and although, as a grazier's beast they have been pushed aside by some of the more favorite breeds, there are still found some fine dairy herds, and others bred in high perfection for the shambles, for which purpose their breeders contend they are a highly profitable beast.

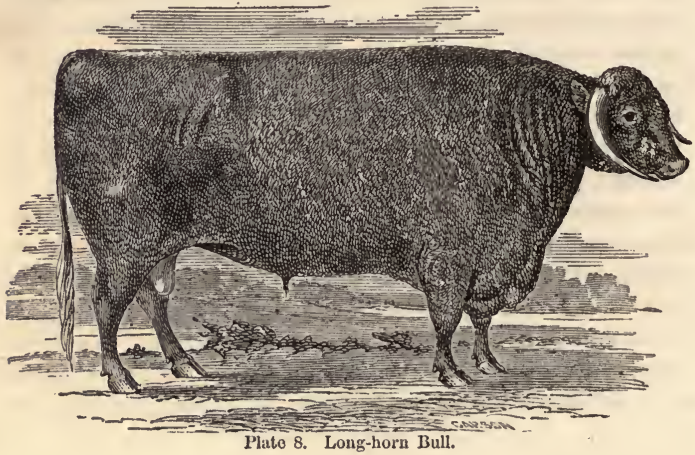


The preceding cut represents one of the best of the improved long-horn bulls of the present day. From all we can gather of their early history, they appear, before their improvement began, to have been of rather sleazy appearance, loose jointed, sway. backed, and coarse in the bone,-points yet not altogether bred out of them, and perhaps never can be bred out by the use of their own blood alone. Still, in the animal before us, we see a com. pact, rangy beast, with many excellent qualities.

We have not introduced the long-horned cattle into this work because we recommend them, or expect them to be, to any extent, brought into the United States as rivals to other popular breeds which are already here to improve our native stock, although we confess there are some salient and taking points of character in them; but chiefly to record the career of a man, distinguished in his time as one of the greatest improvers of farm stock of which we have any account-Robert Bakewell-and of whom our American stock breeders should have some more distinct history than what floats about among the fugitive papers of the time. Our account of him is taken from Youatt, and his account from a paper in the "Gentleman's Magazine," a London publication of the last century.

Robert Bakewell was a farmer and stock breeder by profession-as were his father, and grandfather before him-and born at Dishley, in Leicestershire, England, about the year 1725. His father and grandfather, during their lives, had both resided on the same estate. In the course of his career, he bred the common carthorse of England to high perfection, giving him greater size, weight, and more muscular form than he before possessed, together with more beauty of form. He also bred the coarse, long-wooled sheep into such marked improvement that they assumed in his hands, the new names of "Dishley," "Bakewell," or "Leicester," by the latter of which names (since further improved, in other hands, by a cross of the "old Cotswolds" 
and "Lincolns," noted "long-wooled" varieties of the present day,) they are now known. His practice and experience were long, as he died at about seventy years of age.

About the year 1720 the first known improvement of the long-horns was attempted. A blacksmith and farrier, of Linton, in Derbyshire, on the borders of Leicestershire, who had rented a little farm, had the honor of being first on the list of improvers. His name was Welby. But a fatal disease broke out and took off his cows, of which he had several, and put a stop to his further progress. Soon after this, Mr. Webster, of Canley, near Coventry, distinguished himself as a breeder. His herd had come from Sir.Thomas Gresley's stock, from whom also the unfortunate blacksmith, Welby, had obtained his animals. Webster had also obtained bulls from Lancashire, and Westmoreland. He bred them to a high degree of perfection, so that they were called the "Canley" breed, and from his herd were afterwards drawn the chief and most valuable progenitors of the "improved" race.

Then came Bakewell on the stage, as a further improver of the long-horns, and it must be confessed, with a race of cattle already prepared to his hands on which to exercise his ingenuity and skill. His plan was to improve the stock from their own blood alone, and without intermixture of any other. $\mathrm{He}$ pur. chased two heifers from Mr. Webster, and a choice bull from Westmoreland. He bred closely "in and in," but was careful to have his crosses, although of the same family, sufficiently separate to avoid any defects which might be perpetuated in the direct descent, where they might exist, from parent to offspring by the intensity of their interbreeding with each other.

"Many years did not pass before his stock was unrivalled for the roundness of its form, and the smallness of its bone, and its aptitude to acquire external fat, while they were small consumers of food in proportion to their size; but at the same time their 
qualities as milkers were considerably lessened. The grazier could not too highly value the Dishley, or New Leicester long. horn; but the dairyman, and the little farmer clung to the old breed as most useful for their purpose."

By what strange gift, or skill, Mr. Bakewell improved his cattle, he left no record. He was not a man of learning, science, or wide observation beyond his own line, but he studied his pur. suit with great attention. He used to dissect the slaughtered carcasses of his cattle, hang up and preserve their joints, bones and sinews, in his rooms, and put their flesh in pickle, and study them, as a surgeon studies his anatomical specimens of humanity. By this he was enabled to detect their faults and imperfections, and by comparison with living animals avoid the perpetuation of like imperfections in the young progeny. He was kind-hearted, and treated his cattle with great tenderness, never using anything heavier than a little switch to control the young things; thus he rendered them docile, and gentle in temper, a quality tending much to their thrift and rapid growth. In the course of years he probably raised the long-horns to the highest point of perfection of which the race was capable. The upshot was, he had sacrificed the milking quality of his herd for the promotion of their flesh, and the symmetry of their forms; and after all, it may be questioned how valuable his improvements, in an econom. ical point of view, were to the common farmers, who kept and bred them.

Youatt gives a long and particular description of many points in Bakewell's practice, made up of inferences chiefly, some of which may be correct, but as they are matters of opinion, we do not care to follow them. He names a fact, however, which it is worth while to notice, viz.: After Bakewell's death, and his stock went into other hands, they declined. His spirit, skill, sagacity, tact, experience and knowledge-for he possessed all these in an eminent degree-did not go with them. "Tradition," 
too, says that the long horns have never been so good since Bakewell's time. "Tradition," however, is not accepted in the present day as evidence in a court of justice, and many of her rumors and sayings may be apocryphal. We are inclined to believe, from accounts which we have occasionally seen, and up to a late date also, that there do now exist in England as good long-horns as Bakewell ever bred, although not in numerous herds, nor of wide-spread fame.

A Mr. Fowler, of Rollwright, in Oxfordshire, bought some cattle of Bakewell, and bred them with great care. He had a sale in the year 1791, in which seven bulls and six cows were sold. The prices of his bulls ranged from $\$ 760$ to $\$ 1,250$, and his cows from $\$ 446$ to $\$ 1,365$ each, and his whole herd of fifty averaged $\$ 429$ each, showing the high value put upon the breed at that day. But it is needless to pursue this branch of the subject further, as we have no definite interest in the breed, as yet, in this country. Indeed, we have only introduced this information here as a matter of collateral interest to our American cattle breeders, and to give an outline of one branch of $\mathrm{Mr}$. Bakewell's course, and success.

\section{AS A DAIRY COW,}

The "old-fashioned" long-horn ranks high, and is extensively used in some of the dairy counties of England,-many, in their purity of blood, and more in their grades with other breeds and admixtures. Her milk is good, and the quantity given satisfactory to the dairyman; and without both these qualities, a people so systematic as they, and looking sharply to profits, would certainly discard her.

Aside from the plate, which is that of a very fat cow, we give a more particular description. The head is long; the neck none too clean; the dewlap small; the shoulder fair; the rib tolerable; the brisket good; the back a little swayed, or 
hollow; the loin good; the hips wide; the rumps and tail high; the thighs moderately round. The colors-red, red-roan, blueroan, yellow-red, or inclining sumetimes to fawn color; and sometimes white on the back and belly. The horns show for themselves-the most objectionable, uneconomical, and inconvenient feature altogether, although giving her a most picturesque and unique appearance. In size they are above medium, ranging

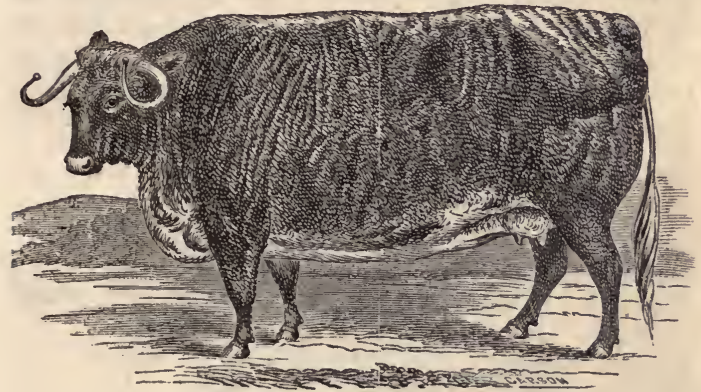

Plate 9. Long-horn Cow.

in bulk and weight fully with the Hereford. The cow here represented was ten years old, kept some years as a milker, and then fed off for the shambles. She shows a wonderful development of flesh, indicating a high feeding quality.

\section{AS A WORKING OX.}

We do not see, in this connection, how the long-horn can be superior, or as good as the Devon, or Hereford, although he is somewhat used in England for that purpose, in the districts where he is bred. His horns are decidedly in the way, and his sway, or depressed back, must detract from his strength for a heavy pull. Although kind and tractable as other beasts in temper, the objections on other scores are sufficient to make him 
undesirable for labor when other oxen, as in this country, can be plentifully found.

\section{AS A BEEF ANIMAL,}

The long-horn is good. They feed well, and kindly. They prove well at the shambles, and the quality of the flesh is fair, but not superior to that of other approved breeds. Their advocates, of whom there are many in England, have exhibited some fine specimens at the Smithfield market, in London, and claim for them an equality with any other breed; but that claim is not generally admitted by the breeders and graziers of other estab. lished breeds.

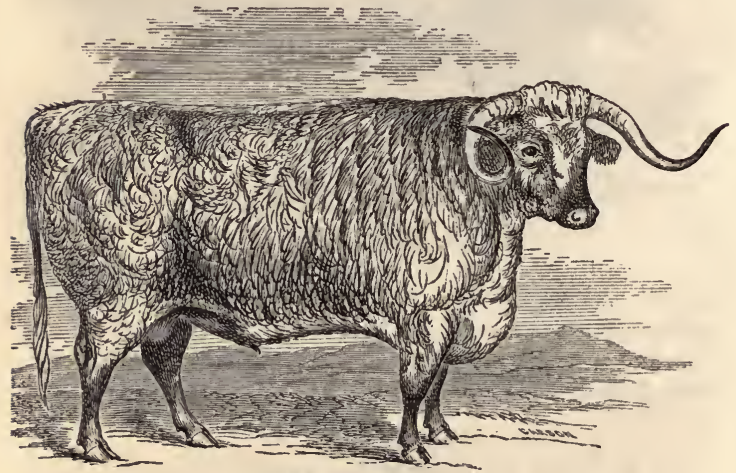

Plate 10. Long-horn Ox.

In the specimen before us is seen a well-formed and full-fleshed animal, highly bred, and in his best condition-much better than anything within the range of "common" cattle. $\mathrm{He}$ is a good "handler," with an elastic touch, good skin and hair, and his "proof," in tallow, must be good;-altogether a very creditable beast. His true profit, however, as an economical animal, must 
be tested by the amount of food he has consumed, in proportion to his dead weight at the shambles.

\section{THE LONG-HORNS IN AMERICA.}

On this item, our record must be short. Among the early importations of English cattle in the Northern States, and pos. sibly in the Middle, and Southern, that some long-horns came also there can be no doubt, for we well recollect, in our boyhood, cattle which had some of their distinctive marks, too obvious to be mistaken, as inherited from that race. The first definitely known introduction of them, was by a Mr. Smith, a merchant, we believe, of Lexington, $\mathrm{Ky}$., who brought out a bull and cow, and took to that town about, or in, the year 1817. They were there bred, but whether together, or with other cattle, we have no direct information. At all events, they were soon merged in the "Patton" stock, and the "Short-horns of Col. Sanders' importation of 1817." The blood of those cattle still exists in a remote degree in some of the grade Kentucky herds, as we have distinctly seen, not many years ago, in steers sent from there to the New York cattle markets. The long-horns were not received with much favor in Kentucky, as the merits of the short-horns soon overshadowed them.

When a youngster, just emerging into the gristle and bone of manhood, during a temporary residence in northern Ohio, we made a horseback journey, in the month of September, 1821, down into the Scioto valley, as far as Circleville, in the county of Pickaway. In the valley, below Columbus, were "the Virginia military grants," in which numerous settlers from that State and Pennsylvania had come at an early day-for that country, 1790 to 1800 - who took up large tracts of its rich lands, and cleared and cultivated them into broad pastures and rich cornfields. A mile or two nurth of the town, on the Columbus road, spying a dozen or so of strange looking cattle, in a rich blue. 
grass pasture, shaded with groups of grand old oaks and walnuts, we reined up to the fence, dismounted, hitched our horse, and went into the field. The cattle were just as Youatt and our pictures describe them, blue, and red roans, and white backs and bellies, with horns long, curving forward, and drooping under the jaws; their bodies were round and full, showing high marks of growth and thrift, -a bull, some cows, and calves. How they came there, or who they belonged to, we did not particularly inquire at the time, having then little curiosity, or interest in cattle. Not again going there until thirty years later, we heard nothing more of the cattle, and then, on inquiry of one or two of the oldest settlers in the vicinity, we could learn nothing of them, only, "that they recollected some man, rich, and a large landholder thereabouts, had driven some 'imported' cattle in there, but what became of them they did not know, and no trace was left of them."

Thus ends our story of the long-horns in America. We trust that they may again be imported here, and have a fair trial. 


\section{CHAPTER X.}

THE CATTLE OF SCOTLAND.

Having examined the two marked and best approved of the middle-horned races of England; and taken a sufficient notice of the long-horns, we proceed to examine three of the most approved breeds of Scotland, as now concentrated, and improved from original races there, and fashioned to the uses of the present day.

Lying north of England, with a surface more or less mountainous in its northern territory, and a much severer climate, its cattle, from time immemorial, have been of a far different order, and applied to somewhat different purposes than those of England. Youatt describes the breeds, or varieties of the different sections of the country minutely, and with great interest. It is not necessary for the present purpose to follow him throughout, but we shall extract largely from him, both in text and opinion. His information is solely from Scottish authorities, and such an air of fidelity to truth runs through them that we may wisely adopt, so far as our purposes need, their conclusions.

The reader may inquire, why, when England contains all of improvement in her best breeds that an American demands, should we seek the inferior cattle of Scotland to multiply, and further mix up the already sufficient varieties of cattle on our soils? Our answer is, that the vast scope of climates, soils, and altitudes of the United States, and their territories, embrace those of both England and Scotland, as well as the tropics. No one, two, three, or even four different breeds are best suited to them 
all, and when we find those already fitted to our hands, and applicable to the best economical uses for all the different parts of our broad country, it is the part of wisdom to adopt them, instead of striving, by a long course of unprofitable experiment, to change and acclimate those by nature unfitted to new localities. Let us take advantage of the labors of others, and apply them immediately to our uses and demands.

Thus Youatt: "Scotland contains several distinct and valuable breeds of cattle, evidently belonging to our present division'the middle-horns.' The West Highlanders, whether we regard those that are found in the Hebrides, or the county of Argyle, seem to retain most of the aboriginal character. They have remained unchanged, or improved only by selection, for many generations, or indeed from the earliest accounts that we possess of Scottish cattle."

It is well to remark, as a matter of geographical information, that the western coast of Scotland, north of Ireland, is skirted for a distance of two hundred miles by a cluster of islands greater or smaller in extent; and further west and north of these extends another cluster called the Hebrides, or Western Islands, all thickly inhabited with a population more or less agricultural in their pursuits, and having with them the aboriginal race of cattle mentioned by Youatt. Beyond these, and on the extreme north of Scotland proper, range another group of islands, called the Orkneys, and to the extreme north of them, another, called the Shetland Islands, famous for a hardy people, and producing a diminutive race of tough, rugged little cattle, and also those wild looking, diminutive horses called "Shelties," or Shetland ponies, of late introduced among us. These several groups range from $5512^{\circ}$ to $61^{\circ}$ north latitude; and although their climates be not so severe as in corresponding American latitudes, they are harsl, austere and boisterous. 
Leaving out the Orkneys, and Shetlands, whose cattle are too diminutive to attract our particular notice, these western groups of islands, together with the Highlands proper, of Scotland, possess a hardy race of middle-horned cattle, long termed "Kyloes," so called, as Sir John Sinclair asserts, "from their crossing so many kyloes, or ferries, which abound in the west of Scotland." "Others," says Youatt, "and with more propriety, one of whom is Mr. Macdonald, the author of the "Agriculture of the Highlands,' tell us, that it is a corruption of the Gaelic word which signifies highland, and is commonly pronounced as if spelled Kael." These cattle, all, probably, of one generic origin, have been intermixed by varous crosses, within them. selves, so as to become homogeneous in nature, habit, and sppearance, and as Scottish agriculture in the islands and the lighlands has progressed, the cattle have also been better cultivated and cared for, and within a century past highly improved, so as now to assume a distinct name and character, as "West Highlands." To these our attention will now be directed.

\section{THE WEST HIGHLAND CATTLE.}

There are no "Highland" cattle in the United States. At least, we do not know of any. Our impression is that a few were imported some years ago into Upper Canada, but what has become of them, if such was the fact, we have never learned. We have immense ranges of land in our mountain districts, in various parts of the older States, which when properly subdued, will become a pastoral country. The vast plains west and north of the Missouri, as well as the wide mountain ranges which traverse them, must mainly be occupied in breeding and grazing cattle, if anything. Those lands will be admirably adapted to a class of cattle like the "West High. lands." No really superior class of our present cattle are, as yet, properly fitted for the wild and roving life of such a country. 
The subject is a new one in our agricultural economy. Vast spaces of these now wild lands, covered with a short and abundant herbage, fed with limited streams of water, and unfitted for profitable tillage crops, must be owned in large tracts, and sparsely populated. Their distance from a dense population will preclude the possibility of taking their surplus grains to market, at a profit, even if they could be profitably raised, and they can hardly be so profitably used as to stock them with cattle. They can breed, and graze while young, on the broad plains, and when fit for market, be driven far away down to the more fertile districts, and fattened, as the Scottish Highlanders drive theirs to the richer lowlands, and to England. Our herdsmen of the plains and mountains would be at a far greater distance from their markets then the graziers of Scotland, but that distance is not insurmountable, nor over expensive.

This is looking somewhat into the future, we admit, and by some it may be thought chimerical; but when we have seen, within twenty years past, California discovered; a State made of it; two other States, and more organized territories, soon to become States with them, adjoining it; several traveled routes for vast caravans of emigrants, and merchandise, and stage coaches passing over them; a railroad under construction and to be completed within the next five years, across the continent; telegraph lines, and the appendages of wealth and civilization introduced with an energy and rapidity hitherto unparalleled in the annals of human progress; it is not too much to assume that an enlightened agricultural interest will soon direct its efforts thitherward, and plant itself firmly and permanently beside the various mining and other enterprises which are already established, and becoming thicker and more substantial continually. In view of these possibilities-probabilities, rather-we need no further apology for the space we shall occupy in introducing this valuable foreign race of cattle to American study and attention. 


\section{Again Youatt:}

"We have been favored with the following excellent description of the true Kyloe, or West Highland bull, by Malcolm M'Neill, Esq., of the Isle of Islay, the southernmost of the inner range of the Hebrides: 'The Highland bull should be black, the head not large, the ears thin, the muzzle fine, and rather turned up. He should be broad in the face, the eyes prominent, and the countenance calm and placid. The horns should taper finely to a point; and, neither drooping too much, nor rising too high, should be of a waxy color, and widely set on at the root. The neck should be fine, particularly where it joins the head, and rising with a gentle curve from the shoulder. The breast (brisket) wide, and projecting well before the legs. The shoulder broad at the top, and the chine so full as to leave but little hollow behind them, (that is, the crops are full.) The girth behind the shoulder deep; the back straight, wide, and flat; the ribs broad, the space between them and the hips small; the belly not sink. ing low in the middle; yet, in the whole, not forming the round and barrel-like carcass which some have described. The thigh tapering to the hock-joint; the bones larger in proportion to the size than in the breeds of the southern districts. The tail set on a level with the back. The legs short and straight. The whole carcass covered with a thick, long coat of hair, and plenty of hair also about the face and horns, and that hair not curly.'

"The value of the West Highland cattle consists in their being hardy, and easily fed; in that they will live, and sometimes thrive, on the coarsest pastures; that they will frequently gain from a fourth to a third of their original weight in six months' good feeding; that the proportion of offal is not greater than in the most improved larger breeds; that they will lay their flesh and fat equally on the best parts; and that, when fat, the beef is closed fine in the grain, highly flavored, and so well mixed or marbled, that it commands a superior price in every market. 
"The different islands of the Hebrides contain about one hun. dred and fifty thousand of these cattle, of which it is calculated that one-fifth are sent annually to the main land, principally through Jura, or across from the ferry of the Isle of Skye. * * * * Cattle, therefore, constitute the staple commodity of the Hebrides. Three thousand five hundred are annually exported from the island of Islay alone.

"Mr. Moorhouse, from Craven, in Yorkshire, in 1763, was the first Englishman who came into the Hebrides to buy cattle. In the absence of her husband, Mr. M'Donald, of Kingsburgh, he was kindly entertained by Flora M'Donald, who made up for him the same bed that, seventeen years before, had received the unfortunate Prince Charles.

"From Skye, Mr. Moorhouse went to Raasay, whither in three days, Kingsburgh followed him; and, during a walk in the garden, on a fine harvest evening, they bargained for one thousand cattle, at two guineas a head, to be delivered free of expense at Falkirk. Two days before, he had bought six hundred from Mr. M'Leod, of Waterside.

"Forty years ago, (from 1763, the time at which Mr. Moorhouse dates back, say in 1723,) the treatment of cattle was, with very few exceptions, absurd and ruinous, to a strange degree, through the whole of the Hebrides. With the exception of the milk cows, and not even of the calves, they were all wintered in the field; if they were scantily fed with hay, it was coarse, and withered, and half-rotten; or if they got a little straw, they were thought to be well taken care of. The majority got little more than sea-weed, heather, and rushes. One-fifth of the cattle, on an average, used to perish every winter from starvation. When the cold had been unusually severe, and the snow had lain long on the ground, one-half of the stock has been lost, and the remainder have afterwards been thinned by the diseases which poverty had engendered. 
"It proved the excellency of the breed, that in the course of two or three months so many of them got again into good store condition, and might almost be said to be half-fat, and could scarcely be restrained by any fence; in fact, there are numerous instances of these cattle, which had been reduced to the most dreadful state of impoverishment, becoming fattened for the hutcher in a few months, after being placed on some of the rich summer pastures of Islay, Lewis, or Skye.

"The cows were housed during the winter; but among the small farmers this was conducted in a singular way-for one rude dwelling contained and sheltered both the family and the cattle. The family had their beds of straw or heath in the niches of the walls, while the litter was never removed from the cattle, but fresh layers of straw were occasionally laid down, and so the floor rose with the accumulation of dung and litter, until the season of spreading it upon the land, when it was at length taken away.*

"The peculiarity of the climate and the want of inclosed lands, and the want, too, of forethought in the farmer, were the chief causes of this wretched system of winter starvation. The rapidity of vegetation in the latter part of the spring, is astonishing in these islands. A good pasture can scarcely be left a fortnight without growing high and rank; and even the unenclosed, and marshy and heathy grounds are comparatively luxuriant. In consequence of this, the farmer fully stocked, or over-

"* Mr. Garnet in his 'Tour through the Highlands,' gives a sadder acconnt of the frequent joint occupancy of the same hut, by the peasant and hia cattle, in the Island of Mull. He bad been apeaking of the privations of the peasant; he adds : ' Nor are his cattle in a better aituation; in aummer they pick up a scanty aupport among the morasaes and heathy mountains, but in winter, when the ground is covered with anow, and when the naked wilda afford them nelther ahelter nor subsistence, the few cows, amall, lean, and ready to drop for want of pasture, are brought into the hut where the family reside, and frequently ahare with them their little stock of meal which has been purchased or raised for the family only; while the cattle thus sustained, are bled occasionally to afford nourishment for the chiluren after the mingled oatmeal and blood has been boiled or made into cakes.' 
stocked, even this pasture. He crowded his fields at the rate of six or eight beasts or more to an acre. From their natural aptitude to fatten, they got into tolerable condition, but not such as they might have attained, whether destined for the salesman or the butcher. Winter, however, succeeded to summer; no provision had been made for it, except for the cows; and the beasts that were not properly fed even in the summer, languished and starved in the winter.

"It is contrived, as much as possible, that the calves shall be dropped from the first of February to the middle of April. All the calves are reared; and for the first three or four months they are allowed to suck three times in the day, but they are not permitted to draw any great quantity at a time. In summer all the cattle are pastured; the calves are sent to their dams twice in the day, and the strippings, or last part of the milk, is taken away by the dairy maid, for it is commonly supposed, that if the calf is allowed to draw all the milk he can, it will keep the dam in low condition, and prevent her being in calf in proper time. The calves are separated from their dams two or three weeks before the cast-cows are sent to the cattle-tryst at the end of October, for it is believed that if the cows had milk in their udders they might be injured in the long journeys they are then to take; the greater part of them being driven as far as the lowland districts, whence they gradually find their way to the central and southern counties of England.

"The calves are housed in the beginning of November, and are highly fed on hay and roots (for the raising of which the soil and climate are admirably adapted,) until the month of May. When there is plenty of keep, the breeding cows are housed in November, but in general they are kept out until three or four weeks before calving. In May, the whole cattle are turned out to pasture, and, if it is practicable, those of different ages are kept separate; while, by shifting the cattle, the pasture is kept 
as much as possible in eatable condition, that is, neither eaten too bare, nor allowed to get too rank, or to run into seed.

"In the winter and the spring, all the cattle except the breeding cows are fed in the fields, the grass of which is preserved from the 12th of August to the end of October. When these inclosures become bare, about the end of December, a little hay is taken into the field, with turnips or potatoes, once or twice in the day, according to circumstances, until the middle or end of April. Few, only, of the farmers have these roots to give them, and the feeding of the out-lying cattle with straw is quite abolished. If any of them, however, are very materially out of condition, they are fed with oats in the sheaf. At two, or three, or four years old, all, except the heifers that are retained for breeding, are sent to market.

"There is little or no variety of breeds of cattle in the Hebrides. They are pure West Highlanders. Indeed, it is the belief of the Hebridean farmer, that no other breed of cattle will thrive on these islands, and that the Kyloes could not possibly bo improved by being crossed with any others. He appeals to his uniform experience, and most correctly so in the Hebrides, that attempts at crossing have only destroyed the symmetry of the Kyloes, and rendered them more delicate, and less suitable to the clinate and the pasture.

"By selection from the choicest of the stock, however, the West Highlander has been materially improved. The Islay, the Isle of Skye, and the Argyleshire beast, readily obtains a considerably higher price than any other cattle reared in the Highlands of Scotland. Mr. M'Neil has been eminently successful in his attempts to improve the native breed. He has often obtained $100 l$. ( $\$ 500)$ for three and four-year-old bulls oui of his stock; and for one bull he received 200l. $(\$ 1,000$.) He never breeds from bulls less than three years, or more than ten years old; and he disapproves, and rightly in such a climate, of 
the system of breeding in and in. He also adheres to that golden rule of breeding, the careful selection of the female; and, indeed, it is not a small sum that would induce the Hebridean farmer to part with any of his picked cows.

"It will be concluded, from what we have said of the milking properties of the Kyloe, that the dairy is considered as a matter of little consequence in the Hebrides; and the farmer rarely keeps more milk cows than will furnish his family with milk, and butter and cheese. The Highland cow will not yield more than a third part of the milk that is obtained from the Ayrshire one at no great distance on the main land; but that milk is exceedingly rich, and the butter procured from it is excellent.

"The management of the dairy is exceedingly simple, and, from the very simplicity of it, other districts may learn a useful lesson. The cows are driven as slowly and quietly as possible to the fold; the wild character of the animals, as well as a regard to the quality of the milk, show the propriety of this. They are carefully drained to the last drop, not only on account of the superior richness of the latter portion of the milk, but because the retention of any part is apt to hasten, if it does not produce, that which is one of the principal objections to the Highland cows as milkers, the speedy drying up of their milk. 'The milk is carried to the house with as little disturbance as practicable, and put into vessels of not more than two or three inches in depth. The cream is supposed to rise more rapidly in these shallow vessels; and it is removed in the course of eighteen hours. A cow will not, on the average, yield more than $22 \mathrm{lbs}$. of butter (of $24 \mathrm{oz}$. each, ) in the summer season; she will yield about 90 lbs. of cheese, which is much liked by some on account of the aromatic flavor which is given to it by the mixture of rose-leaves, cinnamon, mace, cloves, and lemon with the rennet.

"Oxen are never used for the plough or on the road, on any of the Hebrides. 
"We have stated that more than 20,000 of the Hebridean cattle are conveyed to the mainland, some of which find their way even to the southernmost counties of England; but, like the other Highland cattle, their journey is usually slow and interrupted. Their first resting-place is not a great way from the coast, for they are frequently wintered on the coarse pastures of Dumbartonshire; and in the next summer, after grazing awhile on the lower grounds, they are driven farther south, where they are fed during the second winter on turnips and hay. In April they are in good condition, and prepared for the early grass, on which they are finished.

"Many of these small cattle are permanently arrested in their journey, and kept on low farms to consume the coarse grass, which other breeds refuse to eat; these are finished off on turnips, which are given them in the field about the end of Autumn, and they are sold about Christmas."

\section{AS $\triangle$ BEEF ANIMAL,}

The flesh of the West Highland ox, is considered of the best quality in the London markets, and usually worth $1 d$., or two cents per pound more than that of the ordinary breeds. $\mathrm{He}$ is usually put upon high feed at three years old, and in good pas. ture in summer, and a full allowance of turnips and meal, with plenty of hay or straw in winter, is fitted for the shambles at ahout four years old. Taken from their native ranges, and put upon the rich feed of the better lands, they thrive and ripen wonderfully, and make flesh more rapidly than any other cattle. It is the habit of many English noblemen, as they visit, with their families and numerous retinue, their several estates and castles during the "country season," to have a herd of Highland bullocks driven by their servants, to supply their table with beef-the small, compact size of these cattle, as well as the superiority of their flesh, eminently fitting them for the purpose. 
The animal lays his flesh generously on the choice parts, and it is so interlarded with fat as to make it beautifully marbled,-a capital point in its feeding. The weight of a well fed bullock ranges from 600 to 800 pounds-flesh, hide, and tallow.

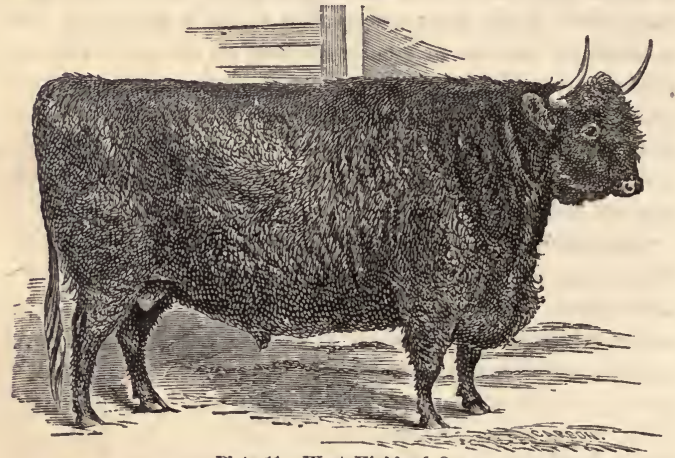

Plate 11. West Highland $\mathrm{Ox}$.

After saying thus much, and at such length, of the Highland cattle, giving Youatt's admirable account of them, we may sum up their qualities pretty much as follows: They are an original breed, bred for untold centuries in one of the roughest climates; of great hardihood and endurance; homogeneous in their natures and habits; strong in blood, with a tendency and power to transmit it upon anything with which they may be connected. The cows are not fitted for the dairy, nor is it necessary they should be for the purposes to which they are intended, yet giving milk enough to rear their progeny well. They mature early, and when matured are full in all their points. They feed their pastures closely, are active in movement, capable of ranging over wide fields, gathering their subsistance without trouble, adapted to climates and soils where other cattle would glean a 
bare subsistence, and thus a valuable race to introduce into the regions of country which we have named.

The manner of doing this would be simple. A cargo of them might be selected near Glasgow, Scotland, where the choicest of them may be purchased at an average not exceeding $\$ 150$ each, and shipped to New York, or Boston; thence transported cheaply in return cattle trains westward, which usually go empty, and then distributed to their destinations. We know of no cat. tle enterprise, for the purposes we have named, conducted with proper intelligence and spirit, which can promise more fairly and profitably; and we hope to see it undertaken by men whose means and foresight are equal to the object. A cargo of one hundred, about equally divided between bulls and cows, might come out by way of experiment. A single bull or two should be retained with the cows for thorough breeding, and the remainder might be placed with small native cows, for the immediate propagation of grades. The progeny of these cows, continuously put to thorough bred bulls, would soon raise them to that degree of blood to satisfy the main object of their introduction, and in a comparatively few years, for all practical purposes, they would become an established race, with but a fraction of the American blood remaining in them; and finally-holding con. tinuously to the pure blooded bulls in propagation-become all that we need in that description of cattle. Thus, our far southwestern grazing regions which now send us only the ragged and comparatively worthless Texan cattle, and the far north-western wilds which send us none at all, together with our intermediate mountain ranges, would ultimately-even shortly-furnish our interior rich lands with grazing material for the best of beef, and our markets would be supplied with the choicest of flesh for consumption.

Our suggestions on this subject are not visionary-not even enthusiastic. We only open one of those sure fields of enter- 
prise, which, compared with every day ventures, even in the agricultural line, usually so common-place and probable, may lead to success and fortune. We hope yet to see the Highland cattle introduced into the country. Their introduction could be no bar to the progress of the other valuable breeds we have now among us, as these latter must always occupy our good soils, on which, if the Highland cattle were placed, they would soon lose their distinctive qualities and become mere common things. They are never bred on the good land of Scotland or England.

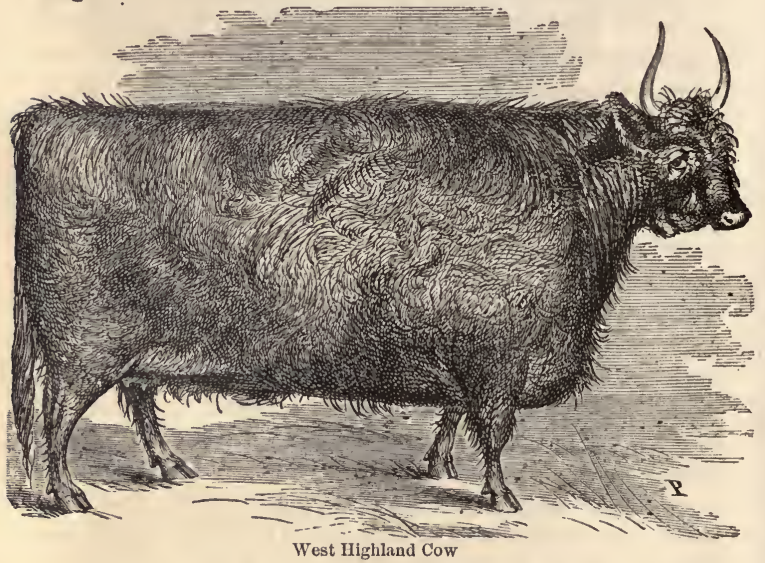

We give above, the portrait of a beautiful dun, or light mousecolored Highland cow, in the possession of Captain Gunter, at Witherby, Yorkshire, England, drawn purposely for this work from life, last summer, by our artist, Mr. Page. A more perfectly developed animal, in her flesh producing qualities, can hardly be found of any breed in the bovine race. 


\section{CHAPTER XI.}

THE GALLOWAYS.

ThEse are a polled, or hornless, race, originating in the low. lands and extreme south-western part of Scotland, taking their name from the district where they have been mainly bred. We let Youatt speak of them:

"The stewartry of Kirkcudbright and the shire of Wigton, with a part of Ayrshire and Dumfries, formed the ancient provinee or kingdom of Galloway. The two first counties possess much interest with us as the native district of a breed of polled, or dodded, or *humble cattle, highly valued in some of the southern Scottish counties, and in almost every part of England, for its grazing properties. So late as the middle of the last century, the greater part of the Galloway cattle were horned -they were middle-horns; but some of them were polled-they were either remnants of the native breed, or the characteristic of the aboriginal cattle would be occasionally displayed, although many a generation had passed.

"For more than one hundred and fifty years the surplus cattle of Galloway had been sent far into England, and principally to the counties of Norfulk and Suffolk. The polled beasts were always favorites with the English farmers; they fattened as kindly as the others, they attained a larger size, their flesh lost none of its firmness of grain, and they exhibited no trace of the wildness and dangerous ferocity which were sometimes serious

"* Dr. Johnson gives a curions derivation of the term hnmble. He says of their black cattle (Journey to the Western Isles, p. 186): "Some are without horns, called by the Scots humble cows, as we call a bee a humble bee that wants a sting.'" 
objections to the Highland breed. Thence it happened that, in process of time, the horned breed decreased, and was at length quite superseded by the polled; except that, now and then, to show the uncertainty of the derivation of the breed, a few of the Galloways would have diminutive horns, but these were of a very curious nature, for they were attached to the skin and net to the skull.

"The agriculture of Galloway, like that of every part of Scotland, was in a sadly deplorable state until about 1786 , when the Earl of Selkirk became desirous of effecting some improvement in the management of his estates, both in the shire and the stewartry. He was, however, too far advanced in life to engage personally in the business, and he delegated the whole management of his property to one of his sons, Lord Daer.

"This young nobleman entered enthusiastically into the views of his father, and although he encountered much opposition, and many a difficulty, from the ignorance and prejudice of the tenantry, he was beginning to possess the satisfaction of witnessing the accomplishment of several of his projects, when he was carried off by consumption, at the age of thirty. His plans, however, were adopted and zealously pursued by his brother, who succeeded to the earldom, and Galloway owes much of its prosperity to these liberal and patriotic noblemen.

"In addition to the Selkirk family, we may reckon among the most zealous and successful improvers of the breed of Galloway cattle, the Murrays of Broughton, the Herons of Kirrouchtrie, the Gordons of Greenlaw, the Maxwells of Munches, and the Maitlands in the valley of Tarff in Kirkcudbright; and in Wigton, the Earls of Galloway, the Maxwells of Mouneith, the M'Dowals of Logan, the Cathcarts of Genoch, the Hathorns of Castle-Wig, and the Stewarts of Phygell.

"For much of the description of the Galloway beast, and for the greater part of our account of the management of the cattle 
in that district, we are indebted to an old, and skillful, and wellknown breeder, whose name we regret that we are enjoined to withhold; but he will accept our thanks, and at some future period, possibly, the public will know to whom we and they are much indebted.

"The Galloway cattle are straight and broad in the back, and nearly level from the head to the rump. They are round in the ribs, and also between the shoulders and the ribs, and the ribs and the loins. They are broad in the loin, without any large projecting hook bones. In roundness of barrel, and fullness of ribs, they will compare with any breed, and also in the proportion which the loins bear to the hook bones, or protuberances of the ribs. The Rev. Mr. Smith, the author of the Survey of Galloway, says that, "when viewed from above, the whole body appears beautifully rounded, like the longitudinal section of a roller.' They are long in the quarters and ribs, and deep in the chest, but not broad in the twist. The slightest inspection will show that there is less space, between the hook or hip bones and the ribs, than in most other breeds, a consideration of much importance, for the advantage of length of carcass, consists in the animal being well ribbed home, or as little as possible lost in the flank.

"The Galloway is short in the leg, and moderately fine in the shank bones,- the happy medium seems to be preserved in the leg, which secures hardihood and a disposition to fatten. With the same cleanness and shortness of shank, there is no breed so large and muscular above the knee, while there is more room for the deep, broad and capacious chest. He is clean, not fine and slender, but well proportioned in the neck and chaps; a thin and delicate neck would not correspond with the broad shoulders, deep chest, and close, compact form of the breed. The neck of the Galloway bull is thick, almost to a fault. The head is rather heavy; the eyes are not prominent, and the ears are large, rough, and full of long hairs on the inside. 
"The Galloway is covered with a loose, mellow skin of medium thickness, and which is clothed with long, soft, silky hair. The skin is thinner than that of the Leicestershire, but not so fine as the hide of the improved Durham breed, but it handles soft and kindly. Even on the moorland farms, where the cattle, during the greater part of the year, are fed on the scantiest fare, it is remarkable how little their hides indicate the privations they endure.

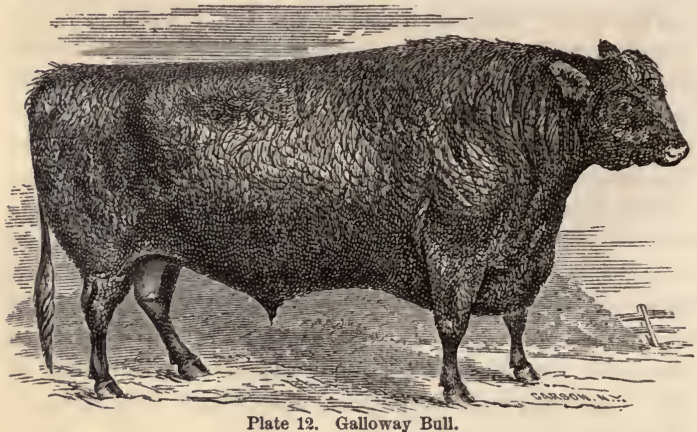

"The prevailing and the fashionable color is black-a few are of a dark brindled brown, and still fewer are speckled with white spots, and some of them are of a dun or drab color, perhaps acquired from a cross with the Suffolk breed of cattle. Dark colors are uniformly preferred, from the belief that they indicate hardness of constitution.*

"* Mr. Culley, who is great anthority in these cases, thus describes the Galloways: 'In most respects, except wanting horns, these cattle resemble the longhorns, both in color and shape, only they are shorter in their form, which probabiy makes them weigh less. Their hldes seem to be a medinm between the long and the short-horns; not so thick as the former, nor so thin as the latter; and, like the best feeding kind of long-horns, they lay their fat upon the most valuable parts, and their beef is well marbled or mixed with fat. They are mostly bred upon the moors or 
"This cut represents the Galloway bullock, almost ready for the butcher. The beautifully level laying on of the flesh and fat, will not escape the notice of the reader.

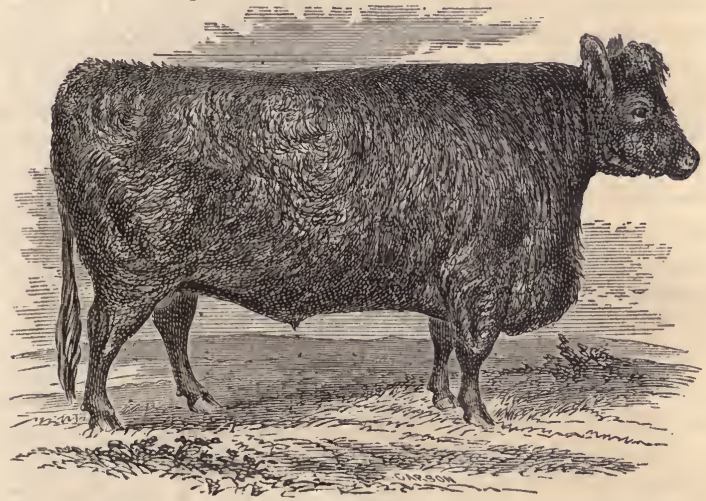

Plate 13. Galloway $\mathrm{Ox}$.

"The breeding of cattle has been, from time almost immemorial, the principal object of pursuit with the Galloway farmer; indeed, it is calculated that more than thirty thousand beasts are sent to the south every year. The soil and face of the country are admirably adapted for this. The soil, although rich, is dry

hilly country in Galioway, until rising four or five years old, when they are taken to the fairs in Norfolk and Suffolk, previous to the tnrnip feeding season, whence the greater part of them are removed in the winter and spring (when fat) to suppiy the consumption of the capital, where they are readily sold, and at high prices, for few or no cattle sell so high in Smithfleld market, owing to their laying their fat on the most valuable parts; and it is no unusual thing to see one of these little bullocks outseil a coarse Lincoinshire bullock, although the latter is heavier by several stones." "

"Mr. Lawrence says, in his excellent trestise on cattle, that "the pure Galloway breed exists, perhaps, no where in original pnrity, except in the moors of Monigaff, and Glenlove, and that these cattle are thinner in the hind quarters, than snch as have been crossed by other breeds." " 
and healthy, particularly in the lower districts, the substratum being either gravel or schistus rock. There are many large tracts of old grass land, that have not been ploughed during any one's recollection, and which still maintain their superior fertility; while the finer pastures are thickly covered with natural white clover, and other valuable grasses. The surface of the ground is irregular, sometimes rising into small globular hills, and at other times into abrupt banks, and thus forming small fertile glens, and producing shelter for the cattle in the winter, and early vegetation in the spring. In the low districts there is little frost and snow, but the climate is mild and rather moist; and thus a languid vegetation is supported during the winter, and the pastures constantly retain their verdure.

"The ealves are reared in a manner peculiar to Galloway. From the time they are dropped, they are permitted to suck the mother more or less, as leng as she gives milk.* During the first four or five months they are allowed, morning and evening, a liberal supply; generally more than half the milk of the cow. The dairy-maid takes the milk from the teats on one side, while the calf draws it at the same time, and exclusively, from the other side. When the calf begins to graze a little, the milk is abridged, by allowing the calf to suck only a shorter time, and he is turned upon the best young grass on the farm. In winter, he is uniformly housed during the night, and fed upon hay, with a few turnips, or potatoes; for the breeder knows that, if he is

"* Mr. Culley gives a curious acconnt of this: " The calves, from the time they are dropped, until able to support themselves, are allowed to run with their dams, but are prevented from sucking by means of a small piece of leather, with sharp spikes of iron fixed upon the ontside, tied upon the upper part of the calf's nose, which, by pricking the cow every time the calf attempts to suck, prevents her from letting it, until the milk-maid comes, when she takes off the muzzle from the little animal's nose, and while she strlps two of the teats, the calf takes care to empty the other two. As soon as the maid has done, she fixes on the instrument again, but it is done in such a manner as not to hinder the calf from feeding npon the grass.' This might have been the practice in Mr. Culley's time, but little or nothing of it is seen now." [Culley wrote in the latter part of the last century. I. F. A.] 
neglected or stinted in his food during the first fifteen months, he does not attain his natural size, nor does he feed so well afterwards.

"The practice of allowing the calf to suck its mother, is objected to by some, and is apparently slovenly, and not econom. ical; but the rearing of cattle is considered of more importance than the money that could be realized from the milk and butter saved by starving the calf. It is also imagined that the act of sucking produces a plentiful supply of saliva, which materially contributes to the digestion of the milk and the health of the calf. The Galloway farmer maintains that an evident difference may be perceived between the calf that sucks its dam, and another that is fed from the pail-the coat of the former is sleek and glossy, indicating health; while the hide of the other is dry and hard, nor is the unthrifty appearance removed until some time after the animal has been weaned and fed wholly on grass. It is also said that a greater proportion of calves, fed from the pail die of stomach complaints, than of those that suck the cow.

"It is desirable that the calves should be dropped in the latter part of winter or in the beginning of spring. A Galloway farmer attaches a great deal of importance to this, for he finds that nearly a year's growth and profit is lost if the calf is born in the middle of the summer.

"The regular Galloway breeders rarely sell any of their calves for veal; ${ }^{*}$ that is obtained only from those who keep cows for

"*It is an old proverb in Galloway, that a good farmer would rather kill his son than a calf. "The people of this country do very seldom, or rather not at all, kill or sell their calves, as they do in other places, so that it is a rare thing to see veal, except sometimes, and at some few gentlemen's tables. They give two reasons for this: one is, because, they $8 a y$, a cow will not give down her milk without her calf, and so, should they sell or kill the calfe, they should want the use of the cow ; but this, I suppose, might be heiped, would they but traine up the cow otherwise at her first calving. The other reason is of more weight, viz.: aince s great part of their wealth consists in the product of their cattel, they think it very ill husbandry to sell that for a shilling, which, in time, would yeeld ponnds.'-Symson's 'Iarge Account of Galloway,' 1682." 
supplying the villagers with milk, and from the few dairy farms where cows are kept for making cheese.

"The best heifers are retained as breeders, in order to supply the place of those whose progeny is not valuable, or who are turned off on account of their age. The other female calves are spayed during the first year. The spayed heifers are usually smaller than the bullocks, but they arrive sooner at maturity; they fatten readily; their meat is considered more delicate, and in proportion to their size, they sell at higher prices than the bullocks.

"Mr. Culley says, 'In Galloway, they spay more heifers than perhaps in all the island besides, and in this too their method is different from any other part I am acquainted with, for they do not castrate them until they are about a year old, whereas in every other place I know, the heifer calves are spayed from one to three months old; and it is now generally admitted as the safest practice to castrate calves and lambs, male or female, while very young.' They are now generally spayed nuch earlier than they used to be, but some of the breeders adhere to the old custom.

"The young cattle are rarely housed after the first winter; they are on their pastures day and night, but in cold weather, they receive hay and straw in the fields, supporting themselves otherwise on the foggage left unconsumed after the summer grass. Many of the farmers are beginning to learn their true interest, and the pastures are not so much overstocked in summer as they used to be, and a portion of herbage is left for the cattle in the winter; therefore, although the beasts are not in high condition in the spring, they had materially increased in size, and are in a proper state to be transferred to the rich pastures of the lower district.

"The following were the proportions of a fat heifer of this breed: Height of shoulder, $5 \mathrm{ft}$. 2in.; length from nose to rump, $10 \mathrm{ft}$. $4 \mathrm{in}$; width across the hip, $2 \mathrm{ft}$. 6in.; across the middle of the 
back, $3 \mathrm{ft}$.; across the shoulders, $2 \mathrm{ft}$. 4 in.; girth of leg below knee, 8in.; distance of breast from the ground, $1 \mathrm{ft} .3 \frac{1}{2} \mathrm{in}$.; width between fore legs, $1 \mathrm{ft}$. $5 \mathrm{in}$. The live weight was 1520 pounds. She was exhibited at the Smithfield cattle show, and her portrait engraved under the sanction of the club.

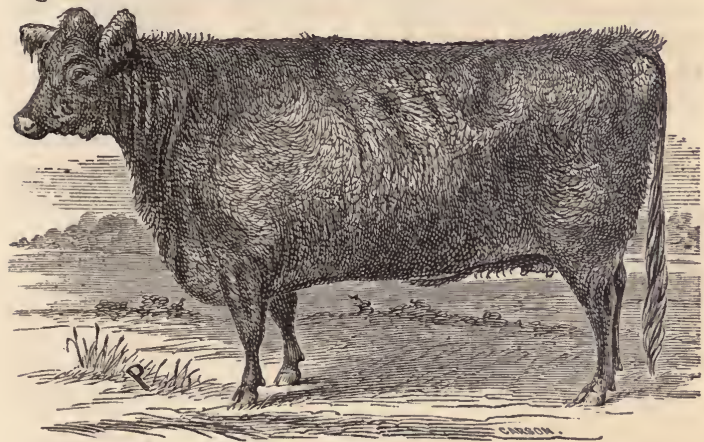

Plate 14. Galloway Cow, four years old.

This cut is an accurate portrait of a beautiful young Galloway cow, in Canada West, as taken by our artist.

"The Galloway cows are not good milkers; but although the quantity of the milk is not great, it is rich in quality, and yields a large proportion of butter. A cow that gives from twelve to sixteen quarts of milk per day, is considered a very superior milker, and that quantity produces more than a pound and a half of butter. The average milk, however, of a Galloway cow, cannot be reckoned at more than six or eight quarts per day, during the five summer months after feeding her calf. During the next four months she does not give more than half of that quantity, and for two or three months she is dry. 
"A bullock well fattened, will weigh from 560 to 840 pounds, net, at three or three and a half years old, and some have been fed to more than 1400 pounds at five years old.

"There is, perhaps, no breed of cattle which can be more truly said to be indigenous to the country, and incapable of improvement by any foreign cross, than the Galloways. The short-horns almost every where else have improved the cattle of the districts to which they have traveled. They have, at least in the first cross, produced manifest improvement, although the advantage has not often been prolonged much beyond the second generation; but even in the first cross, the short-horns have done little good in Galloway, and, as a permanent mixture, the choicest southern bulls have manifestly failed. The intelligent Galloway breeder is now perfectly satisfied that his stock can only be improved by adherence to the pure breed, and by care in the selection.

"The Galloway cattle are generally very docile. This is a most valuable point about them in every respect. It is rare to find even a bull furious or troublesome."

After this minute and excellent description by Youatt, little further need be said of them at home, and we proceed to speak somewhat of

\section{THE GALLOWAYS IN AMERICA.}

Whether they were imported at an early day into this country, in their purity of blood, we have no knowledge; but as Youatt says: "So late as the midule of the last century, $(1750$,$) the$ great part of the Galloways were horned," (which we somewhat doubt,) the probabilities of their coming here are light. It is eertain, however, that polled cattle came over with some of the early importations, as such have been known here for more than a century past. As they were red, spotted, and of all colors usual among our native cattle, they probably were picked up from the polled herds of Norfolk or Suffolk, in England, where 
they have ahounded for centuries. In the year 1837 , we saw a very fine, black, polled Galloway cow, at the General Hospital, in Philadelphia. How she came there, we could not ascertain.

About the year 1850, some enterprising Scotch farmers made the first importations of Galloways into the vicinity of Toronto, in Canada West. They already had the short-horns there, of high quality, imported many years before, and some of them were kept and much liked by the same farmers who brought out the Galloways. But the latter were the cattle of their native land, and their attachment to them there was too strong to be overlooked or forgotten in their new homes. The cattle possessed certain qualities which they found here in no other race, and with a characteristic love of their native land, as they loved the poetry of Burns, and repeated his songs, they also longed for, and sought the cattle of their native hills and heather. There must have been several different importations, for in the year 1857 , we saw upwards of forty of them exhibited by competing owners at a Provincial agricultural show, at Brantford, and have since met them in equal numbers at other shows in the Province.

They were fine cattle-full, round, and comely in form; robust in appearance; showing a ready aptitude to take on flesh; elastic to the touch; a good skin, with long, thick, wavy hair; of placid look, and apparently kindly temper. In addition to these good qualities, some of their owners declared them to be "good milkers." But their indications in that line did not show it, although, in practice, there may lave been exceptions to what we thought indicated an opposite tendency. Their colors were black, generally, although we found one or two dull reds, or duns, and a brindle (black and red mixed,) among them-which colors, according to Youatt, are admissible. Taken altogether, the cattle fully answered his description. 
That they are well adapted to the soil and climate of Canada, and of the Northern and Middle States of America, we have no doubt, as a grazing beast; but, for the dairy, an intimate and persistent trial of their qualities in that line, will only convince us of their superiority, or even average excellence with our own good dairy cows. In the hilly and more rugged parts of our country, adapted for the rearing and grazing of the lighter and more active breeds of cattle, they must be a desirable stock to introduce, and as such, we consider them entitled to confidence.

Their lack of horn, is by some thought a point of great merit, as rendering them more peaceable in a herd, and harmless to do injury. It may be so; but if those charitable people could once see a fight between one of them and a full-horned beast, they would soon find that their conical skulls can butt as hard, and force as vigorous a push as the others; and aithough they can inflict no injury by the horn, the skull is as impenetrable and actively managed as the most enthusiastic admirer of adroit "hits" would desire. The fact is, a Galloway can fight, either in defence or attack, as well as a horned beast, and the safety of him who handles them lies more in their docility of temper and good training, than in their inability to inflict injury.

The peculiar shape of the skull is a prominent point in determining the purity of blood, and high breeding in the Galloway. It should be high, and pointed round like the head of a doe, with no place for a horn to plant itself, and a thick and long growth of hair, almost shaggy, in front. In fact, an expert in Galloways will detect a deficient or false point in them, as readily as the most fastidious judge would do in a short-horn or a Devon. 


\section{CHAPTER XII.}

THE AYRSHIRES.

The third, and with dairymen, the most important variety among the Scottish cattle, now comes under our notice. All the authorities respecting the origin and history of this noted breed, are condensed and fully treated in Youatt. We have read and studied several English and Scottish writers on them, and heard tales innumerable; but as they more or less quote Youatt, and his authorities, we conclude to make him responsible for them all, and add only such observations, as our own personal acquaintance of some twenty-five years with them has made us familiar. The increasing interest with which the Ayrshire is regarded in this country, will justify what we have thought proper to insert from that generally correct author:

"The county of Ayrshire extends along the eastern const of the Firth of Clyde, and the North Channel from Renfrew to Wigtonshire, by the former of which it is bordered on the north, and by the latter on the south, while it has Kircudbright, Dumfries, and Lanark on the east. It is necessary to mention this, in order that the reader may better comprehend the rapid distribution of the Ayrshire cattle over all these districts. The climate is moist but mild; and the soil, with its produce, is calculated to render it the finest dairy country in Scotland, and equal perhaps to any in Great Britain.

"Mr. Aiton, in his 'Treatise on the Dairy Breed of Cows,' thus describes the Ayrshire cattle: 'The shapes most approved of in the dairy breed, are as follows: 
" 'Iead small, but rather long and narrow at the muzzle; the eye small, but smart and lively; the horns small, clear, crooked, and their roots at considerable distance from each other; neck long and slender, tapering towards the head, with no loose skin helow; shoulders thin; fore-quarters light; hind-quarters large; back straight, broad behind, the joints rather loose and open; carcass deep, and pelvis capacious, and wide over the hips, with round fleshy buttocks.* Tail long and small; legs small and short, with firm joints; udder capacious, broad and square, stretching forward, and neither fleshy, low hung nor loose; the milk veins large and prominent; teats short, all pointing outwards, and at considerable distance from each other; skin thin and loose; hair soft and woolly. The head, bones, horns, and all parts of least value, small; and the general figure compact and well proportioned.'

"Mr. Aiton also informs us, that "the Ayrshire farmers prefer their dairy-bulls, according to the feminine aspect of their heads and necks; and wish them not round behind, but broad at the hook-bones and hips, and full in the flanks.

" "The qualities of a cow are of great importance. Tameness and docility of temper greatly enhance the value of a milk cow. Some degree of hardiness, a sound constitution, and a moderate degree of life and spirits, are qualities to be wished for in a dairy cow, and what those of Ayrshire generally possess. The most valuable quality which a dairy cow can possess, is, that she yields much milk, and that of an oily or butyraceous, or caseous nature, and that after she has yielded very large quantitios of milk for several years, she shall be as valuable for beef as any other breed of cows known; her fat shall be much more mixed through the whole flesh, and she shall fatten faster than any othor.'"

* Mr. Rankine very properly remarks, that, 'compared with other improved brecds, the thighs, or what is called the twist of the Ayrshire cow, are thin. She is, characteristically, not a fleshy animal." " 
We give a cut of the most fashionable modern style of the Ayrshire cow, of late importation. drawn from life.

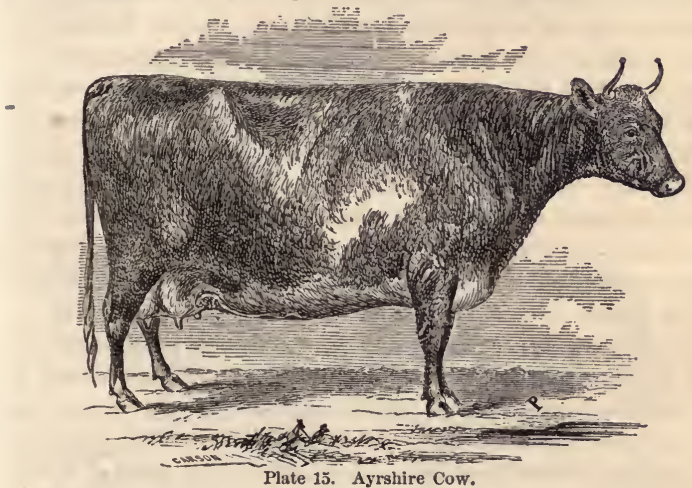

"The origin of the Ayrshire cow, is even at the present day a matter of dispute; all that is certainly known about her, is, that a century ago, $(1733$,$) there was no such breed in Cumning-$ ham, or Ayrshire, or Scotland. Did the Ayrshire cattle arise entirely from a careful selection of the best of the native breed? -if they did, it is a circumstance unparalleled in the history of agriculture. The native breed may be ameliorated by careful selection, its value may be incalculably increased; some good qualities-some of its best qualities-may be for the first time developed; but yet there will be some resemblance to the original stock, and the more we examine the animal, the more clearly we can trace out the cliaracteristic points of the ancestor, although every one of them improved.

"Mr. Aiton gives the following description of the Ayrshire cattle, $(1783$,$) fifty years ago: 'The cows kept in the districts'$ 
of Kyle and Cunningham, were of a diminutive size; ill-fed, ill-shaped, and they yielded but a scanty return in milk; they were mostly of a black color, with large stripes of white along the chine, or ridge of their backs, about their flanks, and on their faces. Their horns were high and crooked, having deep ringlets at the root, the plainest proof that the cattle were but scantily fed; the chine of their backs stood up high and narrow; their sides were lank, short and thin; their hides thick and adhering to the bones; their hair was coarse and open, and few of them yielded more than six or eight quarts of milk per day, when in their best plight; or weighed, when fat, more than from 300 to 400 pounds avoirdupois, sinking offal.'

"He very naturally adds-'It was impossible that these cattle, fed as they then were, could be of great weight, well-shaped, or yield much milk. Their only food in winter and spring, was oat straw, and what they could pick up in the fields, to which they were turned out almost every day, with a mash of a little corn with chaff daily, for a few weeks after calving, and their pasture in summer was of the very worst quality; and that coarse pasture was so overstocked, and eaten so bare, that the cattle were half-starved.' "

"If Mr. Aiton's description of the present improved Ayrshire is correct, the breed is very much changed, and yet there is so much indistinct resemblance, that a great deal of it must have been done by careful selection, from among the native cattle, and better feeding and treatment; but when we look closer into the matter, the shortness, or rather diminutiveness of the horns, their width of base and awkward setting on-the peculiar tapering towards the muzzle; the narrowing at the girth; the bellying; and the prominence of all the bones-these are features which it would seem impossible for any selection from the native breed to give. While, therefore, the judge of cattle will trace the features of the old breed, he will suspect, what general tradition confirms, 
that it was a fortunate cross, or a succession of crosses with some foreign stock, and that, probably, it was the Holderness (an old variety of the short-horns-great milkers,) that helped to produce the improved Cunningham cattle.

We give a correct cut of a modern Ayrshire bull, of late importation, drawn from life, in which will be seen more roundness and symmetry of style, than in the bulls of even twenty years ago.

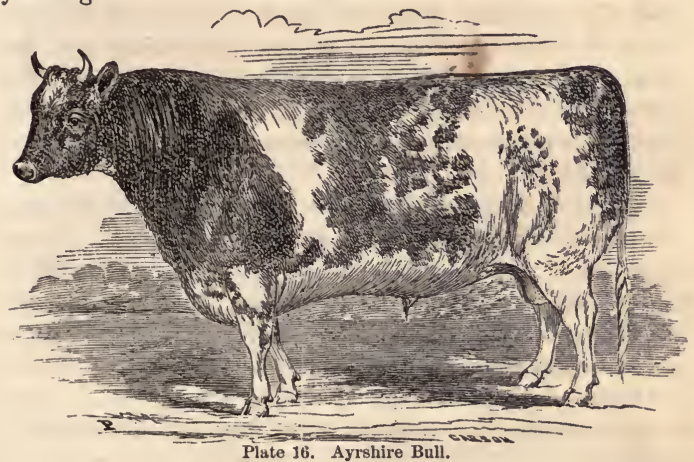

"In many a district, the attempt to introduce the Teeswater breed, (short-horns,) or to establish a cross from it, had palpably failed, for the soil and the climate snited only the hardihood of the Highlander; but here was a mild climate-a dairy country; the Highlander was in a manner out of his place; he had degenerated, and the milking properties of the Holderness, and her capability of ultimately fattening, although slowly, and at considerable expense, happily amalgamated with his hardihood, and disposition to fatten, and there resulted a breed, bearing about it the stamp of its progenitors, and, to a very considerable degree, the good qualities of both. 
"Mr. Robertson, in his 'Rural Recollections,' says: 'Who introduced the present breed is not very precisely ascertained, but the late Colonel Fullarton, whose account of 'The Husbandry of Ayrshire,' which was published in 1793, and whose authority is of considerable weight in everything relating to it, states, that a gentleman of long experience, Mr. Bruce Campbell, asserts that this breed was introduced by the late Earl of Marchmont.' The Earl of Marchmont, alluded to, must have been that Alexander Hume Campbell, who married Margaret Campbell, heiress of Assnoch, in the same parish, and who became Earl of Marchmont in 1724, and died in 1740. The introduction then, of this dairy stock, must have happened between these two dates, and so far corresponds with the tradition. ary account.

"Mr. Robertson goes on to say: 'From what particular part of the country they came, there appears no evidence. My own conjecture is, that they are either of the Holderness breed, or derived from it; judging from the varied color, or, from somewhat better evidence, the small head and slender neck, in which they bear a striking resemblance to them."*

"These cattle, from which, by crosses with the native breed, the present improved Ayrshire arose, were first introduced on

"* Some breeders, however, have maintained that they were produced from the native cow, crossed by the Alderney bnll. It requires but one moment's inspection of the animals, to convince ns that this supposition is altogether erroneous.

"In Rawlin's + Complete Cow-doctor,' published at Glasgow, in 1794, the following account is given of the Ayrshire cattle at that time: "They have another breed called the Dnnlop cows, which are allowed to be the best race for yielding milk in Great Britain or Ireland, not only for large quantities, bnt also for richness in quality. It is said to be a mixture, by bulls brought from the Island of Alderney, with their own cows. These are of a small size. These are allowed to yield more milk daily than from any other kind of cattle, when a just comparison is made of their size and pasture. They are much leaner and thinner than any other of the Scotch or English breeds, when in the best grass. They are not deemed a race of handsome cattle, but rather the contrary, being shaped more like the (common) Dutch breed than any of the natives of Scotland. Thelr horns are small, and stand remarkably awkward; their color is generally pled, or of a gandy red, rarying in this from all other races." " 
Lord Marchmont's estates in Berwickshire. They were soon afterwards carried to the farms belonging to the same nobleman, at Sornbergh, in Kyle. A bull of the new stock was sold to Mr. Hamilton of Sundrum; then Mr. Dunlop, in Cunningham, inported some of the 'Dutch cattle, and their progeny was long afterwards distinguished by the name of the Dunlop cows. These were the first of the improved, or stranger breed, that reached the baillery of Cunningham. Mr. Orr, about the year 1767, brought to his estate of Grongar, near Kilmarnock, some fine milch cows of a larger size than any which had been on the farm. It was not, however, until about 1780 , that this improved breed might be said to be duly estimated, or generally established in that part of Ayrshire, although they had begun to extend beyond the Irvine, into Kyle. About 1790, according to Mr. Aiton, Mr. Fulton from Blith, carried them first into Carrick, and Mr. Wilson, of Kilpatrick, was the first who took them to the southern parts of that district. So late as 1804 , they were introduced on the estate of Penmore, on the Stonchar, and they are now the established cattle of Ayrshire; they are increasing in the neighboring counties, and have found their way to most parts of Britain.

"The breed has much improved since Mr. Aiton described it, and is short in the leg; the neck a little thicker at the shoulder, but finely shaped towards the head; the horns smaller than those of the Highlanders, but clear and smooth, pointing forwards, and turning upwards, and tapering to a point. They are deep in the carcass, but not round and ample, and especially not so in the loins and haunches. Some, however, have suspected, and not without reason, that an attention to the shape and beauty, and an attempt to produce fat and sleeky cattle, which may be admired at the show, has a tendency to improve what is only their second point-their quality as grazing cattle-and that at the hazard or the certainty of diminishing their value as milkers. 
"We agree with Mr. Aiton, that the excellency of a dairy cow is estimated by the quantity and the quality of her milk. The quantity yielded by the Ayrshire cow is, considering her size, very great. Five gallons daily, for two or three months after calving, may be considered as not more than an average quantity. Three gallons daily will be given for the next three months, and one gallon and a half during the succeeding four months. This would amount to more than 850 gallons; but, allowing for some unproductive cows, 600 gallons per year may be considered as the average quantity obtained annually from each cow.

"The quality of the milk is estimated by the quantity of butter or cheese that it will yield. Three gallons and a half of this milk will yield about a pound and a half avoirdupois, of butter. An Ayrshire cow may be reckoned to yield 257 English pounds of butter per unnum, or about five pounds per week all the year round, beside the value of the butter-milk and her calf.

"When the calculation is formed, according to the quantity of cheese that is usually produced, the following will be the result : -twenty-eight gallons of milk, with the cream, will yield 24 pounds of sweet-milk cheese, or 514 pounds avoirdupois per annum, beside the whey and the calf.*

"This is certainly an extraordinary quantity of butter and cheese, and fully establishes the reputation of the Ayrshire cow, so far as the dairy is concerned. $\dagger$

"*A Scoteh pint is nearly two English quarts. An Ayrshire pound consists of 21 onnces, and sixteen of these pounds, or 21 ponnds avoirdnpois, make a stone. $\mathrm{Mr}$. Fullarton, in his 'Statistical Account of Duiry,' in this county, states that in 1794, before the establishment of this improved Ayrshire cow, each cow would yieid, on the average, in the course of the season, 18 stones, or 288 lbs. of sweet-milk cheese."

" + In some experiments condncted at the Earl of Chesterfield's dairy, at BradleyHall farm, it appeared that, in the height of the season, the Holderness wonld yield 7 gallons and a quart; the long-horu and the Alderney, 4 gallons 3 quarts; and the Devon, 4 gallons 1 pint per day; and when this was made into butter, the resuit was, from the Holderness, $38 \%$ ounces; from the Devon, 28 ounces ; and from the Alderney, 25 onnces. The Ayrshire yields 5 gallons per day, and from that is produced 34 onnces of butter." 
"Mr. Aiton rates the profit of the Ayrshire cow at a high value. He says: "To sum up all in one sentence, I now repeat that hundreds and thousands of the best Scotch dairy cows, when they are in their best condition and well fed, yield at the rate of 2000 Scotch pints of milk (1000 gallons) in one year; that, in general, from $7 \frac{1}{2}$ to 8 pints ( $33 / 4$ to 4 gallons) of their milk will yield a pound of butter, county weight (11/2 pounds avoirdupois); that 55 pints ( $271 / 2$ gallons) of their milk will produce one stone and a half, imperial weight, of full milk-cheese.

"Mr. Rankine, the author of an excellent report of a Kyle farm, and some of whose observations, with which we have been privately favored, we have embodied in our account of the Ayrshire cattle, very justly, we think, maintains that Mr. Aiton's statement is far too high, and his calculations not well founded.

"'I quote with confidence,' Mr. Rankine proceeds, 'the answers to queries which I sent to two individuals. The first is a man of superior intelligence and accuracy, and who has devoted himself very much to dairy husbandry. He keeps between twenty and thirty cows, and his stock has for years been the handsomest I ever saw, and his farm being close to a small town, he had every inducement to keep them in the highest condition that is requisite for giving the largest produce in milk. He states that, at the best of the season, the average milk from each is 9 Scots pints ( $4 \frac{1}{2}$ gallons, ) and in a year, 1300 Scots pints $(650$ gallons); that in the summer season, 64 pints (32 gallons) of entire milk will make an Ayrshire stone (24 pounds) of cheese; and 96 pints ( 48 gallons) of skimmed milk will produce the same quantity; and that 180 pints (90 gallons) will make 24 pounds of butter.

" 'Another farmer, in a different district of this county, and who keeps a stock of between thirty and forty very superior cows, and always in condition, states that the average produce of each is 1375 pints (6871/2 gallons). My belief, on the whole, is, that 
although there may be $\Lambda$ yrshire cows capable of giving $900 \mathrm{gal}$. lons in the year, it would be difficult to bring half a score of them together; and that in stocks of the greater number, most carefully selected, and liberally fed, from 650 to 700 gallons is the very highest produce of each in the year.'

"Mr. Rankine concludes with giving his experience on his own farm, the soil of which is of an inferior nature, and on which his cows produced about $\mathbf{5 5 0}$ gallons per cow.

"We have entered at considerable length into this, because it is of some importance to ascertain the real value and produce of this celebrated Scottish breed of cattle, and also to correct an error in an agricultural work, deservedly a standard one in Scotland, and which may otherwise be implicitly relied on.

"The fattening properties of the Ayrshire cattle we believe to be a little exaggerated. They will feed kindly and profitably, and their meat will be good. They will fatten on farms and in districts where others could not be nade to thrive at all, except partly or principally supported by artificial food. They unite, perhaps, to a greater degree than any other breed, the supposed incompatible properties of yielding a great deal of milk and beef. It is, however, as Mr. Rankine well observes, on the inferior soil and the moist climate of Ayrshire, and the west of Scotland, that their superiority as milkers is most remarkable. On their natural food, of poor quality, they give milk abundantly and long, and often until within a few days of calving. In their own country, a cow of a fleshy make, and which seldom proves a good milker, may be easily raised from 560 to 700 pounds, and bullocks of three years old are brought to weigh from 700 to 840 pounds weight. There is a lurking tendency to fatten about them, whioh good pasture will bring to light; so that when the Ayrshire cow is sent to England, she loses her superiority as a milker, and begins to accumulate flesh. On this account it is that the English dealers who purchase the Ayrshire cows, generally 
select the coarsest animals they can find, in order to avoid the consequence of the change of climate and food. It is useless to exaggerate the qualities of any cattle, and it cannot be denied, that even in this tendency to fatten when their milk begins to fail, or which often causes it to fail, the Ayrshires must yield to their forefathers, the Highlanders, and also to their neighbors, the Galloways, when put on a poor soil; and they will be left considerably behind their short-horn sires, when transplanted to luxuriant pasture. It will be long, perhaps, before they will be favorites with the butchers, for the fifth quarter will not usually weigh well in them: Their fat is mingled with the flesh, rather than separated in the form of tallow; yet this would give a more beautiful appearance to the meat, and should enhance its price to the consumer.

"Two circumstances, however, may partially account for their not being thought to succeed so well when grazed: they are not able to travel so far on the same keeping, as the Highland cattle can do; and, from their great value as milkers, they are often kept until they are too old to fatten to advantage, or for their beef to become of the best quality.

"The advantage of feeding well in winter, and sending a cow to grass in good condition, is now generally understood; but the defect in practice is, that what can be afforded to the cow in this way, is given only while they are in milk, or when they calve. The return is, indeed, rendered more immediate, but it would be still more advantageous if a fair portion of the proper winter's food were given to the dairy cows, after they were dry of milk.

"Mr. Aiton gives a satisfactory account of the rearing of dairy stock. They are selected from parents of the best quality, and few are brought up that are not of the fashionable color. Those are preferred that are dropped about the end of March, or the beginning of April, as they are ready for the early grass, and attain some size before winter. 
"Calves reared for dairy stock are not allowed to suck their dams, but are always fed by the hand from a dish. They are generally fed on milk, only for the first four, five or six weeks, and are then allowed from four to five quarts of new milk, twice in the twenty-four hours. (Mr. Rankine says 'from 10 to 12 quarts.') Some never give them any other food when young, except milk; and lessen the quantity when the calves begin to eat grass or other food, which they will generally do at about five weeks old; the milk is totally withdrawn about the seventh or eighth week of the calf's age. If, however, the calf is reared in the winter, or early in the spring before the grass rises, it must be longer supplied with milk, for it will not so soon learn to eat hay or straw. Some mix meal with the milk after the third or fourth week; others add new whey to the milk, which has been first mixed with meal; and when the calf gets two months old they withdraw the milk, and feed it on whey and porridge. Hay-tea, broths of peas, or of pea straw, linseed beaten into powder, treacle, \&c., have all been sometimes used to advantage in feeding calves; but milk, when it can be spared, is the most natural food.

"The dairy calves are generally fed on the best pasture during the first summer, and have some preference over the other stock, in food, during the next winter, or they are allowed to run loose in a yard with a shed, and are supplied with green food in cribs. When the green food is eaten, they get with straw as many turnips as can be afforded them, and that is generally a very small quantity. Mr. Rankine says that 'there is no reason to doubt that this mode of feeding during the first season, is preferable to pasturing. Besides the excellent dung produced, the animals arrive, under this treatment, at a much greater size.' From that time, until they drop their first calf, they are generally turned on inferior pasture, and are no better fed in winter than any other species of stock. They are allowed what oat straw 
they can eat during the night and morning, and, except in time of snow, are turned out to the fields during the day time. The greatest part of the young dairy stock are kept in byres, or in sheds during winter, but some are laid out, and supported with straw in the fields."

After these prolonged and exhaustive dranghts from Youatt, and his authorities, which we consider mainly an argument in favor of the Ayrshire- -and have thought it a duty in a work of this character, to give for the benefit of the great and increasing dairy interest of our country-we have something to say on our own account about them. And not in a partizan spirit, either, but in that of a fair investigation of the breed and its merits. And first, as to their origin and history.

The Ayrshires first began to be imported into the United States about the year 1831-thirty-six years ago. They were sumewhat different in appearance from the later importations, being in color usually deep red, or brown, flecked with white; of rather plain look, and having, mostly, black nóses. In recent importations, or those within the last fifteen years, many of them have assumed more the "short-horn" colors, the red in them being of a lighter shade, and less of it-white being the prevailing color in many-and some of them a lively patched roan, with yellow noses, and handsome, and more symmetrical forms, but alike bearing the marks of good milkers. These remarks may appear inconsequent now, but their bearing will be found in further speaking of their history, and course of breeding.

In the array of fact, tradition, and inference relating to their origin, as given by Youatt, a strange jumble is made of their history, and still, most of the relations given by the authorities may be admitted. The fact that the common Scotch, or Kyloe cow, previous to the year 1724, was a creature of but ordinary value for the dairy, is easily understood; and the "conjecture" of Mr. Robertson, that the Earl of Marchmont, in some of the 
years between 1724 and 1740 , brought "Holderness" cattle, or "those derived from them," on to his estates to improve the dairy qualities of his cows, is probable, as the old Holderness cattle were extraordinary milkers, and had the colors described in the early Ayrslires. It was on the Earl of Marchmont's estate that the improvement in the Ayrshires first began. Some years afterwards, it appears that "Mr. Dunlop imported some Dutch cattle" and crossed on the Ayrshires, or their immediate progenitors. This "Dutch" importation we must be permitted to doubt, as by a long standing British order in Council, passed previous to, and continued many years after the supposed Dutch improvement happened, the importation of foreign cattle was prohibited. "Mr. Orr, about the year 1767, brought to his estate near Kilmarnock, (in Ayrshire,) some fine milk cows of a larger size than any which had been on his farm. It was not, however, till about 1780 , that this improved breed might be said to be duly estimated, or generally established in that part of Ayrshire." In 1790, and in 1804, the Ayrshires were further disseminated, and about the latter year, Mr. Aiton takes them up. Youat, also says, "the breed has- been much improved since Mr. Aiton described it." And now the grand question arises: what bulls were used to make that improvement? for it appears that up to Aiton's time, the Ayrshires were a composition of different breeds, based mainly on the Kyloe.

As Mr. Aiton is made the chief authority for this origin, and improvement, we wish that gentleman had been more particular in facts, and dates, for he leaves the matter altogether to inference, and guess work; as to how the improvements were effected; and in that dilemma we venture a guess. It could be from no other than a direct cross of small, compact short-horn bulls, descended from the best milking cows in the north-eastern counties of England, on the cows descended from the "Holderness" bulls of Lord Marchmont, and their crosses from the "conjec- 
tured" Dutch bulls, brought in by Mr. Dunlop. From no other race of cattle, either Scotch; English, or Irish, could the improved Ayrshires get their shape, color, and milking qualities combinedcolor and shape resembling the short-horns more than any other, and the milking quality also possessed by them in an eminent degree. And although a persistence in such crosses has been kept out of sight, or not acknowledged, the further improvement of the Ayrshires shows still greater marks of a continued cross from the same quarter.

The late Mr. Adam Fergusson, a distinguished statesman, farmer, and stock breeder, of Upper Canada, a native, and fifty years a resident, and connected with agricultural interests in the Lowlands of Scotland, repeatedly informed us that the improvement of the Ayrshires was effected by the use of short-horn bulls, and the more intelligent of the Scottish agriculturists considered them as simply grade short-horns. The Ayrshires resemble the short-horns more than they do any other cattle, and as they do not claim originality in breed, and have been made up mainly within the last hundred years, there need be no hesitancy in aeknowledging both the facts and inferences concerning them. That they are a good breed of cattle, useful, and eminently qualified for the dairy, and capable of perpetuating among themselves their good qualities, are facts now well established, both in Scotland and America; and thus we leave their "origin and history."

\section{THE AYRSHIRES IN AMERICA.}

Their thrty-six years' trial here has been successful. They -are hardy, healthy, well fitted to our climate, and pastures, and prove good milkers, both in the imported originals, and their progeny. Their flow of milk is good in quantity, and fair in quality; yet, we must be permitted to say, that in this country they do not yield so much in quantity, as is alleged they have produced in Scotland. The chief reason for this is obvious. 
Ayrshire has a moist climate-an almost continuous drizzle of rains, or moisture pervading it-making fresh, green pastures; a cooler and more equable temperature in summer, and warmer in winter than ours. Our American climate is liable to extremes of cold in winter, heat in summer, and protracted droughts, for weeks, drying up our herbage. These differences alone account for a diminished quantity in the yield of milk from the Scotch, to the American Ayrshires. They have softer grasses for hay, and plenty of root feeding in winter, which latter we have not. This fact of a diminished yield in milk on this side of the Atlantic, is acknowledged by those most conversant with them in both countries.

In the year 1837, we visited the Ayrshire herd of the late Mr. John P. Cushing, at Watertown, near Boston, Mass. They were of the choicest quality, imported by himself, on an order sent out to an experienced dealer in Ayrshire cattle, "without regard to price, so they were of the best." Two or three of the cows were "prize" milkers at home, and certificates, duly verified, were sent with them, of the quantities of milk they had made. They had then been a year or more at Mr. Cushing's farm, and had the best of keep. We questioned the manager as to the quantities of milk the cows gave since their arrival, com. pared with the certificates. His answer was, "about one-third less, on an average. The best prize cow gave 33 quarts per day when at her maximum, in Ayrshire, and 22 quarts here, and the others in about like proportion; but they are all good milkers, and Mr. Cushing is well satisfied with them." We simply note the fact of the declension in milk of the Ayrshires. in this country, knowing the same to have occurred with cows of other hreeds from England.

\section{AS A BEEF ANIMAL.}

Youatt says little of the Ayrshires in this particular. We get only this: "It will be long, perhaps, before they will be favorites 
with the butchers, for the fifth quarter will not weigh well in them. Their fat is mingled with the flesh, rather than separated in the form of tallow; yet this would give a more beautiful appearance to the meat, and should enhance its price to the con sumer."

We never saw an Ayrshire bullock, and can know little of them as beef. We see no good reason, however, why they should not make proper animals for slaughter, as their general appearance indicates good feeding qualities. Hitherto, attention has been drawn chiefly to their milk, and for that reason, probably, less attention has been given to their fattening properties. That must remain a question for trial.

After all, we have little doubt that the Ayrshires owe their chief qualities, both in milk, as well as in form and color, to their short-horn progenitors, on one side. We have no wish to underrate them, and do not. But we have bred, and seen bred by others, cows which, if declared to be Ayrshires, would pass without suspicion, both in their looks, and milking properties, as good specimens of the breed; and these were simply the produce of good native milk cows, from compact, small, short-horn bulls, of good milking ancestry. The cuts which we give are accurate likenesses of a living bull and cow-both first prize animalsdescended from a late importation from Ayrshire, which were said to be as good as existed in Scotland. A single glance will detect their resemblance to the small, compact short-horns, which we occasionally meet where they are kept more for their milk than for "prize" animals at the exhibitions. 


\section{CHAPTER XIII.}

THE ALDERNEY-JERSEY-GUERNSEY-OR CHANNEL ISLAND CATTLE.

WE regret that Youatt-so elaborate with some other breedshas devoted less than two pages of text to this singular, unique, and truly valuable race. And from other English authorities we obtain but sketches in various unconnected accounts. Youatt calls them-to England-a "foreign breed." They are so, being originally from Normandy, a Province in the north-western part of France, but they were long ago transplanted, and became the peculiar race belonging to the "British Channel Islands" of Jersey, Guernsey, and Alderney, lying off the coast of Normandy.

We glean some partial descriptions of them from foreign publications; but as we have them here, probably in as high qualities of breeding and excellence as in their native Islands, we describe them as we have seen. Beginning with the head-the most characteristic feature-the muzzle is fine, the nose either dark brown or black, and occasionally a yellowish shade, with a peculiar mealy, light-colored hair, running up the face into a smoky hue, when it gradully takes the general color of the body; the face is slightly dishing, clean of flesh, mild and gentle in expression; the eye clear and full, and encircled with a distinct ring of the color of the nose; the forehead bold; the horn short, curving inward, and waxy in color, with black tips; 
the ear sizable, thin, and quick in movement. The whole head is original, and blood-like in appearance-more so, than in almost any other of the cattle race-reminding one strongly of the head of our American Elk. The neck is somewhat depressed-would be called "ewe-necked," by some-but clean in the throat, with moderate, or little dewlap; the shoulders are wide and some. what ragged, with prominent points, running down to a delicate arm, and slender legs beneath; the fore-quarters stand rather close together, with a thinnish, yet well developed brisket between; the ribs are flat, yet giving sufficient play for good lungs; the back depressed, and somewhat hollow; the belly deep and large; the hips tolerably wide; the rump and tail high; the loin and quarter medium in length; the thigh thin and deep; the twist wide, to accommodate a clean, good sized udder; the flanks medium; the hocks, or gambrel joints crooked; the hind legs small; the udder capacious, square, set well forward, and covered with soft, silky hair; the teats fine, standing well apart, and nicely tapering; the milk veins prominent. On the whole she is a homely, blood-like, gentle, useful little housekeeping body, with a most kindly temper, loving to be petted, and, like the "pony," with the children, readily becomes a great favorite with those who have her about them, either in pasture, paddock, or stable. The colors are usually light red, or fawn, occasionally smoky grey, and sometimes black, mixed or plashed more or less with white. Roan colors, and a more rounded form, are now and then seen among them, but we do not like them, (as they savor of a short-horn cross, which they should not have,) as anything but their own blood and figure, and that of the ancient stock, deteriorates then-as Alderneys. The Guernsey cows are usually somewhat larger and coarser than the Jerseys, and Alderneys, showing more the rotundity and symmetry approaching the shorthorns. So we have sometimes seen them. 
Our portraits of the sexes, taken from life, give a correct representation of the true Alderney. They are excellent specimens.

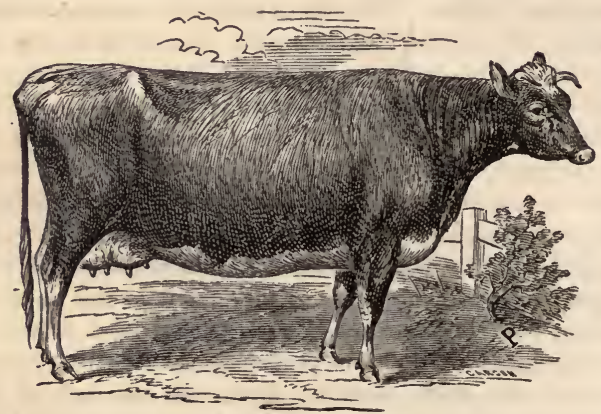

Plate 17. Alderney Cow.

She is simply a milking cow, and for nothing else should the race ever be bred. The bulls may be used in crossing on our common cows, to give the Alderney quality and color of milk in the heifers thus descended from them; but by no infusion of any other blood, can the Alderney cow be improved in the rich, yellow qualities for which her milk is esteemed. Along the coast of Hampshire, in England, she is frequently kept and bred, and many of them are scattered over other counties, but chiefly in individual, or small numbers for family use, to yield the milk and butter so highly prized by nice housekeepers.

The distinguishing quality for which the Alderney is prized, is the marked richness, and deep yellow color of her milk; yet it is moderate in quantity-eight to twelve quarts a day being a good yield in the height of her season-but that wonderfully rich in cream and butter. A gentleman in New England, who had for many years kept quite a herd of them on his farm for 
dairy purposes, a few years since told us that he sent much of his butter to private families in Boston, where he obtained about double the price of good common butter, and that one-half or even less of Alderney milk, mixed with that of the common cow, gave it a color nearly equal to that of the pure breed. We have had like accounts from others who kept them.

Alderneys were occasionally imported into America as early as fifty years ago, and in considerable numbers within the last twenty years. The late Mr. John A. Taintor, of Hartford, Conn., was probably the largest importer, having brought in a good many about the year 1850 , and later, from which he bred and sold many choice cows and bulls. Other importations have been made into New York, by the late Mr. Roswell L. Colt, of Paterson, New Jersey, and by others into Boston, Mass., Connecticut, and Philadelphia. They are now considerably kept in various parts of the New England States, New York, New Jersey, Pennsylvania, Maryland, and a few of the States further south, and west. They are favorites where well known, are increasing in numbers, and bear good prices-from $\$ 150$ to $\$ 300$ each, for cows, depending on appearance and quality. Natives of a milder climate than ours, they are more delicate in constitution, and require good shelter and food. They will not rough it so well as our common cows, or some of the English breeds; but they well repay all the care given them, and should not be neglected. John Lawrence, an English writer, quoted by Youatt, gives an account of an Alderney cow, which made nineteen pounds of butter each week, for three succossive weeks, "and the fact was so extraordinary, as to be thought worthy of a memorandum in the parish books." Extraordinary, most truly, for a cow of any breed.

There is no necessity for telling a story of large quantities of either milk or butter being produced by an Alderney. They are not made for great yields of anything. 
Our portrait of the bull much resembles that of the cow, but showing an arched neck, and the more masculine appearance common to his sex.

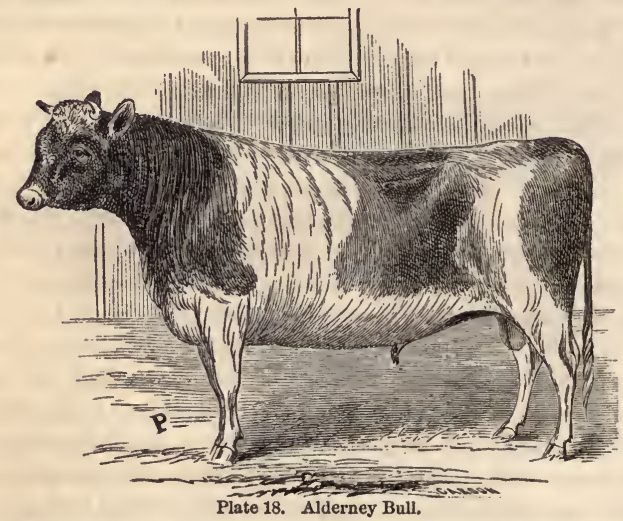

The chief foreign writer on Alderney cattle, is Mr. Le Couteur, a native, and, if living, a resident on one of the Channel Islands. They are the caltle of those Isiands; kept and bred with scrupulous care to their purity of blood, and the preservation of their distinctive qualities. The people of the Islands have laws regulating the introduction of foreign cattle among them, and the exportation of their natives abroad. It is estimated that upwards of four thousand cattle of the pure breed are annually exported from the Channel Islands.

Their mode of keeping them is quite systematic, and their fecd somewhat peculiar. Parsnips, of which the Islands yield great quantities, are much fed to them in winter and spring, as they are thought to promote, in a high degree, their flow of milk and 
its richness. The general facts detailed by Mr. Le Couteur, however, are much as we have related. Their calves are reared in the ordinary way, sucking the cow but a short time, and fed on milk diluted with meal and water, or whey, yet kept with care, and a good supply of food, until fitted for grass. The heifers usually bring their first calves at two and a half to three years old. In short, the Alderneys are calculated altogether for the pail.

\section{AS A WORKING OX, OR BEEF ANIMAL,}

We leave them out of the question. They are little fitted for either, compared with the best of English breeds, or even our good native cattle. Indeed, they make no special claims for those purposes, although used to some extent for both in their native lands. Here, we do not think of them in these connections. That the cow, out of milk, will fatten to a reasonable carcass, or the steer, if made so, will feed fairly, and produce a tolerable quality of beef, we have no doubt; but as that is not the purpose for which they are sought, or reared, we dismiss them as not particularly valuable in either item of labor or food. 


\title{
CHAPTER XIV.
}

\author{
THE SHORT-HORNS.
}

WE now approach a racc of cattle, which, within the present century, have received more of public attention, and acquired a wider popularity, both in England and America, than perhaps all the other races put together. It is due to this attention and popularity, that we give all the information regarding them (as, indeed, we have with the others,) which our reading and observation will admit. Their history has been involved morc or less in doubt and controversy, and from a study of some years of all the various authorities regarding them, unbiased by either partiality or prejudice, we shall strive to draw truthful conclusions, and place them in such light that all may understand both their early and present conditions.

English agricultural history, (for the Short-Horns, in their present appearance, were known only in England,) previous to dates down towards early in the last century-say one hundred and forty years ago-is silent respecting them. The farming interests of Britain had gradually awaked to the improvement of their condition, through the wants of a growing commerce and population. The necessity for increasing the products and revenues of the lind, and the consequent stocking them with better breeds of neat cattle than had previously occupied them, had become imperative. It was in the latter years of the last century, that the agricultural writers of the day began to give to the public some notion of the existence and value of this now celebrated race. Among these writers were Culley, Marshall, Bailey, and Lawrence, who wrote upon short-horn cattle in 
those years, and Berry, Youatt, Martin, Bates, and some others, in a brief way, in the present. We shall use all these authorities, without particular, or but partial mention of either, in relating their history and progress down to the present day. We must acknowledge, also, many facts derived from American writers and breeders of the race, whose information is of particular value, touching their recent history, or breeding, which will be duly acknowledged; and wherever pretended history, either English or American, has been found in error, we shall strive to correct it.

For a proper understanding of the matter, here at the threshold, we may as well assert (better here than elsewhere,) that the prevailing impressions of the history of the improved shorthorns, (as they are called,) to some extent in England, and almost altogether in America, is a false one. With a charge of that character, an explanation is necessary.

Youatt, already frequently mentioned, is given as the principal and most important English authority on "British" cattle. $\mathrm{He}$ compiled his work, as we have before stated, at the request of, and published it under the superintendence of, the "Society for the Difusion of Useful Knowledge," a body then existing, and whose press was in London. He was competent to the task, and the chief parts of his work have been admitted to be correct. The various breeds of "British cattle" received a due share of his attention. With well-established authorities for his accounts of most of the breeds which he noticed, he left the short-horns for the last; and with a strange infatuation, when he came to them-the most important in value of any other-instead of doing the work himself, he farmed it out, with the exception only of a few running notes of his own, to one who had been a breeder of them for a few years only, the "Rev. Henry Berry." A brief account of Mr. Berry, and his short-horn experience, must be given. 
It appears that a few years previous to 1824 , he commenced breeding, his stock being derived principally from the herd of Mr. Jonas Whittaker, a cotton manufacturer, near Otley, in Yorkshire. About that time a controversy had arisen as to the comparative merits of the short-horn and Hereford breeds of cattle, as a grazing and fattening animal, between their respective advocates, and Berry, as the champion of the short-horns, wrote a pamphlet on the subject, purporting to give a history of the "Improved Short-horns, derived from authentic sources; to which is added an enquiry as to their value for general purposes, placed in competition with the improved Herefords." This pamphlet bears an imprint of the year 1824. In the year 1830, he printed a "second edition" of the same work. With this controversy, or the comparative merits of the two breeds, we have nothing to do, as it does not appertain to our present subject. His facts respecting the short-horns, and their history, so far as derived from others, we let stand, and do not particularly dispute, as such facts have been equally accessible to us, as to him, and we are content to let them remain as authority. In this pamphlet he ascribes the chief merit, as the "improver" of the short-horns, to Charles Colling, who commenced breeding them about the year 1780. The only other breeder he prominently mentions, is Mr. Whittaker, of whom he (Berry) purchased his own cattle.

But when, in 1834, Berry produced his "history" for Youatt, it was quite another affair. It is said that, in the meantime, between the "pamphlet," and the "history" for Youatt, he had ceased his relations with Whittaker, and also obtained some of the "alloy" stock descended from one of Colling's experimental crosses, (which will be hereafter noticed,) and in his own hands, he had an object in writing them into credit, which explains this second history. The account in Youatt is much unlike the history in the pamphlet in othèr particulars, some being added 
and others left out. He retains Colling's narae in Youatt, but omits Whittaker's altogether, and introduces facts in the course of Colling's breeding, which he omitted in the pamphlet.

The main point of falsity, however, (left out in the pamphlet and put into Youatt,) which we propose to detect, as the source of all the mischief about the improvement of the short-horns by Colling, is this: While Colling was successfully breeding shorthorns from the best blood he had obtained of older and cotemporary brecders around him, a neighbor, "Col. O'Callaghan," bought a couple of Galloway heifers, and brought them home to his farm. He arranged with Colling to put them to his short-horn bull "Bolingbroke;" if the calves were heifers, he (O'Callaghan) was to retain them; if bulls, Colling was to have them. One of the heifers-a red one-dropped a bull calf, a half-bred short-horn, of course, which, by the arrangement, belonged to Colling. This bull calf being a good one-as a mongrel-Colling brought him up to a yearling. He had a short-horn cow, Joanna, quite old, and not having bred a calf for two years, he put her to this yearling cross-bred calf, "Son of Bolingbroke." She became pregnant, and in due course, in the year 1794, dropped a kull calf-three-fourths short-horn and one-fourth Galloway-a grandson of Bolingbroke. He proved a likely calf, also, and Colling kept him, as he had kept his sire, until he became a yearling. He had a very fine, aged cow, "Phœnix," from which had sprung some of his best stock. She had produced a thorough bred short-horn calf in 1793. Although afterwards put to some of Colling's thorough bred bulls, she continued barren, and in the winter of 1795-6, was put into the straw yard, and the young "Grandson of Bolingbroke," then a yearling, turned in with her. To him, Phœnix became pregnant. Colling then disposed of this "Grandson of Bolingbroke." In the autumn of 1796, Phœnix produced a heifer calf, seveneighths short-horn and one eighth Galloway blood. Being a 
good one, Colling called her "Lady," and raised her. When matured, he put this heifer "Lady" successively to his best bulls, and reared several calves from her. Her first calf was a bull, which he called "Washington," and Colling bred him to two or three of his cows, but nothing came from him of any particular value. He also bred her daughters to his good bulls, but never bred one of the bull calves, of either Lady or her heifer descendants, except the bull Washington, to any thorough bred cows in his herd; nor is it known that he ever sold one of them, as a thorough bred. He kept this "Lady" family separate, and by way of distinction from his thorough-breds, called them the "Alloy." They were good feeders, had good carcasses, and made a good appearance, but they were no milkers. At Colling's great sale of his short-horns, in the year 1810, when he quit breeding, this "Lady" family were catalogued with his others, and sold, with their full pedigrees distinctly given, so there need be no deception as to their breeding. Of this "family" there were quite a number, and being in fine condition, and cattle of all kinds in demand, they brought good prices, but not near so much, individually, as the cattle of some of his other families. These "alloy" were bought by the young, or new short-horn breeders, and not by the older veteran breeders who attended the sale. Thus "Lady" had one-eighth Galloway blood, her daughters one-sixteenth, their descendants less, and so on.

Now, Berry works up the story, and the prices the 'alloy' sold for, in his own way, leaving the impression that they were the favorite cattle at the sale, and stamps this Galloway cross as the root, foundation, and origin of the "improved" short-horns!

In giving an account of Colling's sale, and the prices the cattle brought, we let Berry tell his own story: "It will probably be admitted that the prejudice against the cross (alluding to the "alloy") was at the highest at the time of Mr. Charles Colling's sale. The blood had then been little, if at all, introduced 
to other stocks, and it was the interest, whatever might be the inclination of the many breeders who had it not, to assume high ground for the pure blood, and to depreciate the alloy. Under these circumstances, what said public opinion, unequivo. cally certified by the stroke of the auctioneer's hammer?" And with this flourish of trumpet, he then proceeds (in Youatt,) to give an illustrated portrait of one of his own cows, a descendant of this celebrated "Lady!" Youatt, in a quiet foot-note to Berry's account, rather rebukingly says: "As the grandson of Bolingbroke is not known to have been the sire of any other remarkably good animal, it is most probable that the unquestion. able merit of Lady and her descendants, is to be attributed more to her dam than to her sire." This must be so, as "Phœenix," the dam of Lady, was one of the best cows of her day, and the dam of "Favorite,"-(252) Coates' Herd Book-perhaps the very best bull of his time. He was the sire of Comet, who brought at the sale, the unprecedented sum of 1,000 guineas$\$ 5,000$. (Cattle of all kinds were enormously high at that time in England,-war times-and at this sale of Colling's, the shorthorns sold at higher rates than ever known before or since, until Lord Ducie's sale in 1853.) The names and pedigrees of those bulls, O'Callaghan's "Sou of Bolingbroke," and "Grandson of Bolingbroke," will be found in Coates' English Herd Book, Vol. 1.

Now, this is the falsehood, plausibly told by Berry in Youatt's history, and which has since been adopted as authority, both in England and America, and drawn upon by many subsequent writers in both countries, who did not know any better-and reported a thousand times, until half the world believe it-that makes the "improved" nodern race of short-horns originate from a bull of the "old Teeswater stock," and a "Galloway cow !" when in truth, scarcely a particle of Galloway blood runs 
in the veins of one in a hundred of the approved short-horns of the present day, in either country.

We have made rather a long story in showing up this deception; but the truth of short-horn history has demanded it; and if we shall have succeeded in putting this matter right, before the large interest concerned in pure short-horn breeding, our object will be accomplished. From the late Mr. Thomas Bates, a distinguished short-horn breeder, of Kirkleavington, Durham, Eng., a cotemporary of Charles Colling, and other corroborating testimony, the above account is given.

Having disposed of this historical swindle, we proceed to give, from the best authorities at command, a correct account of the origin, rise, progress, and present condition of this breed of cattle.

\section{HISTORY OF THE SHORT-HORNS.}

For some centuries anterior to the conquest of England by the First William, (of Normandy,) the north-eastern counties of England, Northumberland, Durham and York, (then called Northumbria,) had been possessed, with occasional interruptions, by the Danes, and other Scandinavians of North-western Europe. They were a warlike people, not only conquering, by their bold raids, the countries along the continental coast to the south of them, even into Holland, but pirates and "sea kings" as well, carrying their devastations across the water into Northumbria, and some adjoining parts of Britain. While they held the frontier coast of England, they established trade in many articles of merchandise and agricultural products, and shipped them to and from both sides of the ocean channel. $\Lambda$ mong these were cattle in considerable numbers. Southern Denmark, Jutland, Holstein, and Utrecht, long held by the Danes, possesscd a breed of cattle - short-horns essentially-having their general appearance, and peculiar colors, but coarse in form and flesh, yielding largely of milk. It is supposed by the majority of the earlier English 
writers on agriculture and cattle, who paid particular attention to these subjects, that it was from these foreign cattle, imported at that early day from the neighboring continent, that the present race of short-horns are descended, and that for some centuries they inhabited that part of England only. The earliest accounts we have seen, first found them there. Holderness, a district of Yorkshire, was said to number these cattle in considerable herds. They possessed a great aptitude to fatten, in addition to their milking qualities, yet their flesh was coarse, accompanied by a large amount of offal. That they possessed valuable characteristics in their high and broad carcasses, and contained within themselves the element of refinement, when brought within the conditions of shelter, good fare, and painstaking, we may well conjecture. The people of those days were rude and uncultivated, and the cattle must have been rude also. Oftentimes pinched with poverty and scant fare, subject to the storms and blasts of an inclement winter climate, unsheltered, probably, in all seasons, except as the woods or hollows of the land could protect them, the worst points of their anatomy took precedence in looks, and they were but a sorry spectacle to the eye of an accurate judge, or breeder.

Following down to near the middle of the last century, we find that some of the authors named speak of these cattle, on the banks of the river Tees, (a stream dividing the counties of York and Durham, ) existing in a high degree of improvement, and superior to almost any others which they had seen. As we have before remarked, it is not surprising that they were found in these counties only, as every district in England had its own local breeds to which their people were partial, and cattle were not interchanged as now, except for the purposes of feeding, and going to London, or other large sea coast markets, for consumption. No doubt, in the agricultural progress of the country, these cattle had received considerable attention, and were much improved in their forms, flesh, and general appearance by their 
breeders, until they arrived at a considerable degree of perfection. Here, then, we find them existing in several excellent herds, and bred with much care. Some pedigrees can be traced, more or less distinctly, back to the year 1740 , or even earlier. The late Mr. Bates, in one of his accounts of these cattle, says, in 1784 the estates of the Earl of Northumberland had fine shorthorns upon them, for two hundred years previous to that time.

Let us see: Bailey, in his survey of Durham, written in the year 1808 , says that "Seventy years eince $(1738$, ) the colors of the cattle of Mr. Milbank and Mr. Croft, were red and white, and white, with a little red about the neck, or roan," as related to him by old men who knew them at the time. Culley also states the same fact. Milbank and Croft were both noted cattle breeders of that day, and into their herds many modern cattle trace their pedigrees. The Duke of Northumberland had good short-horns on his estate at Stanwick, in that county. The Aislabees, of Studley Park, and Sir William St. Quintin, of Sicampston, also kept excellent short-horns; and the Stephensons, Maynards, Wetherells, and many others, too numerous to mention, were breeders. As a sample of what these early shorthorns could do in the way of flesh, Mr. A. B. Allen mentions, in the American Agriculturist, Vol. 1, p. 162, that in 1740, Mr. Milbank, of Barningham,--for it is on record there-fed an ox five years old, which dressed 2,100 pounds in the four quarters, and had, besides, 224 pounds rough tallow; and a cow of the same stock, which weighed 1,540 pounds, equal to almost anything of the present day. Had we space, we could record the weight of many other short-horns in the last century, which approached these in excellence.

As the merits of these cattle became more known, they rapidly increased among the local breeders and farmers of those counties, but they did not obtain anything like a general reputation over the country, until Charles and Robert Colling came on 
to the stage and commenced breeding them. They were young farmers, brothers, and their father had been a short-horn breeder before them. They established themselves as farmers and cattlebreeders about the year 1780 , each having separate herds, but working more or less together, and interchanging the use of their bulls. Charles the younger, was the more enterprising, but not a better breeder than his brother. With great sagacity and good judgment, they picked up some of the best cows and bulls from the herds of the older breeders around them, and for many years bred them with success and profit. They early possessed themselves of a bull, afterwards called "Hubback," claimed, by some, to be the great progenitor of the improved short-horns. He proved a most excellent stock-getter while in the hands of the Collings, as well as before they obtained him, and after he left them-perhaps one of the most valuable of his race. He was a pure short-horn, as his pedigree in the first volume of Coates' Herd Book attests, although Berry, in his Youatt history, attempts, for purposes of his own, to throw a cloud upon his lineage.

The possession of "Hubback" proved fortunate for the Collings, as some of their best cattle traced into his blood, which was more or less participated in by the breeders around them. The blood of this bull became so famous, indeed, that any good and well bred beast which could trace its pedigree to him, was counted of rare value.

We have said that Charles Colling was a sagacious man, in his line. He knew, as well as the breeders around him, that the short-horns were a superior race of cattle, but their reputation, as yet, was a local one, and he determined to make them known in other counties of England, where they were strangers. For this object, Colling took a bull calf got by "Favorite," before mentioned, made him a steer, and fed him to a bullock, for the purpose of exhibiting him throngh the country. Berry says, "the ox was the produce of a common cow," but, as he gives 
no proof, it may be doubted,-unless the "common" cows of the neighborhood were all short-horns,-as his portrait shows the full points, ripeness and refinement of a thorough bred.

Colling kept the steer till five years old, and called him the "Durham Ox." In February, 1801, he sold him to a Mr. Bulmer, to be taken around the country for exhibition. At that time, his live weight was 3,024 pounds-his weight of beef, hide and tallow, if dressed, was computed to be 2,352 pounds; and this extraordinary weight did not proceed so much from his great size as from the exceeding ripeness of his points. Mr. Bulmer procured a carriage for his conveyance, and traveled with him only five weeks, when he sold him to Mr. John Day, of Rotherham, in May, 1801, for $£ 250,(\$ 1,250$.) Mr. Day traveled with him nearly six years, through most of the counties of England and Scotland, when, in February, 1807, he dislocated a hip bone, and had to be slaughtered. Although he had lost. much flesh, not being killed until April, his carcass weighed as follows :

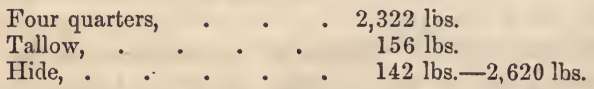

He was, at his death, eleven years old, and Mr. Day could at one time on his travels have taken $£ 2,000(\$ 10,000)$ for him, so much was the ox admired.

Colling afterwards fed a thorough bred heifer, also got by "Favorite," and sent her out for exhibition. She was called "The White Heifer that traveled," and, as her portrait (Frontispiece to Vol. 5, American Short-horn Herd Book,) represents, a creature of wonderful ripeness of points. Her profitable weight, when slaughtered, was estimated at 1,820 pounds, and her live weight at 2,300 pounds.

The exhibition of these wonderful cattle, aroused public attention to their merits, and raised Charles Colling, as their breeder, 
to a high reputation, and, in the demand created for his stock, soon secured him a fortune. Meantime other breeders were not idle. The Collings, as before said, first got their best early stock from the older breeders around them, and while those older breeders kept on improving their herds to a quality perhaps equal to the Collings, the travels of the "ox" and "heifer," known to be bred by him, had achieved a high reputation for Charles, and stamped him, in the minds of many, as the real "improver" of the race. There was, by the way, no Galloway, or "alloy" blood, in these traveled animals, nor did any breeder ever boast of having it, but whenever they did have it, bred it out by the use of thorough bred bulls, as fast as possible. To show the style of the old short-horns in Colling's time, we give a portrait of a cow, copied from the first volume of Coates' Herd Book. She is only in moderate condition, but shows the , strong and well-defined marks of an excellent animal.

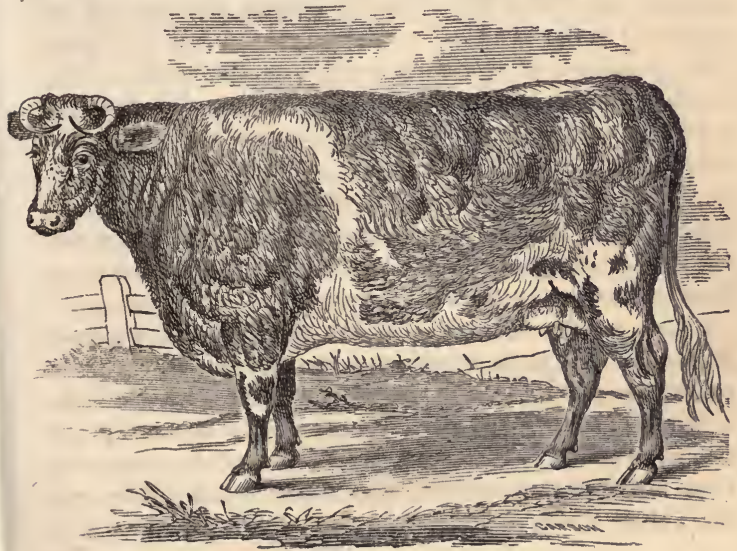

Plate 19. Short-horn Cow of the old style. 
We might follow this subject to a much greater length, in discussing the further progress of the English short-horns down to a late day; but it would be of little interest to any but the breeders of pure short-horn blood, and as the subject is thoroughly canvassed in the several volumes of the American Short-horn Herd Book, to which they have access, a further pursuit of it is omitted. Suffice it to say, that the short-horns now stand in the front rank of all the bovine races in Great Britain, and on some portions of the continent adjacent, and in the Australian and Canadian Colunies, where the soil and climate is adapted to their support. All the breeds of English, Welsh, Scotch and Irish cattle are more or less crossed by them, and although many of these other breeds still hold a high reputation in their purity of blood and their several excellent qualities, the short-horns, in their purity, and much more in their crosses with other breeds, are continually gaining foothold and reputation. They are the heaviest beef cattle driven to.the London markets, and are claimed to be ripe at an earlier age than others; while for dairy cows, as milkers, when bred for that purpose, they excel. These assertions may be taken with allowance, but their still advancing popularity must be supposed to add somewhat of proof to their general excellence.

\section{THE SHORT-HORNS IN AMERICA.}

It has been difficult to collect every account of the earlier introduction of short-horns into the United States. Such as we have been able to obtain we shall relatc.

Soon after the termination of the Revolutionary war with England, a few cattle, supposed to be pure short-horns, were brought into Virginia by a Mr. Miller. These were said to be well fleshed animals, and the cows remarkable for milk, giving as high as thirty-two quarts in a day. Some of the produce of these cattle, as early as 1797 , were taken into Kentucky by a Mr. Patton, where, as little was known of "breeds," they were 
called, after the gentleman who brought them, the "Patton stock. They were well cared for, and made a decided improve. ment in the cattle of the "Blue grass country," where they were first introduced. Some of this early Virginia stock also went out to the "south branch of the Potomac." in that State, a fine grazing country, which, fify years ago, was famous for its good cattle.

In the year 1796, it is said that an Englishman, named Heaton, brought two or three short-horn cattle from the north of England to New York. They were taken to Westchester county, near by, and bred, but no results, in pure blood, have been traced to them.

In 1815-16, a Mr. Cox, an Englishman, imported a bull and two heifers into Rensselaer county, N. Y. These were followed, in 1822, by two bulls, imported by another Englishman named Wayne. Descendants from this Cox stock. were said to be bred pure, and afterwards crossed by Mr. Wayne's bulls. The stock now exists in considerable numbers and of good quality, in that and adjoining counties.

In 1817, Col. Lewis Sanders, of Lexington, Ky., made an importation of three bulls and three heifers from England. They were of good quality and blood, and laid the foundation of many excellent herds in that State.

In 1818, Mr. Cornelius Cooledge, of Boston, Mass., imported a yearling heifer- "Flora"-and a bull- "Cicero"-into that city, from the herd of Mr. Mason, of Chilton, in the county of Durham, England. These were carefully bred, and many of their descendants are now scattered throughout several States.

About the same year, Mr. Samuel Williams, then a merchant in London, but a native of Massachusetts, sent out a bull"Young Denton"-and some cows, bred by Mr. Wetherell, a noted short-horn breeder. The bull was much used to cows of the same and later importations, and their descendants are still numerous among well bred short-horns of the present day. 
The same year, Mr. Gorham Parsons, of Brighton, Mass., imported a short-horn bull-"Fortunatus"- - bred by Geo. Faulkner, of North Allerton, Yarkshire, England. He was used considerably on the native cows of his State, but we have never traced any thorough bred pedigrees to him.

In 1820, Mr. Theodore Lyman, of Boston, Mass., imported a bull, which he sold to Israel Thorndike, of that city, and he sent him to his farm in Maine. Of his produce we hear nothing.

About the year 1820, and during a few years succeeding, several spirited gentlemen of Boston, and its neighborhood, imported a number of cows and bulls from some of the best herds in England. They were Messrs. Derby, Williams, Lee, Prince, Monson, and perhaps others. These were all fine cattle, and of approved blood in the English short-horn districts. Their descendants are still numerous in New England, and some other States.

About the year 1823, the late Admiral Sir Isaac Coffin, of the British navy, a native of Massachusetts, sent out a cow"Annabella"—and a bull—"Admiral" —as a gift to the Massachusetts Agricultural Society. They were good animals, and bred with the other Massachusetts importations.

Shortly previous to 1821, the late John S. Skinner, of Baltimore, Md., imported for Governor Lloyd, of that State, a bull - "Champion" - and two heifers-"White Rose" anc' "Shepherdess"-from the herd of Mr. Champion, a noted Finglish breeder. From these, several good animals descended, some of which are now known.

In 1823, Mr. Skinner also imported for the late Gen. Stephen Van Rensselaer, of Albany, N. Y., a buli-"Washington"and two heifers-"Conquest" and "Pansey"-from the same herd of Mr. Champion. Conquest did not breed; Pansey was a successful breeder, and many of her descendants are now scattered over the country. 
During the years 1822 to 1830 , the late Mr. Charles Henry Hall, of New York, imported several short-horn bulls and cows, from some of the best English herds. Several of these he sold to persons in the neighborhood of that city, soon after they arrived, nnd others he sent to his farm in Rensselaer county, near Albany, and there bred them. Their descendants are now scattered through several good herds.

In 1824, the late Col. John Hare Powell, of Philadelphia, Pa., commenced importations, and for several years continued them with much spirit and judgment. His selections were principally from the herd of Jonas Whitaker, of Otley, in Yorkshire, England. $\mathrm{He}$ bred them assiduously at his fine estate at Powelton, near the city, and sold many to neighboring breeders, and to go into Ohio, and Kentucky, where many of their descendants still remain.

About the year 1828, Mr. Francis Rotch, then of New Bedford, Mass., selected from the herd of Mr. Whitaker, and sent to Mr. Benj. Rodman, of New Bedford, a bull and three heifers. They were afterwards sold to other breeders, and their descendants are now found in several excellent herds.

In the year 1833, the late Mr. Walter Dun, near Lexington, Ky., imported a bull and several valuable cows from choice herds in Yorkshire, England. He bred them with much care, and their descendants are now found in many good western herds.

But the first enterprise in importing short-horns upon a grand scale, was commenced in 1834 , by an association of cattle breeders of the Scioto Valley, and its adjoining counties, in Ohio. They formed a company, with an adequate capital, and sent out an agent, who purchased the best cattle to be found, without regard to price, and brought out ninetecn animals in one ship, landed them at Philadelphia, and drove them to Ohio. Further importations were made by the same company, in the years 1835 and 1836. The cattls were kept and bred together 
in one locality, for upwards of two years, and then sold by auction. They brought large prices $-\$ 500$ to $\$ 2,500$ eachand were distributed chiefly among the stockholders, who were among the most extensive cattle breeders and graziers of the famous S'cioto Valley.

In 1837-8-9, importations were made into Kentucky, by Messrs. James Shelby and Henry Clay, Jr., and some other parties, of several well-selected short-horns, some of which were kept and bred by the importers, and the others sold in their vicinity.

In 1837-8-9, Mr. Whitaker, above mentioned, sent out to Philadelphia, on his own account, upwards of a hundred shorthorns, from his own and other herds, and put them on Col. Powell's farm, where he sold them at auction. They were pur. cliasea at good prices, mostly by breeders from Pennsylvania, Ohio, and Kentucky, and distributed widely through those States.

From 1835 up to 1843 , several importations of fine stock were made by Mr. Weddle, an English emigrant, to Rochester, N. Y., and by American gentlemen, among whom were Messrs. E. P. Prentice, of Albany, N. Y., Mr. Jas. Lenox, and Mr. J. F. Sheaffe, of New York city, Messrs. Le Roy and Newbould, of Livingston county, the late Peter A. Remsen, of Genesee county, N. Y., and Mr. Whitney, of New Haven, Ct., Mr. Gibbons, of New Jersey, and some others, not now recollected, -all valuable animals. They were bred for some years by their owners, with much care. Mr. Prentice, for several years, had a large and excellent herd on his home farm. After some years, all these herds were sold and widely distributed. Their descendants still remain among our valuable herds.

In the year 1849-50, Col. J..M. Sherwood, of Auburn, and Mr. Ambrose Sterens, of Batavia, N. Y., imported from the herd of Mr. Bates a bull, and from Mr. Jno. Stephenson, of Durham, England, three bulls and several heifers, all choice 
animals, and successfully bred them during several years. The stock became widely distributed, and well known.

About the year 1839, Mr. George Vail, of Troy, N. Y., made an importation of a bull and heifer, purchased of $\mathrm{Mr}$. Thomas Bates, of Kirkleavington, the first cattle from that particular herd which had been introduced into the State. A few years later, he purchased and imported several more cows from the herd of Mr. Bates, crosses of his "Duchess" and other families. He bred them with success, and widely distributed their blood. Mr. Vail made a final sale of his herd in the year 1852 .

A period of some years now occurred, in which few more, if any, short-horns were imported. Cattle, as well as all kinds of agricultural produce, were exceedingly low; but as things grew better, the demand for "blood" cattle revived, and the spirit for their breeding was renewed. Mr. Thomas Bates, a distinguished short-horn breeder in England, died in 1849. His herd, fully equal in quality to any in England, was sold in 1850. The choicest of them-of the "Duchess," and "Oxford" tribes-fell mostly into the hands of the late Lord Ducie, at Tortworth Park, already the owner of a noble herd, to which the Bates stock was added. He was a skillful breeder, and of most liberal spirit, and during the brief time he held them, the reputation of the Bates stock, if possible, increased. Within three years from the time of the sale of Mr. Bates' herd, Lord Ducie died. In 1853, a peremptory sale of his stock was widely advertised. Allured by the reputation of his herd, several American gentlemen went over to witness it. The attendance of English breeders was large, and the sales averaged higher prices in individual animals than had been reached since the famous sale of Charles Colling, in 1810. Mr. Samuel Thorne, of Dutchess county, N. Y., bought several of tha best and highest-priced animals, of the "Duchess" and "Oxford" tribes, and added to them several more choice ones, from different herds. Messrs. L. G. Morris, and the late 
Noel J. Becar, of New York, bought othors of the "Duchess" and "Oxfords," to which they aaded more from other choice herds. These were all brought over here, and bred. Mr. Ezra Cornell, of Ithaca, and Mr. James O. Sheldon, of Geneva, N. Y., soon afterwards made some importations, and obtained some of the "Bates" blood also. The late Gen. James S. Wadsworth, and other gentlemen of the Genesee Valley, N. Y., also made importations. These "Bates" importations have since been bred so successfully by their holders here, that several young bulls, and heifers, bred by Mr. Thorne and Mr. Sheldon, have been purchased by English breeders, and sent over to them at good prices, where they are highly valued.

In 1852-3-4, several spirited companics were formed in Clinton, Madison, and other counties in Ohio, and in Bourbon, Fayette, and some other counties of Kentucky, and made importations of the best cattle to be found in the English herds, and after their arrival here, distributed among their stockholders. Mr. R. A. Alexander, of Kentucky, also, during those years, made extensive importations of choice blood for his own breeding, so that in the year 1856 , it may bo said that the United States possessed, according to their numbers, as valuable a selection of short-horns as could be found in England itself.

Keeping pace with the States, a number of enterprising Canadians, since the year 1835, among whom may be named the late Mr. Adam Fergusson, Mr. Howitt, Mr. Wade, the Millers, near Toronto, Mr. Frederick Wm. Stone, of Guelph, and Mr. David Christie, of Brantford, in Canada West, and Mr. M. H. Cochrane and others, in Lower Canada, have made sundry importations of excellent cattle, and bred them with skill and spirit. Many cattle from these importations, and their descendants, have been interchanged between the United States and Canada, and all may now be classed, without distinction, as American Short-horns. 
It will thus be seen that the American investment in this breed of cattle, is large, and many times greater in numbers, and extending over a wider range of country, than with all other foreign breeds collectively. Accurate records of their pedigrees are made, both in Britain and the United States, so that their lineage may at once be understood. The English Herd Book, now numbering sixteen volumes, commenced in the year 1822 , contains the records of 23,252 bulls, and more than 30,000 cows; while the American Herd Book of eight volumes, commencing in 1846, contains more than 7,400 bulls, and over 12,000 cows-items showing that the space we have given to the discussion of their history and present condition, is not more than their importance has demanded.

\section{CHARACTERISTICS OF THE SHORT-HORNS.}

They may be divided into two classes: as dairy, and flesh. producing animals; and first-for the dairy. The early importations into the United States, say fifty years ago, were tbose chiefly of which the cows excelled as milkers. Remarkable yields of their milk and butter were recorded in many agricultural publications of the day, as well as in the American Short. horn Herd Books since.

To show the style of these cattle, on the following page we give the portaits of a bull and cow, from a prominent English herd-Mr. Strickland's - of thorough breds, the cows of which bore a high reputation for milk, forty years ago.

We consider these as beautiful specimens of their kind, with fine bone, excellent points, and every way well developed for the dairy. The cow was a celebrated milker, and took several first prizes at different exhibitions; as a dairy cow. These portraits are copied from the third volume of Coates' English Herd Book. 


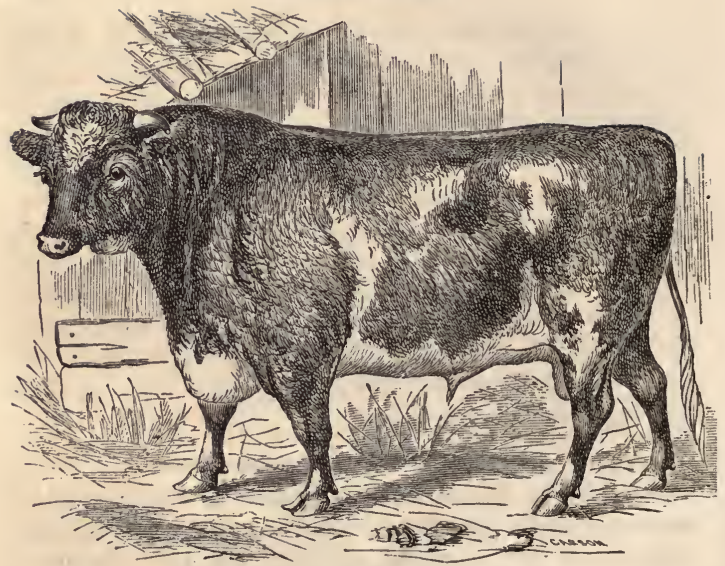

Plate 20. Short-horn Bull, of Milk Stock.
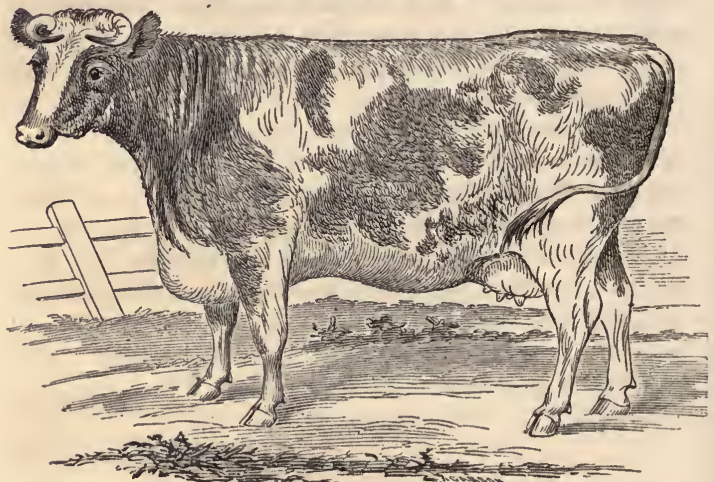

Plate 21. Short-horn Cow, of Milk Stock. 
Second-for flesh. Yielding to their tendency to take on flesh, when not put to regular dairy use, many of the English breeders began to breed more for the flesh-producing property, both in bulls and heifers. This system required abundant food from early calfhood to full maturity. It gave them great rotundity of carcass, rapid growth, and early ripeness. So taking were these well fed animals to the eye, coupled with the early maturity which the bulls imparted to their stock, when crossed on the inferior cows of the country-as beef was a prominent article of production in a great majority of the counties of England-that the tendency to breed the best looking cattle, extended to the generality of short-horn breeders. Another thing, perhaps, encouraged this style of breeding-the increasing demand for their cattle from abroad. The earlier American importations had been mostly into the Atlantic States, where the milking qualities of their cows were more in demand than their flesh for the shambles. But when the Ohio Company sent to England, in the year 1834, for a herd of short-horns with which to improve the western herds, flesh was their chief object, and they sought such cattle as showed that tendency more than the other, although some of the cows which they brought out, and many of their descendants, as we have known from personal observation and experience, proved remarkable milkers, both in quantity and quality. From the Ohio importation of 1834, the successive importations have been mostly of that descriptionfull fleshed, of rapid growth, great development, and early maturity-so much so that the modern style of short-horns appear widely different from the old style, as shown in plate 19, to which, in some importations of many years ago, we have seen almost exact resemblances.

To illnstrate the modern style, which is now almost universally sought by the majority of short-horn breeders in our countryfor out of the Atlantic States they appear to care less for milk 
than flesh-we give a portrait of a well matured, thorough bred bull, at three years of age.

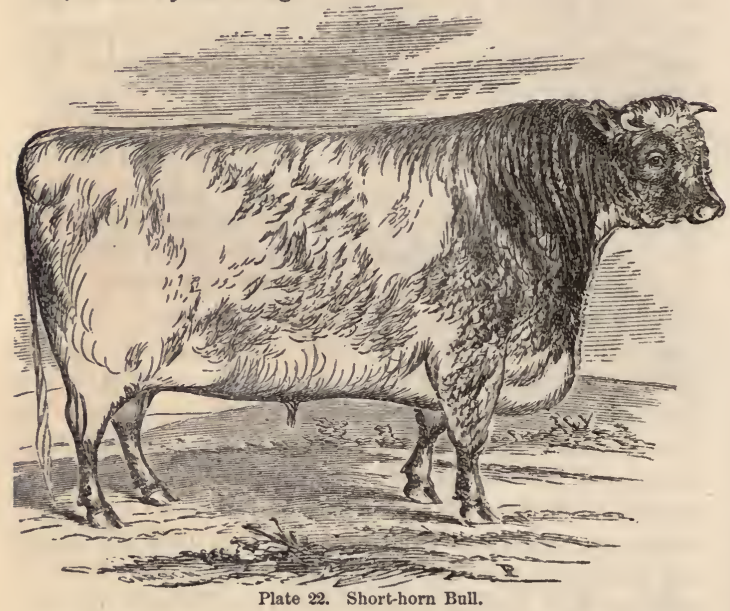

In the above portrait the wonderful fullness in every part of the carcass is illustrated, putting on choice flesh in places where the common cattle fail to give it, and making the animal valuable all over, with no more offal than in a creature of a third less size of an inferior breed. We consider this as showing in an eminent degree, the distinction between the beef-producing and the milk yielding tendency of the short-horn, in appearance. The one is that of exceeding fullness, the other of a tendency, in the cow, (plate 20,) to leanness, while giving much milk, although the latter may feed equally well when no longer used for the pail. In the following portrait, the same flesh-producing tendency is shown in the fomale, as is given in the bull. 
We add the portrait of a heifer at two years, in which is seen the wonderful development of her race at that early age.

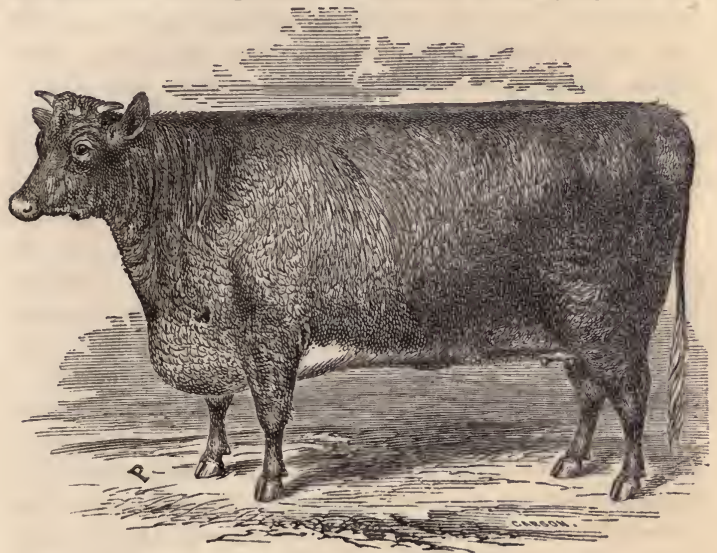

Plate 23. Short-horn Helfer.

They cannot be classed with any other breed of cattle, and are not to be accurately judged by the same rules that apply to them. It has been said that the short-horn is an artificial breed. That is not so. That they have been greatly improved above their original condition, is true-more highly improved, perhaps, than any other breed-but that is a susceptibility of their nature. It is an evidence that they originally possessed the power of such improvement, within themselves, for we have seen, in their history, that there is no known race which has shown itself capable of making them any better. Charles Colling tried a cross of the short-horn with the Galloway. He improved the Galloway, but not the short-horn, and abandoned another trial. Mr. Bates. a breeder for more than fifty years, tried it with the 
Scotch Kyıe, or Highland breed, for two or three crosses, with the same result as Colling, and abandoned it also. Other stealthy crosses may have been made by other early breeders, but with no good results to the short-horns-that they ever acknow. edged. Their advocates claim that they-the short-liorns-improve every other breed with which they have been crossed, as an economical animal. That question, however, we shall not argue.

A general description of a good short-horn, may be as follows. Head-the muzzle fine and yellowish, or drab in color, not smoky* or black; the face slightly dishing, or concave; the eye full and bright; the forehead broad; the horns showing no black except at the tips, and standing wide at the base, short, ovalshaped, spreading gracefully out, and then curving in with a downward inclination, or turning upward with a still further spread, (as either form is taken without prejudice to purity of blood in the animal,) of a waxy color, and sometimes darker at the tips; the throat clean, without dewlap; the ear sizable, thin, and quickly moving; the neck full, setting well into the shoulders and breast, with a slight pendulous hanging of the skin, (not a dewlap,) just at the brisket; the shoulders nearly straight, and wide at the tops; the shoulder-points, or neck-vein, wide and full; the brisket broad, low, and projecting well forward,

* It ls supposed by many persons that a dark, or black nose, indicates impurity of blood. This is not always 80. A black, or even a dark nose is not desirable in a breeding short-horn, because they are decidedly unfashionable, and to a breeder of choice animals they are unsaleable at almost any price. Yet many of the purely bred short-horns (8o adinitted) of a century ago, and even less, had some blacknoses among them. With all modern breeders, the dark-noses have been sednlously bred out of their herds, their repngnance to them often going so far as to slaughtering them in calf hood. Custom has obtained so fur as to rule a black-nosed shorthorn out of competition with the drab, cream-colored, or yellow-noses, as prize animals. A skin-colored, or white-nose is also objectionable, though not to the same extent, as indicative of a want of stamina in the animal, while a black, or dark nose indicates hardhood and good constitution. On the whole, although not conclusive of bad, or mixed blood, black-noses are not, at the present day, admissible. 
sometimes so much as almost to appear a deformity; the arm gracefully tapering to the knee, and below that a leg of fine bone, ending with a well rounded foot; the ribs round and full, (giving free play to vigorous lungs,) and running back well towards the hips; the crops full, but as a rule scarcely equal in fullness to the Devons; the chine and back straight from the shoulders to the tail; the hips uncommonly wide, and level with the back and loin; the loin full and level; the rumps wide; the tail set on a level with the back, small and tapering; the thigh full and heavily fleshed; the twist wide; the flank low and full; the hock, or gambrel joint, standing straiglit, (as with the horse,) or nearly so; the hind leg, like the fore one, clean and sinewy, and the foot small.

Thus, it will be seen that the short-horn differs from most other breeds, in its fullness and rotundity of carcass, and in the small amount of waste flesh and bone, or offal that it carries, in proportion to the consumable flesh it may lay on.

The true colors of well bred short-horns range from pure white to deep red; and between these colors, either of which frequently comprise the whole animal, their intermixtures in all variations of roan; as light roan, with the white predominating over the red; red roan, with the red prevailing over the white, as either may over the other in differcnt degrees; red and white flecked, or spotted in every possible way. The red may also vary in shade from light, or yellow-red, into the deepest mahogany. The old-fashioned short-horns sometimes showed a drab-dun, or fawn color, mixed with white, which we have in some instances seen crop out in one of later days. We have also seen a very few instances of dark brown roan-almost smoky in shade, among those of excellent quality, and unimpeachable pedigree. But the clear white, and full red colors, either by themselves, or intermixed in various beantiful and picturesque proportions, are the prevailing colors of our own time. Some of our breeders 
have a prejudice against the purely white coating of a shorthorn, as indicative of a less hardy constitution in the animal possessing it; but we see no good reason, other things being equal, why a white color-as it truly belongs to the breed, and descended, perhaps, from red or roan parents-should be a defect in the useful quality of the animal having it. It is simply yielding to a popular prejudice outside of short-horn circles.

The cow differs from the bull only in the feminine qualities of her sex, as our illustrations have shown.

\section{AS A DAIRY COW,}

Popular opinion, among those not particularly acquainted with their history or breeding, is widely at variance. They are the greatest milkers, in quantity, of any breed whatever-with the exception of the Dutch-as innumerable facts have shown; or they may be comparatively inferior, as education, keeping, or purpose may govern, as we have just related. These matters will be explained in a subsequent chapter, on breeding. We have numerous well authenticated instances of therr giving six, seven, eight, and even nine gallons a day, on grass alone, in the heighth of their season, and yielding fourteen to eighteen pounds of butter per week, and of holding out in their milk, in proportionate quantity, as well as other breeds of cows, through the year. Cows so much larger in size than of other breeds, should be expected to give more than smaller ones, that consume less food; and without asserting that they do give more, in proportion to their size, it is claimed that when educated and used for the dairy chiefly, they give quite as much as any others. That the inherent quality of abundant milking exists in the shorthorns, no intelligent breeder of them need doubt. Our own observation in more than thirty years' experience with hundreds of them, first and last, under our own eyes, is to ourself, evidence of the fact, both in thorough breds and grades. 
If the breeder's attention be turned solely to the dairy quality, he succeeds in obtaining, with few exceptions, good milkers. If he turn his attention, regardless of milk, to the grazing qualities of his stock, he can gradually breed out the tendency to milk in his cows, beyond a sufficiency to raise the calf to six or eight months old; and perbaps it is to be regretted that the tendency of too many breeders is to the latter. Breeding for the grazing quality solely, tends, indisputably, to give them more.comely proportions, and greater size than when bred for the dairy. It is as the animal is bred, either way, that strikes the observer, whether the short-horn cow, as a race, is either a good or poor milker, without a proper experience to confirm his judgment; and therefore we say that she may be either good or inferior, in that quality, as the breeder chooses to have it.

\section{AS A WORKING Ox,}

We cannot highly recommend the high bred short-horn for that purpose solely. From his massive frame, and inclination under full feed, to take on flesh, he is sluggish in movement. His shoulders are too upright for easy draft, unlike the Devon, or Hereford, or even our native ox. His natural step is slow. We have seen the thorough bred short-horn ox worked in the yoke. We have had, in the dull days of short-horns, several pairs in farm work, some years, and although they proved honest, stout, and obedient, we preferred others for quickness in movement. Crossed upon the native cow, or with the Horeford, or Devon, as half bloods, they prove excellent workers. Some breeders contend that the thorough bred short-horn ox is as good a worker as any other; but the weight of evidence does not confirm the assertion; still, they do work, and that quite tolerably, but they have neither the wind, speed, or bottom of the lighter and more active breeds.

\section{AS A BEEF ANIMAL.}

We give an excellent portrait of a three years (past) prize ox, exhibited, some years ago, at the Smithficld market, in London, 
Eng., copied from "The Farmers' Magazine." We have seen many equally good ones in the United States.

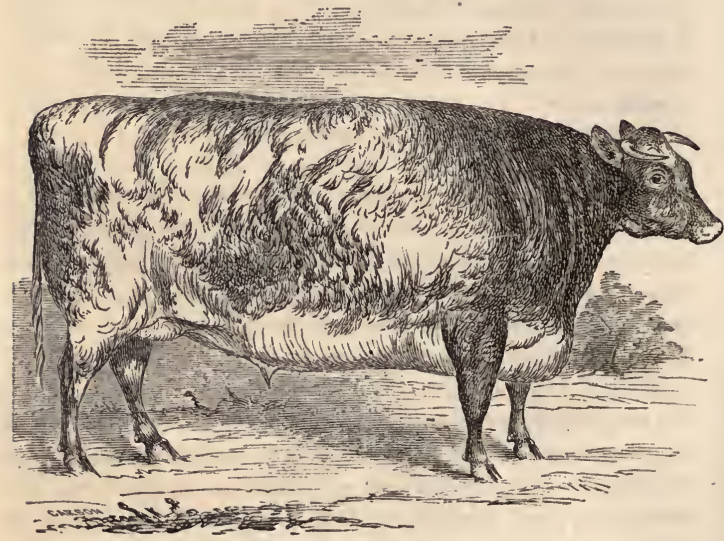

Plate 24. Short-horn Ox.

It is held, as a flesh-producing animal, that in early maturity, weight of meat, ripeness of points, and giving the most flesh in the best places, the great merit of the short-horn is found. We have spoken of the Devon, the Highland, and Galloway, as having flesh of finer grain, and tenderer quality, and bearing a better price in a fastidious market. But choice purchasers are few, compared with the mass, and he who feeds cattle for the general market, wants the animal which makes the quickest and most profitable returns for the capital invested, and the food consumed. The short-horn at three years, past, well fatted, is fit for slaughter, equally with the Devon or Hereford at the same age, or the Highland Scot or Galloway, at four years, or the "native" at five or six years. He is claimed by many to be a 
less feeder for his weight. There may be truth in this, as he is less active, and more inclined to take his rest, than the lighter breeds, which are less sluggish in their habits. All these questions are of great consideration with the breeder or grazier, who rears stock for market. A quick return for capital and food, is the object, and that animal which gives it in the shortest time, is always preferred. Hence one decided advantage of the shorthorn.

\section{THE PROPER HOMES OF THE SHORT-HORNS.}

There is a question, however, with him who breeds or grazes the short-horn that must be considered, notwithstanding his aptitude for early maturity. They must have abundant feed and good pasturage. Broken lands, with short grasses, do not so well suit them. Level, or gently undulating soils, with luxu-. riant grasses upon them, suit them better. We have immense tracts of lean and hungry soils, with scanty herbage, where we would not recommend the short-horn to go, and where some of the smaller breeds, as the Devon, Highland, and Galloway, will thrive and prove profitable; and for such lands they should be preferred.

Some have objected to the short-horns as unfitted for a cold climate. That objection has proved of little weight. Northern England, and the adjoining counties of southern Scotland, have prodnced, and improved them in their highest perfection, and the latitudes of America, from $41 \frac{1}{2}$ to $45^{\circ}$ north, equally as well, under good winter protection, as the milder temperatures of Ohic, Illinois, or Kentucky. The soil and feeding does the work, not the climate, provided the latter be temperate, and proper shelter in the inclement seasons be afforded. For near fifty years, in the better sections of what are considered the comparative sterile and cold New England States, the short-horn has lived and flourished-more rapidly of late than ever-and been successfully introduced into the north-eastern British Prov- 
inces, and both the Canadas. The severe winters of the North appear to be no bar to their success. How far South they may go, is yet to be tried. Wherever the proper herbage will grow - the blue grass, for instance-they may be successfully introduced; but somewhat of care they must have, or they will, unquestionably dwindle.

For the improvement of our native cattle, either for the dairy or the shambles, no foreign breed has been so much sought. They have spread all through the Northern and Middle States, all over the West, have been driven over the plains into California, and even to Oregon, in the valleys of the Williamette and the Columbia. They appear destined to go into every place where cattle are successfully bred, and good herbage abounds, as being the stock which, whatever may be the merits of others, in certain localities, must, in the majority, prevail.

That in their native country, England, the short-horns are rapidly increasing, as well as extending into the more fertile lands of Wales, Scotland, and Ireland, Mr. A. B. Allen, of New York, who visited many of the chief agricultural counties there, in the year 1841, and again in the summer of 1867 , in a recent letter remarks: "When I was first in England, the short-horns were confined to a comparatively narrow territory, and those chiefly in the north-easterly and central counties. Now, they are seen, either thorough bred, or in their crosses, in almost every part of the United Kingdom where good grasses and the best agriculture prevail. Not only in the fields of the ordinary farmers, but in many of the finest parks of the nobility and gentry, their grand forms, and picturesque colors, show, in abounding numbers, grazing among the deer, or in occasional groups among the clustered woods, or in the open pleasure grounds. I found them even working on towards the Scottish Highlands, trench. ing into the homes of the Ayrshires, and Galloways, and crossing, more or less, into almost all the old local breeds. 
"Whether it is because they have become the fashion, or are thus spreading on their own indiridual merits over the others, I did not so much inquire, but conciuded from the fact of their increasing propagation among farmers, where almost everything is made to pay, that they find them their most profitable neat stock. Still, they cannot profitably thrive everywhere, and wide ranges of land exist, both in Britain and America, where different breeds, better fitted to close pasturage and rougher soils, must be kept, as more suitable to the wants and purposes of the people who inhabit them." 


\section{CHAPTER XV.}

THE HOLSTEIN, OR DUTCH CATTLE.

IN a previous part of our work, we have mentioned this breed, as being early introduced into America by the Dutch emigrants at New York; but not as cattle of superior distinctive character, or "improvement," as a race, yet varying from the early imported English cattle in some characteristics of color and form. We know nothing of the early Dutch cattle, in particulars, other than that they were considered valuable for milk, and labor.

There is a class, or breed of cattle, now existing in North Holland, which have been greatly improved within the last century. That is eminently a dairy country, and the cows of the farmers and dairymon there, receive a care and attention beyond any other domestic animal used in the agriculture of the people.

We get little account of these cattle from British authors, except incidentally, and that of so vague a kind as to lead to no accurate conclusions. In our history of the short-horns, we have alluded to the probability that they were, at a very early day, originally derived from the neighboring continent; and they may have descended from the same common ancestry to which the present improved breed of Holstein, and Holland, trace their lineage. Their forms, and general appearance, in all but 
color, indicate that they may have sprung from a common source; but there is a sufficient distinction between them to show that, for centuries past, they have been bred for somewhat different uses, by different nationalities, and under a different system of agriculture.

We need not go into the various past controversies, and suppositions, touching upon the importation of Dutch cattle into England, for the purpose of improving the English short-horns, nor the counter importation of English short-horns into Holstein, or North Holland, to improve their own native stock. Of the facts relating to these controversies, little is positively known, and the traditions, and suppositions, connected with them, are of such uncertain authority, as to lead to no accurate result, if we should attempt their investigation. We are content to let the matter rest on the one indisputable fact, that the improved "Dutch" cattle of the present day, in many of their characteristics, do possess so great a resemblance to the shorthorns, that no wide stretch of imagination need be exercised to presume that the progenitors of each-many centuries agomay have been traced to a common ancestry.

Of the time, at which any very considerable improvement was attempted in the Holstein cattle, we have no definite knowledge. It must have been more than a century-perhaps two or three centuries-ago, as it is only by a continuous and fixed system of breeding, for a long time, that the undeviating, constitutional characteristics of any breed of cattle can become so established as to transmit them with entire certainty to their progeny. These characteristics, the present improved Holstein cattle do obviously possess, in a sufficient degree to class them as a breed by themselves; and as such, we shall treat them.

Their surpassing excellence appears to be in their milking qualities, coupled with large size, and a compact, massive frame, capable of making good beef; and in the oxen, strong, laboring 
animals. They are almost invariably black and white in color, spotted, pied, or mottled in picturesque inequalities of proportion over the body. The horn is short, and the hair is short, fine and silky. The lacteal formations in the cows are wonderful, thus giving them their preeminence in the dairy. Our illustrations will show these prominent characteristics so plainly, that further description is unnecessary.

It was but recently that this valuable breed of dairy cattle, in their now improved condition, except in a few casual importations, found their way to America. The late Mr. William Jarvis, of Wethersfield, Vt., one of the celebrated importers of Merino sheep, in the early part of the present century, brought out a bull and two cows, and put them on his farm, where he bred them successfully for some years. They were crossed with the common cattle of his vicinity, and after some years the pure blood became lost. People were careless of pure blood in cattle in those days, not much knowing or appreciating its value.

The late Mr. Herman Le Roy, a distinguished merchant of New York, between the years 1820 and 1825, imported some improved Dutch cattle into that city, and kept them on a farm in its vicinity. Some of them were, about the years 1827-8-9, sent to the farm of his son, the late Edward A. Le Roy, on the Genesee river, in that State. We saw them, and their produce there, in 1833. They were large, well-spread cattle, black and white in color, and remarkable for their uncommon yield of milk. The younger Mr. Le Roy soon after imported several shorthorns from England, with which the Dutch cows were crossed -not because he disliked the Dutch, but more probably because the short-horns stood higher in popular favor, and more generally in request by the cattle breeding public. In the herds of both father and son, the pure breed was lost, as none but grades were found in the herds subsequent to the sale of the farms of these 
gentlemen, a few years afterwards. It is to be regretted that the blood of those importations, should have been so soon lost by a lack of interest in their propagation. They were of great value as dairy animals, as their qualities in that line were universally acknowledged where they were known.

In the year 1852, an importation, consisting of a single cow, was made into Boston, Mass., by Mr. Winthrop W. Chenery, of that city. Her extraordinary good qualities led him to a further importation of a bull and two cows, in 1857; and to the importation of four more cows, in 1859. Most unfortunately the "cattle plague" broke out in this herd in the year 1859-60, and the originals, and all their thorough bred descendants, with the exception of a young bull, were destroyed under a law of the State, to prevent the spread of the disease. In the year 1861, Mr. Chenery made another importation of a bull and four cows, which came out in good condition. He placed them on his farm in the vicinity of Boston, where they have since been successfuily bred-the only herd of pure bred "Holstein, or Dutch cattle," known in the country; except their descendants, which may be in some other hands.

These animals were procured from the best dairy herds in the vicinity of Beemster and Purmurend, in the Province of North Holland, with a special care to their sanitary condition, and their possession of all the highly esteemed qualities of their race. As such, they were certified by the official authorities of the district where they were bred. As this breed are strangers to the masses of our cattle breeders and graziers, and may in time become important instruments in promoting the dairy interests of the country, a somewhat particular account may be given of some of them, by which to judge of the improvement they may give to our native herds.

A four years old bull girts 7 feet 10 inches; his length is 8 feet 7 inches; height, 4 feet 11 inches; weight, 2465 pounds. 
We give an accurate portrait of the bull, as taken by our artist in the month of February, of this year.

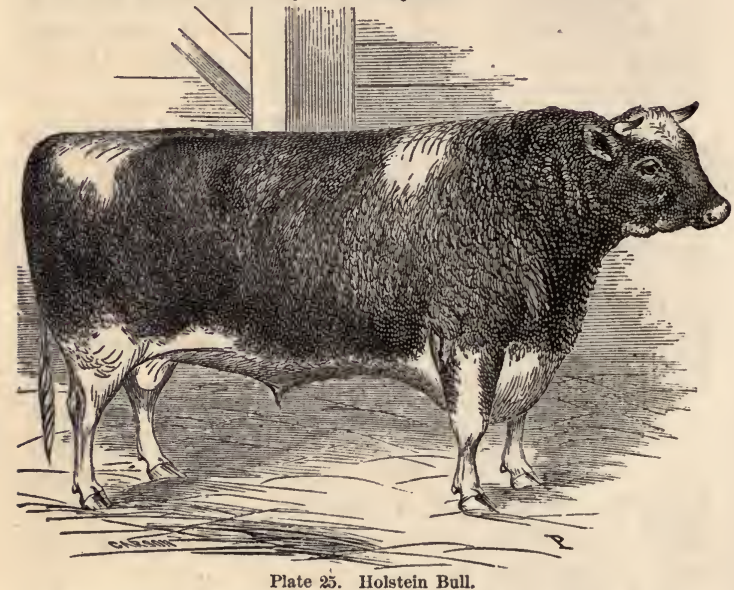

The colors of this bull, like all his race, are jet black and clear white.

The four imported cows, each seven years old, have an average weight of 1325 pounds. The weight of a past two years old heifer is 1240 pounds. A past yearling heifer weighed 960 pounds; and the weight of six calves, at an average of eight montlss, reared in the usual way, without forcing, was an average of 576 pounds each.

The milking qualities of the breed may be judged by the following memoranda: One of the imported cows, when six years old, dropped a calf on the 15th of May, weighing 101 pounds; and from the 26th of May, to the 27th of July, by a careful and 
exact record, gave 4018 pounds 14 ounces of milk. The largest yield in any one day, was 76 pounds 5 ounces, (351/8 quarts.) In ten days, she gave 744 pounds 12 ounces, or an average of 74 ry pounds per day. She gave a good flow of milk during the season, continuing to the 24th of May following, and on the succeeding day dropped twin heifer calves, which weighed 155 pounds. The amount of cream produced from this cow s milk, in a vessel specially prepared for measuring it, produced $22 \frac{\text { Yo }}{100}$ per cent of the milk, as tested by an accurate examination. The nutritive qualities of the milk were also tested by a thorough chemical analysis, and found to be excellent. It was also rich in its caseine, or cheese making properties. Six days' milk of this cow were set for cream, and the produce was 17 pounds 14 ounces of good butter-nearly 3 pounds per day; and it is claimed by her owner that she is not the very best cow of the herd.

These results show not only the remarkable productions of the cow, but the accurate and pains-taking care of the proprietor of the herd, in testing their ability at the pail. Of what the food given to the cow was composed, we are not informed. We are to presume, however, it was of the best, as every cow should have, to test to tlie utmost, her lacteal faculties.

\section{FOR THE DAIRY,}

The qualities of the Holsteins must be acknowledged as remarkable. The short-horns, as in many instances of trial, have hitherto acknowledged no superior; yet they have now, in these new strangers to our soil, to say the least, found most formidable competitors, and an opportunity is here offered, by those who cultivate them for the dairy, to test their long acknowledged good qualities by comparison. The Holsteins have been long bred and cultivated with a view to develop their lacteal production to the utmost; and that they are quick feeders, and physiologically constituted to turn their food readily to milk. must be evident. 
We give an accurate portrait of one of the cows, taken by our artist in February, 1867. She stands the model of a perfect milker, with all the mammary veins and udder glands in the highest state of development.

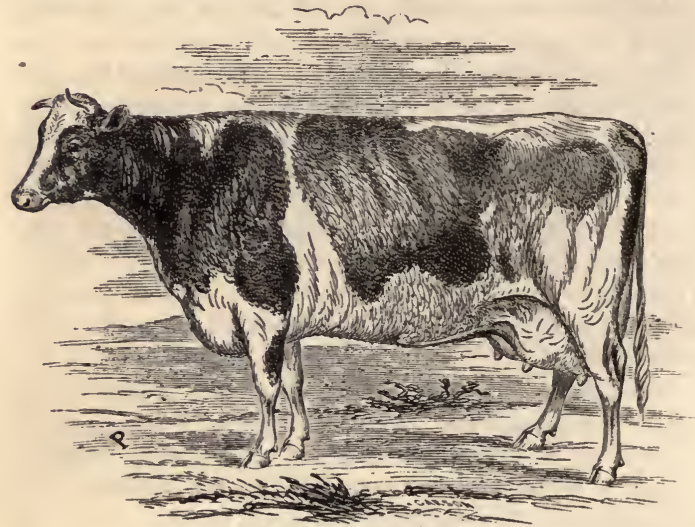

Plate 26. Holstein Cow.

We are gratified that this valuable importation has been made by its public spirited owner, for the benefit of our cattle and dairy interests, and trust that their merits will spread far and wide, beyond the limited territory where they have in such brief time, been so thoroughly tested. The grade heifers, by the Holstein bull, on other cows of different breeds, are said to inherit much of the good milking qualities of the Dutch blood.

\section{AS A BEEF ANIMAL,}

Their merits have been, as yet, but partially tried in the halfbreds, or grades from the Holstein bull, on the natives, or other cows of different breeds. So far, however, they are claimed to 
be satisfactory. A pair of oxen, five years old, gave a live weight of 4,600 pounds, and proved supcrior workers, showing that they were trained for labor, and not for beef alone. We have personally seen and examined several of the animals of this herd, and from those specimens-to which the portraits do no more than justice-we should pronounce them good grazing and feeding cattle, in addition to their preëminence for the dairy.

\section{AS A WORKING OX,}

They will probably rank with other heavy cattle of like quality -better in their grades with the lighter and more active breeds, no doubt, than in the thorough breds-as with the short-horn crosses. They are entitled to a fair trial, and in the hands of proper parties, their entire merits cannot fail to be thoroughly and advantageously developed. We consider Mr. Chenery's importation a decided acquisition to the cattle interests of our country, and trust that they will become widely known and distributed. 


\section{CHAPTER XVI.}

THE SPANISH, OR TEXAN CATTLE.

WE should hardly speak of this strange race of animals, were it not that of late years they have found their way, to some extent, into our sea-board markets. They are the descendants of the early Spanish stock introduced into Mexico in the sixteenth century. What they were when first imported there, we have no knowledge, but presume them to be of the same race as those long kept by the Moors on the plains of Andalusia, and by their successors, the Castilians, for many centuries-of no great excellence in Spain, and not at all improved in Mexico.

In a recent letter from Mr. A. B. Allen, of New York, freceived in July, 1867,) then traveling in Spain, between Gibral. tar and Granada, he thus describes the Spanish cattle of the present day, as he saw them there: "I have seen numerous Spanish herds. They are about the size of our old-fashioned common cattle. They have large, coarse, long and wide-spread horns, mostly with a half, or full twist to them, and set back, rather than forward, with the points outward. Their colors are black, dark brown, reddish-brown, light yellowish-red, with some white on the throat and belly, and occasionally a black and white roan, or dark grey. The cows are nearly as large as the oxen, with the same style of horn. They do not appear to be good milkers. The heads are long, and rather fine. The herdsmen attend them in droves with dogs, like the short-haired Scotch Colleys." 
In this brief description, may easily be detected the origin of the modern Texan cattle, run wild for many generations, while the Spanish are thoroughly domestic in their haibits, and treated witl care, as the density of population, and close husbandry of the Spanish people at home, compel them to be. Undoubtedly the originals are much better animals under the treatment they receive, than their half-savage cousins, at such a far distant removal.

The Texans are, in fact, a semi-wild race in America, the mild climate of the tropics, with its abundant perennial herbage, affording them all of food which their natures require. There they range, propagate and grow, with little care, congregating in large herds, and known by their owners only by the marks, or brands, they put upon them. They are annually gathered for identification, when the young calves are castrated, and those fit to sell, selected and driven sto market. The cattle pay little attention to the widely scattered ranches of their owners, and rove for miles away, attracted by better pasturage, the scattered salt-licks, or in the indulgence of their own vagarious habits. We illustrate on the following page, a group of the bullocks, drawn by our artist as they stood in a cattle yard, on their arrival at market.

These portraits are truthful, as we saw them in a herd of about forty in number, and know them to be correct. Their live weights, at the time-the animals ranging from five to seven years-averaged 1,008 pounds. A short description will suffice.

They are tall, lank, and bony, coarse headed, with enormous horns; (only exceeded in length by a pair in our own possession, brought from the Island of Sicily, in the Mediterranean. The shells of these Sicilian horns, are three feet four inches in length, spiral, and gracefully turned, thin, and almost transparent.) Their legs are long and coarse; they have much dewlap, and little brisket; are flat-sided, swayed in the back, high in the 


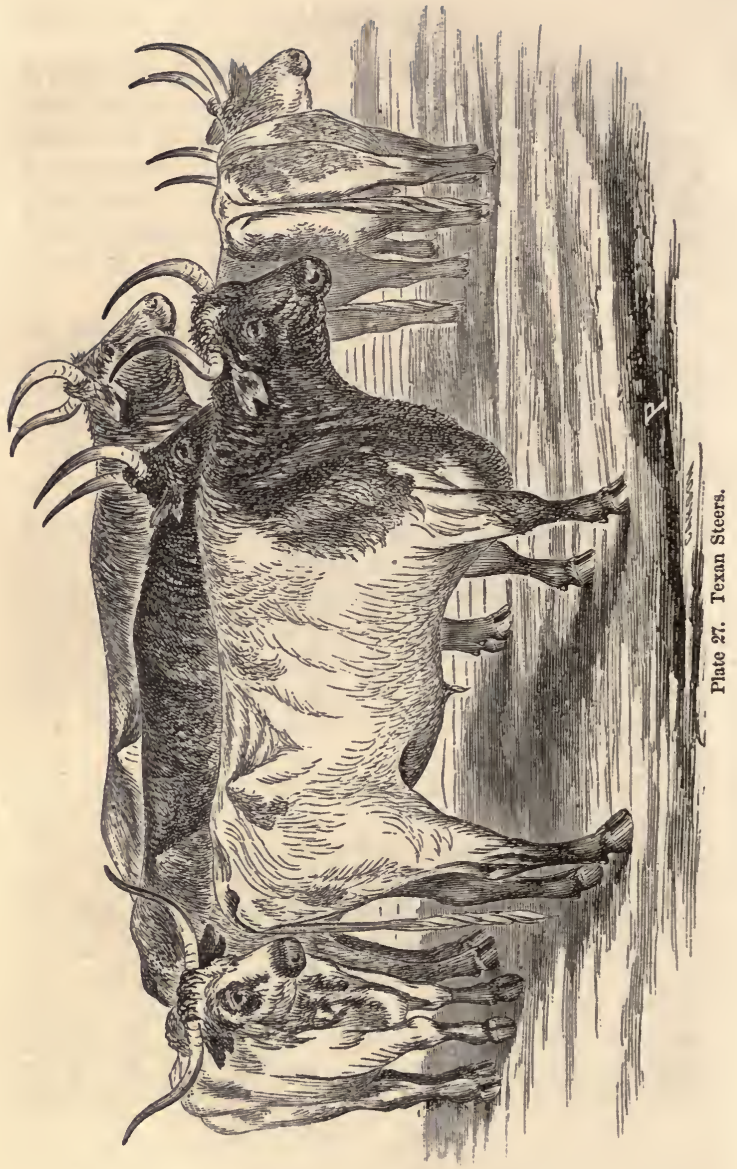


flank, with narrow hips and quarters, great offal in proportion to their consumable flesh, and coarse all over. Their meat must be stringy, tough, and of coarse quality. Wild and savage in appearance, they looked scarcely more civilized than a herd of Dacotah Buffaloes.

In contrast to the specimens above described, it is but fair to say that we have since seen better animals, so far as flesh and condition was concerned, of the Texan cattle. They were a small herd of some thirty in number, which had been brought by the cars to the Buffalo Cattle Yards for sale. They had been well fed on corn and grass for several months, and looked sleek, and in good flesh, so far as such raw boned and loosely made up cattle could be. They were six to seven years old, and made an avcrage weight of over 1200 pounds each. Good four year old grade short-horn Western steers, were selling at the yards, the day we saw them, at $7 \frac{1}{2}$ to 8 cents per pound, live weight. The Texans were sold the same day for 6 cents.

Now, adding the two to three years additional forage which the latter had consumed, the interest on their value after four years old, and then deduct the one-fifth to one-fourth less price they sold for, together with the contingencies of disease or loss by death meantime, and the comparative economy in breeding and grazing such cattle by the side of those of good flesh producing breeds, or their crosses, is easily solved.

Great numbers of these cattle are driven from northern Texas and New Mexico, up through the Indian Territory into Kansas and Missouri, thence into Kentucky, Illinois, and so on eastward. They stop little to graze on their journeys, as they gain but a small increase of flesh in a land of civilization, and the sooner they arrive at the shambles the better. They are worth little to the butcher or consumer, and, that they cost but little to their breeders, would, as a commercial article, be comparatively worthless. 
Their colors are red, dun, yellow, black, brindle, and blue roan, all mixed more or less with patches and strips of white.

As an economical animal to a farmer of the Northern, Middle, or Western States, they can be of little value, as the cows give no more milk than will raise a calf till it is old enough to graze. The bullocks are too light for heavy work, although sufficiently active; and for beef, where a choice article is in demand, their value must be low. Some of the improved breeds may be crossed upon them to advantage, no doubt, but it would take several generations to breed their coarseness and wild nature out. It is a question whether it would not be cheaper to introduce our better natives, even into their own country, with which to commence a profitable herd. The common run of Texan cattle must be doomed to extinction, ultimately, before the better breeds.

We only mention them here, because in their own ranges, and over an extensive territory, they are the prevailing cattle, and many of them there must be of better quality than we have described. A few short-horns, from Kentucky, have, years ago, been taken to Texas, with an effort to improve the native Mexican stock, but we hear of no results worth noting; nor can there be much improvement, so long as they retain their wild and vagrant habits. These cattle, in addition to Texas and New Mexico, are extensively kept by the natives in the Mexican territory of Lower California, the adjoining Provinces, and to a considerable extent in our own State of California itself.

There should be a sanitary law, if nothing else, to regulate the introduction of these cattle into the States north of Texas or New Mexico, as they have either brought with them, or originated within themselves on the way, deadly diseases, which have spread from them while in our Western States, into which they were driven for market, and large numbers of valuable cattle have died from their contagion. We give an extract from one of our agricultural periodicals, touching the disease we have alluded to: 
"The Texan Cattle Plague.-The troublesome and dangerous disease introduced occasionally among the cattle of Missouri and Kentucky, by those driven from Texas, to which we have heretofore referred, is now called by this name in our Western exchanges. The Farmers' Advertiser, (a periodical just established at St. Louis, under the editorship of Dr. L. D. Morse,) says that the Missouri Legislature, now convened, will be called upon to enact some efficient measures to prevent the introduction and spread of this infection:

"'We have seen a letter addressed to a friend, from a gentleman in South-west Missouri, which details his experience with the cattle plague from its first introduction to the present autumn-the substance of which is, that there was no such disease known prior to the introduction of Texas cattle; that up to 1860 , he was a heavy loser annually by it. That from 1861 to 1865, the rebellion broke up the cattle trade from Texas. During those years he lost not a single head, though a large dealer in cattle all the time. That in the present year, soon after the first appearance of Texas herds, the disease broke out again, and he had lost upwards of 150 head during the season-as many as 20 dying in a day. He recommends that the present law be so amended, as to entirely prohibit the introduction of these cattle, from the first of April to the first of October; and that from the first of October to the first of April, there be no restriction.

"“There are not sufficient data to determine how early in autumn they can be permitted to come in with safety; hut as the disease this year broke out in the vicinity of St. Louis (at Cheltenham,) late in October, it appears that the first of October is too early by a month at least. The first victim was a fine cow, bought out of a Texas drove; in the course of ten days, seven other cows running in the same pasture took it and died. On the 30th of October, we had the first white and killing frost; since then there has been not a single case. It would then seem 
that the disease is checked and controlled by frosts; the inference therefore is, that there is no safety in suffering them to come in until cold, frosty weather sets in, which hardly ever comes earlier than the first of November." "

As to their value for any economical purpose, beyond their hides, what little tallow they have, their horns and bones for manufacturing or fertilizing purposes, we consider them of little consequence within the bounds of modern civilization, or intelligent agriculture. 


\section{CHAPTER XVII.}

\section{WHAT IS THE BEST BREED OF CATTLE?}

Thrs is a question daily asked by inquiring men, not well acquainted with the subject, and not very easily answered, except under conditions.

After showing at so much length as we have done, that America has no original "breed" of cattle, as its nwn, and describing with sufficient minuteness the breeds of foreign cattle best suited to our purposes, it is vain to name any particular breeds as best for all our own localities, and all our own uses. That the adoption of some one of these foreign breeds, in their purity, or the crossing of bulls of some one of them on to our native cows, is advisable, we cannot doubt. It is for the interest of every farmer and cattle breeder throughout the country, who takes any particular care of his stock, to do so. For all such as take no care of their cattle, but let them mainly take care of themselves - the poorer the breed, so that they can forage or steal a living out of others, the better-the Texans can perhaps suit them. But, as this book will never get into the hands of such people, nothing more need be said on that score.

No understanding person will contend that any one breed of cattle which we have described, is the best for all our soils and climates, and our running remarks in describing them indicate, to some extent, to what soils and climates they are best adapted. Before concluding his choice, the farmer, breeder, and grazier, must each well understand his own locality, and after efficient 
observation and experience, either of himself or of intelligent men around him, must determine which breed or its crosses 1s, on the whole, best adapted to his uses. There are localities, and extensive ones, where either of the foreign breeds will thrive admirably - a rich soil, abundant herbage, good water, and mild climate favoring them. There are other soils, climates, and positions, where a range of choice is necessary. One, two, three, or possibly more of the breeds named may succeed equally well, and others not at all. For instance, the rich, level, or gently rolling lands, with abundant grasses, invite the Short-horn, Longhorn, or Hereford. The stony, more hilly, and less luxuriant pastures, are better fitted for the Ayrshire, Alderney, Devon, or Galloway; while the proprietor of wild, mountain ranges, with thinner and shorter herbage, requiring more laborious seeking after, or the scantier plains of the far West, would-if he could get them-better adopt the West Highland. As for the Texan cattle, we do not name them as an economical beast at all. We have only described them to be shunned.

After consulting the climate, soil, and position of his locality, the proprietor is next to determine the uses for which he wants his cattle, whethcr for beef, or the dairy. As tolerable working oxen can be selected out of the crosses of almost all the breeds named, and there being no particular object in breeding working steers alone, we do not include them in our list-they will come naturally of themselves. The dairyman wanting the greatest possible quantity of milk, and of good quality, will select the Short-horn, Ayrshire, Dutch, or Devon, and possibly, a dash of the Alderney, as his soil may be best adapted to one or the other. T'he one who breeds for the grazier, or beef only will take the Short-horn, Hereford, Devon, Galloway, or West ilighland, as either may best suit his purpose. Not to confound these selections, we explain, that the Short-horns, and Devons, are both milking and feeding cattle, as they may be bred for either pur- 
pose; therefore, for such uses, we have named them. The Ayrshires, Dutch, and Alderneys, are exclusively dairy cows, although they may fatten well when done for the dairy, but we do not class them as beef animals alone. The Herefords, Galloways, and West Highlands, we class as exclusively beef animals, although not denying that they may, by generations of breeding for that object, become good dairy cows; but having already enough good ones for that purpose in all localities, it is of little use to multiply them. We do not here speak of the Long-horns, as they are not in our country, but in England they are esteemed to be both a dairy and beef animal, and no doubt are. We hope yet to see them introduced to Amcrica-as curiosities, or for trial, if for nothing else.

Now, the breeder for the dairy, or for beef, whichever it may be, should determine, after a full and thorough survey of his premises, which of the breeds he will adopt; and we would advise him to adopt but one, unless his pessessions are large, and well adapted for more; or, for experiment, or his own gratifi. cation, he prefers a variety. A question may here occur, whether the breeder proposes to rear thorough bred cattle with which to supply other breeders, or to supply dairymen or graziers. This question is somewhat to govern the selections he may make, with which to stock his lands. If he intends to breed thorough breds only, his expenditure of capital must be large in propor. tion to the number he keeps, as they are costly. If he breeds for the dairy, or for beef, he has only to determine the breed which he intends ultimately to arrive at; then he is to get the bost cows he can find for his purpose, and those which either do, or will, in their produce, most assimilate to the breed he intends to rear. This accomplished, he will obtain well selected bulls of that breed, commence his herd, and breed continuously on, crossing the young heifers with thorough bred bulls in succeeding generations, until the blood gets as near the thorough 
bred as possible. He will find, if he breeds carefully, that his stock is continually growing better as it reaches toward the full blood, until for all economical uses it is just as good-except for thorough breeding. But no man should ever buy or use a cross bred, or grade bull for breeding, when he can get a pure bred one, for the reason that the grade is quite as apt to throw his bad blood into his progeny, as his good blood, and thus stop the improvement. Some breeders are quite apt to think when they have got a really good thing, although of mixed blood, and a part of it bad, it is good enough. They therefore stop at that, use the imperfect bull, and from that time their stock remains stationary, or more probably goes back. Improvement and pro. gressive excellence, is only to be obtained by a constant persistence in the use of the best pure blood, either in grade animals, or thorough breds.

Thus, every man may have "the best breed of cattle" for his own land, and for his own uses. He may complain that a continuous use of thorough bred bulls, after having stretched his purse to make the purchase of his first one, costs too much. But that is a very narrow and uneconomical view to take of the matter. If he studies and observes sufficiently to surmount the prevailing popular prejudice, about in-and-in breeding, he may keep his first bull from two, or three, to ten years, if a good one, and he can be useful so long-breeding him to his own heifers and grand-heifers; or he may exchange him with one in like circumstances, and by such means, only have to buy a fresh bull once in several years. If this idea of breeding a bull to his own progeny proves a staggering proposition, the breeder is referred to our chapter "on breeding," wherein his views may be enlightened, and possibly, his prejudices somewhat abated.

In suggesting our views in this matter, we may be thought speculative, or theorizing, by the ordinary observer. Let us see. 
We do not yet, in America, afford sufficient examples of the kind to establish, beyond dispute, these facts. We can point to districts of country in Kentucky and Ohio, and perhaps elsewhere, but in those States certainly, where, for thirty or forty years past, the course of breeding which we have pointed out, has been pursued with the short-horns, (and it might have been so with any other established breed, had it been selected,) with the most triumphant success. The "blood" cattle breeders there, have not only bred their pure bloods distinctly by themselves, and sold thousands of bulls to breeders of grades, near and far, in their own and other States, but have bred their grades, by the persistent use of thorough bred bulls, up to a quality-cows for milk, and bullocks for beef-equal in value for all practical uses, to the pure blood itself; and we see their droves of bullocks year after year going to market, at double, or treble the prices of common ones, and their cows, selected as milkers, at equal prices. We name the short-horns in those localities, as they are the only breed they have used, and those are the only considerable localities, within our knowledge, where this system of breeding has been for any length of time pursued.

So it is in England, Scotland, Wales, Ireland, and on the Continent of Europe, where the best agriculture prevails. The farmers and breeders find out what they want; they get it, and having proved its merits, they hold on to it with a pertinacity, which, to many of us would seem an infatuation; and even when they can find a better, sometimes refuse to give up the old breed at all, or do so with a doubting reluctance; and there is a reason for it. They live on the same farms or in the same neighborhood all their lives. They have either found their stock to be what was needed when they first commenced their occupation, or they obtained it in the vicinity of their homes, and knowing it to be profitable, were content to use it as it was, or improve it, without rushing off upon some strange fancy, as we Ameri- 
cans are too apt to do, to try a better; and so they have succecded in establishing the best breed for their own particular uses.

We Americans have not, as a rule, done so. We are enterprising, restless, shifting, more or less, in our occupations, and forever changing our homes on a chance of bettering our condition. Hence there is little steadiness in our pursuits, even when we are farmers all our lives. We breed sheep and raise wool a while; wool gets low, and we abandon our sheep, to go into cattle, either for beef or the dairy; they fall in price, and we abandon them, and go into mixed farming; by and by, these mixed commodities become troublesome, and we think our location a bad one, and sell out and try a new spot, and so on through a purposeless, ever shifting occupation. This remark has little to do with cattle breeding, we admit, but it gives a cause, or reason, why we are not better and more systematic cattle breeders.

Yet there is a better prospect ahead. The internal communications of our country by railway, have become so multiplied and extended that we can select our positions, and choose the staples to which we can best turn our attention, and to which our soils are best adapted. We can ascertain to what prodnct our capital can be most profitably directed, and so apply it. A division of labor becomes thus established. Wide districts, in several States, grow wool more profitably than they can grow anything else; other districts can more profitably grow cattle; others the dairy; and so on, all diversified, and each profitable in itself. Such being the fact, it becomes a comparatively easy matter for the cattle breeder, with a proper location, to prosecute his business with a single eye to both improvement and success. If he have industry and sagacity, he can soon acquire the means, and happily, opportunity is not wanting to gather the material to put him, at no distant time, in possession of the "best breed of cattle" for his purposes. 


\section{CHAPTER XVIII.}

\section{WHAT CONSTITUTES A GOOD ANIMAL?}

IT should be the object of every breeder to rear as good cattle as he can; that is, as perfect in their various points as their natures will permit, for the uses required of them; and this perfection of points gives the most profit in flesh, labor, and milk, according to the development of the various parts of the animal in its anatomy, and their general making up.

There are certain parts of the animal, economically, of little value, but indispensable to its life and welfare, as the head, ears, horns and bones. If these are too large, or ill-shaped, they detract from the value of the carcass by giving more offal than is necessary, and render the animal less profitable in feeding, as it costs a greater proportionate expenditure of food to make this offal, than it does to make either flesh or milk. Cattle having an undue share of bone, we call coarse, and all coarseness is bad, as such animals are gross feeders in proportion to their actual weight. A big-headed, narrow-chested, flat-ribhed, hollowbacked, narrow-hipped, and droop-tailed ox, is a poor worker, and such a cow, if she be not a poor milker, is seldom a profitable one, for both ox and cow are huge feeders. The ox has no room in his narrow chest for full lungs to play. Therefore he is short winded. His flat ribs and narrow hips allow him but a small development of muscular power. His strength is therefore 
contracted. His anatomy being sacrificed in breadth and depth, he has no place to lay on flesh as a beef animal, and he is worthless, comparatively, for any purpose. So with the cow; if she take flesh poorly, she gives a less quantity of milk; but if she do happen to milk well, it is because her food is chiefly thrown into the secretions of her milk veins, which happen, in such instances, to be extraordinarily developed. We have seen such, but they were the exceptions, not the rule, and all such cattle are to be avoided. There is no profit in them, any way; as a calf, the butcher does not want him, except at a reduced price; as a steer, the grazier jews down his price; as a working ox, nobody wants him, except he can get him "cheap;" as a fat bullock-if he ever can be fatted-the butcher "blows" on him; and as for the consumer-he is to be pitied. Soups, and dried beef-and poor at that-is all that he is fit for. $\mathrm{He}$ is a drag on every one's hands unfortunate enough to own him, from birth to slaughter. And so with the cow; poor in every quality, she goes through a miserable life, an object of contempt, and illusage throughout, simply because her breeder did not veal her at six weeks old, for she has never been good for anything in the hands of anybody since, and has taken the place of a better creature, which might have been profitable in every condition of her life, and a pleasure to every owner.

Now, reverse the picture. Here is a creature with a small head, a fine muzzle, and a light bone. He has a clean, sinewy neck, and deep, wide chest; springing ribs, giving ample room for vigorous lungs to play; a straight back from the shoulders to the tail; broad hips, and a deep flank-symmetrical throughout. $\mathrm{He}$ is so anatomically framed as to admit the largest supplies of flesh in the best points; he lias much less oftal, even to the same amount. of consumable flesh than the other, and no more offal to all the additional flesh which can be piled on to his 
carcass. As a worker, he is better than the other. His large lungs give him more wind, and better endurance; his broad, well-spread anatomy gives more sinewy power-of course he is a better worker as a laboring beast. He is remarkable through every stage of his life, from calf hood to maturity; to the feeder, to him who wants a working ox, to the butcher, and finally, to the consumer. $\mathrm{He}$ is good all through his life, and always in demand, at the top price, for one purpose or another. So with the female. If the breed be not of the dairy quality, spayed at a proper age, she thrives apace, fattens readily, and is fully ripe at three or four years, according to her breed, and is a profitable beast altogether. If a dairy cow, her full development of frame gives room for her milk secretions in their proper places. Her food, not only keeps her in good flesh, but assimilates into milk abundantly; and finally, done with milking, she readily takes on flesh for the shambles, and dies profitably.

We need give no further illustration of the contrast between poor and good cattle, than to refer the reader to the group of Texan cattle on a previous page, as a sample of the one; and to either cut of the improved breeds we have described, as a sample of the other. One exhibits the poor qualities of his race, the other exhibits the good qualities, and no one need be mistaken in his choice between them.

It may be asked, is beauty of form a highly desirable quality in a neat animal? Most certainly. But the eye and the judgment must be educated to know in what that beauty consists. A greyhound is a beautiful creature, as a dog; such a figure would not be beautiful in a bull, an ox, or a cow. Beauty is relative in economical animals, and in the eye of judges should always comport with utility. Yet there are outlines of beauty which no one, not a simpleton, can mistake; and beauty is always preferable to ugliness, even when an ugly form, as it sometimes 
does, embraces some desirable qualities. Beauty in a Short-horn would not be altogether beauty in a Devon, or Hereford; neither would the latter be altogether beautiful in a short-horn figure. So with the rotund, long-haired Galloway, the wild, rough looking Highlander, or the meek, domestic, housekeeping Ayrshire; while the unique, diminutive Alderney-a gem in her blond-like and picturesque little ugliness-would lose every attractive characteristic feature, if clothed in the perfect contour of a Devon.

We say, then, perfection of form-according to its breed-is a great excellence in neat cattle. They should be good all over. One most desirable point, unnaturally developed, is apt to be so at the expense of another part equally desirable, which is deficient, for nature usually has its compensations, and is apt to square her account of superabundancies and deficiencies as she goes along, even in animals which are otherwise almost faultless. Thus, if a certain outline of anatomy, when fully fleshed, gives the proportionate quantities of valuable flesh in their proper places, such outlines, according to the breed, is always to be sought for that object. If another outline better develops the milking properties of the cow, such a figure is to be sought, as near as may be, because of its likelihood to furnish the requirements wanted. To sum up the whole matter, perfection of form, according to its kind, should be the aim of every breeder who aspires to success and profit in his pursuit.

Some nice and discriminating breeders and writers on cattle, have given "scales of points," amounting to a hundred in all, to constitute a perfect animal; they give to every feature so many in number, as the importance of that feature may have to all the others, as two to the muzzle, one to the horn, four to the neck, ten to the brisket, twelve to the loin, and so on through the entire animal. We look upon all these nice discriminations as fanciful, rather than real, and have never known anybody gov. 
erned by them, even when on committecs to judge of the relative merits of animals on exhibition, and charged to do so. We doubt even their ability to do it with anything like accuracy; and as these "scales of points" are made to differ in divers brceds, as they should do, they only serve to confuse, instead of simplify and make clear the general judgment of the whole. The eye, the touch, the weight, and measurement, must, after all, tell the story. 


\section{CHAPTER XIX.}

ON BREEDING.-GENERAL PRINCIPLES, IN-AND-IN BREEDING, EXAMPLES.

Physiologically, this subject is first brought to our notice by the sacred historian, Moses, who has narrated the manner in which the patriarch Jacob, near four thousand years ago, retaliated the injustice of his father-in-law, by the use of peeled rods to influence the colors of his cattle; and also by taking the progeny of those of sound health as his own, and leaving the weaker ones with Laban. Jacob was a shrewd physiologist, and probably spent much of the time, during his years of servitude in tending the flocks and herds at Padan-aran, in studied observation of their natures and habits. Jacob's practice gives us a hint, only, but that hint is the key to a wide field of investigation of the true science of cattle breeding, and capable of almost indefinite ramification into every department of animal structure and physiology.

Greek and Roman writers also, tell us of the improvement of flocks and herds in their own times, by the careful attention of herdsmen and shepherds. Their particular modes of improvement are not all related, but the fact is recorded, and history, from ancient days down to the present, establishes the fact, that wherever agriculture had attained an advanced condition with the people, their domestic animals shared in its improvement. What the varieties, or breeds, of the ancient cattle were, is not recorded in their chronicles, but at a later day we have 
tnem with sufficient accuracy to govern our own cnoice, and profit by their example.

We approach this subject with diffidence, and do not expect to say anything particularly new or peculiar. There have been volumes-in books, pamphlets, and essays-written, and indefinite numbers of discussions and controversies on the subject of breeding, at "talks" and conventions. A good deal of sense, and somewhat of nonsense, has been both written and uttered, and all that we can do is to strive to condense, to a practical extent, the wisdom of the one, and aroid the other.

The stock breeder, starting with any one or more varieties in breeds of cattle, does so, in all probability, with the intention of keeping his stock in as good quality and condition of blood as he obtained it, at least, if he have no intention or ability to make it better. But he should, if possible, make his stock better than he found it. To effect that result, a few fundamental rules to govern the selection of his cattle, with which to commence his herd, are necessary. Some of them are herre enumerated. Among their qualifications they should possess:

1st. Sound health, and freedom from constitutional, hereditary, chronic, or local disease, blemish, or infirmity of any kind. And such sound health, and freedom from any kind of fixed disease, should appertain to every young animal which is to be retained for breeding purposes thereafter.

2d. As much perfection of form as may be possible to obtain in the breed, bearing in mind the chief uses for which the animals are intended.

3d. That they possess the strong and marked characteristics of their breed, in the various points belonging to it.

4th. That if of a distinct breed, the blood be thoroughly pure, and that purity be substantiated by well-authenticated pedigrees, through as many generations back as can be ascertained. 
5th. Good temper, and a kindly, docile disposition in the animals so selected or reared for breeding, or other purposes.

To carry out these rules, an enumeration of certain points which all cattle, of any breed, should possess, is necessary. Among them are:

1st. A fine head, small and lean.

2d. A broad, full and deep chest, giving room for welldeveloped and vigorous lungs to play.

3d. Good length, breadth and roundness of body, roomy and full from shoulder to hip, with low flanks, thus giving room for abundant action of the viscera, or bowels, and expansion for the footus, if in a female.

4th. Straight back, broad hips, and good length of loin.

5th. Fineness of bone, and smoothness in the carcass generally.

All these are indispensable, whether in an animal bred for propagating its kind, for flesh solely, an ox for labor, or a cow for milk. The intermediate parts, or points of the animals, may be filled out to promote the objects desired for the particular uses to which the creature is to be applied; but all which we have enumerated, are indispensable in making up a good animal. Any one adopting a particular breed, may refer to the descriptions and portraits already given, to ascertain the chief points necessary to possess in his beast, and they need not here be repeated.

To the rules, and their sub-divisions, here laid down, relating to the general figure of the animal, are to be added certain requisites to be supplied by the breeder, and of these may be named as indispensable:

1st. Abundance of proper food in the various seasons, as grass, or its equivalent, in spring, summer and autumn; nutri tious, well-cured and prepared food in winter; and plenty of good water always. 
2d. Regularity in feeding; no overstuffing; no scantiness of allowance; but enough, always, without waste.

$3 \mathrm{~d}$. Shelter, always, when needed, according to temperature of climate and atmosphere; avoiding extreme cold, violent storms, and excessive heats.

4 th. Kindly treatment; thus promoting docility in the animal; contentment of disposition, and a fearless confidence in its keeper-all promotive of quietude and thrift. Dumb beasts though they be, they appreciate good treatment much beyond what is usually supposed, and all these are indispensable to the successful efforts for the improvement, or even retention of their good qualities.

These rules for selection and treatment being duly observed, some further explanations are necessary.

Nature has certain unerring laws which must be observed; and those laws cannot be violated with impunity. "Like begets like." We have seen in the histories of the various breeds we have named, that each one has its own peculiar and well established features and characteristic, which are perpetuated in their progeny, although not always in the same relative degrees of perfection or imperfection, in which they exist in sire or dam.

Perfection of outward form is seldom found in any domestic animal. If it were, that quality would be less valuable than it is usually considered, and not so eagerly sought by every breeder who aims at a high standard of excellence in his stock; and even when obtained, there is a constant tendency to inferiority in the stock of such perfect animals, unless the most diligent care is exercised by the breeder to couple him, or her, as the case may be, with other animals which possess, to a certain degree, his or her predominating excellencies. Much of this tendency toward inferiority, or, toward improving excellence, will depend on the depth of breeding in the parents-that is to say, the long established purity of blood-in the so perfected sire and 
dam. Uniform perfection or excellence, or the highest quality in appearance cannot always be expected in the produce of even an aimost perfect sire and dam. Every now and then, in the finest herds there will come out a creature of inferior appearance, decidedly lacking some prominent good point possessed by both parents, or one of them. Yet, even this inferior production, having the good blood of his parents-constitution, health, and all esse being right-may prove as good a sire or dam as the very best of their superior relatives. We have known frequent instances of the kind, and may be excused for relating one with which we were for some time familiar. Some years ago, we knew a bull calf, which was selected from a pure bred herd in England, long established, and bred with a special care to retain their purity of blood and general good qualities. He was a good calf, possessing many of the strong and well defined points of his race; but after his arrival in America, although healthy, vigorous and well cared for, he grew up an ordinary, and every way-for his breed-an inferior looking beast. Yet his stock proved remarkably fine, even from inferior and coarse cows of his own breed. It was not known that he ever got a calf but what was really superior, in appearance, and showing the prominent excellencies of the herd from which he sprung. Yet nobody liked the bull, and his importer, after keeping him two or three years, sold him at a low price. His new owner, appreciating the value of the blond of the bull, removed him to his own herd, which was rather miscellaneously composed of several very good, and some only middling, yet all, purely bred cows. He bred the bull to those cows for several years. The improvement he made in their produce, of even the best of the cows, was wonderful-better, indeed, than the produce of bulls of the highest appearance and reputation in some other herds-although no one of common observation would think him, judging by appearance, worth much, comparatively. His stock sold for high 
prices, and after the bull was dead, men wondered what they were about, not to appreciate the value of his bloodl The sole value of the bull was in his blood and pedigree. Of himself, he was nothing; in his blood and pedigree, he was everything. So, on the contrary, we have seen a bull, almost perfect to the eye, pure in blood, and of good pedigree; but his pedigree traced through ancestors whose qualities were incongruous-both coarse and fine, or otherwise defective. His stock were uncertain in their good qualities, and many of them decidedly inferior. The first named bull could trace his lineage through a long line of ancestry, possessing uniformly good qualities; the latter one could not. He was patch-work, although thorough bred, as his pedigree showed; but there was no fixed standard of excellence through his long line of ancestry, and through him, their bad qualities all scattered into his stock, and his own good ones, as seen in his stock, amounted to nothing positively certain. Thus, pedigree is indispensable; and apparent excellence in the animal himself, unsupported by pedigree of undoubted excellence in a long line, is of minor value.

Still, in the selection of breeding animals, good form and appearance, and good pedigree should go together. As a rule, we would not rely on pedigree alone. The appearance of the animal should endorse the pedigree, and when good points and good pedigree are combined, they constitute excellence of the highest order. A sire or dam may be faulty in some minor particular of feature, yet when that minor feature is surmounted by a prominent excellence in a more important and controlling one, the inferior point may be overlooked in securing the better one. Even apparent coarseness in some particulars, belonging to a sire or dam, may be excused, when connected with good constitution and stamina, if either be coupled with one of the opposite sex, having a tendency to over-fineness, or exceeding delicacy. The vigor and apparent coarseness of the one will be 
corrected in the fineness of the other; or the opposite may occur, and an almost or quite perfect progeny may be the result of their union. And so with other qualities. Extremes of size, in both sire and dam, may, in some instances, be coupled together, except in great size of the sire, and diminutive smaliness in the dam; and such should not be bred together; but the conditions and sexes may be reversed, as the finer bull to the coarser cow, to great advantage. A little explanation is here necessary. As a rule, cows of a small breed should not be bred to bulls of a much larger breed, as a Devon, or Alderney, or even a diminutive native cow, to a Short-horn bull. We except the Short-horn bull, or whatever other breed of large cattle he may be, for this reason: The foetus, or embryo calf, will partake more or less of the character of the sire. If the formation be large, after the sire, the growth of the fotus will be correspondingly large, needing an undue amount of nourishment, and taxing heavily the energies of the cow to carry it forward to parturition; and at the time of birth it may be so large that the cow will be unable, of herself, to deliver it-and sometimes, even with the assistance of a farrier-alive. We have known small cows to die under the process, and others to have the calf dissected in pieces to be delivered, when with a calf of her own kind, no danger would ensue. The contrast of size was too violent for safety to either the calf or its dam.

Another ill effect from this coupling of the large bull with the small cow is, that for the want of sufficient room in the womb of the cow while growing, the footus becomes ill-shaped, and the proper proportions of the limbs are not extended as they should be. The consequence is a badly formed offspring. But in putting the larger cow to tho smaller bull, the case is reversed, and a finely formed calf is the result. This latter is the true way to breed the larger and smaller classes together. Still, if it be necessary to breed the larger kind of bull to the smaller cows, 
a bull of the smallest size of his kind, compact and snug in proportion, should be selected, and the larger thus gradually engrafted into the smaller breed, when, in a generation or two, no danger can follow the use of good sized bulls on the heifers of such offsprings from the smaller dams.

In thorough breeding, the bull should always show his own masculine character, energy, and vigor-no cow look about him. The cow should possess the softer and delicate points of her sex in their fullest development, and no masculine features should give her anything of a steer-like appearance. Sexuality, in their highest qualities, should be stamped in every feature, on both sides.

It sometimes occurs that two certain animals-bull and cow, both of excellent quality-do not breed well together. The good qualities of neither of them descend to their progeny, the form and features of such progeny running back into some unknown inferior characteristics of the ancestry of one or both the parents. This cannot be accounted for, only in the occasional uncertainties of nature in transmitting the character of parents directly to their offspring. When such uncertainty is ascertained to be the habit of the cow and bull so breeding, further intercourse between them should cease, and the cow coupled with a different bull. On the contrary, when a certain bull and cow do breed successfully together, producing really good stock, they should continue to be bred together, unless a bull of altogether superior points and pedigree can be found. We know no necessity for changing the bull when the cow breeds well to him, unless the new bull be a great deal better than the one she has previcusly bred to. Changing, merely for the sake of change, is of no benefit. It is mischievously introducing a multiplicity of crosses into one's herd, and thus scattering their blood into uncertainties, and wide variety of offspring, when fixed excellencies might be perpetuated to more advantage. 
We might run into almost numberless refinements, or theories, touching subordinate particulars of sire or dam, without reaching any well defined or accurate result; but when we say that our preliminary rules must be steadfastly adhered to, and after that, to breed from the best sires, in their outward appearance, to be obtained, and good pedigrees attached to them, the main point of the object is accomplished.

There is one question touching the improvement, as well as of maintaining stock in their wonted excellence, in which much controversy has for many years existed, viz.: the advantages or policy of breeding from affinities, more or less near in blood and consanguinity, called

\section{"IN-AND-IN BREEDING."}

Perhaps there is no better place to touch upon it than here. In the improvement and working up to their present degree of perfection, the several races of domestic animals which have attracted the attention of modern stock breeders, we find that the most remarkable and successful results, so far as concerned the outward form, internal structure, and productive power of the animals, have been derived from this system. History, so far as we know it, so instructs us. In order to perfectly understand it, we briefly state the premises.

We throw out of the question the absurd proposition entertained by some, that any one of the present well established breeds of cattle, have been formed by crossing those of divers strange breeds upon each other. Such has not been the case in any long established breeds with which we are familiar. In the history of those breeds, we have seen that with one or two exceptions, they have existed from time immemorial in their own distinct characters and varieties, and that they have been improved from the blood of themselves alone. That question noeds no further discussion. The only question now is, as to the 
fact of that improvement being made, and to what extent, by a course of breeding from close relationship in blood with each other. The practice-as it certainly has been the practiceprobably originated from the selection of animals possessing certain superior and desirable qualities, and after breeding them together, their produce being found to possess the combined good qualities of both parents, in an improved degree, the breeders, with a view of fixing and concentrating those good points still more strongly in the blood and constitution of their animals, bred the sire to his daughter, the sons and daughters with each other, sons to mothers, and any, and all sorts of relationship which, among humanity, would be considered the most incestuous. Yet this practice, among their dumb animals, proved eminently successful. They thus obtained stock of certain and positive qualities of excellence, which, among each other, or when bred upon stock of other families or tribes, would stamp their own character upon them, with a certainty and strength that could be reached by no kind of miscellaneous breeding whatever.

This mode of breeding, to obtain certain results, has been practiced with all domestic animals-among quadrupeds, from the horse down to the rabbit-and with the feathered tribes, through all their varieties, from the swan to the canary bird. Such is the fact; and in support of it, numerous instances might be named, in breeding other animals than cattle, which are not now necessary to notice, as we state the principle on which the practice has been adopted, and the successful results which have followed it. The subject will bear some discussion.

A prejudice, to a considerable extent, exists in the popular mind against blood relation in breeding animals of any variety, and they indulge it in regard to the lower orders of Creation as they do to mankind. So far as the prejudice relates to humanity, it is mainly derived from Divine authority, as a 
general principle, and also from various statistical tables, giving the results of intermarriages between blond relations, in the decline of stamina, physical power, and mental vigor of the parents, in their descendants. Some of these statistical tables may be true; others may be highly colored with the bias of opinion or prejudice entertained by those who made them. These statements might be more or less controverted, by close inquiry into the various circumstances in which the parents were placed, and the modes of life and education to which such families, both in parent and offspring, were subjected.

We do not propose to combat the prejudices above named, nor are we disposed to yield to all the sweeping conclusions to which the objections are carried, either in theory or apparent fact. There are certain physical parallels running through both the human family and the brute creation, to which the same rules may, either directly, or remotely apply; but not all rules; and we may name some of these parallels, with the differences which apply to them. Let us see with how much justice.

Man is far more nicely constituted in his bodily functions than the lower orders of animals. He attains much greater longevity than the most of them. He is liable to infinitely more diseases, and those diseases are more complicated in kind, origin, treatment and result. The chances of life, from infancy to a state of puberty, are far less in human than in the brute creation, from numberless circumstances unnecessary here to mention. $\mathrm{He}$ is endowed with thought, sentiment, understanding, sympathies, imagination, as well as instinct and passion. These qualities are all which need to be enumerated for our present purpose.

The lower orders of animals are less subject to casualties of life or limb; less liable to disease; less exposed to danger in bringing forth their young; less helpless in infancy, and sooner able to provide for their own natural wants. They have little thought; no great degree of sense; little reasoning faculty; 
some memory; dull imagination; not a particle of sentiment; slight sympathy; no lasting affection for their offspring after they can provide for themselves; and no power of mind to rise ahove the order of their natures. Their permanent affections, if they can be said to have affections at all, are towards man alone. They have instinct and passion much stronger than man; and that instinct and passion are uncontrollable-even by discipline, unless under superior force-and they indulge them on every available occasion, regardless of consequences. Thus man and the brute have little in common beyond their animal propensities.

We have spoken of mankind in a state of civilization. But even man can become brutalized; and the lower in the scale of humanity he descends, the more like the brute, in the indulgence of his instincts and passion, he becomes, until, perhaps, the brute is the better of the two.

Medical men tell us, and observing people know, that conception and gestation in mankind, are more or less influenced by the sensations or action of the mind, as sympathy, or imagination, fright or terror in the female during their continuance, as seen by strange marks on their bodies, or strange freaks of character in their offspring in numerous instances. It is seldom seen in the brute creation, and then only by sudden and startling emotion, or long familiarity with particular associations. Man, unless he becomes thoroughly brutalized, revolts at known incest. The brute, in either sex, gratifies its lust with the first object of its kind it meets, no matter what the blood relation, and in this indulgence, only acts out its nature. In domestication, they are but machines in our hands, with which to work out certain desired results, and their relations in blood have nothing to do with propriety or impropriety, in the coupling them together in any conceivable blood relationship. 
Wild animals of every race and variety, herd together, come in heat, copulate without regard to blood relation, the stronger males taking precedence in such service, and the young usually, unless accident occur, being healthy, robust, and keeping up the qualities of their sires and dams. Put a pair of wild deer in a park, and let them breed together for years, and their young also, promiscuously together; no deterioration is found in them-provided their natural habits and food are not interfered with. There are herds of wild cattle in some parks in the north of England, which have been bred together for centuries, without molestation or interference, save when they are occasionally slaughtered, and they remain the same in vigor, form, and appear. ance. Instinct and desire are the passions which govern them in procreation, regardless of blood relation, and with no evil con. sequences. A pair of pigeons, geese, swans, ducks, rabbits, or other small domesticated animals, are put together in the same way, and they and their offspring breed at will, promiscuously, for years together, with no bad results, and we think nothing of it. So with cattle, horses, sheep, pigs and goats-every brute animal, in fact, which breeds at all. They have no family affections or sympatinies, no permanent likes or dislikes, after the mother has weaned her young, and it has become able to provide for itself. The female, when in heat, freely receives the male, comely or uncomely, no matter what, if of her own kind; and the male, with the same ungovernable propensity, seeks his gratification with her. Blood relation among themselves amounts to nothing, even if they had the capacity to think of it, which they have not. The indulgence of their lust is the sole object of their desire, and that is effected regardless of consequences.

We say, then, that the question of brute incest amounts to nothing. Breeding in-and-in, so far as the animal is affected, is no more than breeding "out-and-out" into strange blood at every cross, under like conditions and circumstances. 
Let us understand: Conceding that our point is well taken, there is one grand fundamental condition upon which all progressive breeding is founded, viz.: Sound health and constitution in the parents whose produce is sought to be improved. If closely related animals have constitutional disease of any kind, their offspring will inherit it, and interbreeding will intensify the disease in every descending production of the family. Fven the out-and-out breeding of unhealthy animals, with healthy sires or dams, will not altogether eradicate the disease inherited, or chronic, as it may be. Unsound, or diseased animals, or those having a tendency to disease or unsoundness, when bred together, no matter how distant their blood relation, their produce will be unsound; and if the disease be apparently checked or obliterated in the young stock, it may lie dormant for a time, and then break ont in their descendants in all its original virulence, as seen in their ancestors of some generations back. Diseased animals should never be used in either progressive or any other breeding. Also, if barrenness (although barrenness is not properly a disease,) be a constitutional tendency in the first dam, or lack of virility be a constitutional tendency in the first sire, those tendencies may become perpetuated to such degree, by close interbreeding from parents to offspring, or between such offspring, as to finally result in almost total barrenness on both sides, in the entire family. If such tendency increase in the produce, new blood of an opposite tendency must, of course, be introduced. But, if the blood of these barrenly inclined animals, otherwise than in that particular fault in either sire or dam, be of great value, they should be coupled with other fruitful ones of different families, possessed in as high degree as possible of the same distinctive qualities, sought to be perpetuated through the original parents, so that the same distinct characteristics may be retained in the herd. "Like produces like," is the inexorable law of nature, only departed from, under strange and extraor. 
dinary influences, and the axiom should never be neglected by the breeder. To follow its teachings, generally, is the road either to success or ruin. Good animals, as a rule, will produce their kind; bad ones will produce theirs. - Our remarks regarding barrenness and its tendencies, as well as the recovery into full fruitfulness, might be illustrated, had we the space, by several well authenticated examples, now unnecessary, and perhaps invidious to mention.

To follow up the "in-and-in" theory: Suppose, after breeding thus closely for a series of years, some failing in vigor or quality is detected in the young stock; should further interbreeding be continued? No. What then? There always will be, if your stock be of blood having any currency at all, a distantly removed family of the kind, possessing mainly, or fully, the identical blood of your own herd, in a locality not far distant, to which, if their good qualities be still retained, a resort may at once be made to reinvigorate your stock, and a fresh cross be obtained. We may be here met with the objection, that if the same blood be resorted to, the cross will not be a fresh one, and the like ill results follow, as with your own previous in-and-in breeding. Such fact, by no means, need follow.

Suppose that an importation of a number of cattle of a closely bred family-bulls and cows-be made into New York, Boston, or Philadelphia. A part of them are taken into New England, another part into Pennsylvania, or Western New York, and another into Kentucky, Ohio, or a farther Western State, whore the soils are quite unlike, and the climates somewhat different from each other. These animals, thus widely soparated, will soon acquire somewhat different characteristics from each other family of the same original stock, although all may be kept and bred with equal care. The water they drink, the soil on which they graze, the food they eat, the climate they inhabit, will work somewhat of a change in their constitutions and habits, and one 
of the families, although bred in the same manner, and with the same care in keeping, may be different from, or superior to the others in some peculiar quality. Thus, these families become estranged in constitutional blood, and somewhat in habit, from each other. They do, in their wide separation, become new herds, so far as their close original blood is concerned. After some years' continuance in their varied localities, they may, therefore, be reunited, in the application of bulls to the cows of their distant relations, with entire safety to the quality of their future offspring. We have seen this very thing already done with admirable effect, in the United States, and with an improvement, if possible, on the good qualities of the originally imported stock. Under such circumstances, a resort to the old blood can be made, and kept intact in the herd without deterioration, and thus prevent an infusion of baser, or less desirable quality, in the herd proposed to be kept perfect in its lineage, and no outside cross need be admitted. Bakewell did so with his Long-horns, through his whole course of cattle breeding, going only twice out of his own herd for a fresh bull, and then into the same family blood, at the distance of a few counties away, and no breeder of his time had better, if as good cattle of the kind as he. Price, a noted breeder of Herefords thirty years ago-no better in England-asserted that he had not gone out of his own herd for a bull for forty years, and at his final sale, when he gava up breeding, his cattle bronght the highest prices-for Herefords-that had been known. The two brothers Colling began breeding short-horns, from the best cattle they could obtain from other breeders, about the year 1780. They soon got the bull Hubback, a thorough bred of their own breed, and although they retained him only three years, they bred pertinaciously from his blood until the year 1810-thirty yearsexcepting only in Charles Colling's "alloy" family of the Gallo. way cross. Charles, in that year, sold out his stock at the 
highest prices ever known. His brother Robert so bred his stock-no "alloy" about them-until 1818-thirty-eight yearswhen he sold out at prices larger than any other short-horn herd would sell for at the time. By a change of times, (it was war times when Charles sold, and the country was at peace when Robert sold,) all agricultural prices were much lower in 1818. Their stocks stood in the very highest repute, and no men had bred so intensely in-and-in, by every possible intermixture, as they, adhering to their old blood to the last. Charles, in some instances, bred his bull "Favorite" to his own dam, and sister, and granddaughters, and so down, for four or five generations.

So also, bred Mr. Bates, who bought his first "Duchess," deeply bred in-and-in, of Charles Colling, in the year 1804. He bred her and her near relations together, all closely allied in blood, and never went out of his own herd for a bull, with any success, as he frequently asserted, until the year 1831, when he obtained the bull "Belvedere," of the same blood, in another herd. $\mathrm{He}$ also introduced into his herd, the "Matchem cow," an animal showing excellent points of character, a stranger to his own stock, but which he contended had a back cross of his favorite blood in her, and thus possessing good quality, with which to reinvigorate the energies of his deoply in-and-in bred stock. He crossed his best bulls on that cow, and then interbred her produce with others of his old blood, and adhered to that blood thus crossed, and still further interbred, for the remainder of his life. Mr. Bates died in 1849, and for more than fifty years was a short-horn breeder.

So, also, bred the Booth brothers, Juhn and Richard, long time breeders of great celebrity, and their stock still remains in high repute, both in England and America. They bred deeply in-and-in. So did the Wetherells, Mr. Mason, Wright, Trotter, Charge, Earl Spencer, Sir Charles Knightley, and other noted breeders of their day, although we know less of their particular 
breeding, only as we trace them through the early Herd Books, than of the Collings, and Bates. All these herds were of high reputation, and their blood, passing since through the hands of other breeders, is now widely, by importation, scattered over the United States and the Canadas.

We would not be invidious in naming these particular breeders and their stocks, nor the short-horn breed, but to illustrate a fact. Every improved race of cattle in Britain has been more or less so in-and-in bred-Devons, Herefords, Long-horns, Ayrshires, Highlands, Galloways, Alderneys, and the famous "Dutch" cows of Holland. It was indispensable so to do, to concentrate their good qualities until a standard of excellence had been attained, from which the breeders could strike out into more divergent blood.

Thus, the fact that in-and-in breeding, of itself, having a tendency to deteriorate the quality of the produce is shown to be fallacious, so far as those breeders were concerned: the manner of doing so is quite another thing. Interbreeding in such close relation, is a nice-possibly a hazardous-thing, and can only be practiced by experienced men who are good physiulogists, have a just appreciation of both the good and indifferent qualities which their cattle possess, and the knowledge how to couple them together to produce favorable results.

The great merits and object claimed for in-and-in breeding, is the concentration of good blood in the animal so bred, enabling him or her to transmit that blood strongly, not only in the herd where they originated, but in other herds to which they may be removed. We do not, in fact, believe that many who object to the so-called "in-and-in" practice of breeding, really appreciate their own course of practice, while they are constantly pursuing that which they condemn.

Our attention has been recently called to this subject by $\mathrm{Mr}$. T. S. Humrickhouse, of Coshocton, Ohio,-a breeder of cattle 
himself-who has evidently paid much attention to the subject. We give his notes as sent to us:

"IN-AND-IN BREEDING.-SHORT-HORNS.-ESTABLISHING OR FIXING THE VARIETY AS AN IMPROVED BREED.

"In my essay, published in the Ohio Agricultural Report for 1854, on 'The General Principles of Propagation,' \&c., page 179, I use this language:

" And, if there are advantages arising from the having placed in the line of the direct ancestry, near and remote, of our herds, a great number of approved individuals, both male and female, as has been seen, it follows that there must be far greater advantages arising from having the same one individual-if he be of marked superiority-placed in that line the greatest possible number of times. This is done by 'in-and-in breeding,' and is the object of it. Now, it is easier to find this one unsurpassed individual than to find many, for, in the many, there will most certainly be one to be preferred to all the rest. Then, under the operation of the principle of atavism, (ancestral excellence or peculiarity, ) the chances, that the resemblance of such unequalled ancestor will be obtained, must be in the ratio of the number of times that he occurs in the ascending lines. Hence greatgr uniformity and greater excellence in'all the progeny. An apt illustration of this is found, in the frequent occurrence of the Godolphin Arabian, in the pedigrees of all our blooded horses, carried back to him as their founder.'

"To give greater force to the thoughts expressed in this quotation, I have, ever since they were committed to paper, entertained the purpose, at some time, to make the actual count. Instead, however, of using the thorough bred horse as the illustration, I now find it much easier, owing to the greater completeness of the materials at hand for making such a count, to carry out that design by using the improved short-horns as an illustration, and 
taking Mr. Charles Colling's famous bull Favorite (252)-one of the most celebrated of the variety-as the individual, the number of descents from whom, in the pedigrees of some of our living short-horns, is to be ascertained. Accordingly, I have made the count, in the cases of several animals selected for that purpose; and, for the better understanding of the subject, their pedigrees, as contained in the Herd Book, have been transcribed, and, together with the result of the count as made for each, given below."

$\mathrm{Mr}$. H. then gives the names and pedigrees, from the American Herd Book, of eight thorough bred short-horns, some of them bred in England, and imported into America, with their produce since arriving here-the names of which we have not room, nor is it necessary, to insert-each of which number from 672 to 8,104 descents-through all their collateral ancestryinto their own blood from the aforesaid bull Favorite (252).

Thus, although our short-horn breeders, by the substitution of "new crosses," as they suppose, are infusing fresh blood into their herds, are, in reality, persistently breeding back into essentially the same blood with which they started, or still retain, varied only by their change to different localities, yet deriving their lineage from the same original ancestry.

It is so with all improved breeds, or races of cattle, and other animals. A very few breeders and improvers, with a few well chosen animals, started the system, and from the produce which they reared from them, scattered through numerous individual hands, they have spread and multiplied, as did the children of Israel first descended from Abraham, into their own chosen races, each of their kind, but all chiefly one blood, and one lineage.

We feel much indebted to the acumen and industry of $\mathrm{Mr}$. Humrickhouse for his hint and illustration.

We have discussed his subject of breeding, at some length, mainly historically, rather than from a wish to commend it, as 
we are aware that much misapprehension has been entertained regarding it, and consider it necessary, in the present advanced state of cattle breeding in our country, that it should be fully understood.

We are not an advocate of the practice now, except in partic. ular cases, and under peculiar circumstances. There is, indeed, no necessity for it, to any extent, as our popular breeds of cattle are so widely distributed as to permit advantageous selections to be made from various herds for fresh crosses, without running into close relations of blood. Yet, two or three direct crosses may be made in successive generations, with a choice bull on his own descendants, even now, to decided advantage.

To sum up this prolonged discussion, we would, as a rule, only advise the breeder, either of pure bred cattle, or grades, to commence his herd with the best and most perfect animals he can find, or which he can afford, both cows and bulls; and so often as he needs a new bull, to again get the best one he can. Then, with due care, skill, and diligence, he may succeed, keeping always in mind the governing principles and rules laid down at the beginning of this discussion. A volume of writing would not much further enlighten him, as he is presumed to lave some discretion and judgment of his own to guide his conduct.

We close this, we fear, too long extended branch of our subject, by quoting Sir John S. Sebright, a distinguished English authority, who early in the present century acquired much celebrity as a stock breeder among the smaller varieties of domestic animals. It was written in the year 1809, and entitled "The Art of Improving the Breeds of Domestic Animals: In a letter addressed to Sir Joseph Banks, by Sir John Saunders Sebright."

"The best breeds, after having been obtained at great expense, too frequently degenerate from mismanagement. Men conceive that, if they have procured good males and good females, they 
bave aone all that is necessary to establish and to continue a good breed; but this is by no means the case.

"Were I to define what is called the art of breeding, I should say that it consisted in the selection of males and females, intended to breed together, in reference to each other's merits and defects.

"It is not always by putting the best male to the best female, that the best produce will be obtained; for, should they both have a tendency to the same defect, although in ever so slight a degree, it will, in general, preponderate so much in the produce as to render it of little value.

"A breed of animals may be said to be improved when any desired quality has beer increased by art, beyond what that quality was in the same breed in a state of nature; the swiftness of the race-horse, the propensity to fatten in cattle, and the fine wool in sheep, are improvements which have been made in particular varieties of the species to which these animals belong. What has been produced by art must be continued by the same means, for the most improved breeds will soon return to a state of nature, or perhaps defects will arise, which did not exist when the breed was in its natural state, unless the greatest attention is paid to the selection of the individuals who are to breed together.

"We must observe the smallest tendency to imperfection in our stock, the moment it appears, so as to be able to counteract it before it becomes a defect; as a rope-dancer, to preserve his equilibrium, must collect the balance before it has gone too far, and then not by such a motion as will incline it too much to the opposite side.

"The breeder's success will depend entirely upon the degree in which he may happen to possess this particular talent.

"Regard should not only be paid to the qualities apparent in animals, selected for breeding, but to those which have prevailed in the race from which they are descended, as they will always 
show themselves sooner or later in the progeny. It is for this reason that we should not brced from an animal, however excellent, unless we can ascertain it to be what is called well bred; that is, descended from a race of ancestors, who have, through several generations, possessed, in a high degree, the properties which it is our object to obtain.

"If a breed cannot be improved, or even continued in the degree of perfection at which it has already arrived, but by breeding from individuals so selected as to correct each other's defects, and by a judicious combination of their different properties, (a position, I believe, that will not be denied,) it follows that animals must degenerate, by being long bred from the same family, without the intermixture of any other blood, or from being what is technically called bred in-and-in.

"Breeding is sometimes done with father and daughter, and mother and son. This is not what $\mathrm{I}$ considêr as breeding in-andin; for the daughter is only balf of the same blood as the father, and will probably partake, in a small degree, of the properties of the mother.

"Mr. Meynel sometimes bred from brother and sister. This is certainly what may be called a little close; but should they both be very good, and, particularly, should the same defects not predominate in both, but the perfections of the one promise to correct in the produce the imperfections of the other, I do not think it objectionable..

"Mr. Bakewell had certainly the merit of destroying the absurd prejudice which formerly prevailed against breeding from animals between whom there was any degree of relationship. Had this opinion been universally acted upon, no one could have been said to be possessed of a particular breed, good or bad; for the produce of one year would have been dissimilar to that of another, and wo should have availed ourselves but little of an animal of superior merit, that we might have had the good fortune to possess. 
"The effect of breeding in-and-in may be accelerated or retarded by selection, particularly in those animals who produce many young ones at a time. There may be families so nearly perfect as to go through several generations, without sustaining much injury from having been bred in-and-in.

"Breeding in-and-in, will, of course, have the same effect in strengthening the good, as the bad properties, and-may be beneficial, if not carried too far, particularly in fixing any variety which may be thought valuable.

"If the original male and female were of different families, by breeding from the mother and son, and again from the male produce and the mother, and from the father and the daughter in the same way, $t$ wo families sufficiently distinct might be obtained; for the son is only half of the father's blood, and the produce from the mother and the son will be six parts of the mother and two of the father.

"Although I believe the occasional intermixture of different families to be necessary, I do not, by any means, approve of mixing two distinct breeds, with the view of uniting the valuable properties of both. This experiment has been frequently tried by others as well as myself, but has, I believe, never succeeded. The first cross frequently produces a tolerable animal, but it is a breed that cannot be continued.

"It is well known that a particular formation generally indicates a disposition to get fat, in all sorts of animals; but this rule is not universal, for we sometimes see animals of the most approved forms, who are slow feeders, and whose flesh is of a had quality, which the graziers easily ascertain by the touch. The disposition to get fat is more generally found in some breeds than in others. The Scotch Highland cattle are remarkable for being almost all quick feeders, although many of them are defective in shape. The Welsh cattle have but little disposition to get fat; not from being particularly ill-shaped, but because they are almost invariably what the graziers call bad handlers. 
"No trouble or expense will be spared by those who expect to derive profit, not from the quantity, but from the quality of the animals which they breed. The competition, which must always exist between breeders of this description, will be a never. failing stimulus to exertion.

"The common farmer, who seldom sees any stock but his own and that of his neighbors, generally concludes, that his own have arrived at the summit of perfection. But the breeder must frequently submit his male animals to the inspection of the public and criticism of his rivals, who will certainly not encourage any prejudices he may entertain of their superiority.

"These observations are the result of many years' experience, in breeding animals of various descriptions. But the life of man is not long enough to form very decisive conclusions upon a sabject which is so little understood, and which is darkened by innumerable prejudices. Many experiments must be tried, to establish a single fact; for nature is sometimes so capricious in her productions, that the most accurate observer will be frequently deceived, if he draws any inference from a single experiment."

To conclude, we give a different view to the supposed benefits of in-and-in breeding, against which some of our most experienced stock breeders entertain, as they conceive, well fortified opinions. Mr. Thomas C. Jones, an eminent lawyer, as well as a veteran short-horn cattle breeder, of Delaware, Ohio, from whom we requested a paper on the subject, says the following:

"Your idea of my preparing a paper, giving facts to show the advantages of 'out-crossing,' as compared with in-and-in breeding, I find to be impracticable, for several reasons. The number of instances that could be cited in such a paper, or indeed in an article of any length, is so small in comparison with the number of cattle bred, that the value of such instances, as evidence, in support of my position, would amount to very little. All discussions based upon such evidence have been unsatisfactory. 
“'Stonehenge,' speaking of breeding race horses, says, 'that by referring to distinguished animals, it will be found that the proportion of in-bred and crossed horses is about equal.' But of those that he calls in-bred, I have found none that were the produce of nearer connection than first cousins. The instances you cite of the old in-and-in breeders, do not, in my opinion, prove their success. I deny that they have, in the aggregate, bred more good animals than others who have not so bred. From the in-and-in families they have had less calves, and more bad ones than other breeders of less intelligence, who did not follow in their track.

"The assumption that occasional animals produced by such close in-and-in breeding as some have practiced, and which were really highly meritorious, and sold for enormous prices, (thereby establishing distinct families of cattle,) is a false one, as compared with other animals not so incestuously bred, although descended originally from the very same animals. This, I say, is against reason, as well as against experience of the great mass of practical breeders.

"I do not say that we should never breed in-and-in. I agree that it would be better to breed to a good animal closely related to our stock, than to breed to a poor one that was not so related; and I agrec that many instances can be cited where no bad results have followed, where they have not been carried too far. But I deny that in any case, such close brecding has been more beneficial than the breeding together of animals of the same blood and quality that were not akin.* Occasionally, hy such close connection, an extraordinary animal is produced, but such

\footnotetext{
* Judge Jones is a breeder of short-horn cattle. If he will tax his memory, or refer back to the early good short-horn familics in the first volnme of the English Herd Book, he will find that all those of superior excellence, trace their pedigrees into the herds of but a limited number of breeders, from which have descended, by continuous interchanging crosses, the best blood and animals of the present dsy.L. F. A.
} 
a result is apt to be followed by equally inferior ones. According to my observation, whenever this system has been long continued, the number of poor animals has outnumbered the good ones. A system that produces such results cannot be the true one. That practice is the best which produces the greatest average excellence, and the united experience of the great body of practical breeders attests this as best accomplished by avoiding incestuous breeding. Such testimony is worth more than a reference to a few distinguished animals, produced by even the most eminent breeders, while numerous other inferior beasts of the same families and blood are left out of the account."

Thus we leave the subject. We are aware that Judge Jones speaks the sentiments of many veteran cattle breeders, whose practice has been eminently successful in improving their thorough bred cattle, and for whose opinions we have a high respect. We have but repeated history, and facts, founded as we believe, on sound physiological principles, leaving those who are to practice in the exercise of a sound judgment in the course they choose to pursue in striving either to improve, or to maintain in their present excellence, the stock of which they are possessed. or may hereafter control. 


\section{CHAPTER XX.}

TREATMENT OF BREEDING COWS.

THis is purely a practical matter. It may be said to belong properly to the subject of breeding; but we purpose to give it emphasis in a chapter by itself, and not mix it with topics in part theoretical.

The whole subject is important, whether applied to cattle which range in miscellaneous herds, or in choice collections of either grade, or pure bred animals for particular, or ordinary purposes. The cow, as has already been observed, is a creature of instinct, impulse, and passion. Her instinct is, to breed her kind; her impulse is, to seek the male when that instinct becomes active; her passion is, to be gratified with the first opportunity. She has no fancy, no taste, and little imagination. She as readily receives the embraces of the most villainous scrub that falls in her way, as the bull of comeliest proportions; and if it so happen that she encounters them both in her phrenzy, the inferior brute is almost sure to impregnate her, even under the stealthiest, and apparently, least available opportunity. Under such circumstances, therefore, it is necessary that cows associate only with their kind, and so far as possible, with those of their own breed; and when pure bred animals, with only those of decided excellence.

We say that the cow has little imagination; but she may have some, and that imagination is emotional, acted upon suddenly, and for only a brief period during sexual heat, or the early stages of pregnancy. Her associations at such a season, 
should familiarize her to the sight of the best of her kind. If an inferior male, a steer, or ox, for instance, be running in the same field, or an adjoining one, where she can see him (and such steer, or $\mathrm{ox}$, will always strive to appease her passion, if they can get together, to which attempt she readily submits,) he may so affect her imagination thus operated upon, as to impress to some extent the foetus which may soon be conceived under the action of a proper bull. Therefore she should be prevented any such familiarity with inferior brutes. This, to the common observer, may appear absurd; but we will give an instance: Some years ago, in the winter season, we had a thorough bred shert-horn cow, which the herdsman had just let out of the stable with other cows to water. She was immediately discovered to be in heat. As she was passing through the yard, a villainous black scrub of a bull from a neighboring farm, had strayed away, and broke into our premises, and at that moment had come into the yard. He encountered the cow, and before the herdsman could reach them, a hurried coition had taken place. The cow was imnediately separated from him, put into a small enclosure, and a thorongh bred bull of her own breed admitted to her, with the usual and repeated effect. But it proved of no avail. In due time, the cow produced a black-roan bull calf, "steel mixed." He turned out a good one, taking more the form of the cow than of his sire, and we made a steer of him. The winter in which he became a yearling, when running in the yard with some other calves, the door of the stable, in which several thorough bred short-horn cows were standing, tied in their stalls, was open. That calf, in a frolic, ran bounding into the stable. One of the cows but a few days previous having received the bull, (a thorough bred short-horn,) started in alarm, threw her head on one side, saw the calf running by, and gave a loud, sudden bawl. It was only an emotion of fright, and in a moment she was over it. At the proper time she calved, and that calf, a pure roan 
short-horn heifer, had one side of its face (the same side which its dam in her fright, had thrown around to look at the bounding black yearling,) and jaw, back on to her neck, colored the same as the calf that caused the fright of its dam, the black hair running in a straight line from the middle of her skull down the face to the center of her nose, half of which was also black. The fact needed no further explanation. We reared the calf. She proved a fine cow, and bred us several excellent calves, with no mark of anything but a pure short-horn in them. We have heard, and seen accounts, of similar accidents in other herds, but differing in circumstances, and character. A cow may become so infatuated with the presence of a male unable to copulate with her, that when admitted to a proper bull, instead of resembling him, the foetus takes the impression from the one to which the cow had become familiar. She was merely passive, under the action of the bull which begot and should have impressed his own likeness on her calf. Such instances are not common, but they are possible, and of sufficiently frequent occurrence as to warn all good cattle breeders to be cautions of the associations permitted with their cows.

When the cow comes in heat, she should be allowed to see the bull fully and deliberately when introduced to him, and apart from the company of other cows. A single, or at most a once repeated service is sufficient, and immediately after the service she should be confined in her stall, or a small enclosure by herself, until her heat fully passes off. If she be let out immediately with other cattle, they only tease, and worry her, to no good, but frequently, positive injury. If the calf to be bred is of no consequence, only to be made into veal, or destroyed soon after birth, this pains with the cow need not be taken; but when cattle of any considerable value are to be reared, the little extra labor required should be cheerfully bestowed. 
In breeding thorough bred cows, some writers contend that if the heifer be first bred to an inferior bull, not only her first calf will resemble him, but her succeeding calves will resemble him also, whatever may be the qualities of their own sires. This supposition is based on the principle that the heifer's first impression of the bull at coition, are so strong as not to be effaced, and that her imagination at the time continued to influence her future progeny. It is possible that such may have been the fact in some peculiar cases; but they have been very uncommon. We have known many instances of cows with their first calves being bred to bad bulls, but no known bad result has followed her succeeding progeny. It is well, however, to say that none but the best bulls should always be used, and any inferiority of blood in them strictly avoided.

In a pamphlet entitled, "On a Remarkable Effect of CrossBreeding: by Alex. Harvey, M. D., Physician and Lecturer in the Royal Infirmary, at Aberdeen, Scotland; printed in 1851," a work of considerable research, are found, aside from much philosophy, and some speculation, some striking facts. We have heard some of the facts before; but as they are important in their bearing in the case of cows in connection with breeding, although of considerable length, we quote them for the study of those who choose to look deeper into the subject than a casual, or slight observation will admit.

There are some rather fine-spun theories suggested, which actual investigation will not corroborate, but we give the matter as written by its author:

"There is a circumstance connected with the process of breeding in the higher classes of animals, which seems to me to merit a larger share, than it has yet received, of the attention of the Agricultural body. It is this: that a male animal, that has once had fruitful connection with a female, may so influence her future offspring begotten by other males, as, to a greater or less 
extent, to engraft upon them his own distinctive features; - his influence thus reaching to the subsequent progeny in whose conception he himself has had no share, - and his image and superscription being, so to speak, more or less legibly inscribed upon them.

"Accordingly, if the female be of a different breed or species from that male, and have thus borne a cross or a hybrid by him, her subsequent offspring, got by males of the same breed or species as herself, may yet have, more or less, the characters of a cross or hybrid.

"It seems not improbable, indeed, that on every occasion of fruitful intercourse between a male and a female, some effect of this kind is wrought on the breeding powers of the female; but it would appear that the greater effect results from the first sexual connection. Whether the effect is absolutely permanent, and might show itself in all the offspring which the female is capable of subsequently producing, is at present uncertain; but it would seem, in some instances at least, to disappear after a time.

"Of this singular phenomenon, examples will presently be given. That it is not less practical in its bearing than singular in its character, must be evident to every one. If it be a general fact,- - that is to say, a fact having the character of a law of nature-it is one obviously of practical application in the breeding of stock. It will at once appear how important it must be that care be taken in the selection of the male, and particularly of the first male, in the coupling of animals even of the same breed; and, if the preservation of a pure breed be an object of regard, that crossing be in every instance religiously eschewed. Whether it be a fact of that description, cannot, in the meantime, with any confidence be alleged. At present, the fact itself is probably known to comparatively few, and what is known regarding it, is deficient both in scientific accuracy and in practical value. But the conjecture may be hazarded, that were the 
subject brought prominently under the notice of breeders, and were the communication of illustrative cases solicited by Agricultural Societies, a large collection of examples, presently known only to individuals, and, therefore, lost to science, might be obtained, sufficient to exhibit the commonness of the fact, and thus enhance its importance in public estimation.

"The following examples of the phenomenon, and statements respecting it, comprise what is presently known to me in regard to the facts of the subject.

"1. A young chestnut Mare, seven-eighths Arabian, belong. ing to the Earl of Morton, was covered in 1815, by a Quagga, which is a sort of wild ass, from Africa, and marked somewhat after the manner of the Zebra. The mare was served but once with the Quagga, and, in due time, gave birth to a hybrid, which had distinct marks of the Quagga, in the shape of its head, black bars on the shoulders, \&c. In 1817, 1818, and 1821, the same mare was covered by a very fine black Arabian Horse, and produced, successively, three foals, all of which bore unequivocal marks of the Quagga.*

"A mare belonging to Sir Gore Ouseley was covered by a Zebra, and gave birth to a hybrid. The year following, the same mare was served by a thorough bred horse, and the next succeeding year by another horse. Both the foals thus produced were striped, that is to say, partook of the characters of the Zebra.

"* The first and the second of these foals are thus described: "They have the character of the Arablan breed as decidedly as can be expected, where fifteen-sixteenths of the blood are Arabian: and they are fine specimens of that breed; but both in thelr color, and in the hair of their manes, they have a striking resemblance to the Quagga. Their color is bay, marked more or less like the Quagga in a darker tint. Both are distinguished by the dark line along the ridge of the back, the dark stripes across the fore-hand, and the dark bars across the back part of the legs. Both their manes are black; that of the filly is ahort, stlff, and stands upright; that of the colt fe long, but so stiff as to arch npwards, and to hang clear of the sides of the neck; in which circumstance it resembles that of the hybrid. This is the more remarkable, as the manes of the Arabian breed hang lank, and closer to the neck than those of most others.'" 
"It was long ago stated by the illustrious Haller, and also by Becker, that when a mare had a mule by an Ass, and afterwards a foal by a horse, the foal exhibits traces of the ass; a statement which I find recently confirmed by Professor Low, of Edinburgh, in a letter to Sir John S. Forbes, of Pitsligo.

"In the foregoing cases, the mares were covered in the first instance by males of a different species from their own. But there are cases recorded of mares covered in every instance by horses, but by different horses on different occasions, where the subsequent offspring exhibited the characters of the horse by which impregnation was first effected. Of this, Mr. M'Gillavray gives two examples. Thus, in several foals, in the royal stud at Hampton Court, got by the horse Actæon, there were unequivocal marks of the horse Colonel, by which the dams of these foals were covered the previous year. Again, a colt, the property of the Earl of Suffield, got by Laurel, so resembled another horse, Camel, 'that it was whispered, nay, even asserted, at New Market, that he must have been got by Camel.' It was ascertained, however, that the only relation which the colt bore to Camel was, that the latter had served his mother the previous season. In farther illustration of this point, I adduce an interesting statement, made by Professor Low. After remarking that 'sometimes there is difficulty in getting a thorough bred mare to breed for the first time with a thorough bred horse,' and that 'in this case, in order to cause her to commence breeding, a coarse stallion is put to her,' Professor Low adds, 'but the effect never fails to be seen in the progeny, the coarser characters of the first male re-appearing, however highly bred the subsequent stallions may be.'

"2. Breeders of cattle are familiar with analogous facts as occurring in the Bovine race. The two following cases, taken from Mr. M'Gillavray, may serve as examples: A pure Aberdeenshire heifer, was served with a pure Teeswater bull, by $10^{*}$ 
which she had a first-cross calf. The following season, the same cow was served with a pure Aberdeenshire bull: the produce was a cross calf, which, when two years old, had very long horns, the parents being both polled. Again, a pure Aberdeenshirc cow was served, in 1845 , with a cross bull, that is to say, an animal produced between a first-cross cow and a pure Teeswatcr bull. To this bull she had a cross calf. Next season she was served with a pure Aberdeenshire bull: the produce was quite a cross in shape and color.

"3. With regard to the Dog, it has often been observed, and, indeed, it seems to be matter of notoriety, that a well bred bitch, if she have been impregnated by a mongrel dog, will not, although lined subsequently by a pure dog, bear thorough bred puppies ever after, or at least in the next two or three litters. And it appears farther, that the progeny are affected in respect, not merely of their shape and color, but of their natural instinct also. A pure Terrier bitch, (of the Skye breed,) of a dark brown color, with red legs, was lined the first and second time she came in season, by one and the self-same dog-a mongrel cur,-and produced-in the first litter four, and in the second, three puppies, all of which took very decidedly after the cur, which was black, with rod legs and white feet. On the third occasion she was lined by a pure dog (of a grey color) of exactly the same breed as herself; and, in order that no other might have access to her, she was locked up with this dog the whole time her heat lasted. The issue was two puppies, buth of which bore the closest possible rosemblance to the cur, in color, shape, and appearance generally.

"4. The like occurrence has been observed in respect to the Pig. A sow of the black-and-white breed, (known as Mr. Western's breed,) bclonging to Mr. Giles, became pregnant by a boar of the wild breed, of a decp chestnut color. The pigs produced were duly mixed, the color of the boar being in some of 
them very predominant. The sow being afterwards put to a boar of the same breed as her own, some of the progeny were observed to be stained, or otherwise marked, with the chestnut color that prevailed in the former litter. And, on a subsequent impregnation, the boar being still of the same breed as the sow, some of the latter were also slightly marked with the chestnut color. What gives additional value to this observation, is, that in the course of many years' experience, the breed in question was never known to produce offspring having the smallest tinge of the chestnut color.

"5. Not the least striking examples, perhaps, of the phenomenon, are the two following, observed in the Sheep; - the first communicated to me by my friend, Dr. William Wells, of the island of Grenada-the other by Mr. William M'Combie, Tilly. four, in Aberdeenshire:

"A small flock of ewes, belonging to Dr. Wells, were tupped a few years ago by a ram procured for that purpose from the manager of a neighboring estate. The ewes were all of them white and woolly. The ram was of quite another breed, being (besides having other marks of difference,) of a chocolate color, and hairy like the goat. The progeny were of course crosses, bearing, however, a great resemblance to the male parent.

"The next season, Dr. Wells procured another ram of precisely the same breed as the ewes. The progeny of this second connection showed distinct marks of resemblance to the former ram in color and covering. And the like phenomenon, occurring under the like circumstances, was observed in the lambs of some other adjoining estates in Grenada, and was the occasion of equal surprise and perplexity to the owners of the animals.

"Six very superior pure bred black-faced horned ewes, the property of Mr. Harry Shaw, in the parish of Leochel-Cushnie, in Aberdeenshire, were tupped in the autumn of 1844,- - some of them by a Leicester, i.e., a white-faced and polled ram, -others 
of them by a Southdown, i.e., a dun-faced and polled ram. The lambs thus begotten were crosses.

"In the autumn of 1845 , the same ewes were tupped by a very fine pure black-faced horned ram, i.e., one of exactly the same breed as the ewes themselves. To Mr. Shaw's astonishment, the lambs were all, without exception, polled and brownish in the face, instead of being black-faced and horned.

"In autumn, 1846, the ewes were again served with another very superior ram of their own breed. Again the lambs were mongrels. They did not, indeed, exhibit so much of the characters of the Leicester and Southdown breęds, as did the lambs of the previous year; but two of them were polled, and one dunfaced, with very small horns, while the other three were whitefaced, with small round horns only. Mr. Shaw at length parted with those fine ewes, without obtaining from them one pure bred lamb.

"To the foregoing examples, I may add two important general statements on the subject, made by Mr. M'Gillavray and by Professor Low. The former, after referring to several of the cases just given, adds: 'Many more instances might be cited, did time permit. Among cattle and horses they are of every day occurrence:' and the latter, after giving the particulars already qnoted respecting the horse, observes, 'many analogous examples could be given in the case of other animals.' And I may remark, generally, that since my attention was first particularly drawn to the subject, inquiry made in various quarters has satisfied me of the accuracy of these general allegations. I have not, it is true, seen any examples of the sort; but opportunities for doing so have not lain in my way. I have learnt, however, that many among the Agricultural body in this district are familiar with the thing to a degree that is annoying to them; finding that, after breeding crosses, their cows, though served with bulls of the same breed, yield crosses still, or rather mongrels. 
"Now, an ingenious explanation of the phenomenon has recently been offered by Mr. M'Gillavray, of Huntly. 'When a pure animal of any breed (says Mr. M'Gillavray,) has been pregnant to an animal of a different breed, such pregnant animal is a cross ever after; the purity of her blood being bost, in consequence of her connection with the foreign animal;' and again: 'If a cow, say of the pure Aberdeenshire breed, is in calf to a bull of the short-horn breed, (known as the Teeswater breerl, ) in proportion as this calf partakes of the nature and physical characters of the bull, just in proportion will the blood of the cow become contaminated, and herself a cross, forever incapable of producing a pure calf of any breed.' 'It is maintained, therefore, (Mr. M'Gillavray adds,) that the great variety of nondescript animals to be met with, are the result of the crossing system; the prevailing evil of which is, the admission of bulls of various breeds to the same cow, whereby the blood is com. pletely vitiated.'

"This theory, of course applies only to that class of animals (the mammalia) where the female is provided with a womb, and has her offspring lodged there for a time. And in order to the better understanding of the theory, attention is requested to the following considerations: By the formation of the after-birth (placenta, a connection is established between the mother and the living creature (foetus) in her womb, through which the latter is continually drawing supplies from the mother's blood, for its growth and, maintenance. But there are good grounds for believing that, through the same channel, the mother is as constantly (though, doubtless, in much less quantity) abstracting materials from the blood of the fœetus. Now, is it all unreasonable to suppose that the materials in question may be charged with (or have inherent in them) the constitutional qualities of the fœtus, and that, passing into the body of the mother, and mixing there with the general mass of her blood, they may impart those 
qualities to her system? This supposition will, perhaps, appear the less improbable, if regard be had to the length of time during which the connection between the mother and foetus is kept up, and during which this transference of materials must go on-a period of some weeks, or even of several months. But the qualities referred to must in part be derived by tho foetus from its male parent, and be to that extent identical with his. The distinctive peculiarities, therefore, of this parent may thus come to be engrafted on the mother, or to attach in some way to her system; and if so, what more likely than that they should be communicated by her to any offspring she may afterwards have by other males?

"The influence thus supposed to be exerted by the male par. ent, through or by means of the foetus, on the constitution and on the breeding powers of the female, may appropriately be designated inoculation influence. To go more largely, however, into this part of the subject, were beside our present purpose, and would involve details, perhaps fully intelligible only to the professed physiologist. But it is due to Mr. M'Gillavray, to state, that his theury not only furnishes a satisfactory explanation of the phenomenon, but is consistent with acknowledged facts in physiology, and is borne out to a greater extent than he was perhaps aware, by the known history of blood diseases.

"In a practical point of view, however, it is quite immaterial whether this theory gives the true explanation of the phenomenon or not. All that is to prove and be assured of is, that the phenomenon is exclusively referable to something corporeal (that is, material or organic) connected with the prior impregnation of the female. And were this indubitably certain, all that need be sought after in a practical inquiry into the subject is, to observe accurately the appearances presented by the animals produced in the subsequent, connections of the female with other males-to note the degree of resemblance which obtains to the first or to 
a former male- to ascertain, out of any given number of cases, in what proportion this effect is observed-and, generally, when it is observed, to determine the circumstances under which it holds, as also those under which it varies in different classes of animals, or in different individuals of the same class."

[NотE.-We consider this theory of the "vitiation of the blood" of the mother, by her blood connection with the foetus in her womb, stated by Mr. M'Gillavray, as altogether too "ingenious" and finely drawn. The "theory," however, has had an existence, to more or less extent, among the popular uneducated mind, perhaps from time immemorial. In our own boyhood, more than fifty years ago, when there was a great rage for introducing the blood of the Spanish Merino Sheep into the flocks of the Eastern States, some farmers indulged the fancy that if their coarse common ewes could he tupped by a Merino ram, not only would the lamb be of half the Merino blood, but the ewe herself partake of such proportion of his blood also, so as to cause her future offspring, by whatever ram she might bo connected, to retain a share of the Merino! How such an absurdity should obtain credence we know not, otherwise than by the same influence which created ghosts, spooks and witches.

The foetus is enclosed in a case (placenta) within the womb, and receives its nourishment only through the peculiar organs of the mother, which are in play during its location there. That process is an extraordinary function of the female, active only during pregnancy, and in no way common with her ordinary habits. The theory would make the fœtus, in the circulation of its blood back into the system of the mother, a part of her own organization, whereas, the fœtus is only an offshoot of her system, nourished by a peculiar internal process, or secretion, like the milk she gives for its support after birth.

If the blood of the fotus circulated, or were returned into the veins of the mother, the fœtus would be a part of herself, instead 
of an offshoot. Its birth would be a wrenching out of a part of her internal system, instead of relieving her of an increasing burthen which is in itself complete, and wholly separated from her own being, so far as the ordinary functions of life and circulation are concerned.

Our author, Dr. Harvey, has also mentioned several instances in the human family, where children of a second husband have strongly resembled the children of his wife by a previous husband, or some male friend with whom she had only been on terms of social intimacy. That may be, but we ascribe it wholly to imagination, or sympathy of the mother with the memory of the first one. He also speaks of white mothers, who, having their first child by a man of another race, as a Negro, Moor, or Mongolian, and afterwards bearing children to men of their own 'race, the children resembled more or less the fathers of their first born. That may be so, owing to the same influences as in the other cases; but they are too few and isolated to make a rule. We, ourself, have known cases where white women had their first child by a negro, and were afterwards married to white men, but their children were as purely white as any others.

We consider the theory as entirely fanciful, so far as humanity is concerned, where the imagination has vastly more play than in the brute creation; and in the latter, so extreme and wide apart in its examples from the ordinary product of their species, as to be classed among the occasional monstrosities which occur in the conception and breeding of all animated beings.-L. F. A.]

\section{A gain Doctor Harvey:}

"But it so happens that a phenomenon precisely similar to the one before us-so like it, at least as not to be distinguishable from it-is sometimes seen under very different circumstances. An animal (for example,) is sometimes observed to present the same sort of resemblance to another animal, with which its mother has never, at any time, had sexual connection,-a circumstance 
ascribed, and (in many such cases,) on good grounds, to some state of the mother's mind, having a relation to that other animal, at or some time before the period of conception, or during her pregnancy. It is conceivable, therefore, that in many cases, -nay in every case, where an animal resembles another (not its progenitor,) by which its mother had formerly borne offspring,that is to say, in the whole set of cases which form the subject of these pages, - the resemblance may be explained quite as well on the principle of mental influence, as on that of inoculation; or, at least, that in ascribing it, with Mr. M'Gillavray, to the latter cause, -or to any purely corporeal cause arising out of the prior sexual intercourse, a manifest source of fallacy attaches to the assumption. The phenomenon may really be resolvable, in any, and in every instance, into an affair of the mother's mind.

"The possibility, therefore, that mental influence may furnish the true explanation of the phenomenon, at once raises a question which bears so directly on the present subject, as to demand consideration in connection with it. To consider it fully, how: ever, at this stage, would keep the test to be proposed for its solution too long out of view. I shall, therefore, here content myself with one example in illustration of this kind of influence.

"A mare and a horse (a gelding) had, for some years, worked togethor on the same farm, occupied adjacent stalls in the same stable, and pastured together in summer in the same fields. The gelding was of a black color, with white legs and face, and had a singular peculiarity in the form of the hind legs, which, when the animal was standing, appeared quite straight, there being no appearance of the leg being bent at the hough-joint, as in ordinary cases; the pasterns, likewise, were very long, so as to cause the feet to look as if placed almost at right angles to the legs. After having been some years thus associated with this gelding, the mare was covered with a stallion of the same color as herself-both stallion and mare being of a bay color, with black legs 
and a small spot of white only, on the forehead. The foal which was the produce of this connection, very exactly resembled the gelding in color and in shape, and very remarkably in the shape of the hind legs, as above described.*

"The striking feature of this case, besides the circumstance that there could have been no sexual connection between the mare and the gelding, is, that the resemblance of the foal to the gelding was at once general, and yet extended to a marked pec1liarity of conformation; thus identifying the resemblance with something having a relation to that particular horse. This relation could be no other than a mental one, on the part of the mother, arising out of her association with the horse. But had this horse been a stallion, and had he previously had fruitful intercourse with the mare, the resemblance might very fairly havo been attributed to something material co:nected therewith.

"It is clearly important, then, in regard to the proper subject of this essay, to guard against a fallacy of this kind."

"It appears that many breeders of stock are impressed with the belief, that certain colors present to the eye of the parent animals, and particularly of the female, at the time and in the act of their being coupled together, - and to the eye of the female, both before and during her pregnancy, influence the color of the progeny; and that they make this belief a practical principle of action in the breeding of their stock, in order either to prevent or to secure the admixture of any particular color in the offspring, different from that of the parent animals. 'We know,' says an anonymous writer, 'a great breeder of pure Angus stock (black polled breed,) who makes it a rule to have every animal about his farm of a black color, down to the very poultry.' And an

\footnotetext{
"* Communicated to the anthor by Dr. John R. Trail, of Monymnsk, Aberdeenshire. 'From the description I have attempted to give you, (Dr. Trail writes me,) you conld not form any very distinet ides of the peculiar conformation of the gelding ; but the resemblance of the foal to him was remarkably clear." "
} 
eminent breeder of the same kind of stock in this county, informs me, that he extends this rule to the steadings in which his cattle are kept.

"To illustrate generally the grounds of this belief and practice, the following cases may be cited:

"A black polled Angus cow, belonging to Mr. Mustard, a farmer in Forfarshire, came into season while pasturing in a field bounded by that of a neighboring farmer. Out of this field there jumped into the other field an ox, of a white.color, with black spots, and horned, which went with the cow till she was brought to the bull-an animal of the same color and breed as herself. Mr. Mustard had not a horned animal in his possession, nor any with the least white on it; and yet the produce of this (black and polled) cow and bull was a black and white calf, with horns.

"In 1849, twenty cows of the black polled Angus breedbelonging to Mr. William M'Combie, in this county, and whose stock is perhaps the finest in the kingdom-produced as many calves, all of them black and polled, except one single calf, which was yellow and white spotted. Mr. M'Combie had, as usual with him, taken the precaution of causing the cows, both before and during their pregnancy, to mix with none save perfectly black cattle, except in respect of the mother of this calf, which cow had unwittingly been put to an out-farm, to be starved, in order to fit her for the bull. There, for a considerable period prior to her being served with the bull, she had grazed with a large yellow and white spotted ox, of which ox the calf she sub. sequently bore was the very picture-the likeness, however, extending no farther than to the color, and the calf still retaining the shape and configuration of its parents, which were both of the same breed and color.

"Out of a large herd of cows, of the pure Teeswater breed, all of them of the brown or roan color, (belonging to Mr. Cruick- 
shank, Sittyton, near Aberdeen,) there is every year dropped one, or at most two, white calves, which, in order to prevent the introduction of this color among the cattle, are invariably sold, and sent away. In 1849, however, concurrently with the whitewashing of all the farm-steadings, the very large number of twelve white calves were produced. And the like occurrence happened the same year also, in the herd of an extensive breeder of the same kind of stock, in Yorkshire, in connection with the like process of white-washing-this process having, in both cases, been very extensively carried out before the breeding season began, with the view of preventing the breaking out of the pleuro-pneumonia, then epidemic in the neighborhood, and very destructive.*

"At the time when a stallion was about to cover a mare, the stallion's pale color was objected to, whereupon the groom, know. ing the effect of color upon horses' imaginations, presented before the stallion a mare, of a pleasing color, which had the desired effect of determining a dark color in the offspring. This is said to have been repeated with success in the same horse more than once.

"I was told (Mr. M'Combie writes me,) by an old servant of mine, Morrice Smith, that when he was a servant in the parish of Glass, (Aberdeenshire,) a black bull served a black cow at the time when a white mare passed them, and that the produce was twin white calves. There were no white cattle upon the farm where this occurrence happened. $f$.

"* Communicated by Mr. Craickshank, who says further, that he has had too many proofs of the agency of the cause in question, to allow him entertaining any doubt on the subject."

" + My friend, Dr. J. M. Duncan, of Edinburgh, writes me that he has "more than once heard farm-servants say, that it is a sure plan to get a white foal, to hang up a pure white sheet before the mare when she conceives.' Probably hanging up such a sheet in the stable during the whole period of pregnancy would be equally effectual." 
"Such cáses as several of those now cited, can scarcely fail to recall to the reader's mind the story, given in the book of Genesis, of Jacob and his peeled rods, and the effect of these in causing the flocks, before whom they were placed at the time of conception, to bring forth ring-streaked, speckled, and spotted cattle.

"It does not appear from the sacred narrative whether the influence of the rods was exerted on the minds both of the male and female cattle, or confined to those of the female.

"All that need be said, in the way of direct inference from the facts here brought together, may be comprised within a narrow compass.

"Supposing the statements respecting them to be authenticand no question, I apprehend, as to this can well be raised-the cases are nearly unequivocal. The only fallacy that can attach to them, is that arising from the possibility, that the peculiarities in the progeny were either purely accidental, or owing to corresponding qualities latent in the parents, but breaking out in the offspring. The relation, however, in most of the cases, between the peculiarities in question and their presumed causes, is too close and of too special a character to admit of either supposition. We are, therefore, well entitled, I think, to regard the greater number, if not the whole of them, as examples of mental causes, so operating either on the mind of the female, and so acting on her reproductive powers, or on the mind of the male parent, and so influencing the qualities of his semen, as to modify the nutrition and development of the offspring.

"How, in respect of the female, this influence is exerted, and what the conditions of its action, it is not easy to determine. The mental affections seem to have been in most of the cases, and were probably in all of them, of a strong and enduring kind; and we can easily concaive this to have been essential to the result. That the alteration in the growth of the fotus was 
determined solely, as is vulgarly supposed, by the images in the mind of the mother, i.e., by the mere sensations and perceptions therein produced, independently of the emotions excited by them-cannot well be supposed. It is, doubtless, to this 'compound state' of mind-to use an expression of Sir James Mackintosh - a state 'easily called to mind,' in consequence of the vividness of its first impression, 'frequently recurring,' and 'warmly felt,' that we must ascribe the effect.

"It is not unlikely, that this particular agency of the mind is more frequently exerted in the females of the lower animals, than in those of our own species; and that cases exemplifying it, are oftener met with in the brutes than in man. If this be so, a reasonable explanation of the fact may be given. We know that the minds of the lower animals are in a great measure limited to particulars, and these few in number, and almost exclusively external objects of sense; that the external senses are more perfect in them than in us; and that the perceptions resulting from their exercise seem, in various instances, to follow more surely and more quickly - to be more intuitive and wider in their scope, and more vivid-in them than in man; and that the simpler emotions (excited by those perceptions) of joy, fear, affection, anger, \&c., of which they are manifestly susceptiblo, seem often to be peculiarly strong. We know also that they possess the faculty of memory; and we may well suppose, from their limited range of association, (or suggestion,) that sensations that formerly made a powerful impression on their minds, will be more easily and oftener recalled in them than in us, who, though more apt to be 'troubled about many things,' are proportionally less apt to be affected, or at least permanently or continuously impressed, by any one thing. These circumstances and peculiarities of mental action, must obviously be singularly favorable to the production of the results in question. 
"It may be remarked in conclusion, that the word imagination, generally used to designate the mental states here concerned, is, perhaps, an unfortunate one; and it may be questioned whether much of the scepticism prevalent among physiologists as to the effects, or alleged effects, on the development of the fœtus, of certain complex mental affections, be not, in great part, owing to the use of that term. Certain mental conceptions or ideas, suggested to the mind, independently of any present or actual exterual object, and exciting strong and enduring emotions, constitute that state of mind, to denote which, imagination is used here. Often, however, it is used to denote the power by which the mind forms to itself pictures which have, in such a combination, no prototypes in nature-the power of creative or poetical imagination, which, manifestly, is not possessed by the brutes. The state referred to here, that of simple imagination, is one componnded only of simple conception and emotion."

[Note.-The reader may, perhaps, tire of this long, and somewhat philosophical, as well as speculative essay; but, in the breeding of valuable stock, we wish to give all the information which may instruct us in so important a branch of physiology.

In addition to the several instances already narrated of the influence on color of progeny in the course of gestation, Captain Charles Bryant, of Fairhaven, Mass., recently related to us an instance. A gentleman, residing in that vicinity, owning an island in Buzzard's Bay, some miles off the coast, one summer sent a considerable number of black cows, which were in calf to a black bull, over there to graze, wishing to keep them by them. selves, and breed calves of the same color. A dun-colored steer was either sent with them, or a short time afterwards, and ranged in their company all summer. When the calves were dropped, every one of them was the color of the steer I So strangely will influences, almost unaccountable, determine results adverse to the most natural probabilities.-L. F. A.] 
"The subject of mental influence has been here considered without reference to any inquiry in to the specialities of its operation. But were such an inquiry to be entered on, it would be proper to make such experiments as should exhibit how far the influence in question may operate- first, at any time prior to the period of sexual connection,--secondly, at the time of such connection, - and thirdly, during pregnancy. The modes of devising and conducting experiments of this kind, will readily suggest themselves to any one conversant in these matters."

OCCASIONAL BARRENNESS IN THE COW.

It sometimes occurs that heifers, or cows which have been kept in high condition, do not readily conceive, although they come regularly in heat at the proper times, and are properly served by the bull. If they continue refractory, the better way is to reduce their flesh by low keep, and plenty of exercise. Turning them into short pasture, is the best way during the grazing season, and short keep in winter may reduce them. They seldom fail to breed under such treatment. If they still prove unfruitful, a drenching dose of mild physic is advisable, (as glauber salts,) which is usually effective, and harmless. Sometimes, after receiving the bull, they will pass weeks, or months, without showing sigus of heat, and then seek him as before, without any signs, meantime, of abortion. This however, is seldom the case, unless the cow, or heifer, be in high condition. To make sure and constant breelers, it is a better course to keep them only in good flesh, without forcing. They are uniformly healthier under such treatment, as it is a more natural condition, and the calves are better than from over-fed, or highly pam. pered cows.

Barrenness in high bred cows, is a serious matter to the owner, or breeder. With common, or grade cows it is of less consequence. as the unfertile ones can be readily turned off for beef. 
But with a thorough bred cow, worth perhaps, $\$ 500$ or $\$ 1,000$, the case is different, and if the cause of it can be in any way overcome, the remedy should be resorted to. In addition to the few remarks we have made, we consider the subject of sufficient importance to introduce a part of a recent discourse on "The Reproductive Powers of Domestic Animals: by Henry Tanner, Professor of Rural Economy in the Queen's College, Birmingham;" from the Journal of the Royal Agricultural Society, England:

"An enfeebled condition of the breeding organs is one of the first sources of trouble for the breeder. It seldom precedes, but often accompanies, that delicacy of constitution to which reference has been made. Instead of the females breeding in a regular manner, we find them come into season, again and again, after most irregular intervals. This results from one of the following causes: either the female does not become impregnated, or else the embryo is imperfectly developed. The non-impreg. nation of the female, may generally be traced to an excessive fatness in one or both animals, and an absence of constitutional vigor. The breeding powers are most energetic when the animals are in moderate condition, uninfluenced either by ex. treme fatness or leanness. The impregnation of the female is in some cases prevented by natural defect or malformation; but I am strongly inclined to believe that such cases are compara. tively rare.

"Many animals are condemned as barren which are only tem. porarily so, in consequence of injudicious feeding and management, or relatively so; in consequence of the male being unsuited, from too close proximity of blood, or from both animals being deficient in constitutional vigor. Examples of each of these cases are frequent. Some very well bred heifers which had been condemned as barren, because, after very persevering trials with various bulls, they failed to breed, I placed for four or five 
months upon poor hilly pasture, to bring them down in condition, and immediately after this they bred without difficulty. Captain J. T. Dary has communicated to me some similar instances, in which most hopeless cases of barrenness were overcome, by turning the heifers upon poor common land with a young bull. $\mathrm{He}$ states that in other cases the same result had been attained by working the heifers in the plow, like oxen, after which there has been no trouble in getting them to breed. I am also informed by Mr. Strafford, of another instance, in which apparent sterility has been successfully overcome. The late Mr. Jonas Webb, purchased a valuable cow from the herd of the late Lord Spencer, for a moderate sum of money, in consequence of her being condemned as barren.

"After the purchase, she was driven from Wiseton to Babraham, (her old home to her new one,) a distance of between one hundred and one hundred and twenty miles, and within a short time she bred. 'Dodona,' the cow in question, when a heifer, produced twin calves, and subsequently she produced another calf, but, as she then ceased to breed, she was sold. A change of climate, however, brought her into breeding condition, and at the time of her decease, no less than one hundred and sixty valuable animals could be traced to this cow, which had been sold on two occasions as barren. Mr. Webb had an almost parallel case in 'Celia,' which, under somewhat similar treatment, after being condemned as barren, had a progeny of over one hundred and eighty traced to her at the time of her death.

"These results were all gained by somewhat severe treatment, whereby unhealthy accumulations of fatty matter, previously existing in the body, impeding generation, were taken up into the system for the support of life. I have known cases in which heifers which could not breed were exercised daily, by being led ahout for a certain length of time; but this treatment is seldom sufficient to reduce those accumulations which impede gener. atiou. 
"Highly satisfactory results have been gained by a thorough change of climate, when the stock were sent to hilly districts where the air is bracing, and they have to take plenty of exercise. Barrenness may also be traced to too close relationship, or a similarity of temperament. This is, however, a qualified barrenness, to be overcome by proper selection on the part of the breeder. The fat condition of the male animal, and his want of constitutional vigor, are frequently the chief causes of diffculty. I have known of bulls, which had become valueless for breeding purposes, being worked upon the land in carts, and thereby rendered serviceable.

"I believe that we have the condition of successful reproduction, very much under our own control, and that the cases of legitimate barrenness, either on the part of the male or female, are much more rare than we imagine. I know that animals which are naturally capable of breeding, can be rendered incompetent by adopting a special course of treatment; and I consider that in our usual system of management, we must retard and interfere with the healthy performance of this natural function of animal life.

"For the purpose of more fully investigating the causes of barrenness, I have examined the ovaries of several heifers, which were, after careful trial, condemned and killed as barren; and I have every reason to believe that by far the larger proportion, were naturally quite competent for breeding, and that in the majority of cases, non-impregnation arose from the seminal fluid never reaching the ovum, which was ready for fertilization, or from that fluid not being of a healthy character. In some cases in which the ova were, to all appearance, perfectly healthy, the tubes-whereby the seminal fluid should have been conveyedwere so overcharged with fatty matter, that impregnation was rendered impossible. In other cases, the ovaries were in an unhealthy condition, either one or both having, to a great extent, 
wasted away. Sometimes one of the ovaries had been suffering from atrophy, and the other in such an irritable and sensitive condition, that it might be almost described as inflamed; and - under such circumstances, the formation of a healthy ovum could scarcely be expected. In other instances, the ovaries had become considerably enlarged, in consequence of a fatty degeneration of these organs having taken place. I have not sufficient data before me, to trace these several results to their respective causes, except in some of those cases in which a fatty degeneration of the ovaries had taken place.

"Through the kind help of Mr. Reece, of Ross, and Mr. Thos. Duckham, of Baysham Court, near Hereford, this fatty degeneration of the ovaries has been traced to the use of food rich in sugar. I have every reason to believe that the action of sugar, in its various forms, is most important in its influence upon the generative system; and I think there is just cause for considering that any animal may, by its use, be rendered incompctent for propagating its species. Since my attention has been drawn to this fact, numerous instances have come under my observation, tending to confirm this opinion. From among the cases which I could mention, it will probably be sufficient for me to state that of a breeder of some eminence, who, with a view to an improvement in the condition of his herd, added molasses to the dry food he gave to his stock. It certainly produced the result he anticipated, for their improvement in appearance and general condition was most satisfactory; but this was accompanied by an influence he had never expected; for his stock, which had always realized high prices as breeding stock, now, with very few exceptions, proved to be valueless for that object, male and female being alike sterile. As soon as this was discovered, the supply of molasses was stopped. But whilst the animals, which had not been under its influence, maintained the original character of the herd, as being good 
breeding stock, it is very doubtful if any of the stock which had been fed for any length of time on food mixed with molasses, ever regained their breeding powers. It is more than probable that a fatty degeneration of the ovaries took place, from which they would but slowly recover under any ordinary treatment.

"In another case, in which molasses had been used for some heifers which were fattening, it had the effect of suppressing those periodical returns of restlessness which prevent heifers feeding as well as steers; and it kept them so steadily progressing during the whole period of their fattening, that the result was highly satisfactory. If, therefore, upon further trial, we find sugar influential in checking the reproductive functions, we can at any rate exercise a proper discretion in its use; and whilst avoiding it for breeding animals, we may encourage its employment where cows or heifers have to be fattened.

"The action of sugar upon the human system is very similar. The negroes in the sugar plantations are said to lose all ${ }_{\alpha}$ power of reproduction during the sugar harvest, and are permanently influenced, although in a lesser degree, by the juice of the cane, which they are so fond of chewing; there is also reason to believe that the negroes have become relatively more productive with the diminished growth of sugar.*

"Until my attention had been drawn to this action of sugar upon the reproductive powers, I was not aware that its influence had been previously acknowledged; but I find that this has been observed by continental physiologists, of whom it will be sufficient to mention Moleschott and Proreucal.

"It would be premature for me to attempt any explanation of the manner in which sugar exerts this powerful influence upon the animal system. We shall probably find that it has a twofold action; it may not only produce a fatty degeneration of

* This information probably relates to the British West India Islands, as we have never heard of any such influences among the laborers of the sugar plantations of the United States,-L. F. A. 
the ovaries in the female, but by the glandular excitement it causes, it may also favor a re-absorption of the seminal fluid of the male, and thereby the desire for breeding be diminished, if not finally destroyed. That sugar has a powerful influence upon the reproductive powers, scarcely admits of a doubt; but it is more important that we should be more fully acquainted with its action.

"We shall, however, find that other agencies produce a somewhat similar tendency to fatty degeneration, if not in the ovaries, at least in the surrounding parts, whereby the healthy ova of females fail to be fertilized in a natural manner; or when they have been fertilized, they are, from the same cause, subsequently aborted. It is also probable, that in some cases, in which the female possesses healthy ovaries, and yet, in consequence of the defective powers of the male, fails to breed, a very unnatural excitement takes place in her, that induces an irritability which is fatal to impregnation. In these, and similar cases, the removal of the clitoris of the vulva (as spoken of by Mr. E. Bowley, of Siddington, in Vol. 19 of this Society's Journal, page 151,) would allay this excitement, and thereby favor successful breeding. This is, however, a practice which few would be disposed to recommend; and Mr. Bowley rather mentions the fact of the operation than advises its adoption.

"The moderate use of salt is also stated to have a powerful effect upon the breeding powers of animals. Moleschott states that the favorable effect of common salt upon the formation of blood, and upon nutrition, also produces an influence upon sexual life. Boussingault found that bulls, which in their food receive a large addition of common salt, show a greater inclination to cover; and Ronlin states that the females of our domestic animals, are rendered less productive by want of salt.

"No evideuce as to this action of salt, has come under my own observation, still I think it probable that we shall find the 
more general use of salt very important and beneficial in its action upon breeding stock. When salt is used for any animal producing milk, care must be exercised not to allow it to be taken in such quantity as to check the production of milk; for a free supply would speedily stop this secretion.

"The general system of diet must also be looked upon, as taking its share in influencing the reproductive functions. When the fall of rain has been small, and the herbage more than usually parched, we find unusual difficulty in getting ordinary farm stock to breed. A dry dietary is very unfavorable for breeding animals, and very much retards successful impregnation. On the other hand, rich, juicy and succulent vegetation, is very generally favorable to breeding. Apart, therefore, from the direct influence of the food given, it is certain that the condition in which it is consumed, materially influences the breeding powers of stock.

"Little is as yet definitely known as to the comparative influ. ence of different kinds of food upon breeding animals; but the information we possess, leads us to desire further evidence.

"We know that the healthy semen of male animals, with few (if any) exceptions, contains a large proportion of albuminous matter, in the form of vitellin and albuminate of soda; and it follows, as a natural consequence, that unless these bodies are present in the food, although they may for a time be supplied by exhausting the animal system, still, his career cannot long be maintained without prejudice to the animal, and disappointment to the breeder.

"The presence of phosphorus is also essential; and it has been observed that food rich in phosphorus, such as the leguminous seeds, ${ }^{*}$ hay, grass, corn fodder, \&c., are especially valuable in promoting the fertility of breeding animals.

*Indian corn, oil cake, and all oily grains are "fatty." Peas, oats, barley, rye and buckwheat, are more albuminous, producing muscle, and lean flesh.-L. F. A. 
"It may also be stated that though a moderate supply of fatty matter is desirable in the food, still, it should be limited, so as to prevent any unhealthy accumulations of fat in or about the breeding organs; and it should always be accompanied by food rich in albuminous matter.

"The influence of climate upon the health of our domesticated animals, has never received that attention which it merits. I have already made some reference to the effect of a change of climate upon the breeding powers, and I may add, that the beneficial influence extends both to male and female. The results which have attended the importation of English stock, which had been exported to other climates, or their immediate descendants, show that considerable advantage is often realized in this manner, and the practice is probably capable of extension. It is, however, well worthy of an inquiry, whether we do not possess in our country sufficient variation of climate and district, to accomplish the desired results at less cost. There is undoubted evidence to show that we may thus engraft upon our stock greater constitutional strength.

"The formation of milk is intimately connected with the reproductive powers. The secretion of milk is dependent upon the activity of the mammary glands; and these are either under the direct influence of the breeding organs, or else they sympathize very closely with them. Those animals which breed with the least difficulty, yield the best supplies of milk, and produce the most healthy and vigorous offspring. Now, it must be admitted, that however much we have improved the symmetry and feeding power of stock, we have suffered them to deteriorate in value as breeding animals, by the decrease of their milking capabilities. In proportion as we adopt a more natural system of management, for the purpose of keeping stock in a healthy and vigorous breeding condition, so shall we reap the indirect benefit of a better supply of milk. It is true, that a deficiency in the yicld 
of milk may be met by other resources, but since a short supply of milk is indicative of, and associated with, enfecbled breeding powers, every care should be taken to obviate this defect.

"There are few subjects connected with agricultural literature, which offer such a scope for inquiry and research, as that which I have now discussed; for whether we look upon the reproductive powers of domesticated animals, from a practical point of view, or a scientific inquiry, we have very strong inducements to investigate the subject more completely. The very circumstances under which barrenness can be produced or removed; the influence of various kinds of food upon the breeding capabilities, and also upon the production of milk; the circumstances which favor or check abortion; the conditions which regulate the sex of the offspring-these, and many kindred subjects, demand careful consideration."

In corroboration of the foregoing remarks on the effect of sweet foods inducing barrenness in breeding animals, we give a note from Mr. E. W. Stewart, on the subject. It is proper to say, that at the time of his writing it, Mr. S. had not seen the paper of Professor Tanner.

"My attention has lately been particularly turned to the chem. ical qualities of foods, and to determining how a practical appli. cation may be made, to the feeding of animals.

"I find there bas been much chemical research which has never been applied. Some three years ago, while my Sorghum cane was being manufactured into syrup, the skimmings were given to the cows, and drank with great relish. One cow was so greedy for the sweet scum, and indulged to such an extent, that she was barren for a year. I have seen since, a number of cases mentioned, where the breeding qualities of animals have been injured or destroyed by a free use of sweet-the females barren and the males impotent-but no explanation of the phenomena. It occurred to me that chemistry should furnish the $11^{*}$ 
explanation, and I was confident that some author must have discussed the point, but I could find no direct allusion to it. Still, there are abundant facts from which to draw a conclusion. All the animal tissues contain, as an essential element, nitrogen. Sugar, fat, starch and water, are non-nitrogenized components of the animal body, but are not organized or living substances.

"It is only the muscular and nervous systems that have sensation. The semen of male, and the ova of female animals, are albuminous or nitrogenous fluids, containing, besides soda and phosphate of lime, all the essential elements of the young animal. It is held, by some of the greatest animal chemists, that 'nitrogenized foods alone nourish the tissues.' It is not difficult, then, from these premises, to infer the reason that too carbonacious food, such as sugar, should, when fed in large quantities, render the female animal barren, and the male impotent. And yet chemists have not applied these facts. It will readily be seen, to what an important account this may be turned by the breeder of animals. In raising heifers and bulls, for instance, how important it is to give them a thorough muscular development; and to this end, glutinous or albuminous food should be given. There has, in fact, been very little intelligent feeding with cattle breeders. They have fed what was most convenient, without tasking their brains with the question of food elenents, and how best to combine them."

\section{FEEDING IN ADVANCED STAGES OF PREgNANCY.}

As the cow approaches maternity, she should be well kept. If the climate demands it, she should have good shelter, and warm beds. If she has become reduced by scant feed, or profuse milking, she should have additional feed while running dry, in order to promote the growth of the fœetus within hor, and prepare her botter for the labor of parturition, as well as the sustenance of the coming calf, and a good flow of milk afterwards. No 
cow. should give milk from the birth of one calf to that of another. It is too heavy a draft on her physical powers, and a period of six weeks to three months' rest from milking is necessary, when the breeding of choice animals is an object. Some cows, we know, will yield their milk naturally from the birth of one calf to that of another, but it wears on them, and an abundance of the best food is necessary to keep them up through so exhausting a process.

A cow cannot well perform two such important duties at a time, as to give a profitable yield of milk, and mature, in the last stages of growth, a healthy, well developed fœtus. The milk must be drawn at the expense of the coming calf. When the calf is of no importance, and milk the only thing wanted in the cow, her flow of it may be continued, by stimulating food, up to six weeks, or even a shorter time, of her period of bringing forth, but in any event, some time should be allowed her for rest. As the birth of the calf approaches, she should be kept quiet, have gentle exercise, and be carefully looked after daily. Her udder, for a few days in advance, should be watched and examined, that it be not "caked" or inflamed, or secrete more milk than may be retained in a healthy condition. Some young cows or heifers secrete milk in such quantity, in advance, that it is necessary to draw it from them for some days before calving, to prevent the udder from spoiling by inflammation. When parturition is immediately expected, she should, according to the season, be confined in a loose box stall in the stable, or under a shed, or in a small outside enclosure, where she may be readily seen and attended to in case of accident or difficulty, as such are liable to occur frequently with heifers in their first calf, and sometimes afterwards. The chances of difficulty are certainly worth the littls extra attention required. The immediate duties attending parturition will be hereafter noticed under the proper head. That process once completed, the udder should be thoroughly 
drawn by the calf, and completed to perfect emptiness by the hand of the attendant.

It is of the first importance in the rearing of good stock, that the cow be always kept in good condition-not pampered, and fat, on stimulating food, but in fair "working" order, on the simple and nutritious food natural to her. A poor, half-starved cow must, of necessity, be scrimped in her proportions. Live herself, she must, and as the growing fœetus within her must live also, and grow, its proportions will be more or less circum. scribed, and perhaps in its most valuable points. So, also, overfeeding, and excessive fatness may have the same effect on the fœtus. The filling of her viscera with masses of fat, will crowd the fotus into too small compass for proper expansion, and be as fatal to the development of its proportions, as the want of full subsistence in that of the starved cow, besides subjecting her to difficulty in parturition, puerperal fevers, inflammation, or other risks not common to cows in simply good flesh. We have seldom known young stock improved when the cows were in very low, nor when in very high condition. Cows should be well fed, and attended throughout the year, with all the nutritious, palatable food they need, or will take, and under such treatment only, will their produce be superior to themselves, or even, perhaps, as good. Their food may be more abundant, and stimulating, according to the quantities of milk they may yield while pregnant; and if good milkers, and their expected produce are intended for milkers, such milk-producing food should be given to perpetuate that faculty in the young. A watchful eye, and a steady hand, are indispensable in breeding good stock of any kind.

\section{DURATION OF PREGNANCY.}

The time of pregnancy in the cow is not always uniform. Nine months is the commonly estimated time. It almost always runs so long, but usually longer-sometimes even to ten months. 
Two hundred and eighty days is given by some writers as the average time; others state it at two hundred and eighty-four. We, one year, kept an accurate account, on our own farm, of upwards of fifty cows, consisting of thorough bred Short-horns, Herefords, Devons, and their grades, and common ones. We found no average difference in the time of one kind from another, and in casting up, and averaging the time of them all, we found it to range from two hundred and sixty-eight to two hundred and ninety-onc-the average being two hundred and eighty. four days. 


\section{CHAPTER XXI.}

BREEDING GRADE CATTLE FOR GRAZING.

IN breeding cattle for grazing, and the shambles, early maturity, rapidity of taking on flesh, and the distribution of it on the best parts of the carcass, are the main objects for profit and quick returns. In selecting the breed to be adopted, the same rules in relation to climate, and the land they are to occupy, are to be observed as with dairy cows. The foundation of the herd, in cows, should be of those, whether of common, or more or less of any improved blood, which combine flesh-produeing qualities in as high degree as possible. The quantity of milk they will yield is of less importance. Almost any cow will give milk enough to rear a calf well to six or eight months old, and if in a locality where milk is of no particular value, that time is enough for her to yield it.

The bull selected to breed from, should, if possible to obtain such, be pure in blood, of whatever breed may be adopted. $\mathrm{He}$ should be masculine in appearance, strong, and vigorous, but not coarse. He should be fine in bone, his skin, and the flesh under it, elastic to the touch, with good, thick, woolly hair; no particular matter about the color, so that the color be true to his breed. His flesh should be well laid on in the best parts for beef, and combining as nearly the points of a model Devon, or Short-horn in that particular, as his breed, if of another kind, will permit.

Abundance of good food, water, shelter, and care, the young should always have, and the cows and bulls should always bo kept in good condition-not pampered-that the young do not 
suffer from the misfortune of their parents in such particular; for any young beast to carry flesh well, and increase it rapidly, should have the propensity to do so bred into them from the womb. A poor half-starved cow cannot produce any but a lean calf. "What is bred in the bone stays long in the flesh," is an old and true adage. A bull, perfect in the points of his breed, is as superior to a deficient one, used even on common, or grade cows, to a certain extent, as to breed on thorough breds; and an inferior one should not be used at all;-better pay a round price for a good bull, than take a poor one as a gift.

The age at which heifers should be bred, must depend somewhat on circumstances. For grazing cattle, two years old is "early enough to put heifers to the bull. They should acquire somewhat of maturity, and fair size, to produce good graziers; and that general remark will suffice.

\section{BREEDING DAIRY COWS.}

If the breeder intends to rear dairy cows, he will select as good milkers, with which to commence his herd, as he can find, whatever their condition, or blood may be, and they should be descendants of good milkers also, if he can ascertain the fact. Then he must select a bull from a tribe of good milkers in his own breed. The descriptions we have given of the dairy qualities of the different breeds, and his own good judgment, must guide the breeder in that particular. The bull chosen should bear, in himself, the dairy marks or points-for they show in the bull as well as in the cow - and he should be descended, on the side of both his dam and sire, if possible, of good milking ancestors. His head should be small, his fore parts lighter, in proportion, than his hind parts, as in the cow; yet he should be vigorous, of sound constitution, and well formed throughout. Examine his scrotum and see that the embryo teats on the sides of it are well, squarely, and uniformly placed; that his twist (space between 
the thighs,) is wide, with yellowish skin, and soft to the touch, and it may be reasonably assured that such a bull, with well selected cows of the common or grade varieties, will produce good milkers. Then one has only to proceed, adhering to these rules, and breed on. Every young cow which does not prove a good milker, should be turned off for fattening, and her heifer calf to the butcher. The heifer. calves of the good milkers only should be reared. The milking faculty will then become well established in the herd, and by the persistent use of such bulls as we have described, although the cows are but grades, all the substantial advantages of the pure blood, on the side of the bull, will virtually be obtained.

We have seen in the history of the Ayrshire cow, in previous pages, how an inferior race of catcle, by the long and persistent use of well bred bulls, of choice blood, have been elevated into an established milking "breed." That process was a simple one, and easy to follow; it can be followed with any kind of cattle which it is desirable to improve, provided the first improving blood is adhered to, until it stamps its individual character on the baser blood with which it was first crossed.

Now, at this point of successful attainment, is the very place where the breeder will be apt to fail in further progress, and lose a portion of the advantages which he has been at so much expense of time and cost, in his pure bred and well selected bulls, to attain. He may think his cows "good enough;" that his tribe of milkers is established, and he need go no further. "A pure bred bull is expensive, and I cannot afford to expend so much money to keep on in the same way. I'll now get, or raise a grade bull of this good milking stock." But let it be understood that this grade bull has got bad blood in him. Away back in the generations on the "common" side of his ancestry, a worthless brute has occurred, either in the male or female line, and that very bad blood may crop out in a large majority of the 
calves he may get, as the cows which he is to serve have, through their "common" ancestry, a share of bad blood also. If it be said there is no probability of that, the answer is, there is a possibility, and that risk should be avoided. The inevitable tendenoy of interbreeding grades with each other, is to throw out all sorts of intermixtnres of the ancestral blood, and all improvement in the herd there stops-it retrogrades, even, from the very time the grade bull is adopted. It may be said "the Ayrshires were so made." True, but it took a hundred years so to make them into an established breed, and they are still kept up with the most painstaking care and selection; and no three, or four, or half a dozen crosses of the best pure blood of any breed, on our native cows, can be trusted to perpetuate, within themselves only, their qualities so recently and artificially bred up. Aside from this, the ultimate destination of the dairy cow is the sham. bles; and as a gond one, if of an improved breed, will, in almost every instance, when done for the pail, feed well, a risk of making the most of her in that particular, when at so trifling a cost as the keeping a pure bred bull, should not be ventured. No; keep on with the thorough bred bull. If obtained at two years, he will last till he is six, eight, or ten years old, breeding him to his own daughters, and even granddaughters, before he is discarded. If "blood" in an animal is good for anything, that blood should be concentrated in his descendants-fixed so as to be retained in his stock, where it will exercise its full power and faculty in reproduction. It is quite as necessary in the grade as in the thorough bred. There is no danger in in-and-in breeding from such wide affinities in the first parents, for two or three generations.

\section{DO NOT CHANGE THE BREED.}

It is presumed that the breeder of dairy cows has selected for his use, that race which, on a deliberate examination of his soil, climate, and locality, is the best adapted for his purposes. If, on 
full trial, he is not disappointed in his selection, that breed should not be changed, unless under the sure conviction that he can make a change for the better. The labor and experience of years, when successful, no thriving man can afford to throw away on a mere impulse, or venture; and only on a certainty that a change will be advantageous to his interests. If he be a dairyman himself, and a good one, he has probably established a character and reputation for his butter or cheese, which might be lessened either in price or quality by a change. If he breeds milk cows for sale, he has also acquired a reputation for them, which it is worth while to retain.

When a fresh bull becomes necessary, he should combine the same good qualities which have been cultivated in the herd, so as to continue the uniformity of character already established in it. The breeder should carefully look over the various points of his cows; see where they are deficient, and obtain his bull as perfect as possible in his own points, when a deficiency exists in his cows, that in their future produce by him, those faults may be corrected. The same rules in breeding grade animals to as near perfection as possible, are to be observed, as in breeding thorough breds. Recollect nature's unerring law is, "Like produces like;" and as the bull is to stamp his impress on the produce of many cows, it is necessary that he combine all the good qualities possible to be concentrated in him. Nor, when he possesses extraordinary good qualities, should a moderately high price in his purchase, over an ordinary one, be objected to. Pay the advanced price cheerfully, for it will be repaid ten-fold in his produce, perhaps the first year of his use. Good-looking animals of any kind will always sell for more than those of ordinary appearance. It costs no more to raise them than ugly ones, and as a rule, the more perfect the proportions of the animal, the less food it requires for subsistence. 
We say, do not change the breed, when it is once settled that your breed is the proper one for your purposes. Some men have an irresistible penchant for crossing different breeds on each other, in grade stock-as a Devon bull on grade Ayrshires; then a Short-horn, afterward on Alderney, and so on. Nothing but ntter disorder, uncertainty and disappointment, can be the result of such repeated bastardy. No truth in blood can descend from such mixtures, and no economical benefit can arise from them. Neither flesh nor milk can be promoted, for what is gained by one cross may be lost in the next.

Any one proposing, or expecting to breed good cattle at all, must have a definite object in view at the commencement, with whatever breed he uses, and it will be only by a persistent course of breeding up in the blood, that he can expect to succeed. For the dairy, select a good dairy breed, and persist in it. For beef, take the breed of a kind fitted for the soil and climate, and so keep on. A purchaser will always pay more for a uniform lot of steers or bullocks, than for a mixed one of all sorts of character, even if equally good in the individual animals themselves. And so with the purchasing dairyman. He wants his cows alike, if good. The upshot is, that with a parcel of mixed crosses of no definite character, they range but little above conmon stock, and always to the disadvantage of the breeder. Therefore, we again say, keep your stock as uniform in blood and appearance as possible.

AGE AT WHICH HEIFERS, FOR THE DAIRY, SHOULD BE BRED.

This will depend much on the manner in which they have been fed from calfhood, and the condition of flesh that they may be in. If they have been fed on good muscle-making food, with growth unstinted, they may safely be coupled with the bull at fifteen, to eighteen months of age; and if possible, to a small, rather than to a large bull, thus, in probability, producing a 
smaller foetus, and calf, than if bred to a large one, and drawing less on the foetal nourishment which the heifer is obliged to furnish.

The advantages of breeding thus early are:

1st. The milking faculties of the growing heifers are more easily stimulated into action than if neglected to twenty-seven months, or later, (bringing her calf at three years of age,) and thus apt to prove a better milker.

2d. She is inclined to be more docile, and easier handled, and managed.

3d. She arrives at her maturity of production for dairy purposes $a$ year earlier; and

4th. A year is gained in her profit.

These are decided advantages. Objections may be made that the strain from such early maturity may weaken ber system and constitution, and lessen her value in after life. This may be so when she has been stinted in food, and stunted in growth, but the objection has little weight when a thrifty and healthy growth has been given her. One of the finest thorough bred Short. horn cows we ever owned, brought her first calf at sixteen months old. We have had them, Devons, Herefords, Shorthorns, and common heifers, frequently calve at two years, and they grew to be among the best cows of their several kinds. It has been our habit for many years-and we still practice itfor dairy purposes, to breed our heifers at fifteen to seventeen months, so as to cast their first calves at two years to twenty; ; ix months of age; and we have found a decided advantage in it. They come in fine, thrifty young cows, in good condition, and prove excellent milkers, lasting as many years as if bred a season later. We have seen it practiced by others, and the great majority of evidence, under the circumstances we have named, is in favor of thus bringing them to early maturity, and consequent profit. 
The only drawback to this early breeding may be, and it prob. ably is the fact, that the first calf may not be so good for rearing as when the dam is at a maturer age; but the second calf will be equally as good as at any later age. The first calf of a dairy cow, may thus be profitably sacrificed, if it prove a weak one, to the increased profit of the cow herself. Yet, the first calf may not always be thus weakly or inferior. The calf before mentioned, of the sixteen months heifer-begotten accidentally, by a scrub highway bull breaking into the pasture, where she was running with her dam-being a female, was bred at two years old, and proved one of the best in quite a herd of dairy cows, which we for several years kept. In view, therefore, of all circumstances-the condition of good keep, and thrifty growth being attached-we recommend, decidedly, to let heifers bring their first calves at two years old.

Nor have we, in our practice, given extra food to these heifers. They were reared either by hand, as we have recommended in feeding stock calves, or with a part of the mother's milk only, until four months old, with the addition of plenty of good grass and hay in their proper seasons, and never fed with a morsel of grain, or meal, or roots, although they might possibly have been the better for it. But they had enough of what they did eat, and good care always, with warm shelter in the inclement seasons.

We admit that heifers thus early bred, do not attain their full growth so soon as if left to three years, before they bring their first calf. But good keep will carry them to it in a year or two, and at four or five years, little, if any, difference in size will be found between them.

Let us be distinctly understood. We only commend such early breeding to good, painstaking farmers and dairymen. Those who neglect, starve, and bang about their cattle, exposing them to all kinds of hardship, should never breed their heifers until three, possibly four years of age, and thus incur the penalty, 
sure to follow, in their neglect, of losing one or two years' use of their cows, and the insubordination sure to follow their own mismanagement, and want of good husbandry. There are circumstances, however, in the locality, and other conditions of even the good farmer and dairyman, when it may be policy to keep their heifers to three years, before bringing their first calves, and those we leave to their own proper judgment. It is, however, both possible, and profitable, to make the best of dairy cows from heifers casting their first calves at two years old.

\section{REARING AND TREATMENT OF BULLS.}

A bull intended for getting thorough bred, or grade stock, should be well fed from his birth, whether he be nursed at the udder, or the pail. There is no necessity for forcing his growth -he is rather the worse for it. His growth should be steady, and made on milk, a little oat, pea, or barley meal, and grass or hay, according to the season, for five or six months. If he be only intended for breeding grade, or stock cattle, six months on milk will answer; if for breeding thorough breds, seven, or even eight months is better. After weaning, his food should be suc culent and nourishing, not rich. We are aware that in thorough breeding, it is the disposition of many breeders to feed inordinately high, so as to make "show" calves of their young bulls. But the practice is not a good one for the future bull. $\Pi$ arrives at earlier maturity, it is true, but at the expense of lasting usefulness. A calf may be so forced as to make the size in one year, that he would make in eighteen months of moderate, yet good keeping; but it is to his future disadvantage, and quite unnecessary, as he should not be used, other than very sparingly -better not at all-at a less age than two years.

He should be tied up when but a day or two old, and as soon after, as convenient, learned to lead. He should also be learned to eat herbage as soon as he will take to it, say at a month, or 
six weeks. A strap head halter is the best fastening for him. At nine months, a ring should be put in his nose, and the way to do it is this: The ring should be of copper-steel, or iron will answer, but it corrodes more than copper. It should be two and one-half inches diameter inside. It should have a joint in its circle, about two inches in length, and when in place, fastened with a small screw, or rivet. When ready to insert, put a strong rope around the horns, and draw the head of the bull close to a post, by this halter, that he may not throw it about; then scize his nose, and with a small, sharp pointed instrumenta three cornered saw file, with the point sharpened, is the bestrun a hole quickly through the thin cartilige behind the nostril, which is there not more than a quarter of an inch thick; give the file a turn or two, then put in the ring, close it together, either screw, or rivet it, and the work is done. Little blood will follow the operation, and scarce any soreness. In a week when the soreness is healed, the leading snap, or strap may be put into it, and he can be led. Some herdsmen use only a rope, or leather halter for leading their bulls, and many of them are so gentle as to be so trusted; but our own rule has usually been to have a strong stick, six or seven feet long, with a link or two of chain, and a snap hook at the end, to hold him at arm's length in case he should be too playful, or possibly vicious. A young bull may be easily made vicious by improper treatment, and when once he becomes so, and knows his power, he is hard to be broken of it. Some are so from birth, naturally, but more are made vicious by inproper treatment.

As bulls are treated when young, will their usefulness longer, or shorter, be retained. A yearling, as we have observed, should scarcely ever be used, and nnly on extraordinary occasions, when a calf of his particular strain of blood is required, and cannot be obtained by a postponement of his services. At the age of two years, he may serve fifty to a hundred cows during the 
seascn, not exceeding eight or ten services a week. He should be kept stabled, or confined to a small yard or paddock, and well and regularly fed, with reasonable daily exercise, by leading out to walk, if stabled. If in a yard or paddock, he will exercise himself. At three years he may have full service, a hundred cows or more, without injury, and so on until he is a dozen years old, if his virility last so long, which it will usually do, if not early overworked. One perfect service of the bull to the cow is as efficient as more. His resources should not be lavishly expended.

Some men have a strange notion that after a bull arrives at the age of four or five years, he should be discarded. It is at the age of four or five only, that the quality of his stock can be proved. A very fine calf may turn out a poor thing at two or three years old, and an unpromising calf may prove a first-rate animal at the same age, as we have sometimes found; therefore it is only at the age of four or five years that the stock of the bull can be fairly tested. If it prove good, the longer he can be used, the better, provided his vigor and stamina be retained. Charles Colling's celebrated bull Favorite, (252, English Herd Book,) was calved in 1793 . In 1803 , when ten years old, he got Comet, (155, E. H. B.,) the famous 1,000 guinea bull; and the next year, when eleven years old, he got North Star, (458, E. H. B.,) another famous bull, both of them out of his own daughter from his own mother, (the cow was both daughter and sister to him,) and better cattle in their day did not existalthough here was cattle incest, and breeding in-and-in with a vengeance, such as would astonish most of the blood cattle breeders of the present day at such temerity! "Favorite" was, no doubt, an exception to the common short-horns of his time. He was a bull of wonderful stamina and vigor, and probably got more good stock than any bull of his generation. He also got the famous "Durham Ox," and "The white heifer that trav- 
elled." (In frontispieces, Vols. 5 and 6, American Short-horn Herd Book.) He was useful ten years, beginning his service at two years, and during that time, Colling seldom used any other bull in his large herd of thorough bred cows. The bull Marske, $(418$, E. H. B.,) a famous animal, bred by Robert Colling, and many years used by him, died at the age of fifteen years, and was nseful for thirteen years. These, and others which might be named, are examples which our breeders of blood cattle may well look to-provided they do so with proper discrimination-and profit by it.

When a bull evidently loses his vigor, and conception by him becomes uncertain, he should be put aside, as his uncertainty may adhere to his coming stock-a fault always to be avoided. We believe that more bulls are spoiled by forced feeding, and over-service when too young, than in any other way; and when one is possessed of a bull of really choice blood, a careful husbanding of his use should be looked to by his keeper.

The bull should always be kept on substantial, nutritious food; never suffered to become poor, nor fat, but always in good working order. $\mathrm{He}$ is a surer sire in such condition, than when pampered and over-fed. When little, or not at all used, his food may be slackened to simple grass, hay, or cut feed, with a little grain meal mixed. When much used, his food should be increased, and of better quality. Oat or barley meal produces more muscular flesh, and seminal and muscular vigor, than the fatty, sugary meal of corn; and muscular and seminal vigor is greatly serviceable in procreation. Sugar-producing food, in breeding animals of either sex, may be hurtful, as demonstrated in the previous remarks quoted from Professor Tanner, and Mr. Stewart, on barrenness.

The quantities of extra food to be giren to a bull in the season of service to cows, cannott here be particularly stated. It will depend much on the size of the bull, and the extent of service 
required of him. The observation of his keeper must regulate the quantity. The feed should be regular, at each meal, and given three times a day. No positive rules for the hours of feeding can be laid down, and the discretion of those who have charge of the animal, must mainly govern. When in service, if confined in a stable, a moderate amount of exercise by walking, should be given him daily. It not only adds to his activity, but stimulates his virility, and better insures the certainty of his procreation.

Grooming with the curry comb, or card and brush, and frequent washing with water, and occasionally the use of soap, is as necessary to a choice bull as to a stallion. A clean skin, and lithe limbs, promoting good action, are a decided advantage to him-not altogether for like purposes as in the horse, to show his paces. The bull should have a majestic walk, and be quick and rigorous in movement. So treated, his calves cannot but be the better for it. A dirty, dandruffed bull, unkempt, and slovenly in appearance, always shows to disadvantage, and any breeder having a just pride in his cattle, will bestow equal pains in keeping his bull in the best condition of appearance, as he who prides himself in owning an "Ethan Allen," or a "Lexington" horse. 


\section{CHAPTER XXII.}

REARING STOCK CALVES-THEIR TREATMENT.

THE method of rearing calves depends much on the future use to be made of them. On this subject, breeders and writers hold different opinions, and each may be correct, according to circumstances.

The best time for calves to be dropped, which are intended for rearing, is in the spring of the year. Nature has taught us that, and all experience is in its favor.

As observed in a previous chapter, the calf should, at its first meal, and as soon after birth as inclined, suck its dam. This is indispensable to its health, in enabling it to discharge the foetal nutriment remaining in its stomach and bowels, and give it strength for future action. Even when it is intended to bring it up by hand, in feeding from the pail, three or four meals from the udder are all the better, and it will as readily take the finger for feeding then, as immediately after its first meal. When the calf is of no value, and milk only is the object, two or three days are enough for it to live, until the milk be thoroughly fit for use. If the cow's udder be diseased by inflammation, or otherwise, it may be necessary to retain the calf a few days longer, to draw the milk and soften it, for no draft upon the udder is so natural and soothing as that of the calf.

\section{REARING BY HAND.}

The very first thing to be done with a calf, after he has drawn his first few meals, is to put a rope, or strap around his neck, and tie him to a fastening, with three or four feet play to his 
rope, to let him know he has a master. He will not soon forget it, if so kept for a few days. The rearing is done in various ways, according to the necessities of the keeper of the cow, and the use which is to be made of the milk. The interest of the dairyman is apt to give the calf as little food in new milk as possible; but for the benefit of the calf it should have undiluted milk for a week or ten days, at the shortest. After that time, the new milk may be slackened, and skimmed milk added. Flax seed, boiled for hours, into a jelly, may be mixed with it, slightly at first, and in a few days, to the extent of one-half this foud may be given; or, in its place, fine boiled Indian, oat, or barley meal gruel, mixed with the milk, may be substituted.

But, the calf should always have enough to satisfy its hunger, and fed regularly, as to time, twice a day, at morning and evening. If not at a time to turn to grass, and kept in a stable, a wisp of fine sweet hay should be tied in a cord, and suspended against the wall, or loosely laid in a manger, where it can nibble it. The hay will amuse the calf, at the least, and it soon learns to love it, aside from adding much to its nourishment. As soon as the grass is ready, it should be turned into a small paddock to range at will. If running water be not at hand, it should be provided in a tub, or trough, that constant access may be had to it-for your calf is a great drinker, aside from its ordinary meals of milk, or gruel. This process of feeding should be continued during quite four months, or longer, according to the purpose for which it is to be reared, with a little salt, either in its food, or placed in a trough, as often as once a week, to keep its bowels regular, and promote its general health. In a dairy, whey may take the place of skimmed milk, and where whey is not made, and skimmed milk is scarce, after the first six weeks, flax seed jelly, or gruel porridge, may be used altogether. Other substitutes may take its place, but nothing is so natural food for the calf as milk. 
We have raised stock calves in different ways, but in none so satisfactory as on their mother's milk, drawn by themselves. It is more expensive, where the milk is of considerable value, we admit, but less troublesome to the farmer. Our way is to let the calf take-according to its necessities, and the quantity the cow gives-one, two, or three teats-first drawing clean what can be spared to the dairy, from the teats so milked, and then letting the calves take the residue. We are satisfied that one-third less milk drawn by the calf from the cow, will give as much nourishment as the full quantity fed him by hand. The saliva secreted in the process of sucking is beneficial in aiding the digestion, such being the natural process. Cows that are good milkers will thus rear a stock calf, to three or four months old, on onehalf or one-third of their milk, and when the increased value of the heifer calves for future dairy cows is considered, the value of the milk they take for three or four months may be a good investment in them. For convenience, two calves may be nursed by one cow, which is often preferred, as by such method the remain. ing cows may be devoted altogether to dairy use.

After four months, the calf, if intended only for stock, or dairy purposes, may be turned out to pasture without further hand feeding, or nursing at the cow. The grass should be good, with water always at hand. In this way the calf will be in good condition for going into winter quarters. Then, with enough good, soft hay, or corn blades, salt once a week, and plenty of good water, it will go through the winter well, and come out a thrifty, sprightly yearling at the next grass. Oats in the grain, or corn, pea, rye, buckwheat, or barley meal, at the rate of a pint, or quart a day, in addition to their ordinary forage, is an excellent food for stock calves, and will add to their growth and condition; but if the hay, or corn blades be ohoice in quality, they will go through well without grain. We have thus reared, and seen reared by others, very fine thorough bred calves to yearlings, minding only, to give them all they would eat. 
In the extracts which we have previously given in the chapters on the Galloway and Ayrshire breeds of cattle, will be found valuable information in rearing stock calves, to which we refer the reader. It may be thought superfluous to have introduced it; but on so important a subject, none too much information can be suggested.

\section{CALVES FOR YEAL,}

Should have all the milk, direct from the cow, that they will take, until four to six weeks old, with corn meal added, if they will take it. No artificial feeding will make them so fit for that purpose as their mother's milk, drawn by themselves; and it may be added, that no veal made otherwise is worth eating. Veal calves should be confined to a small space, with clean bedding, and pure air. Otherwise, their flesh may be tainted with the effluvia of foul stables.

\section{CALVES RUNNING WITH THE COWS.}

This, at the best, is both a loose, and a bad practice. We are aware that in many localities, where land is of low value, the milk of little account, and labor dear, many farmers let their calves run at large with the cows through the season. As calves, they are the better for it, no doubt; but as yearlings, and afterwards, they are but little better than when well reared by hand, and not so good as when kept separate from the cow, and suckled at regular hours. They never should run loose with the cow, for various reasons:

1st. It is a practice of neglect on the part of the breeder, which should not be tolerated. The cow brings her calf when lying out in the field, and may, possibly, suffer much in parturition, when a little aid would make everything easy and comfortable for her. If her udder be full, and she give more milk than the calf may need at first, which is almost always the case, one or more of the teats will be neglected by it. These teats become 
inflamed, and hard, and as the calf has no judgment in the matter, he will not touch it, and as a consequence, after causing the cow infinite pain, the quarter of the udder affected soon dries up, and is from that time lost, not again, even at a future time of calving, to be restored. We have seen very fine cows subjected to such practice, with only one or two teats left, and poor nurses they must be, as the quarters of the udder still left in milk, give only their proportionate quantity to the whole when in full action.

2 d. The cow grows wild, and refractory, not becoming so tractable after running with the calf through the season.

3d. From constant sucking, the udder cannot be distended by its full secretions of milk, and it becomes contracted by habit, seldom giving so much milk afterwards as when drawn but twice a day.

4th. The calf grows up wild and unmanageable. If a steer, intended for grazing, it is of less moment; but if a heifer, intended for the dairy, she is much harder to manage and break in than if subjected to early handling.

5th. The calf grows up coarse, and heavy necked, and is never so fine as when brought up separate from the cow. In short, we have not a word to say in favor of the practice, only in those great cattle ranges, where, from various circumstances it is impossible to keep them within bounds, and the breeds are such, that no neglect, or bad management, can make them worse.

\section{HANDLING YOUNG ANIMALS-SHELTER.}

The advantages of bringing up young stock tame, and manageable, are, that they feed better than when running wild; they learn the call of their keeper; they are fearless.of his presence, and seek his companionship with confidence. No cattle breeder knows into what hands his young stock may fall, and to the buyer of them it may make a difference of some dollars in the value of 
a heifer, or steer, whether they be easy to handle, or otherwise, according to the use he may make of them. We have at different times bought both steers and heifers at the West-one for the yoke, or beef, the other to make dairy cows. They were treated in the common way of many Western breeders, always running out in winter, as well as in summer, and the labor of breaking them into the stables after taking them home, aside from the risk of injury, was a heavy tax on both time and patience. Some would be intractable altogether, and have to be turned out for beef before their profitable time, while others, after a few days' tying up, would become gentle, and give no further trouble. We know that in large breeding herds, and under all circumstances, it is not possible to always bring young cattle up to familiar handling, from the want of stables, or sheds; but every breeder should have some accommodation of the kind. It will pay him a better interest on the investment, for the benefit of his stock, than any other expenditure, to a moderate amount, after the farm is fitted for occupation. The practice so common with many farmers, of giving no winter shelter to their stock, is a losing one in food, as well as by their exposure to the sudden change of the atmosphere and weather. Such practice should be reformed.

\section{REARING THOROUGH BRED HEIFERS.}

When intended for breeding only, and early maturity and ready sales are the object, all the milk from the cow should be given, and the calf may draw it either from the udder, or pail. She should be confined in her stall, or paddock, kept under perfect control with the halter, and in addition to milk, fed with all the hay or grass-according to the season-she will eat. She may nurse her dam, or be fed milk from the pail through the entire season, if necessary; but six to eight months are enough, so that she have a sufficiency of other good food, and the succeeding calf will be all the better for the long rest of her dam. 
It has been, and is still, a matter of discussion with breeders, as to what extent the growth of a heifer calf should be forced, to attain her best estate, as a breeder, and to promote improvement in her kind. So far as we can learn, Bakewell was a generous feeder of his young stock, and forced them by such means to early maturity, and increased ripeness in their points. So too, but hardly in so great degree, were the Collings, and the Booths. Bates, perhaps an equal improver with any other breeders of his later day, fed well, but not so lavishly as they. But all good breeders, of whom we have any particular account, fed their stock freely. Almost all the imported cattle which we have seen -bulls, cows, heifers, and calves alike, came over, in very high condition-in most cases, "stall fed." Whether they were so fed at home to better fill the eye of the purchaser there, or for sale after landing here, or because the whole stock of their breeders were usually so kept at home, we do not know; but it is certain that heifers so forced from calf-hood do not usually prove so sure breeders, as when only well fed, without the forcing process. No doubt high feeding produces earlier maturity in the young heifer than low keep will do; and, it is possible that the high feeding of heifers up to their breeding age may have a marked effect on the fleshy propensities of their offspring. But the process is not a natural one, and it should be managed with great caution.

Where competition actively exists for sale breeding, the tendency for high feeding is almost irrepressible. The merits of young animals are too often decided on the show grounds of the annual cattle exhibitions in favor of the highest fed ones, and in the beef producing breeds the practice may not be objectionable. But for milking purposes it should never be done, as the milking tendency may be held in abeyance by over fatness, and it should not be prematurely stimulated for the welfare and long usefulness of the future cow. Breeders usually pursue that course 
which is most for their own immediate interest, and probably, if we were to write a volume on the subject contrary to that interest, their practice would not be changed. The theory, and the direction, at most of our American cattle exhibitions, are, that the condition in flesh, of the animals placed in competition for prizes, is not to be considered by the judges in awarding their premiums; but the result of the awards has in most cases been, that the high fed ones get the prizes, and the leaner ones do not. Much flesh, like charity, sometimes covers a multitude of sins, in the anatomy wrapped within it. Hence, the tendency is to high feeding with all who wish to make sales-as almost every breeder does-and in all public sales of cattle that we ever witnessed, the fat breeding cows outsold the lean, even when of inferior anatomical excellence. The eye will, in a majority of cases with men, as they run, take precedence of the judgment, and so long as the popular feeling tends that way, breeders will take that course which gives them the most ready money. Still, the fact remains, that the forced feeding of young heifers is a hurtful practice, in the long run.

\section{INFLUENCING THE SEX OF CALVES.}

We have, at different times, seen sundry papers, mostly by fanciful writers, directing the way to produce different sexes, at will, by the treatment of the cow, or bull, at the time of procreation; but we confess, without convincing us of any truth in the methods prescribed. The most ingenious of these various processes, and of course, the most painstaking, are given by French or Swiss writers. We do not repeat them, for the simple reason that we have no faith in them. The English breeders appear to have little, if any, confidence in such artificial efforts, considering them, as most sensible people do, abortive. "Male and female created He them," is the great law of production, and in about equal proportions in all animated nature, so far as history and experience has proved; and all man's ingenuity to the con- 
trary has been ineffective. Our own credulity has been exercised in various trials of the kind, only to convince us of the folly of pursuing them, and on comparing notes with experienced breeders, who have also tried various methods, our conclusions have been alike. In some years, to be sure, we have had a preponderance of one sex, in calves, over the other; in another year it would be reversed; but on an average of several years, the sexes were about equal, yet differing in proportion, within the same neighborhoods. There may have been peculiar hidden influences to control the result in a given herd, of one year beyond another; but as no human observation has yet arrived at a certainty in its solution, we may more wisely let it alone, and be content with what nature gives us, being careful, by our own attention, that it be as good as possible, of its kind. 


\section{CHAPTER XXIII.}

BEEF CATTLE. DIFFERENCES IN BREED-REGULARITY OF CONDITION-PROPER AGES FOR FATTENING-MODES OF FEEDING -SHAPE OF FAT CATTLE.

THe rearing of cattle for beef only, is purely an economical question, and the profit or loss in rearing and feeding them, depends, in a measure, on the breed of the animal, and the locality where they are reared and fed.

We have already shown the money value of the beef product of the country. We have discussed the different breeds best adapted to make it, and to a wise selection from them, both the breeder, and the grazier must look, measurably, for the profit they are to receive in their production and feeding. It costs the breeder no more to breed a good calf than a poor one. It costs the grazier no more to feed a good steer or heifer than a poor one. It costs the stall-feeder no more to fat a good, than a poor one-all owing to the superior fitness of the animal for the purpose. Some cattle are so anatomically formed as to make it impossible for them to take on flesh in the right places, or even to take much flesh at all. It is therefore of the highest consequence, that only the right kinds be used for that purpose. Some animals will only mature their carcasses into good beef at five, six, or more years old, while others will be well matured at three to four, or in spayed heifers, at two years. The first of these, as slow feeders, are unprofitable to all who touch them; the others are profitable at every age, from calfhood to slaughter.

If, in light of all the observation and experience we have on 
this subject, men will raise poor cattle, they must suffer the consequences. No good grazier or stall-feeder ought to touch them. Little money is to be made out of them, at almost any price.

Cattle intended for beef only, as for other purposes, should always be well fed, and kept growing. Full pasture during the grazing season, and plenty of hay, or corn forage in winter, with straw, more or less, to lie upon, with salt every week or ten days, throughout the year, up to two years and a half old, they should have. According to their ripeness for feeding off, the third winter they may be fed some grain. At three full years old, they should have the best pasturage, that they may get fat on grass, as that is the cheapest possible way to put on flesh. The next winter and spring, when coming four years old, any animal intended for beef ought to be fit for slaughter, and if of the proper breed, or a good grade of that breed, it will be.

We maintain that where cattle pasture and winter forage is of any value, no neat animal, for beef alone, can be profitably kept after four years old-from three to four years of age being the maximum of time which should be allowed for feeding; up to slaughter. No animal, unless it be a milk cow, or a working ox, can pay for keeping, unless for some extraordinary purpose, a longer time. It has been conclusively proved that cattle of good breeds acquire their full profitable ripeness, at three and a half, to four years of age. Such bullocks, of the Short-horn or Hereford breeds, or high grades of those breeds, well kept as store cattle, and fed off on grain during their last autumn and winter, will easily attain 1,600 to 1,800 , or even 2,000 pounds, live weight, and the Devons and other good lighter breeds, 1,300 to 1,500 pounds, and spayed heifers in proportionate weight, with somewhat earlier maturity. They can be kept profitably up to those ages and weights; but unless for "show" purposes, or to develop some extraordinary point or characteristic, their further keeping must result in a loss, comparatively, for the food consumed, and the flesh they will lay on. 
Steers of common, or inferior breeds, which will not be well covered with flesh at the ages, and under the circumstances of those above named, are scarcely worth breeding and rearing at all, where good beef is in question, and fair profits in the business are considered. The modes of feeding, the materials on which they are fed, and their values, vary so much in different sections of the country where the cattle are prepared for market, that no directions can be given to govern all circum. stances alike. In the Eastern and Middle States, where land is dear, and forage of most kinds proportionately so, all the food given to fattening cattle, should be prepared in the best manner for ready assimilation to nourishment, when it goes into the stomach. Grain should be ground into meal-no corn-cobs in it, for cob meal is no better than sawdust-hay should be cut into chaff, and moistened, and with a due proportion of meal, mixed together for easy mastication, with warm shelter for stall-feeding during the winter, thus saving at least twenty-five to thirty per cent. in food, to make a given quantity of flesh, over feeding unground grain, or uncut hay. If roots be fed, they should be cut also. The policy of cooking the food for cattle, by steaming, is discussed elsewhere. It is a question for trial, and its economy must depend on circumstances touching the price of fuel, the value of labor, and other circumstances; but as food, cooked and warm, is made easier to the digestive powers of the stomach, there is no doubt that a less quantity will make more flesh, than when uncooked. That ground grain, and cut hay, will make more flesh than if not so prepared, has been too thoroughly tried to admit of a question. The item of expense in so preparing it must determine its policy.

With the mass of Western feeders, where land is compara. tively low, labor dear, artificial sheltor does not abonnd, and mills are scarce, the case is different. Corn fed from the shock, where the stalks and blades supply the place of hay, as is almost uni- 
versally the custom below the latitude of $40^{\circ}$ north, may be more economical. Time and trial must solve these questions. But as railways penetrate the country, making corn more valuable to the producer, as he is in greater or less proximity to them, the different modes of feeding will be worthy of consideration.

Let us examine this important matter of fattening off, or stallfeeding, a little more minutely, as to its economy. A few years ago, we met a gathering of graziers and breeders in a Western cattle growing State bordering the Ohio river, when the subject of breeding, grazing, and feeding beef cattle, came under discussion. They were among the most intelligent, thrifty, and wealthy of that class of farmers who deal largely in neat stock, and feed them for market. We asked the question: "How much corn, fed from the shock, in the usual way of out-door field-feeding, does it take to carry a three to four year old Short-horn grade bullock, (as those, in that region, are admitted to be the most profitable,) from the fall of the year, when corn is needed, to fit him for market at any time from February to April?" A half-dozen replies were made to the question, not from any actual measurement that they had ever made-for the inquiry appeared to be a new one, in their great abundance of corn forage, which they had not always been in habit of closely saving-but only of estimate. One replied, "about fifty bushels;" another, "sixty;" another, "seventy-five;" another, "perhaps eighty," and so on up to, "at the very most, a hundred." Another "estimated" that "an acre of good corn, taking it as it run, would usually feed off a bullock well."

Not one of these graziers, and feeders, although they had been in the business many years, and some of them made large sums of money in it, had even gone into nice estimates, and probably for reasons which they could not well control. In the first place, they had corn enough, and the cattle must be fatted, let the quantity consumed by them be what it might. A better reason, we 
think, for the difference in estimate, was the inequality of the seasons and weather during the feeding time; as, if the winter were colder, or warmer, and the cattle being unsheltered, the amount of food consumed would depend much upon the severity, or mildness, of the weather, and the storms to which they were subjected, the cattle eating much more, and taking less flesh in cold, and eating less, while making more flesh in mild weather. Thus, we can readily conceive, that in a mild season fifty bushels of grain would give as much flesh as a hundred would in a very severe one. That is a fact so palpable, that no one, of any experience in the business, will dispute it.

STALL-FEEDING.

Now, if those cattle were properly housed, and kept dry under an equable temperature, their hay, or corn fodder cut, and their corn ground, the food would be consumed in nearly uniform rations, and the feeder could know, nearly to a certainty, about how much his bullocks would cost per head to fatten them. The scales, and measures, would decide the matter. Nor need the labor question here interfere against the latter method. With a good horse power-not an expensive one-a good straw cutter, (both costing not to exceed two, or three hundred dollars,) and a horse of the cheapest kind to propel them, two men will cut and mix, for feeding, two tons of food every day. We have seen it done when every thing was handy for the work; and the forage at hand.

The process of feeding beef cattle in this way, is quite simple. The stalls being properly prepared, the bullocks, even if they never before went into a stable, and wild in habit, once being inside and finding good fodder, will soon eagerly return, take their proper places, and submit to be tied by the rope, or chain, or put their heads through stanchels. At the first few feedings, the quantity of grain, or meal, should be moderate, but daily increasing until the stomach will dispose of all that may be necessary 
to crowd the flesh on to them in the shortest time. They should not be over fed, nor ever given more than they can clean up at a meal. By giving every beast his accustomed place, or stall, the feeder soon learns to gauge the quantity he usually eats; or, if they take their places promiscuously, the feeder must watch, and see that each one have his proper allowance, for this is not. a business to be neglected by simply throwing the feed carelessly into the mangers, and then leaving the cattle to themselves without further care, as though his work was completed. The eye of the feeder must be upon his stock continually.

Finely cut hay, or corn stalks, (above the ear,) through the cutting box, with fine ground Indian corn, barley, rye, buckwheat, pea, or oat meal, or oil cake, measured by weight, not bulk, well mixed, with plenty of water sprinkled equally through it, is the very best way possible to put flesh on to any ruminating animal. The cut fodder should be so proportioned as to fill the stomach, and meal enough mixed with it to give all the nourishment required in the way of fattening. These proportions may have to be changed, somewhat, according as the weather may be mild, or frosty, less grain being required in soft, and more in severe day"s. If the cold affects the temperature of the stables adversely, the animal heat must be kept up by a greater quantity of food than would be needed when the temperature is milder. All this must be a matter of close observation with the feeder.

Now, if this food could go into the stomach of the animal at blood heat-and here comes in the additional advantage of cooking it-so much of animal heat as has to be expended in warm. ing that otherwise cold food after entering the stomach, would be saved to go into flesh, for the animal heat has to be created by this food, and is therefore expended in producing it, and cannot, to such heat creating extent, of course, make fat, or flesh. So, also, would be saved the amount of food expended in producing the muscular strength and work of the jaws in grinding, for 
this power has to be furnished from some source, and we hold that the power so produced in the internal system of the animal itself, is the dearest possible way of making it. Cooking, or warming the food, is, therefore, a great economy, much more, we consider, than its additional expense. We shall examine this subject hereafter.

Cattle thus stall-fed, should only leave their stables for water, and a little exercise. An hour in a day, altogether, is quite enough for both, at either once, or twice, as they may need it. With their food well moistened, water once a day may be enough, or twice, at the extent. They should have all the rest they need, and if kept clean, as they should be, and well bedded with straw, or other litter, which is better than on a bare floor, they will lie down most of the time when not feeding, and take on flesh much faster. Such, we esteem, the perfection of the stock-feeding process.

In opposition to this expensive process, as many Western graziers may consider it, they contend that, by feeding corn in the ear to cattle, and letting swine follow them in the fields, all the grain is consumed. What passes the cattle wholly, or in part, unmasticated, as a considerable portion of it does, is taken by the swine, swelled and partially cooked, and better prepared for them. We admit the fact, but it is a dirty and slovenly way of swine feeding, and the flesh they thus take on is of an inferior quality. 'Besides this, the jaws of the cattle must be the grinding mill for the grain, and their stomachs the cooking cauldron for the process; and a more expensive method for either cannot well be imagined. The muscular power for grinding, and the heat for cooking, must both be supplied by extraordinary quantity of grain fed to them. We fully admit the manual labor saving in this more primitive process over the other, but contend, also, that the greater economy in the saving of food, is much more than a compensation, and a larger profit is left to the stock owner by the improved process. 
To the objection of the absence of mills for grinding the grain, the husking and shelling the corn, the bagging and drawing to mill and back, the toll for grinding, cutting the hay, stalks for straw, and other expenses, we place on the other side, full onethird gain in the quantity of forage and grain expended, a much shorter time in fitting the cattle for market, and the additional quality of the manure made. Taken all together, we are satisfied the balance sheet will tell in favor of the improved method. If grain mills are now scarce in the feeding districts, a demand for grinding will soon supply them, propelled either by water, or steam, and like all other wants in these days of machinery, they will be soon supplied.

A word or two more in relation to manure, the economy of which is often overlooked or neglected. It is valuable on almost any land. We care not how rich the land, in its virgin state, may be. The manure will help it, on all uplands. We never saw land too rich for growing Indian corn, or grass. Stable manure, or manure made under sheds, is of better quality than manure dropped from cattle promiscuously in the field. It can be put where it is wanted. That which is dropped in the fields by the cattle, must, of necessity, lie unevenly on the surface, and be used where dropped, and the labor of hauling it from the sheds, or stables, is amply compensated in the uniformity of its distribution, over that which is accidentally deposited by the cattle as they roam over the fields. Those who have practiced the loose way of ordinary cultivation, may not so estimate the fact, but a trial will soon sottle it. Thousands of acres of lean uplands may, every year, be seen giving only twenty to thirty bushels of corn, or a ton, or less of hay to the acre, while a river bottom, or a small enriched "home lot," will give twice, or thrice, the quantity of both; and the same lean uplands, by the application of those so saved manures, may be made to yield just us well, from the advantages of the improved modes of feeding. 
Another item which may be taken into account, as to the manner of fceding, is the number of cattle which the grazier or stall-feeder has on hand. It takes but little more labor to feed fifty cattle than ten, or in like proportions of number. In the way of transportation, it costs little more to carry a fat beast to market than it does a lean one. They mostly go by rail. They are charged by the car load, and a given number of pounds is allotted to the car; so, according to the price he brings, the lean bullock costs more to carry than the fat one, as he has as much length and breadth of bone, if less flesh, and takes nearly as much room as the fat one, while his selling value may not be more than half, or two-thirds as much; and this, in a transportation of a thousand miles or more, is a considerable sum in the aggregate. The drover is paying a huge price for transporting bone, horn, hoof, and paunch, for no good whatever, for they are all waste, and when in market his stock is "blown" upon by every buyer he meets, and at the best they go off at low prices. We have seen hundreds of car loads of what are called, in the Eastern markets, "Durham Steers"-grown in all the States where Short-horns, or any other choice breeds, in their high grades are kept, and well fed-which cost not over five to ten dollars a head more in their transportation, than the poorest scrub. Such cattle sell readily, at good prices, in almost any state of the market, while the ragged ones wait, perhaps some days for a buyer, and then at two, three or four cents lower, in every pound of estimated weight.

\section{SHAPE OF A FAT NEAT ANIMAL.}

The proper shape of a fat ox or cow of a good breed, when the head, neck, and legs are cut off, should be nearly an oblong square, and the nearer they approach that shape, the more perfect they are. A square anatomy gives a broad space for the lungs and the viscera, and room for the deposit of inside fat. 
Thus constructed, the animal feeds profitably, and dies wellsatisfactory alike to both feeder and butcher.

We illustrate our point, in giving four cuts, representing the back, front, rear, and side views of a fat ox. They are no exaggeration of one fed up to his greatest capacity, although the profit of such extreme feeding, beyond that to produce "firstclass" beef, may be questioned. The quality of such highly fattened flesh, is less savory than when only well fatted.
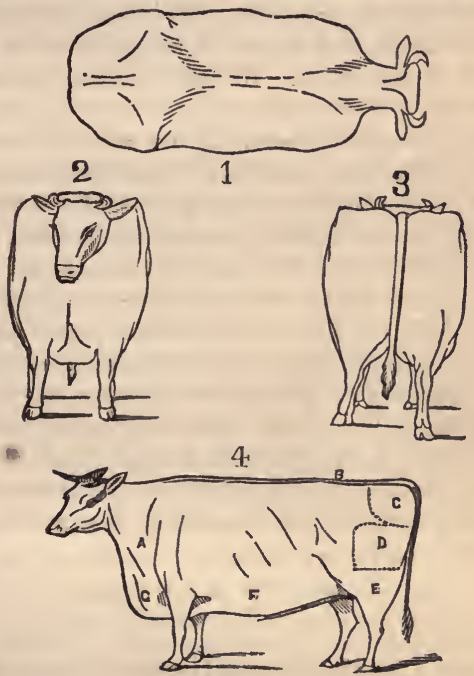

Plate 28.

In this ox, every part of the meat, throwing out the hide, tallow, and bone, of course, is good, consumable flesh. There are the best of steaks, roasts, corning pieces; and the least valuable 
parts, which would be nearly worthless in a lean ox, are good for drying. When dressed, there is really no loss in the carcass, except bone. In Fig. $4, \mathrm{D}$ and $\mathrm{C}$, the (brisket and round,) make the finest mess beef, and in large quantity. The loin, at $\mathrm{B}$, and following up the back to the shoulder, being broad and full, gives the best of steaks, and roasts. The "plates," at F, are full and thick, and give excellent corning and packing pieces; while the shoulder points, or neck vein, at $\mathrm{A}$, and the thigh, at $\mathrm{E}$, make good pieces for drying or smoking. It is easy to see, therefore, that such an animal turns all the extra food given to him, into profitable flesh and tallow. He has no more bone, and little more hide, than if he were lean.

The economy of good feeding is too palpable for extended observation. We have stood in the extensive sale cattle yards of Buffalo, the past winter and spring-1866-7-in the midst of two thousand or more bullocks, and seen hundreds of first quality high grade "Durham Steers," three to four years old, reared in Ohio, Kentucky, and other Western States, go off briskly, from drover to dealer, at nine to eleven cents a pound, live weight, while the great majority of inferior things hung back, and went off slowly at four and a half cents for the worst, and so on up to five, six, seven, and eight, for "poor," "middling," and "fair."

Two items only, made this wide difference-breed, and feeding. Some were so execrably bad, in shape and inferiority of breed, that no amount of good feed would make them profitable to the breeder, grazier, or feeder; the others were so good in breed and flesh, that they were profitable in every hand through which they passed, from calf hood to the butcher's block.

\section{CATTLE OF THE LONDON (ENGLISH) MARKETS.}

To show the comparative condition of our American beef cat. tle with those of England, we give an extract from a letter just received from our brother, Mr. A. B. Allen, of New York, 
written from Liverpool, in September, 1867, soon after he had visited the great London cattle market. It may interest our American cattle breeders:

"The great cattle market of London, some twelve years ago was removed from Smithfield to Islington, formerly a distinct village from London. It is now incorporated with it, the streets thither and beyond, and all around, being solidly built up since I was there in 1841, when they were only partially built. I have visited the market twice. Monday is the great market day of the week, and it begins at $6 \mathrm{~A}$. M. I was there a little before this hour, and found the yards full-6,280 cattle on the ground, besides calves, sheep, and swine. It is the most complete thing you can imagine. It was opened in June, 1855, by Prince Albert, with a great public display. It cost $£ 440,000$-over two millions of dollars! Fifteen acres are.enclosed in a square, which will hold 7,600 bullocks; 40,000 sheep; 1,400 calves, and 900 pigs. In the center of this is a high clock tower; at its base, attached to it, are banking houses, telegraph offices, rooms for the officers of the market, clerks, \&c. Around this square are streets with hotels, yards, solid, handsome sheds, and eight slaughter houses. All these belong to the market, and the whole occupy thirty acres. It is about two miles in a direct line north of St. Paul's Cathedral, but the streets wind about so much, I think one travels at least three miles from this point to get there. The old Smithfield market was only about half a mile north of St. Paul's.

"At Smithfield, in 1841, all the cattle there were nativesnow not over one-fourth to one-third are natives. Denmark, (mostly Jutland,) alone furnishes about one-sixth; Holland, France, and other countries many; so it was no great place after all to fully judge about British cattle, only by comparison with others. The foreign mostly, except the Dutch, were coarse, rawboned, paunchy, and deficient in valuable points, (like our old 
natives,) to the British. The black and white Dutch had short legs, tolerable heary carcasses, and moderately good points. I saw very few, perhaps none at all, of pure short-horns-for I presume the full bred males are too valuable to make into steers, except a very few for the Smithfield fat cattle club show, annually, in December. But among the British cattle, on that Mon. day I was at the yard, short-horn grades predominated in number and good beef points, to all others, and to my surprise, the butchers informed me that they ranked in general quality as high as thorough bred Herefords and Devons. The Scotch Highlanders still rank highest, the well bred Scotch black polled, or Galloway, next, then come grade short-horns, Herefords and Devons-pretty much all others go in one general mass with foreign, except the Dutch. Some butchers might have other fancies, and rank Herefords or Devons before shorthorn grades, but this was the general answer, so far as my enquiries extended. When in Smithficld, in 1841, Devons ranked next to the Scotch, then Herefords, then grade shorthorns, but these latter were fewer at that time in the country, and coarser, and not so high graded as now, which, I suppose, makes the difference. The Herefords, and Devons, lack in fullness between the hip.bones to the end of the rump. They are often low and thin in that valuable point, in comparison with the short-horns, and you cannot get so good rump pieces from them as from the short-horns, and this for corned beef is one of the most valuable parts of the carcass. These breeds, also, arc deficient to the short-horns in breadth of loin; I mean across the hip-bones; also in the brisket, which is a valuable point. The Devons had a little the advantage of the short-horn grades in the crops-the Herefords are about equal in these parts to them.

"In fact, I found the short-horns better here than I expected. Then they handle so well, look so fine, and ripe, and mellow to the eye, that I cannot compare any other beast to them. I may 
be prejudiced in their favor-perhaps I am-but the oftener I look at them, and the more minutely I compare them with other breeds of cattle, the better I like them.*

"The Highlander is so small I do not take him into view in this comparison. His live weight, I should think, is from 700 to 900 pounds, as the extremes of steers brought to market. The best of them are as near perfection of form as you can imagineexactly like a small, well bred south-down sheep, in comparison to other sheep. The heads and horns are fine, eyes bright and prominent, face dished, and small muzzles, with large nostrilsbetter in the crops than any other animal, being as full and round as the very best of others over the shoulders, and preserving this fullness and roundness much further on each side of the back-bone towards the hips. I wish I had had time to see one cut up by a butcher-as I had not-as he must carry an extra nice, lean, tender, juicy piece along the back. The brisket is equal to the best short-horns, for their size, and they are as well let down in the twist as the best south-down sheep. The hair is soft and long, so you may judge what a nice little beast he isin fact, to other cattle, what an Arabian is to other horses. You cannot improve him by a short-horn cross. Select the best and improve them by themselves, is the true way. As to the colors of the different herds of Highlands I saw, I should think twothirds were black; most of the others a light yellow, slightly inclined to dun, or light mouse color. I prefer the yellow, and have no doubt but they handle best; at any rate, they are the handsomest to my eye, and with continued selection, might be soon bred of that color almost entirely.

"Of the polled Scotch black-Galloway or Angus-the best do not weigh more than about two hundred pounds over the

* Ever since he knew them, Mr. A. has been an enthusiastic admirer of the shorthorns,-L. F. A. 
Highlanders, as I judge, and they approach them in perfection of form.

"The short-horn crosses were the most numerous of British cattle the Monday I was there; Herefords were next, then Devons, one of which was very perfect, except in the twist, (and that was a good point with him,) almost as much so as the Highlanders. They stood near together, and I had, therefore, a good opportunity to compare them. Of the polled, and High. landers, only a few were present. The rest were made up with some good South Devons, or Suffolks, and various colored beasts, not worth particularizing. The Smithfield club show, I fancy, is now the only true one to fairly judge of English and Scotch cattle. They are then all brought together in their perfection.*

"The calves brought here, were nearly all short-horn crosses, - and from two to four months old. The sheep were very fine, mostly long-wooled, and south-down, and their crosses, and incomparably superior to the ragged trumpery called "mutton" common in our American markets. The pigs have changed almost entirely since I was here in 1841. Then they were mostly thin, slab-sided, long-legged, long-eared brutes. Now they are mostly all Neopolitan, Suffulk, Essex black, and Berkshires. Of the latter, many are of the old original color-sandy or reddish yellow, with black spots. All the above varieties were good; some very fine and perfect. I still prefer the Berkshire, as they have the best, largest, and most meaty hams, the broadest backs, roundest barrels, and best shoulders. In fact, they are the best farmer's swine ever known in England. They cannot be improved.

"I left London the following Wednesday, for Liverpool, over two hundred miles. As I noticed the cattle along the way, three-fourths of these were short-horn crosses, the remainder

\footnotetext{
* Some of our cattle cuts show what the different breeds are at the Smithfield club exhibitions.-L. F. A.
} 
were Herefords, Scotch,-being far North of the Devon districts -and common natives, indicating that the short-horns are rapidly becoming the majority of English cattle."

TRANSPORTATION OF STOCK TO MARKET.

In all parts of the country penetrated by railways, cattle are now transported, from the nearest station to which they are kept, in cars. It is the readiest, and cheapest mode of getting them to market, and when under proper regulation, they lose less flesh, and go in better condition than by any other way. Still, owing to want of proper conveniences in many places, cattle often suffer loss of flesh, and are liable to frequent accident. But, so important to the earnings of the roads has this traffic become, and the competition between the various lines so great, that good accommodations for the cattle and drovers, are rapidly becoming established on all the main competing lines-so much so, indeed, that a comparison between the earlier and latter modes of transportation, is wonderful, in their improvement.

Crowded into the cars, as they must of necessity be, and standing on their feet throughout the passage, no cattle, or other animals, should be more than twenty-four hours between their feeding stations and yards; and those yards, in every way, should be commodious, dry in all weathers, and comfortable, where the stock can have perfect rest, good shelter, abundant forage, and pure water for any time they may remain there.

\section{RAILWAY CATTLE YARDS.}

The most commodious, and best systematized cattle yards we have yet seen, are those which have been recently erected at Buffalo, where the New York Central, the Lake Shore, and Erie Rail Roads center, and discharge and take on their stock. The yards cover many acres; are thoroughly floored with plank, and paved with stone, enclosed with tight and high fences, laid out in broad alleys, with sufficient gates and outlets, and will hold 
from two hundred down to fifty cattle each, as the various lots, in numbers, may require accommodation. These yards are all supplied with racks and mangers for feeding, troughs for watering, (the water being let in from aqueducts,) and well roofed over head, with abundant room for the animals to lie down and rest at pleasure. Hay and grain barns are conveniently situated on the premises, and the forage, accurately weighed and brought in on wagons, distributed at any and all hours when demanded. The rail tracks run close on two sides of the yards, for ingress and egress, as occasion may demand. Everything relating to the comfort and convenience of stock of every description, is compact and commodious, with perfect safety to animals, and their keepers, and the dispatch of whatever business relates to them. Several thousand cattle, besides swine, and sheep, weekly, are thus entered and distributed, with less labor and inconvenience than a third of the numbers could be in a common yard, and under the ordinary management so long practiced with the old and less matured system, under which the business has heretofore been managed. Yards of like character have been fitted up at other large railway centers, and will probably soon become quite common on all the leading cattle routes to market. 


\section{CHAPTER XXIV.}

WORKING OXEN.

INDISPENSABLE for draft in many laborious occupations, aside from farm work, the $o x$ is quite as valuable in aiding our industry, as the horse. We lave read much that has been written on the comparative economy of ox and horse labor on the farm, and elsewhere, without arriving at any satisfactory conclusion, other than that circumstances must control the employment of either to the exclusion of the other, or that they may both be profitably used in different labors. On rough and stony soils, the ox is almost indispensable in farm labor, while he is there more profitable than the horse. In varions other labors of draft, as lumbering, mining, and on roads, in certain localities, he is equally available, and more economical.

His advantages are, cheapness in cost; easy to keep; simplicity, as well as cheapness in his gear; patience, and endurance under labor; less liability to accident; safety against loss, or straying when turned to pasture; and, when done as a worker, the conversion of his carcass into beef. All know his value who have need of his labor; yet, but a part of those who employ him, are aware of his greatly increased value under proper treatment. No laboring beast is so much abused-not excepting the mule-as the ox. His patience, endurance, and fidelity under rough usage, gives him many a hard and neglectful master, who sins either through ignorance or brutality, agaiust the generous nature of the brute, when care and kindness would add both to his utility, and profit. 
A working ox, according to his necessities, should be as well fed, groomed, and sheltered, as a horse, and his labor would be as much better for it. We have seen many a well kept yoke of oxen, that would do as much ordinary farm labor as a pair of horses, with much less expense of keep, and not a tithe of the wear and tear of gearing. But the great drawback with almost every farmer, where himself cannot direct the labor, is the difficulty of finding good drivers. As the ox goes without a rein, he is directed by the word, and the motion of the whlp, or goad. $\mathrm{He}$ is slow in movement, incapable of being hurried, yet, when well trained, is obedient to command, and always equal to any reasonable requirement. It requires some skill to drive an ox well, as it does a horse, and as long as brainless men exist, who care for nothing but to get through the day, and take in their own provender while at service, we may despair of much reform in the management of ox labor.

REARING, MATCHING, AND TRAINING.

None but likely, thrifty, well built steers, should ever be kept for working, and no different treatment in calf hood is required than with other young farm stock. They should be castrated at any time not exceeding six months old, to give them a truly ox like character when grown-a stag being always uncouth in appearance, and less saleable. A pair of steers, intended for matching, should be as near alike in breed, in looks, color, temper, and action, as possible, as these qualities add much to their selling value; and uniformity in temper and action make them more valuable in labor. Training may be commenced at any age, after six months, with a small yoke; and small boys, when they take a fancy to such work, can do it as easily as a grown man. We know that all farmers cannot well do this at that early age of the calves, but where circumstances admit, it is less labor to train them at an early age than when older. They are less liable to injury, and more tractable. 
With older steers, at the age of two or three years-and they should not exceed three-they should be handled separately, and be tied side by side in a stall, or under a shed, if possible, and made gentle. The yoke should be first put upon them in the stall, that they may become accustomed to it, and know what it means; or if oxen of suitable size, already broke, be at hand, they may be yoked and gently used with them. When once accustomed to the yoke, a chain may be hooked into its ring, and they may be gently driven around the yard-gentleness, and docility, being always practiced with them. We have seen pro. fessed "steer breakers," who could break a yoke of "wild three year olds" in a day, and called them fit to work; but turn them loose for a day or two, and the steers forget it all, and are as unbroken as ever. Steady, persistent training for some days, is necessary to let them know what is wanted of them, and gentle, every day labor must be practiced for weeks before they can be trusted. The various manipulations of guiding them to the right or left, and backing, must be managed by a practiced teamster, for no written instructions will learn a raw hand to break a yoke of steers. There are several good methods to do this work, and every "teamster" is apt to think his own way the best.

The yoke should always be well fitted to the neck, and of proper crook, and size-the bows of proper shape, one and a half to two and a quarter inches in diameter, according to the size of the steer, or ox, well fitted to the breast and shoulders, and every thing so arranged as to work easy, and permit the steer to give his full strength in a pull. The same care and judgment should be exercised in the labor, feeding, watering, and cleaning a yoke of oxen, as with a span of horses. They require less care, indeed, but what care they do need should be as freely given, and it will be attended with quite as profitable results. A team of well grown, well matched, and well trained oxen, is a noble sight, and every one who owns them, and properly values them, feels an honest 
pride in their possession. When he no longer needs their labor, they are always saleable at a good price. An ox team should never be overworked, especially when young. They cannot endure heat, particularly in the spring of the year and hot sum. mer weather, so well as the horse, and their work in those seasons should be spared in the middle of the day. At five to six years old the $o x$ is in his prime, and so continues until nine or ten; but he seldom feeds so well after passing eight years, and is better to be turned out and fatted at that age, or earlier, after the spring farm work is over.

As to the best kinds for working oxen, we have said enough in our remarks on the various breeds, in previous chapters. Many excellent work steers may be selected from the native cattle; but an infusion of Deven, or Hereford blood, improves them; and where great size and extraordinary power is required, grade short-horns frequently make patient, honest workers. If the farmer wants them only for his own use, so that the pair have size, temper, and action alike, it is little matter what be the breed, provided they be of good form and substance. They will answer well his own purposes, and feed off profitably, at last. It is a business with some farmers, where working oxen are in demand and much used, to pick up, match, and break steers for sale, and when they have a taste and genius for it, it is profita. ble, as much so, perhaps, as any other commerce in cattle. In such vicinities, breeding steers, for that purpose, may well be worthy of attention. 


\section{CHAPTER XXV.}

CATTLE FOOD-THE GRASSES.

THE discussion of a subject so simple as proper food for cattle, may he thought superfluous. In some localities, it would be so. But when we have the power, in most cases, to measurably control both our summer and winter forage, it is worth attention.

The most natural summer food for neat stock of all kinds, is grass, and in winter, hay. We have grasses in great varietyboth natural, and cultivated. The natural grasses of all dry lands, which hold a firm sod, north of $35^{\circ}$ latitude, are such as cattle like, and thrive on; and on some of the moister lands, not absolutely swampy, they are also good. Our wild prairie lands, of the Western States, yield several kinds of native grasses, and some of them, when young, or in their prime, are of great excellence, both in their fattening, and milk producing qualities. All our cleared forest lands, of any fertility, produce a spontaneous growth of pasture grasses, as the spear, or June grass, and white clover, those being their usual production, and more or less intermixed with occasional patches, when moist, of fowl-meadow, and red-top. We call these natural grasses, because when the land is free from the plow, whether their seeds be sown or not, they naturally work in, and appear indigenous to the soil, whatever may be its geological formation. How the seed, to produce them, gets there, is not now the question. At all events, the grasses grow. They are our best pasture grasses, and can 
scarcely be improved when well established, although other kinds may assist in making up a variety, and filling the surface with a compact, well rooted turf.

We say these grasses grow, irrespective of the geological com. position of the soil. They do so, but not in equal luxuriance in some formations, that they do in others. For instance: In strong limestone soils of great richness, as in the clayey loams of some of our States, the June, or spear grass, by its luxuriance, has taken the distinctive name of "blue grass." Of this, there are two varieties, classed by the botanists as poa pretensis, and poa compressa; the former, deeper in color, is the "blue grass" proper; the latter, lighter in shade, and somewhat earlier in ripening, is sometimes called "green grass," and both are about equally nutritious. The compressa is known by the stalk being flat at the joints, while the other is round. So marked a character has the poa pretensis taken from the rich limestone soils on which it luxuriates, as to be, by many, supposed a distinct variety, and frequently called "Kentucky" blue grass; while all that Kentucky has done, is to give it a marked superiority of growth, on its strong limestone land. That superior growth and quality is equally given by all soils, of the same distinctive character, in other States, or Territories. The white clover-trifolium repensis almost always its companion in the more northern latitudes, and only in less amount where the richer quality of the soil pushes the blue grass into a more luxuriant preponderance.

Where land has been some years laid down, other grasses work in, and ou analyzing the products of an acre of old pasture, several varieties may be found, all nutritious; but the poa's are nsually the best.

These various grasses, intermixed, are the very best for making either milk, or beef. They seldom, or never need breaking up, or re-seeding on dry lands, and as a rule, the older the pas. tures, the better and more nutritious the feed. They are good 
from early spring to late autumn, and if kept ungrazed during the latter summer and antumn, where the ground is bare of snow, and the climate mild, make an excellent winter forage, equal, perhaps, to the best of hay.

Beside these, there are varieties of local grasses, which grow spontaneously in different parts of the country, quite nutritious in substance, and on which cattle thrive well. The quality of such grasses has only to be tested by use, to determine the policy of retaining them. Timothy, and red clover, usually sown together for heavy crops, make palatable pasturage for cattle, but are less relished, unless when young and fresh. When closely cut, for hay, they are longer in making a new growth than the pasture grasses we have described. They fail in making a close turf, like the others, but add to the variety of a well stocked pasture, and, to a certain extent, are desirable. So it is with the orchard grass, and some other varieties, that are sometimes mixed with them.

Many of the prairie grasses are valuable while in their spring and summer growth. There are none whatever on which, early in the season, stock thrive so rapidly as on some of these. We have known instances in which cattle, actually "on the lift," from their wretched winter fare, turned upon them early in the season, have become fair beef in six or eight weeks. They are wonderfully nutritious, both in flesh, and milk. But the difficulty with these grasses is, as they ripen, they grow woody, and tough, thus becoming distasteful to the cattle, and the early autumnal frosts kill them utterly, when all their nutritive quality is destroyed. By close and continuous feeding from year to year, they gradually die out, and the land works into the "tame" grasses. The plowing and thorough cultivation of the land, destroys the wild grass altogether, and then, with seeding, other and better kinds quickly take their place. We have already referred to the native grasses far West, and South, on which the buffalo ranges, which 
may become of immense value to future cattle herds; but of them too little is, as yet known, to speak definitely.

\section{FULL FEED AND WATER.}

For the greatest benefit to grazing stock, the pasturage should always be abundant. When a bullock, or cow, has to work, by continuously ranging over a broad surface to glean its food, they cannot be expected to get fat, or yield much milk. A "full bite," to the beast, is the only profitable way of feeding. Cattle love rest. Any creature should be able to fill itself in two or three hours' time, and then lie down and ruminate. Water, too, should always be handy. When they can get water at will, cattle usually drink three, or four, times a day, when at pasture. Many people suppose that if they are let out of a dry pasture twice a day, and conducted to water, that is sufficient. Not so. Cattle have little forethought, and cannot, as men do, anticipate a want which may occur an hour or two hence, and provide for it in advance. We have seen a herd driven out in the early part of the day to water, and many of them would not touch it, and in two hours afterward they would be lowing about the fences, gates, or bars, in distress for water, and not obtaining it, they suffered throughout the day, eating little, or nothing, until the next watering hour arrived, and then drinking so inordinately as to injure and disarrange all their digestion. Men may say that cattle will become habituated to such stated watering, by practice. They may, to some extent; but any one who will try the two methods, of giving them water at will, or only at certain hours, once or twice a day, will soon perceive the difference in their condition of flesh, or yield of milk.

\section{SHADE IN PASTURES.}

We have heard from experienced and successful graziers and dairymen, different opinions, of both the advantages and disadvantages of shade in pastures. One advocates the presence of 
trees, either singly, or in groups, under which the cattle can lie, or stand when at rest, thus screening them from the heats of the sun, besides adding to their thrift and enjoyment, as where shade abounds, there the cattle gather, and enjoy it. The other would strip every tree from his pasture grounds, contending that in the heat of the day, when the grass is dryest, and most nutritious, they can feed heartily and more to their benefit, and rest at night-the proper time for it. As to flies, they trouble the cattle less in sunshine than shade; the cattle, when shade is in the field, lie there all day, and feed only at night and morning, when the grass is wet with dew; it is then "washy," and less nutritious than when dry and only moistened by its own sap.

Whether this last be a real, or only a fanciful theory, we do not decide. The cattle themselves being judges, we should call it only a fancy, for it is certain they love the shade during excessive heats, as they do the sun in excessive cold.

There is another question concerning the land, however, worthy of consideration, in stripping it altogether of shade trees. They add much to the pastoral beauty of the landscape, and in the estimation of most men, to its value. Who, of any taste in the attractions of a fine landed estate, would permit a farm to be denuded of its majestic trees, or woody clumps of shade, for the mere fancy that his herds would gain a few more pounds of flesh, in their summer pasturage? Scarce one in a hundred. No; let the trees, singly, and apart, or gracefully grouped in their own free luxuriance stand, a shelter to the herds, and a pleasant spectacle to their possessor-a "most living landscape" in its summer repose.

\section{CHANGE OF PASTURE.}

This is also a subject of controversy. Some contend that it is better for stock to have frequent change from stale to fresh feed during the grazing season. Its utility will depend somewhat upon the varieties of grass which the pastures contain 
and the convenience of the proprietor. Small fields are more expensive in fences than larger ones, because there are more of them to build and keep in repair. That item, therefore, is an inconvenience. A sudden change of diet with cattle, always, to some extent, deranges their stomachs, and bowels. Taken from shorter, or dryer grass, and put on to flush herbage, is apt to scour them, and while under such operation, the fattening beast loses flesh, or at least does not gain it, and the cow loses in her usual flow of milk. This we have known from repeated trials. Not that animals should not be changed from poor feed to better; but whether, in the small fields which are to keep them through the grazing season, and with an abundance of feed, it is not better to let them range over all of them at will, and enjoy the whole of it as they choose.

We incline to the latter. Cattle are quite local in their attachments. They best like the places to which they are accustomed. They also like a variety in their food. Large fields usually offer a greater variety than small ones, and almost every day they seek that variety. For twenty-five years past, we have had a pasture of more than a hundred acres in a single field, in which we have grazed cattle, horses, and sheep. In that pasture are different elevations, most of it being dry upland, covered with blue grass, white clover, and other mixed grasses; some lower grounds, growing red-top, and fowl-meadow; some lowland copses of wood, and undergrowth of bushes, and rank, wild grasses interspersed; and a range of marsh by a river shore, covered with a rank growth of sedge grass. Almost daily, throughout the season, the cattle range over every part of that field, feeding in every quarter on which they roam, and frequently leaving the highest, sweetest grass, to fill themselves from the coarse, and what we would deem the least palatable, herbage of the marsh, or woods. It is certain that they like this variety, or they would not indulge in it; and had they been 
confined to either alone, would have hankered after the other. We admit that some of the grass where cattle continuously feed, by being much trodden over and laid upon, becomes soiled, and distasteful for the time, but the next rain washes it off, and it becomes palatable as ever. Cattle, in their tastes, are somewhat like men, and as those accustomed to the highest luxuries, like, occasionally, a lunch of brown bread, with a smoked herring, and partake of it with great relish, so cattle, from the choicest blue grass and white clover, love to plunge into the coarser grasses, or browse the green leaves from the tangled brushwood. Our impression is, that the experience of both graziers and dairymen is growing in favor of the larger pastures without change, to the smaller ones with frequent alternations-provided the grasses be equally abundant.

WINTER FORAGE, AND CARE OF NEAT STOCK.

A foreign traveler, accustomed to the economical methods of feeding and caring for cattle among the densely populated nations of Europe, would, in his exaninations of our general American ways of stock feeding in winter, suppose us to be the most negligent, careless, and wasteful people on earth. And he would not be far out of the way-in that particular.

It is true, we have a great many painstaking, economical farmers among us, who not only raise good cattle, but take pains to secure proper forage for them, feed them enough of it, and provide for their comfort by way of shelter, whenever needed. In contrast to them, however, the common rule, particularly in the newer States, is quite the reverse. A quantity, more or less, of bad conditioned hay, corn fodder, or straw, is stacked upon the premises, around barns, or sheds, and in a great miany cases, in the yards, or fields of the farm, without artificial shelter of any kind. To these stacks the stook are driven, when the snows, or storms of approaching winter compel them to be fed. The 
cattle come up in such condition as they may happen to be from the fullness, or scantiness of the summer and fall pastures, young, and old, good, bad, and indifferent mixed together. The fodder is pitched from the stacks, and strewn over the yards, or fieldsor what is worse, the stacks themselves left to be foraged upon by the cattle running loose around them. Much of the food is trampled into the mud, or slush of snow and water lying around, and altogether lost. Some of it is eaten by the ravenous animals, as they hunch, hook, and drive each other away from a cleaner morsel before them, while all the time they are subjected to the changes, vicissitudes, and severities of every storm that occurs, through a tedious winter of several months. The consequence of all this is, that through irregularity of feeding, and carelessness in distributing their food, and want of shelter, the cattle lose flesh every day, and be their condition what it may on coming into winter quarters, they go out "spring poor," or "on the lift," with no growth whatever in the young stock, and just about strength enough in such as have survived their wretched poverty of condition, to crawl out into their spring pastures!

This may be thought an overdrawn statement; but it is no exaggeration of numberless instances which have occurred under our own eye. Surely no practice can be worse than this for the welfare and comfort of the poor suffering cattle, nor for the profit of the farmer. There is no profit in it. Land so stocked and managed, pays little, or nothing, and cattle so utterly neglected can be of little value. No guodness of quality can be expected in them, while disease, arising from neglect and poverty, is always making inroads on their numbers. Every spring, our cattle markets are filled with the wretched rubbish driven from such herds. We have seen thousands of them annually, at our large railway cattle yards, and the wonder is that they find purchasers at any price above absolute ruin to their owners. 
We have only touched upon this sorry phase of cattle winteling, to condemn it as both cruel to the beasts, and unprofitable to the keepers of them.

WHAT WINTER FEEDING AND CARE OF STOCK SHOULD BE.

Good hay and plenty of it, is, no doubt, the most available and convenient winter feed for stock cattle, in our hay producing States. For fattening beef, and making milk, other foods are to be added; but those are not now in the exact order of discussion. Hay, too, in a grass country, is altogether the cheapest. In the wide Indian corn regions of the South and West, where that grain is largely raised, and the stalks properly cured, they furnish an amount of good forage; and clean, bright straw, when necessity compels it, is a rather poor substitute for either; but cattle will scarce hold their own upon straw alone, much less thrive. Some farmers believe, or act as though they do, that if a creature can get through to its spring pasture, with half as much flesh on its bones as it carried into winter quarters, it is doing well. That is a much mistaken idea, for in such condition, its winter growth is lost, and it takes half the summer to recover it. There is no truer adage, than that "a beast well summered, is half wintered; and well wintered, is half summered."

The hay most generally preferred for that puropse is timothy, with a sprinkling of red clover in it-if cut in the right timewhich, in timothy, is just at coming into its blue, or first bloom, and before the succeeding white bloom passes. In the first stage, the seed is in its milk, and the stalks and leaves in their full succulence. It then requires more drying in the field after being cut, and is better for milk cows, calves, and young stock. In the white bloom, the seed is glazing and ripening; the stalks and leaves are at full maturity; the sap is conceutrated, and the grass has more substance, yet quite as profitablo for steers, and dry cows. When filly ripe, and the seed begins to fall, the grass 
becomes hard, and woody, and loses a part of its nutritive, as well as palatable quality. Still, if delayed cutting until that time, it is valuable, and should not be lost. Blue grass, white clover, and red-top, if cut before their seeds ripen, make quite as good cattle hay as timothy. Fowl-meadow, bent, and orchard grasses, make quite tolerable stock hay. As a rule, all grasses should be cut before going out of bloom, and well, but not too much cured. Much hay is spoiled by over drying. When early cut, the hay should be thoroughly wilted, and then thrown into winrow, or cocked, where, according to the weather, it may remain for twenty-four to thirty-six hours. It will then sufficiently cure for housing, and the sooner it is put in barn, or stack, or barrack, the better. Later cut hay will cure more readily, and may oftentimes, when cut in the morning, be carried in during the afternoon. The judgment of the farmer must regulate all this. Salting hay, to assist in the curing, we think of no account, and never practice it, as it does little to preserve green hay, without putting on so much as to spoil it for fodder. We prefer giving salt to the stock, by itself, at the proper times, than to put it in their hay. Field grown corn fodder, to be at its best, should be cut up and shocked when the grain is fairly glazed, so as to ripen without molding. It is then fresh, succulent, and nutritive. Every frost, while standing uncut in the field, injures the stalks as fodder; and although it makes a tolerable winter forage, when allowing the stock to gather it for themselves, half its nutriment is gone. But, circumstances often compel this practice of so leaving it, and it need not be further discussed.

WINTER FEEDING, BARNS, AND SHEDS.

Living in the latitude of $43^{\circ}$ north, we believe in barns, and sheds, for all kinds of farm stock alike; and so we would if in thr latitude of $37^{\circ}$, - anywhere, in fact, where snow lies on the ground for three davs at a time, and the Fahrenheit thormometer 
holds, for any length of time, as low as $20^{\circ}$ above zero. Sudden alternations of heat and cold affect cattle as they do men,-not to the same extent as they do the latter, but measurably so. Cattle eat much more in a low temperature than a high one, and are subject to take cold with sudden changes of the weather. Fat cattle are less affected by sudden changes of weather than lean ones, but those changes do affect them more than we are usually aware. In view of these facts, we consider it sound economy for every cattle breeder, grazier, and stall-feeder, to provide good barns, stables, and sheds for the winter keeping and feeding of his stock. The arrangement of these is a branch rather foreign to our general subject, and may better belong to farm architecture than this; embracing also the management of manures, and various other matters belonging to the department of farm husbandry; yet, we may safely give a few hints concerning them.

We believe that in any part of the country where prepared winter forage is required for farm stock, it will pay the farmer for building barns, stables, and sheds for his store cattle during the winter. For dairy cows, tight barns and stables are indispensable everywhere, and we are happy to say that the latter are almost everywhere found in well managed dairies. We believe it sound economy to provide such shelters. In the barns, aside from storing the fodder and grain, the stables may be cheaply arranged, with sufficient mangers for feeding. Two cattle may stand in a stall, six to seven feet wide, according to their size, and each animal tied to his own side of it, with space for the feeder to go between; or stanchels, without partitions, may be used, if preferred. The food may be thrown into the manger in front, and the corn stalks, as drawn in from the field, cut off just above the ear. (The stalk, below the ear, is worthless for fodder.) This cutting may be rapidly done by a knife, something like a butcher's cleaver, though lighter, by laying the 
stalks on a block, or better, in a cutting machine. The beasts may be bedded with straw, and quantities of the best manure made. Thus the cattle are kept snug, and warm, while in good weather they can range in the yards through a part of the day, and take their water at pleasure.

Sheds may be built eight, ten, or twelve feet high, with good mangers in the rear, for their hay, or corn fodder, and open in front, to go out and in at pleasure. So with calves, only their accommodations should be closer, and warmer. We are aware that long practice, cheap lands, and low prices for grain, have led the mass of our Western farmers to think all this preparation useless; but they will come to it at last, and wonder they had not known it before. Thrift in their stock, and a saving in the expenditure of their forage, will soon solve the question of its superior economy, as also in the lightened labor of taking care of them, and the retention of stores of manure, which is everywhere valuable, though not now appreciated. If, to the housing of their cattle, sufficient roofing to protect their stores of hay, and grain, is added, an equal advantage will be found in it. 


\section{CHAPTER XXVI.}

\section{SUMMER FOOD FOR DAIRY COWS.}

EVER owner, or keeper of a cow for milk purposes, wants a good one. At least, that is what they inquire for, when purchas. ing her for either family or dairy use-one yielding a large quan. tity of rich milk, good in creamy quality. The possession of such a cow accomplished, the owner has a fair start, so far as the capital invested in the creature herself is concerned. But there is another item quite as important connected with the product to be obtained from her; and that is, her food.

Let the milk-producing faculties of the cow be ever so good, those faculties will fail if the requisite food, both in quality, and quantity, be withheld from her. The manufacturer or machinist may have the best propelling power in the world with which to work his machinery, but if he hare a scant supply of water with which to drive his wheel, or is short of fuel to make the required amount of steam for his engine, his power in both cases fails, and a portion of his capital expended in the construction of his machinery is lost. It is so with the cow. She may be so anatomically and physiologically constituted, as to yield the greatest possible production of milk, of which her nature is capable, but to obtain that production an abundance of the proper food must be given.

The cow is simply a piece of animal machinery, composed of stomach, lungs, viscera, milk secretions and udder, so far as her dairy quality is concerned, and that machinery will not work to 
its full power, without the necessary food and care to keep it in action. We are satisfied that one-fourth to one-half the profit which might be drawn from our American cows, is annually lost to their keepers by a want of the necessary quantity, and the proper quality, of food which should be given to them, and consequently a considerable portion of the capital invested in their purchase, or value, is thus unproductive; and that only from the short supply of food, and want of care given to them. A gocd family, or dairy cow, without regard to her breed, anywhere in the United States, and at any time, is worth fifty, to seventy. five dollars. Such a cow will produce 600 to 800 gallons of milk, or 200 to 250 pounds of butter, or 500 to 600 pounds of cheese in a year, and possibly more-if properly fed; or, she may produce but half those quantities of each, or either, if scantily fed. In both cases, the original cost, or value of the cow is the same; the care is, or should be, nearly the same, while all the loss in her production is caused by the inadequacy of her food, a full supply of which would be but a partial percentage added to the cost of poor feeding. This we think a fair statement.

Now what shall that food be? Fresh, succulent grass of good quality, and as much of it as her digestive powers will consume during the grazing season, is the readiest and most natural food of the cow, giving her not only the most nutriment, but producing the best milk. Therefore she should have it in unstinted abundance. When at pasture, she should not toil for her food. She should have it within easy reach, with good water always at hand. No matter how active her breed, or habits, the easier she obtains her food, with abundant time for rest, the more abundant will be her yield of milk, and the greater will be the quantity of cheese, or butter, she will make. The judgment of her keeper, will determine when the pastures fail in their supply of grass, and then other food, as an equivalent, must be given. 
Fresh growing grass gives quantity of milk; that which is riper and dryer gives better quality, or more richness, and perhaps an equal quantity of butter, or cheese, from a less amount of milk. The particular state of the grass, whether in its most sappy, or succulent, or in its dryer, or more matured condition, so that the cow have enouyh of it, is of less consequence to the cheese and butter dairyman; but the sale-milk dairyman must supply the succulence wanting in the dryer grasses. This must be made up in other material, and also, in short pasturage, to the other class of dairies, under the head of

\section{SOILING.}

To many old-fashioned cow keepers, and dairymen, who have never practiced any thing but the old jog-trot way of their fathers, in the common way of pasturing for summer food, and hay feeding at the mangers, or stacks, in winter, this term may be startling, as involving an extra outlay of capital and labor altogether unwarranted. If so, they may as well abandon the business at once, if they intend to compete with the more enterprising dairymen of these advancing times, so far as making the most profit out of their vocation is concerned. The old hum-drum idea of having their work half done, and in the slip-shod, slat. ternly way of past generations, must be ignored, and a new method introduced. A tidier fashion must be adopted, and more skill introduced, as well in feeding the cows as in manipulating the milk into butter and cheese. The whole process of keeping the cows, milking, and manufacturing it into marketable commodities, musst be as thoroughly improved as that of making cloth by modern machinery, over the old way of hand-carding, spinning, and weaving cloth for household uses; and they who are unwilling to adopt these better ways, had best at once retire from the business, or be content to accept the meagre gains which their inferior articles, as well as lack of enterprise will give. 
The term "soiling," is applied to artificial feeding, when the pastures fail. To manage this department properly, due prepa ration must be made for enclosing the cows in yards, sheds or stables, while taking their prepared food, as well as permitting them to have ample range in a larger enclosure near by, that they may have plenty of air and exercise in dry weather. No better arrangement need be made than to use the winter stables for feeding purposes, when soiling, as the cows should always be secured in their stalls, morning and night, for milking, throughout the dairy seasson. At these times they can be fed. Open, airy sheds, with proper racks or mangers, can also be used for the purpose. When milked and fed, they should always, during the warm season, be turned out to enjoy the fresher and-cooler air, as the stables, even if well ventilated, are sometimes too warm for them. At noon, or at other times also,-for they require feeding at least three times a day, and four or five times, even, may not be too much-they can be turned in to receive their regular mid-day rations. Water, of course, they are to receive at will, outside, if not furnished within.

This mode of feeding is indispensable, when a full flow of milk is required throughout the season, and whenever the pastures fail. It will pay, too, in the increased products of the dairy. There is no doubt of its economy, also, with all kinds of cattle, where land is valuable, as one-third to one-half the same area of ground, in the same condition of fertility, will yield an equal quantity of forage, to that fed off by the usual mode of grazing. That is to say: one acre of land, well cultivated in good soiling crops, will yield as much nutritive food for the cow, as two or three common acres will yield in pasture.

For soiling purposes, ample preparation must be made in the spring, that when the pastures fail, if fail they do in any part of the grazing season, they may be readily resorted to, and if not 
needed, the forage may be secured at its proper time of harvesting, for winter consumption.

\section{THE PROPER AND BEST SOILING CROPS,}

We name in the order of their coming in nse, viz.: Fall sowed rye; red clover; orchard grass; blue, or June grass; timothy; red-top; early sowed oats; millet, or Hungarian grass; Indian corn, sown either broadcast, or in drills-the latter way the better. The grains and grasses may be cut at any season when necessary, but are most nutritious when just coming into bloom, being then in full sap and succulence. After cutting, they should lie a few hours before feeding, so that they be partially wittednot dried. Their watery particles are then more consolidated, and will not become too washy in the stomach and intestines of the cow. The Indian corn may be used at any time after it has attained a growth of three or four feet in height, but is best when in the tassel, and silk, and the ear is forming. It should be cut close to the root, as then every part of the stalk is sweet and tender.

\section{THE BEST KIND OF CORN FOR SOILING.}

We have tried them all, from the tall "gourd seed" of the South and West, to the "Canada," and "Nantucket" small yellow "flint," and the garden sweet corn commonly cultivated in gardens for the table. Either of the common field growing varieties are good. The gourd seed is coarser in the stalk, and when grown to tasselling, the stem below the ear is larger, more woody in its fibre, and not so palatable or nutritions as the smaller varieties. For that reason we prefer the latter, as they can be cut close to the root, their smaller, and less woody fibre being better liked by the animals fed upon it.

But by far the best variety is the sweet corn of the gardens. We have thoroughly tried it and know the fact. The stalk, from the ground upwards, is more nutritious, and as much sweeter to 
the taste of cattle, as the grain is to the human palate when cooked for the table. Even after the ears are plucked for table use; if suffered to grow so long, cows will eat the entire stalk when cut close to the roots, as we have often tried. Swine, so fed, will eat the stalk entire, greatly to their benefit, while with other varieties, they seldom eat anything below the setting of the ear. The sweet corn is as easily raised as the others; the seed, too, is easily produced, and with no more expense than the common field kinds.

If a trifle of salt be sprinkled on each mess, as fed, it will be better. Give the cows all the food they will eat. If the green food be too loose in its action on the stomach of the cattle, a little mixture of finely cut hay or straw with it, will correct the difficulty. It is scarcely necessary to say that the stables should be cleaned night and morning, thoroughly ventilated, and every thing kept scrupulously neat as when the cows are at pasture. A good plan, when cows are soiling, is to turn them, when not feeding, into an adjacent, well fenced, mowing field, where the hay crop has been gathered, if in season, or on another field where their droppings may be useful to enrich it for a coming crop, thus saving much labor in removing their manure otherwise made in the barn, or feeding yards.

The system of soiling has long been practiced in Britain, and on the European continent, particularly in the neighborhood of large cities, for milk dairies, and found to be the most profitable mode of summer feeding. Lands, for that purpose, when advan. tageously located, frequently rent for $\$ 25$ to $\$ 75$ an acre for the season. It is becoming much practiced near our own larger American cities, where land is high in value, and proximity to a good milk market.important. It will also tell equally well in our cheese and butter dairies, where a continuous full flow of milk is necessary. The labor of the suiling process, is not greater than that of driving back and forth to pasture, the repair of fences, 
and the interest on their cost. With lean pastures, and a short supply of milk, the income from the cow is partially lost, while the outlay for all the dairy expenses is the same. Soiling is, therefore, a necessity, in most seasons, to a profitable dairy.

Since writing the foregoing, at our request we have received from Mr. E. W. Stewart, of North Erans, Erie Co., N. Y., a most valuable article on the summer soiling of stock. We consider it so admirable, (although it embraces some items incidental to the main one under consideration, yet closely allied to it, and well worthy of study by the dairyman, and also the common stock farmer,) that we insert it in full. We need hardly add, that Mr. S. has.proved himself, although for many years practicing one of the liberal professions, a thrifty and excellent farmer.

So important a branch of our dairy economy needs all the light which we can throw upon it.

"One of the most difficult problems connected with the agri culture of the older settled States, is, how to keep the soil from exhaustion? And any system that promises well, in this direction, should be carefully examined. The old proverb, 'No cattle no manure, no manure no crops,' applies here with great force. If soiling, or cutting and feeding green food in summer, enables the feeder to maintain, in full condition, more animals on the same space of ground than pasturing, then it certainly affords him more manure to return to his soil, and so far, makes the future prospect of fertility more cheering. The writer has practiced the soiling system for over ten years, and is desirous to present all its strong points to his fellow farmers. He began by soiling his horses, and found the saving so important, and the convenience so great, that the next season he experimented with his cows and colts likewise. Let us first detail some

\section{EXPERIMENTS.}

"Three experiments were tried by the writer, in three different seasons, to determine how long a certain number of animals 
could be kept on forty rods, or one-quarter of an acre of ground. Let it be premised that the soil is a strong clay, put in fine condition after twenty years of bad farming-the crop heavy clover, just coming into blossom. On the first experiment, seven cows and four horses, equal to twelve cows, were fed fifteen days. On the second experiment, six cows and five horses were fed fourteen days, and on the third, eleven cows were fed sixteen days; in each case upon one cutting of clover, on forty rods of ground. It will be perceived, that in each instance, it was equal to keeping one cow from one hundred and sixty-eight to one hundred and eighty days, or about equivalent to the pasturing scason for one cow. It is admitted that these crops were much above an average, and that forty rods of ground could not be regarded as a sufficient allowance to a cow for a season, unless the land is in fine condition, and the crop a maximum.*

"Another and larger experiment was tried in the summer of 1862, when twenty steers, four years old, seven cows and six work horses, equal to thirty-five cows, were soiled from the 20 th of May to the 1st of December. No measurement of the exact amount of land cut for soiling, was made, but one hundred acres were occupied as follows: Ninety acres in timothy grass, five acres in timothy and clover, two acres in clover, one acre in oats, and two acres in sown corn. Only about four acres of this hun. dred were in extra condition, and fifty in poor condition. First, the two acres of clover were fed, then the five acres of clover and timothy, next the acre of oats, then timothy until it became too ripe, next the two acres of corn, and lastly, the second and third cuttings of clover. In short, they were fed from this hundred acres, for six months and ten days, with a surplus of sixtyfive tons of hay, which were sold for $\$ 972$. Now, had these animals been pastured upon this hundred acres, nothing would

\footnotetext{
* On the best of Western grazing lands, if an acre will feed a bullock through the season, it is considered as remarkably good.-L. F. A.
} 
have remained, and the food would have been insufficient in the dryest part of the season. These steers averaged 1,100 pounds per head, and were good light beef cattle, being then worth only" three cents per pound, on foot, and cows at that time being low, the $\$ 972$ for which the surplus was sold, would have purchased the twenty-seven head of cattle, and one of the horses. This latter circumstance is mentioned to show how disastrous, in this particular case, would have been the results of pasturing. But it may be said this case would, perhaps, stand very differently if the labor account were stated! This point was particularly cared for in the experiment. It was found that it took three men, two hours each day, to do the labor of cutting for, and feeding these animals. Wages at that time being only $\$ 12$ per month and board, the whole labor account, including board, was only $\$ 65$. This included all, except the use of a horse to mow and haul in the grass. We will also deduct the expense of cutting and putting in barn, the sixty-five tons of hay, say $\$ 1.25$ per ton, or $\$ 71.25$, to which add the $\$ 65$ for labor of feeding, and you have $\$ 136.25$, which, deducted from the $\$ 972$, shows $\$ 835.75$ as the net profit of this soiling experiment. But this is not the full statement of the profits, as there were one hundred loads of manure saved, and in the best condition, under cover, worth $\$ 100$ more. And had the land all been in good condition, the surplus would have been double. To us, this experiment was conclusive, as ta the profits of soiling.

\section{CONDITION OF THE ANIMALS SOILED.}

"The next point to be considered, is the comparative condition of the animal, as soiled or pastured. And here, facts, not theory, are to be considered. The writer has tried some experiments on this point. Five steers and heifers were put into a good pasture and kept for three months, during the best part of the pasturing season, while others of the same age and condition, at the start, 
were soiled, and on comparison, at the end of three months, those soiled were found in decidedly the best condition. The same cows were pastured one season, and soiled the next, and their condition was better when soiled than when pastured; and uniformly soiling has improved the condition of his animals. $\mathrm{He}$ has cows that have been soiled for five consecutive seasons, and kept in good condition and uniform health. In fact, he regards soiling as very conducive to the health of animals, as it places always within the power of the feeder, an abundant supply of the best food; while pasturing, frequently affords a large supply at one season, and a very meager one at another. And to those who are fattening animals for the market, it is of great value, as by adding a small quantity of grain to the summer feed, they will fatten very fast. Summer is the best time to fatten animals, for they will fatten in less time, and with one-third less grain, than required in winter. It also offers every facility for graduating the feed to each animal, according to its condition and the object to be attained. A dairyman may prepare a cow, he desires to part with, for the butcher, while giving milk, and thus save any loss.

EFFECT OF SOILING CPON THE PRODUCT OF MILK.

"The experience of the writer is that the cow will average one-tenth more milk through the whole season. When the pasture is fresh and full, and the cow can easily get all she wants, she will give as much milk, but soiling enables the feeder to give a uniform supply of food, and consequently the flow of milk will be more uniform. Some American farmers have estimated the increase of milk much greater than the above, and some very interesting experiments have just been published by Dr. RhodeEldena, of the Royal Academy of Agriculture, in Prussia, of the comparative yield of milk from cows, by pasturing and stable feeding, or soiling, through seven years of each system. The pasturing experiment began in 1853 , and continued to the end 
of 1859 , and stable feeding began in 1860 , and ended with 1866 . From forty to seventy cows were pastured each year. The lowest average per cow is 1,385 quarts, in 1855 , when seventy cows were kept; and the highest, 1,941 quarts, in 1859, when forty cows were kept; and the greatest quantity given by one cow during the time, was 2,938 quarts. In the stabling experiment, from twenty-nine to thirty-eight cows were kept, and the lowest average per cow is 2,930 quarts, in 1862 , when thirtyeight cows were kept; the highest, 4,000 quarts, in 1866, with thirty-five cows; and the highest quantity given by one cow was 5,092 quarts. The average per cow, for the whole seven years in pasturing, was 1,583 quarts, while the average per cow, for the seven years of stabling, or soiling, was 3,442 quarts. This result is very remarkable, and were it not supported by such high authority, would be almost incredible. The explanation is to be found, perhaps, in the fact that the owner of the stabled herd, Mr. Herman, in 1860, began to discard the poorest milkers, and substitute the best Dutch breed. His cows were also fed highly in winter, with rye-bran, oil-cake, and sometimes potatoes. The yield of the same cow is compared for several ycars. As a sample, cow No. 24 gave, in 1860, 3,293 quarts; in 1863, 4,483 quarts; in $1865,4,800$ quarts. This shows a regular progress, and a high state of feeding, and is most encouraging to the dairy. man who wishes, by intelligent feeding, to improve his herd. We do not claim all this for soiling, but it is only under this system that such a method could be pursued, and the increase here, must fairly be set down at fifty per cent., as referable to green soiling alone. And we must be considered very modest in stating, that the extra product of milk in soiling, will more than pay for the labor of feeding.

\section{SAVING IN FENCES.}

"This question of fences is becoming more and more important every year, and soon the fences must be dispensed with, whether 
cattle are soiled or pastured. It is now the most onerous tax upon agriculture. Let us suppose the dairyman keeping fifty cows, and that 150 acres are devoted to pasture. Suppose this to be divided into six lots, of 25 acres, each 50 by 80 rods, and that it all lies in a body 160 by 150 rods. This would make the fencing more than ordinarily economical, and he would have 1,090 rods of fence. Suppose it to cost $\$ 1$ per rod,* and that it will last twenty years. This will make the first outlay $\$ 1,090$. The interest of which is, $\$ 76.30$. The average expense for the whole period, of keeping it in repairs, cannot be less than five per cent., or $\$ 54.50$ per year, and add to this the loss of capital yearly, $\$ 54.50$, and you have the whole annual expense, $\$ 185.30$, for fencing a pasture adequate to keep fifty cows. Now, this is more than enough to pay for the labor of soiling the same animals, as one good man, with the proper conveniences, can cut for and feed fifty cows. Soiling renders fences useless, except to enclose a yard for the animals to exercise in. In fact, it, would cost less to employ a herdsman, constantly, with the cattle. Besides, the fences are always in the way, and are infested with foul weeds and bushes, which, by neglect, get distributed over the farm. Every farmer will find it a great convenience to be able to plow without the obstruction of fences, to drive into and from his fields without letting down and putting up bars, or open gates, to run his mower and reaper without leaving the corners of the fences to be cut by hand.

"Another item of economy not to be overlooked in dispensing with fences, is, the saving of one-half rod of ground where the fence stands. This would amount to about three and one-half acres, covered by the 1,090 rods of fence. And this land, when in good condition, would soil seven cows through the grazing season. Thus it appears, by an examination of the facts, that

* Mr. Stewart, living in a region where wood and lumber are chenp, estimates the nverage expense too low. The expenses of good farm fences cannot be less than $\$ 1.50$ to $\$ 3$ per rod, according to locality, and the materials of which they aro made, at the cheapest.-L. F. A. 
the great objection usually urged to soiling animals, namely, the extra labor involved, has no foundation, but on the contrary, that soiling, in point of labor, is the cheaper of the two systems. And, from his experience of ten years, the writer would rather perform the labor of soiling fifty cows for a series of years, than to fence and pasture them.

\section{SAVING IN MANURE.}

"This is a most important consideration.

"1st. It will double the amount of manure from each animal kept, as the summer manure will all be saved, and in good condition to be applied as needed.

" $2 \mathrm{~d}$. The saving in land will enable the feeder to kecp double the number of animals, and, therefore, to produce four times as much manure as under the old system. By keeping an increased number of animals on the same land, it is evident that the condition of the soil will be improved, and that this will, when fully adopted, prevent the dreaded exhaustion, which those of wise forecast, have seen approaching in the not distant future.

"The value of manure is not appreciated as it should be by the farmers of the United States. Johnston informs us that in Flan. ders the liquid and solid manure from a cow is valued at twenty dollars per year. This wonld give us the value of the manure saved by soiling each cow, ten dollars per season. There can, at least, be no doubt that the manure will pay the whole expense of soiling.

\section{SAVING LAND.}

"How the farmer may double his farm without increasing the number of his acres, should be a problem of great interest. And since the great business of the farmer is in rearing and keeping animals, any method which will enable him to keep, in good condition, two animals where he has kept one before, will come very near solving this problem, by showing how the income of the farm may be doubled, without any proportionate increase of the labor. On most grazing farms of this State, not more than one $14^{*}$ 
cow is kept to four acres of arable land, and in many cases only one to five, and six acres. Three acres of pasture, and one acre of good meadow, keep the cow through the year. The fact that three times as much land is usually devoted to summering a cow, as to wintering her, should, of itself, be quite enough to show the wastefulness of the pasturing system. Especially, when it is considered that it takes one-eighth more food to keep the same animal in cold than in warm weather. Let us compare this with soiling. It appears, by the experiments detailed, that land may be so fertile, that forty rods of ground will be sufficient to soil a cow for the whole pasturing season, but we will not assume so extreme a position. If we take twice this amount, or one-half acre of fertile land, devoted to soiling crops for each cow, no disappointment will result. Then, if one-half acre will soil a cow, instead of three acres pastured, we have saved five-sixths of the land, or two and one-half acres. This two and a half acres will, certainly, soil and winter another cow. But we will divide the four acres into two parts, giving each cow two acres, and estimate three-fourths of an acre for soiling, and one and a fourth acres for wintering the cow. This can, most confidently, be relied upon to furnish abundant food, when in good condition, to keep a cow through the year. And thus, we see that the land usually devoted to a cow, under the pasturing system, is abundant, in soiling, to keep two.

"In fact, the writer has never used so much as two acres in good condition, to keep a cow through the year. And as it has been shown that the aggregate amount of labor is not increased by soiling, it follows, conclusively, that this system, properly con. ducted, will double the income of the stock feeder, without any increase of his land.

\section{SOILING CROPS.}

"The field or fields which are to furnish the summer food, should be near the place of feeding-and being near the barn, it 
may easily be made fertile, if not originally so. Of the grasses, clover will furnish the earliest green fodder. It can usually be cut about the 20 th of May, -or earlier, or later, according to locality - and on moist land, will furnish three or more cuttings. Where winter rye flourishes, it makes an excellent soiling crop, and may be cut even earlier than clover, and will furnish several cuttings in a season, and, according to Liebig, if kept back the first season, by cutting, will mature a crop the second summer. On good land it will furnish a large amount of food. Oats are also used for soiling. Indian corn sowed at times, fifteen days apart from the earliest planting, until the 20th of July. Sorghum, on land suited to it-light, warm soil-free from weeds, makes a valuable soiling crop, yielding abundantly.* But clover and Indian corn must be the principal reliance for early and late feed. The writer generally uses clover till timothy is sufficiently matured; after timothy, early sowed corn; then second cutting of clover and sowed corn till freezing weather. There is little difficulty in arranging for a regular succession of succulent food, from the 20th of Mayt to December. It would be well to have one-fourth acre for each cow, in clover, and onefifth acre per cow, in corn, sowed at different periods. The balance of the feed can be obtained from the timothy meadows. If any fears were entertained of a scanty supply for late autumn feeding, more corn might be put in, and the surplus would be ready for winter use.

\section{METHOD OF FEEDING.}

"Different methods may be adopted in summer feeding. The yard, - a small field enclosed with a hurdle fence,-the open shed,-the stable,-all, or either, may be used as a place for

* It mnst be borne in mind, however, that the effects of sweet foods, as sorghnm, msy prove injurions to the conception of breeding cows, as snggested in a previous chapter, on barrenness.-L. F. A.

+ In some sections of our conntry the green feeding will commence some days, or weeks earlier. Mr. Stewart dates from his own locality.-I. F. A. 
feeding. But the stable is preferable for cows. Feed the animals in the same position winter and summer. Once a day let them out for air and exercise. Give them a small field, or a lane, leading to the wood lot, to run in. Being always fed at the stable, they will be there at the appointed time. They should be fed with perfect regularity, say at six and ten A. M., and at two and six P. M., giving air and exercise between ten and two. Some prefer more numerous feedings. Mr. Quincy, of Boston, Mass., - a strong advocate of soiling, who has had large experience, and written a treatise on the subject-recommends six. There are good arguments for numerous feedings. Less will be fed at a time, and the food will be fresh. A good feeder will give no more at each time than the animal eats up clean, and with a relish. Too much at a time tends to cloy the animal and impair easy digestion. It is better to give less than the appetite craves, than more. It is especially necessary to be prudent in this particular in summer, as animals are more easily cloyed in warm than cold weather. When the clover is first cut for soiling, and is very green and succulent, it is better to cut and mix it with one-fourth the quantity of cut hay, or straw. This cut. hay, or straw, will absorb much of the moisture and prevent bloating, but when more mature, the clover may be fed alone. The food should be slightly salted once or twice a week. For milk cows, the green food should be fed fresh, and not suffered to be much wilted.

\section{ARRANGEMENT OF ANIMALS.}

"Next, how shall the animals be arranged for feeding? This will vary according to the idea of order and convenient arrangement, entertained by the feeder. Perhaps the method of fastening by stanchions, or chain and stanchion, so generally used, is the best for holding the animal to its position, and is not found to be injurious to the health. They should be so arranged as to feed conveniently from the barn floor, and when a large number 
of animals are to be kept, a stable should be on each side of the floor, so that a one-horse cart may be used to bring the summer food. By this arrangement, there is little more labor in feeding fifty, than twenty-five animals in the ordinary way. Then water should be convenient. A tank in the yard near the stable; more convenient still, pipes arranged for pumping the water in front of the animals, so that a man, or power, at the pump, may water any number of animals at once. Some barns are so arranged that the manure is dropped, by a trap door through the floor, into a cellar. This is an economy of labor, and also a great saving in manure, as it is kept from all exposure to sun, wind and rain.

"Let us, in conclusion, epitomize the soiling system. There are three incidental sources from which the extra labor is more than compensated.

"1st. The extra product of milk, butter, and beef, will pay the labor.

" 2 d. The manure, being all saved, will more than pay the labor.

" $3 \mathrm{~d}$. The saving in fences, as we have seen, is a great item, and will more than pay the labor.

"And lastly, the saving in land, when turned to full account, will enable the stock feeder to double the net income of his farm. That this is a moderate calculation, we have only to look at some of the small German States, where eight cows are fre. quently kept upon ten acres. There, fences are unknown-all animals are soiled, and necessity has compelled economy of land; thus we see the result. American farmers are ever seeking for more land-too seldom for greater products. The small farmers will find their interest in using the land they have, before striving for more, which they do not well cultivate. Tillable land, worth even twenty-five dollars per acre, cannot be profitably pastured. Let the small farmers, at least, try soiling. If 
they can keep a cow to every acre and a half, or two acres, their farms will be, practically, as large as their more favored neighbors. And when the system is demonstrated by the small, the large farmers will adopt it in mortification at the comparison."

\section{ANOTHER EXPERIMEXT.}

Exhaustive as these extended remarks may appear, we add an article, which has since come under our notice, from the "Practical Farmer," published in Philadelphia, which confirms our own opinions, as a tried test, of the benefits of soiling dairy cows in summer. The great value of this improved mode of feeding will justify its insertion.

"It is an account of a dairy farm in Chester Connty, $\mathrm{Pa}$., owned and carried on by a merchant in Philadelphia. He began farming four years ago, having about one hundred acres of cleared land, for which he purchased twelve cows and two heifers. $\mathrm{He}$ engaged a farmer, who continued in charge two years, and made one thousand four hundred and thirty-two pourds of butter the first year, and one thousand five hundred pounds the second year This was principally from pasture alone, no provisions having been made, by growing early rye, corn fodder, or any other green food, to keep up a plentiful supply, either early or late in the season, when pasture was short, and it is so indispensable, in order to keep up the condition of the cows and their milk. The third year, the proprietor undertook the management himself, and made two thousand eight hundred and seventy-eight pounds of butter; and during the fourth year, ending April 1, 1867 , he made four thousand and fifty-five pounds, having increased his stock from fourteen up to twenty head-five of the latter, heifers with their first calves. He says:

" Now I suppose it will be asked by what management the butter was increased from one thousand four hundred and thirtytwo pounds, to four thousand and fifty-five pounds. There was 
but little change in the stock, almost all of the original cows having been retained, and the increase being but three cows and three heifers, but the increase in the butter was from twice and a half to three times the quantity. The difference in the management was this: My original farmer kept the cows only as I have before stated, on pasture; the farm then had nothing grown expressly to fodder or soil them with, which was, and is now, the custom with many farmers in our country; neither was there any meal fed, except it might be to a cow that had calved early in the spring, before the pasture was sufficient to turn out upon; also, the cows were permitted to remain out, exposed to cold, wet storms, (when they should have been stabled and kept dry,) thus early in the season checking the flow of milk, wlich is afterwards difficult to restore.

"'Early in the season, the young grass, when cows are first turned out to pasture, is watery, and tends to make the cows scour very much; and although it will in that state increase the flow of milk, and also the quantity of butter, yet it will be at the expense of the condition of the cow, reducing her in flesh, and telling upon her during the whole season. At this time, I consider it important that a cow should be fed with ship-stuff, or bran and corn meal, mixed night and morning. This not only assists in preventing scouring, but by keeping up the condition of the stock, increases the quantity of butter to a very considerable extent. My opinion is, that meal fed at this time, pays better, certainly as well as at other times during the season, not excepting in mid-winter.

"I am well satisfied that the condition of the cow, in order to obtain from her a full yield, or one that will be profitable, must at all times be well looked to. She must be well wintered and fed, so that when she comes out of the barnyard in the spring, after having calved, she is in good flesh, showing her keep, and the care taken of her, and not like what is too nuch the custom 
of the country, namely, dry cows, wintered on straw, and no shelter except it be the lee side of the barnyard, until the calf is dropped, when it is too late, for the poor in flesh cow, to yield her full capacity.

" A cow should at all times, when milking, be fully supplied with meal; not stimulated to excess, however, for that would certainly produce reaction afterwards; but she must have a full and plentiful supply, at all times, of good food and water. For that purpose, I have grown early rye to begin with in the early season, before the grass is sufficient to turn out on; then, after harvest, during the dry weather, when the pasture fails, Hungarian grass, (millet, ) to be followed with corn, sowed in drills for fodder, which, cut morning and evening, and fed to the stock whilst milking, fills them twice a day, and with the pasture, makes up all that is required. During the last season, while it was necessary to soil with Hungarian grass and corn for fodder, we have also fed two quarts of ship-stuff each night and morn. ing, as we feel satisfied that, although the Hungarian grass and green corn will keep up the yield of milk, yet they will not alone make as much butter, as a full supply of pasture or the natural grasses.

"I look upon a cow as similar to a steam boiler; no matter how good they may be, unless the boiler is well supplied with water and good fuel, also well attended to, the supply of steam will be short, or it will be in proportion to the fuel and attention. So, also, with the cow; no matter how good she may be, if she is not well and plentifully fed and cared for, her product will be shortened.

"'A nother very important matter with cows, is, that they should be protected from storms and bad weather. They should be fed and kept under shelter when the nights are wet and inclement; this more particularly in the early season, when the cow is fresh and in full milk; one exposure to a cold, wet night, has frequently reduced the milk one-half. Also in the fall, when the 
nights become frosty, never let them remain out; be particular to stable them; and in the morning never turn them out on the pasture until the frost is melted off by the sun, as nothing, perhaps, dries a cow, or reduces her milk, more than eating grass with the frost on. To many of these requirements, the generality of farmers pay no attention whatever. In the early season, as soon as there is any pasture whatever, the cow is turned out of the barnyard to eat what she may find, and to remain day and night until the winter comes. There is nothing grown or fed to eke out the scanty supply of pasturage that almost invariably occurs at some time in each season.' "'

Although the writer, in these last two paragraphs, has expressed nearly the same views which we have elsewhere given, they are recorded as strongly fortifying our own.

In this somewhat elaborate, and in some of its necessary incidental duties, repeated discussion of the benefits of soiling, we do not anticipate an immediate revolution, or indeed any great degree of reform in the long practiced methods of cattle keeping, in this country of comparatively cheap land and dear labor-excepting, possibly, the feeding of milk cows. Yet it is a subject deeply concerning the economy of our cattle husbandry throughout. A snug, compact system, widely different from the too generally loose way of managing stock, must be adopted in order to carry it out. Our smaller stock farmers will probably be the first to adopt it, and it will ultimately, to a considerable extent, be adopted by the larger ones as their land becomes more valuable, and its advantages become better understood. Those living immediately contiguous to the larger towns and cities, must adopt it of necessity; the large dairies will follow; then the stall-feeders; and ultimately a great many of the stock breeders, and graziers, will fall into it from a sheer conviction of its advantages. The farmers inhabiting the wide pastoral regions of the far West, will be slow in coming into a plan requiring so much of system, of close calculation, but no long cycle of years will 
elapse before soiling will be as common in the densely peopled sections of the United States, as its benefits will be advantageous.

\section{FALL FEEDING OF COWS.}

As the season of green food passes by, soft, early cured hay, cut short in a machine, and mixed with grain meal, or "middlings" from flour mills, is the best material as a substitute for the failing grass, or green clover and corn. The quantity of the hay and meal giver must be judged by the dairyman, (see next chapter,) but the cow must have enough. Understand, all this extra food must be regulated by the supply of grass, which she may obtain from the pasture, or otherr green food.

The food of the cow, in its kind, influences, to a greater or less degree, the richness of her milk, and the quantity of butter or cheese it will make, as well as its quality. The dairyman, who sells his milk for immediate consumption, regards quantity more than quality, and is therefore apt to use that food which will most readily produce it. But it must be remembered that the flesh of the cow is to be kept in good condition all the time, to render her permanently serviceable, and the flesh-producing quality of her food should not be neglected, while that most favorable to the secretion of her milk is provided.

As the nights now grow chilly, the cow should be kept in her stable through the night, and if stormy, through the day. When the frosts begin to nip the pastures, even if there be a good growth of grass, she should not eat it early in the morning, nor until the frost be melted off. She should be fed in her stall before going out to graze. A moderate amount of good hay-if finely cut, the better-may be laid at right in her manger, to make more solid the succulent food otherwise fed, that her bowels may be kept equable.

WINTER FEEDING OF cows.

For winter food, much will depend upon the time at which the cow is to be dried, and also upon her bodily condition, in each 
of which the dairyman must be the judge. If she has been thoroughly driven in her lacteal yields for the past eight or nine months, three months is none too much time for her to rest, and properly recuperate her faculties for another season. It is also doubtful whether, in ordinary cheese and butter dairies, the extra expense of forcing her with stimulating milk-producing foods, will pay during the inclement seasons, when all dairy work must be prosecuted at comparative disadvantage. That must be left to the judgment of the dairyman.

If the cow be reduced in flesh by her severe toils at the pailand she cannot but be somewhat so, if a really good milker, and with plenty of milk-creating food-she must, to continue her usefulness, be fully recrnited during the winter. She may be dried off in December. She should produce her calf in the latter part of March-or by the tenth of April, at the latest. Her winter forage should be soft, sweet, well cured hay - cut when the grass is not earlier than in its first bloom, and before the seed hardens into ripening, of whatever kind of grass the hay be made. Whien a large stock is kept, the hay may not always be thus seasonably made. If not, it should be as near to it as possible. Hay alone will not recruit lean cows during the winter, into good dairy condition for the coming season. Indian corn, oat, barley and rye meal, or wheat bran, or middlings from flour mills, buckwheat meal, or roots, may be resorted to for assistance; but at all events the cow should be restored to good con dition for the proper production of her calf, and the wear and tear of the succeeding season of hard milking. The hay for feeding should be cut short, as when in giving milk, say a quarter, and not to exceed half an inch long, in a machine. It is better, and a saving of at least one-fifth to one-fourth in quantity of consumption. If the meal, with plenty of water, be sprinkled upon it, and well mixed, she will thrive all the better.

Roots are a good winter and spring food for cows, particularly to promote the flow of milk when about calving. The kinds of 
roots we most recommend are mangold-wurtzel, sugar-beet, and carrots. Turnips, and ruta-baga, aside from giving their own taste to the milk, are uncertain crops in our dry and hot climate, and the fly often destroys them altogether. They are an English crop, and are better fitted to its moist, cool summers, than to ours. As a crop to be depended on we do not recommend them. The other roots named are easily raised, and generally sure. Roots, of any kind, should always be well cleaned, and cut in a machine, or by a spade, or knife, before feeding to the cow. The situation and locality of the dairyman, and his facilities for obtaining grain feed, must measurably control his choice of these extra articles. The food should be given three times a day-morning, noon, and night.

In addition to her feeding, the cow should be kept clean, in a warm, well ventilated stable, and bedded with straw, or other coarse litter; and if the time can be spared, curried over daily with a card. She should be salted as often as once a week, at least-a trifle of salt daily, or tri-weekly would be better-and looked after as carefully as her condition requires. The cow is a part of the working capital of the dairyman, farmer, or housekeeper, and no good manager can afford to neglect her. $\mathrm{We}$ may have repeated this injunction in other places; but "line upon line, and precept upon precept," need not be considered superfluous in a work of this importance. 


\section{CHAPTER XXVII.}

SALE MILK DAIRIES.

DAIRIES kept for milk to be sold for immediate consumption, or manufactured into the "concentrated" article for transportation abroad, are of such importance throughout our country, that a full chapter on them may be submitted. To show, somewhat, the value of purchased milk in the United States, the "American Agriculturist," of January, 1867, informs us that the consumption in the city of New York, and its immediate vicinity, comprising about two millions of people, a ratio of less than onethird of a pint per day to a person, amounts, at the sale price, to four and a half millions of dollars a year! Of this sum, the producers of the milk get $\$ 2,300,000$, and the other $\$ 2,200,000$, or about one-half the gross amount, is absorbed by the railroads in freight, and the dealers' profits, which stand between the producer and consumer. Now, as every city, town, and village of any size in the United States, is more or less supplied with milk from dairies kept for that particular purpose, it must be apparent, that of the forty millions of people in the United States, at least one-eighth part of them must buy their milk; and of these one-eighth, or five millions, each consume, as for their health they ought to do, half a pint per day, the average quantity per year will be $114,062,500$ gallons. And if this be worth twelve cents a gallon to the producer, as it probably is, taking the year through, the sum total is the moderate sum of $\$ 13,687,500$ - and that only for one-eighth of our population! We think our estimate is too low-that more than one-eighth 
buy the milk they consume; but as there are numberless family cows kept in cities, towns, and villages, by private residents, who not only thus furnish their own milk, but supply an occasional neighbor, we let the estimate stand as not far out of the way.

As milk is, or ought to be, largely consumed by chilären, and enters also into various processes of table use, and cookery, it should be pure, produced by healthy cows, which are fed on nutritious, and healthy food. It is of the highest importance, therefore, to know how so to produce the milk, as well as to economize, in every possible way, the manner of its production.

SWILL MILK.

It is known to every intelligent person that there are millions of gallons of what is called milk, produced in the neighborhoods of our largest cities-within them, indeed-which is utterly unfit for any edible use whatever,-swill milk, so called, drawn from cows fed upon the refuse of distilleries, and other garbage, poisonous, and offensive. The whole internal system of the cows, so fed, becomes distempered. The fœid liquid merely percolates through the diseased glands and milk veins of the cow, and is drawn off in the color of milk, without its proper substance, and to the detriment, instead of nourishment, of every stomach into which, either directly or indirectly, it enters.

Every such mille dairy is a common nuisance; and as such it should be suppressed, and the owners and keepers of them sum. marily punished, both by fine, and imprisonment. And if a "Humane Society," or a "Society for the Prevention of Cruelty to Animals" exist in the vicinity of where these nuisances are kept, the first should compel the health authorities of the municipalities to prohibit the sale of their milk, and thus cease poisoning children, and the other should rescue the poor suffering cows from further torture, and a lingering death. It would be so in a country where law is enforced-for we already have law enough 
to abate these nuisances-but we fear that nothing less than a knowledge of the imposition, and a determination on the part of those concerned, to refrain from the use of the article, will help the matter. On persons concerned in such establishments, our words, if they ever see them, will make no impression, and we therefore address ourselves to those who pursue an honest and honorable business in their own legitimate dairies.

GOOD MILK.

The establishment and management of a sale milk dairy, is altogether different from the butter and cheese dairy. It is to be continuous in its supply throughout the year. A constant, daily demand is made upon it. No calves are fatted; no rearing of heifers is permitted. If a cow is wanted, the dairyman must strike out and obtain her wherever he can, at any possible price, so that she be a good one. If a cow fails, she must be disposed of at the best advantage; but disposed of she must be, as she can be of no further profit to the concern. It is simply an industrial and commercial matter; "profit and loss," as in any other business, being the only financial items to be taken into account. Therefore the simple proposition to the milk dairyman is, to get his buildings in the best order of arrangement for convenience and economy, and fill his herd with the best cows, of whatever breed, or no breed at all, that will answer his purposes. His cows should bring their calves periodically-every month, or week, as his numbers may be, for the average monthly supply of milk must be maintained-perhaps more in certain months than in others-and that must be calculated. He must keep a bull, as that is the best economy if he have more than twenty cows, and there be none that he can use within a con. venient distance in the neighborhood. Let the bull be as small in breed, as possible, so that his calves, while in fœtus, may be small, and draw as little on the internal foetal nourishment from 
the cow as possible. If the fotus be large, it will detract from her milk production, which cannot be afforded, as the calf when born is worthless, and must be immediately sacrificed to obtain the milk for use.

The dairy once established, the manner of keeping the cows comes next under consideration. For summer feeding, the method has already been given in our previous pages on the summer food of ordinary dairies. (See Soiling.) But the winter keeping is a different matter, and of this we shall go somewhat into detail. In treating of this, as all sale milk dairies are kept in the vicinities of populous places, we assume that land is dear, and winter forage bears corresponding prices. The dairyman may not be able to grow all his own hay, or straw, and may have to purchase it. He may raise his own roots, which he should do, if he feeds the article; and his grain, or mill-feed, he must, to a greater or less extent, purchase. $\mathrm{He}$ must also give to his cows that kind of food which will produce the greatest quantity of good milk, and prepare it in such a manner as to do its utmost in that production. Therefore he must, or ought to, cook it.

\section{COOKING FOOD.}

We have given much thought to this subject,-and some little observation, although we have not personally applied the cooking process to cattle feeding. We are, however, happy to again avail ourselves of the authority of Mr. Stewart.

We so fully accord with his conclusions, that we at once adopt his views, which we most opportunely find in the "Report of the Commissioner of Agriculture," for the year 1865, made to the Congress of the United States, as being more germain to our purpose than anything we can suggest, or find elsewhere. It is equally applicable to fattening cattle for the shambles, as for dairy cows, and may be referred to in connection with our remarks on the subject in a previous chapter. 
The article is entitled, "Cutting and Cooking Food for Animals: By E. W. Stewart, North Evans, Erie Co., N. Y.:"

WHY FODDER SHOULD BE CUT.

"The object of mastication of food is to comminute it, to break down its structure, and to render it more easily acted upon by the gastric juice, thus enabling the animal to appropriate its nutriment. Now, the more finely divided, food is, when subjected to the gastric juice, the more rapidly and easily it is digested. For when finely divided it presents many hundred times more surface to the action of the digesting fluid. This is simply represented in cooking fine meal or whole grain. We know it takes but a few minutes to cook the meal, while hours are required to soften the whole grain.

"When cattle eat succulent food, the fibre is easily broken and reduced to a pulpy mass; but not so with dry, woody fibre, which must be broken and comminuted before the food contained in it is accessible for animal nutrition. This the animal seldom does, and more especially the non-ruminating; therefore, it becomes highly necessary that we should use machinery to assist the animal, as much as possible, in extracting the nutriment contained in dry food. And if it be profitable to cut hay, straw and other coarse fudder, for the purpose of breaking the fibre, and rendering it more easy of mastication and digestion by the animal, then it is well to cut or divide it as finely as is consistent with economy. There is no danger of inventing machinery which will cut or pulverize it too finely. The great want now is, a machine, cheap and durable, which shall reduce woody fibre to pulp. This will require a machine which shall bruise as well as cut, so as to leave the whole fibre thoroughly mashed and divided. It will not be liable to the objection urged, that it will leave nothing for the animal to do; for this dry fibre, when reduced to the greatest degree practicable, will still require more 
mastication than green grass. Our whole effort in cutting and steaming is merely to produce an imitation of nature's green food.

\section{MIXING DIFFERENT QCALITIES OF FOOD.}

"Here, another advantage not to be overlooked, is, that it enables the feeder to mix different qualities of food together, making it all palatable, and thus saving all. This is a matter of great importance, and alone would vastly more than pay all the expense of cutting. In this manner, poor straw and good hay may be mixed, coarse swale meadow hay with fine hay, corn stalks with hay, and pea or bean straw with hay, when the poorer qualities would not be eaten alone; or, if hay be scarce or of too high price, cut straw may be made equivalent to the best hay, by mixing two quarts of fine middlings or bran, or one quart of corn meal with a bushel of straw.

"The writer of this paper has practiced cutting and steaming fodder, of all kinds, in winter, for a stock numbering from ten to fifty-five neat cattle and horses, during the last ten years. $\mathrm{He}$ therefore deems his experience sufficient to enable him to speak with some degree of confidence. He tried a long series of experiments, to determine the quantity of middlings or meal necessary to mix with a bushel of straw, to render it equivalent to the best hay. Ten animals of about uniform size, standing in the same stable, were parted-five being fed upon hay, and five upon the mixture. At first, four quarts of middlings were mixed with a bushel of straw. The animals were fed for one month-five upon this mixture, and five upon the hay. Those fed upon the mixture were found to gain decidedly upon those fed upon the hay alone.

"The experiment was then reversed, putting those upon the mixture that had fed upon the hay, and vice versa. At the end of the month those fed upon the straw and middlings had gained rapidly, while those fed upon the hay had hardly held their con- 
dition. Then the experiment was continued by reducing the quantity of middlings one-half, or two quarts, on which mixture the animals did rather better than those upon hay, while, upon reversing, those at first fed upon the hay when fed upon this mixture did better than those on hay. Upon several trials after. wards, it was uniformly found that a bushel of straw with two quarts of middlings was quite equal to the same weight of cut hay, and was worth twenty-five per cent. more than uncut hay. It was found that the animals would eat twenty-five per cent. more hay uncut than cut. The same experiment was then tried with corn meal, and one and one-half pints were found to make a bushel of straw equal to hay, though the formula is generally given as a quart to a bushel of straw, which will render almost any quality of straw equal to the same weight of good timothy hay.

"The writer has found for many years that he can winter his stock in better condition on straw and middlings, or meal, in the proportions given, than on hay. This is a large item near a good hay market, and where straw is worth but little, or in a grain country, where little else than straw is raised as fodder for animals. In this way all the coarse fodder on the farm, of every description, may be consumed by animals, and thus turned into money. Where steaming is practiced there is also a large profit. Besides, this enables the feeder to prepare a special food to produce such special results as he may desire. It is well known that the intelligent feeder may increase the frame, or muscle, or fat of an animal exclusively, or he may increase them all together. If he wishes to increase the frame and muscle particularly, he will give food rich in phosphate of lime and gluten, without having much oil or a large proportion of starch; and for this pnrpose, pea or bean meal, mixed with his coarse fodder, will produce the desired result. If he wishes to lay on fat principally, he will use corn meal or oil meal. If to produce growth of the 
animal in frame and muscle, as well as fat, let him mix the different kinds of food together. Thus he may produce such results as he pleases, and, at the same time, use what would otherwise be refuse and waste.

"It is shown, by accurate observation, that hay, straw, or other coarse fodder, when well cut, is more uniformly digested by both neat cattle, horses, and sheep, than uncut. In England, large feeders have estimated the gain in nutriment and saving of waste in hay to be equal to twenty-five per cent. Some experimenters in this country have estimated the gain even higher, and certainly the gain is more in cutting coarse fodder than on hay.

\section{WHAT IS GAINED IN CUTTING FOR A SMALL STOCK.}

"An experiment will illustrate the profit of cutting. When keeping a small stock, which would consume thirty tons of hay in a winter, seven tons of hay were sold, and seven tons of middlings bought and used upon cut straw, (two quarțs upon a bushel,) and the stock wintered in fine condition. The straw was thus turned into twenty-three tons of hay, worth, that year, $\$ 18$ per ton in barn, or $\$ 405$; (generally it is worth $\$ 12$ per ton.) Hay, in most localities, is worth as much per ton as middlings, and half to three-fourths as much as corn meal; therefore the avails of one-fourth the quantity of hay requisite to winter a stock of animals, will purchase the middlings or meal necessary to use upon the straw, and the hay (or its value) be saved to the farmer. Indeed, from long practice, the economy of the straw cutter is as well established with the writer of this article as that of the mowing machine.

"But it is sometimes said that it may pay on a small scale, and accordingly many small hand machines are found by which farmers cut for a few cows, or a pair of horses, still feeding the principal part of their stock uncut food. In this idea the ordinary rule of manufacturers is reversed, viz.: that what will pay upon 
a small scale will pay much better on a large scale. It costs more in proportion to make one wagon than one hundred; so it costs more in proportion to cut fodder for five animals than for fifty. To show that it pays on a large scale, to cut hay, we have only to refer to the fact that the large omnibus lines and street railroad companies of our large cities cut all the hay and coarse fodder used for their hundreds of horses. These companies have learned, from practical experience, that the saving is many times the cost of cutting.

"When cutting is done for a large stock, with the largest size two-horse machine, it takes but little longer to cut a ton of hay than to handle it without cutting. Horse or steam power is much cheaper than hand power when more than a few animals are to be fed.

\section{STRAW CUTTERS.}

"Much improvement has been made within a few years in the construction of straw cutters. It is of the highest importance in selecting a machine, to get one that cuts short and with perfect regularity; and to this end great attention must be paid to the feed apparatus. Unless the hay or straw is delivered to the knives with perfect regularity, the work will be badly done. The greatest fault of most machines is the defect in this part of the machinery. Some are fed by hand. These should be discarded, as there can in this way be no regularity of cut. A short and regular cut secured, next in importance is strength, simplicity, and durability. The perfection of this kind of machine is yet to be invented which shall mash or pulp the fodder.

COOKING FOOD FOR ANIMALS.

"Steaming food is less practised but even more important than cutting. Cooking food for animals is of comparatively recent date. A brief notice of its rationale will demonstrate its imnortance, as well to animals as to man. 
"Pereira says: 'To render starchy substances digestible, they require to be cooked, in order to break or crack the grains; for of the different lamina of which each grain consists, the outer ones are the most cohesive, and present the greatest resistance to the digestive power of the stomach, while the internal ones are least so.' 'Starch,' says Raspail, 'is not actually nutritive to man until it has been boiled or cooked. The heat of the stomach is not sufficient to burst all the grains of the feculent mass which is subjected to the rapid action of this organ. The stom. achs of graminivorous animals and birds seem to possess, in this respect, a particular power, for they use feculent substances in a raw state. Nevertheless, recent experiments prove the advantage that results from boiling the potatnes and grain, and partially altered farina, which are given to them for food; for a large proportion, when given whole, in the raw state, passes through the intestine perfectly unaffected as when swallowed.' Braconnot found unbroken starch grains in the excrement of hot-blooded animals fed on raw potatoes; hence he adds, 'the potatoes employed for feeding cattle, should be boiled, since, independently of the accidents which may arise from the use of them in a raw state, a considerable quantity of alimentary matter is lost by the use of these tubers in the unboiled state.'

"So much for the effect of heat upon grain and roots; but it may be asked whether we can derive the same benefit from cook. ing hay, straw, and other coarse fodder for stock. The following quotation from Regnalt will show what difference exists between them, the stems containing woody fibre as well as cellulose, while roots and grains do not:

" A microscopic examination of the various component parts of plants, shows them all to be constituted of cellular tissue, vary. ing in form according to the part of the vegetable subjected to examination. The cavities of the tissue are filled with very diversified matter; sometimes, as in the case of wood, the parietes of the cells are covered by a hard and brittle substance 
called lignin, or woody fibre, which frequently almost completely fills their interstices; while, at other times, as in the grains of the cerealia, potatoes and other tubers, the cells contain a quantity of small ovoidal globules, varying in size, constituting fecula or starch; and lastly, in the case of the young organs of plants, the cells contain only a more or less viscous fluid, holding in solution mineral salts and various organic substances, the principal of which are gums, gelatinous combinations, designated by the general name of albuminous substances.' We conclude, then, that if heat aids in rendering the nutritive principles of roots and grains more accessible to the assimulating faculty, it will also assist in softening the fibre of hay and straw. The cell walls which imprison the alimentary substances mentioned, will, by the joint processes of cutting and steaming, be more or less broken and weakened.

"The following extract from Johnston's Agricultural Chemistry, shows the further effect of heat upon starch itself:

" "When wheat flour, potato, or arrowroot starch is spread upon a tray and gradually heated in an oven to a temperature not exceeding $300^{\circ} \mathrm{F}$., it slowly changes, acquires a yellow or brownish tint, according to the temperature employed, and becomes entirely soluble in cold water. It is changed into dextrin gum. * * * During the baking of bread this conversion of starch into gum takes place to a considerable extent. Thus Vogel found that flour which contained no gum, gave, when baked, a bread of which eighteen per cent., or nearly one-fifth of the whole weight, consisted of gum. Thus, one result of baking, is to render the flour starch more soluble, and therefore more easily digested.' Of starch he says: 'It is a property of starch of all kinds, to be insoluble in cold water, but to dissolve readily in boiling water, and to thicken into a jelly, or paste, as it cools.' It is supposed that, by digestion, starch becomes converted into gum or sugar, and the latter probably becomes absorbed. It is also an element of respiration, and, according to Liebig, con- 
tributes to the formation of fat in animals. His theory is, no doubt, well founded, and explains the fattening of animals when fed upon Indian corn.

\section{VALUE OF STRAW, ANALYSES, ETC.}

"Few farmers are aware of the value of straw. By the present system of feeding in this country, little or no account is made of it. It serves mostly as litter for animals. Let us examine the general analysis of straw, as compared with the forage crops and grains. The following table is from the Cyclo. pædia of Agriculture:

\section{Average composition of wheat straw.}

"Dried at $212^{\circ}$ Fahrenheit, 100 parts con-

tain nitrogenous substances, or-

Muscle-producing substances, _ . 2.05

Heat-producing substances, . . . 35.06

Woody fibre, . . . . . . . 56.87

Mineral substances, . $\quad$ • $\quad$ • $\quad$. 6.02

100.00

Corn fodder and bean straw.

(J. H. Salisbury.) (Prof. Way.) Corn fodder. Bean straw.

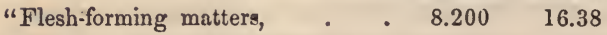

Heat and fat-producing matters, $\quad 35.273 \quad 33.86$

Woody fibre, . $\quad$. $\quad . \quad 50.251 \quad 25.84$

Mineral matters, . . . . . . . $\quad 9.45$

$\begin{array}{lllllll}\text { Water, } & \text { • } & \text {. } & 6.276 & 14.47\end{array}$

$100.000 \quad 100.00$

Cultivated grasses, average, dried at $212^{\circ}$ Fahrenheit.

(Prof. Way.)

"Flesh-forming principles, . . . . 10.34

Fat-producing principles, . $\quad$. $\quad$. $\quad 2.51$ 
Heat-producing principles, . . . 41.29

Woody fibre, . . . . . . 37.18

Mineral matters or ash, . . . $\quad$. 8.68

100.00

(It will be seen that good hay is altogether more profitable food for either flesh, or milk, than any straw.-L. F. A.)

Indian corn and wheat bran.

(Salisbury.)

Ind. corn. Wheat bran.

"Flesh-forming principles,

$15.192 \quad 18.00$

Heat-producing principles, . . $78.866 \quad 63.00$

Fat-producing principles, . $\quad 5.945 \quad 6.00$

Water,

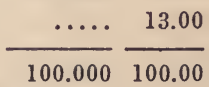

Oats and rye.

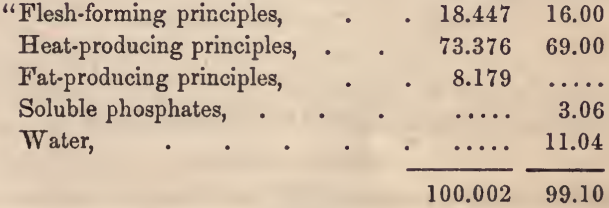

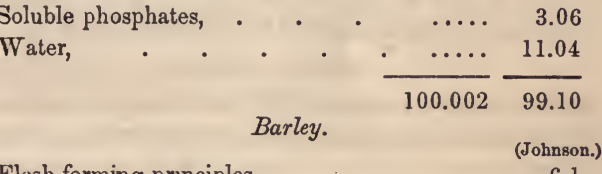

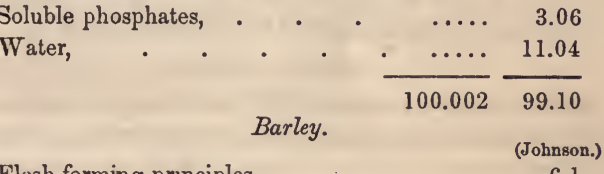

"Flesh-forming principles,

(Emmons.) (Johnson.)

Oats. Rye.

"Flesh-forming principles,

Heat-producing principles, . . $\quad 73.376 \quad 69.00$

Heat and fat-producing principles, . . 69.3

Husk, • • • • • • . 13.8

Water, • • . . . . . 10.8

100.00

Beans and peas.

"Husks,

Peas. Beans.

Legumin, Albumen, \&c.. $\quad$ • $\quad$ • $\quad 26.4 \quad 23.6$ 


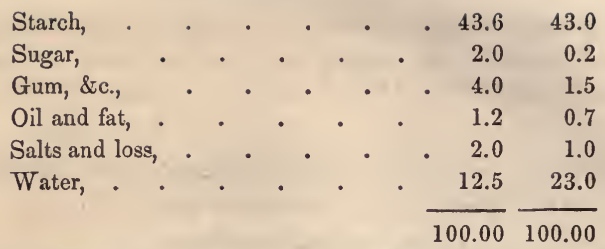

"The analysis of wheat straw, cornstalks, and bean straw, will show at once the large amount of nutritive matter they contain, besides that denominated wood fibre. Bean straw and wheat bran, it will be seen, are very rich in nitrogenous matter, and therefore will build up the muscular system of the animal. From long experience we have found wheat bran to be equal, practically, to the analysis. If steamed, we regard it as valuable, per weight, as corn meal. Its analysis indicates that it has more muscle-forming matter than corn. This will indicate the important use that farmers should make of bran, when it is to be had for the price of hay, in feeding cows and young animals. An examination of these analyses will show readily how to mix a proper food, to build up all parts of the animal system.

\section{STEAM APPARATUS.}

"It will now be in order to give the reader a detailed account of the manner of conducting this cooking process. A perfect steam apparatus is yet to be invented. Many methods are used. The writer will describe the one he uses, and also a simpler and cheaper one for a small stock.

"The one he has now in use, consists of a wrought-iron cylinder, one-eighth inch thick, thirty inches in diameter, four feet long, with one-quarter inch iron heads. The front end has an elliptical opening, by which to draw off the water and clean it out, secured, when in use, by an iron stopper with rubber pack ing. On the top is another like opening, through which to fill 
it with water, and secured in like manner. An iron pipe, one and a half inch in diameter, is fastened to the top of the boiler, passes over the side of the brick-work, and down to the bottom of the steam box, where it enters the side near the center. This boiler is set in brick-work, in a horizontal position. It is raised about sixteen inches above the fire bed or grate. The fire is conducted under the length of the boiler, and partly up the back end; then carried along each side, to near the front end in a flue, and carried back to the chimney in another flue above this. This leaves the front end of the boiler exposed, in which there is a cock from which to draw hot water if wanted. My steam box is made of matched pine plank, one and a quarter inch thick. It is four and a half by five feet, and three feet deep, holding over fifty bushels of feed. It might be larger if the stock required it, as my boiler generates steam enough for one hundred and fifty bushels. The box is closed with a wooden cover.

\section{PREPARING FOOD FOR STEAMINO.}

"The feed is prepared for steaming, thus: The cut straw, hay and straw, roots, or other cut feed, sufficient to fill the steam box, is measured in a square six-bushel basket. It is then moistened by a four-gallon watering pot, with twenty gallons of water to fifty bushels of feed, while it is being stirred up with a fork. Then two quarts of wheat bran to the bushel of straw, is mixed in the same manner, and a little salt added, when it is put into the steam box and steamed for an hour and a half. This feed will keep warm for two days in the coldest weather.

"The reader will readily see the defect in this arrangement, as, with such a steam box, no considerable pressure can be obtained; hence it does not reduce the feed to such a pulp as is desirable. Yet it modifies and softens it very much. My boiler would safely bear a pressure of thirty pounds to the inch, and, with an iron steam box, the feed could as cheaply be put under that pres. 
sure, and reduced to such a pulp as is desirable, as it now is, steamed in the wooden box. When iron work shall be reduced to the price charged before the war, an apparatus with iron boiler and iron steam box, will be within the easy expenditure of every considerable cattle feeder, costing not over one hundred and fifty dollars. This amount would be more than made up by its use for a single year.

\section{CHEAP STEAMER.}

"We will next give a description of a very simple apparatus, which is within the reach of every farmer. It is described, with. out the improvement which should be made to it, in the transactions of the American Institute for 1863. 'Get a sheet of No. 18 iron, (No. 16 would be better,) thirty-two to thirty-six inches wide, and seven or eight feet long, (or two sheets may be riveted together, and thus make one fourteen feet long, if much work is to be done.) Take 2-inch pine plank, (maple would be better,) about two feet wide; let the sides extend three inches past the end plank; make a box a little flaring at the top, and wide and long enough, so that the bottom sheet will cover and project half an inch on each side and end. Let the ends into the sides, $1 / 4$ to $3 / 8$-inch, in making the box, and put it together with white lead and oil, and put two $3 / 8$-inch iron rods through the sides at each end, outside of the end plank; then nail on the bottom sheet with two rows of five-penny nails, the nails about one inch apart in the rows, and breaking joints, and bend up the sheet where it projects.' This will hold some thirty bushels. 'Now take flat stones or bricks, and make a fireplace the length of your box, and eight inches narrower on the inside, than your box is wide on the outside.' Fire bed should be sixteen or eighteen inches deep. 'Put across at each end, a flat bar of iron, $1 / 2$ by $1 \frac{1}{2}$ inches, so as to lay a row of bricks on these for the ends of the box to rest on, and at the back end, let the arch run out so as to build a small chimney, and put on some joint3 of stove pipe, and you have a cooking apparatus.' This is a 
good boiling arrangement, where only water, or some thin liquid is to be heated; but if hay or straw, or even potatoes, are to be boiled with little water, as would be the case, especially in steaming fodder, it would settle and burn on the bottom. We have many times tried this in a large kettle, with this result. This difficulty can be obviated entirely, and a good steaming apparatus be made of it, by placing a false bottom one inch above the real bottom. This may be done in the following manner: Take a sheet of No. 18 iron, of the size of the box, or, perhaps, onehalf inch wider; have this punched with small holes, so as to let the water down and the steam up. It can be let into the side of the box, or a half-inch cleat can be nailed on the side and end of the box, for it to rest on. This would not sufficiently support the weight of feed to put on it, and, therefore, $3 / 8$-inch rods must be put through the sides, under this false bottom, to sustain itone, perhaps, every foot. Then a wooden or iron faucet, must be put through the side, between these bottoms, to draw off the water. Now, a wooden cover, on the top of the box, to keep the steam in, and here is as complete, effectual, and cheap a steamer for cooking without pressure, as can be desired. The whole apparatus would not, probably, cost over $\$ 25$, for the seven feet, or $\$ 50$ for the fourteen feet length. This largest size would be ample for fifty to serenty-five head of cattle and horses. The chimney should be as long as the steam box, to make a proper draft.

- "There is, also, D. R. Prindle's agricultural caldron and steamer, a portable apparatus used for boiling and steaming. It has been used in various parts of the country, and highly spoken of, for its convenience in being adapted to cooking for stock, as well as for most other heating purposes on the farm.

ARRANGEMENT FOR A LARGE STOCK.

"For the benefit of those who wish to feed a large stock, one to two hundred head of cattle, or more, we will suggest an 
arrangement which will save much labor, cconomize the material, and produce more uniform results.

"A portable steam engine of five horse power provided, we will arrange the animals, steam box, food, \&c., as follows:

"The stables are in the lower story, on each side of a feeding floor ten feet wide. It would be more convenient to have room behind each tier of animals, to pass a cart, or wagon, to carry off the manure, than to throw it out at the side. A wooden track should be laid in the center of the feeding floor, on which to run the steam boxes. Two, holding one hundred bushels each, should be provided for one hundred cattle. One would be run under the upper floor to be filled and steamed, and then moved away for use; while the other could be run to the spot, filled and steamed. On the upper floor, the straw cutter would be placed, provided with a feeding apron to feed itself, with two bins overhead, one for cut hay or straw, the other for meal and bran. Elevators, to carry up the cut feed from the straw cutter to the feed bin, as fast as cut, would be necessary.

"There would also be necessary, a water pipe connected with a pump or an elevated reservoir, to furnish water to moisten the feed. A tank might be placed overhead and filled by a force pump. Then, in a scuttle through the floor, directly over the steam box, there will be placed a cask or cylinder, three feet in diameter and five feet long, without a bottom, but a bar across the lower end, on which an upright revolving shaft will be set in the center, provided with six arms, just long enough to turn inside. This shat will pass through a like cross-bar on the top, and extending above enough to receive a pulley of the proper size, to revolve it some six hundred times per minute. Now, a spout will extend from the elevated feed bin to the top of this cylinder, with a slide to open or shut it; also, a spout extending from the meal or bran bin, so as to communicate in the same way with the cylinder, and a water-pipe, also, furnished with 
stop-cock and movable cover, will be placed on top of the cylinder. A belt will run from the engine to the pulley on top of this shaft. Now, when ready to fill the steam box, this shaft will be set in motion-the spout for cut feed will be opened so as to discharge a definite quantity, the spout for meal opened to discharge the proportion desired, and the water, so as to let in twenty gallons for fifty bushels of feed. It will be seen that the feed, and meal, and water, in passing through the cylinder, will come in contact with these swift moving arms on the shaft, and be thoroughly mixed, and fall into the steam box, ready for steaming. The feed should be pressed into the steam box, as more will be steamed, and better. With this arrangement, one expert man may cut and steam feed for one hundred head of caltle, and two men could easily care for two hundred. It will be seen that, with proper system and machinery, the expense of cutting and steaming for a large stock, will be little more than in the ordinary way of feeding. This steam engine may be used to grind the grain, cut and steam the feed, and do all the work requiring stationary power on the farm. The engine should be placed as near the steam box and straw cutter, as it can be with safety. A double spark extinguisher must be placed over the chimney, to prevent fire.

\section{RESULTS OF COOKING.}

"It now remains for us to give the results of cooking by the method detailed.

"1st. It renders mouldy hay, straw, and cornstalks, perfectly sweet and palatable. Animals seem to relish straw taken from a stack, which has been wet and badly damaged for ordinary use; and even in any condition, except 'dry rot,' steaming will restore its sweetness. When keeping a large stock, we have often purchased stacks of straw which would have been worthless for feeding, in the ordinary way, and have been able to detect no difference, after steaming, in the smell, or the relish with which it was eaten. 
" 2 d. It diffuses the odor of the bran, corn meal, oil meal, carrots, or whatever is mixed with the feed, through the whole mass; and thus it may cheaply be flavored to suit the animal.

" $3 \mathrm{~d}$. It softens the tough fibre of the dry cornstalk, rye straw, and other hard material, rendering it almost like green, succulent food, and easily masticated and digested by the animal.

" 4 th. It renders beans and peas agreeable food to horses, as well as other animals, and thus enables the feeder to combine more nitrogenous food in the diet of his animals.

" 5 th. It enables the feeder to turn everything raised into food for his stock, without lessening the value of his manure. Indeed, the manure made from steamed food decomposes more readily, and is therefore more valuable than when used in a fresh state. Manure made from steamed food is always ready for use, and is regarded by those who have used it as much more valuable, for the same bulk, than that made from uncooked food. (This manure has another great value, as there can be no foul seed in it. Being cooked, and dead, they cannot grow.-L. F. A.)

" 6 th. We have found it to cure incipient heaves in horses, and horses having a congh for several months at pasture, have been cured in two weeks, on steamed feed. It has a remarkable effect upon horses with a sudden cold, and in constipation. Horses fed upon it, seem much less liable to disease; in fact, in this respect, it seems to have all the good qualities of grass, the natural food of animals.

" 7 th. It produces a marked difference in the appearance of the animal, at once causing the coat to become smooth, and of a brighter color-regulates the digestion, makes the animal more contented and satisfied, enables fattening stock to eat their food with less labor, (and consequently requires less to keep up the animal heat,) gives working animals time to eat all that is neces. sary for them, in the intervals of labor; and this is of much importance, especially with horses. It also enables the feeder to fatten animals in one-third less time. 
" 8th. It saves at least one-third of the food. We have found two bushels of cut and cooked hay to satisfy cows, as well as three bushels of uncooked hay; and the manure, in the case of the uncooked hay, contained much more fibrous matter, unutilized by the animal. This is more particularly the case with horses.

"These have been the general results of our practice, and, we presume, do not materially differ from thuse of others who have given cooked food a fair trial.

"George A. Moore, of Buffalo, N. Y., at the New York State Fair discussion, 1864, says: 'I was feeding sheep, and cutting for them timothy hay, millet, carrots, and feeding with bean and oat meal. Before steaming, I found, by weighing, I was putting on two pounds of flesh per week. After steaming, I put on three pounds per week, and the stock eat the food cleaner, and I noticed they laid down quietly after feeding. I also experimented with sixty-four cows. Used one of Prindle's steamers; had a quantity of musty hay which I cut and steamed. They would eat it entirely up, and seemed better satisfied with it than the sweetest unsteamed hay. Steamed food does not constipate the animal; the hair looks better. I think cutting and steaming combined, insure a gain to the feeder of at least thirty-three per cent. The manure resulting from feeding steamed food, is worth double that from feeding in the ordinary way. Have kept eighty head of stock, and had a surplus of food, on a farm where, previously, only fifty were carried through, and hay bought at that. After cows come in, steamed food increases the milk one-third, and the cows do better when put out to grass.'

"George Geddes, in the same discussion, says: 'I find if I take ten bushels of meal, and wet it in cold water, and feed twenty-five hogs with $\cdot$ it, that they eat it well; but if I take the same and cook it, it will take the same number of hogs twice as long to eat it up, and I think they fatten quite as fast, in the same length of time. By cooking you double the bulk.' 
"A. B. Conger, ex-president of the New York Agricultural Society, said at same discussion: 'But steaming alone is not sufficient in the preparation of the food. It must be first wet, so that if left alone ten hours it will heat. Water, in large proportion, must be added to the hay or straw after cutting. And so prepared and steamed, thirty head of stock may be kept on the same amount of food, as twenty on unprepared food. The mistake made in the early experiments in this country and England, was, that the food was not sufficiently wet before steaming.'

"Professor Mapes says,(Transactions A merican Institute, 1854, page 373): 'Raw food is not in condition to be appropriated to the tissues of animal life. The experiment, often tried, las proved that eighteen or nineteen pounds of cooked corn, is equal to fifty pounds of raw corn for hog food. Mr. Mason, of New Jersey, found that pork fed with raw grain, cost twelve and a half cents a pound, and that from cooked food, four and a half cents. Cooked cornstalks are as soft, and almost as nutritions as green stalks. Cooking is an improvement that pays. Cattle can be fattened at about half the expense upon cooked food, in a warm stable, that others can out doors upon raw food.'

"S. H. Clay, of Kentucky, says: 'Fed two hogs on uncooked corn in thirty days, 405 pounds, and they gained 42 pounds; while two hogs fed on cooked corn meal for thirty days, ate 270 pounds, and gained 80 pounds. The food was then reversed, and the two hogs that had previously had dry corn, were fed on cooked meal. In twenty-six days, the two hogs that were fed on dry food, ate 364 pounds of shelled corn, and gained 44 pounds; while the two hogs fed on cooked meal, ate, during the same time, only 234 pounds, and gained 74 pounds.' Here it appears that a bushel of raw corn makes $53 / 4$ pounds of pork, while a bushel of cooked meal makes $17 \frac{1}{2}$ pounds.

' James Buckingham gives, in the 'Prairie Farmer,' an experiment with cooked corn meal, corn in the ear, and raw meal. Hc 
put three hogs into separate pens. 'One ate three and a half bushels of corn in the ear, in nine days, and gained nineteen pounds. Another ate, in the same time, one and threc-quarter bushels of corn ground, and gained nineteen pounds; while the third ate, in the same time, one bushel ground and boiled meal, and gained twenty-two pounds.'

"The society of Shakers, at Lebanon, N. Y., communicated the following to the agricultural report of the Patent Office: 'The experience of thirty years, leads us to estimate ground corn one-third higher than unground, as a food for cattle, and especially for fattening pork. Hence, it has been the practice of our society, for more than a quarter of a century, to grind all our provender. The same induces us to put a higher value upon cooked than raw meal; and for fattening animals, swine particularly, we consider three of cooked, equal to four of raw meal, Our society, annually, for some twenty-seven years, has fattened 40,000 to 50,000 pounds of pork, and it is the constant practice to cook the meal, for which purpose six or seven potash kettles are used.'

"Such is the general tenor of the testimony of those who have tested sooking fairly in this country. It will be seen that most of the experiments relate to cooking grain. Steaming coarse fodder has not been extensively practiced here, but when a fair trial has been given, the result has been quite satisfactory. "Professor Horsfall, of England, has practiced mixing a special food for milk cows, to produce a large yield of milk of good quality, and to keep up the flesh of the cow in a full flow of milk. He says: 'I now proceed to describe the means I am using, to carry out the purposes which $I$ have sought to explain. My food for milk cows, after having undergone various modificacations, has, for two seasons, consisted of rape cake, five pounds, and bran, two pounds, for each cow, mixed with a sufficient quantity of bean straw, oat straw, and shells of oats, in equal 
proportions, to supply them three times a day, as much as they will eat. The whole of the materials are moistened and blended together, and, after being well steamed, are given to the animals in a warm state. The attendant is allowed one to one and a half pounds per cow, according to circumstances, of bean* meal, which he is charged to give each cow, in proportion to the yield of milk; those in full milk getting two pounds each per day, others but little. It is dry, and mixed with the steamed food on its being dealt out separately. Bean straw, uncooked, is dry and unpalatable; by the process of steaming, it becomes soft and pulpy, enits an agreeable odor, and imparts flavor and relish to the mess. In albuminous matter, which is especially valuable for milk cows, it has nearly double the proportion contained in meadow hay. Bran undergoes a great improvement in its flavor by steaming, and is probably improved in its convertibility as food. Rape cake has a large proportion (nearly thirty per cent.) of albumen, rich in phosphate and oil. * * * During May, my cows are turned out on a rich pasture near the homestead; towards evening they are again housed for the night, when they are supplied with a mess of steamed mixture and a little hay, each morning and evening. I have cooked, or steamed food for several years, and my experience of its benefits is such, that if I were deprived of it, I could not continue to feed with satisfaction.'

"Mr. Mechi, near London, England, has practiced cutting and steaming straw, mixed with materials similar to Professor Horsfall. He estimates straw worth about ten dollars per ton, to feed after steaming. His experiments have been quite extensive, and the results most farorable to cooking food. His practice has not generally obtained yet in England, but it is constantly extending,

* This is the English "horse bean"-B very different article from our American field bean-which our climate does not well produce,-L. F. A. 
and in this country stock feeders are just beginning to turn their attention to the subject.

AMOUNT OF STRAW AND COARSE FODDER WASTED.

"If we take the amount of grain and Indian corn raised in the United States, as by the census of 1860 , we shall find, by allowing forty bushels of grain to the ton of straw or corn fodder, that there were about $30,000,000$ of tons. Now, at least onethird of this is wasted, for every purpose except manure, and vast quantities not even used for that. Suppose we estimate this at one-half the value put upon it by Mr. Mechi, or five dollars per ton, and we have the enormous sum of $\$ 50,000,000$ wasted, for want of proper economy, in a single year. We believe this estimate much below the real loss."

To this valuable essay of Mr. Stewart, we add a most oppor. tune communication, from a thoroughly practical proprietor of a sale milk dairy, taken from a late number of "The Country Gentleman," published at Albany, N. Y. The article is from Mr. Wm. Birnie, of Springficld, Mass.

"I have practiced steaming feed for my stock since 1858, with constantly increasing confidence in its economy. In the autumn of that year I found myself with a stock of twenty head of cattle to carry through the winter with the forage provided for six, and was consequently forced to cast about for the most economical method of solving that seemingly impracticable problem. I immediately set about preparing to cut and steam the fodder.

"My barn is built on a side-hill, and is three stories in part, the principal story on which the barn floor is sitnated being level with the ground on the highest side, and used entirely for the storage of hay, grain, \&c. The next story below opens on to the barnyard, and is used for stabling and a root cellar, being under ground at one end. Under a portion of this story is a 
manure cellar fifty by twenty-eight feet, and eight feet deep, which opens on to a still lower yard.

"On the stable story is located the steam arrangement. In one corner of the under-ground part, is the boiler room, about ten feet square, made as near fire-proof as possible. The chimney is built of brick, on the outside, against the corner of the barn, and extends about six feet above the roof at that point. The boiler (tubular) is about the capacity of a four-horse engine. The vat, or chest, in which the steaming is done, is built of brick and lined with two-inch plank, tongued and grooved; is six feet square inside, and eight feet deep, and extends from the stable floor to the barn floor above, with a lid the whole size of the top, opening on a level with the floor. There is also a door four feet square on one side, near the bottom, for the purpose of taking out the feed. The steam pipe passes directly from the boiler to the vat, and extends around the four sides and across the middle, about six inches above the bottom. It is perforated with small holes, about six inches apart, for the escape of the steam. Conveniently located at one side, above the vat, is a cask which holds about two hundred gallons of water, which is kept full by a pipe connected with an aqueduct.

"The fodder is cut by horse-power on the barn floor, and consists usually of about one-half corn stalks and straw, and one-half good hay. It is thrown from the floor into the vat, and thoroughly wet and mixed with a small quantity of meal or bran, according to circumstances, continuing the process until the vat is full, and taking care to tread down well, using as much water as possible, to cause the fodder to absorb as much water as it will hold.

"I usually direct my foreman to start the fire in the boiler before he begins to fill the vat, and by the time it is full the steam begins to pass into it. I never attempt to get up much pressure, but let the steam pass into the vat as fast as it is generated, and like to keep it on three or four hours-the longer the better. 
"I feed with the steamed mixture morning and evening, and with good dry liay at noon. When feeding time arrives, the door at the lower side of the vat is opened, and a sufficient quantity withdrawn into a box, and the door closed at once; it is then carried to the cattle in a basket, giving to each about a bushel, less or more, according to size and condition. By the time it reaches the cattle it will be quite warm, but not hot.

"Last winter I steamed but twice a week, finding no unfavorable effect from keeping the feed so long. This was done to save labor and fuel. Three times a week is better.

"My stock for several years has consisted of about fifty head of thorough bred Ayrshire cattle, and five horses.

"Since writing the above, I have seen the article by Mr. Stewart, of North Evans, N. Y., and fully endorse all that he says in regard to the economy of this method of feeding, and as to the condition of the cattle thus fed, I consider the saving even more than he names."

We close this prolonged dissertation, by giving the following sensible remarks from a late number of "The Country Gentleman," which, although not strictly applicable to cooking food, are important as showing the necessity of fully feeding the cow for milk purposes:

"A certain amount of food is necessary for the mere maintenance of the cow. Suppose this is $\mathbf{1 5}$ pounds of hay a day, or its equivalent in straw. On this diet, the cow gives no milk, and does not increase in fat or flesh. The food is all expended in keeping her alive. Now, if we give 20 pounds of hay a day, we may get one-fourth of a pound of butter per day; if 25 pounds, one-half pound of butter per day; if 30 pounds, threefourths pound of butter per day, and with 35 pounds, one pound of butter per day. If the cow could eat and digest, and turn into butter, 40 pounds per day, we should get one and one-quarter pounds per day. In other words, 15 pounds of hay per day gives us nothing; 20 pounds gives us one-quarter pound of but. 
ter, and 40 pounds gives us one and one-quarter pounds. We double the food, and get five times the amount of butter. If we could get the cow to eat and turn into butter 60 pounds of hay a day, we should get two and one-quarter pounds of butter per day. In other words, three times the food would give us nine times the amount of butter. If the cow had sufficient capacity to eat and turn into butter 80 pounds of hay per day, she would give three and one-quarter pounds of butter per day. In this case we feed four times the amount of food, and get thirteen times the amount of butter.

"To put the matter in another light, suppose a farmer has 54 tons of hay. If he fed it to cows at the rate of 15 pounds per cow per day, it would be nearly enough for twenty cows for one year. From these, on the basis supposed, he would get nothing. He would lose all his feed, (except manure,) all his time and labor, all the interest on the money invested in the cows, and probably some of the principal.

"If he fed 20 pounds per day, he could keep sixteen cows a year. These would give him 28 pounds of butter per week.

"If he fed 40 pounds, he could keep eight cows a year, and these would give him 70 pounds of butter a week.

"If he fed 64 pounds per day, he could keep five cows a year, and these would give him 86 pounds of butter per week.

"In other words, reckoning the season at 40 weeks, the 54 tons of hay when fed to

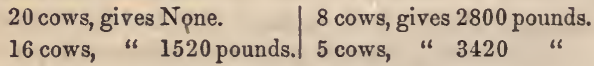

"Now, if we could get our cows to eat 64 pounds of hay a day, or even 40 pounds good clover hay, at the prices namêd, it would be by far the cheapest food we could use. But this cannot be done; the digestive organs of the cow are not powerful enough. But we can get a cow to eat 40,50 or 60 pounds of hay equivalent. We do this by feeding in conjunction with hay or roots, corn meal, oil cake or other food containing a large 
amount of nutriment in a small bulk. Such foods may not afford a given amount of nutriment at as cheap a rate as it could be got in hay, but for the reasons we have mentioned, may be much the more profitable food for the dairyman.

"There is manifestly a great gain in giving a cow all the food she can turn into butter and cheese, and the judgment and skill of the dairyman is shown in ascertaining this amount. Some cows will bear much higher feeding than others.

"The great aim of a dairy farmer should be to get hay of the very best quality. Few people realize what a difference there is in the quality of hay. The time of cutting and the method of curing affects it very much-and this is a point often discussed by our agricultural writers. But the quality of the land has equally as much to do with it, and this is seldom alluded to. The hay from deep, clean, well drained land, highly manured, is worth as much again per ton as that from poor, weedy, wet land. And if we have succeeded in showing the importance of more nutriment in a given bulk, it will be understood how much we gain from having rich grass lands."

To all the foregoing, for a full summary of the worth of the various kinds of cattle food, we give the following analysis of nutriment contained in the articles named, taken from a late number of the "American Agriculturist:"

"According to experiments conducted in France and Germany, one hundred pounds of good hay is equal in alimentary value to 400 lbs. greén clover.

275 " green Indian corn.

374 " wheat straw.

442 " rye straw.

195 " oat straw.

400 " dried corn stalks.

275 " carrots.

54 " rye.

45 lbs. wheat.

54 " barley.

59 " oats.

57 "Indian corn.

62 " sunflower seed.

69 " linseed cake.

105 " wheat bran. 


\section{TO CONCLUDE THE SUBJECT,}

We might multiply recorded experiments of the kind, showing, beyond controversy, the economy of cooking cattle food, either for fattening them into beef, or producing milk, during the winter season.

In the various public discussions which we have heard on the subject, where experienced and practiced men have given their opinions, the labor question appeared the main obstacle to its more general adoption. The extra cost of preparing the proper buildings and machinery, for cutting and cooking food, offers another objection. This may be a valid one where only a temporary pursuit of the business is intended; but as a permanent occupation, the investment of the additional capital required to make a complete and perfect arrangement, is of paramount importance. Milk dairies are as necessary, and will be of as long continuance, as the production of any other food for man. There is no reason, therefore, why the milk dairyman should hesitate to establish the machinery, for the most profitable production of the article, than the miller, or other manufacturer should shrink from building a good mill, for fear that at a future time he might change his business. The milk dairies about London, and other large European cities, are as permanent in their pursuits, as any other which minister to the wants and necessities of the population demanding their supplies.

It is hardly within the province of this work to go into the plans of building, necessary to carry out the various details to which our suggestions may lead. Indeed, were we to submit plans or diagrams of barns, stables, sheds, and feeding arrangements, for stock cattle, stall-feeding, or milk dairies, the particular locality of the various parties needing them might require different ones; perhaps no one of them, in all its details, would answer the purpose demanded by the immediate circumstances of the dairyman, or stall-feeder. Mr. Stewart's suggestions of 
the machinery for cooking cattle food, are sensible, and a part, if not all of his details, may be safely adopted. The same may be said of Mr. Birnie's.

We consider steam, or at least horse power, indispensable to the economical prosecution of the work, where any considerable number of cattle or cows are kept. To the remarks of the above named gentlemen, we will add, that the machinery should be placed in a compact position, in a central building-of, at least, two stories for the storage of the food and its manipulation. From the main building, wing stables of ont, or two, stories may stretch off on either, or both sides, with double rows of stalls, and a six-foot passage, for a tram railway, between them-the heads of the cows to the passage-for distributing the food. Over them, hay, or other forage may be stored for use, as wanted. Wells, cisterns, or other water supplies, should be made in close proximity, and other conveniences added, that the best economy of labor, and expenditure of forage may demand.

We may as well say here, as anywhere, that the best development of the productions of our cattle, either in flesh, or dairy, require thought and investigation, as well as moneyed capital. These pursuits are most mistakenly considered, by many aspiring people engaged in the more active, and speculative, yet uncertain branches of industry, to be of a vulgar order, fitted only for uneducated minds. We deny the fact altogether. Large fortunes may not be so rapidly accumulated in these pursuits as in some others; nor are they so readily lost. They are just as honorable, and just as respectable as any others; and it is because the same amount of brain and investigation have not been exercised in them, as in some other branches of business, that they are not so considered; and when it is demonstrated that the proper application of knowledge and skill, will add to the profit of their productions, there can be no good reason why these 
labors should not be embraced by men of mind, as well as means. We have shown, conclusively, as we believe, that a saving of material, to the extent of full one-fourth, to one-third, can be made in the expenditure of forage, by cutting and cooking cattle food, for the production of both flesn, and milk; and that saving, added to the ordinary gains under the common negligent system, would result in a haudsome additional profit. The business is certainly profitable now, as so negligently carried on, or it would not be pursued. A due reform, in an improved, over the present wasteful system, in either of these branches of feeding, would add many millions annually to our aggregate wealth. 


\section{CHAPTER XXVIII.}

MILK COWS-THEIR SELECTION.

WE have elsewhere remarked on the breeding of milk cows; but a special chapter is necessary to fully enforce our ideas on so important a branch of this treatise. The great mass of our dairy cows are yet of the common, or native kind-good, perhaps, in the main, but, in the mass of them, capable of great improvement in their lacteal qualities. Could we, by a dash of the pen, at once convert them all into high grades, of one or more of the established milking breeds, it would add a large percentage to the ordinary yield of milk now obtained from them, and the consequent profit in their use. But, that being impossible, our only course is to show how we can select the best, and obtain from them an average of one-fourth, or one-third more milk, butter, and cheese, than they now yield, and at little, or no more expense in keeping-thus adding largely to the productive capital invested in them.

We now labor under two important difficulties in using the common cows of our country. One is, their average low capacity for yielding milk; the other is the uncertainty in their selection for that purpose, when young, and untried. These difficulties are radical, and cannot be remedied short of many years of time in selection and breeding, on the part of both cows and bulls, and then with still uncertain results; while to make sure of permanent, certain, and unfailing milkers, we have only to resort to breeds already long established, and which are measurably within our reach. We find that in these established milking breeds, they 
have certain positive narks which indicate their high milking qualities, with a considerable degree of certainty. This is no small advantage in their possession. It is certain that we are less liable to be mistaken in their selection, than in cows to which no such distinctive marks attach.

As we have elsewhere said, no one breed is equally fitted for all localities. Therefore, the dairyman, or he who keeps but one or two family cows, should know from observation, if not by experience, the best variety for his use, and adopt it. Yet, all good milkers show certain indications of possessing that quality, and we shall speak of those indications only, leaving it to the dairyman to make his own proper selection of breeds.

We are in the possession of a little book, published in Edinburgh, Scotland, in the year 1843, entitled, "How to Choose a Good Milk Cow," by a French author, J. H. Magne, Professor of the Veterinary School, Alfort, with a supplement, containing, "Hints for Selecting," by John Haxton. It is so applicable to our purpose that we shall offer no apology for presenting extracts from it-although it may partially repeat what we have already written-as being better than anything which we can offer wholly from our own pen:

GENERAL MARKS. BREED.

"We find good milkers in all breeds, but they are rare in some, and very common in others. It could not be otherwise. Milking properties, depending on the conditions which determine the formation of breeds, are due partly to the climate, the soil, the air, and the plants of the countries where the breeds have originated; and must, therefore, vary in our different breeds of horned cattle, with the hygienic conditions peculiar to each locality.

"Milkers, and more especially animals intended for breeding, must be selected among breeds celebrated for abundance of milk. Not that we can hope to import into our devartment, with a 
dry and warm climate, all the qualities of the cxcellent milking breeds possessed by countries in which the soil is fertile, the air moist, and the sky often cloudy; but as the inflnences of climate, though very marked, take effect only in the long run, the properties of the animals imported are maintained-though subject, doubtless, to gradual deterioration-during a period which varies with the precaution taken to preserve thern; and for several generations, the descendants of the individuals of a good imported breed, give more milk than individuals belonging to a breed formed on the spot, when hygienic circumstances are not favorable to milking properties.

"It is not to be forgotten, moreover, that under the influence of particular circumstances, which it is sometimes impossible to call into existence, animals manifest properties which we cannot produce directly. This explains why it is often more advantageous to import qualities possessed by foreign stock, than to try to develop them in native stock.

\section{DESCENT}

"As milking qualities are, in a great measure, dependent on structure and temperament, which are more or less hereditary, descent exercises a great influence.

"In each breed, therefore, we should choose individuals belong. ing to the best stocks, and the offspring of parents remarkable for their milking qualities; for it is certain that good milk cows produce others which resemble them.

"But it is, especially, when selecting stock for the purpose of breeding milk cows, that particular care should be taken to select individuals belonging to good families. A cow of a bad milking family, or even breed, may occasionally be an excellent milker, and more than this is not wanted when it is not meant to breed from her. The same cannot be said when breeding is intended, because there would be little chance of her transmitting the accidəntal, or exceptional qualities possessed by her; whereas the 
qualities forming the fixed and constant characters of the stock would, almost to a certainty, be transmitted to descendants.

"These remarks, with regard to breed and parentage, apply to the selection of the bull, which, as experience demonstrates, acts like the cow in transmitting the milking qualities which distinguish the breed and stock.

\section{DIGESTIVE ORGANS.}

"These organs have a powerful influence on the exercise of all the functions, and particularly on the secretion of the milky glanids. Where the digestive organs are defective, good milk cows are rarely met with.

"A good state of the digestive organs is evinced by the following particulars:

"A belly of moderate size, with yielding sides, free from tightness: in aged beasts, the belly is often large, though the organs which it contain are in good condition;

"A large mouth, thick and strong lips;

"A good appetite, easy and quick digestion;

"Glossy hair, supple skin, with a kind of unctuons feel.

"Animals possessing these anatomical and physiological properties, eat well, drink much, and if they are properly fed, make much blood, and yield large quantities of milk.

\section{RESPIRATORY ORGANS.}

"The respiratory organs complete the system of nutrition. The object of the lungs is to bring the substance furnished by the food into contact with the air, and make it capable of nourishing; they digest air as the stomach digests food. Hence a good form, and a bealthy condition of the organs of the chest, are necessary to the production of much milk.

"Their ability to fulfill their functions is evinced-when they are large, and lodged in a spacious cavity; in other words, when the chest is wide, deep, and prominent-when the ribs are long, 
and strongly arched thronghout their whole length, and more especially at the upper extremity-when the withers are thick, and the brisket rounded behind the arm and elbow-when the spine is long, straight, horizontal, (not saddle-backed,) and the loins are wide-when the air is inhaled without any appearance of hurry, and exhaled from the chest in great puffs.

"The movements of the flank are free, easy, and extensive, in beasts which breathe well.

"These properties of the digestive and respiratory organs indicate that digestion and respiration, being well performed, furnish an abundant and rich blood; all the organs being in a state of activity favorable for the exercise of their functions. Animals combining these properties in full vigor, are capable either of performing much work, or fattening rapidly, or giving much milk, according to the predominance either of the power of motion, viz.: the bones or muscles; or of the nutritive system, viz.: the cellular and adipose tissues; or of the organs for providing milk, viz.: the glands giving milky secretions, and the milk vessels.

\section{SHAPE.}

"Active milking glands are seldom found united with the graceful, rounded forms, which constitute what is vulgarly called beauty in quadrupeds. Most frequently, good milkers have sharp points, and appear more or less loose and flabby. In regard to bony structure, they may be as well formed as cows remarkable for their readiness to fatten, or ability to work; but, being seldom in plump condition, they seem lean and raw-boned.

"Hence, when a herd of cows have all been fed and kept in the same way, it would not be proper to fix upon the beautifnl as the best milkers. In so doing, we should be almost invariably mistaken. In the hind-quarters, there is often something defective in regard to form: they are largely developed, but the flesh is not in proportion to the bone, and the bony protuberances are very visible; the haunches stick out, and the pelvis is wide; 
the legs, standing far apart, leave a considerable space as a receptacle for large milk vesseli. (See plate 30 .)

"The blood flows in great abundance to the milky glands, and keeps them in activity at the expense of the other organs; the muscles are slender, the buttocks and thighs small and narrow.

"The cows we recommend as milkers, are those whose chine, instead of being all of one piece, shows, towards its center, a space occupied by a kind of shrivelling, the cffect of the distance between the spinous processes of the vertebræ:* the process of the last dorsal + vertebræ is strongly bent forward.

"In some cows, we have observed that this distinguished mark, is owing to the processes of the last dorsal vertebræ. In that case, the back has, at its middle, instead of a wrinkled or shrivelled part, a depression which is continued to the rump.

"When this mark exists, the chinef is often double in its posterior half; the ridge of the vertebræ is large and wide, and seems forked, and a slight depression prevails along the medial line of the body, and is more especially visible near the rump.

"This mark is much looked for in Flanders, where great importance is attached to it; and among the dairymen of Paris, as well as the south of France, where a common saying is, that a cow will be productive of milk, especially when, towards the middle of the spine of the back, the processes stand apart so as leave two spaces of two fingers' width.

"If the chine is double, the vertebræ are thicker, the haunches more apart, and the loins and rump of greater width; in this case, the hind quarters are more largely developed, the pelvis more ample, and, consequently, the organs lodged in the cavity, and even the milk vessels, of larger dimensions.

\section{coNstituTion.}

"It is desirable that the special marks which indicate a great activity of the milky glands, and, consequently, a good milker,

* Joints of the back bone. + Pertaining to the back. $¥$ The back bone. 
should be united with those which imply a good constitution. These are large lungs, a broad and prominent chest, a somewhat slow respiration, an abdomen of moderate dimensions, a good appetite, and a great inclination to drink-an inclination stimulated by the abundant secretion of milk.

"Such cows eat much, digest easily, and breathe well: they make good blood. This fluid gives activity to the nervous system, makes all the organs lively, and furnishes the glands with the materials of a copious secretion.

"Cows possessing these properties last long, give much milk, and, when they become dry, soon fatten.

"But it often happens that activity and vigor in the milky glands, are united with close ribs, narrow, feeble lungs, delicate digestive organs, a moderate appetite, and frequently an ardent thirst. In that case, the cows have a bad constitution, they can give much milk, but it is watery, and of bad quality, and they often die of disease of the lungs.

"These cows seldom have many calves, though they show a great inclination for the bull; and they are difficult to fatten, even when they are in good health, and not giving milk.

\section{GENERAL APPWARANCE.}

"In all breeds, the preference should be given to cows which, in form, are the farthest removed from that of bulls; to cows with small hones, fine and slender limbs, and a tail which is fine at its base; a small but longish head, narrowing towards the horns; the horns themselves of a bright color, tapering finely, and glistening; a supple and soft, unctuous skin, covered, even on the forehead, with erect, glossy, soft hair, and provided, near the natural passages, with a short, fine, and silky down; a small neck, and shoulders apparently long, because slender, especially near the head; small eyelids, well divided, but not much wrinkled; prominent eye, and a gentle, feminine look. 
"With these marks of a feminine description, cows should unite a sanguine-lymphatic temperament, and especially a mild disposition. Good milkers allow themselves to be easily milked; often, while ruminating, they look with a pleased eye, eazily recognized, at the person who milks them; they like to be caressed, and caress in return.

\section{COLOR.}

"We do not mention color as a sign of milking qualities, for we find good milkers among black Dutch cows, and red Flemish cows, as well as among white cows, and the wheat-colored cows of Bresse. Color may be of great value, but it is chiefly as indicating the origin of the animal. The Flemings and Normans are very careful in preserving the colors of their horned cattle, but it is only because a red color, serving to characterize animals of Flemish, and a brindled color those of the Norman breed, facilitate the sale.

THE HYGIENIC CONDITIONS TO WHICH COWS HAVE BEEN SUB-

JECTED, THEIR AGE, AND THE NUMBER OF CALVES THEY HAVE HAD.

"Cows which have been calved in a mild and somewhat moist climate, and which have received due care, and abundance of good moist food, are generally good milkers.

"As happens in the case of all organs, the milky glands are developed by the exercise of their functions, and hence cows never give so much milk after their first and second, as after their subsequent calrings, especially when they have been made to calve young, before the development of their organs. It is after they have reared several calves, and been treated with regularity for a long time, that they give most milk.

"Here, however, we may take the opportunity of advising those who wish to have excellent cows, not to select animals five or six years old, exposed at fairs. Cows at that age are seldom sold, if free from fault. 
"We have observed, in all fairs and large markets, that there are very few good cows among those which have had three or four calves; the good are confined to the young or aged.

"Artificial nursing has numerous advantages, in several respects, but some persons think that it is not favorable to the secretion of the milky glands; they believe that cows which have suckled their calves, and whose glands have been long stimulated by the mouth of one or several sucklings, have always much more milk than those whose teats have only been in contact with the hands of a milker.

"It is conceivable that the gentle heat, the moisture of the lips, the agitation produced in the glands, and the powerful suction of the calves, may have much more effect in stimulating the milky glands than a hand, sometimes brutal, and almost always defective in intelligence. It does not seem, however, that this influence is so great as might be supposed, for there are many countries where they get on very well without allowing calves to suckle; indeed, artificial suckling is very much on the increase.

\section{DISEASES BY WHICH COWS HAVE BEEN AFFECTED.}

"The influence of disease, which may be easily comprehended, is sometimes very great, and lasts during life. Affections which make great changes on the principal organs-the lungs, the stomach, the intestines, and the womb, and those which derange the functions of digestion and respiration-lessen the secretion of milk, and often render the liquid watery and bad.

"Local diseases-those which cause acute pain-those which have their seat in the extremities, or in the mouth, and hamper the animal, either in walking among the grass, or in taking food, diminish the secretion of milk, even when they do not affect the exercise of the principal functions of life.

"But among local diseases, affections of the milky glands have the greatest influence in regard to milk. They attack sometimes 
a part, and sometimes the whole of the udder. Thus cows, which, after their first calf, give milk equally by four teats, often after a disease of the udder, give it only by three, two, and occasionally hy no more than one.

"It is not always easy to discover diseases of the milky glands, when they have become chronic, and the organs have ceased to be painful. Most commonly, however, the diseased part is harder, or more flabby, or more bulky, or somewhat shrivelled; sometimes, too, it is painful on pressure. The teat corresponding to the diseased gland, may be hardened or shrivelled; it is blind if the disease is of very long standing.

"Cows which have the udder unequal, covered with lumps, and not of the same consistency and suppleness throughout, must be classed with those having diseased glands.

LOCAL MARKS. UDDER, INCLUDING MILKY GLANDS AND TEATS.

"This organ is formed principally by the glands which secrete the milk, and called milky glands. These, four in number, two on each side, are sometimes designated by the name of quarters, each constituting nearly a fourth part of the udder.

"The udder is composed, moreover, of skin, cellular tissue, fat, lymphatic ganglions, vessels, \&c.

"In almost all cows, the abundance of milk is proportioned to the size of the mamelles. The marks indicating that these glands are constituted so as to produce much milk, are as follows:

"A very large development of the hind-quarter, a wide and strong lumbar region, a long rump, haunches and hind legs wide apart, a large space for lodging the udder, milky glands well - developed, and causing the udder to be of considerable size. (See plate 29.)

"We may here observe that it is necessary to pay attention to the nature of the udder; its size may depend on the quantity 
of cellular tissue, on the thickness of the skin, the abundance of fat, or the largeness of the gland. In good cows, the gland constitutes a very great part of it, and accordingly, after milking, it shrinks much, and becomes soft, flabby, and very wrinkled.

"A greasy udder, also called fleshy, is of uniform texture, and firm; it resists pressure, and scarcely lessens on being squeezed; it is almost as bulky, and has as much consistency after milking, as before.

"Dealers, to prove that the udder is not fleshy, draw back the skia which covers it; when it stretches much, they consider it a good sign, and call the attention of buyers to it. In fact, it is conceived that skin which has been habitually distended by great quantities of milk, should be looser, and more capable of stretching, than that which has not undergone the same alternations of distension and relaxation. (There are "jockeys" in the cow trade as well as in horses.-L. F. A.)

"Another object of the dealers, in thus stretching the udder, is to show that the cows are of a good kind, that they have a fine, soft, and supple skin. We must observe, however, that in all cows the skin of the udder has these properties; in different degrees, it is true, but still in degrees, the difference of which few buyers are able to estimate. It is on the ribs that the skin ought to be examined, for that is the region where the differ ences, presented by the different breeds of cattle, are most perceptible.

"Some persons attach importance to the form of the udder. We know some who look for an attached udder; that is, an udder, the glands of which extend forward, and seem glued to the belly.

"But we have seen very good cows among those in which the udder is bottle-shaped, and hanging much, as well as among those in which it is placed high. The size and nature are the points which it is of importance to take into consideration. 
"The udder should be large and not fleshy. If so, we may rest assured that the milky reservoirs are spacious, and that the glands, consequently, furnish much milk.

"The teats are of less importance than the glands. In the cow there are five or six, of which one or two behind are very small, and seldom give milk.

"The four in front, the only ones necessary to be taken into account, are nearly equal. They become large or small, according to the time during which the cows are milked or sucked; and this explains why they are large in cows which give nuch milk, because such cows must be milked often, and for a long period. Indeed, it is only in this way that their size indicates the quantity of milk.

"The two hinder teats usually furnish more milk than the two in front, because the two hinder glands, or, as they are called, posterior quarters, are almost always the largest in size.

"The teats should be pliant, not blind, covered with a soft skin, and free from indurations, such as those produced by shrivelling. The warts, which are very frequently observed, are usually without sensation, and cause no inconvenience: it is better, however, when they are wanting, for they may make milking painful, and, by causing the cows to become restive, spill the milk, or lessen its quantity.

"The name of uddered, is given to cows which, having been left long unmilked, have the udder hard, swollen, and painful. Dealers, to give the appearance of good milkers, go the length of tying the teats. (A most dishonest way, which we have sometimes seen.-L. F. A.) This practice night have troublesome consequences. It is sufficient to make it known. It is a sure sign that cows have been left long unmilked, when the udder is hard, and much distended, in proportion to its size; when the teats are stiff, wide apart, often painful, and allow milk to escape, though they are not touched. 
"The position of the teats is not of great importance, and yet it is desirable that they be apart from each other, as indicating that the milk vessels are spacious. This peculiarity is observed in the best cows. (See plate 30.) When the teats are crowded together, the glands are small, and the milk by no means abundant.

"It is necessary, however, in determining the influence exercised, by the position of the teats, to pay attention to the form of the udder. When it is long, like a bottle, the cow may be good, though the teats be close. The milk vessels are then developed from top to bottom, instead of from side to side, and between, before, and behind. (A hanging, or bottle-shaped udder, we would never select, unless assured that the cow was an extraordinary milker. They are always in the way of accidents, when the cow is traveling, besides unsightly.-L. F. A.)

\section{VEINS.}

"Of all marks for ascertaining good cows, the best are afforded by the blood vessels; if the veins which surround the udder are large, winding, and varicose, (dilated at intervals,) they show that the glands receive much blood, and, consequently, that their functions are active, and that the milk is abundant.

\section{VEINS OF THE STOMACH, OR LACTEAL VEINS.}

"The veins on the lateral parts of the belly are most easily observed, and all authors have fixed on them, as one of the best tests for ascertaining the activity of the glands.

"These veins issue from the udder, in front, and at the outer angle, where they form, in very good cows, a considerable varicose swelling. They prcceed toward the front part of the body, forming angles, more or less distinct, often divide towards their anterior extremity, and sink into the body by several openings. (See plate 26.)

"We can make the size of the lacteal veins visible to the eye by touching them, by compressing them in their passage, or, in 
fine, by pressing them at the place where they penetrate into the flesh. In the last case, we sink the skin and the finger into the opening through which the vein passes: the width of this opening represents the diameter of the vein, and then the thickness of the finger, which stops it, represents that of the column of blood whose place it occupies. It is superfluous to add that, when the veins are divided, it is necessary to examine all the openings by which they pass, in order to form a correct estimate.

"Milk ways, is the name given to the openings of which we have just been speaking. They are traversed by the lacteal veins at the moment when these disappear in the body.

"At the times when cows are not giving milk, the lacteal veins, little swollen, are not in accordance with the milking qualities. It is then necessary, for determining these qualities, to compress the vein at its anterior extremity, in order to stop the blood, and make the vein swell up. A good method of producing this result, consists in thrusting the finger into the opening by which the vein penetrates into the body. This process enables us, moreover, to determine the size of the vein, for when the blood diminishes, this opening contracts less rapidly than the vein.

VEINS OF THE UDDER, AND OF THE PERINEUM.

"The veins of the udder, and the perinæum, or twist, to which hitherto sufficient importance has not been given, are able to furnish valuable indications. They should, in both cases, be highly developed, large and varicose; that is, exhibit inflations and nodosities.

"The veins of the udder have no definite direction. They present themselves very irregularly, under the form of zigzag lines, knotted, and more or less oblique. They are never of very large size, except in cows which give great quantities of milk. (See plate 28.)

"The veins of the twist directed from above, downward, form. ing a winding line, interspersed with knots, resemble those of the 
udder, in not being visible either in heifers or in beasts of middling quality. We cannot ascertain their presence in any but very good cows.

"Of all the marks of abundant milky secretion, the best, and indeed the only infallible marks, are furnished by the veins of the twist and of the udder. But, although the surest, they are not absolutely decisive.

"To estimate them, it is necessary to take into account the state of the caws in respect of flesh, the thickness of the skin, food, general activity, fatigue, journeys, heat; all the circumstances, in short, which cause variations in the general state of the circulation, and in the dilatation of the veins. It is necessary, moreover, to recollect that in both sexes, all the veins are larger in the old than in the young; that the veins which encircle the udder are those which, if the cows are in milk, vary most, according to the different periods of life; though scarcely apparent in youth, they are of considerable size, when, after several calvings, the operation of milking has given the gland its full development.

"This proportion between the size of the veins and the milk secreted, is observed in all females without exception. The largeness of the veins and their varicose state, being a consequence of the quantity of blood attracted by the activity of the milky glands, is not only the sign, but also the measure of this activity; the connection between the two phenomena is such, that, if the glands do not give an equal quantity of milk, the larger veins are on the side of the gland which gives the larger quantity.

DURATION AND QUALITIES OF THE MILK. MARKS FOR ASCERTAINING HOW LONG MILK IS GIVEN.

"The length of time during which milk is given, corresponds with the activity of the organs which supply it. Cows which give most milk a day, also give it longest; and hence, if no 
special mark is perceived, we can judge of the duration of milk, by the marks which determine its quantity. Here we are rarely mistaken.

"We ought to add, however, that we have never observed any cow very well marked in regard to veins which did not keep her milk. We repeat, therefore, that the marks of an abundant milker, may be considered as indicating a long continuance of milk.

MARKS FOR ASCERTAINING THE QUALITY OF THE MILK.

"The quality of the milk depends much on the quality of the food, on the period which has elapsed since calving, and on the precise moment when the milk has been taken; immediately after calving, the milk is always of bad quality, and it is always better the older it is, or the longer it is since the cow calved. At each milking, and as long as milk is given, that which is drawn off at first, is more watery than that which is obtained last. We remark also, that the milk is improved by remaining in its reservoirs, and that cows which are milked twice a day, give better milk than those which are milked thrice during the same time.

"Cows fed with fresh, watery food, give a milk which is too wheyey and too poor; those kept on dry, hard food, give a milk which is not abundant, but of good quality; the cream, however, separates with difficulty if it is not aided in its ascent by a mild temperature, and by adding a little lukewarm water.

"Cows whose food is varied, tolerably liquid, and devoid of bad smells and tastes, have a good milk; those fed on articles with a strong taste, on cabbages, turnips, radishes, and garlic, give a milk which, in taste and smcll, bespeaks these plants. Oleaginous food, and oilcake, also produce bad milk.

"In fine, it has been several times observed, that even the mineral poisons taken by cows and goats, in too small quantities 
to hurt them, reappear in their milk in quantity large enough to impart noxious properties to it.

"All the causes which make the quantity of the milk to vary -labor, drinks, perspiration-also modify its composition, and consequently its qualities. In general, cows which perspire littlo and give most milk, give it inferior.

"Temperament exerts a great influence on the quality of the milk; for, of several cows, placed under the same apparent conditions, and fed in the same way, some give a better milk than others; but the causes which determine these differences are unknown, and we cannot give any mark which ascertains their effects with certainty.

"Still, according to M. Guenon, there is a correspondence between the composition of the milk, and the state of the skin which covers the perinæum, or twist; a soft, unctious skin, of a yellow saffron color, parting with a fine, yellowish dust, when it is rubbed, and a fine, pliant, furry hair, indicate a milk of good quality, and rich in butter.

"We know only one method of ascertaining the qualities of milk, and that is by examining it; good milk is of a very slightly yellowish-white color, and of considerable consistency; its consistency may be ascertained by pouring it in little drops on a solid body. Bad milk, of a bluish and watery white, spreads in thin sheets when it is poured out.

"Some persons have the organ of taste in sufficient perfection, to determine the quality of the milk by sipping it.

"As to the dust which adheres to the perinæum, or twist, and whose unctious feel, fineness, and yellow color, indicate, according to some authors, a buttery milk of good quality, we have never been able to study it, though we have often tried on cows whose milking qualities we knew to be very good.

"The nature of the dust taken from the skin, and the state of cows in regard to flesh, may one day furnish indications as to the 
quantities of butter contained in their milk, but science still requires to make new observations on this subject.

SELECTION OF STOCK FOR THE PURPOSE OF BREEDING GOOD MILK COWS.

"It is more difficult to select stock for breeding good milk cows, than to select good milkers; for the breeders must, like good cows, possess well-developed properties, and must, moreover, have the faculty of transmitting these properties to their descendants. Now, this latter condition is not indicated by any known mark; we can only have probable ground for believing that animals possess it-first, by employing animals on trial; and next, by a special application of the marks which have now been considered.

"The fixed characteristics of breed-the characteristics which have existed in races for several generations, are those which are transmitted with most certainty. Hence, as we have said, in speaking of breed and parentage-follows the necessity of choosing milk cows in good breeds and good families; and this, as we have also said, applies particularly to breeding stock. The anatomical arrangements which cause much milk to be given by cows, combining all the properties of good milkers-large hindquarters, wide rump, highly-developed milk arteries and nerves, and large udder veins-are more surely hereditary than the exceptional properties observed in some individuals, which milk well, though they have not the marks which usually distinguish good milk cows.

"A cow, then, which has none of the marks of a good milker, however excellent she may be, ought not to be employed, without extreme caution, in raising stock; for it is to be feared that her progeny, male and female, will not inherit the exceptional properties which she possesses. Even should they resemble their mother, they will always be difficult of sale, and unprofit- 
able, from not possessing the marks which are now looked for in milkers. For the breeder who wishes to find buyers, it is not sufficient that his stock possess good qualities; it is, moreover, necessary, that these qualities be manifested externally by the recognized marks.

"It must not be thought, however, though it is often said, that nature is capricious, "or that chance presides over her operations, because it is sometimes difficult for us to explain her works! Her procedure is uniform, and her plan always skillfully framed, but her methods are numerous, and her products diversified.

"To explain the variations in the hereditary transmission of milking qualities, let us not forget that these qualities are not observed in wild cows; that they are produced, when man is able, by a particular discipline, by the act of milking, the separation of the sexes, \&c., to make certain natural powers more active than others; but that the qualities disappear as soon as these powers, the nature of the soil, the peculiarities of climate, the properties of plants, the temperament of the cows, are again allowed to act, according to the original plan of creation; so that the variations which we consider as caprices of nature, are incontestable proofs of the uniformity of her works.

"It is only by examining animals carefully, by taking accurate notes of their qualities and defects, by attending to the circum. stances in which individuals are produced, reared; and maintained, that we shall be able to account for what seems to us a sport or caprice of nature. It will then be easy to tell, first, how the same bull and the same cow have been able to produce three calves with different properties; and, second, to trace out the rules which we must follow, so as to be almost uniformly successful in obtaining stock of first-rate quality.

"Experience proves that the qualities which are transmitted with most certainty, depend on the most important organs of life; accordingly, in the forms of the viscera and the skeleton, 
variations are very rare, not only in breeds of the same species, but even in different species of the same genera.

"On the other hand, where the transmission of properties is so uncertain as to seem the result of caprice in nature, these properties are formed by superficial organs, by the skin, the horns, the state of the hair, \&c.

"But it is in qualities which are in some sort artificial, quali. ties produced under the influence of domestication, and often more hurtful than useful to the health of the animals, that variations most commonly occur; these change, not only with the breed of one species, but with the different individuals of one same breed, of one same half breed, and often of one same family.

"Let us bear these elementary principles of natural history and physiology in mind, and we shall comprehend how cows and bulls, well marked in regard to scutcheons, have produced stock which did not resemble them. The influence of the scutcheons is very feeble in the act of reproduction.*

"In this point of view, the scutcheon is almost nothing in itself. It depends on the-state of the hair, on one of the most fleeting of peculiarities, on that which is least hereditary in animals. It has no value, as a mark of good getters of stock, unless it is supported by marks superior to it from their stability-a larger skeleton, double loins, a wide rump, highly-developed blood-vessels; unless it is united with a spacious chest, rounded ribs, large lungs, and a strong constitution.

"The more manifest the correspondence between these marks; in others words, the more the milking quality is connected with the general condition of the animal, the greater the chances of transmission; and when, with a view to reproduction, we shall make choice only of animals possessing the two-fold character of

\footnotetext{
* The allusion to "scntcheons," will be better understood in the subsequent remarks on that particular point.-L. F. A.
} 
general vigor, and activity of the mammary system, and place the progeny under favorable circumstances, the qualities will rarely prove defective."

The foregoing remarks of the French author, Mr. Magne, are both sensible and ingenious, as the results of experience in one long observant of rules, both in breeding cows, and their economical uses.

For further instruction, although at the hazard of partially repeating Mr. Magne, we give the observation of Mr. Haxton, on the same subject, from a somewhat different stand point:

\section{POINTS INDICATIVE OF A GOOD MILK COW.}

"Among practical dairymen, there has long existed a number of rules, by which the milking properties of a milk cow are judged of; and as these rules are the results of long experience, transmitted from one generation to another, they contain, when collected together, the sum of all that information which is known by the name of practical knowledge. That this knowledge is correct, in a general way, cannot be questioned, because it is the result of actual experiments repeated, and confirmed not only for a long period of time, but in a great variety of ways, and under circumstances so different, that any errors must long ere now have been detected. Notwithstanding the existence of these established rules, of judging, by external signs, of the qualities of an animal suitable for the dairy, there are very great differences in the modes and results of applying them practically. Some men have a natural turn, or peculiar adroitness, for minuts and careful observation, which others are devoid of; and consequently the former are far more successful in rearing, selecting, or buying dairy stock, than the latter; and hence, too, we find that to these instinctive judges of stock, a glance or a touch will reveal a greater amount of information, than the closest inspection of others. While it is necessary, however, that there should 
be long and habitual familiarity with recognized data, in order to their being successfully applied in practice, they at the same time furnish a set of rules, a knowledge of which is of very great advantage, to those who have been prevented from acquiring an experimental acquaintance with the points to which such rules refer, either by youth or want of opportunity.

"The points to be attended to, in judging of a good milk cow, are, by universal consent, considered to be shape and size of the animal, both as a whole, and in detail; texture of the skin and hair, development of the lactiferous parts; temperament or habit of body and dispositions; and finally, strength or endurance of constitution. A maximum development of these points, marks out a first-class cow of the breed to which she belongs; but the milking properties differ in endless variety, not merely as these points are prominent, or the reverse, but also in proportion to the circumstances of climate, soil, and treatment. The escutcheon test of M. Guenon, is a new element in the question; and when fully established, and better understood, will probably occupy the first rank among the external signs, which indicate the natural milking properties of cows; but as yet it is rarely recognized in Britain; and there are few farmers, even in the best dairy counties, that have even heard of such a test. How far M. Guenon's observations have been horne out, by facts supplied by the examination of a great many dairy cows in our own country, both by the writer and others, will be discussed at the close of this section; meantima, we shall direct the reader's attention to those points which experience has proved to possess a marked influence on the milking properties of cows.

\section{SHAPE.}

"Whatever may be the breed to which a cow belongs, there are certain points of configuration which are considered essential, as regards her milking properties. There may be, and are frequently, great discrepancies between the one and the other; but 
still, generally speaking, the rule holds good that, all things being alike, the cow which approaches nearest to a certain standard, will be the best milker. The head must be rather lengthy, especially from the eye to the point of the nose; the nose and muzzle should be cleanly cut, and free from thick skin or fleshy lumps; the cheek-bones thin, and, in like manner, devoid of thick skin or flesh (not thick chapped;) eye prominent, of a placid and benignant expression, with little of the white exposed to view. If horned, the horns should taper gradually to a point, and have. a clean surface, free from rugosities: the breed will determine the shape and set of the horns. The neck should be long, thin, and free from loose skin. A good milk cow may be deer or ewenecked, but never bull-necked. The chest and breast should be deep, rather than broad, and the brisket should project forwards and downwards; and, whether large or otherwise, should be round, well shaped, and without loose folds of skin depending from it. The girth, behind the shoulders, moderate, and arising more from depth than breadth of chest; shoulders rather narrow at top; back-bone on a line with the shoulder-top; ribs arched, and well home to the haunch-bones, which should be wide apart, and form a straight line across, neither depressed in the center, at the lumbar* vertebræ, nor drooping at the extremities; hindquarters lengthy, and the rump, or tail-top, nearly on a line with. the back-bone; thighs rather thin, but broad, well spread, and giving plenty of room for the udder; belly projecting outwards rather than downwards, with plenty of room for food; the udder should be large in a lineal direction, that is, well backward as well as upward, between the hind legs and forward on the belly; also broad in front, filling up the space between the lower flanks, but rather short vertically; $a$ deep hanging udder, from its swinging motion, being always the cause of great fatigue to the animal when walking; the teats should be moderately long, straight, and

* Near the loins. -L. F. A. 
equal in thickness from the udder to the point,* and also at con. siderable and equal distances from each other: the two front teats especially, should be well apart, and the direction of all four should be downward. When full of milk, the udder should be greatly enlarged in size, and, when newly emptied, shrink in a corresponding degree, and the skin gather into soft creases. (To judge accurately of a good milker, the udder should be seen both before and after milking.-L. F. A.) The mammary glands, running on each side of the belly, large throughout their whole course, and swelling into large puffs at or near their junction with the udder; thigh veins also large and easily felt by the hand. (See plate 26.)

"Of all these shapes the more important are the long, finely. formed head; long, thin neck; rump nearly on a line with the back-bone; broad quarters, long udder, from back to front, and large veins underneath the belly, and downwards, from the loins and thigh, to the udder. When seen in front, the body of a good mille cow should present the appearance of a blunted wedge, the apex of which is the breast and shoulder. Seen from behind, she should present a square, well-spread shape. Seen sideways, she should be lengthy, but not lanky. (See plate 26.)

\section{SKIN, HAIR, AND COLOR.}

"The skin is ever a true index of the milking properties of a cow. It should be soft and flexible on every part of the body, especially on the back ribs, and also on the rump bones, situated on each side of the insertion of the tail. The latter is a point much prized by dairymen; so much that a very successful farmer in Cheshire, Mr. Jabez Wright, told the writer that, in buying a cow, if the skin on the rump was soft and easily lifted from the

* We prefer that the teats be slightly tapering to the point, as more delicate in appearance, and easier to milk.-L. F. A. 
bone, he never sought for further signs of her milking powers. Of course, while feeling this point, Mr. Wright's practiced eye would at once take in, at a glance, those other points which constitute the general whole of a good milker; but the one referred to, he considers indispensable. The skin in these parts will vary, however, according to the condition of the cow. If full of flesh, the skin may be loose, and yet the animal be a poor milker; but if in lean condition, with loose skin on the rump bones, she will milk well, and fatten quickly when $d r y$. The skin on the ribs is the next in importance; and if it corresponds in softness and looseness, with that on the rump bones, another point of excellence is established. These two points, conjoined, are correct exponents of the internal constitution, and are always accompanied with more than an average tendency to milk freely, and fatten rapidly. The former indicates a more than ordinary power of producing milk; the latter a great aptitude to fatten; and their conjoined presence indicates the union of both tendencies. The skin on the udder, generally partakes of the quality of that on the rump and ribs, and will therefore be soft and flexible, in proportion to their softness and flexibility. Still there is a difference to be observed, viz.: that the skin of the udder must not be thick, whereas thickness on the rump and ribs is quite con. sistent with the best properties, provided it be loose, soft, and flexible. In fact, a thickish, soft hide, generally indicates hardiness of constitution, from its greater capability to resist or modify external influences, whether of climate, or cuticular irritation from the bites of insects.

"The hair is the next point to be studied. It should be moderately long, closely set, and, above all, soft and woolly. As the thick, soft skin is an indication of hardiness, much more so is "this the case when covered with long, thick, woolly hair. A bare, hard-haired cow is ever to be avoided by the dairyman, as well 
as the grazier. If even a moderate milker, yet she will be a great eater, and never pay for her food.

"Color is immaterial, and depends on the breed.

\section{TEMPERAMENT AND CONSTITUTION.}

"Animals, like human beings, are differently developed in their nervous, sanguineous, muscular, and lymphatic constitutions, and their tempers and dispositions vary accordingly. Each breed of cattle is characterized by peculiarities of temper, activity, and endurance. The muscular temperament is disappearing before the march of improvement, as animals of this description are neither good for the grazier nor the dairy, being fleshy, thickskinned, and poor milkers. Constitution is the result of natural temperament and physical configuration, but each temperament has its own particular diseases to which it is liable. The nervous temperament predisposes to fevers, the sanguine to inflammations, and the lymphatic to lung diseases; but as these tempera. ments are never found distinct, but always combined together in some proportion or other, the peculiar diseases to which these unions give rise, are as endless as the constitutions themselves. "Atmospheric causes, and artificial treatment, also impress certain physiological characteristics upon cattle. Exposure to cold, when young, has a tendency to develop those parts of the system, whuse office it is to protect the vital functions from being injured by this cause. When an animal is early exposed to cold, the hide thickens, and becomes covered with long, thick hair. It becomes inured to exposure, and is little affected by atmos. pheric changes. A long continuance of such treatment, as in the case of the Scotch Highland cattle, from one generation to another, soon impresses a peculiar habit of growth upon them; and this, in time, settles into a fixed and permanent temperament, or physiological oharacter. Even, however, among individuals of the same breed, exposed to the same external influences, there 
are great discrepancics as regards individual constitution. Some are more hardy than others, simply because certain causes, either accidentally or designedly induced, have given them better digestive powers, stronger lungs, and more vital energy. This superiority of constitution, whatever may be its cause, is generally indicated by a large, round body, a soft, flexible skin, by no means thin, which is covered with a thick coat of soft, silky, or woolly hair. A large paunch is usually the sign of an animal which can, and will, consume a great quantity of fodder in the shape of hay and straw; and this we know, by experience, to be one of the best indications of a good, healthy, hardy, thriving animal, whether cow, horse, or sheep. Strength of constitution can be trartsmitted, as well as other peculiarities; so that a careful breeder, by always breeding from animals that he knows to be of good constitution, will ultimately succeed in strengthening and improving his stock."

Thus much from Mr. Haxton,-and it could not be better said,-showing him to be a close observer, and understanding well his subject.

\section{GUEXON'S THEORY.}

We now come to the theory of $M$. Guenon, the ingenious French writer, before named. Before discussing him, we wish to remark, that he has reduced his theory, to what he considered, a science, and in its treatment has so ramified it into degrees, and shades, as to somewhat confuse the ordinary observer, who does not care to go into minute researches, and seeks only to become familiar with the truth, if there be any, of his theory.

His theory, or science, by whichever name called, is simply this: It is well known that the hair, just above the udder of the cow, grows transversely, or upward. This growth of the hair he calls the escutcheon, and asserts that the more that upward growth of the hair extends outward from the udder and inner parts of the thighs, and upward towards the urinary passage from the bladder, the better milker the cow is; and as the hair 
fails to extend outward, and upward, in these directions, so much the less is she a good milker. To illustrate his theory, he has given twenty-seven different plates, or diagrams, running from the fullest development in its various ways of growth, down to as near nothing, in those outward and upward directions as the cow ever shows it-every one having more or less of that peculiar growth of hair on those parts.

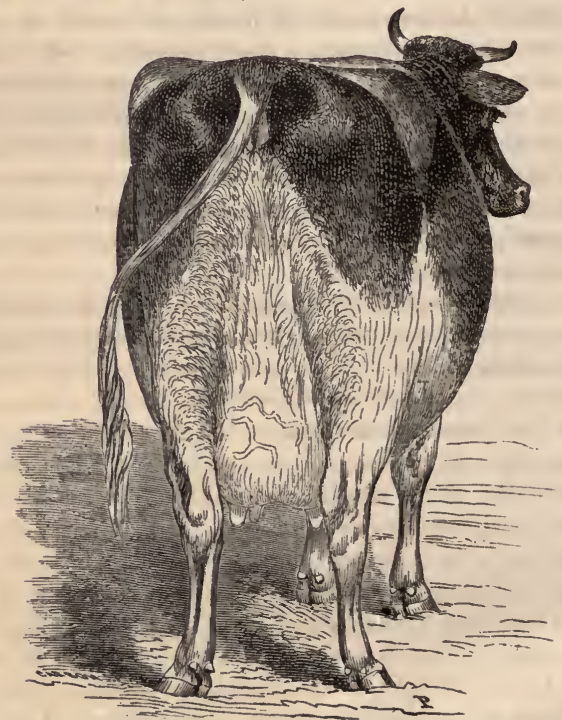

Plate 29. The greatest development of a Milk Escutcheon.

We have paid some attention to the theory, and the marks as the author has delineated them, but without evidence of their 
truth, to the extent which he claims. In some cases they have proved true; in others not. We believe there is, really, something in it, but our examinations have been more or less contradictory.

We give on the opposite page, an illustration from one of his plates, showing a perfect escutcheon, developing, in the highest degree the milk marks, by the escutcheon, of a largely producing udder and its connections. It is a rear portrait of the cow (plate 26) belonging to Mr. Chenery, as taken in February, 1867 , although we are not aware that she possesses the escutcheon so thoroughly developed as is here illustrated.

We have not considered it necessary to copy more of M. Guenon's diagrams, so intricately explained by him, as they would lead the common inquirer to no satisfactory results. To those who wish to go into a close investigation of the matter, we must refer them to the treatise itself.

As both Mr. Magne, and Mr. Haxton, have, with much par. ticularity, gone into the practical workings of Guenon's theory, and at too great lengths to insert in these pages, we give a careful synopsis of the results of their investigations, both in France and England. Of these, we first examine Mr. Magne:

RELATIONS BETWEeN THE SCUTCHEONS AND THE FUNCTIONS OF THE MILKY GLANDS.

"The relations existing between the direction of the hair of the perinæum, and the activity of the milky glands, cannot be disputed. Large lower tufts are marks of good cows, whereas tufts near the vulva are observed on cows which dry up shortly after they are again in calf.

"But what is the cause of these relations? What connection can there be between the hair of the perinæum, and the functions of the milky glands?

"Having tried to answer this question in the 'Moniteur Agricole,' for 1848 , we will only say in this treatise, which is wholly 
of a practical nature, that the direction of the hair is subordinate to that of the arteries; that when a large plate of hair is directed from below, upwards, on the posterior face of the udder, and on the twist, it proves that the arteries which supply the milky system are large, since they pass backwards beyond it, convey much blood, and consequently give activity to its functions. Upper tufts, placed on the sides of the vulva, prove that the arteries of the generative organs are strongly developed, reach even to the skin, and give great activity to those organs. The consequence is, that after a cow is again in calf, they draw off the blood which was flowing to the milky glands, lessen, and even stop the secretion of milk.

"In the bull, the arteries, corresponding to the mammary arteries of the cow, being intended only for coverings of the testicles, are very slightly developed; and there, accordingly, the scutcheons are of smail extent.

VALUE OF THE MARKS FURNISHED BY THE SCUTCHEONS.

"After this explanation, which accounts very well for all that has been observed, it is easy to comprehend the value of the scutcheons. The more the lower ones are developed, the greater the quantity of milk; but shape is of no consequence.

"Still, whatever be the cause of the relations existing between the secretion of milk and the scutcheons, these marks cannot. furnish data so certain as some have affirmed them to be.

"In fact, the quantity of milk, and its quality, do not depend solely on the form and size of the scutcheon; they depend on the food, the particular management, the climate, the season, the temperament, the size and energy of the principal internal organs, the capacity of the chest, the influence of the generative system, \&c. All these circumstances cause the quantity of milk to vary, without making any change on the extent of the scutcheon; consequently, it is impossible that the same relation can always exist, between the scutcheons and the quantities of 
milk. We often see cows equally well shaped, having exactly the same scutcheon, and placed under the same hygienic con. ditions, yet not giving either equal quantities, or equal qualitics, of milk. It could not be otherwise. Assuming that a given tuft has the same value at birth, it cannot be the same in adult age; since, during life, an infinite number of circumstances occur to diversify the activity of the milky glands, without changing the figure or size of the tuft.

"Is it not sufficient to refor to the inequality of milk given by the same cows, according as they have had one, two, or three calves, in order to make it clear that M. Guenon has assigned too much value to the mark which he has discovered?

"It often happens that two horses, having exactly the same structure, and the same extcrnal forms, have not the same energy, the same fitness for work. The difference is owing, evidently, to the temperament, and the activity of the principal external organs; in other words, to conditions which it is often impossible to estimate by any direct method.

"Now, seeing that temperament has an influence on muscles and bones, the action of which, however, is partly mechanical, resembling that of a lever, and exerts this influence so powerfully as to render their movements unequal, in respect both of power and promptness, can we suppose that it has no influence on the entirely vital, or, at least, the entirely molecular working of the mammary gland?

"It might, therefore, have been argued $a$ prior $i$ that the mathematical precision, assigned to a classification of cows, is contrary to the most general laws of physiology; to propose a mark indicating that a cow will give so much milk daily, and for so many days, is to deceive ourselves, or to attempt deceiving others; the study of the phenomena of life, proves that the action of the organs depends, not merely on their size and their form, but on the general condition of each individual. 
"IVe are able not only to oppose argument to the assertions of M. Guenon; we can also appeal to the difficulties hitherto experienced in applying his classification to practice. $M$. Guenon has not yet formed a single pupil worthy of him. And among the thousands of persons who occupy themselves with his method, is there a single one who has acquired sufficient skill to justify the claims which the author makes for it?

"It may be affirmed that, to form pupils as skillful as himself in judging of cows, M. Guenon would not only have to teach them that a certain figure for the tuft corresponds to a certain number of pints of milk, but he would have, above all, to com. municate to them his perspicacity, his talent for observation, and his great experience; he would, in fine, have to fit them for estimating, in addition to the direction of the hair of the twist, the whole of the marks usually employed in making choice of milk cows.

"All the attempts made on the Guenon method, not excepting those of the author himself, prove the soundness of our opinion. The most skillful, when called to decide on the quantities of cows, whose yield of milk was well known, erred seven times on eight cows, and fifteen times on twenty-one. And, least these errors may be attributed to chance, on account of the small number of cows submitted for trial, we should mention that other estimates proved erroneous, 152 times on 174 cows,* and 321 times on 352 , and that the error amounted to 921 pints of milk on a total of 2,683 pints; $\nmid$ in other words, there was error in regard to almost all the cows; and error amounting on an average, on each, to more than a third of the yield. On some individuals the estimates were wrong to the extent of from $17 \frac{1}{2}$ to 21 , and even from 26 to 28 pints a day!

"* Report to the Central Society of Agriculture, by M. Yrart, in name of a Committee.

"+ Report to the Minister of Agriculture, by M. Lefebvre Sainte Marie, in name of a Committee. 
"Such is the truth, as to the perfect nicety, claimed for the scutcheon system. This system cannot do more than furnish an approximate estimate of the quantity of milk, and that in regard not to all, but only to the majority of cows.

"What, then, has led so many persons to put confidence in M. Guenon's discovery? The great talents and knowledge of the author. The system has obtained the credit of results due to the experience of him who applied it.

" "If, instead of employing M. Guenon personally, to give judg. ment on cows, he had been employed to train pupils, and teach his system as Daguerre has taught how to take likenesses, his discovery would long ago have been estimated at its true worth. And the services rendered by it would not have been less great. For although the mark furnished by the scutcheons, is far from having the perfect certainty which some persons, unacquainted with physiological science, have wished to ascribe to it, it must not be thought that the mark is of no use.

"By his discovery, M. Guenon has rendered great service to agriculture; the scutcheon has the advantage of furnishing a mark which can be easily discerned, and estimated even by persons of no great experience in the selection of cows-a mark perceptible on very young animals, and on bulls as well as heifers-a mark, in fine, which, when disencumbered of the complicated system in which it has been wrapped up, will, ere long, be in common use, and facilitate the increase of good cows, by not allowing any but those of good promise to be reared.

"It has been proposed, as a means of ascertaining the qualities of the milk, to have regard to the fineness of the hair which forms the scutcheons, the color of the skin, and the dust which falls from them when they are rubbed; but experience has not yet demonstrated that these marks have the value which has been ascribed to them. M. Guenon, in deciding on the qualities of the milk of three hundred and eleven cows, was wrong one hundred and nineteen times." 
Thus, we see, that Mr. Magne dissents from much of the fan. ciful science of Guenon.

To the opposite, somewhat, let us hear Mr. Haxton. "He had examined many hundreds of dairy cows in Britain, and the conclusion arrived at, in regard to M. Guenon's test of judging of the milking propertes of a cow by the development of the escutcheon, is, that in a large majority of cases it is borne out by facts. In a London dairy, where about four hundred cows are kept, and nine-tenths of them above average milkers, the upward growth of the hair on the posterior part of the udder, thighs, and twist, was too remarkable to be accounted fully accidental causes."

In another stock of forty cows-a very fine one-the results were in favor of the Guenon theory, although some very contradictory cases were found, the signs proving exactly the other way, even among the same classes, or breeds of cows.

In another herd, composed of different breeds, there was little or no uniformity in the escutcheon marks, even among the best milkers of either breed. Some escutcheons were largely developed, others not-the latter milking equally well.

Another herd, of "very fine Ayrshires," had all sorts of devel. opment in their escutcheons, yet were all good milkers.

On the whole, Mr. Haxton, in his investigations, decides in favor of M. Guenon's system, believing that in a majority of cases the best milkers will show the highest developed escutcheons, which, possibly, may prove to be the fact. Still, were we to select a good dairy cow, the escutcheon would be only one, and about the last mark we should rely on, looking more to the other, and decidedly certain indications enumerated in the previous parts of this chapter. To fortify this remark, we have now a family cow of our own breeding, half Short-horn and half Devon in blood, which we have milked twelve years. She has bred many calves, never missing a single year, and frequently 
giving milk up to the time of her next calving, and an extraordinary good milker, both in quantity, and quality. She has none of Guenon's scutcheon milk marks upon her. The hair on her udder and twist all grows downward.

\section{EXPLANATORY ILLUSTRATIONS.}

We now present our readers with the plate of a good milk cow, drawn for special illustration by our artist. She is not a pure bred cow of any breed, although a strong dash of improved foreign blood will be readily detected in her form. As described by Mr. Haxton, we deem her a model for the dairy

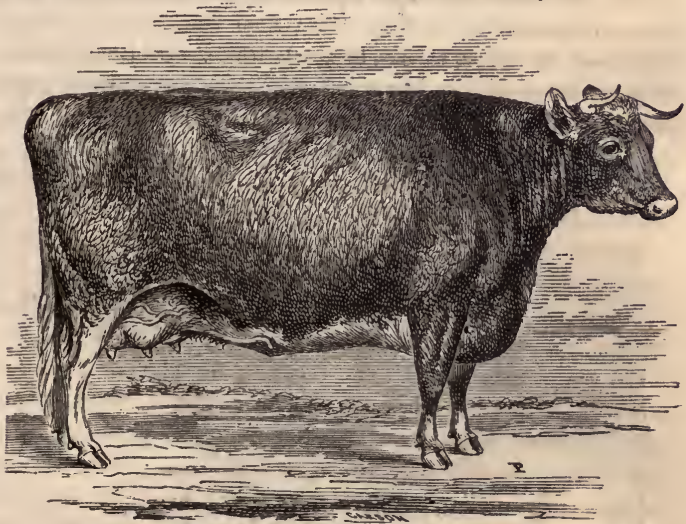

Plate 30. A model Horned Milk Cow.

This cow yields a great flow of milk, and has only oeen dry, or out of milk, three weeks in two years.

There is still another kind of cow to which some people are partial. She is of a polled, or hornless variety, of which many are kept on Long Island, near the city of New York, in New 
Jersey, about Philadelphia, and in some other sections of the oountry. They appear to be of no distinct breed, other than in the lack of horns, but are probably descendants of the polled cows of the counties of Suffolk and Norfolk, in England, famous there for their good milking qualities, and which, no doubt, were brought to this country at an early day. We have seen many of them in and about the localities we have named, from our boyhood down to the present time, and so far as we could learn, they have proved, as a class, excellent milkers. We have seen oxen of this variety-honest, good workers-but their lack of horn detracted from their popularity with those who use ox labor. These cows are of all colors, from black, smoky brown, brindle, red, in various shades, to nearly white. On Long Island, we have seen some of a handsome short-horn roan, with evident marks, otherwise, of having a strong dash of that blood.

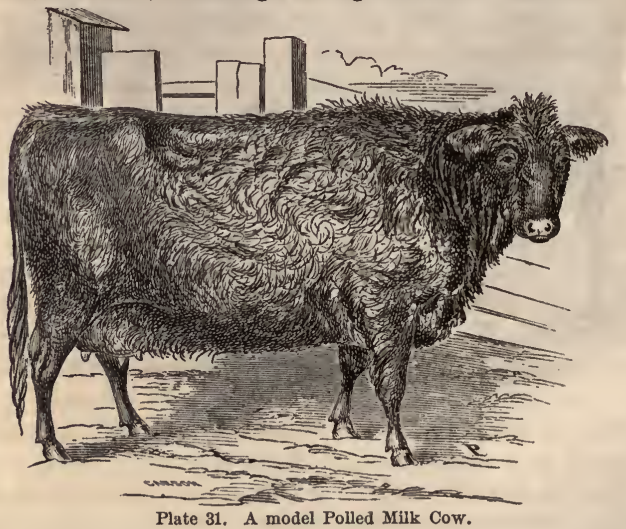

We have little doubt that by selecting good milkers from these hornless cows, and using a compact, moderate sized short-horn 
of a good milking family, or a Dutch, Ayrshire, or Alderney bull upon them, a race of valuable hornless cows may be bred by those who prefer them to a horned breed. To give an idea of them, we have had a faithful portrait, of a good one, (on the opposite page,) taken by our artist, which embodies the main excellencies of her kind.

This cow was taken, when in her highest flow of milk. The plate shows her lean in flesh, and ragged in bone, but of good frame, and when dried off, and well fed, capable of taking on a round carcase of excellent flesh. She has the quiet, docile expression, and the strong milk marks of a choice family cow, and is a capital specimen, in her meek, shaggy appearance, of what Englishmen call "a good poor man's cow;" but a rich man, might well congratulate bimself in the possession of one, so abundant at the pail, and bounteous at the cheese vat or butter churn. It is evident that, in this specimen, her food all goes to milk. Cross such a cow with the right bull, and a heifer from her would be "a gem of a cow" for either family, or dairy use. 


\section{CHAPTER XXIX.}

THE COMMON MODE OF OBTAINING COWS, MILKING, \&C.

We cannot dismiss the subject of "selecting a good dairy cow," without alluding to the common method to which our dairymen are now subjected, in obtaining their cows, instead of breeding them, as they can much better, and more economically do.

A cheese, butter, or milk dairyman, is in want of good cows. He starts out, either himself, or by an agent to pick them up through the country where cows are for sale, or goes to the "drove yards," where they are congregated, and tries his hand at a purchase. He knows the kind of cows he wants, and their value, and can tell a good one when he sees her. He finds a herd of them, and looks about until he gets his eye on such as may possibly suit his purpose. But he knows nothing about their breeding, their education, or mode of treatment, what good, or what bad qualities, tricks, faults, or vices, as well as virtues they possess. "His eyes are his chap." After a deal of chaffering, higgling, and perhaps jockying on the part of the seller, he bargains in the best way he can, for what he thinks may answer his necessities.

Getting them home, and putting them to use, they then come to trial. One proves a gentle, fine, generous creature, producing an abundant flow of good milk, and found serviceable-just what he wants. The next milks hard. The next is troubled with garget, or gives bloody milk out of a teat or two, and so much of the yield is actually lost. A third kicks, taking an 
extra hand to hold her while milking, or having to strap her legs during the process. A fourth has lost the use of a teat or two, and gives but little out of the others. Another is breachy, jumps, or throws down fences, and lets the herd into mischief. Perhaps half a dozen others have faults, or vices, before he gets through with them, and so on. Possibly a third, or one-half of the cows answer his purpose-after a fashion-and there may not be more than two or three first-rate ones out of the whole. They have been picked up by drovers, from those who culled out their own dairies, having no really prime cows to dispose of, and will at no price sell their best ones.

If a cow drover comes along to sell his commodities, the result is the same, let him recommend them to the dairyman as he may, for ten to one he knows nothing of the real qualities of the cows which he has on sale. The result with our dairymen is, that at the end, or lalf way to the end of his dairy season, he is obliged to turn off a portion of his herd. Some go to the butcher, if he can get flesh enough on their bones to partially cover them. Others are dried off, and turned out to pasture for the next winter's beef. Some are sold to another itinerant drover who comes along, and buys them at a cheap rate, to victimize another innocent purchaser, and so on, to the end of the chapter. Out of twenty, the dairyman may perhaps find half a dozen which answer his purpose, and prove really good cows, when they once get wonted to the place, and feel at home-for your cow is a wonderfully home-feeling body, and it frequently takes some weeks, or months, for her to become reconciled to a new locality, and yield her natural flow of milk.

We have given some thought, as well as observation to this matter, and think there is a better method for the dairyman to supply himself with cows, and in a cheaper way, in the long run, with much less labor and vexation of spirit. Let him breed and raise his own cows, by following the directions laid down in 
our previous chapters. He can raise a heifer to two and a half, or three years old, at an expense of thirty to fifty dollars, according to his locality, and she then proves altogether a good, satisfactory cow, for the next ten or twelve years; or, if she does prove a failure for the dairy, she can be readily fatted, and pay the cost of her rearing in a good carcass of beef at the next autumn. But if the directions be strictly followed, the chances are scarcely one in ten that she does not prove a good onemuch better than the average of those he can buy, as cows usually run.

We know that the impression with most of our dairymen has been, that they can buy cows cheaper than to raise them, and thus turn all the cattle food of their farms over to their milk cows. Such, however, has proved not to be the fact. In process of time, when the division of labor among our stock breeders and raisers shall become so systematized that men on the chenp western lands shall go into cow breeding as a business, and raise choice dairy cows for market, it may be that dairymen may depend upon purchasing, with some assurance that they can do so satisfactorily. But, as things now are, they cannot, and the sooner they adopt the plan of breeding and rearing their own cows, the sooner will they be rid of the pestilent mode to which they are now subjected, of buying what they do not want. We are satisfied that, with less labor and expense, they can be sup. plied, on their own farms, with the very best material with which to prosecute their business to advantage, and at infinitely less wear and tear of patience than they are now annually subjected to.

\section{MILKING.}

All persons reared to farm labor should know how to milk a cow. So they do, generally, as far as drawing the milk from the udder is concerned. But that is only a part of the process. We have often seen this important labor so dirtily, bunglingly, carelessly, and cruelly done, that we have wished that a milking 
school could be established to show people how to treat their cows, and get the most milk, and to the best advantage, out of them. As every dairyman ought to know how a cow should be milked, either by ones, twos, or fifties, we have some suggestions to make on the proper and best modes of doing it, both in the treatment of the cows, and the conduct of their milkers.

It has been much too common a way, where several cows are kept, in the grazing season, to drive them into yards, more or less filthy from their droppings, half the time muddy under foot, the cows hunching each other about, frequently without sheds for shelter in bad weather, and doing up the work in a helterskelter way, as time, chance, or opportunity may offer. In the winter season they are confined in filthy stables, frequently unbedded, poorly ventilated, and terribly noisome with the odors and ammonia from urine, and the fotid breath of the cattle within them.

Happily, we believe a better system is prevailing, and milking, among our better farmers and housekeepers, is usually done in a cleanly way; but not always to the advantage that it might be, in having all the conveniences for doing it in the best manner. We object to milking in open yards, where the cows are liable to interruption by each other, or by storms, and often becoming restive by accidents not altogether under the control of their milkers. After long practice in the management of cows for dairy purposes, and their keeping arranged into a regular system, we are satisfied of the decided advantage of milking them, in all seasons, under shelter, and in the stalls which, during the winter months, they regularly occupy.

Thus, we say, in a well regulated dairy, cows, in every season, should be driven into their stables, or sheds, and secured in stalls by ties, chains, or stanchels, for milking. They are thus under control, and every animal is secure from injury or annoyance by her neighbors. Each milker should be furnished with a stool 
for sitting on. A bucket of water and a cloth should be at hand, to either wash, wipe, or otherwise clean the udder and teats before commencing the work, if necessary. The cows may be fed just before, or after milking, as the season of the year, or the habit of the dairyman may be; but the habit, whichever way, should be regular, always. No noise, or loud talking should be indulged among the milkers. No scolding, fretting, thumping with stools, or otherwise; and if, in refractory cases, some discipline of a restive cow be needed, none other than a light switch should be used for punishment. Mild treatment, and soothing terms in most cases, are more effectual than harslsness in making cows gentle. They should learn to regard their milkers and keepers as friends, to love their presence, and confide in their kindness.

The milk should be drawn rapidly, and with hoth hands, in as cleanly a manner as possible. Sometimes, if the milker be musically inclined, the cow is soothed and entertained by the droning of a low-voiced song. We have seen an unquiet, and restive one, stand quite still while the milker hummed his tune, when, without it, she would be timid and uneasy;-not that it is necessary in usual cases, but we have known such. One person will milk eight to twelve, and sometimes more cows at a time, and the times of nilking should not occupy more than an hour each. There is a great slight in this work, and some will milk a dozen cows better, and in less time than another will six. The cows should be taken in regular turn, with the same milkers to the same cows, as nearly as possible; as they both become better used to each other. The times should be as equally divided in the twenty-four hours of the day as possible, and be the division of time as it may, it should be regular, that the udders be not subject to undue distension. System, order, and regularity in milking, has much to do with equable flows of milk, and cows habituated to certain times, yield their messes more regularly in quantity, than when irregularly milked. 
In breaking young heifers to the pail, harsh treatment is seldom necessary. If they have been carefully handled in calfhood, and as yearlings, they usually come quietly to the hand of the milker. Scarcely one in a dozen is ever troublesome to break in, or to have difficulty with afterwards, and seldom do they need a harsh word spoken to them. We know this method to be a good one, by practice in our own dairy, and commend it with confidence. By thus treating cows, they become orderly and systematic in their habits. Each one goes into her own stall quietly as she enters the stable, without huddling, hooking, or quarreling, and they become orderly as a file of soldiers when going on duty. Perhaps we have been more fortunate in this line than many others who could not have the immediate supervision of their cows, as our own herdsman has been in his present employment with us sixteen years. His practice has uniformly been as we have written. 


\section{CHAPTER XXX.}

VALUE INVESTED IN COWS; LOW AVERAGE OF PRODUCTION; DAIRY SOILS; DAIRY FACTORIES; DAIRY WOMEN; LOVE OF FINE CATTLE.

WE have now given an exhaustive and thorough discussion to the subject of milk cows-too extended and tedious, perhaps, for the ordinary reader-but none too minute for the dairyman who embarks his capital for the most profitable production in their management, or even for the individual householder who keeps his one or more cows for family use.

We have seen that many millions of dollars are invested in cows throughout the United States, and that these investments have been made with a view to pecuniary profit, in the way of young stock, and milk, and butter, and cheese, aside from the comfort and luxury they yield the household.

It is a fact too palpable for dispute, that the average of cows kept throughout the country, for milk production, is a low one. Various exceptions show what amount of milk a really good cow can produce, under proper selection, with abundant food of the right kind, and good care. With such examples as the latter for a standard, at which, in due time, we may arrive, if the proper means be taken to accomplish it, we can add twenty to fifty, or even a hundred per cent. to the production and profit of our cows, with little additional cost. We have known-we now know-men who derive an income from a single cow, in the sale of her milk, beyond the annual cost of her keeping, besides supplying their own families with milk and cream, and sometimes 
butter. The average of our milk dairies, as they are usually kept, is not over five hundred gallons a year; of the butter dairies, one hundred and fifty pounds; of the cheese dairies, three hundred and fifty pounds per cow. These averages can be increased full one half, in the simple items of selection of cows, more suitable and abundant food, and increased care in their keeping. The requirements to constitute a really good dairy, may be somewhat more expensive, but much less so in proportion to the additional yields to be obtained from it, than in the loose and negligent way in which they are now managed. All these improvements we have suggested; and why not at once adopt and act upon them? A wise forecast will do so.

The dairy is already a large and increasing interest in our country. Wide regions in the Northern States are admirably adapted to it, and poorly adapted to any other branch of agricultural production. They can grow neither grain, wool, horses, or beef cattle profitably. Under a mixed system of crops and farm stock, in past days, the average value of such farms was scarcely twenty dollars per acrc. Under the dairy system, well brought into use, they are now worth fifty to a hundred dollars, even with the moderate yields we have mentioned. The majority of these farms occupy elevated, moist localities, where the neat stock require six months of stable-feeding, with a winter climate severe and inhospitable. But they are compensated with an abundance of the sweetest grasses, and the purest water-grand aliments of the choicest dairy production. They teem with broad, rich landscapes, pure air, a most health-sustaining atmosphere, giving stamina to a vigorous, industrious people.

These superior dairy regions, too, are limited in extent. The States of New York and Pennsylvania, possess more exclusive dairy lands than any others yet known, although other adjoining States furnish them to a limited extent. There may be other lands at the North-west yet untried, as in Northen Michigan, 
Wisconsin and Minnesota, which may prove equally good. We hope so. And these lands, being restricted in area, as population and the foreign demand for dairy products increase, will be constantly augmenting in value. Great improvements have been recently made in manufacturing cheese and butter, even to "concentrated" milk for city use, and exportation. The establish. ment of cheese and butter factories has improved the quality of those articles, and cheapened their production. The tests of science, and accuracy of method, have been adopted in them, raising their flavor and quality to the highest standard, both at home and abroad.

Knowing, thus, what has been accomplished in these particulars, we have every incentive to a still further improvement in the material-cows-to furnish these most satisfactory results. Dairy factories, aside from improving the quality of their products, and increasing their prices over the old household way of making them, have accomplished a most beneficent and merciful mission, in relieving the wives and daughters of our dairymen of a routine of slavish and most wearing labor. The life of a household dairywoman is toilsome in the extreme. Perpetual watch. fulness, anxiety, and work throughout the dairy season, frequently beyond her physical endurance, has been her destiny-over the cheese tub, and shelf, the churn, and butter bowl-to say nothing of her labors in the milking yard, over the wash kettle, and scrubbing brush. No relaxation whatever is permitted. Necessity knows no law, nor mercy for those patient, over-worked solaces of the household. Even hired female labor is impatient of the task, and shirks it, except at the highest wages, and for a limited period.

We trust that dairy factories may soon become the rule, and the household thus relieved of an intolerable drudgery. In factories, the strength and ingenuity of man is employed almost solely, and the female assistance required is so mitigated in its 
toil, as to be easily and cheerfully accomplished. In the spirit of drowsy Sancho, who invoked blessings on the man who invented sleep, we utter unbounded thanks to the benign brain of him who contrived the cheese and butter factory!

Although the chief cheese dairy districts of our country may be mainly limited to the soils and localities we have described, as being the most available for that article, butter is universally made wherever cows are kept at all; and it is none the less necessary that proper breeds be obtained, and selections for butter, as well as for sale milk dairies, be made. Equally so, should the cow be selected for the breeding and rearing of beef animals, and of oxen for labor. Every farmer, every owner of a cow in the land, should take a pride and a pleasure in having her the best, most nseful of her kind. There is no more comely creature living than a fine, well developed cow or heifer, a steer or an ox, and the whole majesty of the bovine race stands forth in a well bred, stately bull, of an established approved breed. No higher ornament to the farm, the park, the paddock, or the stall, can be found than in them. Their presence is ever a pleasure to those who appreciate their valne, whether in the humbler walks of rural life, or enjoying the highest social or public distinctions.

Having discussed our cattle chiefly from a utilitarian view, it may not be out of place to touch them in a different, and somewhat æsthetic character, as connected with country life, recrea. tion, and those periods of quiet leisure, to which men engaged in pursuits other than agricultural, devote a portion of their time.

The breeding and rearing of cattle is an interesting, a pleasant occupation, to all having taste in that line, aside from the profit or convenience connected with it. It is a taste to be cultivated by all whose inclination leads them to its indulgence. It is a pure, a simple pursuit, fraught with continuous interest, hope. 
and expectation. All over Great Britain, and in portions of the European Continent, in the extensive ornamental parks of the nobility, gentry, and great landholders, the choicer breeds of neat cattle, and sheep, within the last half century, have taken the place of comparatively worthless deer, (though the latter may be beautiful objects in landscape effect,) and now add largely to the ornamental, as well as economical keeping of their grounds. In many instances, these nobility and gentry have been among the most spirited and liberal promoters of improvement in the various breeds of cattle, sheep, and swine,-everything of the animal kind, in fact, which commends itself to their tastes, and adds to the value of their agriculture. This taste has become disseminated amung the farmers and tenantry of the land, until it has become a necessity in agricultural progress. The system of cattle culture has thus changed from the oldtime practice, and is still moving in a rapidly increasing course of improvement.

It should be so in America. Here, we have broader and cheaper lands, and of equal, or superior natural fertility. In many of our States-the Western particularly-are spread numberless farms in thousands of acres each, held and occupied by energetic, practical men, whose almost sole occupation is breeding, rearing, and feeding of cattle. They seem, in that pursuit, "to the manor born." It is the business, the pleasure of their lives. In com. pany with their proprietors, we have rode and ranged over numerous of these grand estates-on broad upland, and wide river bottom; on the park-like oak openings; stretches of almost boundless prairie; or what were once heavily wooded lands, long since cleared by the axe and burning log-heap; and over all these luxuriant farms, speckled with herds, revelling in the fullness and fatness of the land, the eye and the heart that would not expand with the outpouring wealth lying around them, must indeed be both shortsighted and impoverished. 
There is a grand, picturesque beauty of gentle hill, and dale, and smoothly rolling landscape, in those broad territories; but enlivened with herds, and flocks, and comfortable dwellings, it exhibits the very fullness of pastoral grandeur and luxuriance. So, too, it is fast becoming in farther Western States, younger in settlement, with an equally active and energetic population. Their farmers are fast assuming the character of thrift which the generous soil encourages, and all are either now, or soon to become the homes of herds almost countless in the aggregate.

It is different in the Middle and Eastern States, which have been longer settled, and the land divided into smaller farms of diversified cultivation, more thickly inhabited, with cities and villages, and their outlying home lots and paddocks-almost within sight or sound of each other's church bells. If the western farmer prefers the bulky Short-horn, or Hereford, to graze over his broad, rich acres, none the less should the calculating, industrious tillers of lesser acres, be attached to their Devons, their Ayrshires, or Alderneys, or the statelier Holsteins, and Short-horns, which are winning their way among them.

We are happy to say there is a growing taste among the more intelligent of these farmers, and particularly among men of fortune and leisure, for improved breeds of stock. We count many acquaintances among commercial and business men of all degrees, who thoroughly understand and appreciate their value, and the profit of their cultivation. Indeed, no successful business man, of spirit or taste, who now seeks a country home, whether for a permanent abode, or a summer stay, thinks his place complete, without some degrees of indulgence in this luxurious necessity.

It is a pleasure to remark, that many of our improved breeds and varieties of farm stock have been intraduced from abroad by men distinguished in various positions, professions, and occupations, who have thus employed portions of their wealth, as well as by those whose pursuits have been strictly agricultural. 
Their far-reaching sagacity had discovered the value of the better breeds of domestic animals, and with ready purses they ventured on what they believed would be appreciated by the less wealthy farmer at home, when once assured of their superior qualities. It is most gratifying to such endeavors, to find their liberality so well considered by those who, in the result, are to be chiefly benefited. Such men are public benefactors.

Thus, the improvement of the neat stock of our country, is attracting the attention of the people at large, and it only needs the proper knowledge of their good qualities and treat. ment, to gain the full advantages of their possession.

It is but sufficient that we impress upon every country dweller, the benefits, as well as necessity to their best interests, of cultivating and improving their herds for all purposes. No country, from the high latitudes of the St. Lawrence, to the tropical shores of the Gulf of Mexico; from the Atlantic, to the Pacific coasts, embraces such a wealth of soil, and climate, in which to produce the finest neat cattle in their appropriate varieties; and to neglect so wide an opportunity, is to abuse one of God's signal Providences for our support and welfare. 


\section{CHAPTER XXXI.}

INTRODUCTORY TO MISCELLANEOUS MATTER. PREgNANCY, AND WHAT FOLLOWS. DISEASES, TREATMENT, AND CURES.

$W_{E}$ have touched somewhat on gestation and maternity, in the chapter concerning the treatment of breeding cows; but further suggestions are necessary.

A breeding, and milk cow, in all her bodily conditions, should be gently and kindly treated.

She should never be driven at a pace beyond a walk.

She should never be jumped oyer fences or bars, and when necessary to pass them, they should be let down low for her to go through, or over easily, and without effort.

She should not be boisterously shouted at in driving; and if, where a number are together, they at any time become crowded, ample time should be given to get out of each other's way without hooking, or hunching.

If they meet with an obstacle in the way, by other animals, or objects occasioning fear, or fright, let them leisurely survey and avoid it by their own impulse, rather than be goaded on to what they may think danger, although such object, or obstacle may, in itself, be harmless.

Never suffer the cow or the herd to be worried by dogs, either in driving, or in the field when grazing.

Be gentle with them, always. Pregnant cows are liable to various casualties from these or any other kind of maltreatments, which may affect either their oftspring, or dairy qualitics. 
After the cow has been served by the bull, mark the date, and her heat having passed, turn her quietly into the field, or stable, with the other cows, provided the bull be confined by himself, as he should be. If not impregnated, her heat will return in about twenty days. If she so return, repeatedly, and be in high condition of flesh, her feed should be reduced; let her be regularly salted, twice a week, (when she was only salted once a week, or less, before,) whether she be at pasture, or soiled, or in the winter stable. If a healthy creature, she will not long remain refractory to conception. If she have a natural, or clironic inclination to barrenness, and a valuable animal, for breed, patience must be indulged with her, and the causes of her difficulty, if possible, ascertained, and if within the power of remedies, corrected. (Many farriers resort to bleeding: we do not much believe in it.) Sometimes a cow or heifer may remain passive for weeks, after her connection with the bull, and still be unimpregnated, when a sudden return of her heat will be seen. Such freaks are not always to be accounted for, and a return to the bull may be snccessful. Within three or four months, if she remain quiet, the signs of pregnancy may be ascertained by any intelligent herdsman. The motions of the fotus may be felt by passing the hand on the right flank; or by putting the ear close upon it, the beating of the fotal heart may be heard. The first pregnancy in young heifers may be ascertained by a gradual growth of the udder, which soon takes place, not to be much enlarged till a few weeks before parturition.

\section{AS MATERNITY APPROACHES,}

The udder of the cow, or heifer, should be closely watched, that it be not inflamed, or caked, with the rapid secretions of milk that may now flow into it. The progress of this milky flow will somewhat depend on her condition, the season of the year, and the succulence of her food. There is less danger of iuflanma- 
tion from cows which have had calves, than of heifers with their first yeaning. We have had several instances in both, and for several days before calving, were obliged to daily draw their teats of some quarts of milk, as the only way to prevent the difficulty. This should always be resorted to, when the milk will flow, before other efforts are made.

Some people have an idea that no milk should be drawn from the udder, until the cow is delivered of her calf, as it would be injurinus to both. That is not so. We have repeatedly done it, much to the relief of the cow, and no injury, that we could discover, to the calf. It sometimes happens that the udder becomes swelled, and hard, when no milk can be drawn from it. In such cases it should be washed, and anointed, to soothe the pain, and bring down the soreness and swelling. A washing of salt and water, weak soap suds, or bathing in water alone is good. An ointment of camphor, mixed with cream, hog's lard, or fresh iutter, may be used, well rubbed in by hand all over the udder and teats. These failing, a sack, or woolen cloth-part of an old blanket or carpet-may be made large enough to enclose the udder and forward along the belly, and in rear up into the twist, secured by strapping it over her back. This sack should then be kept throughly saturated with mildly warm water, which may quite relieve her difficulty - when the washes and ointments fail.

The period which has passed since receiving the bull, is not a sure test of the time she may bring forth, as it may be somewhat earlier or later than the average of two hundred and eighty-four days, which has been noted as the common duration of pregnancy. Therefore a close observation is necessary. A few days immediately preceding parturition, if all is right with her, the udder grows rapidly with its secretions of milk, the belly drops and becomes narrower; forty-eight to twenty-four hours previous to the birth, the "calving bones" fall, (every cow keeper knows what this means,) and the uneasiness of the 
cow indicates that parturition may be expected at any moment. As before directed, she should be within immediate reach by night, or day, and if a valuable animal, a night's watching of her keeper may be well repaid in the result. The natural labor of the cow, and the assistance which she may require, if any, will be noticed in subsequent pages, under their appropriate heads.

When the calf is delivered, let the dam lick it as thoroughly as she chooses, as is natural to her. It dries the calf of its slimy coating, and it is soon able to rise and find the teat, which is its first impulse. If the placenta, or after-birth be immediately voided, it should be removed at once, and buried, either in the manure heap, or under ground.

When the cow, or heifer, as may be, has safely calved, and is not quite gentle, she should be confined in her stall, the calf suckled, (and assisted to do so if necessary,) and the udder thoroughly drawn to emptiness. She should be given a pail full (or even more, if she be a large animal,) of blood-warm mash, composed of bran, or grain meal diluted in water to a drinking consistency - for she has gone through an exhausting process-which will tend much to revive and strengthen her. This may be once or twice repeated, for a day or two, if she lags in her immediate recovery. If she does well, her usual feed may then be given, and she can take her place with other cows, in the regular dairy, or for such purpose as is required. Of the future care of the calf, we have already spoken.

If, after some hours, a part of the placenta be still retained in the womb, or vulva, a laxative drink of boiled flax-seed, or meal gruel, or a dose of salts, may be given her, which is usually effective; but no forced, or violent effort, should be made to expel it, as it is sometimes held by an internal attachment that may not be forcibly sundered without injury to the maternal organs. A slight weight of one or two pounds - a little sand 
bag-may be tied to it, just above the gambril joint, to gradually draw upon, and thus loosen its hold, and expel the noisome incumbrance. It is seldom, however, when the cow is in good condition, that nature itself fails to remove the placenta.

It sometimes occurs that the udder of the cow at parturition becomes caked, swelled, and inflamed, or the teats be sore, or chapped, and not caused by an over secretion of milk. In such cases, the applications before mentioned may be applied, which, frequently repeated, together with the sucking of the calf, will be effective. But no neglect of the kind should be suffered to prevent bringing the udder into its proper condition, as soon as may be. Such cases neglected, or carelessly treated, may either spoil the cow outright, or cause a portion of the udder and teats to be lost, and thus her value materially lessened. In fact, the most assiduous attention of the keeper should be given, in carrying the cow safely through this critical period, and bringing her to the best condition of profit and usefulness.

\section{MARKS INDICATING THE AGES OF CATTLE.}

The horns-when cattle have horns-are commonly examined by most people, to judge of their ages. When not exceeding seven or eight years, these may give a tolerable indication of the time they have lived, by the number of rings at the root of the horns. With steers, at three years old, and heifers not breeding until that age, the first ring appears. Heifers which breed at two years, commonly show the ring during that season, after breeding; so beyond that age, the latter, judged by that mark alone, show a year older than they actually are. An additional ring grows out every succeeding year. Thns, the animal shows one ring at three years, two rings at four, and so on; but after several rings are developed, as at eight, nine, or ten years, they become more or less indistinct, running into each other, and no accurate test, by this measure, is left. The rings on the short, 
stubbed, and rough horns of bulls, seldom show with any accuracy at all. Aside from the uncertainty relating to the rings in old animals, they are easily rasped, or scraped off by designing men-a thing very often done with a view to falsify their true ages-so that no positive test of age may be looked after in that feature.

\section{THE TEETH MARKS,}

However, are a sure indication of age up to seven, eight, or even ten years. We find this whole subject of the teeth so well dis. cussed in Youatt, that we offer no apology for giving his generally correct authority entire:

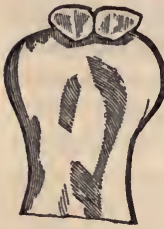

Birth.

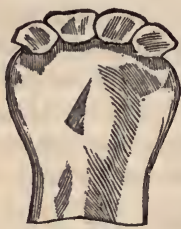

Second week.

"The mouth of the new-born calf presents an uncertain appearance, depending on the mother having exceeded, or fallen short of the average period of utero-gestation. Sometimes there will be no vestige of teeth, but generally, either two central incisors will be protruding through the gums, or they will have arisen and attained considerable bulk.

"At the expiration of the third week the animal will have

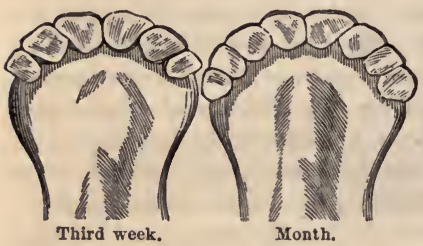
six temporary incisors or front teeth.

"At a month, the full number of incisors will have appeared. These are the temporary or milk teeth. The enamel will be seen covering the whole of the crown of the tooth, but not entering into its composition as in the horse, and it will be observed that the edge is exceed. ingly sharp. The only indication of increasing age, will be the 
wearing down of these sharp edges, and the appearance of the bony substance of the tooth beneath. The two corner teeth will be scarcely up before the center seeth will be a little worn. At two months, the edge of the four central teeth will be evidently worn; yet as the wearing is not across the top of the tooth, but a little out of the line of its inner surface, the edge will remain nearly or quite as sharp as before. At three months the six central teeth, and at four months the whole set will be worn, and the central ones most of all; but after the second or third month, the edge of the tooth will begin to wear down, and there will be more of a flat surface, with a broad line in the center.

"About this time a new change will begin, but very slowly, to be seen. The central teeth will not only be worn down on their edges, but the whole of the tooth will appear diminished, a kind of absorption will have commenced. There will be a little, but increasing space between them. The face of the tooth will

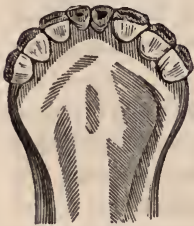

Eight months.

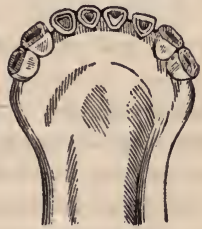

Eleven months. likewise be altered, the inner edge will be worn down more than the outer, and the mark will change from the appearance of a broad line to a triangular shape. The commencement of this alteration of form, and diminution of size, may be traced to about the fourth month, and our cut gives a representation of the two central incisors at eight months. The central teeth are now not above half the size of the next pair, and they are evidently lessened.

"At eleven months, the process of dimunition will have extended to the four central teeth, in the manner represented in the cut. The vacuities between them, will now be evident enough. 
"The first cut gives the mouth of a young steer fifteen months old.

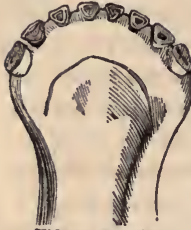

Fifteen months.

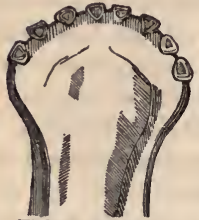

Bighteen months.

"The second cut presents us with the curious and diminutive appearance of all the incisors in a bullock eighteen months old. It would appear difficult for him to obtain sufficient food to support himself in good condition. It is somewhat so, and it may be in a great measure owing to these changes in the teeth, and the difficulty of grazing, that young beasts are subject to so many disorders from seven or eight months and upwards, and are so often out of condition. They contrive, however, to make up for this temporary disadvantage by diligence in feeding; and, to allnde for a moment to another animal, we have known many, not only a broken-mouthed, but a toothless ewe thrive as well as any of the flock, for she was grazing all the day, and ruminating all night.

"At this time, eighteen months old, the corner teeth will not be more than half their natural size; the center ones will be yet more diminished; and, as the cut very faithfully represents, the vacuities between them will be almost equal to the width of the teeth. The faces of the teeth also, such faces as remain, will be lengthened; the triangular mark will diminish, and principally in the central teeth; while another, more or less deeply shaded, will begin to appear around the original mark.

"All this while, the second set of teeth, the permanent ones, have been growing in their sockets, approaching towards the gums; but not as is said to be generally the case with other animals, and with the human being in particular, pressing upon the roots of the milk teeth, and causing them to be absorber, 
until, at length, losing all hold in the socket, they fall out. The process of absorption commences here in the whole milk-tooth, and as much in the crown or body of it as at its root.

"The process of general diminution seems now for awhile retarded; it is confined to the central teeth, and they gradually waste away until they are no larger in the body than crow-quills. About the expiration of the second year, or a little before, the milk teeth are pushed out, or give way, and the two central permanent teeth appear.

"This cut gives the mouth of a two year old beast; the two

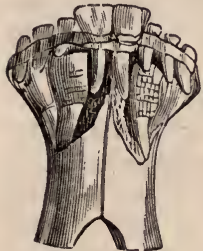

Two years.

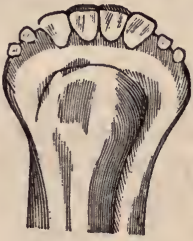

Three years. permanent central incisors are coming up, and the other six milk teeth remain. The bone in front of the lower jaw is taken away, in order that the alveoli, or cells for the teeth, may be exposed. The second pair of incisors have almost attained their proper size, but have not assumed their proper form. The third pair are getting ready, but the jaw is not yet sufficiently widened for the development of the fonrth pair.

"The process of ahsorption will still be suspended, with regard to the two outside pairs of milk teeth, but will be rapid with regard to the second pair, and a little before the commencement of the third year they will disappear. The second represents the three year old beast, with four permanent incisors, and four milk teeth.

"Now the remaining milk teeth will diminish very fast, but they show no disposition to give way, and at four years old there will be six permanent incisors, and often apparently no milk teeth, but if the mouth is examined, the tooth that should 
have disappeared, and the tooth that is to remain until the next year, are huddled together and concealed behind the new permanent tonth. They are often a source of annoyance to the animal; and the tooth whose turn it was to go must be drawn.

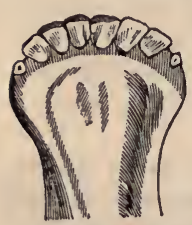

Four years.

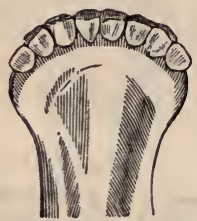

Five years.

The four year old mouth then, as represented in this cut, should contain six permanent incisors and two milk teeth.

"At the commencement of the fifth year, the eight permanent incisors will be up; but the corner ones will be small. 'This cut gives a five year old mouth, or perhaps one a month or two after five years; so that the beast cannot be said to be full-mouthed, i.e., all the incisors fully up, until it is six years old. It will be seen, however, in this mouth of five years, that the two central pairs are beginning to be worn down at the edges, and that in a flat direction, or somewhat inclined towards the inside.

"At six years old, the teeth are fully grown, but this mark has extended over the whole set, and all the teeth are a little flattened at the top; while on the two center ones there begins to be a distinct darker line in the middle, bounded by a line of harder bone.*

"From this time the age can only be guessed at, and not decidedly affirmed; and a great deal will depend upon the manner in which the animal is fed. The beast that is most out, and

\footnotetext{
" * We are perfectly aware against what authority we are contending, when we thus compute the age of cattle by the appearance of the teeth. The pleasing author of the 'Illustrations of Natural History, gives the beast a full mouth at three years old, and so does Buffon, and the editor of the Encyclopedla Metropolitann. Mr. Parkinson says that the month is full at four, although he acknowledges that the teeth are not perfectly up until the animal is six years old. We have no hesitation, however, in appealing to the experience of the breeders of cattle, for the general accuracy of our account."
} 
that is compelled most to use his incisor teeth, will have them worn farthest down. Perhaps, as a general rule, but admitting of many an exception, it may be said that at seven years old,

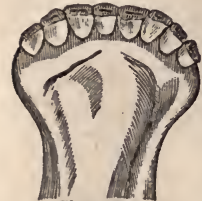

Six years.

this line is becoming broadest and more irregular in all of the teeth; and that a second and broader, and more circular mark, appears within the center of the former one, and more distinct in the central or two central pairs-and which at eight years, has spread over the six central incisors.

"A year afterwards, however, a change takes place which cannot be mistaken. The process of absorption has again commenced, and precisely where it did when the animal was four months old, viz., in the central incisors; but it is slow in its progress, and it is never carried to the extent to which we observed it in the milk teeth. It is, however, sufficiently plain, and the two central teeth are evidently smaller than their neighbors. A considerable change has also taken place on the surface of the teeth; the two dark marks are rubbed into one in all but the corner teeth.

"At ten, the four central incisors are diminished in size, and

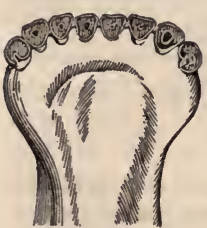

Ten years. the mark is becoming smaller and fainter. The cut represents the mouth at this age.

"At eleven, the six central ones are smaller; and at twelve, all of them are very considerably diminished; but not, as we have already observed, to the same extent as in the young beast. The mark is now also faint, or nearly obliterated, except in the corner teeth, and the inside edge is worn down to the gum.

"The beast is now getting old; the teeth continue to diminish, and it is not often that the animal, after fourteen or sixteen years old, is able to maintain his full condition. He must then be taken 
up and partly fed in the house; yet there are manvinstances in which favorite bulls have been kept until they were more than twenty years old; and we know a cow of the same age who pastures with the rest of the dairy, and gives a fair quantity of milk.

"Some writers have asserted, that a good cow will usually continue good until that age; but the dairyman would discover his error, both in the quantity and quality of his milk, if he received it as a general rule, that a good cow will continue to breed and give milk until twenty years old. Mr. Watkinson, however, had a cow that for seventeen years gave him from ten to twenty quarts of milk every day; was in moderate condition when taken up; six months in fattening; and, being then twenty years old, was sold for more than $£ 18(\$ 90)$. Mr. John Holt, of Walton, in Lancashire, had a healthy cow-calf presented to him, whose dam was in her thirty-second year, and could not be said to have been properly out of milk for the preceding fifteen years.

"This method, then, of judging of the age of cattle by the teeth, is more satisfactory than by the horns, and little of the imposition can be practiced to which the buyer is sometimes exposed, whether the animal is young or old. It is true, that from six to nine we can only guess at the age; but we can form a shrewd guess, and can scarcely be out more than a few months.

"With regard to the horns, we are subject to imposition at all times; we are obliged to ask questions as to the first calf; and, when the animal gets old, the supposed rings often present a mass of confusion, of which the best judges can make nothing.

"The grinders will rarely be examined to ascertain the age of a beast. They are too difficult to be got at; and the same dependence cannot be placed upon them. The calf is generally born with two molar teeth, and sometimes with three in each jaw, above and below. The fourth appears about the expira. 
tion of the eighth month, and the fifth at the end of the year, about which time the first molar is shed. The second is displaced at the end of the second year, and so with the rest, at intervals of a year; but the sixth molar, which is from the beginning a permanent tooth, does not appear until the sixth year."

\section{DISEASES, TREATMENT, AND CURES.}

Having passed through the various topies of breed, and management, we cannot well conclude our work without treating somewhat of diseases, and their remedies. Cattle Farriery is a profession of itself, and when diseases take a distinct and malignant type, few men, except experts in ascertaining their cbaracter and applying their remedies, should undertake their treatment, wherever it be possible to command their services. In America we have few professed cattle farriers-almost every farmer being, more or less, his own physician in that line, so far as local diseases, and the popular remedies for them, are concerned, or usually sought.

As to these remedies, but little is scientifically understood among the mass of our farmers. Father teaches what he knows to sun, or neighbor imparts his knowledge to neighbor, and so the thing goes, partly by observation, some by tradition, and a good deal by guess work. We need schools of eattle farriery, where the subject of anatomy, and diseases, are taught scientifcally, as surgery and medicine are, when applied to the human system. Yet, under proper treatment when in health, our neat stock are liable to so few diseases that a profession of the kind, we fear, would prove but a scanty occupation.

We have consulted several medical works on cattle diseases, and, like those works on human disorders, they differ much; in many things they are contradictory, and perhaps, in due justice to the subject, we should dismiss it by a reference to such authorities as Youatt, Dadd, and others, who have written and pub- 
lished treatises, and are acknowledged as competent authorities. Such a course, however, would hardly discharge the duty expected of a work of the character we have assumed, and we shall, in consequence, treat somewhat of disorders and diseases as they are most likely to occur in the farmer's own herds, insulated as he usually is from the rounds of professional practice.

We may safely assert, that in a large portion of the country, our neat stock are far less prone to diseases, plagues, and malignant disorders, than the cattle of any part of Europe, although our climates, from north to south, are subject to greater extremities of heat and cold, than the European continent. Yet, we do have diseases of many characters and tendencies, sometimes diff. cult to understand, but most of them have proved manageable with proper forethought aud fair treatment. On the whole, our American cattle, may, in general, be called healthy, and liable to comparatively few diseases.

It is an old and true adage, that "an ounce of prevention is better than a pound of cure." So then, he who properly cares for his stock from their birth onward, will be visited with few disorders in his herd, and these, with due precaution, and timely looking after, in most cases, may be safely controlled. Good shelter, proper food, pure water, and timely care, will, in most instances, keep herds in good health-extraordinaries excepted. We have known farmers, with large herds, who scarce ever had a diseased animal. We have known others equally well situated, so far as the opportunity of keeping and caring for them were concerned, who were always afflicted with sickly cattle. They died, annually, with murrain, or some other malady, solely arising from poverty, exposure, bad food, or neglect; and the wonder of this latter class continually was-"what ailed their cattle?" If they will read, and ponder over our previous pages, and act on the suggestions they contain, they will soon find a reform in the conduct of their herds; but if they still go on in their old negligent 
ways, they must suffer; and on their own heads must fall the penalty.

The habits of all domestic animals, are exceedingly simple. Their natural tastes are so; their necessary food is so; and their anatomical and internal organs are such as to dispose of their food, and drink, to the due nourishment of their systems, without much, if any artificial help. So, then, that their food be regular, and sufficient, nature may safely be left to its own course, in the great majority of cases, with a safe result. No farmer should ever bring a creature on to his place having a contagious disease, or permit one to remain there, either in the company, or within the sympathies of other cattle. We once bought a fine blooded cow, diseased with a sort of scrofula, or consumption-some might call it an incipient murrain-and we lost, not only her, but at least half a dozen other cows and heifers, by the contagion, before we got rid of it. That experiment taught us a lesson. We never since, bought a diseased animal, if we knew it. Better knock the thing in the head at once, than to expose the other stock on the farm to contagion of any sort. Accidents have sometimes occurred, as under almost all circumstances they will occur, and not always to be provided against; and so will, sometime, diseases, as milk fever, and other ailments, incident to their condition, which must be promptly looked after; but with due precaution, they seldom occur, under proper management of the herd. We do not say that all such diseases or ailments can be cured, for with the best and ablest treatment, they sometimes prove fatal; yet, with due care they may, in a majority of cases, be relieved.

We may be excused for one remark. There exists, in almost every neighborhood where cattle abound, some quack, or pretender, in cattle disorders-ignorant in almost every thing else, yet professing to be great in that department. He assumes a sort of intuitive knowledge in those matters, and looks profoundly wise on every case submitted to his inspection, and affects great 
secrecy in the material of his remedies, which he is loth to impart to others. He may castrate a calf, a sheep, or a pig, with some cleverness, perhaps, and possibly help a cow to calve in a tough case, when sheer muscular strength is mainly required, and give her a simpla drink, if needed; but as to anything like scientific skill or knowledge, he is as ignorant as a medicine man of the Cheyenne Indians. Such practitioners are frequently resorted to in plain cases, and sometimes with tolerable success; but in cases of inflammatory, or acute disorders, they are to be avoided. They know nothing of them, and should never be employed. A sensible, observing herdsman, who studies symptoms and effects, can far better be trusted with their treatment, and possible cure, when a competent farrier is not within reach. But aside from diseases, there are some

\section{HABITS AND TRICKS OF CATTLE}

That need looking after, as well as to be discussed; and before we touch the former, it may be well to notice a few of them.

\section{KICKING COWS.}

It is sometimes the case that cows, from some cause or other, acquire a habit of kicking. Some would seem to be natural kickers, from their propensity to do so from their first coming in. If such be the fact, and they persist in it, the better way is, if they are not extraordiuary good ones, to turn them off for fattening into beef. But if valuable for the dairy, they can be easily managed. Our own process has been to take the iron forceps, used for holding cattle by the nostrils, and tying them by a rope or strap to a beam overhead, and drawing up their noses at an elevation, and there securing them, while they are milked. If that is not effective, a leather strap, with a loop just back of the buckle end, through which is put the other end, is the best instrument for the purpose. Put this around one leg just above the hock joint, run the smaller end through the loop, that it may oot slip down; then put it around the other leg, and pass it back 
through the buckle so as to confine her legs close together. So secured, she cannot well kick, as the strap holds them fast one to the other, and the cow is easily milked. Or, lacking a strap, a rope passed around one leg and crossed, then lashed around the other, and brought back with a turn or two around the cross between the legs, and tied, will answer the purpose. She soon becomes accustomed to it, and will readily submit to the operation. We have so used valuable cows for years, with little trouble, preferring so to do rather than lose their services. Scolding, fretting, loud threatening, thumping, and flagellations, are of little use. The cow may have a hot temper, as well as her milker, and resist all such sorts of discipline. The law of kind. ness is usually much more effective.

\section{A KICKING OX}

Is troublesome, either in the stable or when at work. Yet we have known some of the best workers which had acquired a most inveterate habit of the kind, and frecly exercised it on even the slightest occasions. In nineteen cases ont of twenty, the habit was acquired by improper treatment of him by his keeper. When steers are kindly treated at breaking, and in their subse. quent work, there is little danger of their contracting such a vice at all. Kind and gentle treatment, with a steady driver, is the best remedy. The owner must exercise his own judgment whether to retain, or discard him.

\section{BREACHY ANIMALS.}

This habit is acquired in most cases through the carelessness or negligence of the person owning them. We have known some cattle that seemed to have almost a natural propensity that way, but in seldom instances. We have seen even calves that would jump with almost the celerity of a deêr, but in most cases, low, and insecure fences first led them to it. As they grew up, they learned to throw fences with their horns; but such enclosures were generally poor and insufficient. We have known others 
that would ingeniously unhook a gate, or open a door, even when properly latched, or otherwise fastened; but such have been rare. The only sure remedy for such disturbances is fattening and slaughter. It is the best use they can be pnt to, unless of great value for breeding, or labor, and if so retained, secure confinement is the best remedy. We dislike to see a creature going about in the pasture with a board hung over its face, or with a poke on, or hobbled. They are thus apt to be set upon by other animals, as they are taken unawares without the means of defence, or escape, and thus frequently injured. Besides, their example is bad. "Evil communications corrupt good manners,"- among cattle as among men. Better to have them out of the way at once, as their examples may be contagious.

\section{COWS SUCKING THEMSELVES.}

This is another bad trick. We dislike to see a cow going about the pastures with a frame-work around her neck. Better serve her the same as the breachy one, and rid the herd of her presence. We never had a creature of the kind, and if we had, would not take the pains to make the complicated machinery for its protection, unless she were of very choice blood, whose preservation was worth any amount of pains to keep her under proper control.

\section{HOOKING-QUARRELING.}

Animals may be prevented from much mischief by putting balls of either wood, pewter, or brass (the latter are best,) on the ends of their horns. They may be either riveted on, or screwed firmly. The manner of doing it is too simple to need direction.

There may be other tricks and vices of a trivial nature, to which cattle may become addicted, but from a long experience and observation in that line, we believe that under proper treatment, these tricks and vices will be few; at least we have seldom been troubled with them. 


\section{CHAPTER XXXII.}

\section{DISEASES PROPER.}

ON this subject we borrow our authority chiefly, and shall pass on to those most common to our herds, as they occur on the farms, or among individual animals kept by householders for their own domestic uses.

We have consulted several different authorities, both European and American. In causes, and symptoms, they generally agree, but in their cures they frequently differ, sometimes radically; and in the latter, both Allopathic, and Homeopathic remedies are prescribed. Either, or both may be correct, or deficient. We do not pronounce an opinion either way, for we are not a farrier. We leave the adoption of either class of remedies, to the judgment of him who owns and cares for his stock.

The whole subject of cattle diseases cannot be discussed short of a thorough treatise, which would occupy a number of pages far beyond what has already been written in this volume, and which, if attempted, would swell it to inordinate dimensions. To him who wishes to examine the subject to a great extent, we can do no better than refer him to the elaborato pages of Youatt, already mentioned, as perhaps the most competent and complete English authority; or to "Allen's Diseases of Domestic Animals," or "Dadd's American Cattle Doctor," more compendious, and perhaps equally good American authorities. We do not propose to quote much from either of them.

We have in our hands a little English work, entitled "The Modern Farrier," by G. Lowson; printed in London in the year 
1850 , from which our own medical treatment of cattle has been practiced for the last fifteen years, with success. It is, in the main, simple, sensible, and unpretending; and as such, we are content to lay it before our readers, so far as its observations extend.

Preliminary to the extracts from Mr. Lowson's work, we give a short paper prepared for us by an experienced farmer, of close observation, on Water Remedies; and if he appears somewhat enthusiastic in his modes of treatment, the reason may be found in the fact that in his farm practice of some fifteen years past, with a considerable stock of cattle on hand, he has never lost a single one by diseases of any kind, and in all cases which have occurred with him, he has applied his water remedy with com. plete success.

WATER TREATMENT FOR DISEASES OF CATTLE.

"As bleeding, blistering, and all violent remedies for the human subject goes gradually out of date, so the milder treat. ment, and greater trust in nature, ought to be applied even to our animals. But still, all the treatises yet extant, for the guidance of the herdsman, after describing the disease, turn only to the medical rocabulary for relief; and the poor animal must be bled, purged, cauterized and irritated, instead of being soothed, quieted, assisted.

"In garget, or swollen udder, for instance, bleeding, or a purgative is first recommended. Let us examine the case. The udder has become inflamed, probably, the teats swollen, the milk coagulated, with more or less fever. Now, the prescription says, 'bleed, purge with epsom salts, ginger, nitrate of potassa, molasses,' \&c. The operation of this purgative is, to irritate the stomach, alimentary canal and intestines, and by sympathy other parts of the system, of necessity increasing, at first, the fever and irritation, which it is intended to allay. All purgative medi. 
cines opcrate by irritation, and not as a solvent. It is a direct attack upon the vital functions, which, in self-defence, pour upon it a watcry secretion from the mucus membrane of the stomach and bowels, to dilute it and render it less harmful, while it is conducted along the alimentary canal by peristaltic motion, and expelled from the bowels-called a cathartic, because nature kicks it out as an intruder, an enemy. Yet this is called science!

"'But,' says the conservative, 'if this is at antipodes with nature, what shall we do to harmonize with and assist nature to recover her balance?' Let us see:

"The greater part of the animal body is composed of water. Three-fourths of the mass of the blood, and nine-tenths of the fluid secretions, are water. All nutrient matters are conveyed in water to the blood, and through it to all parts of the system. Water is the only solvent for the alimentary and excrementitious matter, and through which the waste, or effete matters, are expelled by the excretory organs. Water can circulate through all the tissues of the body, without producing irritation or injury. In short, water is in perfect accord with the whole animal system.

"Fever and inflammation are caused by some obstruction in the circulation of the system, sometimes by a sudden cold, which closes the pores of the skin and prevents the proper excretions. In high fever, or inflammation, it has been said 'the blood is on fire; extinguish the flame, and the patient will be well.'

"What more is there necessary than to cool off the part, to relieve the system of this unnatural heat? Water is the most universal cooling agent in nature, is always at hand, and easily applied. Every thing in nature seeks an equilibrium. Apply cold to the surface of the skin, and the hot blood rushes there to resist it, and to equalize the heat. The tendency to congestion of the internal organs in fevers, is relieved by an application of cold to the surface. Water not only cools the skin, but opens 
the pores and promotes its excretions. And when we reflect upon the large amount of matter that passes off through the pores of the skin, we see the importance of keeping it in a clean healthy state.

\section{GARGET.}

"In the case of garget, the swollen udder only requires to be cooled and cleansed, and kept cool for a short time, to be restored to its originally healthy condition. Water furnishes just the means for this purpose. Without exciting and irritating the whole system of the cow, which is already too much excited, water will quiet and soothe the inflammation, cool and soften the hot dry skin of the udder, and soon give ease and comfort to the cow. But how shall the water be applied to accomplish this?

"W ashing and sponging the bag with water will not answer the purpose, unless most unremittingly applied, which would require a more faithful attendant than is generally found. But if you take an oil cloth or India rubber cloth bag, made to fit the cow's udder, or nearly so, coming up to the body, flaring at the top, held up by a strap over the back, then filled with soft water of moderate temperature, say $65^{\circ}$, you have an apparatus that will require very little attention. This can be applied by anybody, and with much less trouble than a purgative can be given.

"This mild water will absorb gradually the heat from the udder, and not cause any shock to the system, or much determination of blood to the part. Very cold water should not be used unless there is much inflammation in the udder, as it will cause a great determination to the part affected. The water must be changed as often as it gets warm.

"And as there is generally more or less disturbance of the whole system, and an inclination to constipation, give the cow an injection of about three pints of soft blood warm water, sim. ple water, no medication in it. This will produce a movement of the bowels, without any irritation, as the water liquifies or 
dissolves the hard fæeces, and cools off the intestines and bowels. If the first injection does not operate in an hour or two, it proves there is much internal heat, that the water has been absorbed, and another should be given; and if the first does operate, usu. ally a second should be given. These injections are perfectly harmless, and can, certainly, be given as easily as medicated ones; they may always take the place of the purgative, and will answer a much better purpose. When the application is completed, let the udder be slightly chafed with a dry cloth, and rubbed with a little lard. We have several times made this application, and always with most gratifying success; seldom requiring more than a few hours.

\section{PUERPERAL OR MILK FEVER.}

"It mav be thought that this disease offers insuperable obstacles to the use of water; that as the cow, in many cases, cannot stand, the remedy cannot be applied. We admit, that this disease, as heretofore treated, has been alarming and difficult to the herdsman; that as it sometimes comes on so suddenly, runs its course so rapidly, and is drugged so lustily, if not wisely, that it leaves his mind in confusion and uncertainty.

"But there is no real difficulty in using water in this case. The true method is to treat cows, before and at calving, so that this crisis in the disease will not occur. (See remarks in "As Maternity Approaches," pages 416, 417, \&c.-L. F. A.) All stimulating food should be avoided, and the animal kept where she may have uniform warmth and air. And as, in most cases, the udder is swollen and hot, make the application recommended for garget; give copious injections of blood warm water, which will relieve the bowels and intestines; then take matting, or old carpeting, wide enough to reach from udder to foreleg, and long enough to reach around her, put it under her and bring it together over the back, then pour slightly cool water between the blanket and her side, thus wetting her over the principal seat of fever or inflamma- 
tion, producing a fomentation and gradual cooling of the whole surface, modifying her fever, and generally producing relief at once. It is well to wet and rub, gently, her back, hips and flanks. As often as this blanket begins to dry, water should be poured in as before, until the fever passes away, when the blanket may be taken off and the cow gently chafed with a dry cloth till the hair is dry. Moderately cool water should be given her to drink, but no effort made to stimulate her appetite, which will return when nature calls for food. Let it ever be remem. bered, that this treatment, and all treatment of sick animals, should be performed in the gentlest manner. Let roughness and cruelty be monopolized by the butcher, and never used by the herdsman. If this fever should occur in cold weather, a dry blanket may be put over the wet one, to keep the lieat from passing off too rapidly, but if the fever should be high, there will be no danger of this.

"Since writing the foregoing, Mr. George A. Moore, of Buffalo, stated to us, in confirmation of our treatment for milk fever, that finding a cow in the worst stages of this fever, and quite unable to stand, he directed her to be frequently and thoroughly washed, and covered with a blanket to keep the evaporation from being too rapid, and that 'it worked to a charm,' as he phrased it, the cow soon recovering her usual strength and milk.

"The reader will readily see how this treatment may be applied to other fevers and inflammations. In what is called common, or simple fever, the same application should be made. In inflammation of the lungs, a similar application may be made to the chest, and in all cases of fevers and inflammation, injections should be freely used; they answer in all cases much better than the drug purgative. In diarrhœa, the injection is valuable, where a change of food is not sufficient to correct it, as it 
cools off the bowels and intestines, allays irritation, and enables nature to resume her proper functions.

WOUNDS, BRUISES, SPRAINS, ETC.

"The best surgeons now regard water as an important auxiliary in treating wounds. Lavements, pourings, wet compresses, $\& c$. , are used for the human subject; and water answers equally well for animals. Simple cut wounds, when cleansed and dressed with water, usually heal without suppuration, especially, if the blood be in a healthy state. There being a tendency in all wounds to fever and inflammation, water dressings, in the form of wet bandages, keep down the unnatural heat, and allow nature to go on with the healing process. The lips of the wound may, generally, be held together with adhesive straps, and the water application put over. The most dangerous wounds, near some vital part, are frequently healed with the aid of water to keep down the inflammation. We remember a fine mare that stepped on a hoe, the handle of which had been split, leaving a sharp end, and throwing the handle up under her belly, caused a deep, ugly wound, and so lacerating the bowels, that, being in August, it was thought almost useless to attempt saving her. But by dressing the wound constantly with water, the flies were kept out, inflammation prevented, and the wound healed in two months, leaving the animal as valuable as before. Not long ago we had a mare that accidentally struck a nail deep into her foot, and being idle in the stable at the time, it was not discovered till the foot became much swollen; and when the blacksmith took off the shoe, the foot was in such an inflamed condition, that he thought nothing could prevent gangrene and the loss of her foot. But a shallow tub was put into her stall, filled with water, and the foot placed in it. So much did this relieve the pain, that when the water was changed, the animal would, voluntarily, place her foot in it. The inflammation was soon reduced, and the foot became sound. 
"Bruises and sprains are most aptly treated with water, as they are liable to be followed by protracted inflammation. The part should be immersed in, or poured with cold water, and then kept bandaged with water, often changed, till the inflammatory action is passed.

"We did not intend to do more than to point out the simple principles in the use of water, and its application to a few important diseases of cattle, leaving the practitioner to enlarge upon it. We hope the day is not far distant, when this more rational practice will supersede the use of drugs; and as it has, to a large extent, already done so for man, we hope that 'a merciful man, will be merciful to his beast." "

We now commence the extracts from Mr. Lowson's treatise, and, in prefacing it, will only remark, that in view of the "water treatment" just concluded, a modification, to some extent, of the medicinal preparations given by him may be safely recommended, when treatment of the several disorders mentioned becomes necessary. In this modification we particularly name "bleeding," which he so often recommends. In human medical practice of years ago, that was, in the great majority of cases, one of the first things done. Now, bleeding is rare; and with better effect on the disorders so once treated. So with the general use of tartar emetic, and calomel.

As in the human system of treatment, may the lower orders of animal creation be managed. Te now introduce Mr. Lowson:

There are many uneducated farmers who delight in medical receipts, that are mystified and incomprehensible, and the more absurd they appear, the higher opinion they entertain of their efficacious effects.

Mr. John Lawrence, in lis able treatise on Cattle Medicine, nakes the following sensible remarks: "It should be considered that animals living in a state of nature, regulated by the reason 
and experience of man, would be almost wholly exempt from disease; that their appetites, unlike our own, may be held under a constant control: that their diseases result purely from the negligence or erroneous treatment of their owners. They are either too much exposed to the rigors and changes of the weather, or they are gorged with food, denied a sufficient quantity, or supplied with such as is unwholesome. Here we learn the chief causes of their maladies. Learn to prevent them, instead of undertaking the tedious, unsuitable, and hopeless task, of learning to cure them. Of all things, let the proprietors of cattle renounce forever, the insane folly of offering preniums for incurable diseases, and the hope of providing medicines which, by a sort of miraculous operation, will enable men to continue in the habit of exposing their animals to the constant risk of such diseases. I have no infallible receipts to offer; on the contrary, I wish to impress my readers strongly with the idea, that all infallible receipts are infallible nonsense."

In addition to these excellent observations, Mr. J. White states: "Almost all diseases of cattle, arise either from exposure to wet and cold weather, from their food being of a bad quality, or deficient in quantity, or from being changed too suddenly from poor, unwholesome keep, to rich pasture. It is necessary to observe also, that the animal is more liable to be injured by exposure to wet and cold, when previously enfeebled by bad keep, old age, or any other cause, and particularly when brought from a milder and more sheltered situation. I have scarcely met with a disease that is not attributed, by those who have the care of cattle, to a chill; and under this impression, the most stimulating medicines are usually employed; among which we generally find grains of paradise, ginger, long pepper, and mustard, in large doses. It unfortunately happens that the disorders arising from a chill, are often of an inflammatory nature, and require a very different treatment. It must be granted, however, that cattle more frequently require stimulating medicines than horses; and that bleeding is not so often required, nor can it be carried to such an extent in the former as in horses; particularly in milk cows. Many of the medicines of which their drinks or drenches are composed, are quite inert; some are nearly so, and others are very nasty. Hog's dung, stale urine, and a 
pint of the animal's own blood, mixed with salt, are generally held in high estimation."

\section{INFLAMMATION OF THE BOWELS.}

Causes.-This disorder may proceed from costiveness, drinking cold water when much heated and fatigued. It is sometimes produced by a change of pasture and error in diet.

Symptoms. - This disease is accompanied with a very severe griping pain, which causes the animal to lie down and become very restless; frequently turning his head towards his belly, or attempting to strike it with the hind foot. The pulse becomes quicker than natural, the breathing rather quick, and when the pain is violent, a copious perspiration takes place. If proper remedies are not speedily applied, the disease will terminate in mortification and death.

Cure.-In the proper treatment of this complaint, great cantion is requisite, according to the circumstances of the case. If the pulse is much quicker than natural, the under surface of the eyelid unusually red, and the breathing disturbed, let a large quantity of blood be immediately taken away, even five or six quarts; and then, unless the bowels are already unusually open, give the following drink:

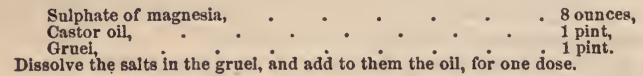

The operation of this drink should be assisted by clysters. When all the above symptoms, however, are not observable; if the under surface of the eyelid is not redder than usual, or if it is rather paler, if the pulse is nearly in its natural state, and particularly if the animal is rather loose, or scours, the bleeding should be moderate; and if he be rather weak, and low in condition, it had better be omitted. The following anodyne drink is to be given:

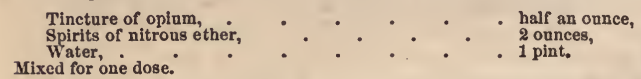

When the animal has been kept for some time upon dry food, and has been observed to dung sparingly, and what he does void 
appears to be discharged with some difficulty, is more solid than usual, of a different color, or of an offensive smell, it shows that the disease is occasioned by costiveness; in which case, relief can only be obtained by the laxative drink and clysters. Bleeding, however, must not be omitted, particularly if the pulse is quickened, the under surface of the eyelid redder than natural, and the breathing disturbed. If the laxative prove ineffectual in removing the costiveness, it should be repeated.

\section{INFLAMMATION OF THE LUNGS.}

Causes.-This disease is most prevalent in working cattle, owing to over-exertion; or from being suffered to drink largely of cold water immediately after working hard, and when in a state of perspiration. It may also occur from exposure to cold and wet, or from sudden and violent changes of weather; indeed, the majority of the internal diseases of cattle may very properly be attributed to the latter cause. This shows the necessity of having sheds, or enclosures, where cattle may be occasionally protected from the inclemencies of the weather. Such accommodation is particularly requisite for such as may be attacked by this or any other external complaint, and without this precaution, medical assistance will be of no avail.

Symptoms. - This disease usually commences with a degree of shivering, and is attended by a loss of appetite, and a general appearance of depression; but may be soonest distinguished by the increasing motion of the flanks, or quickness of breathing. The pulse is more frequent than natural; but small and not easily felt. On raising the upper eyelid, its under surface will be found particularly red, sometimes approaching to orange color. When this disease occurs in a milk cow, she soon loses her milk; and the horns, ears, and legs, are commonly cold.

Cure.-Early and copious bleeding is the principal remedy in this complaint: and from four to six quaris may be taken from a cow or ox in tolerable condition; should the symptoms not abate in five or six hours, the operation should be repeated to the extent of three or four quarts more, unless the animal faint in the meantime; whenever this occurs, on any occasion, the bleeding must be immediately stopped. Faintness, when the disease is known to be an inflammation of the lungs, is, however, 
by no means an unfavorable omen; since it is a proof that the operation has been carried to its full extent, and a recovery is consequently more likely to occur. A large seton should be put in the dewlap, and moistened with oil of turpentine; and the sides should be well rubbed with the following embrocation:

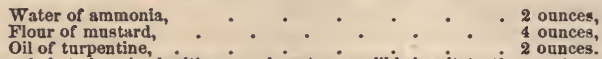

The whole to be mixed with as much water as will bring it to the consistence of cream.

Immediately after the bleeding, the following drink may be administered:

Camphor,

Powdered caraway seeds,

Nitre,

To be given ln a pint of gruel.
- 2 drachms,

1 ounce,

1 ounce and a balf.

Should the animal remain costive, a clyster should be thrown up, composed of about three or four quarts of warm water, and half a pound of common salt. A pint of castor oil may also be added to the above drink: if this cannot be procured, sweet oil, linseed oil, or even melted lard, may be substituted.

Some writers recommend only a small quantity of blood to be taken daily, or every alternate day; but nothing can be more preposterous and absurd. The use of strong, stimulating, or heating medicines, in this disorder, should be carefully avoided. An experienced writer observes: There is an affection of the lungs and parts connected with them. There is not that diff. culty and quickness in breathing; the pulse is weak, hut not much quicker than usual; the kernels or glands, about the throat, are often swollen; sometimes there is a considerable difficulty in swallowing, which is particularly seen when the animal attempts to drink; in short, this is nothing more than a severe degree of catarrh or cold; but even in this complaint, moderate bleeding is necessary, and powerful stimulants are extremely pernicious. When the disease, however, has not been discovered for some days, and the animal appears much weakened by it, bleeding, of course, is improper.

INFLAMMATION OF THE STOMACH.

Causes.-Inflammation of the stomach is generally caused by some acrid, offensive substance, which the animal has swallowed, 
or by giving (agreeably to the directions of some foolish cowdoctoring book,) too strong a dose of astringent medicines to cure the red-water.

Symptoms.-Every ruminating animal has more than one stomach; the cow is possessed of four; the first is considerably larger than the rest, lies on the left side, and is commonly called the paunch. The food having been sufficiently macerated in this stomach, is forced up gradually into the mouth, where it undergoes a complete mastication, which is termed chewing the cud. The food is then again swallowed, and conveyed to the second stomach, for the gullet opens indifferently into both. It ends exactly where the two stomachs meet; and there is a smooth gullet, with raised edges, which leads into the second stomach, and thence to the third and fuurth: the animal, however, has the power to direct it into which he will. The second stomach is named the honey comb bag or bonnet. Its internal surface consists of cells, resembling a honey comb: here the food undergoes a further maceration, and is then conveyed to the third stomach, called manyplies or manyfolds; because the internal surface rises up into many folds. Some of these folds are longer than others, and on their surface small glands may be seen, something like millet seed. From this it passes into the fourth, or red stomach, commonly called the callie or caul. This much resembles the human stomach, or that of a dog; only the inner folds are longer and looser. Here the food is perfectly digested, and prepared for the nourishment of the animal.

Such a complicated structure renders this organ particularly liable to disease; inflammation, however, does not often occur as a primary disorder, but is commonly a consequence of some offensive matter lodged in one of the four stomachs, or from the animal feeding so greedily as to weaken the organ, and prevent it from performing its functions.

It is usual to consider this disorder in cattle under two distinct species; one affecting the first stomach or paunch, and the other the third stomach or manyplies. This latter is commonly denominated lakeburn.

Cure.-When inflammation attacks the stomach, without any injurions matter being swallowed, or any improper accumulation of food, the principal remedy will be plentiful bleeding, absti- 
nence from food, and mucilaginous drinks, such as linseed tea, and the administration of relaxing clysters. Should it proceed from swallowing poison, the cure will be found under a different head.

\section{INFLAMMATION OF THE KIDNEYS.}

Causes.-This disease frequently attacks young beasts that are feeding, or in good condition. The kidneys may become inflamed, either from external injury, or from irritating substances that pass through them in the course of the circulation: but according to the opinion of some eminent practitioners, this disorder is most frequently produced by the indiscriminate use of strong diuretic medicines.

Symptoms. - This disease commences with a shivering, succeeded by increased heat of the body, and is followed by a quickness of the pulse, and loss of appetite; the animal frequently endeavors to stale, and voids only a small quantity, which is of a red color, and sometimes with much difficulty and pain; pressure on the loins gives pain, and causes the animal to shrink or give way to it; there is usually considerable stiffness in the hind parts, perceptible when the cow attempts to walk. This disease varies from that termed red water; and unless properly treated at its commencement, frequently terminates fatally.

Cure.-Bleeding is the first and most necessary measure to be taken in this disorder, after which a pint of castor oil may be administered. Should there be any signs of cristiveness, let dry clysters of warm water with a little sweet oil be given. A liniment composed of:

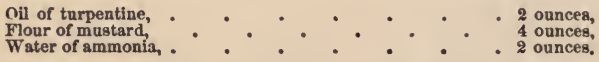

Which must be well rubbed on the loins; after which let them be well clothed, or covered with a fresh sheep's or lamb's skin. If this does not remove the constant straining to stale, let the following clyster be employed:

Crude opinm, . Dissolved in warm water, and mixed with gruel.

1 drachm and a half.

Or the following: Tincture of opium, - . - . - . 1 ounce and a half,
Thin gruel, - . 1 quart. 
If the anmal is very thirsty, an infusion of linseed, or a decoction of marshmallows, is the most proper drink.

\section{INFLAMMATION OF THE LIVER.}

Causes.-Fat beasts, or such as are in good condition, are most liable to this disease, especially in hot weather, when overheated by driving, or being exposed to sudden cold after the body has been overheated. It may also be brought on by blows or bruises on the short ribs, by which the liver may have received some injury: or by sudden changes of the weather.

Symptoms. - Cattle are more subject to diseases of the liver than horses, because the latter have no gall bladder; but in the former is one of a considerable size. The symptoms of a diseased liver are complicated; and hence we shall treat of these subjects under the heads of Diarrhoea, Jaundice, and Hepatic Consumption. When an acute inflammation of the liver occurs, it should be treated in the same manner as an inflammation of the lungs, and is probably produced by the same causes. However, this disease is commonly of a slow kind, causing a defective action in the organ; and consequently, an unhealthy kind of bile is formed, which plugs up the ducts of the liver, and canses a derangement in the organs connected with it.

Cure.-It must be correctly ascertained whether this disease be acute or chronic, before its cure be attempted. The proper mode of treatment will be found under the heads before alluded to.

\section{INFLAMMATION OF THE BLADDER.}

Some cows, during the latter part of the time they are in calf, have a frequent desire to void their urine, owing to the very irritable state of the bladder. When this is observed, it will gener. ally be found to depend upon costiveness; in which case a laxa. tive drink and clyster are the most suitable remedies. This state of the bladder has been often, but very improperly, termed inflam. mation. Skillful practitioners are inclined to believe that this disease very rarely occurs. Should the neck of the bladder appear to be obstructed, or if there be any reason to suppose that there is a retention of urine, the female catheter, or even the finger, may be easily introduced, in order to allow the water to pass off freely. 


\section{INFLAMMATION OF THE BRAIX.}

Causes.-This complaint usually proceeds from redundances of blood in the system, called an overflowing of the blood; or by severe contusions of the head. It is sometimes occasioned by excessive heat, or a sudden change from a poor to a rich diet.

Symptoms. - This serious and fatal disorder is one of the most distressing to which cattle are subject; it is, however, fortunately of rare occurrence. An animal laboring under this disorder, is described as having a peculiar wildness and anxiety in his looks. being usnally watchful, starting often, groaning vehemently, as if affected with sudden and violent pain; his respiration is slow, but he sometimes makes very long respirations, and appears for a time as if his breathing was entirely suspended. Suddenly, the beast will rise, turn about, and instantly lie down again with the same volatility, evincing marks of great restlessness and delirium. When the frenzy is high, the eyes look red and furions; at other times they border on languor and stupefaction; the teeth are ground together, and they will sometimes tear up the turf with their feet, and toss it into the air with the greatest violence; but the beast always appears to labor under considerable fear, dreading the approach of anything; and is often quite ungovernable, scarcely ever inclining to rest, except in the latter stage of the disease, when, if it has been neglected, or has not yielded to the usual remedies, a lethargy takes place, and the animal sinks. Sometimes the urine is hot and high-colored; but it is said that before a fit of the frenzy takes place, the urine is often of a pale color, and thinner than natural.

When the symptoms of fury or irritation suddenly cease, and a lethargy takes place, the pulse becoming feeble, and the strength diminishing, the case is almost hopeless; but should the fever, redness, and tlushing in the eye gradually subside, without any variation of the pulse, or approaching debility, the beast may generally be pronounced recovering.

$\mathrm{On}$ opening the head of such animals as have died of this complaint, very evident marks of inflammation appear about the membranes of the brain, and very frequently in the substance of the brain itself. All the vessels are turgid with blood, and, cutting into the brain, innumerable little red points are to be seen, which do not appear in the natural state. Very commonly an 
effusion of blood, or of purulent matter is found to have taken place in the carities of the brain, or in some part near its surface.

Cure.-This complaint requires the most prompt and decisive measures to be used for its cure. Blood must be taken in copious quantities from the jugular vein, or temporal artery. Nct less than three quarts should be taken from an ordinary ox or cow; and if the animal is very large, four may be taken; and should the symptoms not abate, the bleeding must be repeated a few hours after. When the beast is very furious, it is often dangerous to bleed in a very deliberate way; but as his recovery will almost entirely depend upon a sufficient loss of blood in the earlier part of the discase, it will not be amiss to bleed him in the manner described by Mr. Blaine, who plunged a lancet into each jugular, and permitted the animal to bleed till he fainted, by which means, though the disease was far adranced, be sared the animal. After bleeding, a stimulent blister should be applied to the top of the head, and the sides of the neck should be well rubbed with a mixture of cantharides and oil of turpentine, and other means used to produce external inflammation, for the purpose of determining the blood from the head. In addition to these means, costiveness should be carefully guarded against.

\section{INTLAMYATIOY OF THE WOMB.}

Causes.-This disease is very prevalent, and usually proceeds either from the cow having been kept in too high a condition at the period of calving, or from too much violence having been used in the extraction of the calf.

Symptoms.-This disease is usually indicated by a languid appearance, a quick pulse, loss of appetite, and gradual loss of her milk. As the disorder advances, the bladder becomes affected, and a fetid discharge from the parts frequently occurs. The animal appears sometimes to be almost constantly straining, as though endearoring to roid something; in those cases a small quantity of urine is frequently discharged; at other times the urine is detained so long as to render it necessary to relieve the bladder by drawing it off. This may easily be effected, by introducing an instrument through the urethers into the bladder, or by the finger, the passage being rery short. When the disease has proceeded thus far, the cow frequently becomes so weak as to be incapable of standing. 
Cure.-We have before observed that it is necessary to draw off the urine when too long retained. But the principal remedy is bleeding. The following laxative drink may be administered:
Epsom salts,
Castor oil,
Dissolved in a quart of thin gruel or warm water.

Clysters of warm water and oil are also useful. After the bowels have been opened, the following anodyne may be given:

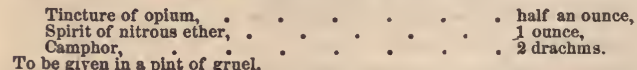

This may be repeated, after ten or twelve hours, should it be found necessary. When the pain and straining are considerable, the anodyne clyster may likewise be given, which consists of one ounce and a half, or two ounces of tincture of opium, and about a quart of thin; fine gruel.

When the womb, or any other internal organ, is inflamed to a considerable degree, a cure is almost impossible. The earliest attention, therefore, should be given to these complaints.

\section{INFLAMMATORY FEVER.}

Causes.-This disease is known among various people by many absurd names, such as Joint Felon, Quarter-evil, Quarter. ill, Shrinking in Back-Quarter, \&c. It usually occurs to young aattle, between the first and third year of their age, but most commonly about the second year. It may be said to arise from feeding them too hastily; such as turning them, when in a lean state, into rich luxuriant pastures.

Symptoms.-The animal that is seized with this complaint, suddenly becomes stupid and listless, hanging down his head, refusing his food, and apparently moves with difficulty. Swellings speedily appear on various parts of the body, which, when pressed by the finger, make a cracking noise. The joints are sometimes particularly affected; at other times the swellings appear on the back, belly, or shoulder. The disease is rather sudden in its attack, and frequently proves fatal, particularly if suitable remedies are not quickly applied.

Cure.-Bleeding is the first and principal remedy, and must be used in proportion to the age, and strength of the animal; from three to four quarts will generally be found sufficient. 
After this, the following purgative drink may be given with considerable advantage:

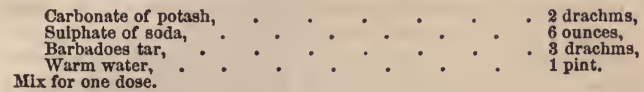

This dose will generally suffice for an animal of two years of age. Should there be any difficulty in procuring these medicines, give from four to six ounces of common salt in a pint of water; the addition of four ounces of castor oil, or even linseed oil, will render it more efficacious. As this disease frequently proves fatal, in whatever manner it is treated, preventive measures should be speedily applied. Should the animal, however, be relieved by the treatment above described, it may occasion considerable weakness: and consequently the following mày be given twice a day:

Ginger, . - . . . 2 drachms.

To be given in a pint of oatmeal gruel, or ale.

Should the joints be affected and swollen, they may be rubbed with the following liniment: Mix.

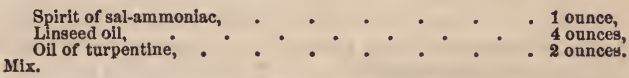

Setons in the dewlap, or other parts of the body, are occasionally applied as preventives of this disorder. Should it be produced by feeding cattle too hastily, Mr. Lawrence has very judiciously advised that a short, or inferior keep should be reserved, as a digesting place, where cattle may occasionally be turned, to empty and exercise themselves. This is certainly preferable to bleeding, or any medical preventive.

\section{BLOODY MURRAIN, RED WATER AND BLACK WATER.}

Causes.-The red water and black water arise from a preternatural quantity of blood being determined to the kidneys, and a consequent rupture of some of the minute blood vessels of those organs. This undue determination of blood to the kidneys is very frequently induced by turning cattle, in the spring of the year, into low pasture grounds, or woodland pastures, where the air is moist, and lessens perspiration, occasioning the blood to 
become too watery. The balance of circulation is deranged from the perspiration being suppressed, and a too great quantity of blood is in consequence determined to the kidneys, which gives rise to the disease. On removing cattle, thus affected from the state of the atmosphere, into a more elevated situation where the air is dryer, the beast will frequently be restored without the aid of medicines. It very often proceeds from cattle being removed from good to bad land, the grass of which disagrees with them, and the vigor of the body is thereby impaired, and they in consequence take cold, which flies to the kidneys, and occasions red water. It is often produced by their taking cold from the changeable state of the weather, or driving them long distances in the day, and turning them into fields at night, where they take cold.

The red and black water is most prevalent in the spring and summer, when the grass is nutritious and produces a plethoric state of the system, or what is commonly called a redundancy or overflowing of the blood, which favors an unequal distribution of the blood, when they are affected by the causes above mentioned. Some cattle are more liable to the red water than others, which may in a great measure be owing to the nature of the soil, and the state of the air they have been accustomed to; these, when removed into pastures where the land is bad, and the air moist, are frequently attacked with it.

Symptoms.-These diseases seldom occur separately, and almost prevalent among milk cows. Mr. Clater conceives the red water to be the original disease, and the black water to come on as the complaint advances, which is generally an unfavorable symptom, often arising from inefficient treatment. When the change takes place from red to black water, the animal in gencral stales free from either for several times. In slight cases, where the blood is passed away with the urine, the beast does not appear to be affected by it; if a cow, she holds to her quantity of milk, and seems no worse. But when the blood so passed away is considerable, and sometimes for a length of time, it reduces the quantity of milk, and likewise the animal itself, to a very low state; and if some powerful remedy is not resorted to, the beast must inevitably sink under the pressure of the disease. In these bad cases, the milk sometimes becomes discolored, and the beast is frequently so weak, that she is unable to rise when down, and requires gruel to be horned into her. 
The red water is sometimes attended with a lax state of the bowels, and in some instances a considerable quantity of blood is evacuated with the thin dung, and none with the urine.

Cure.-Purgative medicines are the best remedies in these disorders. The following is recommended as a safe and efficacious purge:

Mixed.

Castor oil, . . . . . . . 6 onnces,

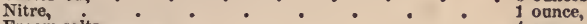

Epsom saits.

4 ounces,

1 quart.

Should this not prove effectual in removing the disease, the following drink must be administered:

Oil of turpentine, . . . . . . . 2 ounces,

Alnm dissolved,

Terra japonica,

Some prescribe the following:

Epsom saits,

Cream of tartar,

Castor oil,

Mixed in whey.

1 ounce,

- 1 ounce.

After this gentle purge, the following to be given:

Roche alum,

Tincture of cantharides,

To be given in a quart of lime water.

Mr. White observes, that an experienced farmer, whose cows were affected by the red water, gave them half a pint of the juice of the white-blossomed nettle, which speedily cured the disease.

When the animal is perceived to be frequently endeavoring to stale, voiding only a small quantity, with considerable pain and difficulty, mucilaginous drinks, such as infusion of linseed and decoction of marshmallows, are most likely to afford relief.

\section{SCOURING ROT.}

Causes.-This disease is met with at every season of the year, but is more prevalent in autumn, particularly in low, swampy situations. This complaint generally arises from suppressed porspiration, induced by the sudden vicissitudes of the weather; particularly when the animal has been over-driven, or heated by working immediately before. Drinking too much water, under similar circumstances, will likewise produce the disease. A want 
of nourishment, especially in cows that are regularly milked, will often cause the scouring rot.

Symptoms.-In this complaint, farmers frequently lose several of their cattle in a season; owing to which it has received the name of the scouring rot. When the purging has been of long continuance, a.general weakness is produced, accompanied with a loss of flesh. The skin hangs loose about the body; sometimes the animal appears hide-bound; the hair turns sandy, or of a greyish color; the eyes grow pale; the pulse is weak and irregular; the excrements thin and slimy, frequently changing color, particularly in the early stages of the disease; but in the further stages of the complaint, the dung appears like half-chewed food; the food appearing to pass through the bowels without undergoing the process of digestion. Some writers state, that when animals have been long affected by the scouring rot, they feel a considerable degree of distress and pain when grasped on each side of the back bone, just behind the shoulders; and this is considered as a certain sign that the beast has become unsound from the scouring rot.

Cure.-In the cure of this complaint in cattle, a variety of remedies have been proposed. Mr. Lawrence recommends, that as soon as the disease is apparent, the cattle should be taken to the home fold, and put on dry food, which will generally supersede the necessity of medicine. The remedy, which Mr. Blaine seems chiefly to rely on, is the following decoction:

Galls,

Nax romica,

Ipecacuanha

White vitriol,

In a quart of water boiled to a pint.

This receipt may probably appear too complex, and its ingredients too numerous. The following will be found of service:

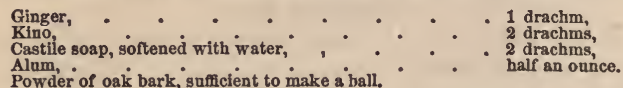

Where the scouring has continued for any length of time, the bowels must be extremely sore and tender. In such cases, mucilaginous or oily substances would be useful, and they should be given frequently, both by the mouth and by way of clyster. 
Mr. Lawrence recommends a pound of fresh mutton suet, boiled in three quarts of milk until the suet is dissolved, to form a drink, to be given warm. This, we should suppose, would answer extremely well. Should the disease increase to an alarming height, starch clysters, with laudanum, may be given as a last resource. Dr. Blaine observes, that, in these cases, he should try animal food altogether; giving broth to drink, or the blood of other animals, with meat balls forced down the throat; as he thinks it very probable that a change might thus be effected in the constitution, which might ultimately lead to a perfect cure.

Mr. White considers that the immediate cause of the disorder is an unhealthy action of the liver, and recommends the follow. ing drink, which he admits will somewhat increase the scouring at first:

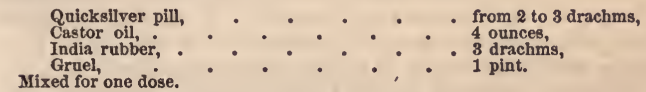

This should be well stirred immediately before it is given, as the quicksilver pill is heavy, and would otherwise soon separate and fall down; for the same reason it is to be given in gruel, which will suspend it longer than a thinner fluid.

This dose should be repeated for three mornings following, unless it causes sickness or griping, or increases the scouring in a considerable degree. On the fourth morning, commence with the following astringent drink, or earlier, should the above medicine produce its effect before the three doses have been taken. During the time the cow is taking the former medicine, she should be supplied with warm fluid, of which thin gruel is the best, and must not be exposed to a cold air.

Starch,
Mixed in a similar manner as is employed for stiffening clothes, with three pints or two quarts of water, so as to form a thick, mucilaginous fluid.

To this add:

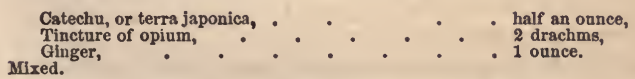

After the scouring has ceased, the cow should be brought back by degrees to her usual state. At first she should be turned out for a few hours, in some dry pasture, when the 
weather is agreeable; and her water should be given gradually less warm. This precaution is highly requisite, as the affected parts do not immediately recover their strength after the scouring has ceased.

In the diarrhœa, which arises from exhausting a cow by constant milking, when she is not sufficiently fed, or is supplied with food of a bad quality, the remedy is sufficiently obvious. But, in this case, it too often occurs that the constitution is worn ont before it is thought necessary to alter the poor animal's condition. Whenever this change is made, it must not be done too hastily, as other diseases may be produced thereby.

When calves are first weaned, they are subject to a species of purging, which sometimes proves extremely obstinate; and some suppose that the principal reason of the calf-feeders giving them chalk to lick, is to prevent this purging. It appears that this disease will take place in calves, when they are fed on the milk of some particular cows; and that when the milk is changed, the complaint goes off. The purging may generally be suspended, by boiling starch and bean flour in their milk; but should it still continue obstinate, a little ginger and laudanum may be added.

The last named writer also observes: "As to the medical treatment of this complaint, much useless expense is often incurred. The most profitable plan is, I believe, to put the animal under cover, especially in winter, autumn, and the early part of spring; and feed on hay, bran mashes, with oats, or oil cake, and endeavor to make her fit for the butcher. If it be a milk cow, she should be suffered to go dry. Should the scouring continue, notwithstanding this change, give, in the first place, the drench before directed, or the following:

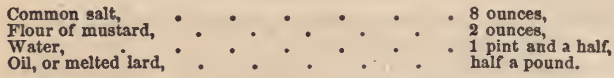

"This will increase the discharge for a short time; afterwards, the dung will gradually become of a more natural consistence. But should the scouring continue, give the astringent drink already prescribed, or the following:

Powdered catechu,

Tincture of opium,

Powdered ginger,

Warm ale,
- 6 drachms, half an ounce, 2 to 3 drachms, 1 pint and $\mathrm{a}$ half. 
"The powder, or tincture of galls, would also be found a pow. erful astringent. Some farmers give mutton suet boiled in milk, with four ounces of oil of turpentine. I once gave eight ounces of oil of turpentine mixed with a quart of gruel, and afterwards kept the animal under cover, upon hay and bran mashes. The dung acquired a healthy appearance in a short time; but on turning her out again, the disease quickly returned."

Dr. Dickson thinks that much advantage may be derived, in these cases, from a strong decoction of hartshorn shavings and cassia, with powdered chalk, in the proportion of half a pound of chalk, four ounces of shavings, and an ounce of cassia, to be boiled together in two quarts of water to three pints, adding the cassia towards the close of the boiling. A horn full of this mix. ture is to be given several times in the day, shaking it well every time.

\section{CATARRH, OR COLD.}

Causes.-The causes of colds are in general imperfectly understood, and ought to be attended to.

Symptoms.-There are two species of catarrh, viz.: simple cold, and epidemic catarrh, or what is frequently termed influenza. The latter sometimes will attack a whole herd of cows, or oxen in one night. When first attacked, the animal seems dull and languid; the eyes appear watery, and are sometimes partially closed; and the appetite is generally diminished; and usually attended with cough. Indeed, there are not unfrequently swellings under, or below the ears, a discharge from the nostrils, and also a difficulty in swallowing. When this complaint rages thus violently, it is commonly called influenza, or the distemper, and thougli some persons suppose it to be conta. gious, it has not been correctly ascertained that it is so.

Though colds are very prevalent, especially in very damp, or cold weather, and are often deemed of too little consequence to leserve particular notice, yet, if the animal is neglected, and suffered to remain exposed to the vicissitudes of the weather, very serious results may ensue. In consequence of such neglect, the animal is frequently observed to decline gradually, both in substance and strength, and also to become hide-bound, and possess a rough, staring coat; tubercles are ultimately formed in the lungs, the mesenteric glands become enlarged, and the passage 
by which nutriment is conveyed to the blood, is thereby obstructed; at length atrophy and death will inevitably ensue.

Cure.-It is highly requisite that this disorder should be attended to as soon as it is apparent. With respect to its cure, very considerable advantage will result from nursing and placing the animal in a warm situation, and allowing him warm, nourishing fluids, such as gruel, infusion of malt, \&c. At some seasons of the year, colds are so prevalent as to be considered epidemic and infectious; generally occurring with great violence, and accompanied by fever; considerable debility also ensues soon after the attack. On this occasion, hot stimulating drenches, though usually recommended, are very injurious.

At the commencement of colds, bleeding is generally proper; but should be avoided when the animal is very weak and low in condition. The quantity of blood, taken, ought rarely to exceed two quarts. Should the animal be costive, a laxative drink may be given; but if he purges or scours, the following powder may be administered:

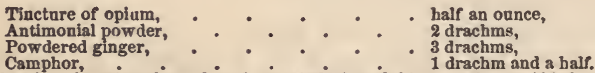

To be given in oatmeal gruel, and repeated after cight or ten bours, if it be found necessary.

Should there be found considerable difficulty in swallowing, apply the following liniment, and let it be well rubbed about the throat:

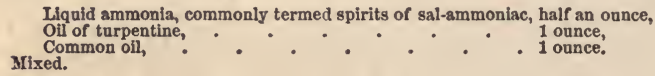

In the case of common colds, it will be unnecessary to admin. ister medicine, but the animal should be placed in some comfort. able situation, and well attended to. Bleeding, in slight colds, is rarely requisite; except the animal, owing to a change of situation, becomes hot and feverish, and the eyes appear red, and the flanks move quickly; in which case, he must be bled copiously. Should the animal prove costive, the laxative should also be given. When no fererish symptoms are apparent, the laxative should be mixed with an ounce of caraway seeds, and three or four drachms of ginger.

When the distemper has been improperly treated, the animal becomes extremely weak, and consequently his strength should 
be recruited as early as possible; on which occasion, a tonic may be given two or three times a day, which, with a warm, nourish. ing diet, and proper care and attendance, will ultimately effect a recovery.

It may be necessary to observe, however, that should the animal become costive, a mild laxative, consisting of about half a dose, will generally suffice. A moderate quantity of grass will be of service, if it can be conveniently procured, bur in favora. ble weather, some warm sheltered situation is the best place.

A laxative, composed as follows, may be used:

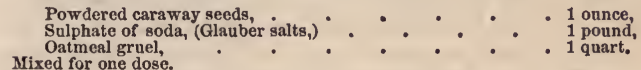

If this disease should appear to be epidemic, speedy measures should be adopted for its prevention, which is more particularly requisite when rain and cold winds prevail: for catarrh, or cold, is frequently an insidious complaint, and if not attended to may ultimately produce very unfavorable results.

\section{THE MANGE.}

Causes.-This disease would seem to arise from poor living and want of due cleanliness.

Symptoms. - This disease generally makes its appearance early in the spring, as soon as the warm weather begins to set in, and is commonly called by graziers, the scab, or scurf; a popular writer thus describes it:

"The skin is stiff, and sits fast to every part of the carcass, as if too small for the body. It makes its first appearance about the head and jaws of the animal, with a scurfy, pale, and dry texture; and the beast begins to scratch against everything that comes in its way; it then shows itself along the back, and behind the shoulders; and if timely aid be not procured, the animal will tear its skin till it bleeds violently, which ought to be prevented if possible, as the scabs, which are the consequence of bleeding, must retard the efficacy of the ointment, and the loss of the time confirms the disorder."

Cure.-The following ointment will prove serviceable in this disease:

\footnotetext{
Elecampane root powilered, . . . . . 2 ounces,

Sulphur vivum powdered, . . . . . 2 ounces. Mixed with hog's lard.
} 


\section{A recent author recommends the following:}
Hog's lard,
Oil of vitriol,
Gradually adding the oil of vitriol to the lard.
half a pound, 1 ounce.

Internal remedies, such as sulphur and gentle laxatives, are occasionally requisite; the most particular attention must be paid to cleanliness, exercise, and diet. In cases where the animals that have canght the disease are very full of blood, it will be necessary to bleed and give cooling physic, before the ointment be applied. The skin should always be thoroughly washed with soap and water, both before and after the application of the ointment, and the animals should be confined till they are perfectly free from the disease.

The following observations, extracted from the "Edinburgh Medical and Surgical Journal," are inserted as tending to show the injurious effects resulting from an improper treatment of the mange:

"For the mange in five cows of Mr. Hatchett, a man, vulgarly called a beast-leech, or cow doctor, applied a preparation containing tobacco and corrosive sublimate. In the course of one hour and a quarter they all died, preceded by convulsions. The facts were proved, on an action against this doctor, to the satisfaction of the jury, who awarded the damages. An experiment has been subsequently made by an intelligent medical prac. titioner, on the diseases of dogs, in which six grains of shag tobacco, infused in about one drachm of water, being applied to the skin of a dog, presently killed the animal. It is, however, well known that dogs are very commonly washed with tobacco water for the mange, without poisoning them; but I have known it occasion long continued nausea, vomiting, purging, and discharge of urine. Prnbably, however, it requires a concentrated solution of tobacco to prove destructive to life. The same observation is made on the effects of corrosive sublimate and tobacco, in the case of Mr. Hatchett's cows. Probably, too, these applications may occasionally have produced death, but the cases were unnoticed. It is also questionable, whether the tobacco or corrosive sublimate poisoned the cows, or the two conjointly. Tobacco does not kill horses, for it is very commonly eaten with corn, to increase the appetite; nor do very large doses of corrosive sublimate, taken internally, poison them." 


\section{DYSENTERY.}

Causes.-This disorder commonly arises from suppressed perspiration, induced by exposure to sudden changes of weather, especially when it has been previously fine and warm. Cattle that are over-heated by driving, and turned into a pasture at night, where they lie down upon wet grass, are sometimes attacked by it. These causes produce the complaint, by occasioning a peculiar inflammation of some parts of the bowels.

Symptoms.-This complaint is accompanied by an inflammatory fever and griping pains, and is sometimes termed the bloody ray. The discharge of dung is frequent, emitting an offensive smell, and is often mixed with the mucus, or natural lining of the bowels. It is very similar to the disease of horses called molten grease.

Cure.-Copious bleeding should first be applied, and a pint of castor oil be taken afterwards. Should the animal not appear relieved, in some degree, in six hours, the pulse remaining quick, and the under surface of the eyelid particularly red, the bleeding must be repeated. After the symptoms liave been subdued, the animal will be very weak; and consequently, every exertion must be used to support its strength. For this purpose, oatmeal gruel, or gruel made with wheaten flour, and malt mashes, may be given freely. Should the discharge be considerable, bleeding would be injurious: the castor oil, however, is commonly necessary; and, if it cannot be easily procured, sweet oil or melted lard should be substituted. Gruel formed of arrow root, is an excellent drink in this complaint. If the disease should still continue, half an ounce, or six drachms of tincture of opium may be given in arrow root gruel.

If calves are improperly managed at the time of weaning, they are liable to a severe diarrhœa, which, if not attended to, very frequently proves dangerous. Flour milk gruel, with a little prepared chalk, is the best remedy for this complaint; a drachm of ginger, and from half a drachm to a drachm of tincture of opium, may be added in very obstinate cases.

THE FOULS.

This complaint in cattle is somewhat similar to canker in the horse, and generally produces a discharge of fetid matter from be- 
tween the claws of the hoof, or occasionally from one claw only, in which cases, cattle are commonly said to be foul in the foot. This disease is usually distinguished amongst graziers by the names of the soft, and the horny foul, and requires different modes of treatment. In the soft fouls, there is a running of very offensive matter from the heels, or between the claws of the hoof, and the animal is exceeding lame. In this case, the treatment consists in cutting away all the soft and spongy parts, and afterwards applying a caustic liquid. The parts should then be covered with a little mild ointment; or, (as farmers frequently do,) wrap a piece of fat bacon around the part, tie it on the foot, and let it remain for two or three days. In the meantime, the animal should stand very clean, and be allowed as much rest as possible.

In the horny fouls, the animal appears very lame, and, on an examination of the foot, the hoof feels very hot, and on pressing it hard, the animal feels considerable pain. Some part of the horn generally penetrates into the softer parts of the foot, either at the heel, or between the hoofs. In undertaking the cure, it will be requisite to cut away these parts of the horn, as well as any other part under which much inflammation is apparent. If it should be necessary to cast the animal, particular care should be taken in selecting a soft place for the purpose of throwing him on. When the hoof is pared away, a rag moistened with vinegar and water, should be tied on, and the animal sent to graze on some soft ground. Should the inflammation and pain be very great, it may probably be requisite to bleed from the veins of the foot.

\section{COWS PREVIOUS TO CALVING.}

"The diseases," observes Mr. White, "which most commonly occur at this time, are stranguary, or difficulty in voiding urine, and costiveness; and these it is highly necessary to attend to, as they may, if neglected, be the cause of the cow slipping her calf. The stranguary is readily known to exist, by the cow making frequent attempts to stale, without being able to void any urine, or only a small quantity. When it is accompanied by costiveness, which is generally the case, and is often the cause of the complaint, the bowels must be opened by a laxative, consposed of a pound of Epsom salts, dissolved in a quart of gruel; 
a clyster should also be given, consisting of two quarts of warm water, and four ounces of linseed oil. The clyster may be repeated two or three times in the course of two hours, should it be found necessary. Should the stranguary continue after the bowels have been emptied, give the following drink: Mix.

Spirit of nitrous ether, . . . . . . half an ounce, Camphor, powdered, . . . . 2 drachms,

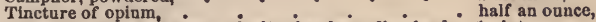

Gruel, in which one ounce of nitre has been lissolved, 1 pint.

"Many cows have been lost, by allowing them to be too fat at the time of calving: they are then said to die of the milk fever, which, in fact, is nothing more than inflammation of the uterus, or womb. It is advisable, therefore, when a cow, far gone with calf, is in too good condition, to reduce her, by chang. ing her pasture, which is preferable to bleeding or physic; but if she has approached too near her time to admit of this change having any effect, then bleeding will be proper."

\section{COWS AT CALVING.}

Nature is, in general, all-sufficient for the purpose of producing the young of the various domestic animals, and consequently, little is left for man to do, except in taking care that the females be placed in such a situation that they may not expose themselves or their young to injury. It is always requisite that a cow, which is near the time of calving, should be attended to, in order that every necessary assistance may be rendered.

Some cows, especially those of the short-horned breed, frequently require particular assistance. The natural presentation of the calf is, with its head and fore feet, the nose between the feet, and the back upwards. Downing enumerates several preternatural positions, namely: First, reverse representation, or tail first. Second, fore feet, no head appearing. Third, side belly upwards, head reversed over one shoulder, legs appearing. Fourth, fore feet with head under the brisket. Fifth, head alone, or one fore leg only with it. Sixth, head and one leg, or head alone. Seventh, calf lying on its back, its fore legs folded nearly togeth. er, and close up to the cow's back; the head appearing, or doubled back, even with the ribs, on one side or other; the hind leg perhaps appearing. 
The following general rules are extracted from an excellent work by Mr. Lawrence:

"Timely assistance before the cow is exhausted.

"Extraction uever to be attempted in an improper position.

"Supple the hand and arm with warm water and fresh lard.

"Examination best made, the cow standing, and in the interval of pains.

"In pulling at the feet, enclose the claws in the hand, that the horn may not bruise the cow.

"Naval string bursting, and the usual flux of blood of no consequence.

"Instruments to be used only in the last resort, and by an experienced and steady person only.

"The proper hook is of hard iron, four inches long, with a loop for the cord at the straight end.

"In a natural position, if the cow should want help, the position of the calf may be ascertained after the waters have been seen. A cord ought to be in readiness to attach to the fore legs of the calf, in order to assist each natural exertion. The head to be kept clear from obstruction.

"Preternatural position. No. 1. as above. No attempt to turn the calf (this position being favorable for extraction,) but nse expedition, for fear it be suffocated. Press the haunches back with the palm of the hand, take hold of the bend of the hough of one leg, pull at it, and reach the foot; both feet may thus be brought forth. No. 2. Reduce the head to its proper situation, between the fore legs, either by hold of the nose, or the face bone. A long arm is needful, which must be kept to the full extent of the body, that instant advantage may be taken of every throe, the fingers being properly fixed. No. 3. Gently move the calf back, and bring the head forth to the legs. No. 4 . Push the calf back to find the head; pull at the nose: this requires address, but it is useless to employ force till the head be in its proper place. No. 5 and 6. Push the calf back against the shoulders and brisket: the feet will be found folded under the belly; bring the feet forward, one at a time, the hand being gently placed on the bend of the knee. Should the head be too much swelled and bruised to be returned, it must be skinned and amputated. Dissect in a straight line from the poll to the nose, force the skin back over the first joint of the neck, divide the 
head from the body, pushing the latter back to obtain hold of the knees. The loose skin must be previously wrapped over the ragged bone, and an assistant should have fast hold, in order to guide it clear of the haunch-bone of the cow; should it hitch there, pull back instantly. No. 7. If one hind leg appear, put it back; the calf cannot be brought forth with a hinder and fore leg together, and the difference between the knee and hough will be immediately discovered. The head being doubled back, must of course be reduced to its proper place. The cow being strong and quiet, the business may be effected with care and patience: and should the hook be positively necessary, hold must be taken, either in the sockets of the eyes, cavity of the ears, or in the jaw. The case of dropsy in the calf will be sufficiently apparent by its preternatural size; use the knife carefully, should that be necessary, to pierce the belly of the calf."

A recent author observes: "When every other plan has failed for turning the calf, so as to put it into a favorable position for delivery, the following has often succeeded. Let the cow be thrown down, in a proper situation, and placed on her back; then, by means of a rope and pully attached to a beam above, let the hind parts be raised up, so as to be considerably higher than the fore parts; in this position, the calf may be easily put back towards the bottom of the uterus, so as to admit of being turned, or his head and fore legs brought forward without diffculty."

A very material obstruction frequently occurs to the calving of cows, which is called a horning of the lye or calf-bed, when the passage of it is contracted into such a very small circumference, as not to admit the smallest hand at the period of gesta. tion, and grows so sinewy or horned, as renders it quite impossible for the cow to calve without assistance; many cattle have perished on account of this dangerous inconvenience which night have easily been prevented. But so little has been hitherto known of many of the diseases peculiar to cattle, that a simple remedy or operation might have saved very great numbers which might have fallen victims to an untimely death.

In the case before observed, a late writer remarks: "It must take a considerable time before it is contracted as it is often found; but no suspicion or dread can reasonably take place, until near the time when the beast has arrived at the end of nine month, 
her full time of bearing young, when they generally make a regular preparation, or falling of the parts of generation, for a few days or week before calving; but in case of this hornedness of the calf-bed, it is observed that they are backward in making these necessary alterations preparatory to the approaching change; and when this is noticed, more than usual observation ought to be taken, for when they do not prepare in a regular manner, they seldom have the efforts of nature in due course, for the delivery of their burden. But when the beast is observed sick for calving, and has reached the end of her time, and any dread of this is apprehended, there is no danger or impropriety in searching with the hand, in order to be satisfied whether that part is open or grown up, as previously described; yet the greatest care is necessary that the enquiry be made with judgment, and the hand that is introduced must be well lathered with soap and water, or greased with tallow, fresh butter, or some such thing, that will not canse irritation in the neck of the womb.

"Now if it be found in the state described, in any degree, and a certainty of the beast being at its full time, with the common sickness and symptoms for calving, no time should be lost until the animal be relieved. The difficulty greatly depends on knowing to what degree it is grown up; it is sometimes so straight as not to admit the end of a finger; but with some exertion, it may give so much way as that a small knife may be introduced, whose blade should not be above an inch and a half in length, and very sharp, with a hollow on the back part of the point for the end of the fore finger, to guide the knife when cutting, and to cover the point and edge when introduced, which must be covered as much as possible with the hand. Its handle ought to be short, and the fore finger of the operator should always be kept. forward on the knife, to prevent any danger that might arise from the edge of it. The horny circle is sometimes so hard and gristly, that it takes more exertion than may have been expected from the nature of the place: but as soon as it is cut through, the beast will find a very material difference, and strive to void her burthen if possible, when every exertion of art ought to be used for her relief. When the business is happily over, the wounded parts within must be taken care of by providing one pint of rectified spirits of wine, camphorated, to anoint the wound, and any other part which may have been exposed to the air, bruised, or over distended. This may be conveyed up the neck of the womb by 
a syringe, sponge, or linen rag filled with it, and carried thither by a small hand, well fomented with some of the foregoing articles for that purpose. Let the beast be kept moderately warm, and in a comfortable situation, allowing her at all times a plentiful supply of good, dry, and sweet litter."

This method of management in preternatural contractions of the passage, is recommended by Mr. Rowlin; but nuch will, of course, depend, in every casc, on the judicious observations of experienced judges.

\section{THE CESAREAN OPERATION,}

-Which is that wherein it is impossible to deliver the cow of her calf, and save her life, and thus lose cow and calf together, is sometimes resorted to to save the calf, if of great value. It is simply that of cutting open the belly of the cow, and taking the calf from the womb while the cow still lives, and immediately afterwards killing her as if for common slaughter. The operation is a most repulsive, not to say a cruel one, but the pain is short, and sometimes the operation valuable in results. We have seen, in this country, a valuable blooded calf which was so saved at birth, but it has only been resorted to under the most desperate circumstances. Youatt twice attempted a thing of the kind, and was unsuccessful in saving the life of either cow or calf in both cases, as he states it; and he had heard of only one successful case of the kind by another surgeon. Our own flock master has saved several lambs by that operation, where, if neglecter, both ewe and lamb would have been lost. The ewes died, of course, but the lambs grew up to fine healthy sheep. A case of this kind with cows, seldom occurs, and it is only mentioned here as among the possibilities.-L. F. A.

SWELLING OF THE UDDER.

Cows are generally attacked by this complaint about the period of calving, and the swelling is sometimes so considerable as to cause an abscess to form. Immediately it is perceived, take a pound of Epsom salts, dissolved in a quart of gruel, to which a little castor or linseed oil may be added. Tle swollen udder 
should be often fomented with a decoction of mallows, elder, or hemlock, by means of large woolen cloths dipped in the hot decoction, and, after wringing, applied in such a manner as to cover the whole udder; this process should be continued for a considerable time, and repeated several times each day. * After the inflammation has been removed, a slight degree of hard swelling may remain; this, however, is not painful: and the fol. lowing liniment rubbed on the part once or twice a day, will soon disperse it:

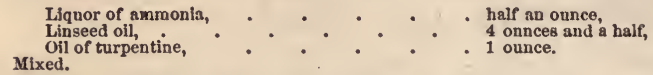

Inflammation of the udder will sometimes happen in consequence of the animal receiving cold; in this case, the coat stares, the appetite is diminished, the breathing is quickened, and some degree of fever is apparent. The following warm laxative may afterwards be applied:

Mixed.

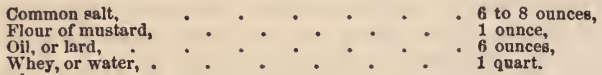

The animal should not be exposed to the weather, but fed with warm mashes of bran or meal; and an ounce of nitre may be put into her water morning and evening.

\section{CHAPS, OR SORE TEATS.}

It occasionally occurs that the udders of cows are chafed by rubbing against their thighs when they are cat-hammed and go close behind; in consequence of which, both the udder and thighs of the cow are frequently raw and ulcerated. Warm water and soap applied to the parts, will be found an excellent remedy; afterwards they may often be bathed with lard or cream, and camphorated spirits mixed.

On account of due cleanliness not being exercised by the milkers, the teats of cows are frequently chapped. A similar treatment as the above will also prove salutary in this case. But should they be very sore, a little laudanum may be first applied to the cracks, and they may be afterwards filled up with fine powdered chalk.

\footnotetext{
* See water treatment of garget, page 436.-L. F. A.
} 
When a slight inflammation of the udder occurs, and matter is collected, the lowest part containing the matter should be opened, in order that the matter may run off freely. After this has been performed, the part should be syringed with warm water, and kept clean, and no matter allowed to lodge in the cavity. An opening may be made in the side of the teat, a little above its extremity, for the purpose of quitting the matter entirely, or in the orifice through which the milk is squeezed out. Sbould it not heal sufficiently quick, a mixture of spirit and water, or a solution of white vitriol, may be injected.

\section{GRIPES, OR COLIC.}

Causes.-Though this disorder will sometimes occur when the bowels are in a regular state, it is commonly produced by costiveness, or a retention of food in the third stomach. Those cows that are kept entirely on dry food, or fed upon grains, are most subject to this complaint. The flatulent colic comes on rather suddenly, when it is occasioned by feeding greedily upon fresh, succulent grass, or by drinking too much cold water when overheated; but the attack is generally more gradual when it is caused by costiveness.

Symptoms.-Young cattle are most liable to the colic. Its first appearance is denoted by the peculiar restlessness of the animal, which will frequently lie down and groan, or strike with the hind feet or horns against the belly. The body is also swollen, which is particularly apparent on the left side, but the pulse is usually in its natural state. The pain becomes more violent if proper remedies are not soon applied; and ultimately inflammation will ensue; in which case the pulse becomes exceedingly quick, and the horns, ears and feet, cold; when this occurs, the disease generally has a fatal termination.

C'ure.-Purging medicines, combined with aromatics or stimu. lants, are the most essential remedy, when the colic originates in costiveness. The following will be found an excellent medicine for this purpose:

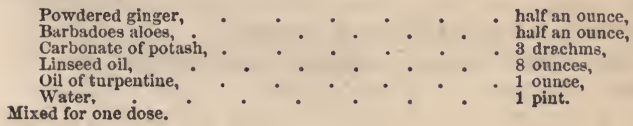


If the above medicine cannot speedily be procured, the following may be substituted for it:

Flour of mustard,

Linseed oll, sweet oil, or any oil that is not very rancid, or even hog's lard,

Water,
A glass of spirits may be added to the above.

1 ounce,

half a pound.

half a pound,

1 quart.

Should the animal be in good condition, or the inner surface of the eyelid appear unusually red, she should be copiously bled; but should the complaint be attended with looseness, or the bowels be in an irregular state, especially if the inner surface of the eyelid be pale, and the animal appears somewhat weak, no blood should be taken, but the following carminative drink may be given :

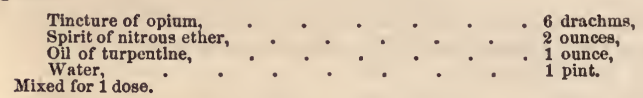

Should the purging drink be found necessary, clysters may be applied for the purpose of promoting its operation. When the colic is produced by feeding greedily upon grains, or any other kind of food, the cow must be fed cautiously for several days after, and have the following stomachic drink administered once or twice a day, in order that the tone or energy of the stomach may be restored:

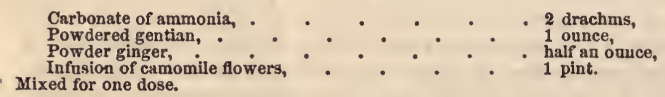

When the colic is caused by costiveness, or feeding upon dry food, the state of the bowels should be attended to, as soon as the animal has been relieved by the operation of the purgative drink. Should the animal not have a change of diet, some salt must be mixed with the food; or, if the animal will not eat it, she should be drenched with three or four ounces of salt, dissolved in water, daily, in order that her bowels may be slightly opened, and her appetite for water increased.

[NotE.-This disorder is probably the equivalent to colic in horses. An intelligent physician assured us that he had cured several horses of violent attacks, by simply giving them a dose 
of powdered charcoal and fine salt-say half a pint of salt to uhree gills of coal, diluted with lard, or butter mixed, or even in water, so that the animal could swallow it. Why may it not be equally efficacious with cattle?-L. F. A.]

\section{CHOKING.}

Various causes may contribute to occasion a difficulty of swallowing; either from the morsel attempted to be swallowed being too large, or from the unusual narrowness of the gullet. The former frequently occurs to cattle that are fed upon turnips or potatoes; and the choking thus produced is so dangerous as to cause the animal's death, if the obstruction is not speedily removed.*

Mr. Alexander, an ingenious farmer in Tweeddale, invented a very useful instrument for the purpose of removing the obstruction. It is described as follows:

"Take three small canes, (rattan or whalebone,) of the thick. ness of the little finger, or thereabouts, of the length of five feet and a half, that they may reach down the throat, and into the stomach of the largest ox. These canes are to be bound together by strong smooth twine rolled tightly about them, (the circles of twine touching each other,) from top to bottom. Beeswax is then to be rubbed along the twine, to fill up any inequalities, and the whole rod is to be well oiled before it is used. There is a round knob at each end; the larger, two inches and a half in diameter for larger cattle, the other less for lesser cattle. These knobs are formed of the twine rolled hard, and when formed, may be strengthened in their position, by being sewed by means of a shoemaker's awl, and a waxed bristled thread, such as they employ. The thread knobs are made tapering up the canes from their broad extremity; but it must be remarked, that the surface of this extremity is not rounded like a clue, but hollowed into the form of a cup. The intention of this hollowed form is, to make certain of catching hold of the obstructing body; as, if the knob was round, it night pass by it. After the knobs are formed, they are covered with soft leather, which, by its flexibility, will adapt itself to the hollow end of the knob as soon as

* The better way is to avoid any such choking by always cutting the roots, or apples fed to the cattle, in small picces.-L. F. A. 
it reaches an obstacle. The knobs must be securely fixed to the canes, for if they fall off, they leave an indigestible substance in the stomach." The above constitutes Mr. Alexander's probang, the only obvious improvement on which, says a recent writer, "is to make the knobs of sponge, firmly fastened to the canes, by passing twine through holes bored in them, and adding to each end two or three bights of twine, for the purpose of catching hold of any obstacle, thus making the instrument almost exactly like a surgeon's probang. 'The sponge is preferable to the twine, as it will not be liable to injure the animal's throat by its hardness, will adapt itself more readily to any form of the obstacle, and may be more firmly fixed in the canes."

[Nотк.-A piece of grape vine, nearly an inch in diameter, or pliable tough willow, may answer, of the size of the three small canes above mentioned.-L. F. A.]

\section{PUERPERAL, OR MILK FEVER.}

Causes.-This is a disease peculiar to cows in high condition at the time of calving; whether young or old, all are liable to be attacked with it. Whenever it takes place, either at home or in the field, it is distressing to the animal, as well as troublesome to the owner: they seldom are able to rise in less than two or three days after. The puerperal, or milk fever, is most frequent during the hot weather of summer. The cows most liable to be attacked with this fever, have large udders that are full of milk for several days before calving, and often very much inflamed and swelled. It is a very dangerous disease when severe, and often proves fatal even under the most judicious treatment. The milk fever most commonly attacks the cow about the second or third day after calving. We have remarked above, that those cows which are in high condition at the time of calving, are the most subject to this complaint; however, it sometimes attacks lean cows, especially if they are deep milkers. We conceive its immediate cause to be an inflammatory state of the udder, which is frequently induced by the animal taking cold, and from a redundancy of blood in the system. About the second or third day after calving, a much greater quantity of blood than usual is determined to the udder for the purpose of the secretion of milk, but when the udder is inflamed, this act 
does not take place, and the blood is in consequence transferred to some other part or parts, as the peritoneum, the bowels, kidneys, \&c., which deranges the whole animal frame and produces the milk fever.

Symptoms.-This disease is first perceived by the animal refraining from food, and looking dull and heavy. A cold shivering fit comes on, accompanied with so much debility that the beast commonly drops, and is unable to rise, until she obtains some relief from medicine. The animal becomes very restless, and appears to experience great pain in the body, as she often looks towards the flanks, and kicks with her feet, and seems very much distressed. The head, as the disease proceeds, is in general so severely affected that the cow loses her senses, and will knock and bruise her head against anything, and do herself much injury, if great care is not taken. The pulse is quick, being about seventy in a minute; and the tongue parching dry. The bowels are costive; there is no secretion of milk; and the slimy discharge from the barren ceases. As the disease advances, the belly becomes enlarged; if purging medicines lessen the swelling of the body, it is a good sign; but if they are made use of, and the belly still increases in size, there are little hopes of her recovery.

Cure.-If the feverish symptoms run high, attended with much pain, it will be proper to take three or four quarts of blood.* A purging drink should always be administered as early as possible. The following is highly recommended by some practitioners:

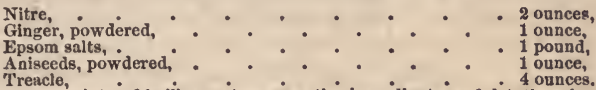

Pour three pints of boiling water upon the ingredients, and let them be giren, when new milk warm.

This drink must be repeated in the space of eighteen or twenty hours, if it does not operate before that time. If the bowels are moved with difficulty, the following clyster may be injectedhaving racked the animal previously:

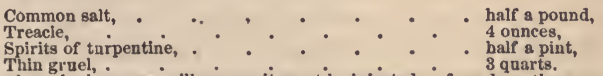

Mixed, and when new milk warm, it must be injected or forced up the anns.

* See this disease, pages 437-8,-L. F. A. 
This clyster will promote the evacuation of fæces, and tend to remove the swelling of the belly.

When the bowels have been opened, and the animal still appears low and unable to rise, it will be requisite that the following cordial drink should be administered:

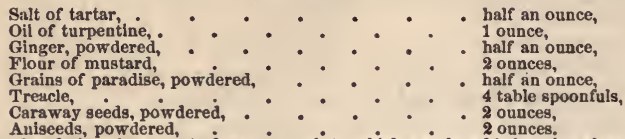
Mixed and given in a quart of warm gruel, to which may be added a wine-glass of gin or brandy.

This drink will tend to invigorate the system, and promote the secretion of milk. It may be repeated once a day, or every other day, for three or four times. Should the bowels be inclined to be bound any time during the complaint, recourse to a purging drink should be had immediately.

Cows afflicted with the milk fever should be taken great care of, and be well nursed. It is requisite that the stall where they lie should be well littered; and it is frequently necessary that, when they are cold and shivering, they should bo covered with a blanket or some other warm clothing. To assist in subduing the inflam. mation of the udder, it should be rubbed two or three times a day, about half an hour each time, with soft soap, or pipe-clay, and cold spring water.

To solicit the flow of milk, the paps should be drawn occasion. ally; it is a good sign when the milk begins to be secreted. As they are frequently unable to take a sufficient quantity of sup. port themselves, it becomes necessary to horn sume nutritious food into them. Good gruel is well adapted for this purpose, and two or three quarts should be given three or four times a day. Linseed porridge, sweetened with treacle, is also proper to be given at this time. The beast must be constantly attended to when the head is much affected, otherwise she may do herself some serious injury.

\section{THE GAD-FLY.}

The gad-fly is an insect which is very troublesome to cattle. Mr. Bracey Clarke has accurately described the various species of these insects, and their effects. The species called Oe bovis, chiefly 
attacks cattle, through the skins of which it pierces, to deposit its eggs. The pain which it inflicts, in depositing its eggs, appears to be much more severe than what is excited by any of the other species. When one of the cattle is attacked by this fly, it is easily known by the extreme terror and agitation that seizes the whole herd. The unfortunate object of attack runs bellowing from among his fellows, to some distant part of the pasture, or to the nearest water, holding his tail, from the severity of the pain, extended straight from the body, in a line with his back, with a tremulous motion, and stretching out his head and neck to the utmost. The rest of the herd, infected with the like fear, though not attacked, fly also to the water, or disperse to the different parts of the pastnre. "Such is the dread and apprehension in the cattle, for this fly," says Mr. Clarke, "that I have seen one of them meet the herd, when almost driven home, and turn them back, regardless of the stones, sticks, and noise of the drivers; nor could they be stopped till they reached their accustomed retreat in the water."

Should one of these flies happen to attack oxen that are attached to the plow, there is frequently considerable danger, since the animal becomes quite ungovernable, often rushing directly forward with the plow, through hedges, or whatever opposes his career.

Steers, heifers, and the younger cattle, are most commonly attacked by this fly; the strongest and most healthy beasts are generally selected by it; thus furnishing a very estimable criterion of goodness to the dealers in cattle. Гanners also have frequently observed, that their strongest and best hides have usually the greatest number of holes in them.

The larvæ of the Oe bovis are generally distinguished among country people by the various names of wormuls, wormils, or warbles.

The larvæ, or the Oe equi are commonly termed bots, and the puncture they make, called puckeridge, is often attributed to the bite of the goat-sucker. In order to accomplish the destruction of the larvæ thus deposited, some recommend the parts to be pressed, and afterwards well rubbed with a little oil of turpen. tine, or some other stimulating application, or the injection of a little oil of turpentine into each hole.

The following is the usual remedy for cattle bitten by these insects : 


\section{Tar, fiard,
Hog's lard,
Melted together and applied to the bitten parte.}

[NotE.-These pests are not much known in America. We have, however, seen instances of them. They are oftentimes very troublesome to cattle in England. When in the larva state, they are readily found by running the band along the back of the animal, and may be pushed out of the little puncture through the skin, under which they live, by a sharp pressure of the two thumb-nails, as one would squeeze a pimple, or other gathering near the surface.-L. F. A.]

\section{LICE.}

Those cattle are most subject to lice, which through bad keep and poverty, are reduced to a low state, so that Nature is unable to cast off her old coat, and consequently an extra harbor is left for the vermin to accumulate in. The best method of destroy ing those vermin, is by rubbing their hides with an ointment composed of cayenne pepper, or Scotch snuff, mixed up with hug's lard.

[Note.-The easiest, and quite an effective remedy, is found in any kind of oil, or soft grease, mixed with Scotch snuff-or even the oil, or grease alone-well rubbed in. This is our com. mon practice, and always a cure. Calves particularly, should be watched after weaning, and during their first winter, as they are quite apt to get lousy. Indeed, all cattle should be closely watched for these vermin, as before one is aware of it they may infest an entire herd, even if in good flesh. Poverty of condition is not always the source of lice in cattle. We have seen mercurial ointments recommended for killing lice. They are nearly as dangerous to the creature infested, as to the lice. We have known valuable animals to die from the use of such ointments._L. F. A.]

\section{FOG SICKNESS.}

This is a common disease amongst neat cattle, and is attended with symptoms of the most distressing nature. It requires speedy 
relief, or the animal will be suffocated from the confined air in the two first stomachs, or a rupture of them takes place, which soon terminates the life of the beast. Hoven usually proceeds from a voracious and greedy disposition, incident to cattle when permitted to satiate their appetite witl food of which they are most fond; such as vetches, rich fog, red clover, or different kinds of grasses; also potatoes, turnips, corn, and sometimes chaff.

Causes.-The immediate causes of this disease is a preternatural distension of the two first stomachs from confined air. It is, as before mentioned, in general, occasioned by the animal feeding for a considerable time upon rich, succulent food, so that the first stomach, or paunch, becomes overcharged, and they, through their greediness to eat, forget to lie down to ruminate or chew their cud. A fermentation of the food in the paunch takes place, and a considerable quantity of air is consequently generated, which so distends the first two stomachs, that by their pressing against the skirt or midriff, the capacity of the lungs for air is diminished, which canses the difficulty of breathing, and suffocation is sometimes produced. This complaint may be occasioned by turning cattle into fresh aftermath pastures, in autumn; at which time the grass is changed in quality, and the weather frequently wet or foggy, and then is called fog sickness.

Symptoms.-This complaint is well known to most cattle keepers. The wind generated in the stomach causes the beast to swell, and a difficulty of breathing produced, with much apparent distress. If relief is not soon obtained, the difficulty of breathing increases, and the animal is unable to stand, and generally dies suffocated.

Cure.-When the beast is hoven or blown by eating too much succulent grass, Mr. Clater recommends the following, as efficacious in checking the fermentation in the first stomach:

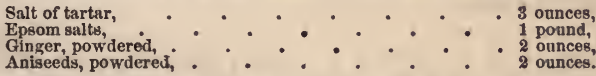

These ingredients may be placed in a pitcher, and three quarts of boiling water poured upon them. When they are new milk warm, add a wine glassful of gin and give the whole for one drink.

Dr. Monro, Sr., of Edinburgh, in the year 1793, contrived an elastic tube, that might be introduced down the throat into 
the stomach of the animal, and thus speedily and effectually evacuate the air. The tube is to be composed of iron wire, as large as a common stocking wire, or about one-sixteenth part of an inch in diameter, twisted round a smooth iron rod, threeeighths of an inch in diameter, in order to give it a cylindrical form; and after taking off the rod, it is to be covered with smooth leather.

To the end of the tube which is intended to be passed into the stomach, a brass pipe, two inches long, of the same size as the tube, and pierced with a number of large holes, must be firmly connected.

In order that the tube may be prevented from bending too much within the gullet, at the time of passing it down into the stomach, an iron wire, one-eighth of an inch in diameter, and of the same length as the tube, is put within it, which is to be withdrawn when the tube has entered the stomach.

$\mathrm{He}$ has ascertained that the space from the fore teeth of the under jaw, to the bottom of the first stomach of a large ox, measures about six feet, and he has passed such a tube, five feet and nine inches long, into the gullet and stomach of a living ox. The tube ought therefore to be six feet in length, or rather longer, that it may be sure of answering in the largest ox.

After the tube has passed into the stomach, it may be allowed to remain for any length of time; as when it is pressed to one side of the throat, it does not intercept the breathing of the animal. The greatest part of the elastic and condensed fixed air will be readily discharged through the tube; and if it be thought necessary, the remainder of it, or the superfluous drink, may be sucked out by a bellows fixed to the upper end of the tube, with two valves, one at its muzzle, and the other at the side of it, so disposed as to allow the air to pass in the direction from the stomach upwards.

By means of such a tube, the air is not only more certainly discharged than by stabbing the animal, but the dangers avoided which are occasioned by stabbing, not so much by the irritation which the wound creates, as that the air, and the other contents of the stomach, getting into the cavity of the belly, between the containing parts and the bowels, excite such a degree of inflam. mation as frequently proves fatal to the animal. This tube will also be found useful for the purpose of introducing into the stom. 
ach, stimulating medicines, when the contraction at the upper orifice would prevent their being given without some similar contrivance.

Mr. Blaine has somewhat improved this mode of relief, by the invention of an instrument, for which he was rewarded by the London Society for the Encouragement of Arts, with fifty guineas. This is simply a cane, six feet in length, and considerable diameter, for oxen, to which a knob of wood is affixed at the end, to be introduced into the stomach. He also invented a contrivance for sheep, which is considerably smaller, and only three feet in length. This instrument is much preferable on account of its simplicity, and is found to occasion the evacuation of the air as effectual as the other. In cases of emergency, the flexible part of a common cart whip might, no doubt, answer the purpose, if applied by a judicious hand.

In performing this operation, an assistant is to lay hold of the cow's horns with one hand, and the part which divides the nostrils with the other. The operator is to take the tongue in the left hand, and with his right he is to force the instrument down the gullet. A great quantity of air will rush out as soon as it enters the paunch. The instrument may remain in the stomach until the air is fully evacuated, without injuring the animal.

Any person unaccustomed to handle cattle would feel some difficulty in using the above instruments, but if the part which divides the nostrils be grasped firmly with the right hand, and the horn be held firmly with the left, the cow will, in general, submit quietly to the operator.

As soon as the animal has obtained some relief by these means, the following drink may be given :

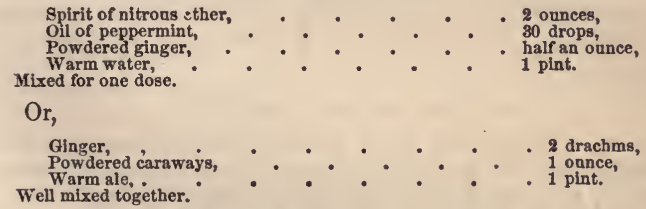

An infusion of camomile flowers, or ginger, is likewise a good stomachic in such cases; and it might probably be much im. proved by infusing the ingredients in hot ale instead of water. 
When cattle have experienced a severe attack of this disease, the stomach is usually much weakened by it; and, consequently great care is requisite to prevent a return of the complaint: they should be fed rather sparingly, or not be permitted to eat much at one time for some days after. One of the above drenches may be administered every morning and evening for three or four days.

\section{LOSS OF THE CUD.}

Causes. - Though this disease usually arises from over-feeding in rich, succulent pastures; it is, however, sometimes owing to the diseased state of the liver.

Symptoms.-In the early stages of this complaint, the animal appears dull and languid, and generally has a tight skin, and a rough unhealthy coat. As the disease advances, the appetite is diminished, and ultimately he ceases to chew the cud. The eyes and mouth usually appear yellow.

Cure.-When the liver has become much affected, the disease commonly terminates fatally; a cure should, therefore, be attempted at an early period. If there be any appearance of costiveness, the following warm laxative should be first given:

Mixed.

Castile soap, . . . . . . . 6 drachms,

Ginger,

Barbadoes aloes,

Cascarilla bark,

3 drachms,

Warm water,

The bowels, however, are generally in a loose state, and the dung has an unhealthy appearance. When this is the case, give the following tonic drench, morning and evening, and let the animal be kept warm:

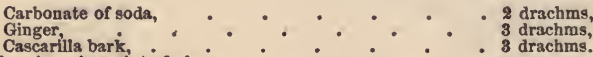

To be given in a pint of ale.

\section{THE JAUNDICE, OR YELLOWS.}

Causes.-It generally arises from a debilitated state of the stomach, which being distended with food, from slow and difficult digestion, particularly the manyfold, press upon the bile ducts, and prevent the bile flowing into the intestines. The bile being thus obstructed, is taken up by the lymphatic absorbents, and conveyed into the circulating mass of blood, and gets diffused 
thronghout the body. Milk cows are the most subject to it in the spring, and the latter end of the year, yet they are not exempt from it at any other time. The fluctuating state of the weather appears frequently to give rise to this complaint; when the weather is very changeable, and they appear not well, great care should be taken to place them within doors.

Symptoms.-This disease is first apparent in the whites of the eyes, which appear of a yellow tint, and the whole skin becomes impregnated with the same yellow hue as the disease increases; the eyes, ears, mouth and taiil, are the parts where it is most conspicuous to the sight. The animals have a weakness and considerable debility of the nervous system, a want of appetite, and an aversion to move, in every stage of this disease. When in the pasture, they are continually wandering about by the side of the hedges, in a dejected manner, by themselves. When a milk cow has this disease, the secretion of milk is lessened; the fore teeth sometimes loosen; and the bowels become costive.

Cure.-In the early stages of this disorder, the warm laxative, directed in the preceding complaint, will generally effect a cure; it may be repeated after an interval of five or six days, and in the interim, the following drink may be given every morning and evening:

Venice turpentine,

Ginger,

Castile soap,

Yowdered gentian root,

The soap and turpentine may be rubbed together in a mortar, till perfectly incorporated; after which a pint of water may be gradually added, and afterwards the gentian and ginger.

The liver becomes generally much injured in the more advancad stages of this disorder, and a cure is then almost impossible.

$\AA$ recent author makes the following sensible observations on this subject: "In cattle, a vomit of emetic tartar may be tried at the first appearance of the disease, as the effort of vomiting may assist in promoting the passage of the gall stone. If, however, the disease should arise in consequence of previous inflam. mation of the liver, vomits will be of no use, and the best rem. edies will be mercurial purgatives, with soap. The food should consist of succulent and watery substances, especially of fresh grass; as it is found that when cattle affected with this disease are sent to pasture, they commonly soon rscover. Warm mashes 
of bran or malt should be given frequently, both to obviate costiveness, and as being good articles of diet. If the disease should continue obstinate, and the use of mercurial medicines should be found necessary, the animal must be confined within doors during night and bad weather. It will be proper, whenever the weather and other circumstances permit, to give the animal regular exercise in the open air; but if necessity obliges us to keep him within doors, the whole body, but especially the belly, should be well rubbed for a considerable time twice or thrice a day. This friction will be proper, even though regular exercise can be taken in the open air."

\section{SNORES.}

A gathering of thick clotted matter sometimes takes place within the nostrils, which very much impedes respiration when arrived at any height, and produces a snivelling noise when the air passes through the nostrils. This affection is termed the snores, or snivels, and is almost peculiar to cattle. The swelling thus caused in the nostrils, usually proceeds to suppuration, and when it breaks the animal is relieved. It should, therefore, be hastened by the application of warm stinulating fomentations or liniments. It is usual to inject the oil of bays up into the nostrils; but probably the steam of warm water would answer, and it might be easily applied by placing a warm bran mash into a canvas bag, and tying it to the animal's head; repeating it till the imposthume breaks. In the interim, the animal should be kept in the house, and fed on gond nourishing diet.

\section{COW·POX.}

In the publications issued by Dr. Jenner, who formerly practiced at Berkeley, in Gloucestershire, where he had frequent opportunities of witnessing this discase amongst the cows, its symptoms and origin are ably described:

"In this dairy country," observes Dr. Jenner, "a great num. ber of cows are kept, and the office of milking is performed indiscriminately by men and maid servants. One of the former having been appointed to apply dressings to the heels of a horse affected with the grease, and not paying due attention to cleanliness, incantiously bears his part in milking the cows, with some particles of the infections matter adhering to his fingers. When 
this is the case it commonly happens that the disease is communicated to the cows, and from the cows to the dairy maids, which spreads through the farm, until most of the cattle and domestics feel its unpleasant consequences. This disease has obtained the name of the cow-pox. It appears on the nipples of the cows, in the form of irregular pustules. At their first appearance, they are commonly of a palish blue, or rather of a color somewhat approaching to livid, and are surrounded by an erysipelatous intlammation. These pustules, unless a timely remedy be applied, frequently degenerate into phagedenic ulcers, which prove extremely troublesome. The animal becomes indisposed, and the secretion of milk is much lessened."

Another kind of eruption is sometimes apparent on the udder of the cow, which has some resemblance to the cow-pox, and may be easily mistaken for it. It consists of a number of white blisters on the nipples, and these blisters are filled with a whitish serous fluid. They are to be distinguished from the pustules that take place in the cow-pox, by their not having the bluish color of the iatter, and by their never eating into the fleshy parts, being confined to the skin, and ending in scabs. This eruption is also considered infectious, though not in so high a degree as the real cow-pox.

Dr. Jenner conceives that this spurious eruption is chiefly produced by the transition which is made by the cow in the spring, from a poor diet to one that is more nourishing, by which the udder, at this season, becomes more than usually vascular for the supply of milk. There is, however, another species of inflammation and pustules, which is not uncommon amongst the dairy counties of the west of England. A cow intended to be offered for sale, and possessing naturally only a small udder, is neither milked by the milker, nor is her calf suffered to have access to her for a day or two previous; thus the milk is preternaturally accumulated; and the udder and nipples becoming greatly extended, inflammation and pustular eruption frequently eusue.

\section{THE SHOOTE.}

This is a most fatal disease to calves, which it in general attacks a few days after their birth. The usual symptoms are at first, a colic that is more or less violent, and is frequently very dangerous and severe, but more especially when it is contagious. The calf is relieved by a discharge from the bowels taking place, 
when the colic is terminated; though this will sometimes prove fatal before the shoote makes its appearance: and secondly, a refusal, and loathing of food, even prior to the discharge, and which will increase and decrease according to the violence and duration of the disease. When the shoote prevails, the cheapest, and probably the most efficacious medicine which has been in general administered by experienced breeders, is eggs and flour well mixed with oil, melted butter, and linseed, aniseeds, or other similar mucilaginous vegetables; or, as some recommend, milk well mulled with eggs, may be administered to the distempered animal.

\section{VENOMOUS BITES.}

There are but few venomous animals in this country, compared with those that are found in warmer climates, and where they often prove fatal both to man and beast. The adder, or viper, is most common in this country, and the bite of this reptile is frequently attended with very dangerous consequences. Neat cattle are much more liable to be stung by this reptile than any other of the domestic animals. Instances have been known to have proved fatal, when the tongue of the animal has been stung while grazing. Cattle are seldom attacked by adders, except they disturb them whilst grazing; and this is the main reason why so many are bitten about the head, and sometimes about the feet. The sting of the wasp, hornet, or bee, are frequently attended with considerable pain and inflammation, and require a similar treatment as the former.

Cure.-The following liniment will be found a powerful remedy in checking the progress of the poison, and destroying it in the part affected:

Spirits of turpentine, . . . . . . . 4 ounces,

Olive oil,

Strong spirits of hartshorn, . . . . . - . 4 ounces.

Let them be put into a bottle together, and well shaken every time before using.

The part affected must be well rubbed with a sufficient quantity of this liniment two or three times a day, until the inflam. mation and swelling abate.

\section{WOUNDS.}

Wounds are most commonly produced by cattle goring each other with their horns, or by breaking through fences; and when deep or extensive, considerable inflammation usually proceeds. 
The proper treatment of wounds depends on the part where they are inflicted, and the instrument that caused them. A clean cut made in the muscular parts is soon liealed by the early application of slips of sticking plaster, in order that the edges of the wound may be kept close together; or, if plaster cannot be speedily applied, a stitch or two may be taken through the edges of the wound, and the strings tied gently together. When the edges perfectly adhere, the strings must be cut away, and the holes caused by them will soon fill up. It is particularly necessary that all wounds should be perfectly cleaned, before any attempt is made to heal them. It will occasionally happen that the wound is so situated as not to admit of its being sewed up; but when this occurs, silver or steel pins may generally be passed from the edges, about an inch apart from each other, and a thread twisted crosswise from one to the other, thus forming what is called the twisted suture. In every case where it is necessary to use sutures, a sticking plaster should be applied over the edges of the wound. But this mode of treatment can only be adopted in those superficial wounds where a flap of the skin is separated; and when this occurs, it is not requisite to apply any stimulating fluid, as some writers advise. When there is any dirt or other matter collected about the wound, it may be washed off with warm water.

Where the wound is considerable, and important parts are affected, the most decisive means should be speedily employed to keep down inflammation. Immediately after which, a purgative, or relaxative drink should be given, and the parts be fomented with a decoction of mallows, hemlock, or elder, until the inflammation, if any, subsides. Keep it always washed clean, and if warm weather, the flies away.

After the intlammation caused by the wound has subsided, it should be examined with a probe, in order to ascertain if any matter be confined; as it is sometimes necessary to give it vent by enlarging the original wound, or make an opening in another more depending situation, that it may run off freely. It may be requisite to apply at this period, the following ointment:

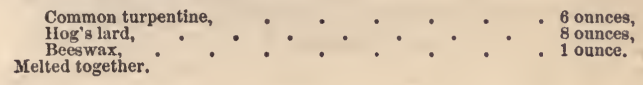


When taken from the fire, one ounce of powdered verdigris may be added; and the mixture must be constantly stirred until it is cold.

Should a lotion be preferred, the following stimulating solution will be found useful:

$$
\begin{aligned}
& \text { Mixed. } \\
& \text { Sublimate, . . . . . . . } 12 \text { grains, }
\end{aligned}
$$

One pint of oil of turpentine, to two quarts of sweet oil with good digestive.

In deep wounds, or when the parts are much divided, sewing is not advisable. Wounds of the belly, through which the bowels pass out, are very dangerous, and require the most delicate management. As soon as an accident of this description happens, the bowel should be put back into the belly as tenderly as possible: and if any dirt, hair, or other matter, be observed upon the gut, it must be carefully washed off with warm water. When the bowel has been replaced, the wound must be stitched up by means of a crooked needle and threads doubled, or small twine well waxed (with beeswax): a roller, or bandage should then be applied. The animal must be kept at rest, on an opening diet, of grass or bran; and, if costive, a dose of castor oil should be administered. The treatment of the wound is of little consequence; the principal object being to keep the bowel in its proper situation. A considerable quantity of air will occasion. ally get into the gut, after it has escaped from the belly, by which it is so distended, as to render it very difficult, if not inpracticable, to replace it through the original wound. "Should this, on examination, be found to occur, the wound must be enlarged, in order to allow the gut to be replaced, which must be done in the most cautious manner, the knife being properly guarded by the fore-finger.

Should it be thought necessary to stop the bleeding from the wound, the most effectual method of doing it, next to that of tying the blood vessel, is by placing bolsters of tow or sponge to the bleeding part, and supporting it firmly with bandages. If the new flesh should rise above the surface, and appear to be produced too luxuriantly during the progress of the wound, it may easily be checked by sprinkling on the oart a little pow. dered blue vitriol. 


\section{STRAINS AND BRUISES.}

Bleeding is most advisable whenever these accidents occur in a considerable degree, or an important part is injured; fomenta. tions are at first the most proper applications, in consequence of inflammation being the common effect of these injuries: but when the inflammation has subsided, the liniment recommended in a preceding article, on the swelling of the udder, may be rubbed on the part twice or thrice a day. When any part of the limbs is so strained as to occasion lameness, and it continues after the above application, a blister should be used. In bruises that occur from the pressure of the yoke, or other slight causes, the lotion prescribed below will be found of service:

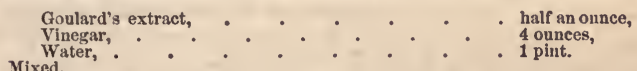

TO DRY A COW OF HER MILK.

Mr. Clater observes that this is a subject with which every gentleman grazier should be well acquainted. It is frequently found necessary to dry cows of their milk at all times of the year, in order that they may the better be fed for the shambles. Some cows are more difficult to dry than others, by reason of their giving too large a quantity of milk, and the gross habits of body peculiar to some beasts.

Without great care and management, these will be liable to the downfall, either in the udder or foot; or otherwise it may terminate in some inflammatory disease.

Cows that are apt to milk themselves, are difficult to dry; they should, therefore, be dried early in the spring, while on dry food. Others may be dried either in the pasture or in any other place. Such cows as are in the pasture, give a considerable quantity of milk, and are in good condition, ought to be brought into a foldyard over night, and from three to four quarts of blood taken from them, and the next morning the following drink administered:

Bole armenic, powdered, ix a large beast, 8 ounces,) $\quad$. $\quad 2$ ounces,
Roach alumn, powdered, (If ances.

Mix and put them in a pitcher, then pour a pint and a half of boiling ale upon the ingredients. Afterwards add one pint of good vinegar, and give when new milk warm. 
The cow mist be milked clean at the time the above drink is given, and two hours after nay be turned into her pasture. About four days after, if her udder appears hard and full, let her be brought out of the pasture, milked clean, and the drink be repeated as before.

This is generally sufficient to dry any cow of her milk; but as some cows give so much that it renders them very difficult to dry, it is therefore frequently found necessary to repeat the drink and milking every fourth day, for three or four times, before they can be completely dried.

\section{MURRAIN, OR PUTRID FEVER.*}

Murrain, or pests, are undoubtedly the most serious epidemic fevers that ever have appeared among domestic animals, owing to their violence and fatality; they have occasionally raged, from the earliest historical accounts. From the several statements that have been made concerning the disorder, it seems to have varied in its symptoms and effects, according to the countries in which it appeared, the various seasons in which its ravages were commenced, and some other circumstances not perfectly ascertained. It is evident that this disease was infectious, since it was easily propagated among the species of animals which it attacked; but it is not certain that it has the power of spreading to other species; as men, horses, sheep, and dogs, that live in the neighborhond of the cattle infected by it, evinced no signs of having received the contagion. Nineteen out of twenty cattle attacked by this disease are said, by Mr. Savage, to have died.

Causes.-The causes and nature of this disorder have not been precisely ascertained. Some have imagined it to be con. nected with a peculiar state of the atmosphere, and that it did not originate in contagion. Many consider the principal cause of the disease to be previous hard winters, obstructed perspiration, worms in the liver, and corrupted food.

* This disease is, no doubt, analagous to, or the same as the Plenro-pneumonia, or possibiy, Rinderpest, hereafter noticed. The disease had not, probabiy, appeared of late, in England, when he wrote, as it has, in a few years since, with such fatal violence. It is evident that, personally, Mr. Lowson had little or no experience in its treatment. We give his notice of it, however, as valuable in contributing somewhat of knowledge concerning it,-L. F. A. 
Symptoms. - The following account of this disease is given by Dr. Brocklesby. For ten days or a fortnight the cattle wero troubled with a dry cough, which is indeed not an uncommon symptom among cattle at the close of a severe winter, and therefore Dr. Brocklesby did not consider it belonging to the present disease; their eyes looked heavy, and, when the principal disorder appeared, they refused fodder, but had an insatiable thirst for a time. The milk cows decreased in their milk, which remained to a certain quantity, sometimes, for two days, before it changed color, but at length often dried up. On ceasing to chew the cud, a shivering seized them all over, and a high fever immediately came on; the milk, if any remained at that time, curdled over the fire, but did not in the first of the disorder. . At first the belly was costive, but for the most part a looseness succeeded within forty-eight hours after the shivering fit. The stools were first green and watery, and of a stinking smoll; their consistence, however, altered afterwards to a viscid, slimy matter; the purging coutinued till about the seventh day, and about that time the excrements became thicker in such as recovered; and these soon chewed their cud again, and tasted the fodder, which they had before absolutely refused through the whole disease. All that had not the looseness before the third day died. The urine was very high colored, and in smaller quantities. The degree of fever was observed very high; upon the third day, the pulse beat nearly a hundred times in a ninute, whereas the ingenious Dr. Hales found a sound ox's artery not to exceed thirty-eight pulses in the same time. At different intervals, after the attack, they all labored under a prodigious difficulty, and panting for breath; some suffered these after the first day, others not before the third. But this disorder suffered remissions, and seemed augmented towards evening and at night. Several beasts discharged, towards the fourth or fifth day, when ill, a very great quantity of frothy liquor from the mouth and eyes; others ran actually purulent matter from the nostrils. As the disorder advanced, the eyes sunk more in their orbits, and some were observed to be quite blind. Towards the conclusion, the fore parts of the body, and particularly the glands about the head were prodigiously swelled; and several beasts had a universal omphysema, or crackling of air beneath their skin; those that were not blooded equally with such as were. Frequently one 
might observe pustules break out, on the fifth or sixth days, all over the neck and fore parts. Some cattle were raging mad on the first day; such were necessarily killed: some dropped down suddenly; cthers died on the third; most on the sixth or seventh; very few alive on the fourteenth day. Before death, the horns and dugs grew remarkably cold.

Cure.-The method of treating the cattle, recommended by Dr. Brocklesby, is as follows: Before the cattle are seized, he advises two setons or pegs to be put deep in the dewlap, and into the under part of the neck; and, immediately upon refusing fodder, the beasts should have three quarts of blood taken away; and after twelve hours, two quarts more; after the next twelve hours, about three pints may be let out; and, after the following twelve hours, diminish a pint of blood from the quantity taken away at the preceding blood-letting; lastly, about a single pint should be taken away in less than twelve hours after the former bleeding, so that when the beast has been bled five times, in the manner here proposed, the worst symptoms will, it is hoped, abate; but if the difficulty and panting for breath continue very great, he sees no reason against repeated bleeding; or at least against taking away the fifth time, instead of a single pint, twice that quantity.

In the meantime, the setons or pegs should be daily promoted to suppuration by moving the cord; and the cattle should have as much bran water as they chose to drink lukewarm. This should be made a little tart or sourish, either with common vinegar or spirit of vitriol: and immediately after the first bleeding, they should have the following drench:*

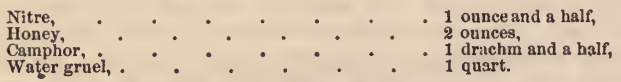

It is rather surprising that this same treatment, with a trifling variation in the internal medicine, is also recommended by $\mathrm{Mr}$. Feron, as the result of his own experience, in what he terms the general inflammation of cattle.

*When the dlsease has once settled itself in the system, all "drenches," or other medicaments are useless-most of all, this everlasting "bleeding," which, if nndertaken at all by the above directions, had better not atop until the suffering benst is relieved-by death.-L. F. A. 
MALIGNANT EPIDEMICS-MURRAIN, PLEURO-PNEUMONIA, RINDERPEST.

We should hardly mention these terrible diseases, had not our attentiou been recently called to them, by the late devastations in the herds of British cattle, within the last two or three years, to such extent, that the Congress of the United States, some two years ago, by a solemn enactment, prohibited the importation of foreign cattle into our country, altogether. That law is still in force, and possibly to the salvation of our own domestic herds, which might otherwise have been endangered by importations, which, of late years, have been frequent.

This disease, or diseases-for they are all malignant epidem. ics-perhaps taking a more extreme type as circumstances may govern, but all attended with a terrible fatality, has existed on the Eastern Continent, at various times, for some thousands of years. Youatt gives an elaborate description of the disease. The first we hear of it is in the Bible, (Exodus ix. 3-6,) when the cattle of Egypt were smote with murrain as a punishment for retaining the children of Israel in bondage. Profane writers, as Homer, Hippocrates, Plutarch, Virgil, and others before Christ, make mention of it, and it has existed in various coun. tries of Asia, and Europe, down to the present day-not continuously, but at different periods-and been attended with devastating fatality, sweeping, at times, the countries which it ravaged, of almost all their herds.

The lights of science and investigation have failed to give the cause or origin of these epidemics; but that they have been contagious is certain, and the immediate extinction of the herds affected with it has proved as yet its only certain cure. We have not space to recount its ravages, even in England of late, and can only allude to it in connection with what we have lately known of it in our own country. "Murrain," as we understand it in America, is only a casual disease, dendly enough whnn it 
breaks out, but mitigated in its virulence from the deadly murrain of scriptural times, which was of malignant type. Pleuropneumonia is worse and more deadly than any domestic murrain, and has prevailed, at sundry times, to mors or less fatal extent in America; but the still more deadly and fatal Rinderpest has visited us but once, and that recently.

These may be called kindred diseases, as the forms they take may rage with less, or greater violence and fatality, or yield to, or resist medical treatment. A brief history of the Rinderpest in America, may be important for our information. We find it in the "Fourteenth Annual Report of the Secretary of the Massachusetts Board of Agriculture, for the year 1865," as a report of a Commission appointed by the State Legislature to investigate the disease. It is there given as the Pleuro-pneumonia :

"We may reasonably entertain the hope, that after a long series of well-meant and well-directed efforts, that contagious disease among cattle, known as pleuro-pneumonia, has been eradicated; while the sad experience of Great Britain in combating a somewhat analagous disease, the rinderpest or cattle plague, which has earried off more than two hundred thousand of the finest animals, has become sufficiently well known to confirm the wisdom and sound judgment of our own State authorities in the course adopted to prevent the introduction and spread of con. tagious diseases among our stock.

"It is possible that in the early stages of our efforts to arrest the progress of the pleuro-pneumonia, when the disease was less understood than it is now, a somewhat larger number of cattlo were destroyed than was absolutely necessary to secure the object in view; but no one ean be so short-siglited as not to admit that it was better to err on the side of safety than to run the risk of incurring the losses which would inevitably have followed neglect; for we know now that every conceivable expedient was 
adopted by the English government to avoid the harsh necessity of a resort to the 'stamping-out process,' and that it was compelled to come to it at last, and to admit that it was the only effectual means of avoiding a far more terrible disaster, the losses in two years being about twenty millions of dollars.

"By a reference to the following report of the Massachusetts Commissioners on Contagious Diseases among Cattle, it will be seen that the aggregate cost to the State of extirpating the disease from our herds has been less than seventy thousand dollars, an amount which must appear trifling when compared with the results attained, and the exemption secured, by the efficient efforts of the State Board of Agriculture, and the too little appreciated labors of the Cattle Commissioners.

"The Commissioners on Contagious Diseases among Cattle, in submitting their report, congratulate the people of the Commonwealth upou the probable extinction of the disease, (no case having come to their knowledge since October, 1865,) which but a few years since threatened to be of so serious a character, viz.: pleuro-pneumonia.

"The Commissioners have been called to several towns during the past year, to examine diseased animals, yet not a case of contagious pleuro-pneumonia has been found.

"A concise history of the disease, from its first appearance in Mr. Chenery's herd in Belmont, to the present time, is deemed of sufficient importance to warrant its insertion in this report.

"In the latter part of May, 1859, four cattle arrived from Holland and were taken to the farm of Mr. Chenery.* Two of them were sick, and in a few days died. Another soon after sickened and died. At the time of the death of the third, three calves were sold to go to North Bruokfield, one of which was taken to the lierd of a dealer for treatment, being sick. The

\footnotetext{
* See notice of Mr. Chenery's importation of Holstein cattle, page 109.-L. F. A.
} 
dealer, trading in cattle, as usual, soon spread the disease far and wide.

"In the following April, an act was passed 'to provide for the extirpation of the disease called pleuro-pneumonia among cattle,' which gave the Commissioners power to cause to be killed all cattle in herds where the disease was known or suspected to exist. The disease had, at the time of the passage of the act, been extensively scattered, and in a short time the appropriation $(\$ 10,000)$ was absorbed. A larger number of cattle having been exposed than was at first estimated, an extra session of the legislature was called to revise the law, and to provide the means of executing it. A new law was enacted, and received the sanction of the Executive on the 12th of June.

"No new outbreak of the disease occurred during that year, nor in that locality, as far as is known, to the present time. The number of cattle killed was nine hundred and thirty-two.

"For more than a year nothing was heard of pleuro-pneumonia. In fact, those most directly interested were confident that the disease was extirpated. Early in the following winter, however, it was reported that it existed in Milton, Dorchester, and Quincy.

"A Board of Commissioners was appointed, who, upon investigation, found the report to be true. A pair of cattle was purchased at Brighton, which were taken to Quincy, and both died. No further history of them could be learned, as it was impossible to identify them; but the spread of the disease could in every instance be traced to contact with the animals in the herd in which they were at the time of their dcath, as shown in the report of that year. The number killed during the year, was one hundred and fifty-four.

"For several months the Commissioners felt confident that the disease was eradicated. In February, 1863, the Commissioners were called to examine sick cattle in the north part of $\mathrm{W}$ altham 
-also in Lexington. It proved to be pleuro-pneumonia, and its origin was directly traced to a dealer, and from the sale of cattle by him, to eight different herds. The appropriation $(\$ 1,000)$ was soon exhausted, consequently the Commissioners resigned.

"The selectmen of several towns were called upon to execute the law, which they (some of them at least,) reluctantly did, yet the disease still prevailed. Accordingly the present board of Commissioners was appointed in April, 1864.

"It was found that several herds were affected, and that the origin of the disease was in Lexington, or that immediate vicinity. Seventy-four cattle were killed during the year.

"In 1865, but three herds werc found affected with the disease, from which four animals were killed.

"The Legislature in its last session, in a proviso to the resolve, allowing the sum of twenty thousand dollars to the use of the Commissioners, require them to make investigation and report upon the curability of the disease.

"No cases of the disease having come before the board the past year, they were of course unable to comply with the request, and can only refer, for information on this subject, to the report of last year, on the experiments made by the Commissioners during the years of 1864 and 1865 .

"The uniform course of the present board has been to isolate all herds they have found affected with the disease, and such other cattle as had in any way been exposed to diseased herds, to kill such as they were satisfied had the disease to that extent, as to make them useless to the owners, and, in but few instances, only such. The result of our action contrasts favorably with that of Great Britain, in the management heretofore of contagious diseases among cattle.

"In Great Britain, during the past two years, public attention has been diverted from pleuro-pneumonia. to the more terrible disease, rinderpest. 
"We here quote from Prof. McCall's introductory lecture before the class of veterinary students, November 6th, of the present year, at Glasgow, Scotland, to show that pleuro-pneumonia is still making its ravages among the cattle of that country:

" "For upwards of twenty years this country has annually lost thousands of cattle from one contagious disease alone, viz.: pleuropneumonia, and at the present moment it is busy among our herds. One gentleman present has lost twenty-two out of a herd of thirty-five; and a few weeks ago I was consulted by a farmer who had lost twelve out of twenty, and now the disease has appeared among his young stock. The number of deaths in these instances are appalling, and the loss, directly or indirectly, cannot be estimated at less than $£ 900$ or $£ 1,000-(\$ 5,000$.)

"'The plague has drained the pockets of farmers and dairy. men of thousands sterling; but, thank Providence, we are now free of the disease in this country. Pleuro-pneumonia has drained our pockets of millions of pounds, and she is still in our midst, the great enemy of our stock. * * * * Use the means I have indicated, and the means which the plague has taught us to be of benefit, in controlling contagious diseases, and if the contagious pleuro-pneumonia of cattle, now decinıting our stock, is not thereby extinguished-stamped out-its operations will be so curtailed, that the losses resulting to stockholders, from the presence of the disease, will sit light upon them.'

" "Prof. Simonds, in his introductory address, delivered at the Veterinary College in London, in October, says:

"'From this time, the disease called rinderpest, spread in all directions, the attacks gradually rising until they reached, in the week ending February 17th, 1866, the alarming number of 15,706. The first order in conncil, was dated July 14th, 1865, and from that period until now, order has succeeded order, with more or less influence in checking the progress of the malady, and providing for the altered state of things arising out of its existence. 
"'The passage of the Cattle Plague Act was, however, the real cause of the diminution of the cases which have since taken place, and which emboldens us to hope that ere long the disease will be entirely exterminated. For the first time in the history of the visitation, the attacks were returned as under one hundred for the week ending September 1st, ninety-nine being the exact number reported by the inspectors.'

"He quotes from the official returns the amount of loss which England herself, apart from other parts of Great Britain, has sustained:

"'The total attacks are returned as 198,406 . The animals killed, (diseased,) amounted to 77,508 ; those which died, to 90,415 ; the recovered, to 21,589 ; and the unaccounted for, to 8,894 . Besides which, no less than 38,356 have been slaughtered healthy, to prevent the spread of the malady. These figures are truly formidable; but they fail to show a tithe part of the distress and ruin which has been brought on hundreds of industrious farmers and cattle owners by this dreadful visitation.'

"In speaking of Scotland, he says:

" 'It appears from the official returns, that the attacks in Scotland amount to 46,861 , being 4.841 per cent. of the entire stock of the country.

"'In Ireland, but fifty cattle were exposed to the disease; twenty-nine were attacked, and either died or were killed, and twenty-one were slaughtered healthy.

" Nothing can show more clearly the propriety of the stamp. ing-out process than this result. In it we have a parallel with what took place in France, where only forty-three animals, healthy and diseased, were sacrificed to the pole-axe, the country being thereby freed from the plague.'

"The Cattle Plague Act, alluded to above, resembles the law passed by the Legislature of Massachusetts, at the extra session, in its general features; and the course adopted by the authori. 
ties of Great Britain, in relation to rinderpest, is similar to that taken by the present Board of Commissioners in Massachusetts, in relation to pleuro-pneumonia.

"Prof. Simonds further says that a focus of the disease still exists; consequently the law passed by Congress, preventing the landing of any cattle from foreign seaports, should be continued in force.

"We append to this report, a statement of the entire expenditure, by the State of Massachusetts, for the extirpation of the disease, since its commencement in 1860 , obtained from the treasurer's books, which is $\$ 67,511.08$. In addition to this amount, the several towns where the disease has been found, have paid one-fifth of the cost of isolation, and of the appraised value of all the cattle killed, amounting to a sum which we estimate at $\$ 10,000$. (There is no printed report of the number of caltle killed by order of the selectmen of towns in 1863.)

"The amount paid from the treasury on account of pleuropneumonia, is as follows:

\begin{tabular}{rr|rrr} 
In 1860, & $\$ 28,733$ & 21 & In 1865, & $\$ 5,62284$ \\
1861, & 14,118 & 43 & 1866, & 38635 \\
1862, & 4,525 & 86 & & $\$ 67,51108 . "$ \\
1863, & 6,657 & 32 & & \\
1864, & 7,467 & 07 & &
\end{tabular}

Thus, it will be seen, that the disease in Massachusetts was effectually "stamped out" by the energetic, relentless action of the Commissioners appointed by the State for that purpose.

We do not find in this report any account of the workings of the disease, and for that omission, we are enabled to supply them from a report of the Commissioners appointed by a law of the Legislature of the State of Ney York, passed in the year 1866, immediately after the passage of the law by Congress prohibiting the further importation of foreign cattle into this country. We cannot do better, perhaps, than to copy the "circular," 
addressed by this "Commission," at their meeting in Albany, June 7th, 1866, "To the Farmers of the State of New York." The danger of the epidemic then reaching our shores, was thought to be imminent:

\section{RINDERPEST.}

"The disease called the rinderpest, which swept across the Eastern Continent with such resistless fury, destroying vast num. bers of ruminant animals, may, at any moment, reach our shores.

"In vicw of such a contingency, the Legislature of our State, at its last session, appointed the undersigned Commissioners, charged to watch over the preservation of our flocks and herds from this disease, and armed them with plenary powers to adopt such measures as might conduce to the result.

"No amount of energy or wisdom, on the part of the Commissioners can, however, ward off the ravages of the disease, without the hearty co-operation of the owners of cattle. United, harmonious action, guided by an intelligent plan, will reduce the number of victims to a minimum.

"As a part of such plan, we desire to offer the following advice, which we hope will commend itself to the judgment of cattle owners, and prevent the spreading of the disease:

\section{Symptoms.}

"After exposure to contagion, the cattle exhibit no external marks of disease until from the seventh to the fourteenth dny, when the following succession of symptoms present themselves:

" $(a$.$) The breath becomes fetid. We urge farmers, therefore,$ to watch their herds, daily, for the occurrence of this symptom, which is easily recognized. The odor sometimes resembles that of small pox, and is the very first symptom presented by the disease.

"(b.) As soon as this odor is observed, the mouth and the vagina will be found unnaturally hot and red. 
"(c.) The temperature of the rectum rises from $100^{\circ}$ and $102^{\circ}$, its normal temperature, to $105^{\circ}, 106^{\circ}$ and $107^{\circ}$, when the pres. ence of the disease may be confidently asserted. This test the herdmaster should never overlook.

"(d.) A few hours after, the lower lip will show, on its internal surface, numerous apthous patches, like small blisters, about the size of a pin's head. As soon as these appear, a thick fluid will exude and run from the mouth.

"(e.) The animal will holl its head to one sinle, and have a peculiar dejected and pitiful look. This is very characteristic of the disease, and cannot easily be mistaken.

"When these symptoms appear, notice of the fact should be promptly transmitted to the nearest Commissioner. We cannot too strongly urge upon cattle owners, the importance of constant watchfulness for the occurrence of these symptoms, and of prompt information to the Commissioner the moment they are observed.

2. What is to be done.

"(a.) Remove all hay or other food from the manger. Do not permit the animal to eat anything.

"(b.) Clean the stall in which the animal is confined. No straw should be allowed as litter. Saw-dust is best, or if it cannot be had, dry sanil may be used in its stead.

"(c.) Dig a grave, at least five feet in depth, and large enough for the animal with its droppings and litter.

" $(d$.$) Scrape up the saw-dust or sand whenever any excre-$ ment or urine, or the 'thick fluid,' mentioned in section 1 , falls upon it, and deposit it in the grave, covering it with sulphate of iron (green copperas) or quick-lime. Cover the spaces thus scooped out with fresh saw-dust or sand. (This recommendation is of very great importance, experience in Europe having shown conclusively that it is through the action of these excretions mainly, that the disease is transmitted. Horses, sheep, rats and oven birds, which have put their feet in these excretions, and 
afterwards walked on a public road, have communicated the disease to cattle which passed over the same road afterwards. We think this precaution will do more than any other to arrest the progress of the disease, should it reach this country.)

"(e.) Every person whose feet have been in contact with these excrements, should wipe them, carefully, before leaving the stable. A box of chloride of lime should stand at the stable door, and after wiping the shoes, the person should stand in this box, to disinfect them. Those who carry out the excretions, should carefully avoid touching them with their clothes, and should thoroughly wash their hands with soap and water, after such work.

" $(f)$ Isolate all cattle from the sick ones, keeping to windward of them.

"(g.) Keep a good supply of disinfectants always on hand.

\section{Medical treatment.}

"It is not worth while for you to waste money on medical treatment. Nearly all the drugs in the Materia Medica have been tried in Europe, and found ineffectual.

\section{Precautions.}

"(a.) Keep your cattle off of and away from public roads as much as possible.

" (b.) Prevent them from having any intercourse with strange cattle.

"(c.) Improve the ventilation of your stables, keep them scrupulously clean, and admit more sunlight into them than is usual.

"(d.) If strange farm laborers come upon your premises, insist upon their dipping their shoes in the box of chloride of lime, mentioned in section $2,(e$.

" $(e$.$) The more healthy the condition in which animals are$ kept, the more likely will thay be to rosist the contagion. 
" $(f$.$) The more highly bred are your animals, the more care-$ ful should you be to keep them from exposure, as experience shows that thorough bred animals are more likely to take the disease than common cattle."

It will thus be seen that, had the disease appeared, the New York Commissioners, being armed with the power, had oocasion required its use, would have as effectually "stamped out" the plague by ımmediate slanghter, as did their predecessors in Massachusetts. Happily such occasion passed, and we trust there may be no future necessity of any action. The commission was renewed in the year 1867 , to continue three years.

A modified pleuro-pneumonia has occasionally broken out in some of the eastern counties of New York, and Pennsylvania, alarming to some extent, at first, but prompt attention prevented its spreading, if it did not yield to treatment. Although we hope the disease may never occur with us, we have thought that a somewhat extended notice of it would not be unprofitable, but indeed serviceable to our American farmers.

We conclude the subject of rinderpest, with an extract from a report by $\mathrm{Mr}$. X. O. Willard, on his recent return from an agricultural town in England, to the N. Y. Agricultural Society, and published in Transactions for the year 1866:

"The southern counties of England through which I passed, have suffered but little from this disease, but in some of the northern counties, especially Cheshire, the plague has been most terrible in its ravages. The immense dairy herds of Cheshire have been swept away almost entire, and a great gloom prevails among the people.

"The cheese product in Cheshire, Lancashire, Shropshire, and Derbyshire, has fallen off this year more than forty millions of pounds. The Cheshire farmers have now no faith in medicine or remedial agents for rinderpest. One farmer, who had lost eighty head, and had tried various remedies advised by veterina- 
rians, said he preferred homeopathic treatment, but the cures, like the medicines, were infinitesimal.

"Professor Gamgee, whom I met in London, said, 'our govermment ought at once to take the proper steps for crushing out the disease, in the event of its reaching our shores. On its first appearance in a herd, every animal should be immediately slaughtered, premises purified, and every precaution taken that it spread no further. We must not dilly-dally with the disease, but employ prompt action and energetic measures. The men employed to do this work should be stern and inflexible in their decisions, and not be swayed by any sympathy for losses sustained by those owning the herds. They should look upon it as a terrible calamity, threatening the nation, which must be walled in and crushed at all hazards, in its incipient stages. Take warning, said he, by England's dilatory action, and you, in America, will be spared one of the greatest calamities that ever befall any country." "

We trust that the rinderpest in Western Europe, as well as in its brief appearancu a few years since on our own side of the Atlantic, has passed into history, not again to disturb our fears with its anticipated ravages.

\section{ABORTION, OR SLINKING.}

This dangerous disorder has, of late, become rife in some of our important dairy districts, to such an extent as to become alarming; and no cause has yet been satisfactorily accuunted for it. It has been seldom, in past years, that cows have aborted throughout the country generally. In our own cow keeping of many years, chiefly in the best common way of farmers, with hundreds of them, we have never had, to exceed, in all, half a dozen cases.

Abortion has, however, within a few years past, become alarm. ingly prevalent in a portion of the dairy districts of the State of 
New York. In the Transactions of the New York State Agricultural Society for the year 1866, it is stated that "the farmers in the counties of Herkimer, Oneida, Lewis, and Otsego, have been for some years, and are now suffering great loss and dam. age from the abortion of their cows. The abortions occur in almost every month of gestation; but more particularly from the sixth to the ninth month.

"In a few cases, the cows die in consequence of abortion; in others, they remain several months in a feeble and sickly condition, during which they cannot be fattened; in others, they continue to give milk, but the flow is poor in quality, and small - in quantity. In some cases, and those appear to be in the majority, from the reports we have received, the farmer loses the use of the cow for a whole year.

"The disease began to manifest itself about $t$ welve years ago, and has been gradually increasing ever since. It was greatly intensified in the year 1865, and continued to increase in 1866 . In the year 1866, from the best information we can obtain, twenty-five per cent. of the cows in the county of Herkimer aborted; in Oneida, twenty-five per cent.; in Otsego, fifteen per cent.; in Lewis, twelve per cent. In the other dairy districts, the disease exists, but we are unable to obtain the measure of loss.

"The farmers' clubs, of those counties, have labored zealously, and have expended a great deal of money to ascertain the cause of the disorder, but hitherto without success.

"On high lands and low lands, on old pastures and on new, in high, and low bred stock, in cows that were purchased, and those which were bred on the farm, in those that were high fed, and those that were fed sparingly, in those that were kept in underground stables, and in those that were kept above ground, in large and small herds, on pastures that had been plastered, (with gypsum,) and those which were unplastered, the same liability to abortion appears. 
"The following are the only circumstancos which seem to be common to all reports :

"In all cases, the meadows and pastures containad much June grass (poa-pratensis.) In nearly all cases the bulls ran with the cows, ${ }^{*}$ and in most of them they drank hard water. In every case the appearance of the calf was unnatural and unhealthy, and the lochial discharges were unwholesome.

"The number of milk cows in this State, (New York,) is $1,123,000$. In Herkimer, there are 41,566 ; in Oneida, 48,510; in Lewis, 26,373; in Otsego, 36,847. These counties, with St. Lawrence, Cattaraugus, Chautauqua, Chenango, Delaware, Jefferson, and Orange, have 465,586 cows.

"The cows of the State produce 103,097,280 pounds of butter, $48,548,289$ pounds of cheese, and about $21,000,000$ gallons of milk, to be sold in cities and manufacturing villages. The value of these dairy products could not have been less than $\$ 48,000,000$. If we assume the loss from abortion to be ten per cent., the money value of the loss is $\$ 4,800,000$ annually."

This is a most sorry story of abortion; and when it is known, as is the fact, that the above mentioned counties are chiefly high, rolling land, abounding in the choicest grasses, and pure springs and streams of water, eminently healthful to man and animals generally, there must be some hidden cause for this calamity. And yet no remedy has been discovered to prevent it.

Much has been written on the subject, within the last two or three years, in our agricultural papers, but without settling the question of its causes, or its prevention. Among our own cows, we do not recollect a single instance where the cow, after a few

* When will people learn to keep their bulls up-confined, away from their cows, either in stables, or yards ? That, of itself, may be one great cause of abortion, the cows being continually run after and teazed by the too officlous brute. In previous pages we have sald quite enough on that very lmportant item of cattle management As June, or blue grass, prevails almost everywhere in the pastures and cattle regions of North America, we cannot imagine that food has anything to do with abortion.-L. F. A. 
weeks, or months, did not return to regular breeding, without a repetition of the misfortune, so that we have had little experimental knowledge of the malady.

Some fifteen years ago, a gentleman in the eastern part of this State had a valuable herd of short-horns. The cows had bred successfully, until one summer, while in their usual pastures, a large majority of them, one after another, slipped their calves. The fact was so extraordinary and continuous in the herd, that their owner at once resolved to send them away to a distance for keeping. They were driven out to a fine grass farm about a hundred and fifty miles distant. Arriving there, no farther abortions took place, and they were not returned to their old home for some months, until the pasturing season had transpired. Meantime, the proprietor of the herd began to examine into the cause of this strange malady, and soon recollected that he had, early in the spring, some time before the abortions commenced, spread over his grounds a large quantity of fur clippings and trimmings, the refuse of a manufactory where caps, and other fur clothing were extensively made. He found these clippings of skin and fur in various stages of offensive decomposition in his pastures, and the cause of the difficulty, in his own mind, was readily solved. By the end of the season the clippings had become entirely decomposed, and absorbed, or amalgamated into the soil. By the next spring, all but their fertilizing power had disappeared, and no further ill effects were produced. It is hard. ly necessary to say that the experiment was not repeated, and the cows were thereafter healthy, and free from further abortions.

This subject should be well understood. It is so admirably and fully treated in Youatt, that in the absence of any mention of it by Mr. Lowson, from whom we have so freely quoted, we give, at length, Mr. Youatt's remarks on the disease, if disease it may be called:

"The cow is more than any other animal subject to abortion. This takes place at different periods of preguancy, from half of 
the usual time to the seventh, or almost the eighth month. The symptoms of the approach of abortion, except the breeder is very much among his stock, are not often perceived; or if perceived, they are concealed by the cowherd, lest he should be accused of neglect or improper treatment.

"The cow is somewhat off her feed-rumination ceases-she is listless and dull-the milk diminishes or dries up-the motions of the foetus become more feeble, and at length cease altogether - there is a slight degree of enlargemeut of the belly-there is a little staggering in her walk-when she is down she lies longer than usual, and when she gets up she stands for a longer time motionless. As the abortion approaches, a yellow or red glairy fluid runs from the vagina (this is a symptom which rarely or never deceives) - her breathing becomes laborious and slightly convulsive. The belly has for several days lost its natural rotun. dity, and has been evidently falling-she begins to moan-the pulse hecomes small, wiry and intermittent. At length labor comes on, and is often attended with much difficulty and danger.

"If the abortion has been caused by blows or violence, whether arising from the brutality of the cowherd, or the animal being teased by other cows in season, or by unskillfully castrated oxen, the symptoms are more intense. The animal suddenly ceases to eat and to ruminate-she is uneasy, paws the ground, rests her head on the manger while she is standing, and on her flank when she is lying down-hemorrhage frequently comes on from the uterus, or when this is not the case, the mouth of the uterns is spasmodically contracted. The throes come on, they are distressingly violent, and they continue until the womb is ruptured. Should not all these circumstances be observed, yet the labor is protracted and dangerous.

"Abortion is sometimes singularly frequent in particular districts, or on particular farms. It seems to assume an epizootic or epidemic form. This has been accounted for in various ways. 
Some have imagined it to be contagious. It is destructively propagated among the cows, but this is probably to be explained on a different principle than that of contagion. It has been stated that the cow is an animal considerably imaginative and highly irritable during the period of pregnancy. In abortion, the foetus is often putrid before it is discharged; and the placenta, or afterbirth, rarely or never immediately follows it, but becomes decomposed, and, as it drops away in fragments, emits a peculiar and most noisome smell. This smell seems to be singularly annoying to the other cows-they sniff at it, and then run bellowing about. Some sympathetic influence is produced on their uterine organs, and in a few days a greater or less number of those that had pastured together likewise abort. Hence arises the rapidity with which the foetus is usually taken away and buried deeply, and far from the cows; and hence the more effectual preventive of smearing the parts of the cow with tar or stinking oils, in order to conceal or subdue the smell; and hence, too, the ineffectual preventing of removing her to a far distant pasture.

"Chabert, in his 'Veterinary Instructions,' relates a singular case of this - a kind of pest or plague in the dairy of a farmer at Toury. For dhirty years his cows had been subject to abor. tion. His cowhouse was large and airy; his cows were apparently in good health; they were fed like others in the village; they drank from the same pond; there was nothing different in the pasture; his servants were not accustomed to ill-use the cattle, and he had changed these servants many times in the thirty years. He had changed his bull many a time; he had pulled down his cowhouse, and he had built another in a different situation, with a different aspect, and on a different plan; he had even (agreeably to the superstition of the neighborhood,) taken away the aborted calf through the window, that the curse of future abortion might not be entailed on the cow that passed over the 
same threshold; nay, to make all sure, he had broken through the wall at the end of the cowhouse, and opened a new door, in order that there might not be the possibility that an elf-struck fœtus had previously gone that way; but still a greater or less number of his cows every year slunk their calves.

"Thirty years before, he had bought a cow at a fair, and she had suffered an abortion, and others had speedily followed her example; and the cow that had once slunk her calf was liable to do the same in the following year, and so the destructive habit had been perpetuated among his beasts.

"Several of the cows had died in the act of abortion, and he had replaced them by others; more of those that had aborted once or twice, or oftener, had been sold, and the vacancies filled up. M. Chabert advised him to make a thorough change. This had never occurred to the farmer, but he at once saw the pro. priety of the counsel. He sold every beast, and the plague was stayed. This sympathetic influence is one main causc of the slinking of the calves. There is no contagion, but the result is as fatal as the direst contagion could have made it.

"Another cause of abortion is the extravagantly high condition in which cows are sometimes kept. They are in a continual state of excitement; and from the slightest cause, inflammation is set up in the uterus, rendered more susceptible by the state of pregnancy, and abortion is the frequent consequence of that inflammation.

"M. Cruzel has given an instructive account of abortion thus produced. He was consulted by a farmer who had ten breeding cows, that occasionally worked at the plough; as is often the case in France. During the first year three of them aborted. They recovered, and were soon again in calf. Two of them slunk their calves a second time, between the fifth and sixth months of pregnancy; the third went her full time and produced a weakly calf, that died on the second day. In the following 
year a fourth aborted, and M. Cruzel was sent for. He was immediately struck with the unnecessary high condition in which all the cows and their calves were. He carefully inquired, but could discover no other probable cause for these repeated accidents, and he at once attributed them to the state of plethora in which the beasts were kept. $\mathrm{He}$ ordered their quantity of food to be materially reduced; he bled every one of them; the farmer took care that nutriment should not afterwards be 80 dangerously wasted upon them, and abortion ceased to appear on the farm.

"Mr. Wedge, in his 'Survey of Cheshire,' confirms this. He says that 'slinking happens generally in wet seasons, or when the cattle are in very high condition, and generally continues for two or three years together. In several parts of North Wales, where the cattle through necessity are kept in lower condition, instances of the kind very rarely happen.'

"The pastures on which the blood or inflammatory fever is most prevalent, are those on which the cows oftenest slink their calves. Whatever can become a source of general excitation and fever, is likely, during pregnancy, to produce inflammation of the womb: or whatever would, under other circumstances, excite inflammation of almost any organ, has at that time its injurious effect determined to this particular one.

"There are some curious illustrations of this. It is well known that cattle of all kinds are sometimes serriously injured by feeding in the autumn on grass thickly covered with hoar-frost. Inflammation of the bowels of a dangerous character, and sometimes palsy of the rumen, have been thus produced. In Switzerland, the commencement of the hoar-frost is the signal for the appearance of abortion. It is occasionally seen at other times in all the cantons, but now its vistims are multiplied tenfold. M. Barruel, V. S., of Chartres, speaks of sixteen cows that aborted at different periods of pregnancy, from this cause, and most of which died. 
"Acrid plants are often prejudicial to cattle. 'There is no farmer who is not aware of the injurious effect of the coarse, rank herbage of low, marshy, and woody countries, and he regards these districts as the chosen residence of red-water;' it may be added, that these districts are also the chosen residence of abortion.

"Hard and mineral waters are justly considered as laying the foundation for many diseases in cattle, and for this among the rest. A writer, in a German periodical, gives the following account: 'In 1822, twelve of his in-calf heifers cast their calves, and in the following year the like accident happened to twelve others, the whole of which used to drink from ponds, the water of which was strongly impregnated with iron. In 1824, ten cows that wcre watered at other places all calved safely, while a single cow that was allowed to drink of the ferruginous water cast her calf. The same occurred in two following years.'

"Cows that have been long afflicted with hoose, and that degenerating into consumption, are exceedingly subject to abortion. They are continually at heat; they rarely become pregnant, or if they do, a great proportion of them cast their calves. When consumption is established, and the cow is much wasted away, she will rarely retain leer calf during the natural period of pregnancy.

"An in-calf beast will scarcely have hoose to any considerable extent without afterwards aborting. The pressure of the distended rumen seems to injure or destroy the foetus. Even where the distension of the stomach does not wear a serious character, abortion often follows the sudden change from poor to luxuriant food. Cows that have been out and half starved in the winter, and incautiously turned on rich pasture in the spring, are too apt to cast their calves from the undue general or local excitation that is set up; and, as has been already remarked, a sudden change from rich pasture to a state of comparative star- 
vation will produce the same effect, but from an oppositc cause. Hence it is that when this disposition to abort first appears in a dairy, it is usually in a cow that has been lately purchased. Fright, from whatever cause, may produce abortion. There are singular cases on rezord of whole herds of cows slinking their calves after being terrified by an unusually violent thunderstorm.* Commerce with the bull, soon after conception, is a frequent cause of abortion. The casting of the calf has already been attributed to the sympathetic influence of the effluvia from the decomposing placenta: there are plenty of instances in which other putrid smells have produced the same effect, and therefore the inmates of crowded cowhouses are not unfrequently subject to this mishap.

"The consequences of premature calving, are frequently of a very serious nature. It has been stated that there is often con. siderable spasmodic closure of the mouth of the uterus, and that the calf is produced with much difficulty and pain, and especially if a few days have elapsed after the death of the young one. When this is the case the mother frequently dies, or her recovery is much slower than after natural parturition. The coat continues rough and staring for a long time; the skin clings to the ribs; the appetite does not return, and the milk is dried up. Some internal chronic complaint now takes its rise, and the foundation is laid for consumption and death.

"When the case is more favorable, the results are, nevertheless, often annoying. The cow very soon goes again to heat, but in a great many cases she fails to become pregnant; she almost certainly does so if she is put to the bull during the first

* "Instructions Veterinaries, vol. 6, p. 154. Dr. Radge, in his 'Survey of Gloncestershire,' says. that there was an enlosnre near Arlingham, close to which was a dog-kennel. Eight heifers and cows out of twenty aborted, in consequence, as it was supposed by the farmer of the frequent exposure of flesh, and the skinning of dead horses before them. The remainder were removed to a distant pasture and did well." 
heat after abortion. The heat again and again returns, but she does not stand to the bulling; and so the season is wasted, while she becomes a perfect nuisance by continually worrying the other cattle.

"If she should come in calf again during that season, it is very probable that about the same period of utero-gestation, or a little later, she will again abort; or that when she becomes in calf in the following year, the same fatality will attend her. Some say that this disposition to cast her young one, gradually ceases; that if she does miscarry, it is at a later and still later period of pregnancy; and that, in about three or four years, she may be depended upon as a tolerably safe breeder; he, lowever, would be exceedingly inattentive to his interest, who kept a profitless beast so long.

"The calf very rarely lives, and in the majority of cases it is born dead, or putrid. If there should appear to be any chance of saving it, it should be washed with warm water, carefully dried, and fed frequently with small quantities of new milk, mixed, according to the apparent weakness of the animal, either with raw eggs or good gruel; while the bowels should, if occasion requires, be opened by means of small doses of castor oil. If - any considerable period has to elapse before the natural term of pregnancy would have expired, it will usually be necessary to bring up the little animal entirely by the hand.

"The treatment of abortion will differ little from that of parturition. If the farmer has once been tormented by this pest in his dairy, he should carefully watch the approaching symptoms of casting the calf, and as soon as he perceives them, should remove the cow from pasture to a comfortable cowhouse or shed. If the discharge is glairy, but not offensive, he may hope that the calf is not dead; he will be assured of this by the motion of the foetus, and then it is possible that the abortion may yet be avoided. He should hasten to bleed her, and that copiously, in 
proportion to her age, size, condition, and state of excitation in which he may find her; and he should give a dose of physic immediately after bleeding. The physic beginning to operate, he should administer half a drachm of opium, and half an ounce of sweet spirits of nitre. Unless she is in a state of great debility, he should avoid, above all things, the comfortable drink, which some persons so strangely recommend; and which the cow-leech will be almost sure to administer. He should allow nothing but gruel, and he should keep his patient as quiet as he can. By these means, he may occasionally allay the general or local irritation that precedes or causes the abortion, and the cow may yet go to her full time.

"Should, however, the discharge be fotid, the natural conclusion will be that the foetus is dead, and must be got rid of, and that as speedily as possible. Bleeding may even then be requisite, if much fever exists; or, perchance, the aforesaid comfortable drink may not be out of place. In other respects, the animal must be treated as if her usual time of pregnancy had been accomplished.

"Much may be done in the way of preventing the formation of this habit of abortion among the cows. The foetus must be got rid of immediately. It should be buried deep, and far from the cow pasture. Proper means should be taken to hasten the expulsion of the placenta. A dose of physic should be given; the ergot of rye should be administered; the hand should be introduced, and an effort made, cautiously and gently, to detach the placenta: all violence, however, should be carefully avoided, for considerable and fatal hemorrhage may bo speedily produced. The parts of the cow should be well washed with a solution of the chloride of lime, and this should be injected up the vagina, and also given internally. In the meantime, and especially after the expulsion of the placenta, the cowhouse should be well washed with the same solution, in the manner that was recom- 
mended when the treatment of the malignant epidemic was under consideration.

"The cow, when beginning to recover, should be fattened and sold. This is the first, and the grand step towards the prevention of abortion, and he is unwise who does not immediately adopt it. All other means are comparatively inefficient and. worthless. It was the charm, by means of which Chabert arrested the plague, which, for thirty successive years, had devastated the farm at Toury. Should the owner be reluctant to part with her, two months at least should pass before she is permitted to return to her companions. Prudence would probably dictate that she should never return to them; but be kept, if possible, on some distant part of the farm.

"Abortion having once occurred on the farm, the breeding cows should be carefully watched. Although well fed, they should not be suffered to get into too high condition. If the pest continues to reappear, the owner should most carefully examine how far any of the causes of abortion that have been detected may exist on his farm, and exert himself in carefully removing them." 


\section{CHAPTER XXXIII.}

CASTRATION, AND SUNDRY MATTERS NOT BEFORE ENUMERATHע.

THIs operation should always be done before the calf is six months old; from one to three months is the better time, as it gives less pain, and is sooner healed. When done, the calf should be in perfect health, and growing condition.

The process is so well understood, by cattle breeders generally, that particular directions are scarcely necessary. But, it is oftentimes so cruelly and bunglingly performed, as to cause great inconvenience and suffering to the animal; therefore, some directions, as to the best mode, are necessary. This may be as follows:

First, grasp the scrotum in the left hand, and bring the testicles down to the foot of the bag; then, with the other hand, and a sharp, small knife-a sharp pointed jack-knife is as good as any-cut a perpendicular slit in the back or rear side of each testicle, close to the bottom, and long enough for the released testicle to pass through; then cut through the skin, and the inner case enclosing it; push out the testicle, and gently draw the cord attached to it out, one or two inches, and cut, or scrape it off, and the work is done. Serve the other in the same way. Then put in a little salted soft grease, and push it upwards towards the belly with the finger. If the weather be hot, a few drops of spirits of turpentine, mixed with water, may be washed just with. in and around the outside cut of the scrotum, to keep off the flies, and the calf may be set at liberty. If the operation be done in rainy; or cold weather, the calf should be housed, if possible, for a few days, until the healing process is well under way. If the scrotum becomos afterwards inflamed, and swells, and 
matter gathers insidn, the calf should be caught, the incision gently opened at the bottom to let it flow out-even pressed out, if it refuses to flow of itself-which it will almost always do, if the cut be made large enough, which is the object of it. In a few days the cut will be healed, and your calf be capering about the lot, yard, or stable, as if nothing had happened to him. All twisting, turning, or cording methods, are cruel and brutal, and neither so good, nor safe as the simple cutting we have described.

The castration of bulls, after arriving at virility, either younger or older, may be done in the same way; but the castration of bulls, after three years old, is sometimes hazardous, and if they are to be fattened for slaughter, the better way is to feed them as bulls. They feed quite as well, and the beef is as good as if they were made into stags. Few persons can tell the difference.

SPAYING CALVES, HEIFERS, OR COWS.

This is an admirable way of converting them into ripe and delicate beef. We know of no finer beef than a three or four year old spayed heifer. The process is a delicate and skillful one, and should never be attempted but by a steady hand. There is no way of describing it, so that one not actually seeing, and practicing it, may sufficiently understand, so as to successfully perform the operation. Therefore, we do not undertake it.

In stock growing districts there are usually more or less experts in the business, and only they should be employed to do it. Where a surplus of heifers exist, and beef cattle are numerously reared, the practice may be resorted to, as both necessary, and profitable. Spayed heifers feed remarkably well-generally better than steers, and when good, are equally sought by all butchers who want to furnish choice cuts for their customers.

FREE-M ARTINS.

Heifers, twinned with a bull, are usually called free-martins, and, as a rule, do not breed. Soma instances have been known 
of their doing so, but it is against general experience. Bulls, twinned with them, almost always are productive, and no objection need be urged against them, on that score.

Heifers, so bred, usually grow up with a steer-like look, and we have known them broken and worked with the steers they were twinned with, making serviceable work animals, though they hardly ever grew to the size of the steer. The cause of their barrenness is found in the want of development, or expan. sion in their maternal organs. They seldom ever come in heat, or desire copulation. We have had many instances of the kind in our own herds, and the heifers always proved barren. Such heifers had, therefore, better be treated as steers, and fed for slaughter at the proper age.

Youatt details some processes of examination into the breeding organs of free-martins, but only to show the utter impossibility of their power of conception. Twin heifers are as productive as single ones, but we do not know that they arc more likely to produce twin calves than they. Indeed, one good calf is quite enough for a cow to produce at a time, and with it, the breeder should strive to be content.

\section{DRINKING WATER.}

We have often spoken of pure water for cattle. As a rule, their drinking water should be so. Yet there are certain medicinal, mineral, or impure waters, of which they are remarkably fond, as springs slightly saline, sulphury, or tinctured with iron, such being the most common of the mineral water. Sometimes, cattle incline to partake of stagnant and filthy waters, and will, if opportunity offers, gorge themselves almost to bursting with them, even to the neglect of the purest springs, or streams to which they have daily access.

Why this apparently vitiated taste exists, we do not always know, for healthy cattle most generally indulge it, nor do we 
know that its use affects them adversely, when only occasionally drank by them. There is certainly something in the taste of the water that they like, but we would not indulge them in its use, to any extent-dairy cows, especially. A constant use of it must affect their milk, in taste, and quality. It may act upon them medicinally for a time or two, but its constant use with cattle, for any purpose, we think disadvantageous to their general health and welfare. Therefore, we say that clean, and pure, and running water, should always be furnished them, if possible.

We are aware that there are wide districts of country, where natural springs and streams are not abundant, and water must be supplied by wells, cisterns, or artificial ponds; and even in such localities, the cattle are healthy, if they only get enough of it. It is only necessary, in such instances, that the water be furnished and kept in as pure a state as possible.

\section{BLOODY MILK-CURDLED MILK.}

It sometimes occurs that a cow will give blondy, and again, curdled milk from one or more teats, but not as a continuous habit. Bloody milk, generally comes from an injury to the udder, or teat, by inflammation, a bruise, or wound, and sometimes from disorder in the interior part of the udder. The curdly milk shows itself in small lumps, or pellets, or stringy issues when milking, while the.milk from the other teats will be perfectly good. Such diseased milk should never enter the pail but be drawn on the ground, or stable floor.

When either of these difficulties occur, the affected teat and udder should be bathed with some soft emollient, as in garget or puerperal fever; an ounce or two of saltpetre, dissolved in water, may be given as a dose. When the curdled pellets, or stringy flows occur, stopping the passage, a smooth, blunt-pointed wire, not larger than a wheat straw, may be gently forced through the orifice of the teat, up into the udder, to remove the impediment, back into the udder where it may be dissolved. 
Such difficulties, however, seldom occur, and are usually overcome without difficulty in a few days, by careful usage. Should the udder persist in yielding such disordered millk for any considerable length of time, and through a majority of the teats, it must be a question of profit with the dairyman whether to dry her off for the shambles, or still retain her in the dairy, or for breeding, in hopes of a better prospect in another year.

\section{"HANDLING."}

This is a technical term which we have frequently used in treating of the quality of cattle, and not, perhaps, sufficiently explained at the time of first using it. It applies, in the manner we have so used it, simply to the skin, and layer of flesh immediately under it, as denoting the condition of the beast for taking on flesh, and its quality, as consumable beef. A "hard handler," is one with a tight, close skin, with little or no yielding of the flesh beneath. A "soft," or "good handler," denotes an elastic or springy touch, both skin and flesh yielding like a small hollow India-rubber ball, to the pressure of the fingers, and the skin easy of movement over the flesh-not fabby, as is sometimes the case with a very thin-skinned, and sleazily made up animal.

A "hard handler," denotes a bad and slow feeder, and tough meat. A "soft" or "good handler" denotes tender, juicy meat, and a quick, profitable feeder. These different kinds of handling, therefore, are a pretty certain indication of the value of animals, either as feeders, or in the quality of their flesh. The flabby handlers, although perhaps preferable to the really hard handlers, are not desirable, lacking compactness in meat, and "running about," as the English butchers say, on the block when cutting up.

The term has been but little used, or even understood, in this country, until within the last twenty-five or thirty years, or since the "improved" foreign breeds have been introduced among us. 
Years ago, we have attended sundry cattle shows, and seen various prizes awarded to breeding and fatted cattle, without their being touched by the viewing committees, they being unconscious of the great difference in handling, or in the value of that quality, and judging only by the appearance and general "make-up" of the animals; while a thoroughly educated English grazier, or butcher, would go blindfolded into the rings, and apply his hand, rather than his eyes, if he were confined to either one sense, or the other, to judge of their quality.

But we have fast learned better. Now, we are happy to say, that the touch, as well as the sight, is considered important in judging of the true quality of the beast. "Handling," therefore, is an important item, and good handling has become indispensable in marking the best quality; and since it has so become, an evident improvement in that particular is found in the majority of all our improved breeds of cattle. The brisket, neck-vein, crops, ribs, back, loin, rump, and thighs, are the important points in determining the quality of either descriptions of handling.

The same remarks will equally apply to dairy, and breeding cows, the best handlers being always the most desirable for both purposes. Our own experience has been conclusive on this point, with animals for any purposes, and we would prefer good handlers, with some strongly defective anatomical points, to others "hard" in their "handling," yet with a more perfect contour of shape and appearance. Good handling, therefore, is a great point of excellence.

\section{"PROOF."}

This is another technical term which we have occasionally used in speaking of beef cattle. In the English, or foreign sense, it denotes tallow, well "marbled" flesh, or the intermixture of fat with the lean in suitable proportion when the beef is exposed. after slaughter. There is much difference in cattle in this par ticular. Good handlers almost always prove well, laying on theil 
fat in good places, and being equally distributed, both inside, as well as next to the skin.

A hard handler seldom proves well. He is apt to be "lumpy." or "patchy" on the surface, when highly fed, putting the fat in undesirable places, with an absence of it in the parts where most wanted. Thus good handling, and proof, are apt to go together; one in the living beast, the other after slaughter, on the hooks, or the butcher's block.

\section{LARGE, OR OVERGROWN CATTLE.}

There is a great propensity with some people for large cattle. Whatever the breed, great size they count a great excellence. This is altogether a mistake. Extraordinary size is apt to be accompanied with heavy bone, and coarseness. Coarse cattle are always large consumers, and generally, slow feeders. They - mature tardily. Their quality of flesh is coarse, and the beast, taken altogether, is undesirable both to the feeder, the butcher, and consumer.

The most profitable of all cattle to the breeder, and grazier, are those of medium size, compact form, low on the leg, and what may be called-chunky; yet they should have good length. Still they should have good size for the breed; as much size as is consistent with fineness, which means, small bone, and well fleshed.

We frequently read accounts in the papers of enormously large calves, steers, and bullocks - oxen which weigh 3,000 pounds, live weight, and upwards. Whenever we hear of such, we immediately couple them with coarseness. It cannot be otherwise, because such size is unnatural to the ordinary nature of the beast. When fully fatted-and they hardly ever do get thoroughly fat until five or six years old-they are patchy, or lumpy, which are bad in beef cattle. Therefore, we say, do not aim at extraordinary size in your stock. If of good breed, the 
feed will regulate the size, and abundant food will give size enough.

We have seen, it is true, some very large cattle that were really fine; but such are exceptions to the common rule, and we would not seek for them as bulls for stock getters, or cows for breeding, at corresponding prices; that is to say, extraordinary prices for extraordinary size, for it is not the rule that such animals will produce their own sizes in their offspring, or beyond the usual growth of the breed to which they belong. They are simply, accidents.

Nor would we choose undersized animals. A fair medium is always the safest, and best, in all stock cattle. Good size, fineness of bone, and full points, all over, is the rule which we would recommend in the selection of all neat cattle, according to their breed. 



\section{ANALYTICAL INDEX.}

Abortion or slinking, 508 ; in the dairies of New York, 504; treatment of by Youatt, 506.

Ages of cattle-Marks indicating, 419.

Alderney cattle-Origin and history, 128; description, 128, 129; cow, 130; introdnction to the United States, 131; wonderful yieid of milk and butter, 131; bull, 132; feeding in Channel Islands, 132; as a working ox, 133; as a beef animal, 133.

Allen, A. B.-Cattle in the London Markets, 256-288; on the increase of Shorthorns in Great Britain, 164, 165.

Amalgamation of the different breeds in Ainerica, 34-39.

America favorable to cattie production, 23.

Anatomical points of cattle, 41 .

Ayrshire cattle, 111; description, 112117 ; cow, 113; bull, 115 ; their origin and history, 116-118; milk prodnction, 118-120; beef qualities, 120 ; manner of rearing calves, 122 ; introduction to the United States, 123; review of their hlstory, 123-125; in America, 125, 126; as a beef animal, 126, 127 ; cows, Mr. Birnie's, 359.

Bakewell, Rob't-Improver of the Longhorns, 77-80.

Barns for stock, 306 .

Barrenness in cows, 240-250.

Beauty in cattle, 189, 190.

Beef-Value of annnal consumption in United States estimated, 15.

Beef cattie-Differences In breed, 276.

Birnie, William-Cooking food, 357-359.
Black water, 451.

Biadder-Inflammation of, 447.

Bloody milk, 519.

Bowels-Inflammation of, 442.

Brain-Inflammation of, 448.

Breachy animals, 431.

Breeding, 192 ; in-and-in, 200 ; grade cattle for grazlng, 254; dairy cows, 255.

Breeding cows-Their treatment, 219; strange influences on them, 220 ; remarkabie effects of cross-breeding, 222.

Breeds-Which are the best, 181-186.

British cattle-Whence derived and their improvement, 45-49.

Bruises, 439.

Bulls-Rearing and treatment, 262 ; instances of remarkable usefulness, 264 .

Butter-Annnal prodnction and value in United States, 16, 17.

Casarian operation, 467.

Calves-Stock, their rearing and treatment, 267-270; for veal, 270; in London market, 290 .

Caiving, 462.

Care of neat stock in winter, 303 .

Castration, 516.

Catarrh, 457.

Cattle-In London markets, 286; ornaments of parks, 412 ; love of fine, 413 ; in the Western States, 412 ; in the Middle and Eastern States, 413.

Cattle yurds-Railway, 291.

Chaps, 468.

Cheese-Annnal production and value,17.

Choking, 461.

Cold, 457.

Colic, 469. 
Cooking food, 336-359; results, 351-350.

Corn-Best kind for soiling, 313.

Cows-Fall feeding, 330 ; winter feeding, $330-332$; dairy value, 408 ; dairy treatment, 415 ; treatment in calving, 417$419,462,463-467 ;$ sncking themselves, 432; hooking and quarreling, 432.

Cow-pox, 482.

Crops for soiling, 313.

Cross-breeding-Remarkable effects of, 222.

Cud-Loss of, 480.

Curdled milk, 519.

Cntting fodder, 337; what is gained by it, 340.

Dairy lands, 409; dairy women, 410; dairy factories, 410 .

Dairy cows-Their treatment, 415.

Devon cattle-Deacription and history, 50 ; English breeders of, 53; as a dairy cow, 53-56 ; as a working $0 x, 56,57$; as a beef animal, 58, 59; in the United States, 60, 61; in the London market, 298.

Diseases-Treatment and cures, 427 ; preventing, 428-430; quack doctors, 429; proper, 433 ; water treatment, 434 ; garget, 436 ; puerperal, or milk, 437,472 ; wonnds, brnises, sprains, 439; Lowson's treatise on, 440 ; inflammation of bowels. 442 ; inflammation of lungs, 443; inflammation of stomach, 444 ; inflammation of kidneys, 446 ; inflammstion of liver, 447; inflammation of bladder, 447 ; inflammatlon of womb, 449 ; inflammatory fever, 450 ; red water and black water, 451; sconring rot, 453457; catarrh, or cold, 457; mange, 459 ; dysentery, 461 ; the fonls, 461 ; cows previons to calving, 462; Casarian operation, 467; swelling of the adder, 467 ; chaps, or sore teats, 468 ; gripes, or colle, 469 ; choking, 471 ; the gad-fly, 474 ; lice, 476 ; fog sickness, 476 , loss of the cud, 480 ; the jsundice, or yellows, 480; snores, 482; cow-pox, 482; the shoote, 483 ; venomons bites, 484 ; wounds, 484: stralns snd bruises, 487.

Doctors-Quack, 429.
Drinking water, 518.

Dutch Cattle-See Hoisteins, 166.

Drying cow of her milk, 487.

Dysentery, 461.

Economical points of cattle, 41.

Experiments in soiling, 315-326.

Fat ox-Shape illnstrated, 285.

Feeding, 278; stall, 280.

Fences-Saving in pastures by soiling, 319.

Fever-Inflammatory, 450 .

Fog aickness, 476.

Food-The grasses, 297-299; cooking, 336; mixing different kinds, 338.

Fouls, 461.

Free-martins, 517.

Gad-fly, 474.

Galloway csttle, 99; their history, 99, 100 ; description, 101 ; bull, 102; ox, 103; manner of rearing in Scotland, 104-106; cow, 107; in America, 108; in the London market, 289.

Gripes, 469.

Guenon's theory-Milk marks in cows, 891 ; illnstrated, 392 ; Mr. Magne's explanation and estimste, 393-397; Mr. Haxton's explanation and estimate, 398 ; disproved, $398,399$.

Handling, 520, 521 ; young animals, 271274.

Heifers-When to be bred for the dairy, 259; rearing thorongh bred, 272.

Hereford cattle-Description and history, 62-74; English breeders of, 61; as a dairy cow, 66 ; as a working $o x, 67$; as a beef snimal, 68 ; in the United States and Canadas, 70-73; bull, 65 ; $10 \mathrm{w}, 66$; in the London market, 288.

History of neat cattle, 25 ; in the Bible, in India, Egypt, Europe, 25-28; American cattle, 29; middle-horns-Devons, 50-61; Hereford cattle, 62-74.

Holstein, or Dutch cattle-History, 166, 167; introduction into America, 168; Mr. Chenery's importation, 169; description, 170; milking qualities, 170, 171 ; bnll, 170 ; cow, 172; as a beef animsl, 172 ; as a working ox, 173.

Hooking, 432. 
Horns-Marks indi ating age, 419.

Illustrations-The anatomical and economical points of cattle, 41; Devon bull, 51; Devon cow, 54; Devon ox, 58; Hereford bull, 65; Hereford cow, 66; Hereford ox, 68; Long-horned bull, 76; Long-horned cow, 81; Long-horned $0 x, 82$; West Highland $o x, 96$; West Highland cow, 98; Galloway bull, 102; Galloway ox, 103; Galloway cow, 107; Ayrshire cow, 113; Ayrshire bull, 115; Alderney cow, 130; Alderney bull, 132 ; old style Short-horn cow, 145 ; Shorthorn bull and cow of milking qualities, 154: Short-horn bull of fiesh quality, 156; Short-horn heifer, 157; Shorthorn fat $0 x, 162$; Holstein bnll, 170; Holstein cow, 172; Texan steers, 176; shape of fat ox, 285; milk cow with scutcheon,(Guenon's theory) 392; milk cow, horned, 399; milk cow, polled, 400; teeth and marks of age, $420,421,422$, $423,424,425$.

Improved breeds of cattle, 45.

In-and-in breeding, 200 ; Price, the Hereford breeder, 207; Robert and Charles Colling, 207; Mr. Bates, 208; the Booth brothers, 208; Mr. Hum rickhouse, 210; Sir John Sebright, 212; Mr. Bakewell, 214 ; Mr. Jones, 216.

Jaundice, 480.

Kicking cows, 430; oxen, 431.

Lice, 476.

Liver-Inflammation of, 447.

Long-horned cattle-History and descriptiòn, 75, 76; bull, 76; cow, 81; ox, 82; as a beef animal, 82 ; Introduction to and extinction in America, 83, 84.

London markets-Cattle in, 286-288.

Lower Canada-Cattle first introduced into, 32.

Lungs-Inflammation of, 443.

Malignant epldemic, 491.

Mange, 459.

Marks indicating ages, 419.

Massachusetts Bay Colony-When cattle were first introduced into, 30.

Maternity-As it approaches, 416.
Mexico-When cattle were first introduced into, 29.

Middle-horned cattle, 50 .

Milk-Valne annually sold, 18; produced and consumed in honseholds, 18; dalries, 333; valne sold in New York, 333; value sold in the United States, 333; swill or distillery, 334; fever, 437,472 ; drying the cow of, 487 .

Milk cows-Their selection, 365-401; gen. eral marks, 366-385; shape, 369386 ; general appearance, 371-388; hygienic condition, 372 ; local marks, 374 ; selection for breeding, 382; $8 \mathrm{kin}$, hair and color, 388 ; illustrated, $392,399,400$; the common way of obtaining, 402-404; their treatment, 415.

Milking-How done, how to do, 104-407. Murrain, 488-491.

Native cattle-How bred and mixed from divers breeds, 31.

Nature-Her laws, 195.

Neatness in milking, 405, 406.

New Hampshire-When cattle were first introduced into, 30 .

New York-When cattle were first introduced into, 30 .

Number of cattle in United States, 11.

Overgrown cattle, 522.

Pastures-Water in, 300; shade in, 300, 301 ; change of, 301-303.

Pedigree-Necessity of, 197.

Perfection of form, 190-195.

Pleuro-pneumonia, 491.

Points of cattle-Good and bad, 41-44.

Pregnancy-Feeding in advanced stages of, 250-252; duration of, 252.

Preparing food for steaming, 347.

Principles of breeding, 192.

Profits of breeding native cattle, 39.

Proof, 521, 522.

Puerperal fever, 437, 472.

Putrid fever, 488.

Quack doctors, 429, 440, 441.

Quality of our native cattle, 34 .

Quebec-When cattle were first introduced there, 32.

Ruilway cattle yards, 291. 
Red Water, 451.

Rinderpest, 491; in America, 492; in

England, 495; law in New York, 498; symptoms, 499 ; treatment, 500 ; precantions, 501.

Rot-Sconring, 458-457.

Sale milk dairies, 393.

Scotiand-Its cattle, 85,86 .

Sex of calves-Influencing, 274, 275.

Shape of fat cattle, 284-256.

Sheds for cattle, 306 .

Shelter to young animals, 271 .

Shonte, 483.

Short-horns, 134; English writers on them, 134, 135 ; Berry's pretended history of them, 135-140; Youatt's history, 136-139; true history, 140-145; the "Durham ox," 144; the "White Heifer that travelled," 144 ; cow of the old style, 145 ; introdnction to America, 146-152; herd books, 153; characteristics, 153-160; bull and cow of milking tribes, 154; as flesh prodncers, 155; buil, 156; heifer, 157; description and colors, 158-160; as a dairy cow, 160; as aworking $0 x, 161$; as a beef animal, 161-163; fat ox, 162; their proper homes, 163; their increasing popularity and distribution, 164, 165; in the London market, 286-288.

Size-Extremes should not be crossed, 198.

Snores, 4 2.

Soiling stock, 311-330; condition of animals, 317 ; effect of on milk, 318; saving in fences, 319 ; saving in manure, 321 ; saving in land, 321 ; crops, 322 ; method of feeding, 323, 324; arrangement of animals, 324 .

Sore teats, 468.

Spanish cattle-See Texans, 174.

Spaying heifers and cows, 517.

Sprains, 439.

Stall feeding, 280-284.

Steam apparatus for cooking food, $\mathbf{3 4}$; a cheap one, 348.
Stewart, E. W.-On soiling, 315-329; on cooking food, 336.

Stock calves-Their rearing and treatment, 267-270; ranning with the cows, 270.

Stomach-Inflammation of, 444.

Strains and bruises, 487.

Straw cutters, 341.

Summer food for dairy cows, 309-313.

Swill, or distillery milk, 334-357.

Teats-Sore, 468.

Teeth-Indications of age, 420-427.

Texan cattle-Descended from the Spanish cattle, 174; description, 175-178; mode of rearing them, 175 ; portrait of a group, 176; comparative value, 177; diseases of them, 179.

Transportation of stock to market, 291.

Tricks of cattle, 430.

Udder-Swelling of, 467.

Value of cattle in the United States, 13, 14 ; different kinds of cattle food compared, 341-346.

Veal-Estimated annual consumption and valuc, 15.

Venomons bites, 484.

Virginia-When cattle were first introduced into, 30.

Water-Treatment of diseases,434; drinking, 519.

West Higbland cattle-Their history, 8739 ; their management, 94,95 ; as a beef animal, 95,96 ; $0 \mathrm{x}, 96$; proposed introduction to America, 97 ; cow, 98 ; in the London market, 289.

What constitutes a good animal, 1S7-189; a bad animal, 187, 188.

Winter forage, 303 ; winter feeding, 305308.

Womb-Inflammation of, 449.

Working oxen, 293; rearing, matching and training. 294-296.

Wounds, 439, 484.

Yellows, 480. 


\section{R. H. ALLEN \& CO'S BUSINESS NOTICE.}

WE wish to call the attention of Breeders of Fine Cattle, and all kinds of Improved Live Stock, to our last publication on Agricultural Impleinents, Farm Machinery, and Small Tools for the Farn and Garden. It constitutes the Fifteenth Edition of our regular Business Catalogue, which we have issued for many years, but is now so much increased in size, as well as perfected in its descriptions, and in the quality of the engravings, that it ranks far in advance of other similar publications in this country, as well as abroad. Although it does not attempt a scientific description of machines and tools, as was the case with the valuable "Farm Implements," of Mr. J. J. Thomas, of the Country Gentleman, (now unfortunately out of print,) yet it is so full in its details that it is a book which every Farmer or Stock Raiser should possess, as they avilt find it valuable for frequent consultation. The edition referred to a book of nearly 300 pages, containing about six hundred wood cuts, nearly all of which are new and by first class artists, and is furnished at $\$ 1$ in paper covers, or $\$ 1.25$ in cloth.

The first few pages are devoted to a brief description and analysis of the best Fertilizers, and after thirty pages of description of Cast Iron, Wrought Iron, and Steel Plows, Cultivators, Harrows, Rollers, \&c., \&c., there is given a full list of all Implements and Machines used in the harvesting of the Hay, Grain and Root Crops, with those used for their preparation for market, or for home use. Among the latter, we include Portable Steam Engines, Wind Mills and all kinds of Horse Powers for driving Threshers and Cleaners, Grain and Feed Mills, Corn and Cob Crushers, Smut Machines, Fanning Mills, Corn Shellers, Hay, Straw and Stalk Cutters, \&c., \&c.; all of these, however, being made of suitable size to be worked by hand as well as power.

For the further preparation of food for Catle, we have several patterns of Root Cutters and Slicers, of various sizes, up to those 
capable of cutting three hundred bushels per hour, together with Vegetable Boilers and Steamers for cooking roots, \&c., to be heated by coal or wood.

We devote considerable space, also, to articles for Dairy use, such as Churns, Butter Workers, Dog or Sheep Powers; to Iron Feeding Racks, Mangers and Troughs; Farm Wagons and Carts; Liquid Manure Carts, Pumps, Fire Engines, Forks, Bows, and many other articles of general utility in and around Farm Buildings.

In smaller articles for a Stock Barn, we have Cattle Ties, Bull Leaders and Bull Rings, Cattle Syringes and Probangs, $\mathrm{Ox}$ Balls and Muzzles, Cattle Cards, \&c., in a great variety of styles and prices.

For Sheep Raisers, we have Shears, both Domestic and Imported, and are about introducing a new Sheep Shearing Machine, in which the inventor hopes to meet the wants of this and other countries.

Although we have enumerated only a few of the goods noticed in our Catalogue list, we think enough have been specified to show the value, to the general Agricultural community, of the book thus described, and especially to Stock Farmers, and our opinion, partial as it may be, has been confirmed by the whole Agricultural Press of the United States.

Copies, bound in paper covers, will be mailed to all applicants, on receipt of one dollar, or, in cloth binding, one dollar and a quarter.

Applications should in all cases be addressed to us as below.
R. H. ALLEN \& CO.,
P. O. Box 376 .
189 and 191 Water Street, New York.

nas Fremtizers.-R. H. Allen \& Co. keep constantly on hand the following popular Fertilizers, which they fully guarantee to be of the best quality, viz.: Phosphate of Lime, Ground Bone, flour of Bone, No. 1 Prenutian Guano, Phanix and other Pacific Guano, Ammoniated Pacific Guano, Fish Guano, \&c., \&c.

A general assortment of Books, for the Farmer, Gardener, Florist, Fruit Grower, \&c., sent by mail on receipt of the retail price. 


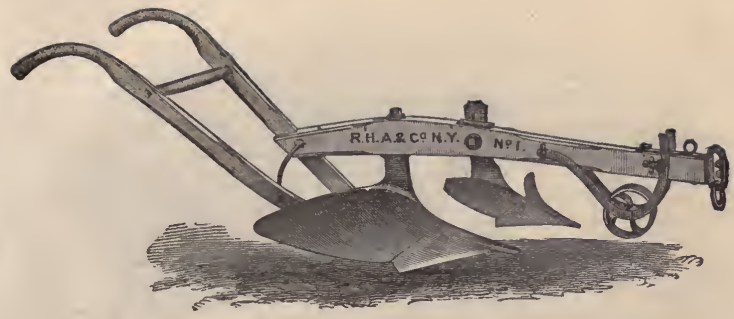

\section{PATENT CYLINDER PLOW,}

WITH SKIM, OR SUBSOIL ATTACHMENT.

-This Plow derives its name from the form of the mold-board, which is a segment of a perfect cylinder, with its ends cut in the style of ordinary mold-boards. Its lines are thus always horizontal to the surface of the land, and consequently it turns the furrow-slice with the same uniformity as a wheel on its axle, and with the least possible friction. The friction is still further reduced by the peculiar arrangement of the share and land side, which, combined with its other improvements, reduces the draught from one-fourth to one-third less than that required by the best class of Plows now in general use.

For lightness of draught, simplicity of construction, ease of holding, and certainty of turning all soils of any required depth and width, it far surpasses any other Plow.

All the sizes are capable of turning either flat or lap furrows, of any required lap, by using shares suited to various widths, all of which can be supplied; and every furrow may be left concave on the under, and convex on the upper side, which gives the lightest and most friable condition to the soil, admitting of easy and thorough pulverization by a light harrow or cultivator.

This front plow can be raised or lowered to turn any required depth of upper furrow, or it can be removed entirely, at the pleasure of the operator.

We have 137 distinct sizes and varieties of Plows on our Price List, and most of the larger ones are arranged with fin or wrought cutters, wheels and draft rods, as may be desired. They are cast iron, polished and half polished, steel, wrought iron, \&c., embracing everything required for sward and fallow plowing, cultivating, deep trenching, subsoiling, \&c.

Send for Price List for particulars.

R. H. ALLEN \& CO.,

P. O Box 376 . 189 and 191 Water Street, New York. 


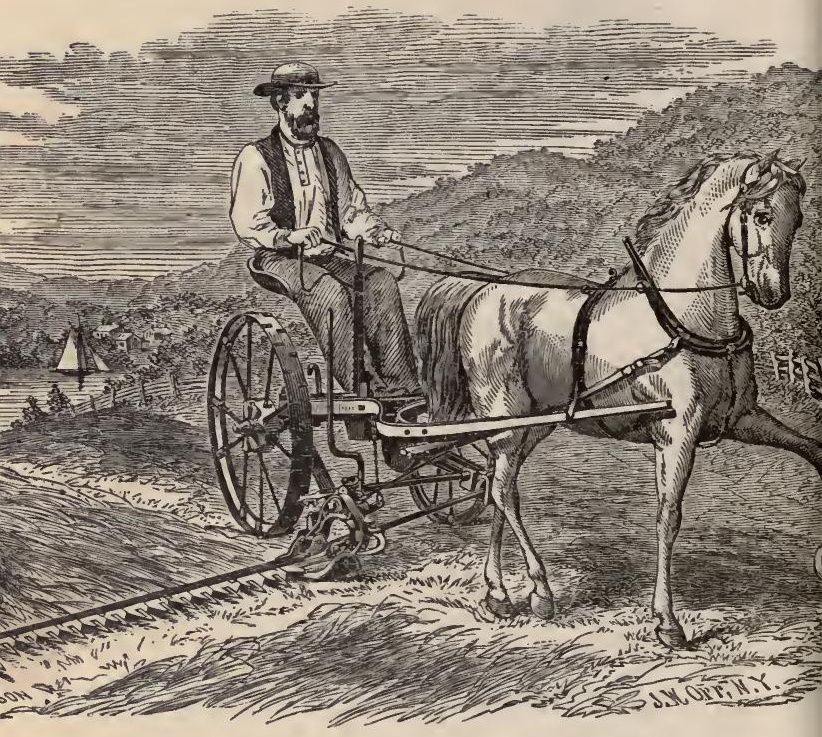

\section{ONE HORSE, OR PONY CLIPPER MOWER.}

A Gold MEDAL, (the highest premium, was awarded to this machine, by the New York State Agricultural Society, at their great trial in Auburn, in July, 1866, when 59 Mowers and Reapers were offered for competition.

This is the only really practical One-Horse Mower in the market. It is constructed on the same general principle as the Two-Horse Machine, and is easily drawn and worked by one horse. It is capable of cutting three-quarters of an acre per hour with ease, without distress to the team, even in the hottest weather.

The Clipper Mowers were introduced by us in 1863. Although they at once took the first place among this class of machines, they have since been modified from year to year, as cach successive season's experience 


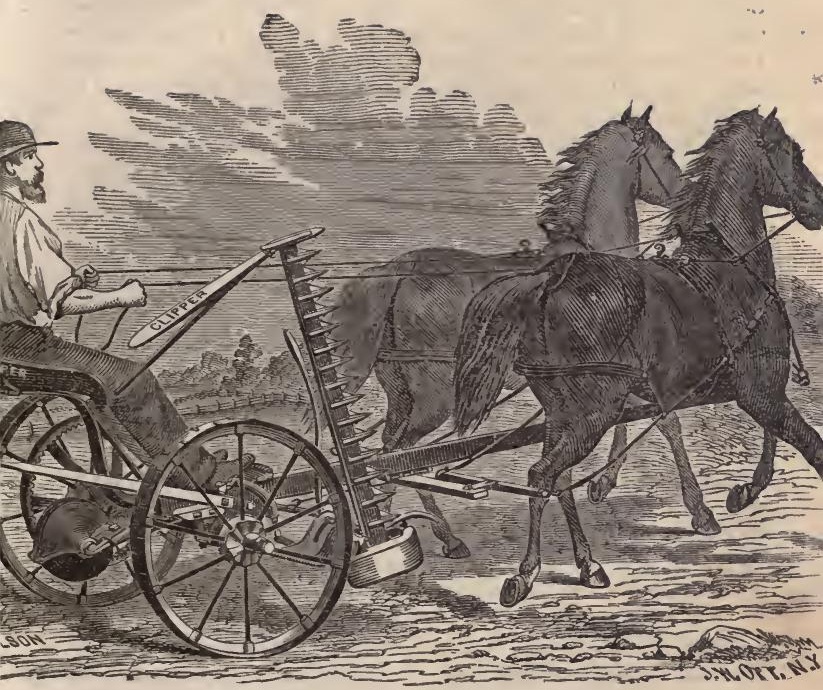

\section{TWO HORSE CLIPPER MOWER.}

in the field showed any point susceptible of improvement, and they now rank among harvesting machines as our modern light steel Tools, Plows, etc., do in comparison with the old fashioned and heavy implements of the past generation.

They are built on the system of interchangeable parts, a system that has not in full, been heretofore applied to the construction of any Mower. The like parts are exact duplicates of each other, and will fit any and all machines of the same size. By this method, we are able to secure exact uniformity in all our machines, and all will work equally well in the field, whether put together at jur manufactory or by our Subbuilders.

While the CLIPPERS possess every point of real excellence found in other machines, they have many important features peculiar to themselves, viz.: 
The Drive Wheels have ten wrought iron spokes, (each bracing the adjoining ones,) thus rendering them lighter, at the same time much stronger, than the ordinary cast iron wheels. Though they are independent of each other, either will drive. Both are in gear while advancing, and out of gear while backing. The inside wheel runs in the track of the shoe, and does not press down the cut grass.

The FRAME is made entirely of cast and wrought iron, not in one piece, as in some machines, but in parts, so arranged that in case any one is injured, that only requires to be replaced, which any farmer is competent to do. A frame of this material is almost indestructible, while it cannot be warped by exposure to the weather in any climate, as is the case with the wooden frames.

The Draft Atтachment is another peculiar and important feature of the Clipper machines. Being applied to the front end of the frame and below the pole,(that serving merely as a guide for the team,) the draft is consequently upward, whereby the inside shoe is made to pass lightly over the ground, rendering unnecessary the leading wheel in front of the shoe, with its attendant evils.

The method of adjusting the Cutting Apparatus of the Clipper is at once novel and peculiar. By means of the adjusting lever the driver is enabled at all times, when the machine is in motion, to raise or lower the points of the fingers and knives, thus varying the angle and height of the cut, and adapting it to lodged grass, or rough, boggy ground.

The patent cast steel FINGER BAR, and solid cast'steel GUARDs, are not liable to clog or break, with the under surface of the finger-slot hardened; and in connection with the ball and socket knife-head they make the most perfect Cutting Apparatus known. They are as much in advance of the common flat bar and malleable iron guard, as the latter are in advance of the old wooden bars and cast iron guards; and to this most important of all requisites to a perfect Mower we invite your particular attention.

The Mowers are made with 30,32 , or 36 inch Drive Wheels, with five different cuts, varying from $3 \frac{1}{2}$ for the Pony to 5 feet for the Two-Horse.

The Reapers are made to cut $4 \frac{1}{2}$ and 5 feet, with 36 inch Drive Wheels.

For further particulars, send for a Circular to
P. O. Box 376 .
R. H. ALLEN \& CO., 189 and 191 Water Street, New York. 


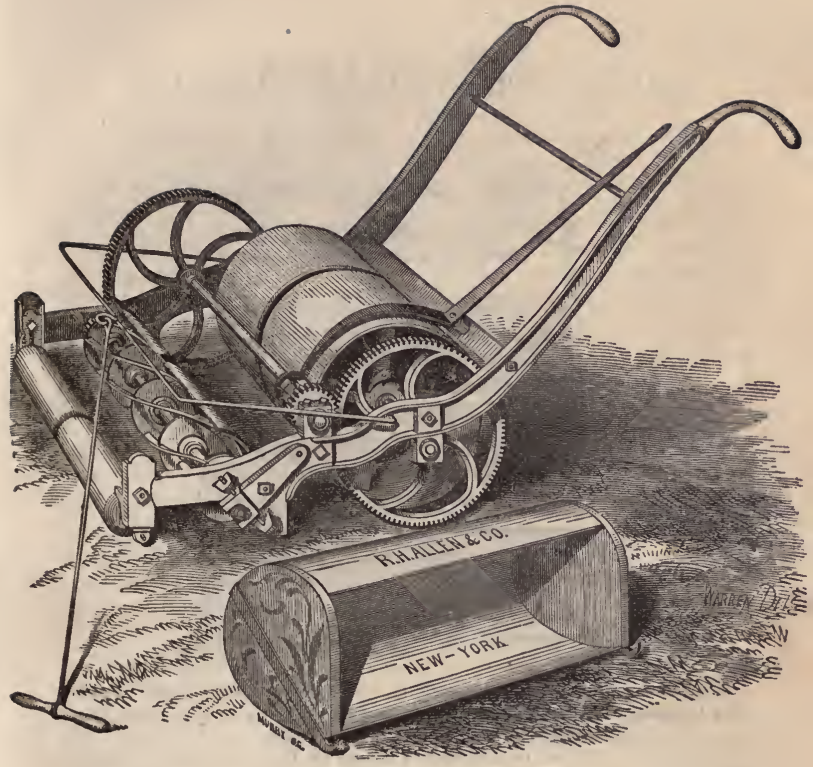

\section{HAND LAWN MOWER.}

THis machine has become indispensable to all owners of Lawns, who value a fine, close and evenly cut turf, which is impossible to be secured by the use of Lawn Scythes, even in the most experienced hands.

When properly used, it leaves the grass not only evenly cut, but the heavy roller compacts the sod and the soil below, with manifest advantage to the appearance of the Lawn, as well as its permanent improvement.

There are two sizes of Hand, and four of the Horse Macbines, cutting from 16 to 42 inches, according to size. Full description and prices will be given, on application to

R. H. ALLEN \& CO., P. O. Box 376 . 189 and 191 Water Street, New York. 


\section{HORTICULTURAL TOOLS AND HARDWARE.}

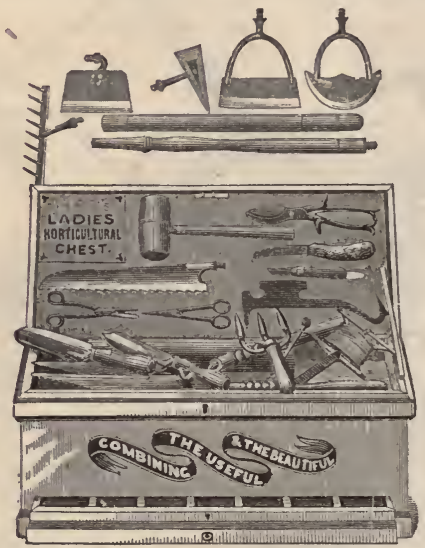

The above cut represents our Horticultural Tool Chest. In our new Catalogue, a large space is devoted exclusively to the above tools, fully illustrated with cuts of the several articles.

The list comprises numerous varieties of Hoes for garden walks; Knives for trimming edges of paths; Grass Hooks for cutting grass where the Lawn Mower or Scythe cannot be used; Garden and Lawn Rakes of Wood, Iron, Steel; Garden Barrows, with high sides, and with one, two and three wheels; Syringes of Tin, Britannia and Brass; Cephydrions, Greenhouse and Garden Engines for sprinkling; Watering Pots and Hose; Fruit Ladders and Gatherers; Fruit Knives; Budding and Grafting Knives; Shears and Scissors, of all kinds, for pruning and trimming; Weeding Forks and Transplanting Trowels; Pruning Saws and Chisels; Tree Scrapers; Garden Reels and Lines; Flower Poles for tying up Petunias, Roses, Carnations, Dahlias, \&c., \&c.; and in fact almost every tool, small or large, that can be of service to the Gardener, Florist, Nurseryman or Fruit Grower.

The tools mentioned above, are furnished singly, or in chests of various sizes and styles, at the option of the purchaser.

Price of the Catalogue, $\$ 1$.

R. H. ALLEN \& CO.,

P. O. Box 376 .

189 and 191 Water Street, New York. 


\section{FERTILIZERS.}

R. H. ALLEN \& CO., keep constantly on hand, the following popular Fertilizers, each of which, they guarantee to be pure, and the best of their kind:

E. F. Coe's Super-Phosphate of Lime.-This is composed wholly of bones, either raw, or such as have been charred and used by the sugar refiners. They are thoroughly decomposed by the addition of Sulphuric Acid, which is itself a fertilizer, and when the charred bone is used, the ammonia-forming material of the bone, (the animal tissues,) which had been expelled by heat, is fnlly made up by adding ammonia. It is applied to crops in drills, or by sowing broadcast, and harrowing lightly in. There will be no injury to seeds or plants, if placed in contact with them.

Gronend Bone.-This is one of the most economical manures, and like the SuperPhosphate, is applicable to all soils, and to all the muscle and bone-forming plants, grains, roots, \&c. It may be sown broadcast, or in drills.

Flour of Bone, is pure bone, reduced to fine powder, and is applied to all crops, as above.

Number One Peruvian Guano, (and we keep no other quality,) is the most concentrated, and hitherto, has been considered the most desirable of the commercial manures. Its principal value is in its ammonia, of which it contains 8 to 16 per cent. It also contains about 25 per cent. of phosphate of lime and magnesia, which, however, may be much more economically provided by either of the foregoing fertilizers. Other manures, containing the mineral constituents of plants, such as potash, soda, the phosphates of lime, magnesia, \&c., (which are always found abundantly in all forms of bone manures, and in ashes, barn yard manures, \&c.,) must be added with Peruvian Guano, or the crops will soon exhaust the soil of these necessary ingredients, in consequence of the excessively stimulating effects of the ammonia, which the Peruvian Guano holds in so large a proportion. It is furnished in bags of about $160 \mathrm{lbs}$. each.

Phoenix Guano is one of the best of the Phosphatic Guanos from the Pacific Ocean, which are generally or commercially, known as AMErican GUano. The origin of this guano is identical with the Peruvian, being the deposits from the innumerable flocks of sea-birds, which have resorted for ages to those islands of the Pacific, where these deposits exist. But in all these islands, the abundant rains (which never occur on the Chincha Islands where the Peruvian is found, have washed out the more volatile and readily soluble ammonia, leaving over 50 per cent. of bone, phosphate of lime, and other fertilizing salts. In consequence of the absence of ammonia, its effects on crops, though more enduring, are not so immediate, as from the application of the Peruvian guano.

Ammoniated Prcific Guano.-This is a manufactared article, the basis of which is the Phosphatic Guanos from the Pacific Ocean, with the addition of ammonia producing ingredients, such ss animal matters, and particularly the residium of fish, after expelling the oil. The slow decay of this animal matter in the soil, forms ammonia, the beneficial effects of which, add materially to its value as a fertilizer.

Fish Guano, is composed exclusively of the remains of fish, (which are caught in great abundance on our Atlantic coast,) after expelling the oil, and thoroughly drying and grinding.

All of the above, except Peruvian Guano, are shipped in barrels of 200 to $275 \mathrm{lbs}$. each. 


\section{SEEDS FOR CATTLE BREEDERS AND STOCK RAISERS.}

In connection with our business in Agricultural Implements, we have constantly on hand a full assortment of Seed and Seed Grains, of all kinds, raised for us by the most reliable Seed Growers of the United States, or imported from the best dealers of England, Belgium and France.

Our assortment includes all that are raised for the feeding of Live Stock, and it is to this branch of our Seed business that we particularly call the attention of Breeders of Cattle and all kinds of Stock.

In Field Seeds, we offer the Clovers, Grains and Grasses, of all varieties, for pasture, for soiling, and for the regular Hay Crop, together with all the new Fodder Plants, the use of which is rapidly increasing in this country, and among which are choice prolific varieties of Sweet Corn, the Italian and Hungarian Millet, Sorgo or Chinese Sugar Cane, in its several varieties, Vètches, Peas, Rape, \&c.

In the list of Roots, we offer all the old standard varieties for Winter feeding, as well as others recently introduced and found valuable in this country. Among them are the Long White Sugar Parsnip; the White Sugar Beet; Long Red and Yellow Globe Mangel Wurzel; the Long Orange, and the Large Orange and White Belgian Carrots; and in Turnips, we have five varieties of value, viz.: the Early White and Red Top Flat, Long Smooth White or Cow Horn, Large White French or Rock, and the Purple Top Yellow Swede or Ruta-Baga.

Orders for any quantity under four pounds, can be safely executed by mail, the General Post Office Department having given particular facilities for this purpose. The rates of postage to all parts of the United States, not including the Territories, is two cents for every four ounces or fraction thereof.

Detailed catalogues of our entire stock, with price lists, will be furnished upon application on receipt of stamp.

Our large Illustrated Catalogue, (15th edition,) containing nearly 300 pages, and about 600 wood cuts of Agricultural Implements and Machinery, and Small Tools, will be sent post-paid on receipt of $\$ 1$.

R. H. ALLEN \& CO, P. O. Box 376, New York City. 


\section{DOMESTIC ANIMALS.}

R. H. ALLEN \& CO. will fill orders for such Domestic Animals of the best and most popular beeeds, as are to be found among our best breeders. These include

Cattle-Short-Horn, Devon, Alderney and Atrshire.

Sheep-BAKEWELL or LEICESTER, Cotsw OLD and LINCOLNSHIRE of the Long Wools; South and Hampshire Downs, of the Middle Wools; and the Silesian, and native bred Mrerinos, of the Fine Wools.

Swine-Berkshire, of the black and white; Essex, of the pure black; Cheshire and Chester County, of the large white; and SuFrouk, of the small white.

Also the Long-Eared RABBITs; choice varieties of FowLs, \&c., \&c.

In ordering any of the above, particular description should be given, not only of the breed, but whether very choice animals are required, as the prices vary very widely in pure animals of the same breed, according to the selection.

All orders executed by us for any of the foregoing Animals, will be fully guaranteed as to purity of breed, and good condition of the animals when shipped.

A beautifully executed CATALOGUE of our Implements, of about 300 pages, and nearly 600 cuts, full of important information for the Farmer, and a valuable addition to his library, will be sent, post-paid, on receipt of $\$ 1$.

DSP PrICE LISTs of our Implements, will be sent gratis through the mail on receipt of postage stamps.

Da A full Catalogue of Seeds to Dealers, also a Retail Cat$\triangle L O G U E$ of Seeds, will be sent gratis, on receipt of stamps. Parties ordering as Dealers, should always state the nature and place of their business.

Full information, prices, circulars, \&c., will be sent of all articles in our large Catalogue, on application. Address all letters to P. O. Box 376, New York. 


\section{TO THE FARMERS OF AMERICA}

And all Whom it may Concern:

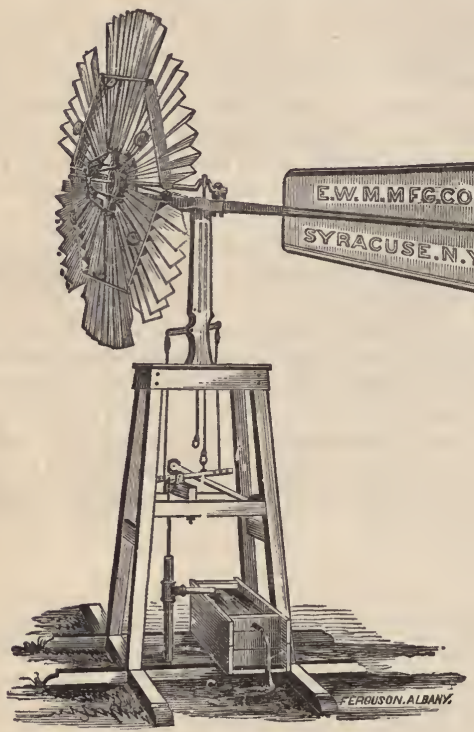

\section{THE RMPIRE WIND MLL MANUFACTURING CO.}

OF SYRACUSE, $\mathbf{N}$. $\mathbf{Y}$.

Solicit your careful attention to their SELF-REGULATING, STORM-DEFYING WIND MILL, as a LABOR SAVING POWER for farm purposes, particularly for Pumping Water.

All allow this to be one of the most tedious performances connected with farm labor, and hundreds of farmers might and would keep 
more stock, could they be watered by a living spring at the surface of the ground.

This can now be brought about, for long and patient effort has overcome the most serious objections to Wind Mills, as heretofore constructed, and this most economical power in the world is made available; so we are fully prepared to sell, erect and warrant our machines, and adapt them to all possible situations, so as to give entire and lasting satisfaction.

Send for circulars, containing further information and testimonials, and after that, if you still doubt, write us:

I. The depth of your well.

II. The least depth of water ever known in it.

III. The height above the platform of the well to where you wish the water discharged.

IV. The lateral or side distance, if any.

$V$. The amount or quantity of water wanted, or at least the number of cattle to be supplied.

VI. The height at which the Mill must be erected to secure a free current of air, with all other particulars-and see if we will not give you a fair chance to TEST the Mill on your own premises till you become satisfied we have told jou the truth.

\section{Price of Mills at the Factory :}

\begin{tabular}{|c|c|c|c|c|c|c|}
\hline & $\begin{array}{l}\text { No. } 0 . \\
\$ 75.00\end{array}$ & $\begin{array}{l}\text { No. } 1 . \\
100.00\end{array}$ & $\begin{array}{l}\text { No. } 2 . \\
150.00\end{array}$ & $\begin{array}{l}\text { No. } 3 . \\
300.00\end{array}$ & $\begin{array}{l}\text { No. } 5 . \\
700.00\end{array}$ & $\begin{array}{l}\text { No. } 6 . \\
1200.00\end{array}$ \\
\hline & 2.50 & 3.00 & 3.50 & 5.00 & 12.00 & 25.0 \\
\hline
\end{tabular}

Pumps from $\$ 5.00$ upwards. Pipe, \&c., at manufacturers' list prices. WE CAN GIVE YOU WHAT YOU NEED.

Address,

\section{EMPIRE WIND MILL MFG. C0.}

SYRACUSE, N. Y.

Notz.-I have seen several of the above named Wind Mills at work, and many testimonials highly recommending them, from Railway managers, using them at their water statiors, as well as from farmers, manufacturers, and others. I have full confidence in recommending them to all stock breeders and farmers needing such machines, as an economical and highly valuable labor-saving apparatus.

L. F. ALLEN. 
In press and will soon be published:

\section{The American Farm Book.}

Treating of Soils, Manures, Crops and their cultivation, Orchard and Garden Fruits, Farm Stock generally, \&c.

Originally by Richard L. Allen. Revised, extended and brought down to the present period, by Lewis F. Allen.

\section{Rural Architecture and Farm Buildings.}

Revised and extended, in all the various departments of Farm and Village occupation, with numerous Illustrations of Dwelling Houses and their appendages, and Farm Buildings generally, with remarks on Grounds, Plantations of Trees, Shrubbery, and other natural decorations, \&c. By Lewis F. Allen.

These books will be of the same style, and of about the same number of pages as "American Cattle," and for sale by canvassers. 

I Stet terompentine

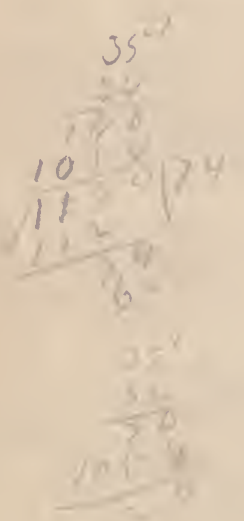


- 




\section{THE LIBRARY \\ UNIVERSITY OF CALIFORNIA \\ Santa Barbara}

THIS BOOK IS DUE ON THE LAST DATE STAMPED BELOW.

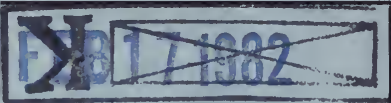


